Fall 2012

\title{
2012 Miracle Yearbook
}

Cedarville University

Follow this and additional works at: https://digitalcommons.cedarville.edu/yearbooks

Part of the Higher Education Commons, Organizational Communication Commons, and the Public Relations and Advertising Commons

\section{Recommended Citation}

Cedarville University, "2012 Miracle Yearbook" (2012). Yearbooks. 31.

https://digitalcommons.cedarville.edu/yearbooks/31

This Book is brought to you for free and open access by DigitalCommons@Cedarville, a service of the Centennial Library. It has been accepted for inclusion in Yearbooks by an authorized administrator of DigitalCommons@Cedarville. For more information, please contact digitalcommons@cedarville.edu. 



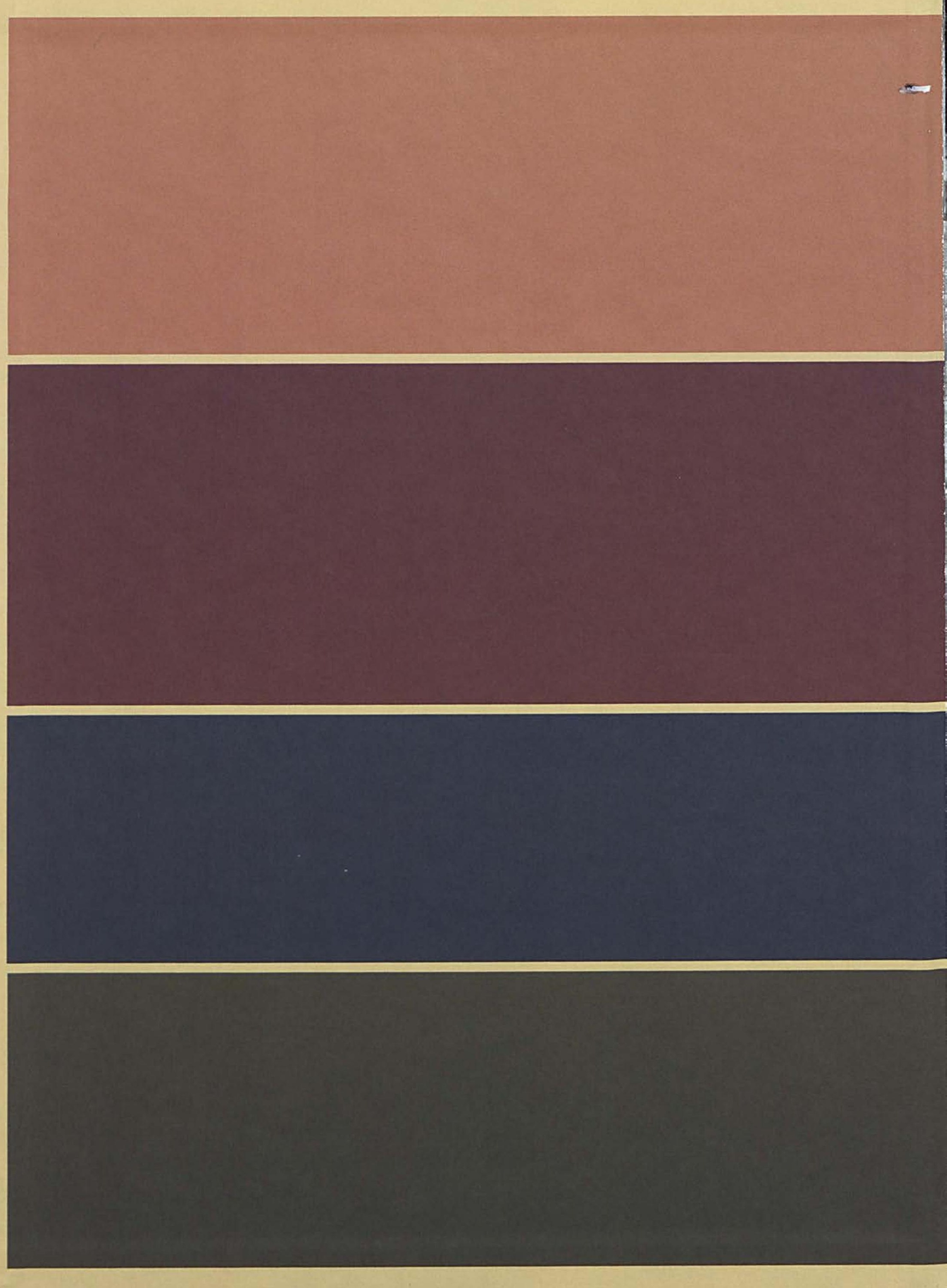




\section{Table of Contents}

Opening.

Dedication .4

Fall 6

Fall Sports 22

Faculty \& Staff 34

Organizations 58

Freshmen. 70

Activities 88

Sophomores 106

Winter 124

Winter Sports 134

Ministries

Juniors

Spring 176

Spring Sports

Seniors

Miracle Staff.

Index 

1887

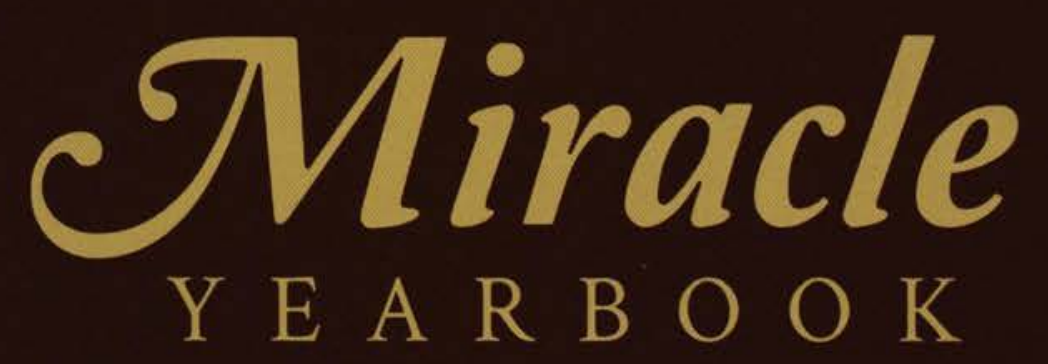

2012

\section{Years of Transformation}




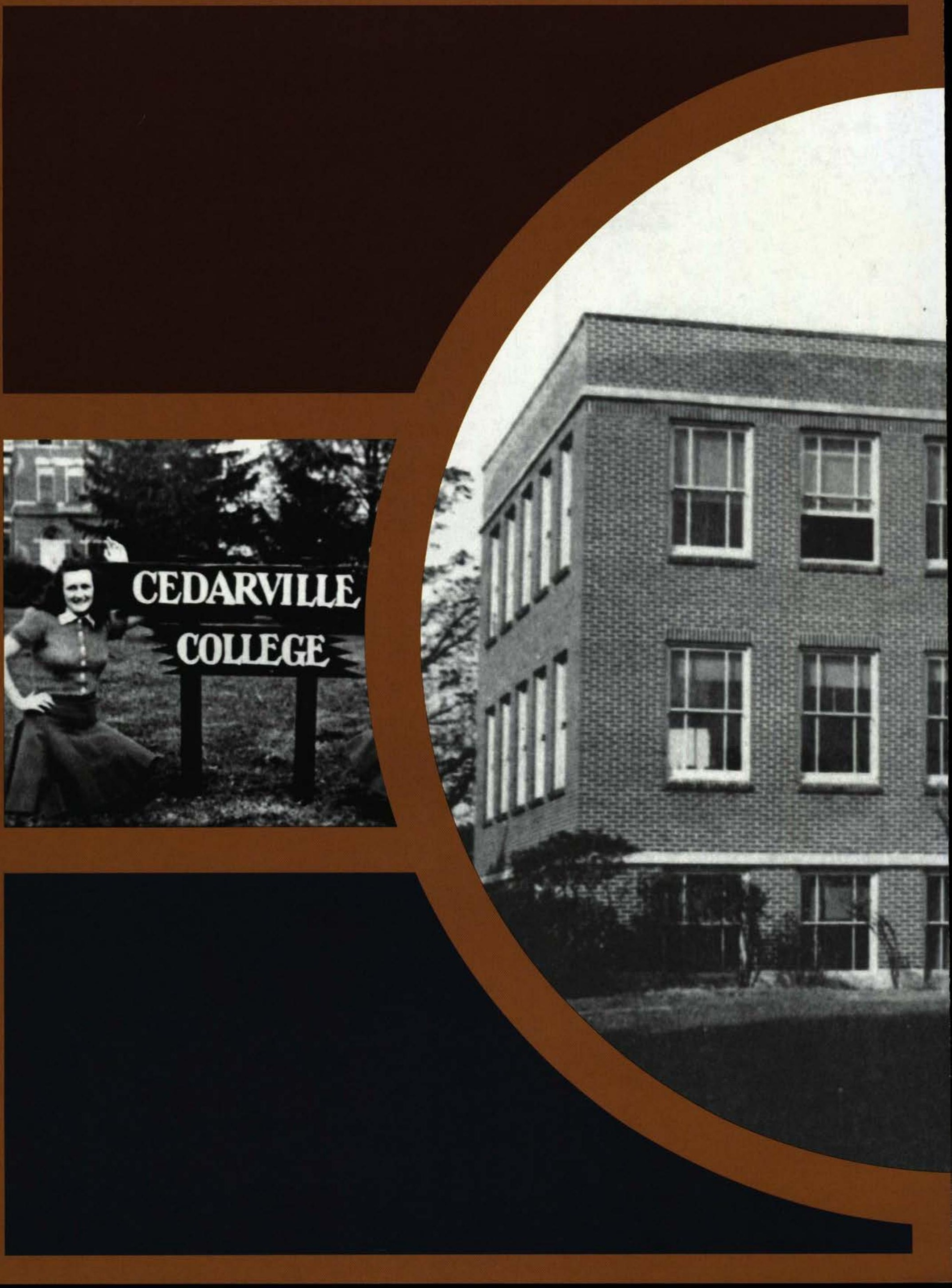




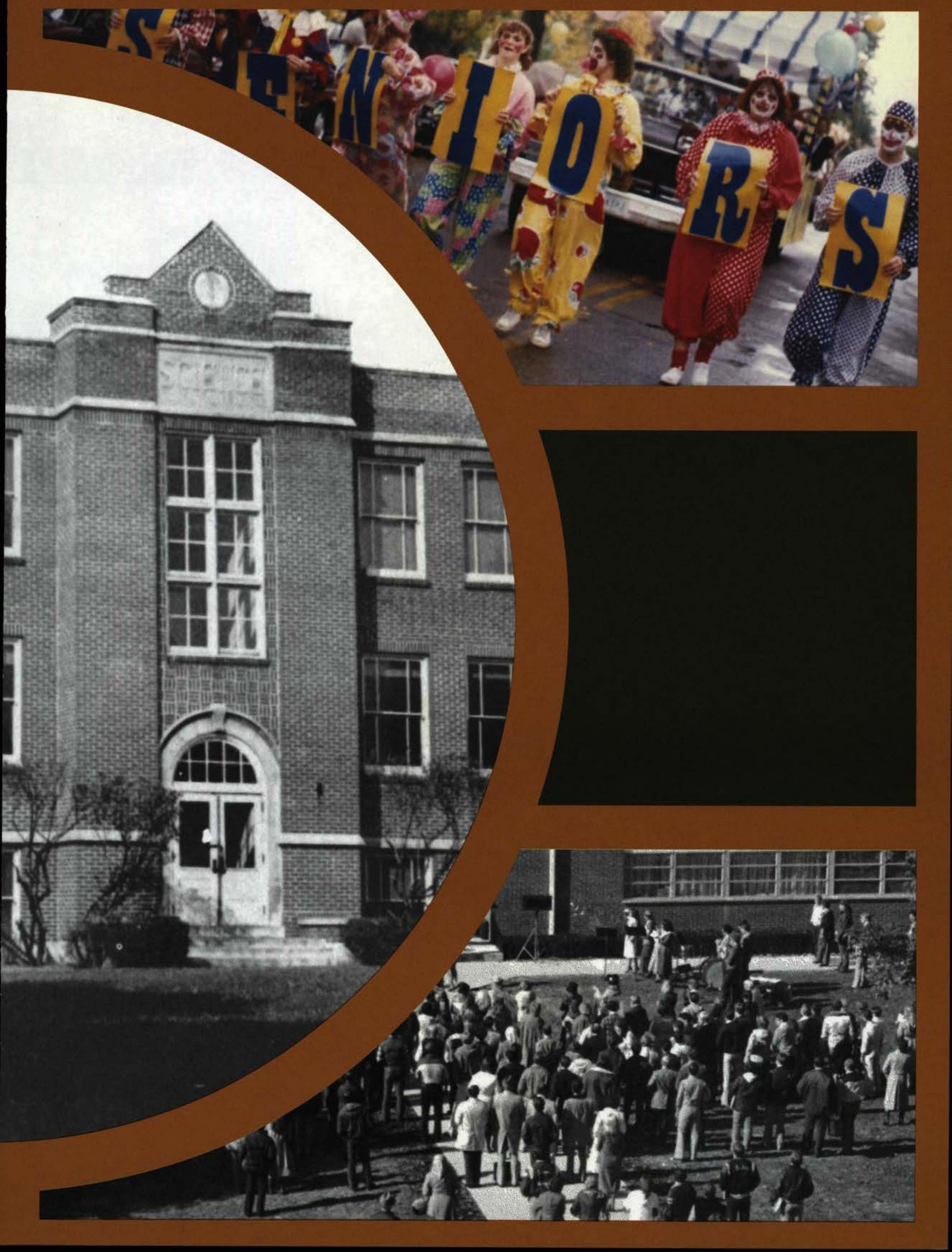




\section{Dedication}

\section{Dr. Terry Chamberlain has been an asset to the Miracle yearbook for many years as the layout and design advisor}

Professor Chamberlain teaches through demonstration during one of his classes.

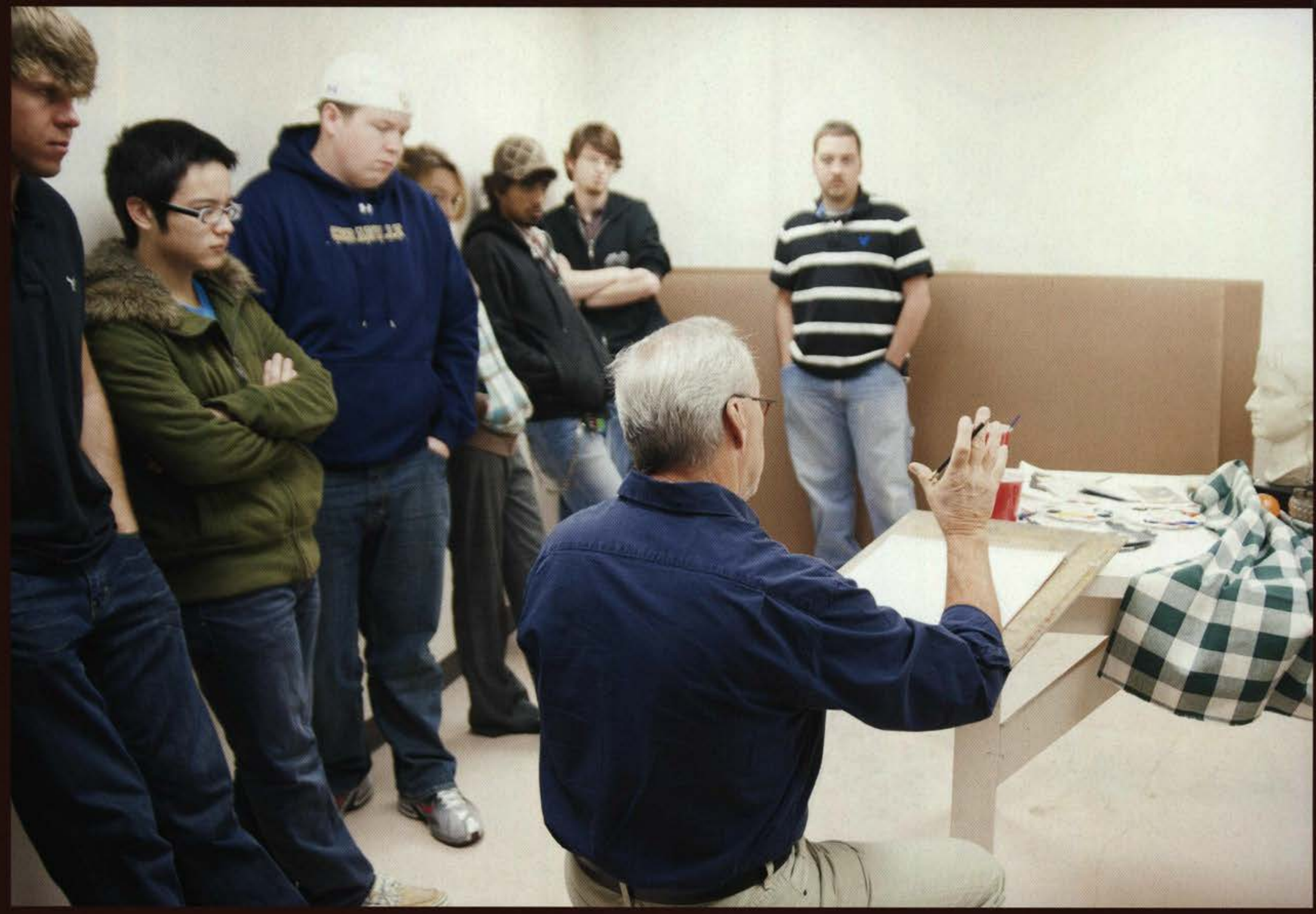

erry Chamberlain earned his B.S.
from Bob Jones in 1970 and his M.A. in 1972. By this, his sixteenth year at Cedarville, he had become the chair of the Art, Design, and Theatre department and an associate professor of art. Both Professor Chamberlain's fraternal twin brother and mother lived in Indiana. Before coming to Cedarville, Professor Chamberlain taught art in Pennsylvania, South Carolina, and elsewhere in Ohio. He grew up in Johnstown, Pennsylvania and started his teaching career at Dayton Christian, where he spent 22 years. At Dayton Christian, he developed the art program into collegiate level, winning numerous national awards. He also continued his own work in the art community. As a highly respected member of the Ohio art community, he was privileged to have his work displayed in various collections throughout the United States. Robert Clements, associate professor of theatre, stated, "The rewards of Terry's students reflect him as a professor. Terry knows how to identify a student's gift and then develop it. He's honest with them, and that's why they achieve." Professor Chamberlain poured himself into his students; in fact, when submitting student work to art contests in Cincinnati, Professor Chamberlain would personally escort the artwork to the judges. The value Professor Chamberlain placed on his students was obvious in the way he treated them and the way he treated their artwork. Professor Clements summed up Professor Chamberlain's love for his students well "That's just Terry." 


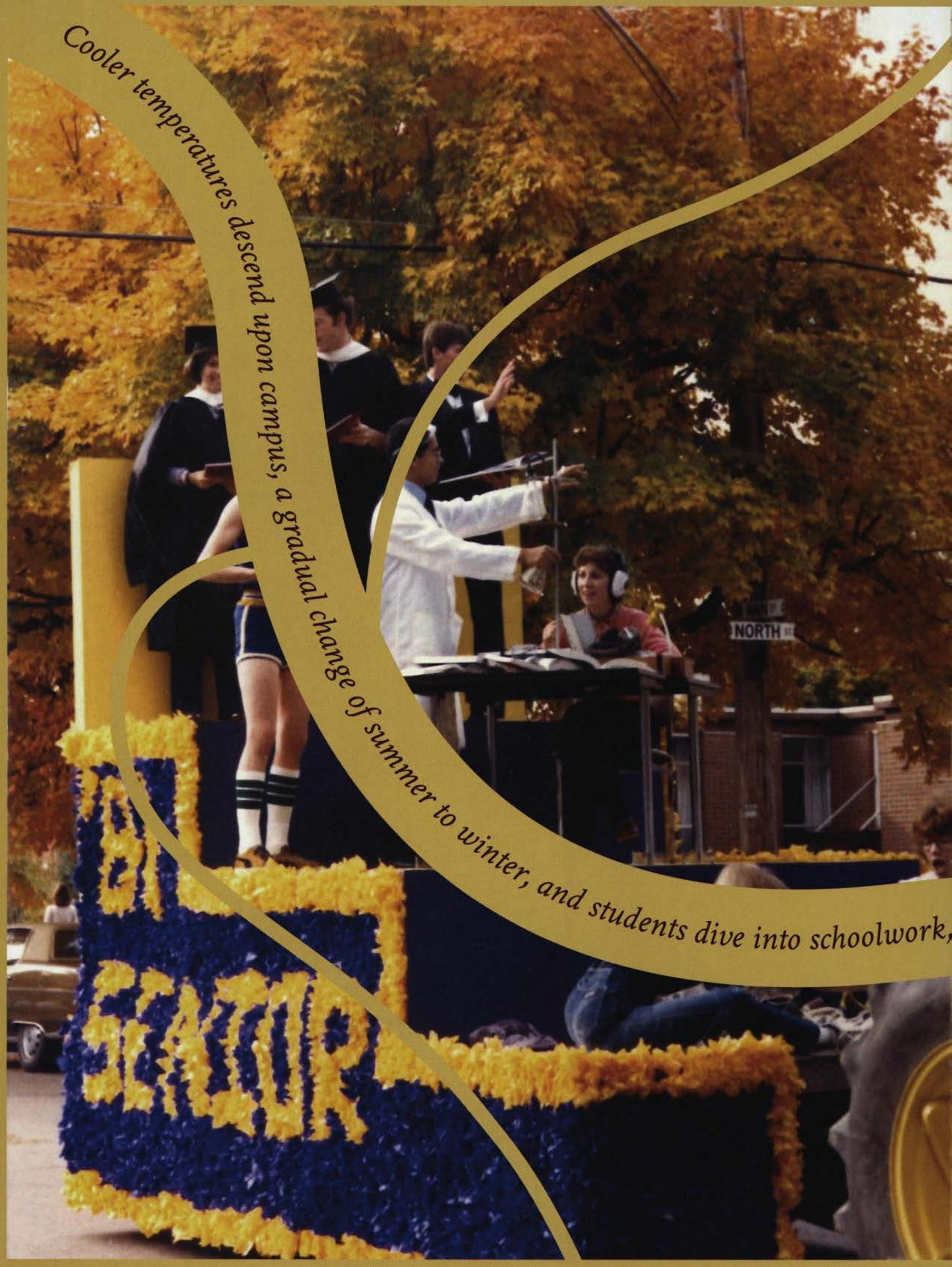



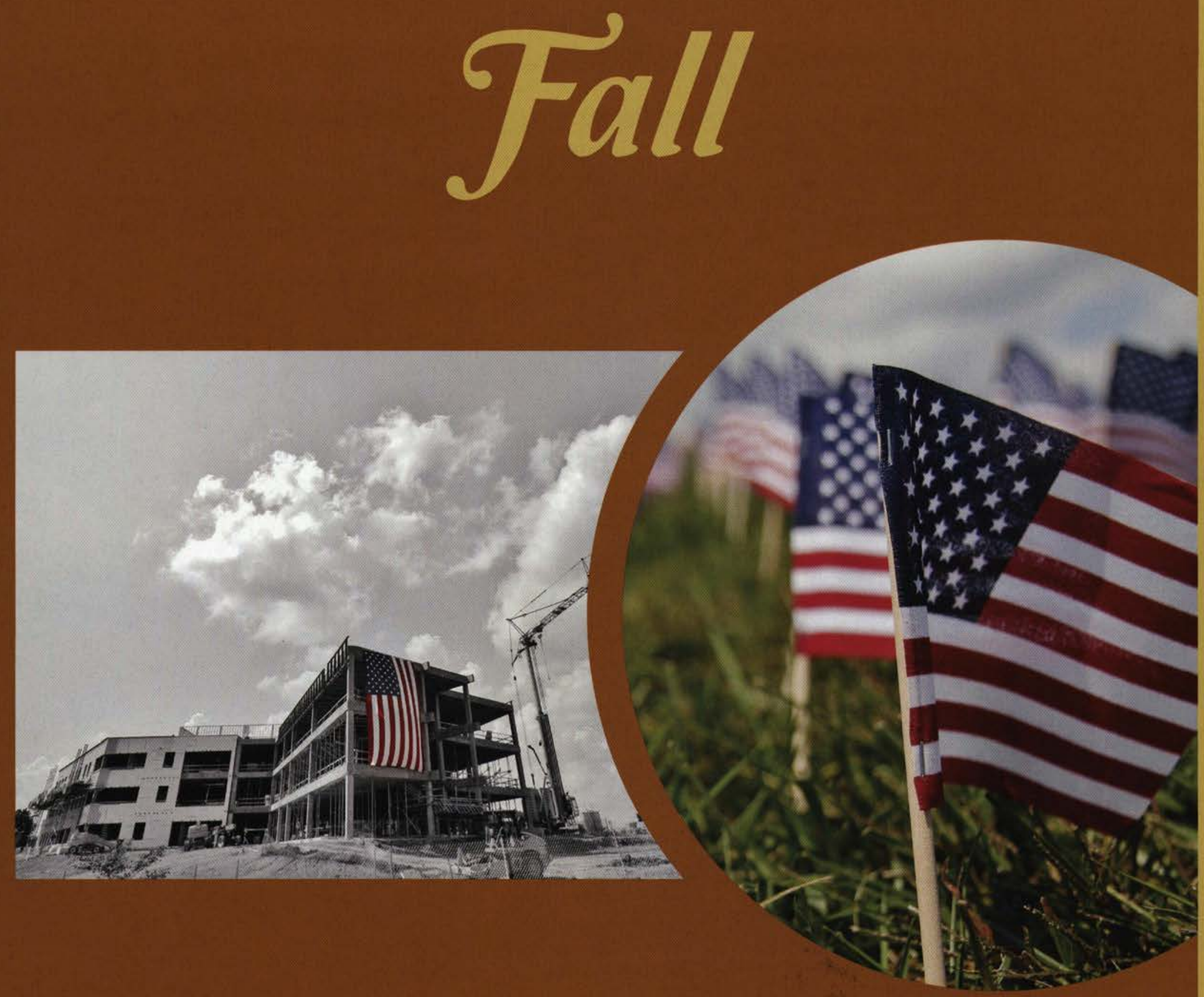

rekindle friendships, and create memories

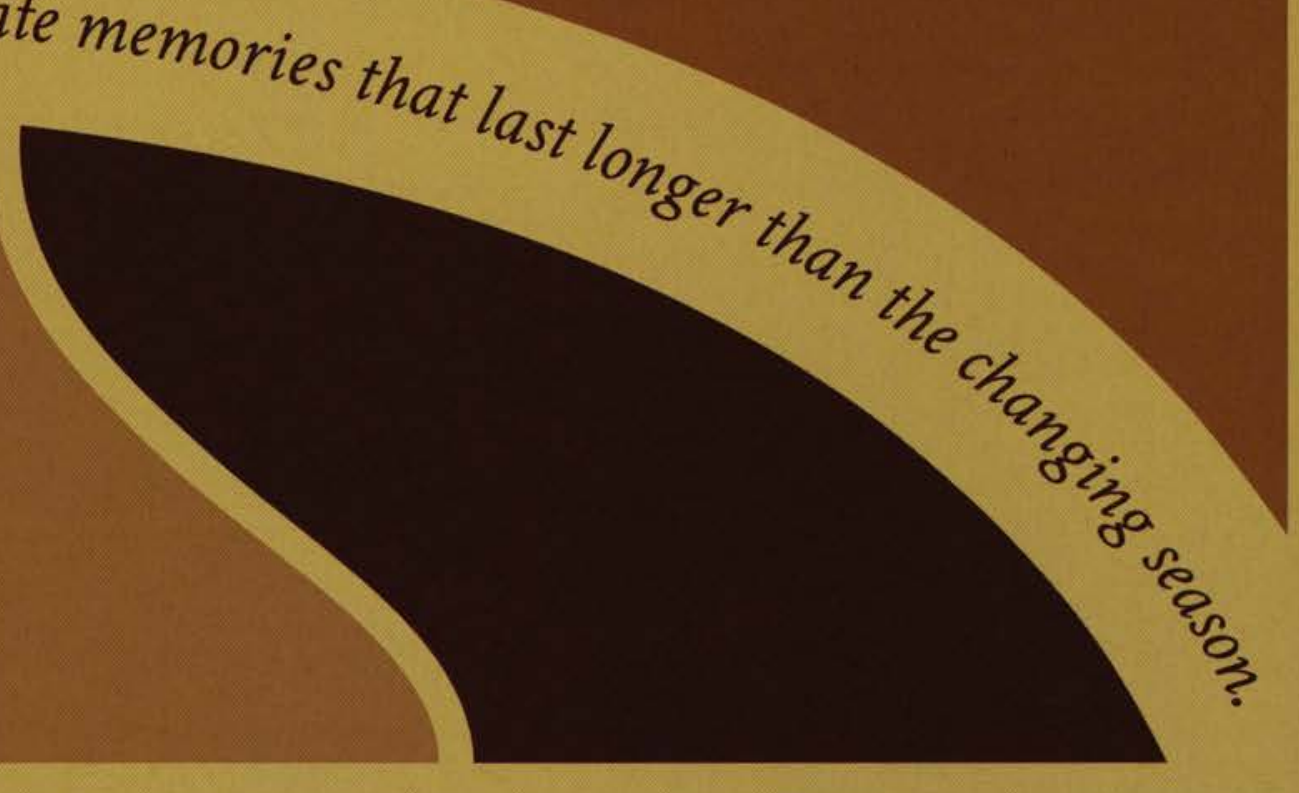




\section{Getting Started}

Getting Started Weekend sparks our excitement for the semester, the beginning of a new year at Cedarville.

$\checkmark$ A powerful, God-centered way to welcome a new year as a student body starts with the Night of Worship in the BTS

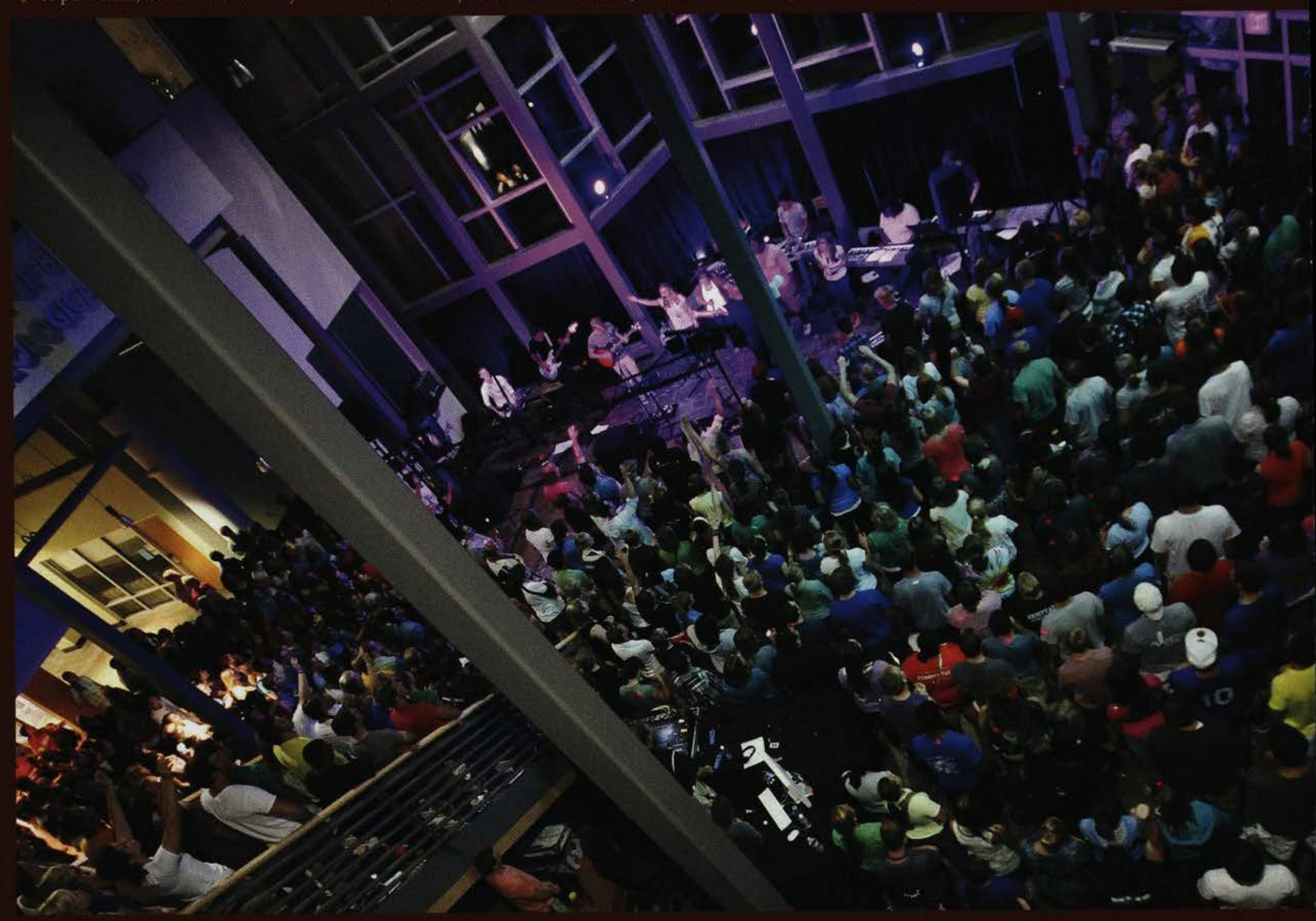

0 ampus finally woke up from its summer-long sleep when students started making their way to Cedarville life for fall semester. Over 900 students, sentimental parents, and car-loads of belongings started flooding the streets for the memorable madness of Getting Started Weekend 2011! From some students there was much uncertainty, mixed with anticipation of the upcoming events of the weekend and the upcoming events of their years ahead. With Resident Life staff, Getting Started leaders, and plenty of upperclassmen to help move in the new students, the transition from home life to college life turned into an unforgettable experience for everyone. Of course, the Freshman Party was one especially memorable experience that any freshman simply will never forget. Every Freshman Party has been a crazy experience each year, but this year the great event itself stepped up a notch; for the first time in Cedarville history, there was dancing! When over 900 new freshmen partook of free Red Bull, combined with activities such as "Just Dance," pedal car racing, trampoline bounce, inflatable obstacles, and the one and only mechanical bull, the result was every freshman's experience of the Freshman Party: crazy, good fun on a night to remember. One of this year's freshmen described the overall experience as, "One of a few times in my life where I could've walked up to anyone and introduced myself without it being weird or awkward!" The Getting Started Small Groups helped contribute to the class of 2015's transition into college life by planning activities, group dinners, and helpful sessions for the young, new faces to catch a glimpse of what they could experience as Cedarville students! 


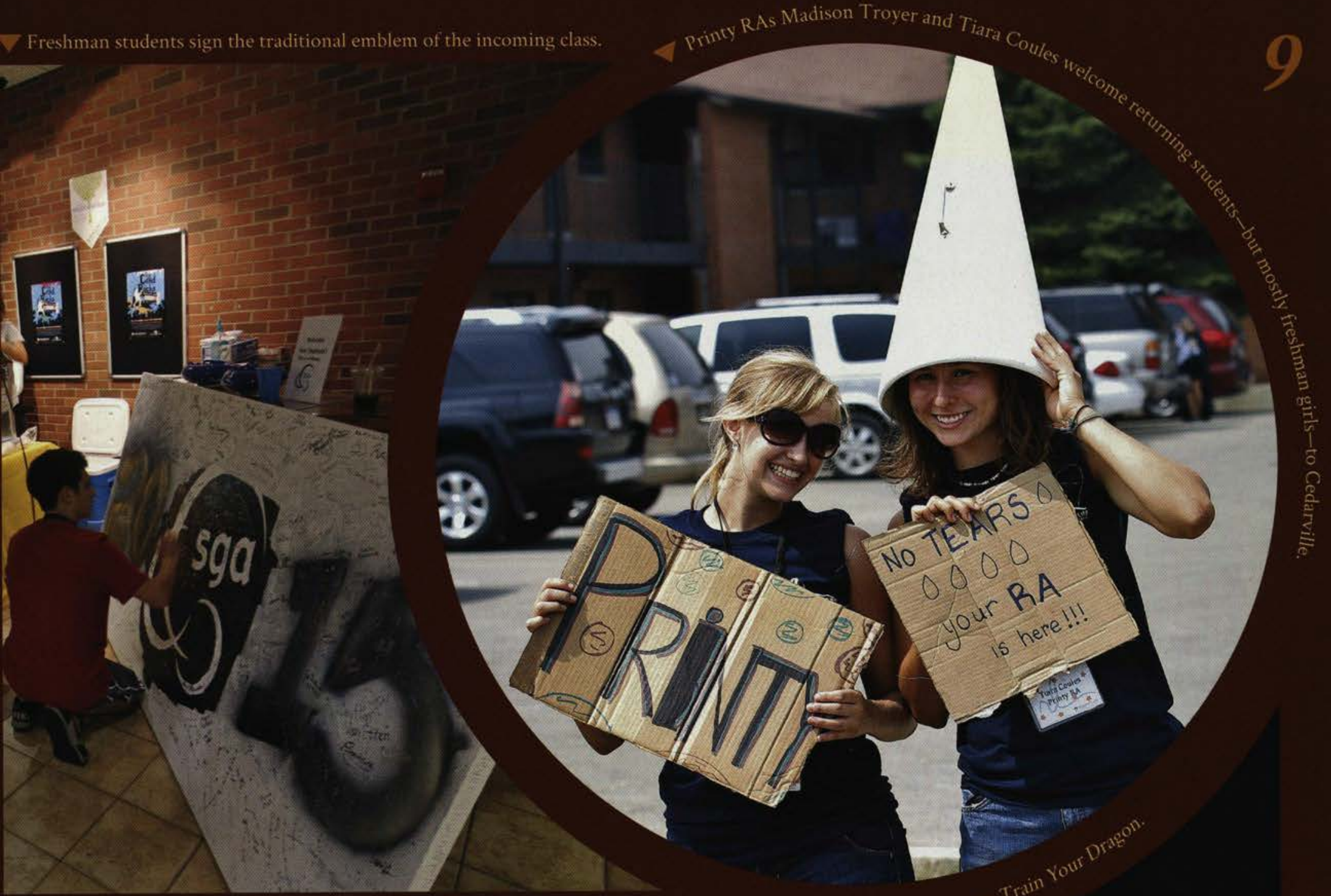

F SCAB hosts the first ALTernative Night of the year with food, live music, and an outdoor movie showing of How to Tral

(1)

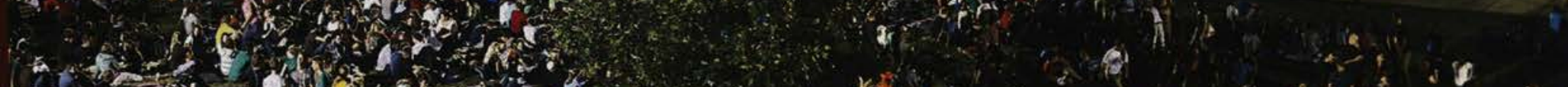

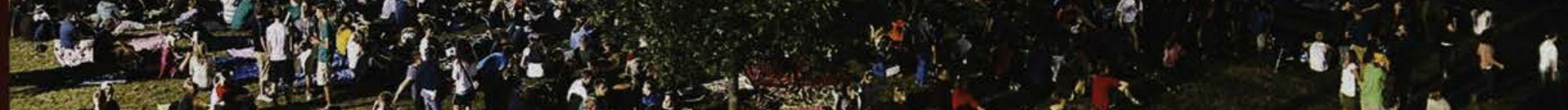

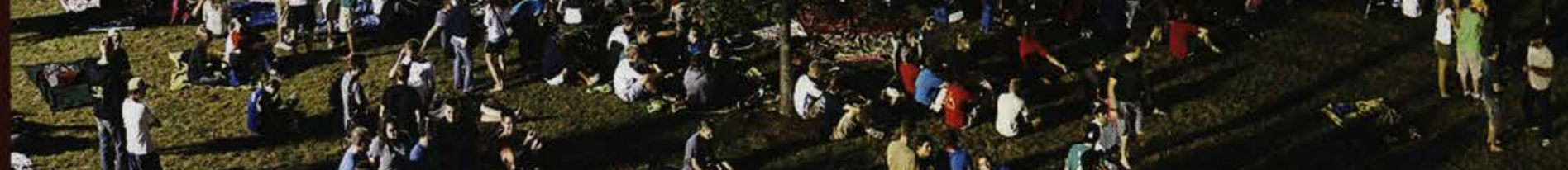

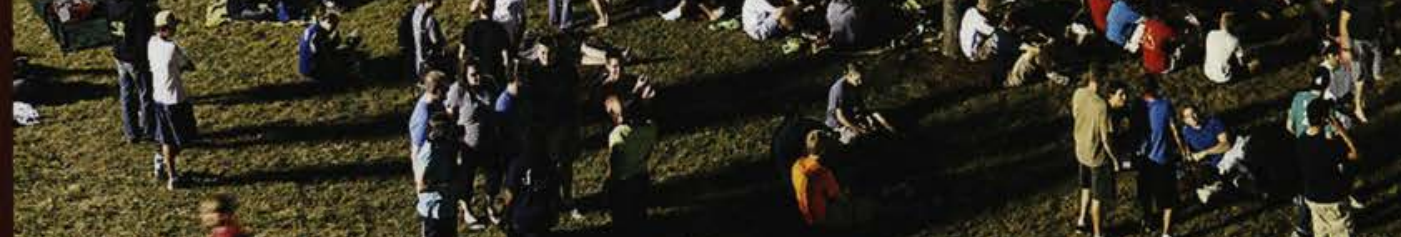




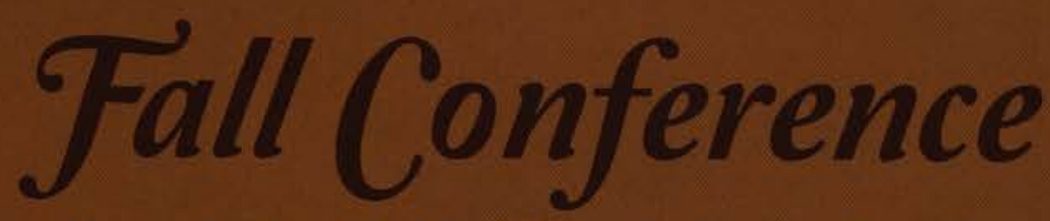

\section{"Be still, and know that I am God; I will be exalted among the nations, I will be exalted in the earth." Psalm 46:10}

Darris Sneed leads the special Fall Bible Conference praise team by uniting students, faculty, staff and guests in a time of worship.

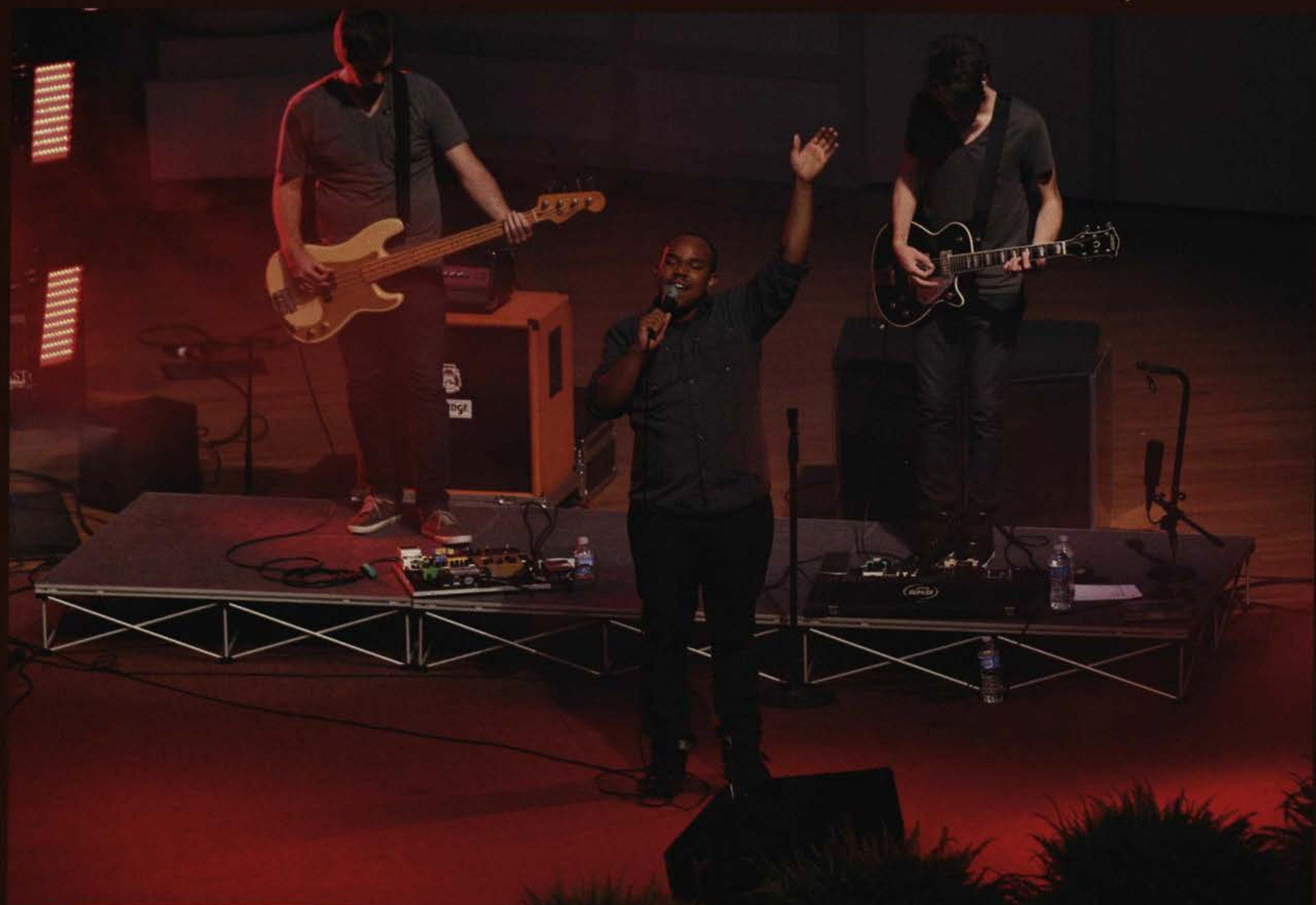

edarville University launched the school year with the Fall Bible Conference, which hosted Dr. Michael Easley, a poignant and articulate speaker of the Christian community. Students coming from either mountaintop or valley-deep summer experiences drew together as Dr. Easley delved into the book of Psalms during the first days back on campus. He encouraged students to feel deeply and to explore the possibilities of using their emotions to honor God. He challenged the Cedarville community not to be blind to pain or suffering, but to be aware of how
God may shape and form through hardships. Students and guests poured in at the regular chapel hour and in the evenings to be encouraged and challenged by Dr. Easley's words. Before his teaching, the Cedarville community worshiped together through an energetic worship band led by some from the Cedarville family. As the lights flashed and the beat filled the room, students raised their hands and their voices in honor of their great God who oversaw the events of the summer and brought them back to campus. Dr. Easley's words resounded with students from different walks of life. Senior Alisa Daum said, "For the past four years I have looked forward to the Fall Bible Conference because it starts the year off with a challenge, and this year was no exception." As Dr. Easley concluded his last message on Thursday morning, students left the chapel knowing they were ready to start this challenging yet exhilarating school year. 


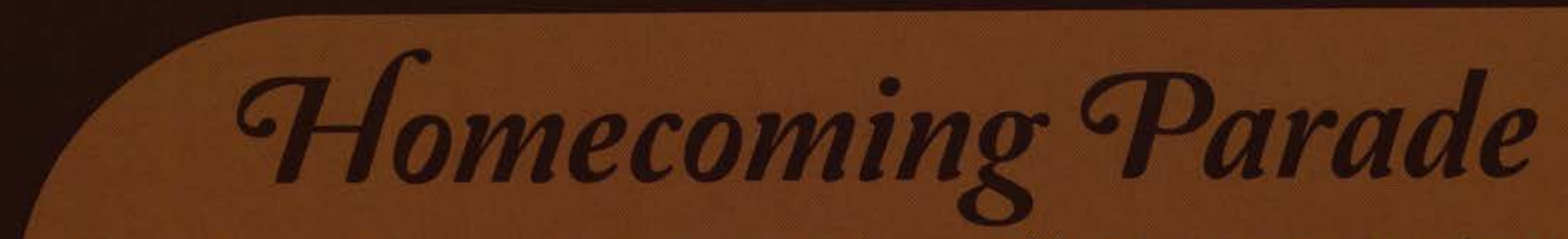

Homecoming provides an opportunity for every component of the university to come together to celebrate as a whole.

Dr. Brown distributes balloons to children in the crowd (an annual tradition!); perhaps some of them will one day be Yellow Jackets themselves!

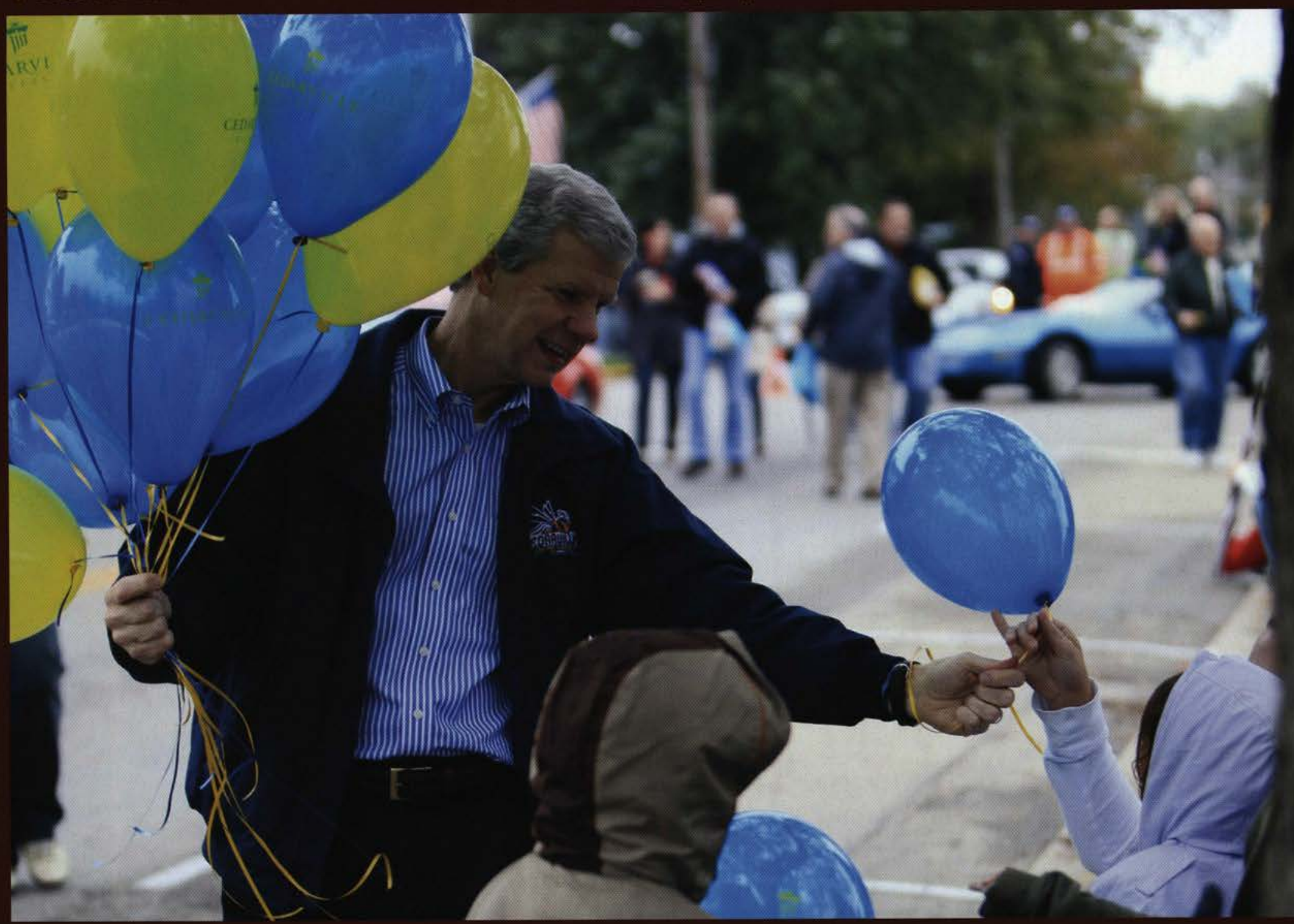

6 ew events can drag students out of their beds early on a Saturday morning; one such event is the annual homecoming parade. Many students, faculty and staff, returning alumni, and residents of Cedarville braved the dreary skies and frigid temperature by lugging umbrellas, adorning winter coats, and sipping hot drinks from the neighboring coffee shops. Young children excitedly ran and danced around their parents in anticipation of the festivities to begin, students chatted and laughed with their fellow acquaintances, and alumni met up with treasured friends from their own college days and reminisced happily with one another as if time had never passed. Amidst the friendly conversation, a loud police siren pierced through the air promptly at $10 \mathrm{am}$, signifying that it was finally time for the parade to begin. Homecoming attendees and those who received alumni awards were honored by being escorted throughout the succession atop various multicolored Corvettes. Creativity flourished throughout the vast display of ideas depicted by other campus groups and orgs, some of which tossed candy toward the crowd, those which sought to display a message related to the homecoming theme, "Beautiful Things," and lastly those with inventive ideas of their own, such as the members of OPE who depicted their own version of the Garden of Eden by ornamenting themselves with foliage or animal disguises. As expected, the parade was a great success in expressing the diversity of the student body, while simultaneously bringing back old memories for alumni and creating a new experience for all who attended this enjoyable occasion. 


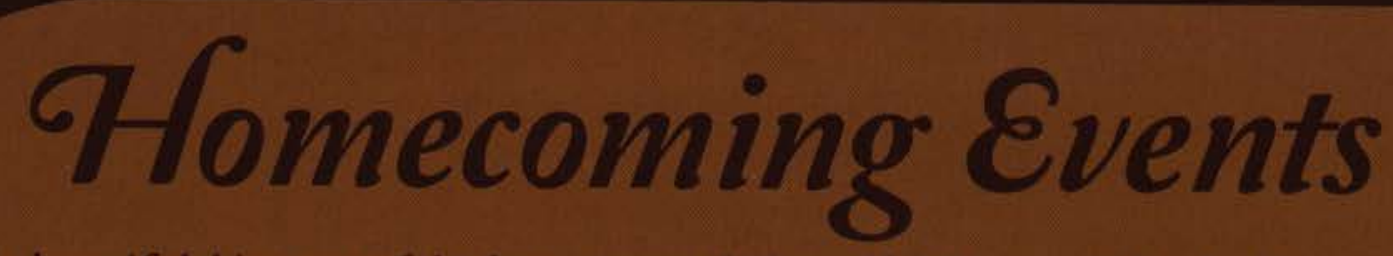

You make beautiful things out of the dust... you make beautiful things out of us." -Gungor

Even when these words will be hidden underneath carpet in the new nursing and pharmacy bulding, they will still be there, just below the surface

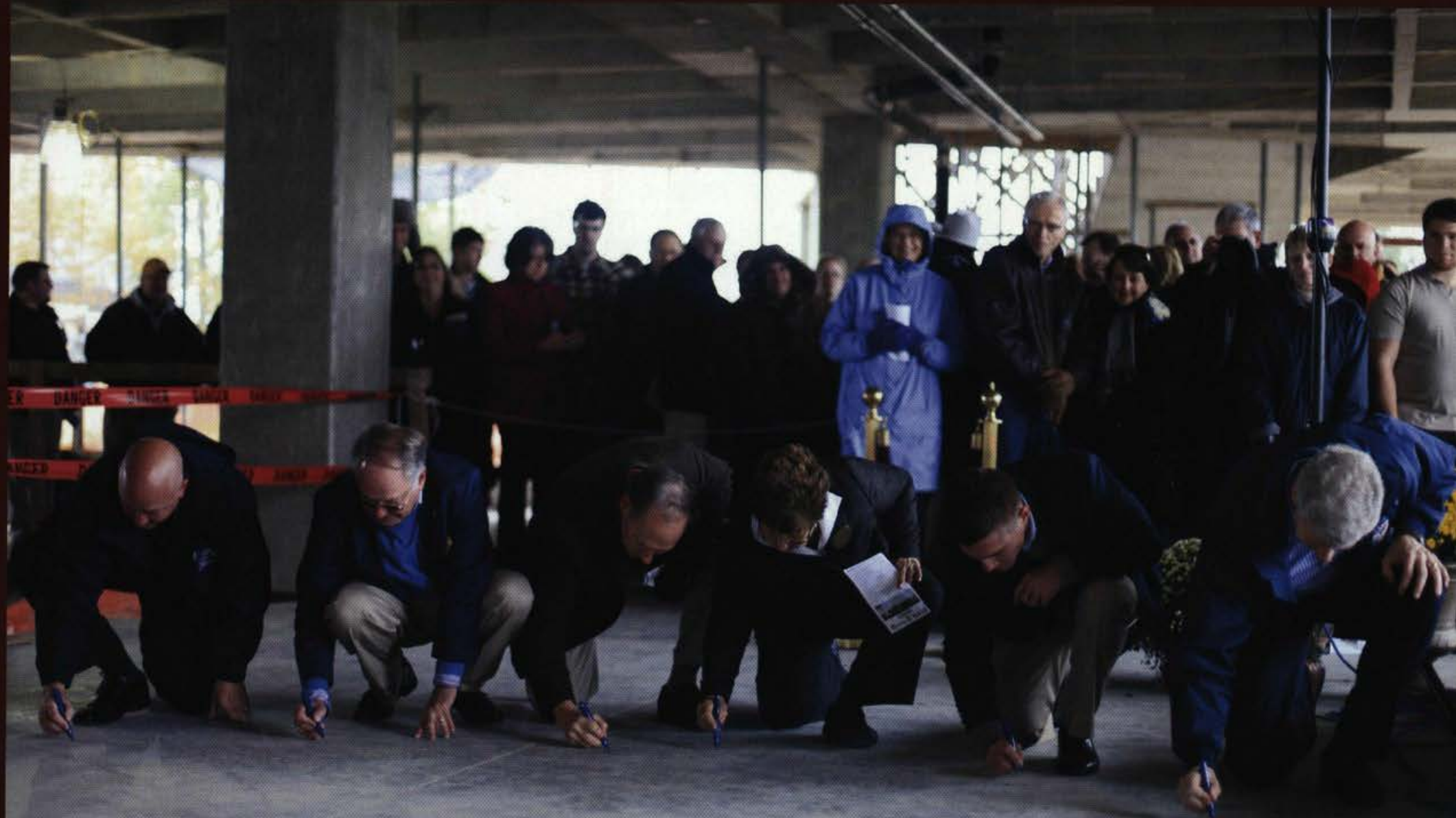

igh school homecoming means
festivities, a football game, and often an excuse to hold a dance. These students would often spend homecoming week talking about whether the football team was going to win Friday night, who was going with whom to the dance, and who would be crowned Homecoming King and Queen. However, Cedarville's homecoming this year was, as usual, a little different from that scenario. Throughout the week, alumni speakers led chapel services, speaking to the student body about their own Cedarville experiences and serving as examples of what God can do in and through a willing servant. Strollers, toddlers, and diaper bags were a frequent sight during homecoming weekend, as recent alumni returned with their young families to share memories of their college days. Elderly couples also returned, graduates from as many as fifty years ago, back when our university was still Cedarville College. Alumni joined current students for chapel, for meals in Chuck's, and for various sporting, fine arts, and student life activities. Special events were also held for the alumni. White tents stood around campus, providing places where graduates could gather with those they knew during their time at Cedarville. All of this allowed alumni to enjoy a meaningful homecoming experience. Using the name of a popular Gungor song, the theme of Homecoming 2011-"Beautiful Things"-placed special emphasis on how God can make something beautiful out of even the ugliest situation. The Young Alumni award recipient illustrated this perfectly; Cody Fisher showed the world how God transformed pain and disease in Iraq into a healing situation through the Preemptive Love Coalition. 


\section{Canoe Races}

The waters are cold and murky, but the prize is tempting... students plunge into Cedar Lake and hope for the best.

Joel Yost and Stephen Bennent dash across the finish line, claiming first place along with their fellow colleagues Isaac Shaffer and Daniel Cape.

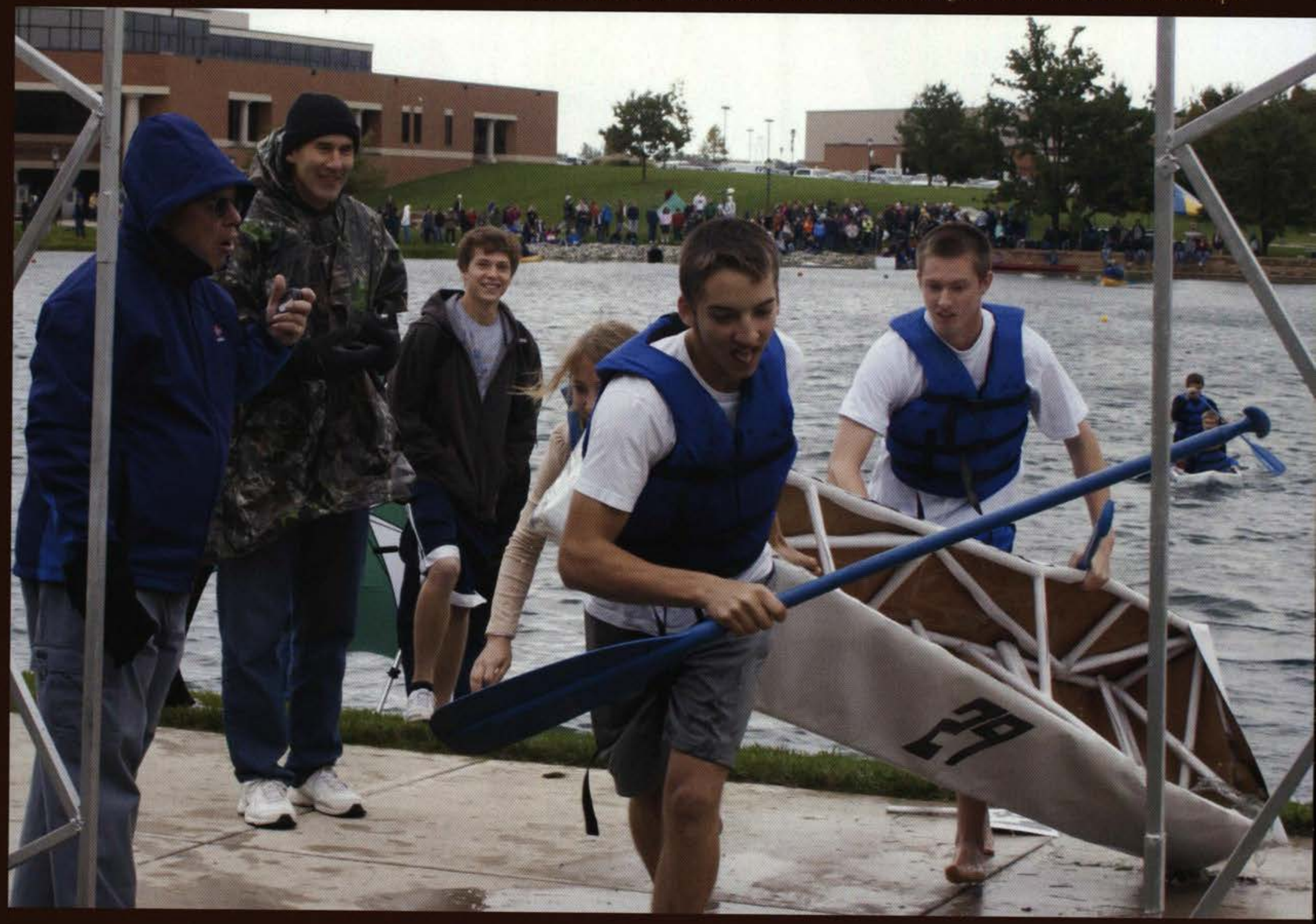

ne roll of packaging tape and one
roll of cardboard - it doesn't look like much. At Cedarville, these supplies could build a canoe that would traverse Cedar Lake, carrying two rowers and a passenger. Canoes shaped like bathtubs with a narrow bottom and high sides, like rafts with a wide bottom with low sides, or like some other nautical design all entered in the race, as contestants hoped to prove their design the winner. Thirty-one engineering canoes and five department canoes entered this year. Small girls found themselves cajoled into being passengers because the lighter the weight, the faster the canoe and the less likelihood it would sink. They hunkered down in the center, trying not to affect aerodynamics, arms shaking as they stabilized the tipsy canoe. This year Stephen Bennett, Joel Yost, Daniel Cape, and Isaac Shaffer of Team 29 carried the victory, taking only 2 minutes and 33 seconds to get to shore. A few brave souls stood thigh-high in water to help the boaters carefully ease into their canoes. Vigorous or misplaced pressure could destroy the fragile lining, ruining the chances of victory before leaving the starting dock. Even with such precautions, some canoes sank mere yards from the finish line. The students paddled faster, desperate to reach their goal, so close yet so far away. Some managed to row their dilapidated paper hull to shore by sheer force of will, while others were left to slosh the last few yards on foot, paddle in hand, paper remains dispersing under the surface. It's a Cedarville tradition, and even non-engineering alumni will recall the competition, its glorious victories, and disgraceful defeats. 

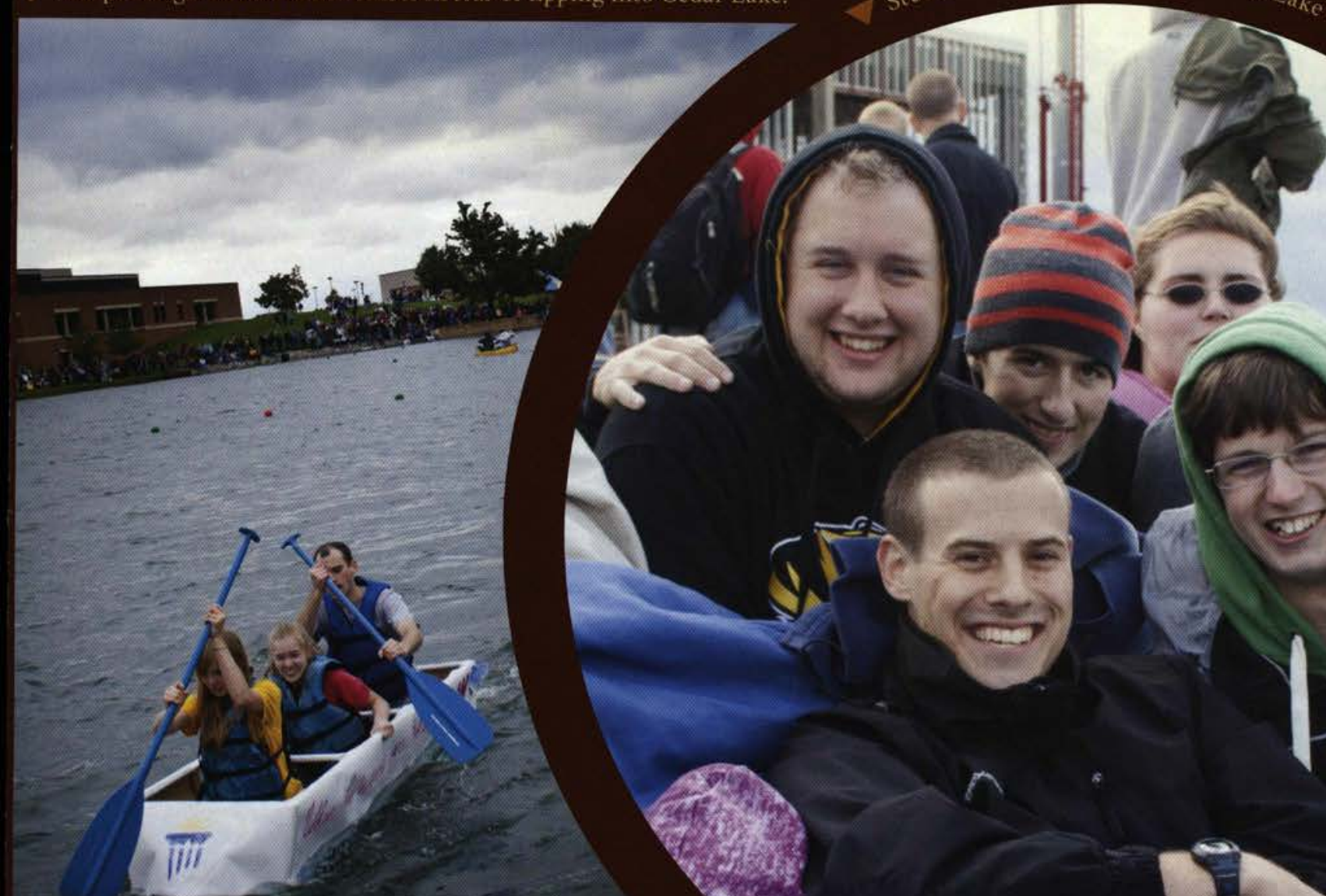
सी 


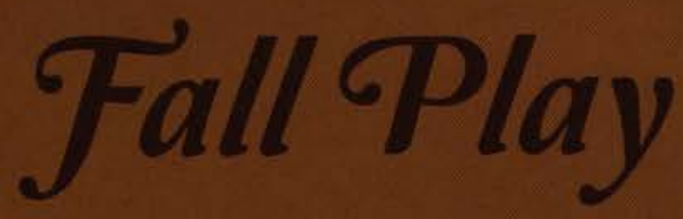

"You'll be glad too, when the end comes." - Agatha Christie, And Then There Were None

The cast of Agatha Christie's And Then There Were None converse with each other on the stage in preparation for the thrilling climax.
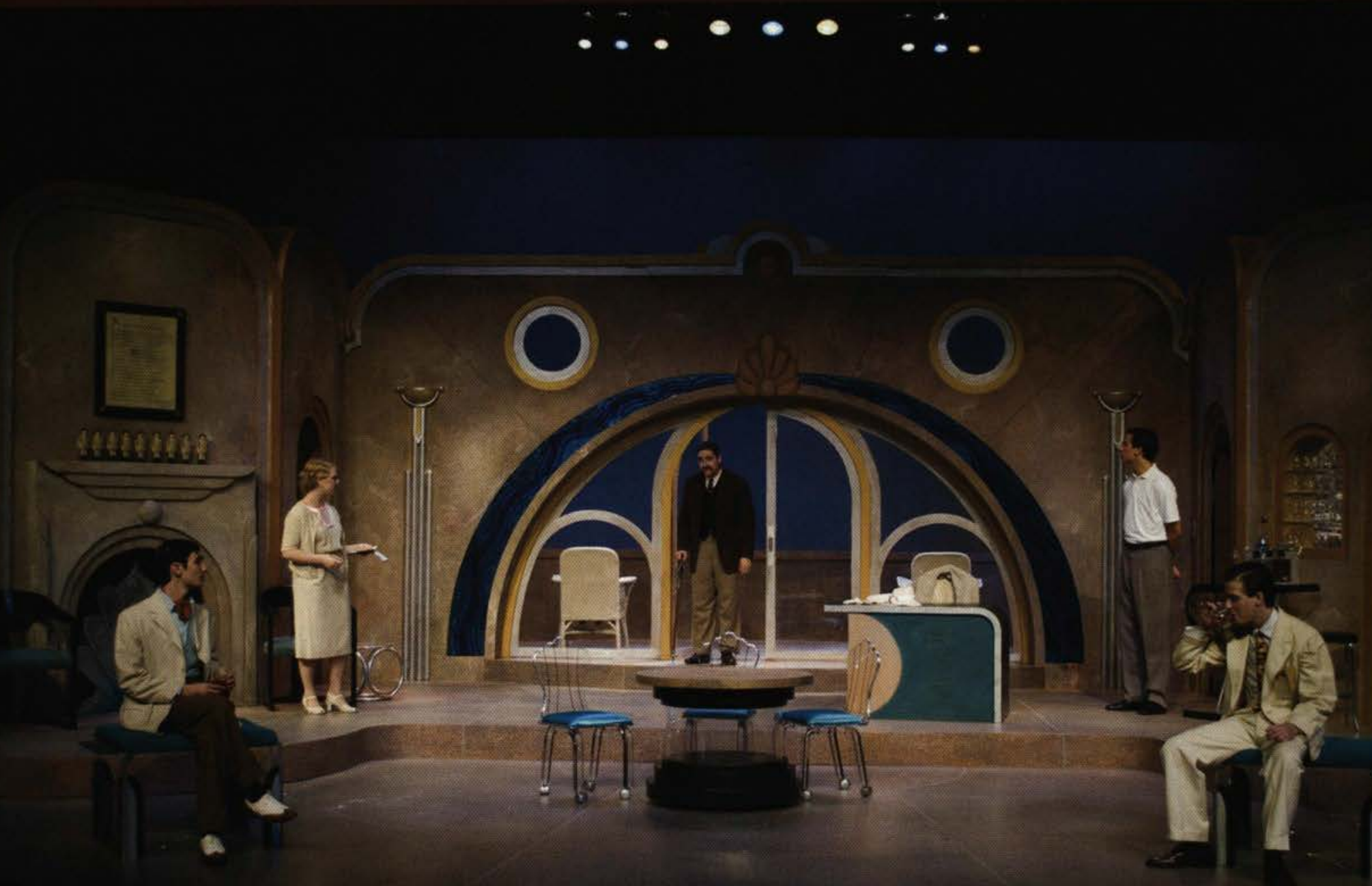

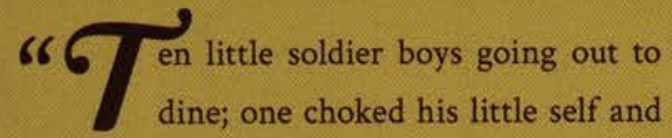
then there were nine..." What does one get when mystery, murder, and intrigue meet a good dose of comedy and plenty of wit at Cedarville University? Some may respond Chuck's at dinner rush, but the correct answer is actually Cedarville University's Fall Theatre Production inspired by Agatha Christie's And Then There Were None. Chaos reigned in this spunky rendition of Agatha Christie's book as ten mysterious visitors to a 1938 England home struggled against all odds for their very lives. A diabolical nursery rhyme dictated each person's fate until, seemingly, there would be none left alive. The murderer, unknown to the audience until the last moments of the production, skillfully picked off each visitor in fashion, eerily mirroring the rhyme. Viewers in the audience were kept on the edge of their seats down to the end. A set of little soldier boy statues (originally ten) that were set on the fireplace mantel provided clues to keep the audience participating in solving the mystery. Slowly their number dwindled as the visitors were eliminated, transforming the group from a lively entourage into a suspicious few. The viewers were also transformed by what they had seen. Many in the audience left the theatre in awe after witnessing the closing moments of the production. Through intrigue and humor, Cedarville's Theatre Department produced a favorite with this one-and there were many who benefited from its charm. 



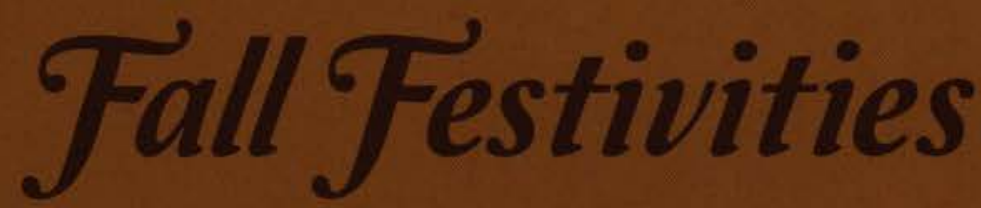

Fall semester overflows with educational, spiritual, and social events, offering ways to grow more than just in classes.

Students embrace diverse backgrounds and ethnicities by eating different types of foods at the Cultural Celebration party.

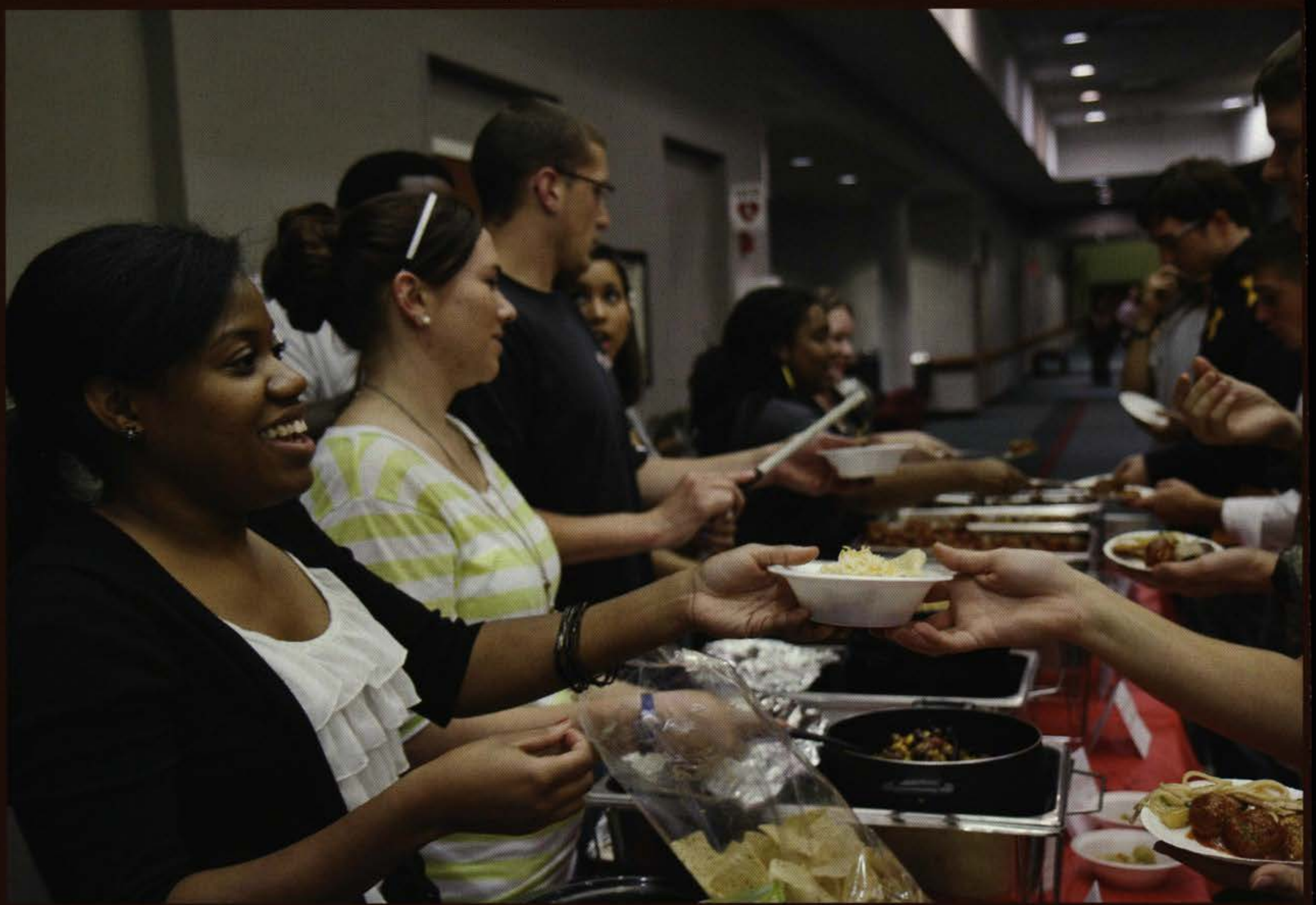

s days grew shorter and the
bright Ohio sunsets came sooner, the heat of the summer refuses to leave, meaning seventy degree days in November and the sound of slapping of flip-flops around campus. The lingering summer pulled fall events and students outside. A new phenomenon on campusswing dancing-became a hit with a yearly event, Fall Back. SGA sponsored the first ever Cedarville Social, which combined swing dancing, group dancing (like the Cha-Cha Slide), hot chocolate, and apple crisp. Ask anyone who attended the event, and he or she will rave about the lights draped across the BTS patio, the smell of apples and cinnamon, and the live jazz music. Another favorite yearly tradition is the Printy/Maddox and Lawlor/Hill football game. Printy fought well but lost to Maddox. The Hill, after many intense practices, demonstrated their football skill s by beating Lawlor. The football game was during Parents Weekend this year, providing stands packed with cheering crowds of family members. After much petitioning and a Facebook group, SCAB achieved an amazing feat... bringing Owl City to
Cedarville on $11 / 11 / 11$. Guests streamed onto the campus, and the chapel was brimming with people for the concert; an adequate demonstration of the power of the people. The G92 Immigration Conference, a conference focused on immigration and the Christian response, sponsored renown speakers like Shane Clairborne, Jim Wallis, Eve Nunez, and Carlos Campo. The conference encouraged students to think and respond, not parrot what other people are telling them. The fall is always packed with new and exciting activites for the student body to enjoy. 


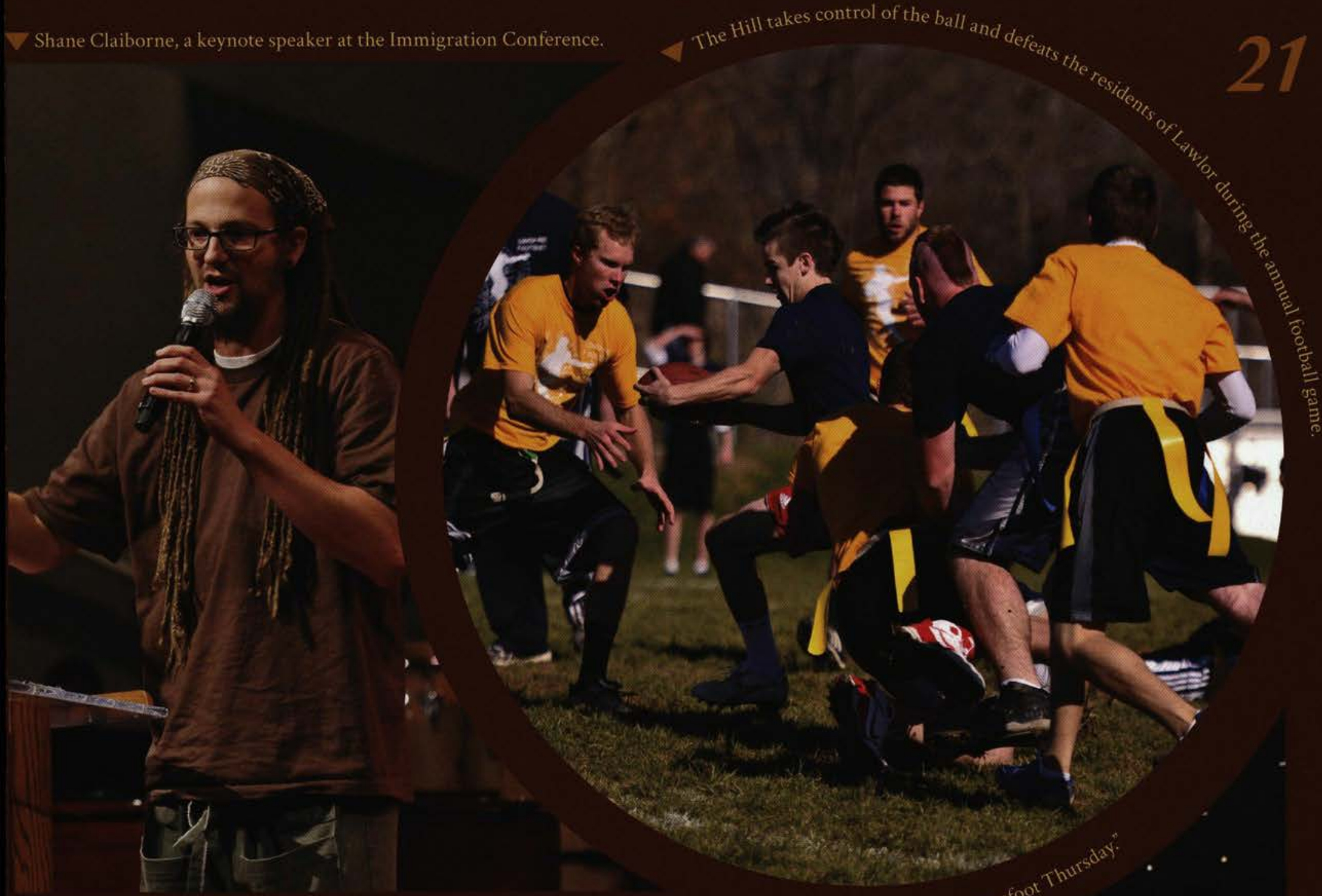

$\checkmark$ Students gather shoe donations for underprivileged people in Africa while going without shoes themselves on ${ }^{4} \mathrm{Barefoot}$. . .

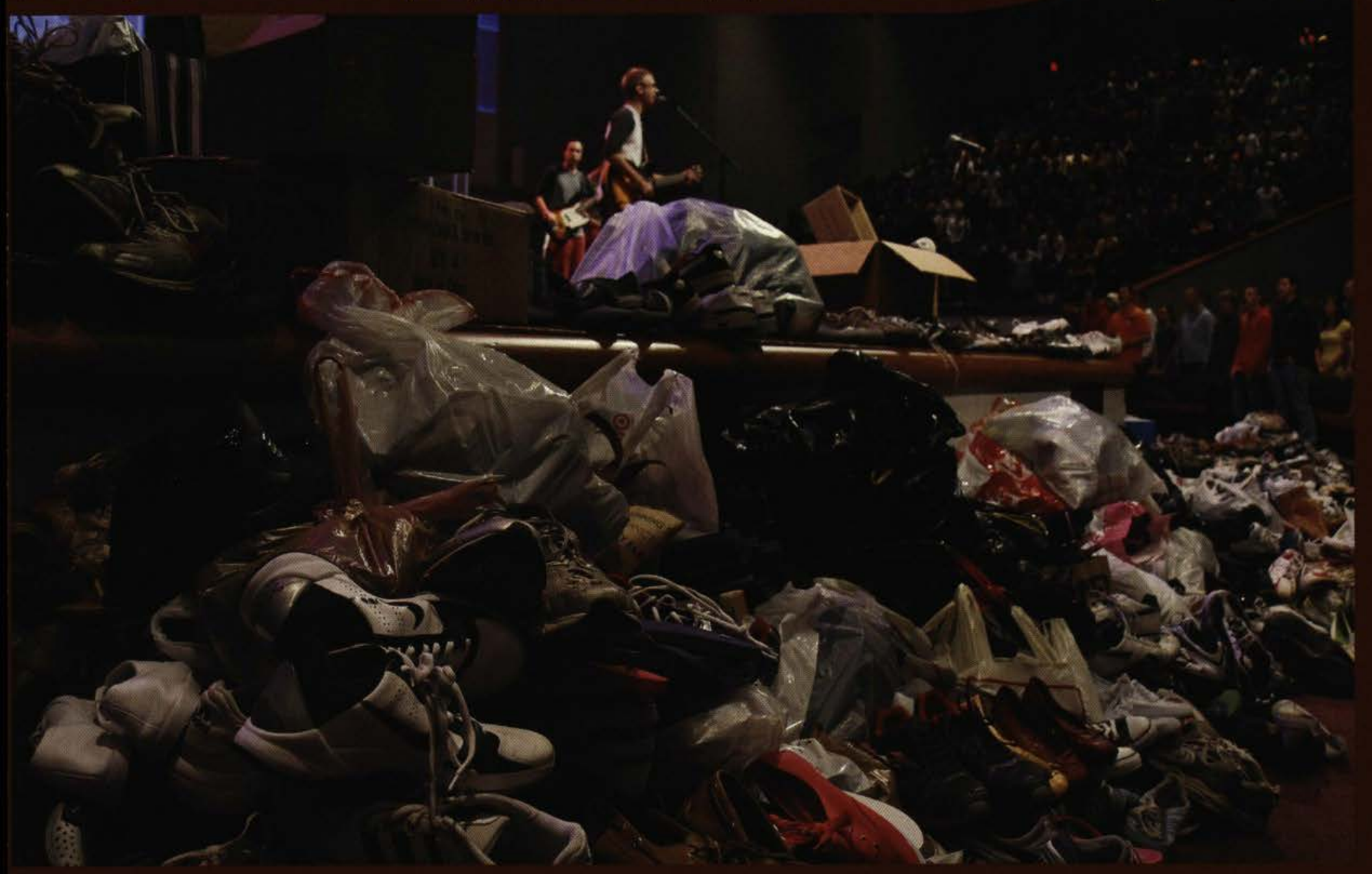




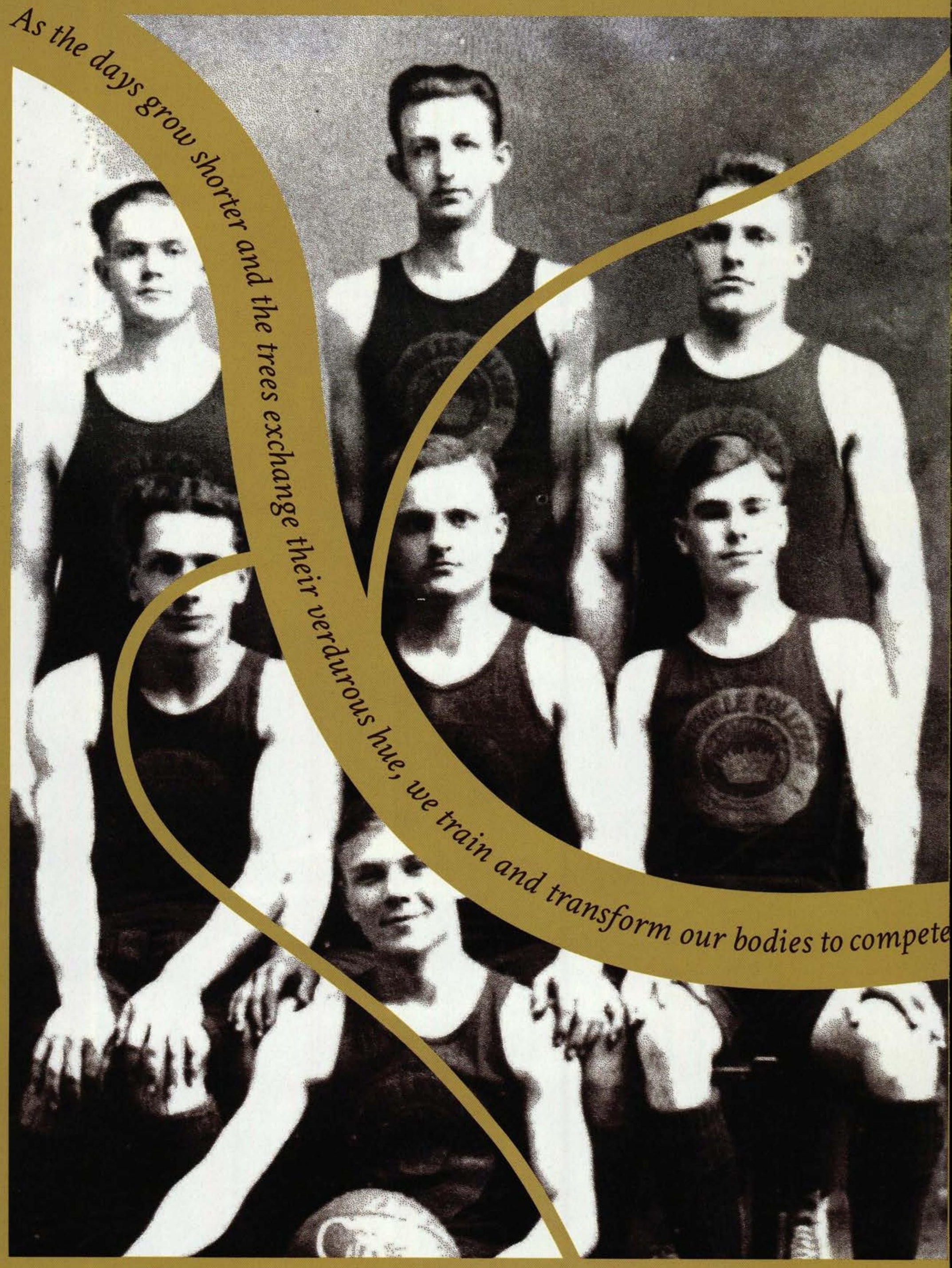



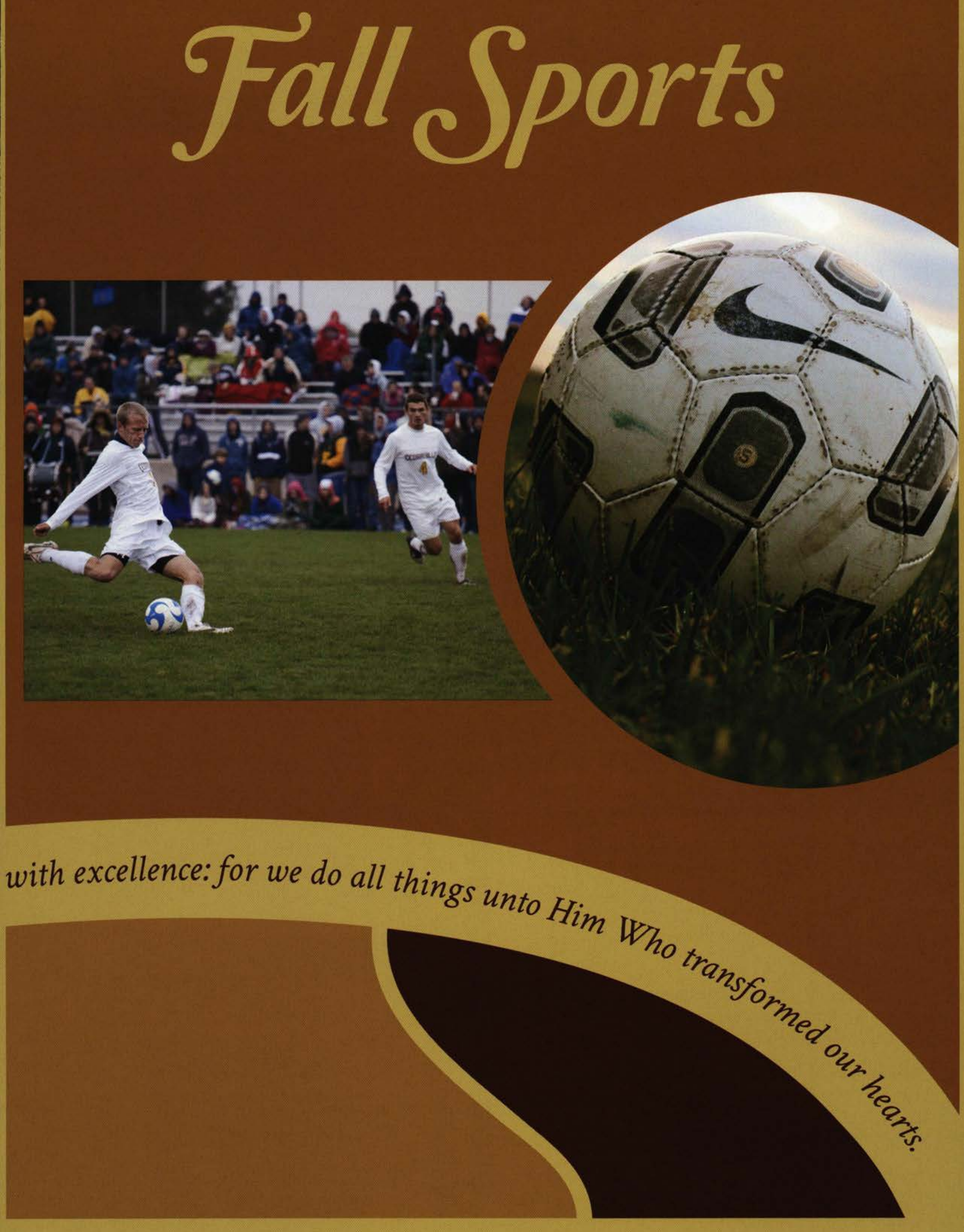


\section{Men's Soccer}

The Yellow Jackets place 3rd in the NCCAA championship game in Florida.

$\checkmark$ The Men's soccer team epitomizes team spirit, winning themselves the NISOA Team Sportsmanship Award.

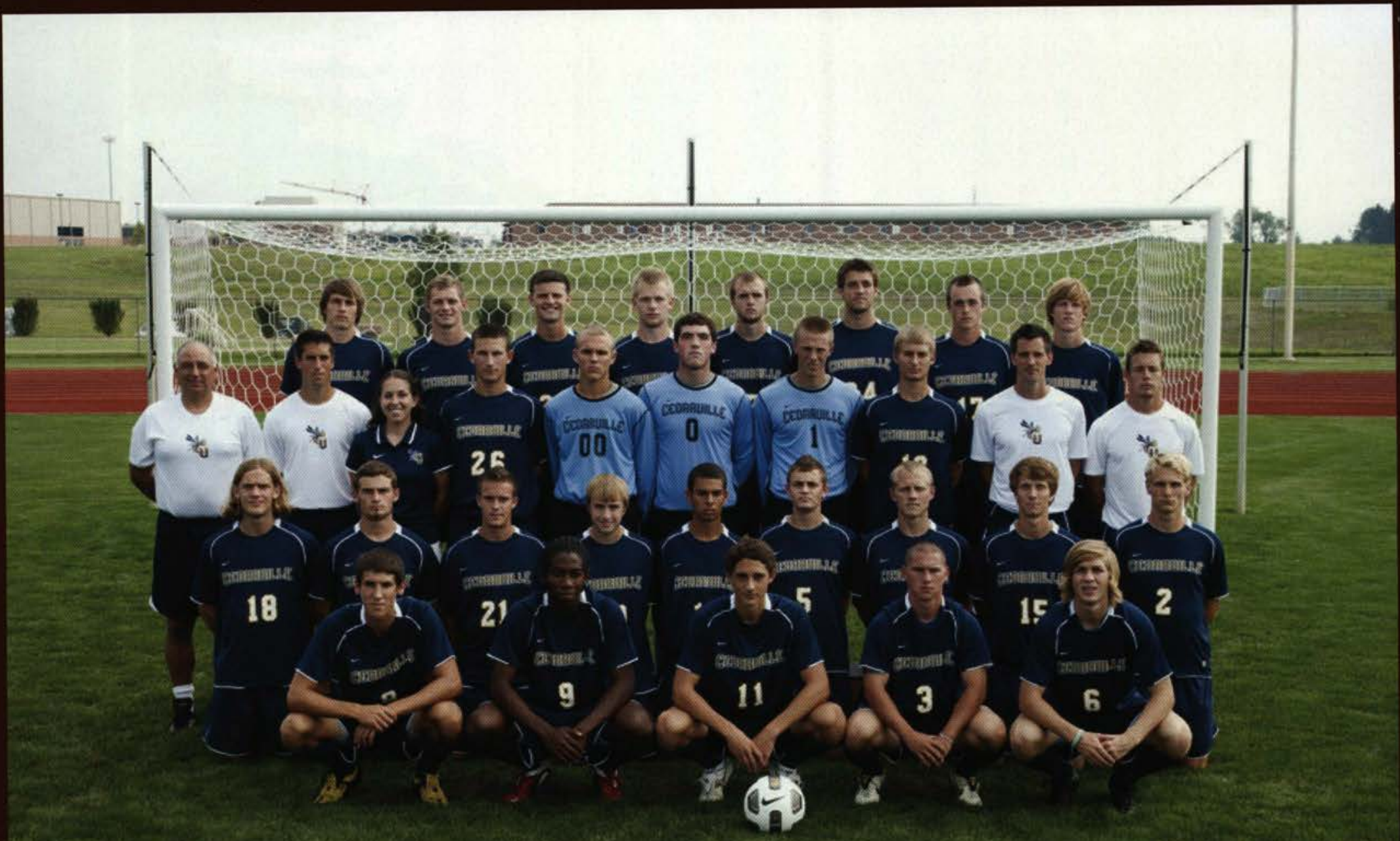

\section{Meet the Team:}

First-row: Scott Erwin, Stephen Morris, Ethan Shula, Ryan Thurman, Joe Bonessi.

Second-row: Timmy Waller, Todd McKinley, Mitch Goodling, Daniel Rigby, Eric Hoober, Zack Gatlin, Jeremy Hoppe, Ryan Connelly, James Twinem.

Third-row: Dr. Kevin Roper (Assistant Coach), Grant Knight (Assistant Coach), Leyna Hebert (Assistant Athletic Trainer), Grant Kovac, Curtis Ranck, Ian MacDonald, Alex Scott, Justin Santoro, Todd Beall (Head Coach), Brett Faro (Assistant Coach).

Back-row: Jon Earl, Myles Greely, Stephen Schindler, Dillon King, Scott Roseberg, Eric Newman, Steve Ellis, Connor Scott.
Record: 14-6-3
Seton Hill

Indianapolis

Milligan

Olivet Nazaren

Shawnee State

Goshen

Notre Dame (OH)

Cornerstone

Wittenberg

Walsh

Urban?
W 6-1

L $0-2$

W 4-1

W 3-1

W 2-1

L 1-4

L $0-2$

L $0-4$

W $3-2$

L $0-3$

W 4-1
Tiffin

Malone

Concord

Obio Christian

Mt. Vernon Naz.

Walsh

Indiand Wceley on W-3:

Grace

Oakland City

California Baptist T 0-0 Judson
T $0-0$

W 2-0

W $2-1$

W 3-1

W 3-0

W 5-1

L 1-2

T 1-1 


\section{Women's Soccer}

They play hard, play well, and have fun. The women's soccer team is a force to be reckoned with.

- The Ladv Yellow Jackets Women's Soccer team had three players selected to the OCSA NCAA Division II/NAIA Women's Soccer Team.

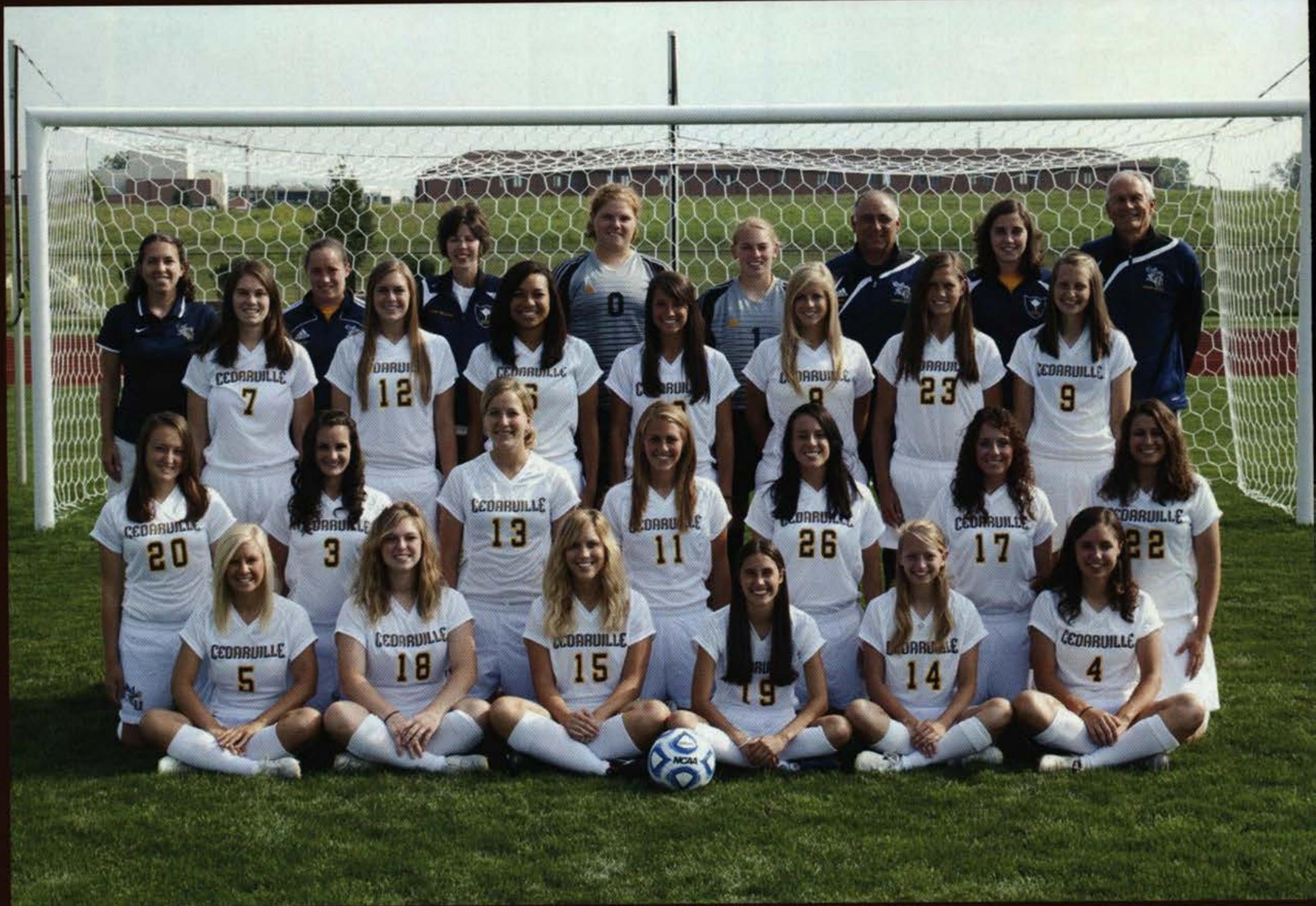

\section{Weet the Team:}

First-row: Sarah Storkel, Alexis Mickle, Jill Davis, Deanne Bradshaw, Elise Hurley, Anna Schmid.

Second-row: Karen McCoskey, Dresden Matson, Kelsey

Watkins, Morgan Ziegler, Rachel Brownfield, Sarah Brownfield, Jill Carroll.

Third-row: Elizabeth Cox, Emily Niedermayer, Amanda

Bunton, Kristie Wolff, Ashlee Wilson, Arianna Pepper, Melissa Ruhlman.

Back-row: Leyna Hebert (Asst. Ath. Trainer), Katelyn Reuther (Asst. Coach), Krista Mattern (Asst. Coach), Christine Faulds, Keri Sachtleben, Dr. Kevin Roper (Asst. Coach), Brianne Barnes (Graduate Asst.), Head Coach John McGillivray.

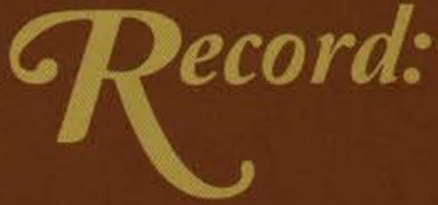

$P=2$

Indiana Wesleyan L 0-5

Wilmington

Defiance

Ohio Dominicin

Bryar

T $0-0$

Notre Dame (OH)

Cumberlands (KY) L 0-1

Malone

Taylo

Ursuline

$\begin{array}{ll}\text { Walsh } & \text { L } 1-2 \\ \text { Mit. Vernon Naz. } & \text { W 1-0 }\end{array}$

Urbana

Asbury

Notre Dame (OH)

Campbellsville
T 0-0

L. 1-2

L 0-1

W 2-c

$1-2$ 


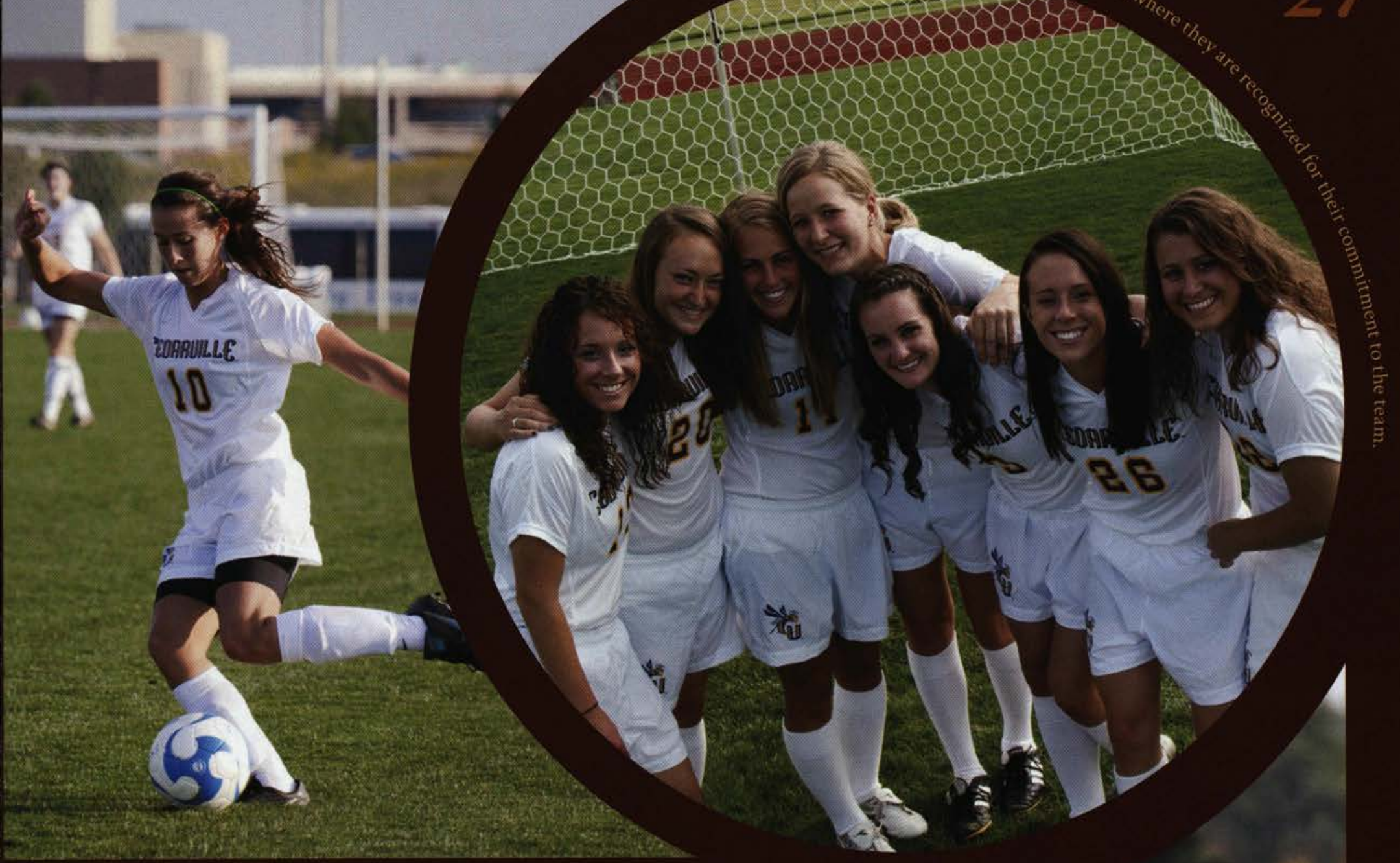

$\nabla$ Junior Anna Schmid's opponents trail behind her accelerated speed as she tries to advance the ball up the field.

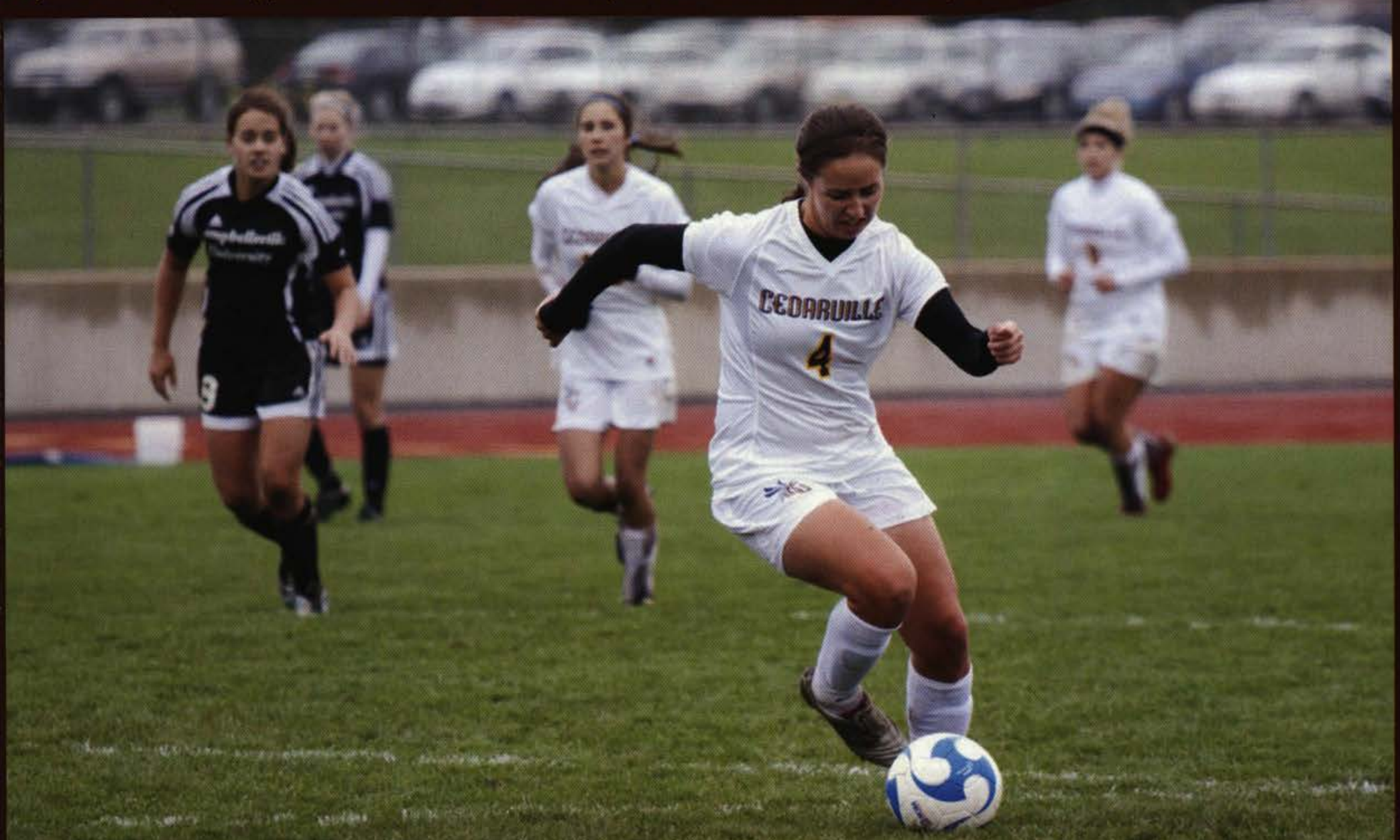




\section{Women's Oolleyball}

This season, the Lady Jackets reched their one-thousandth win during their game against Notre Dame.

Vhe Women's Volleyball Team hosted a game to support Breast Cancer awareness titled "Dig Pink" again this year.

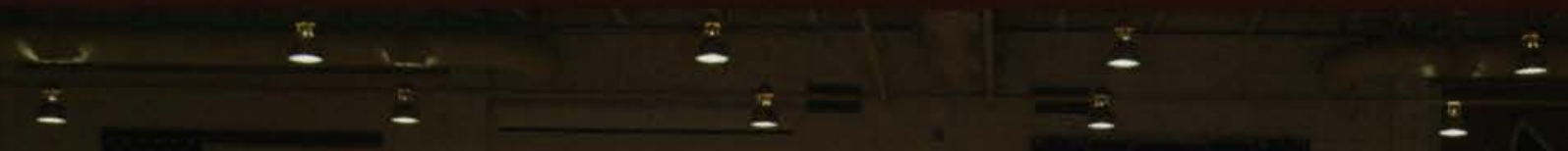

WRVILLE UNTYERSITY YOLLEYBALL CEDAHVILLE UNIVERSITY VOLLEYBN

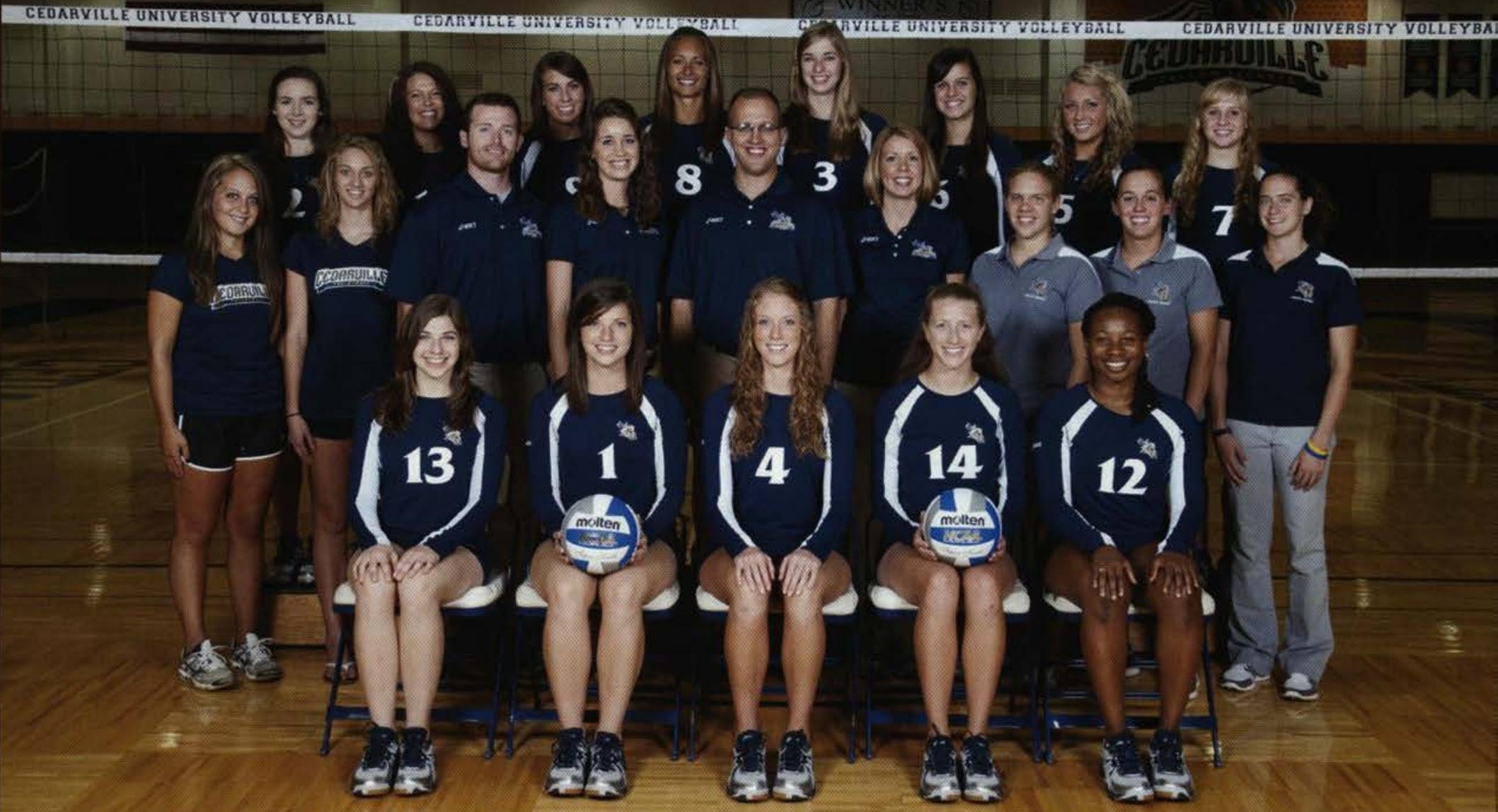

\section{Weet the Team:}

First-row: Sarah Bradshaw, Erica Bartholomew, Emilie Morrison, Kara Yutzy, Lauren Williams.

Second-row: Miranda Davenport (Student Assistant), Micah Motes (Student Assistant), Garrett Maddox (Junior Varsity Coach), Amy Wengrenovich (Assistant Coach), Doug Walters (Head Coach), Libby Aker (Assistant Coach), Marissa Yorgey (Student Athletic Trainer), Ally Stafford (Student Athletic Trainer), Hannah Haynes (Assistant Athletic Trainer). Back-row: Heather Kirkpatrick, Kassi Ernsberger, Stephanie Rogers, Aubrey Siemon, Hannah Wagner, Kelsey Christiansen, Amanda Bell, Maddie Anderson.

\section{Decora: 22-18}

Shawnee State Central State Malone Ursuline

Walsh

Northern KI

Davis \& Elkins

Urbana

Notre Dame (OH) Win W.V. Wesieyan Loss Wheeling Jesuit Loss
Central State

Malone

Notre Dame (OH)

Walsh

Alderson-Broddus Win

Urban

Indiana-East

Mr Vernon Naz.

Ursuline

Notre Dame (OH)

Walsh
Win

Loss

Win

Loss

Win

Loss

Win

Win

Win

Loss 


\section{Men's Cross Country}

The Cross Country men "run the race that is set before them" - finishing as runners-up in the NCCAA.

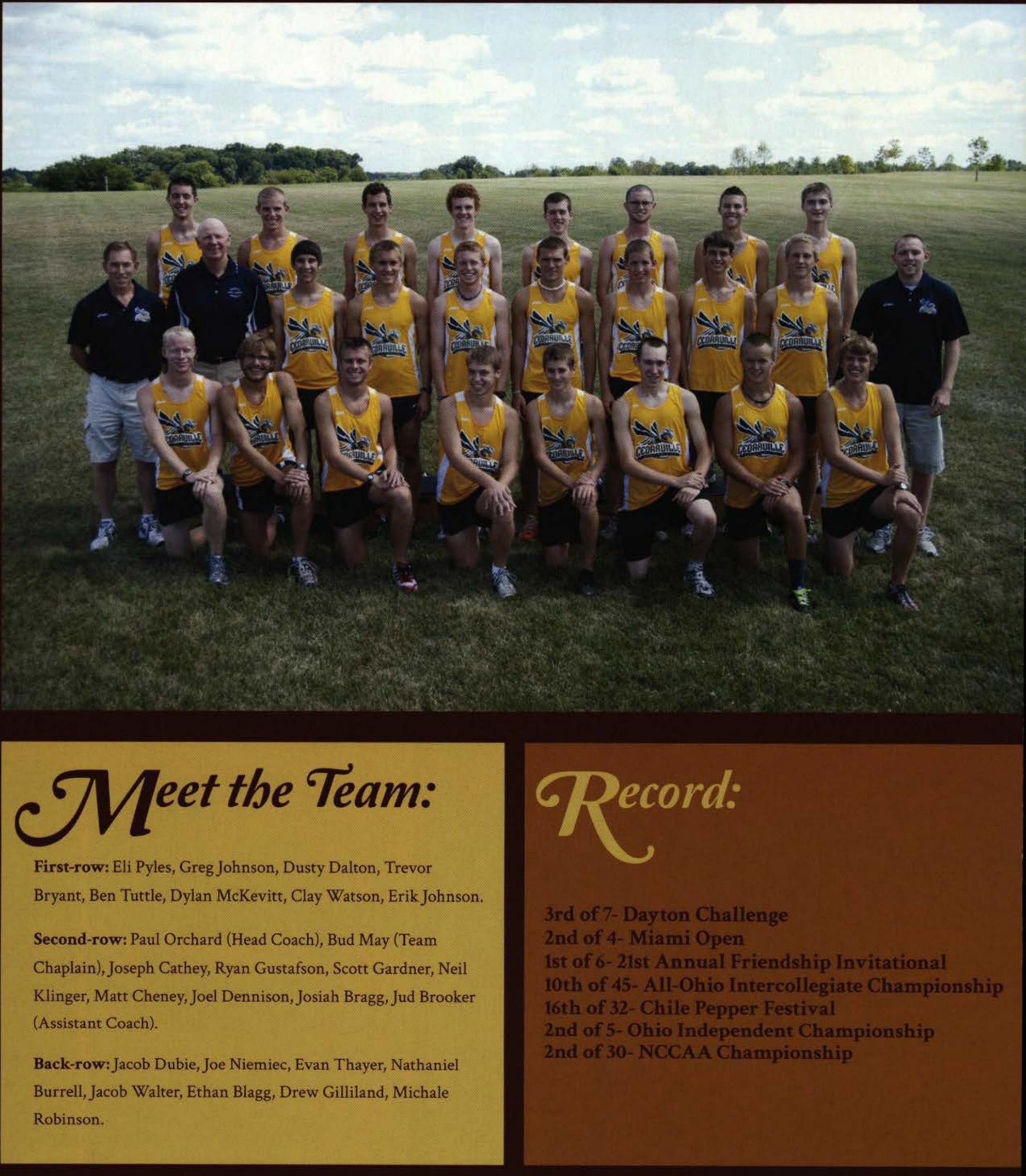




\section{Women's Cross Country}

Winners both on and off the field, nine women of the cross country team are honored as NCCAA scholar-athletes.

Even while missing key teammates, the Lady Jackets place 5 th out of 25 schools in the NCCAA championship.

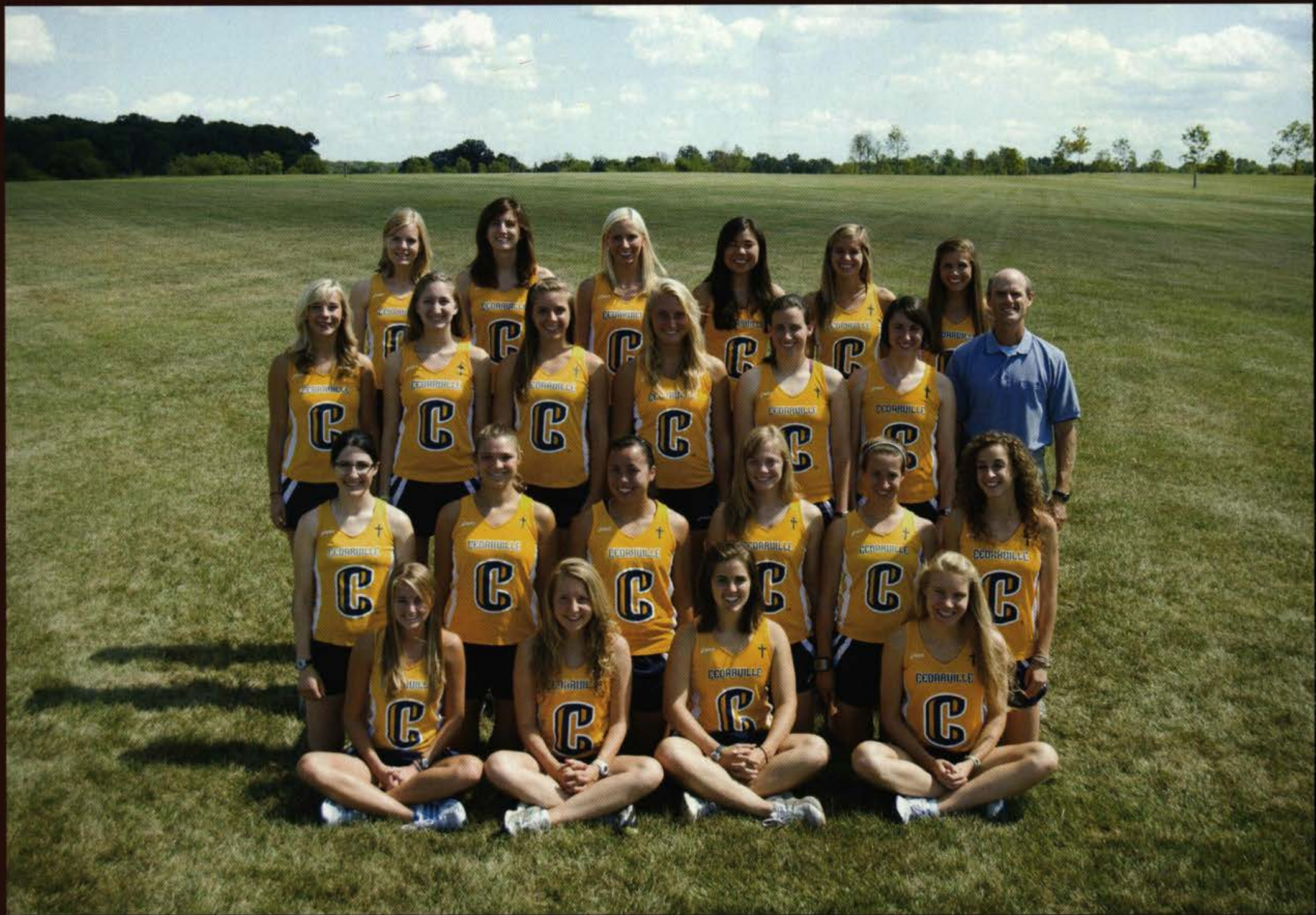

\section{Weet the Team:}

First-row: Tabby Moore, Carolyn Case, Joanna Wheatley, Tabitha DeHart

Second-row: Hannah Lamos, Gina Mattes, Abby Wong, Krista Johnson, Neola Putnam, Louise VanMatre

Third-row: Alyssa Mathis, Katelyn Stover, Katie Lanphier, Jasmin Vanachowski, Elisa Cherry, Grace Campbell, Jeff Bolender (Head Coach)

Back-row: Melanie Redfield, Lauren Callahan, Jessica Smith, Rachel Wong, Meghan Terrell, Jennifer Hollander

\section{Record:}

3rd of 6-Dayton Challenge

1st of 7-21st Annual Friendship Invitational 14th of 47-All-Ohio Intercollegiate Championship 4th of 31- Gettysburg Invitational 2nd of 5- Ohio Independent Championship 5th of 25-NCCAA Championship 


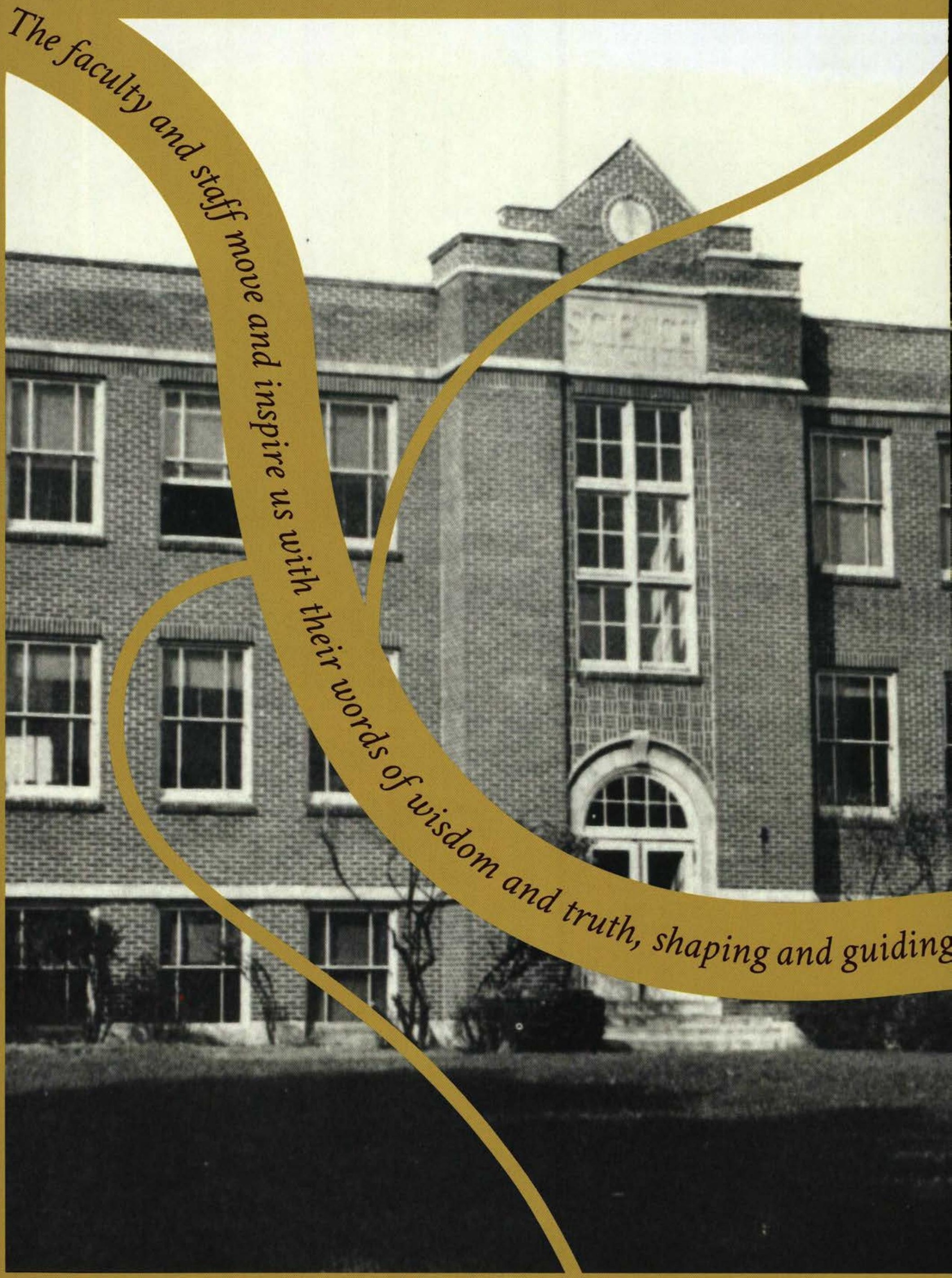




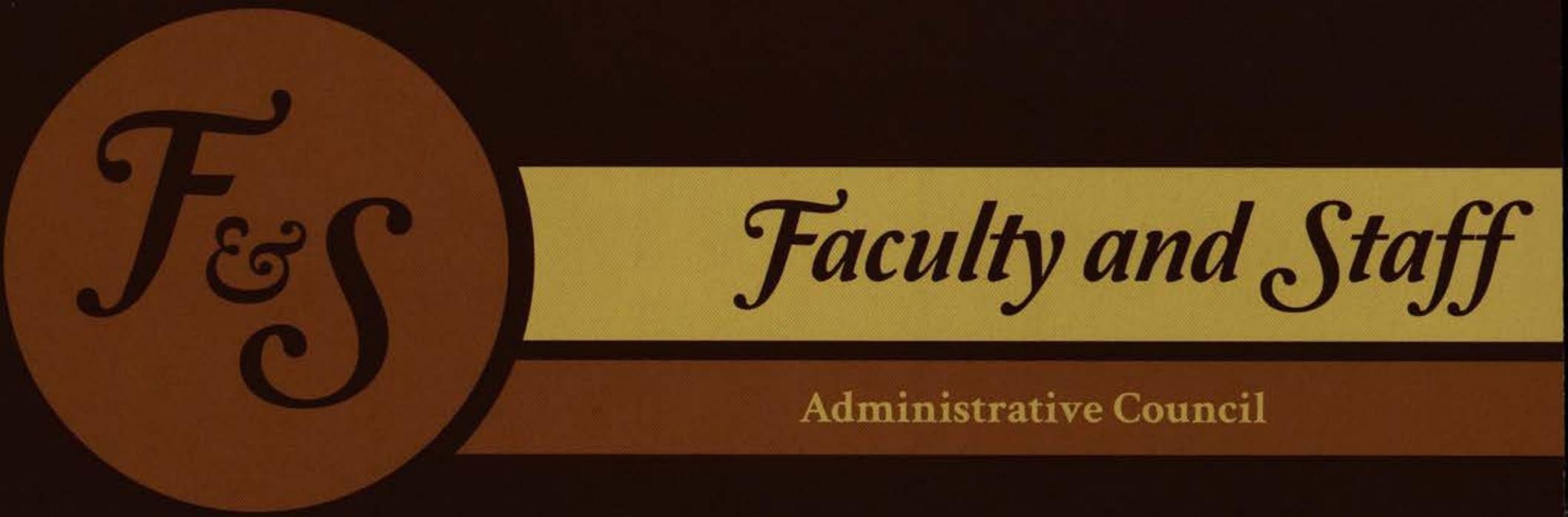

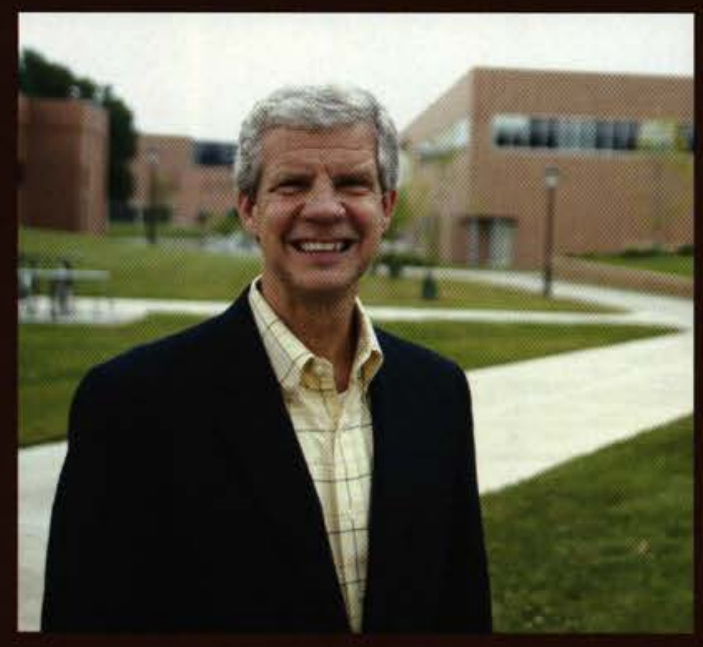

Dr. Bill Brown

President
Welcome to the Miracle 2011-2012. And what a year it has been! We had another record enrollment for the university, a missing winter season, and the completion of another building.

It is always humbling to look back over a school year and remember the number of people and events God brought to campus to encourage and challenge us. Our theme this year, "Sharpening the Christ-Centered Mind," gave us many opportunities to think deeply about being a Christian in today's confusing world. Cedarville students continue to provide incredible examples of
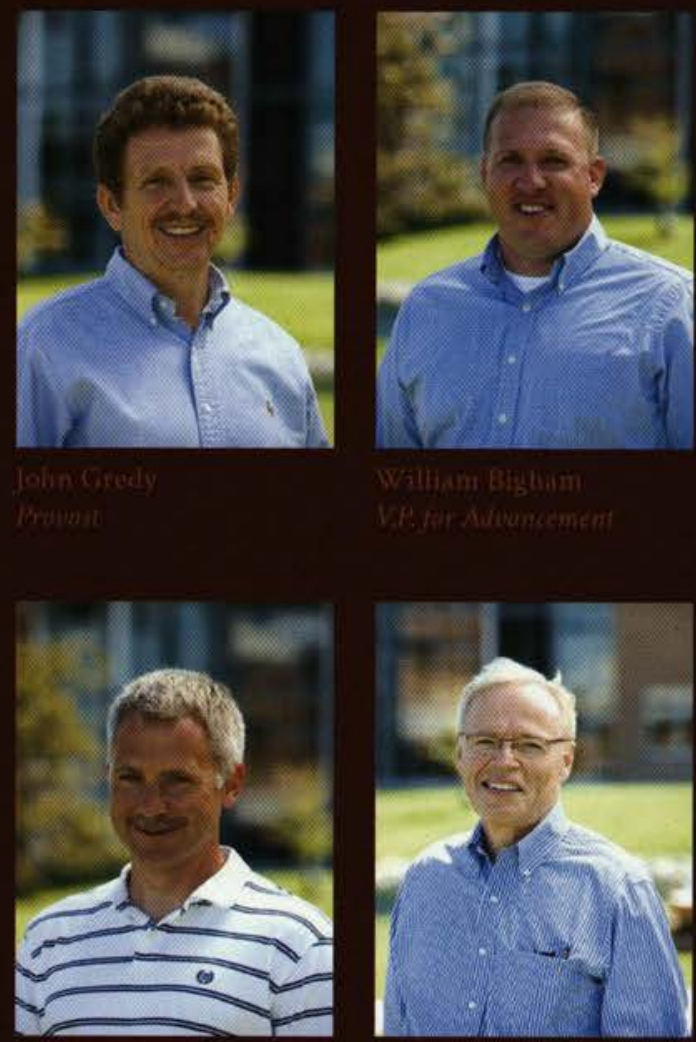

radical lives of service for Jesus Christ. As you thumb through the pages of this yearbook, I pray you will be thankful for God's continued blessing of Cedarville University and be motivated to serve $\mathrm{Him}$ with greater faith and sacrifice.

Lynne and I wish you all the best as you continue in your walk with Jesus Christ. I always like to remind you that you are a part of the Cedarville University family. Thanks for sharing your life with us.
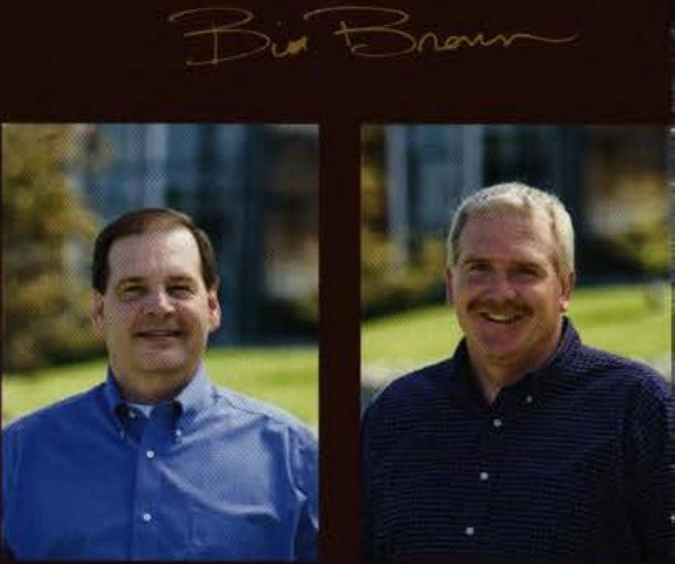

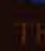
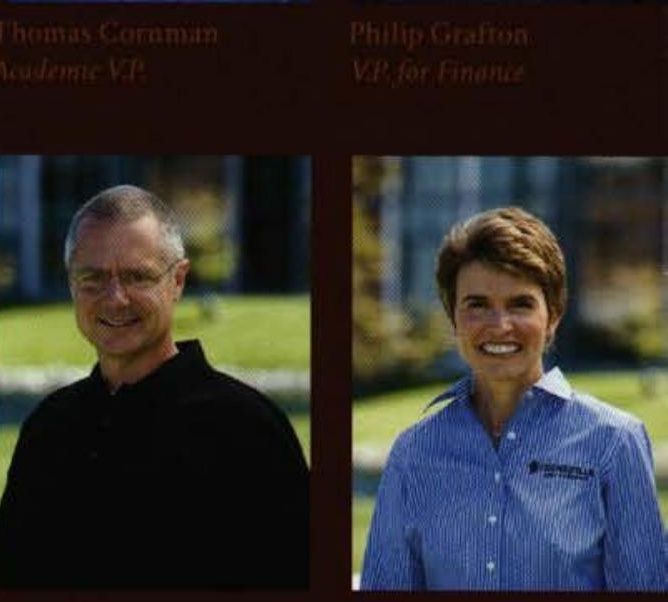


\section{Trustees}

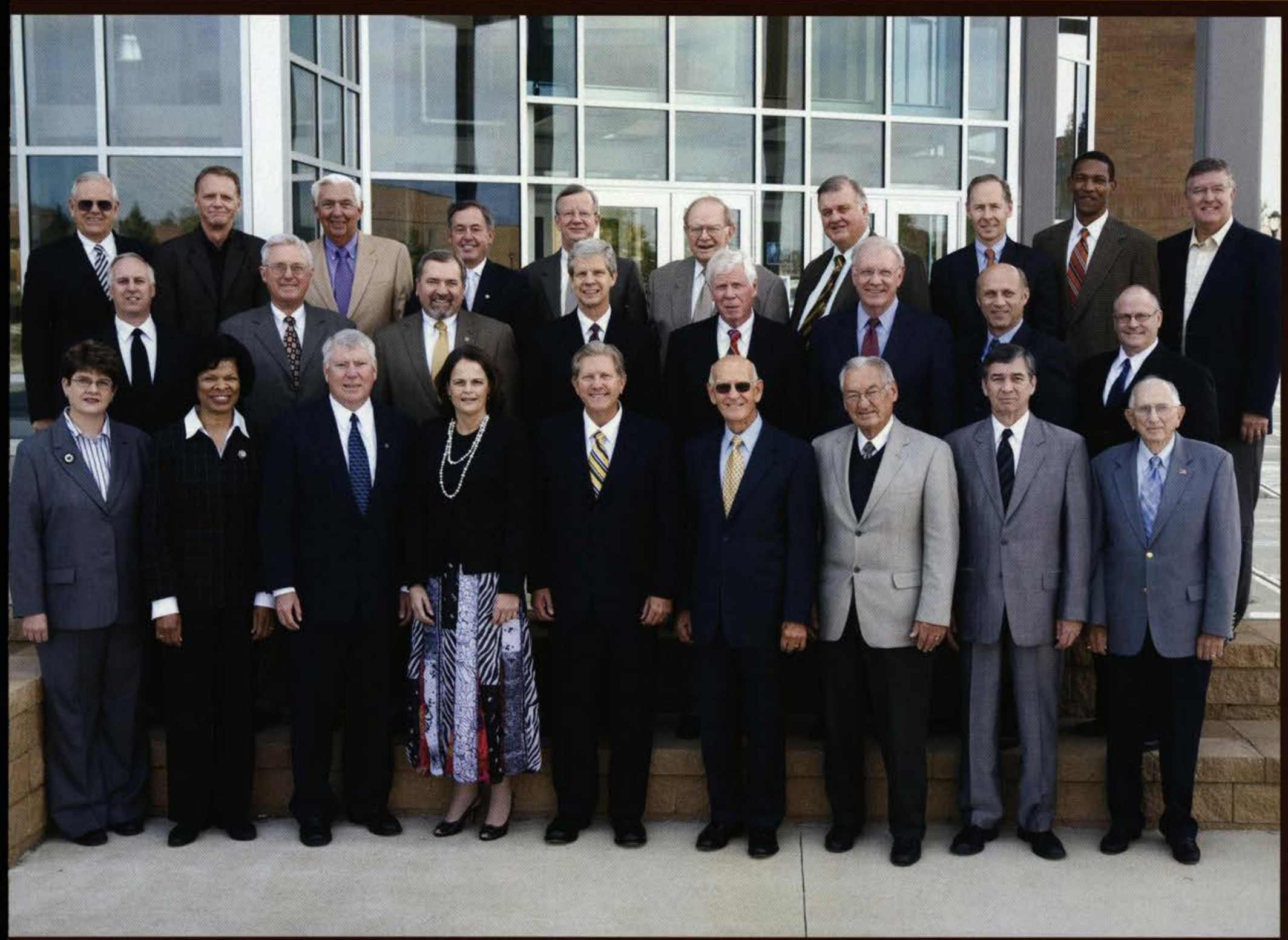




\section{College of Arts and Sciences}
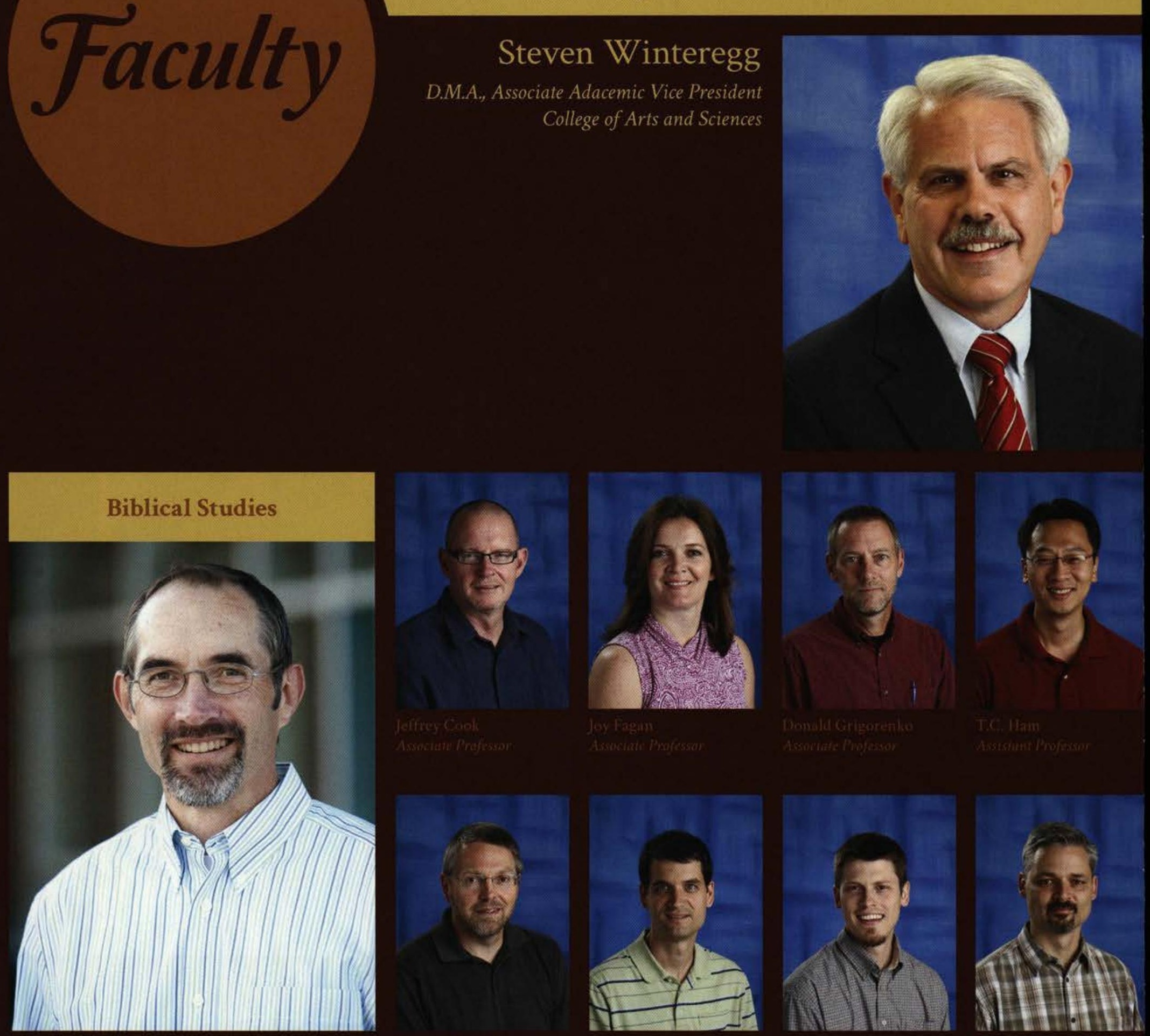

Chris Miller
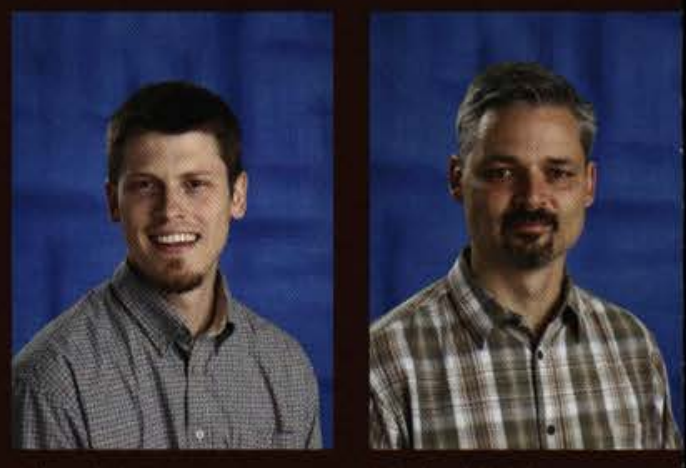

Chair Biblical Studies
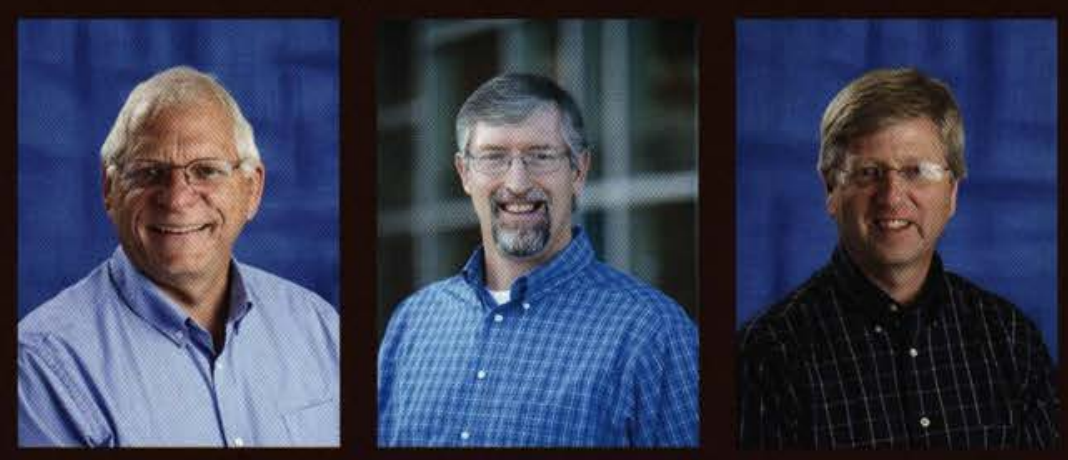


\section{College of Arts and Sciences}

\section{Art, Design and Theatre}

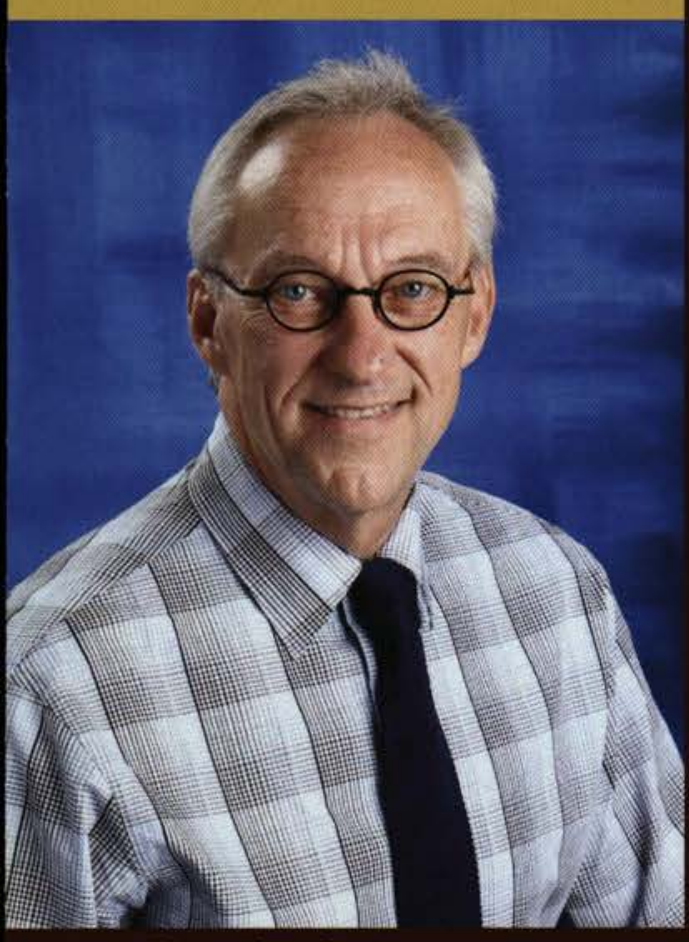

Terry Chamberlain
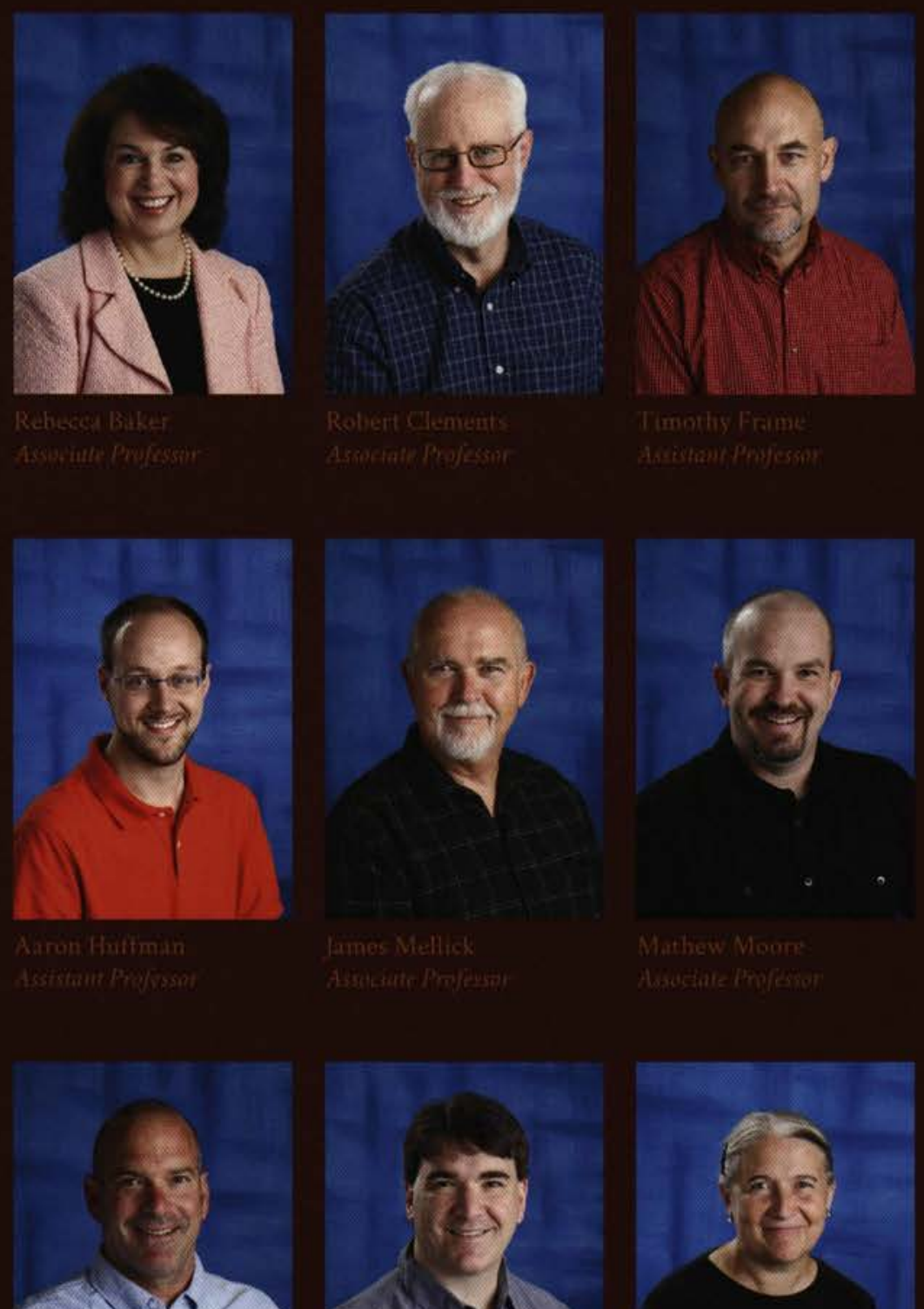
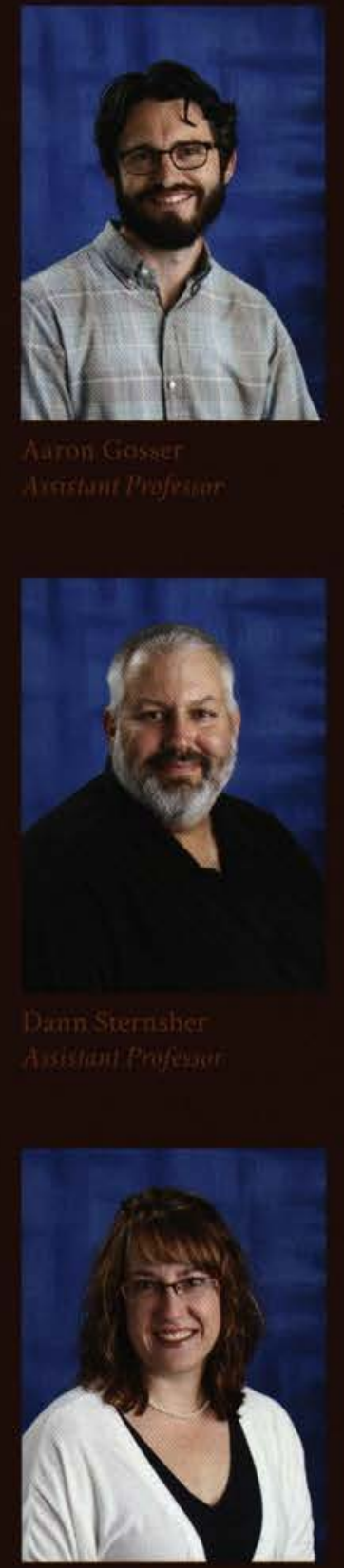
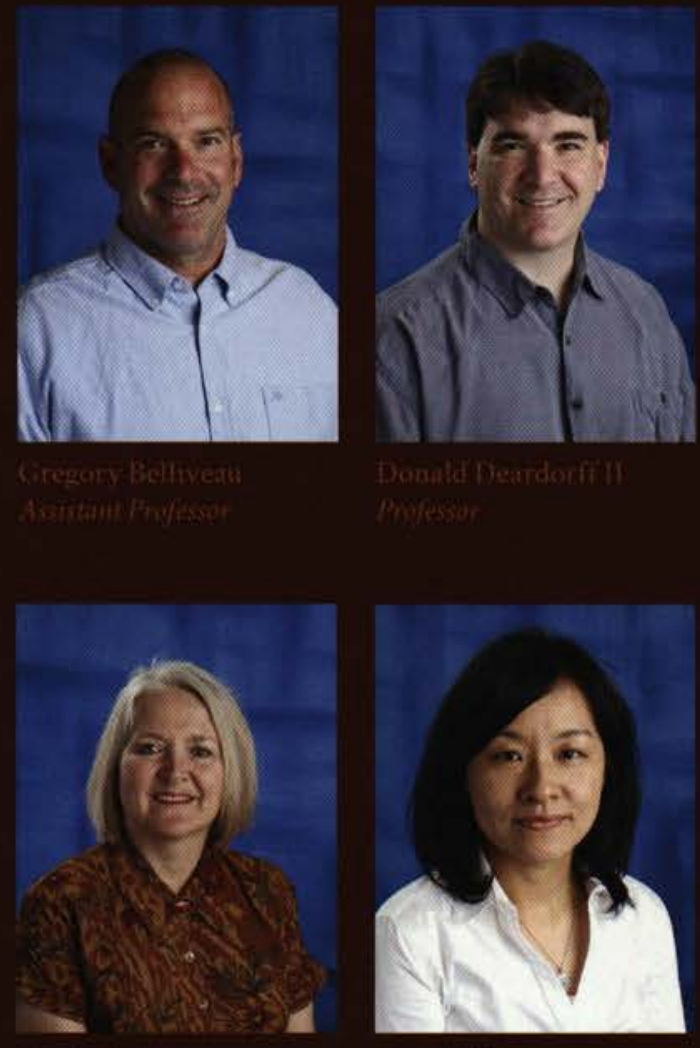


\section{College of Arts and Sciences}
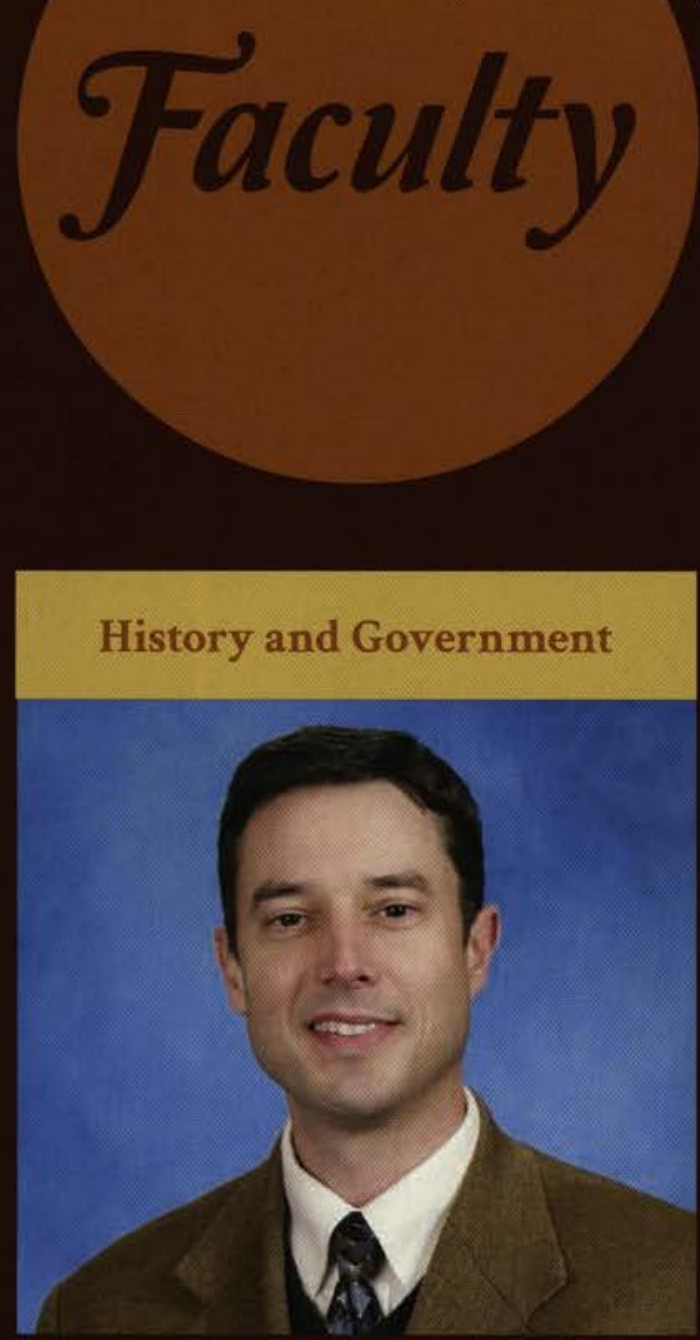

Thomas Mach

Chair, History and Government

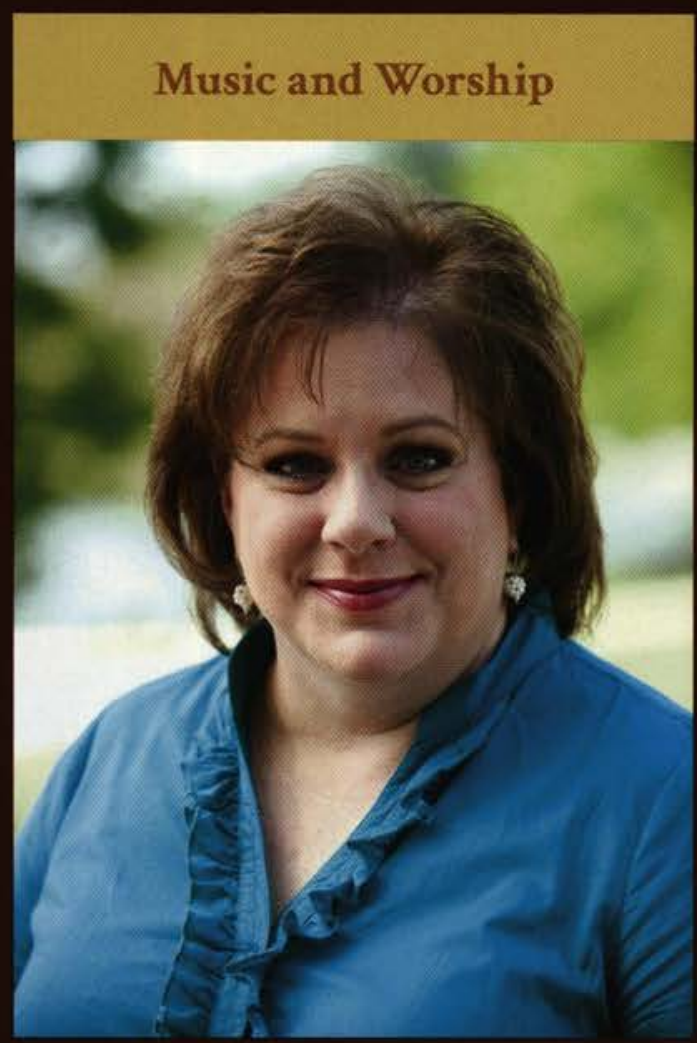

Beth Porter

Chair, Mustic and WWorship
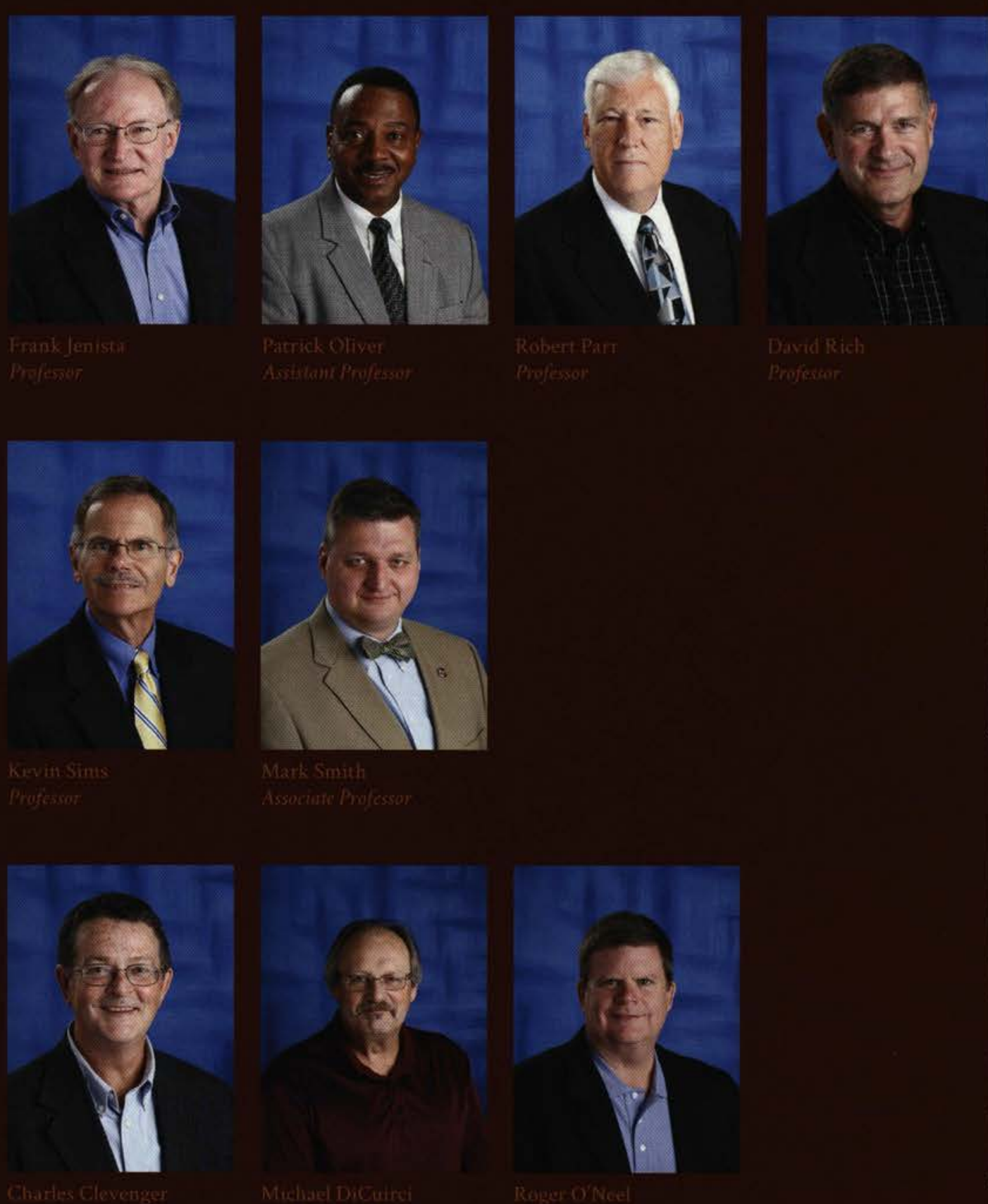


\section{College of Arts and Sciences}

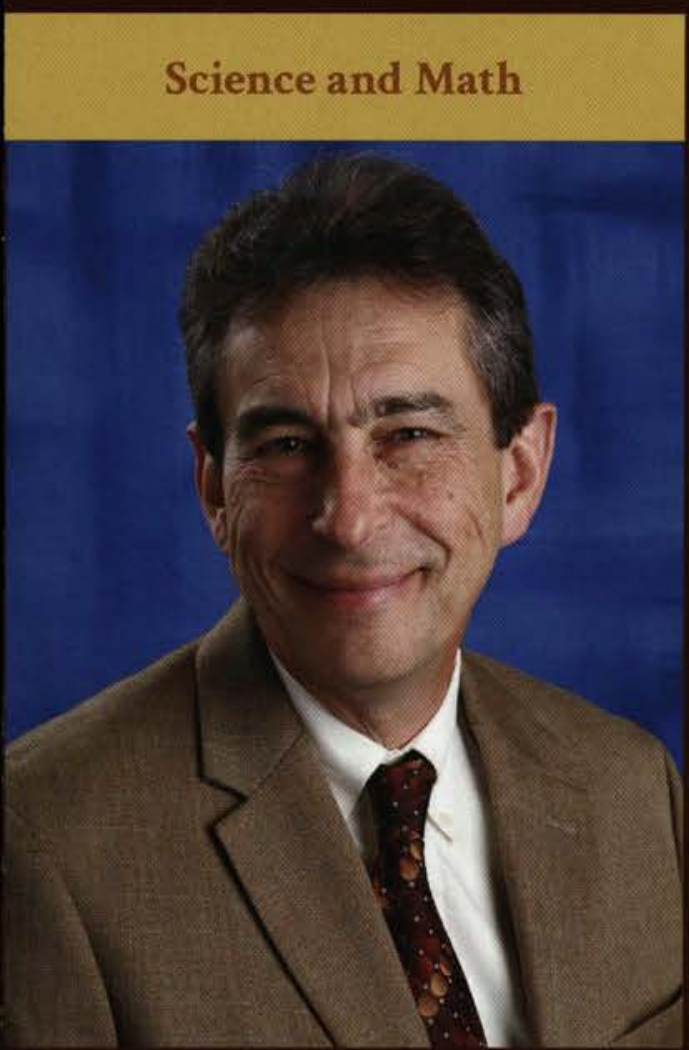

Dennis Flentge

Chair, Science and Mafh
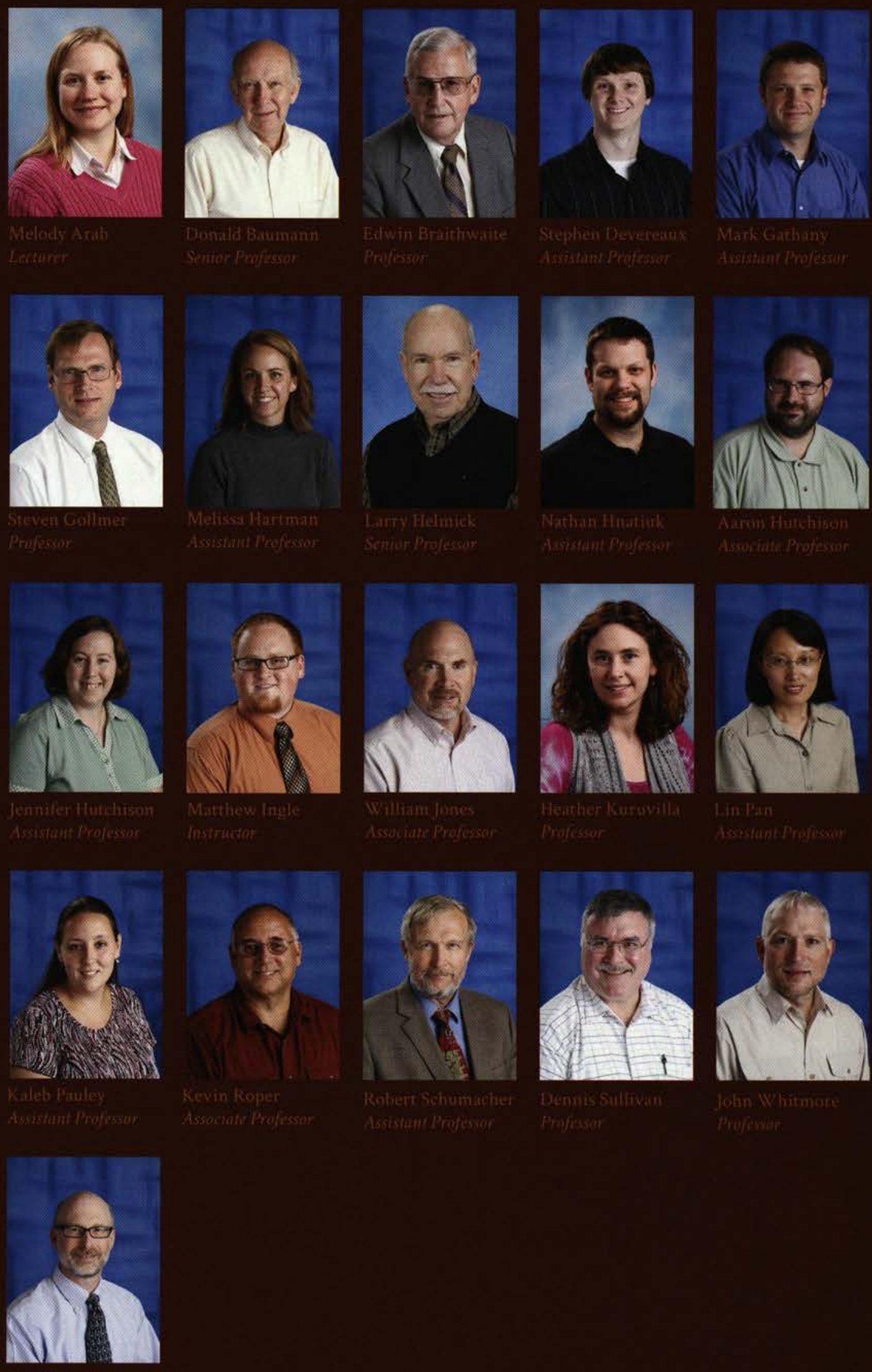


\section{College of Health Professions}
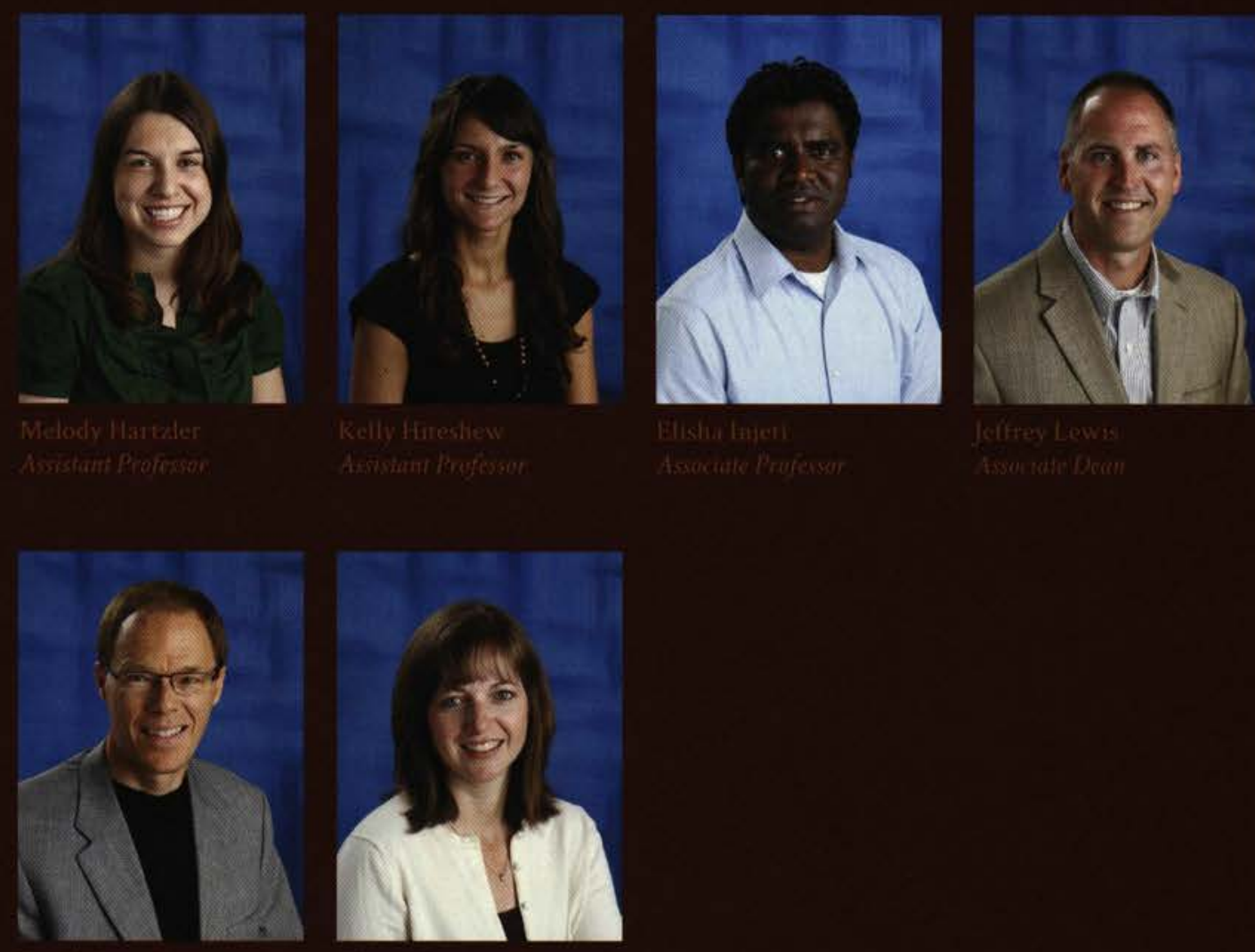

\section{Kinesiology and Allied Health}
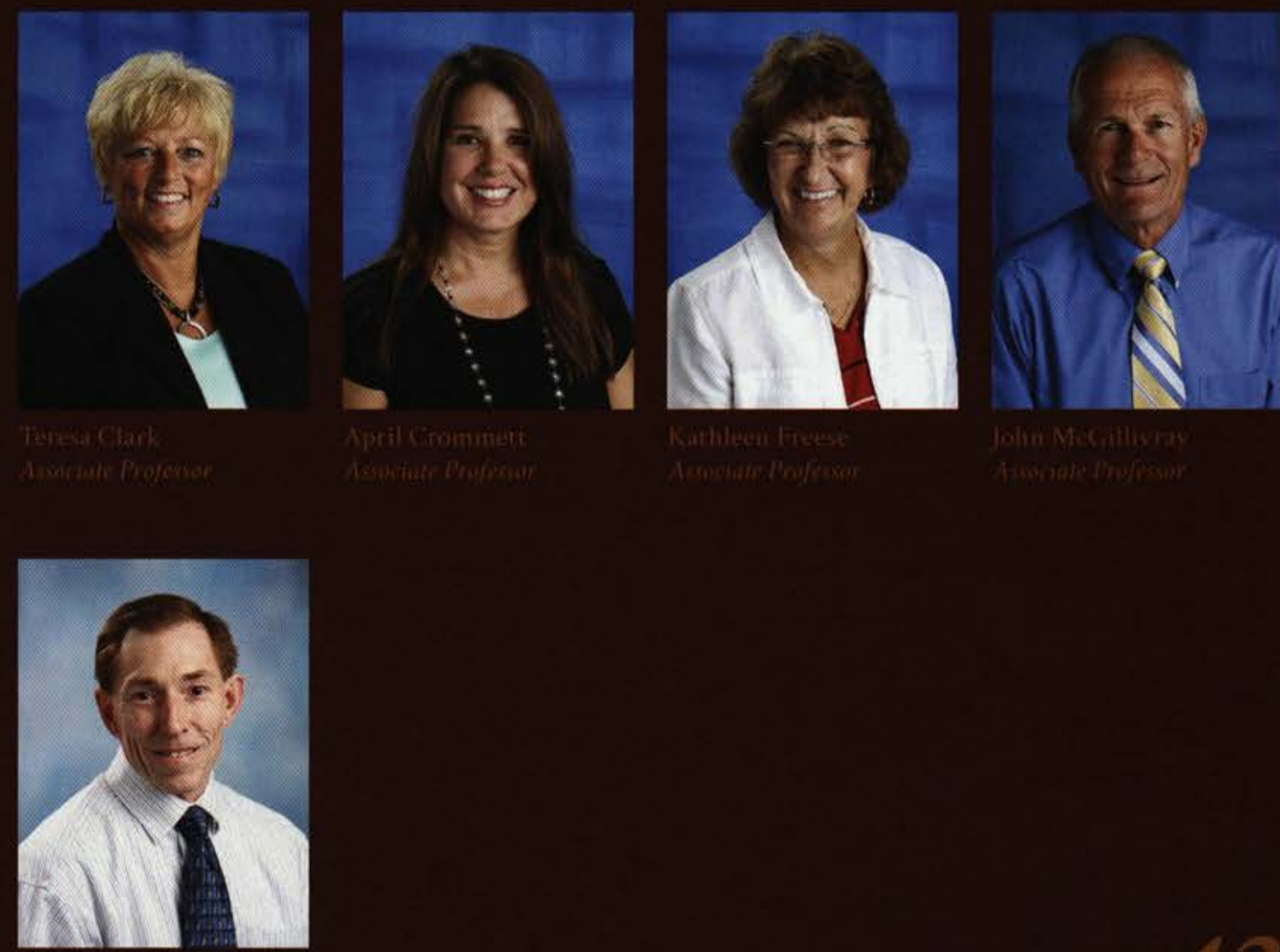


\section{College of Health Professions}

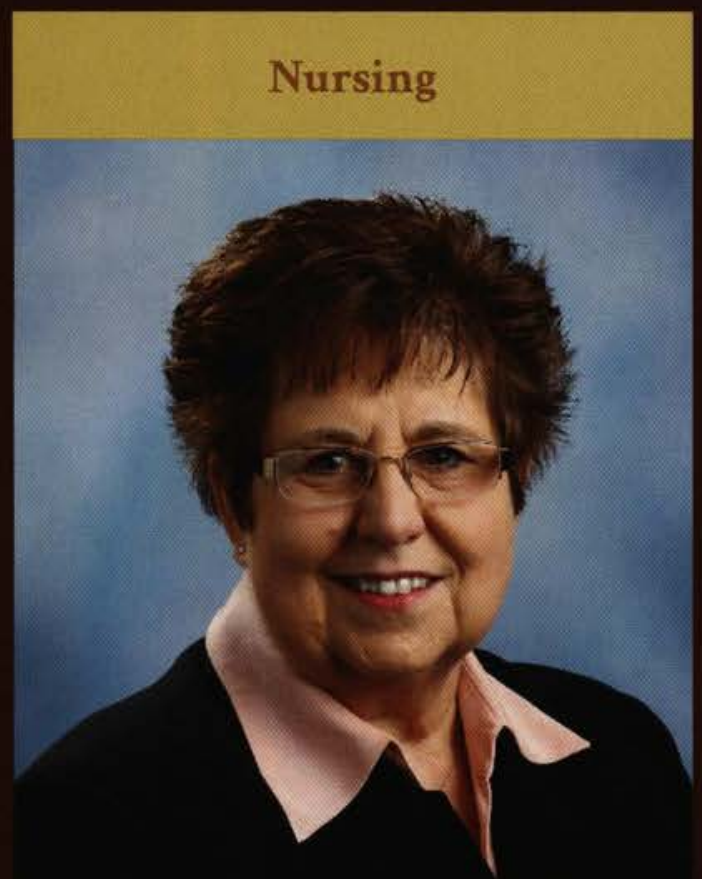

Janet Conway

Chain: Nursing

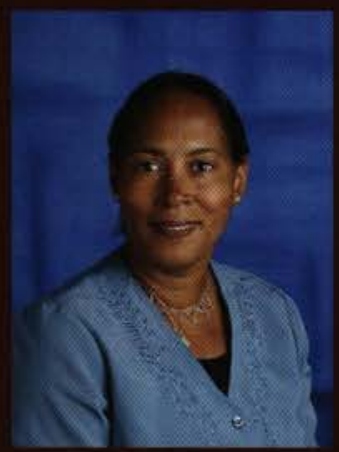

Givalyn Barnet

Assotani trotesen
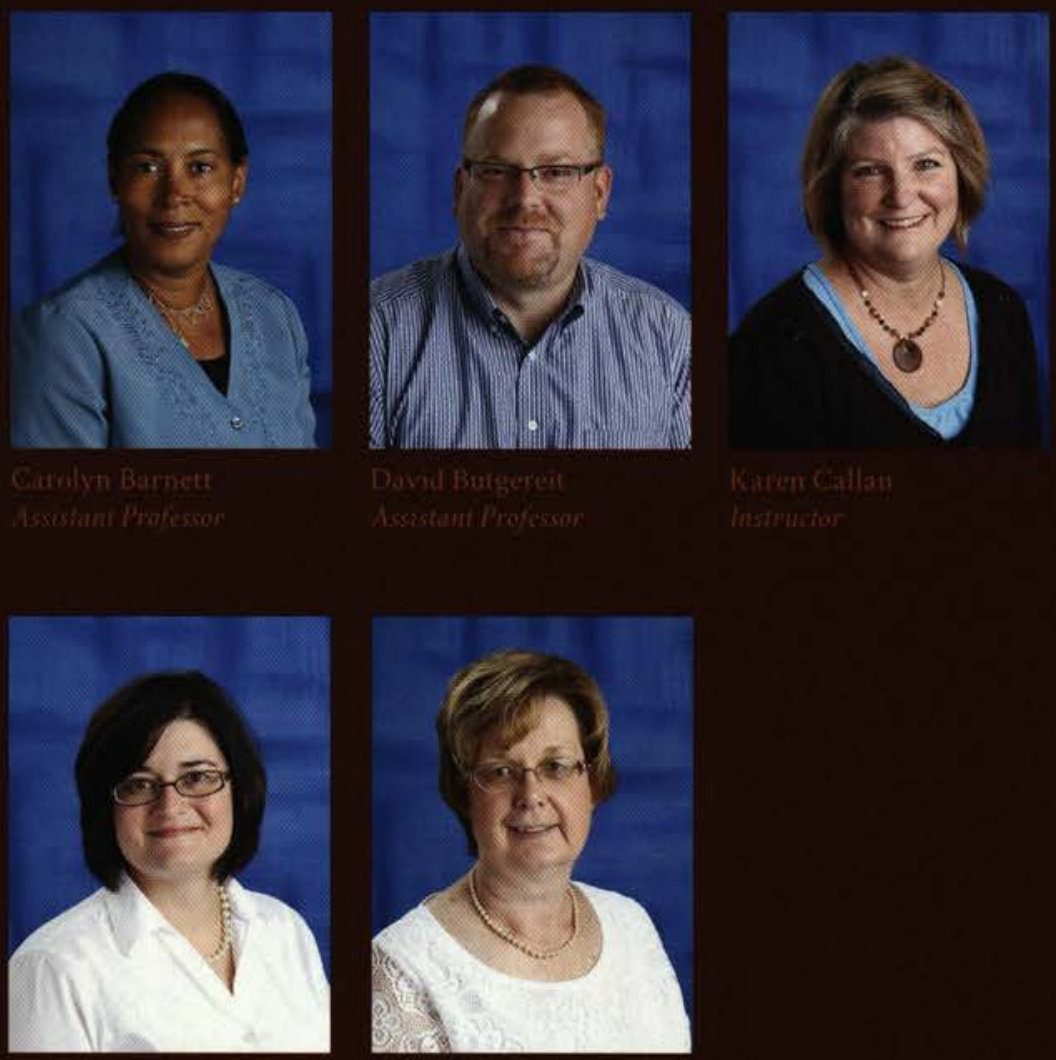

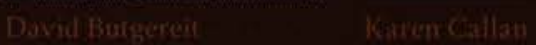
Assistani Propesson

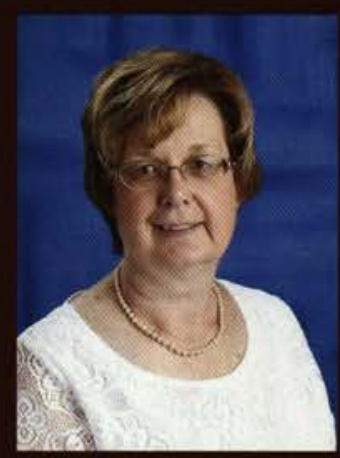

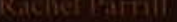

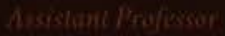

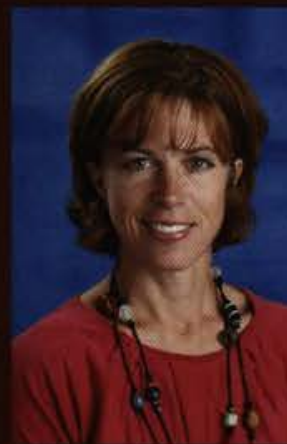

Mertich $\mathrm{Cos}$ 


\section{College of Health Professions}
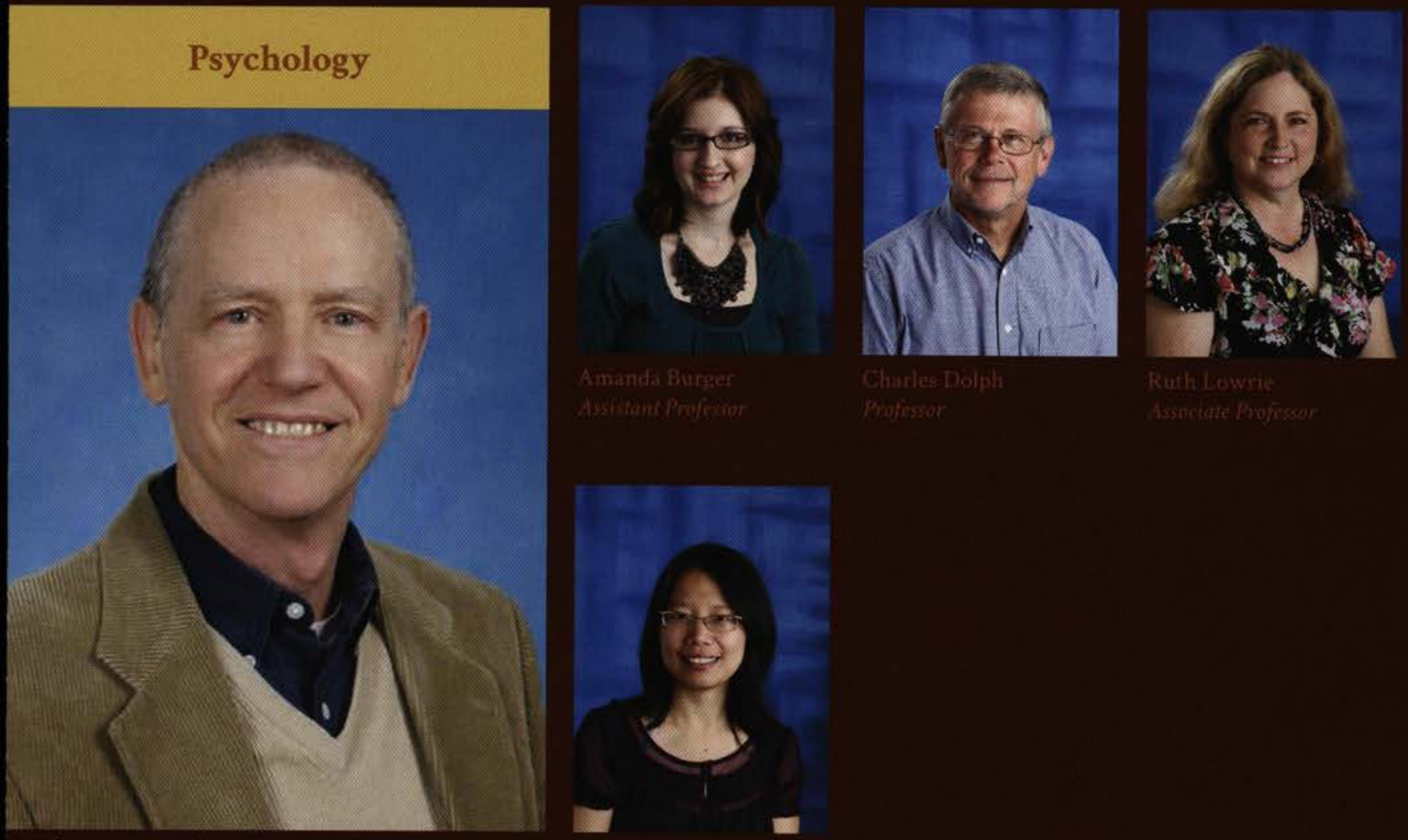

Churies:Dolph

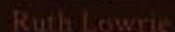

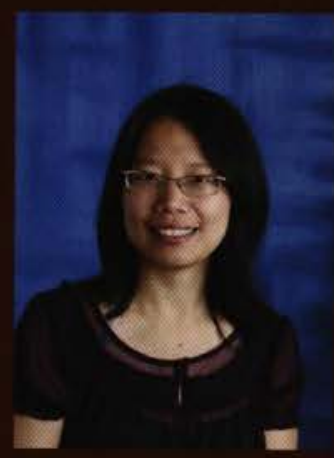

Milton Becknell

Chair, Psychology

\section{Social Work}
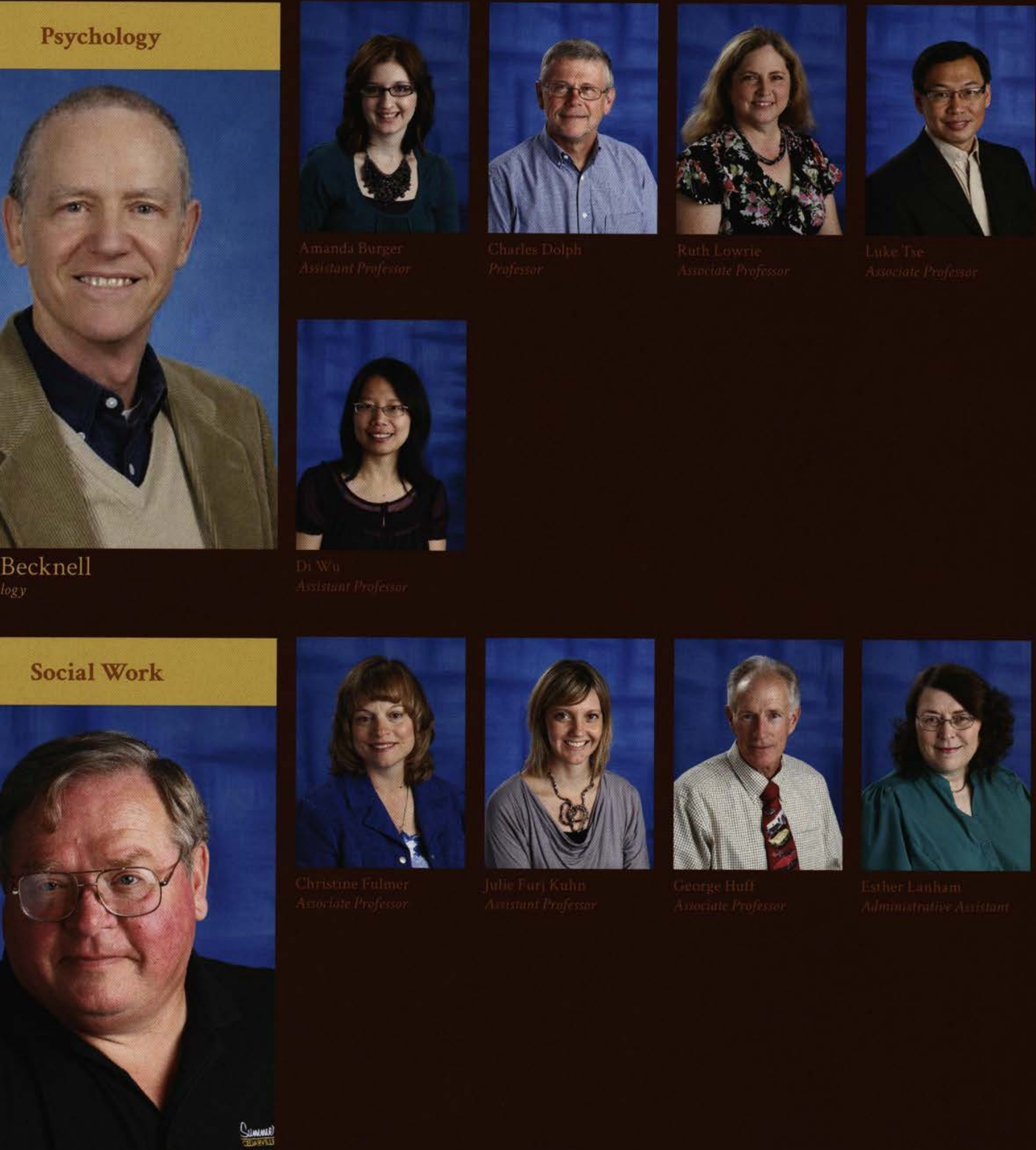

istiturtewitim

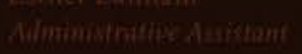




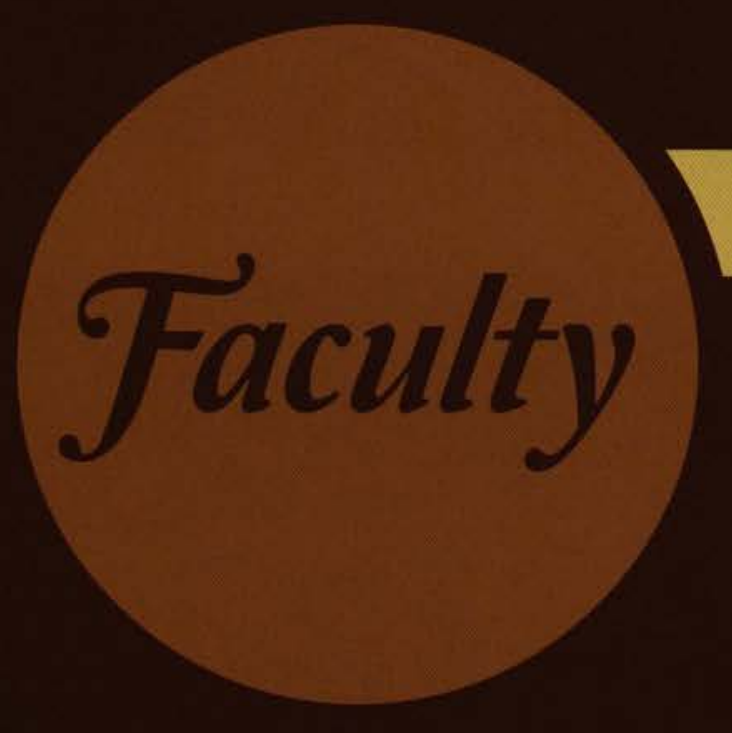

\section{College of Professions}

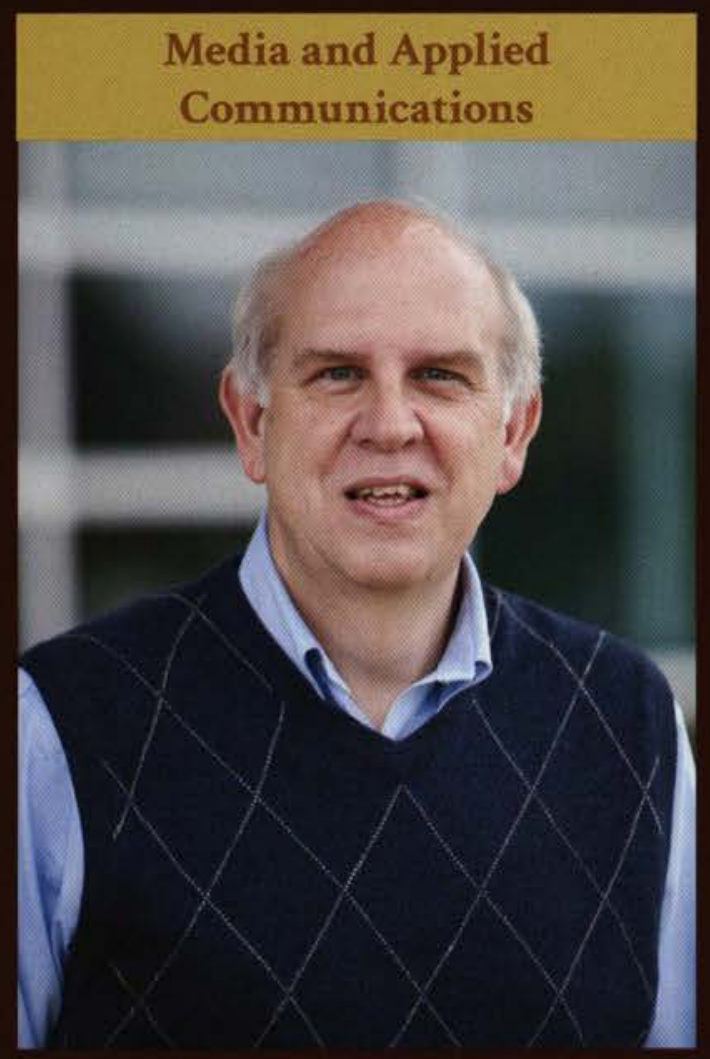

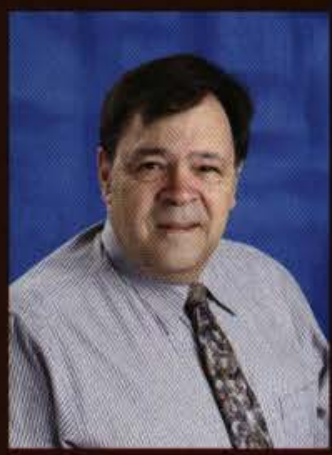
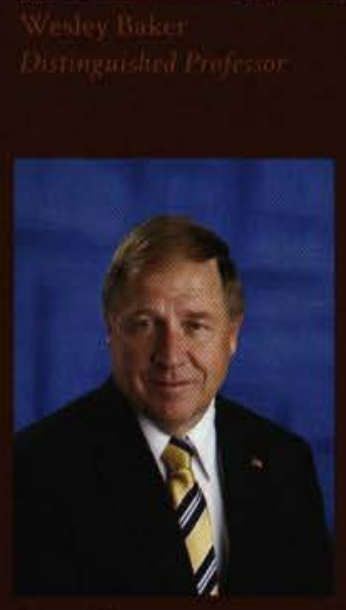

fonction bitio

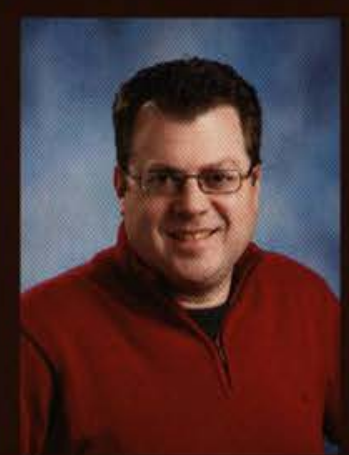

fon Ginitixy

Aissitunil Powtisso

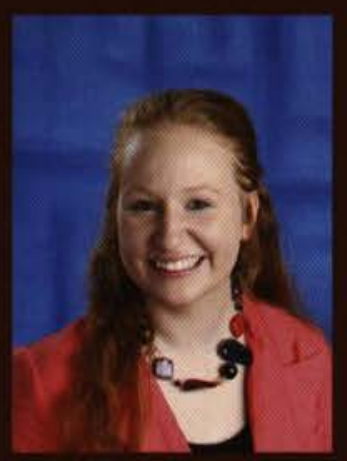

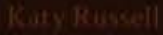

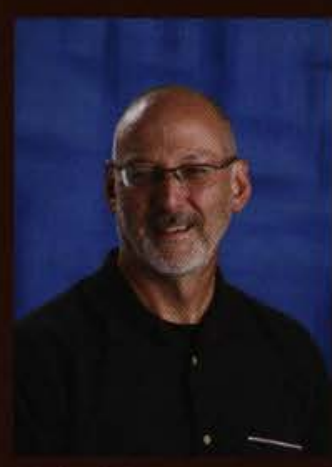

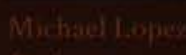

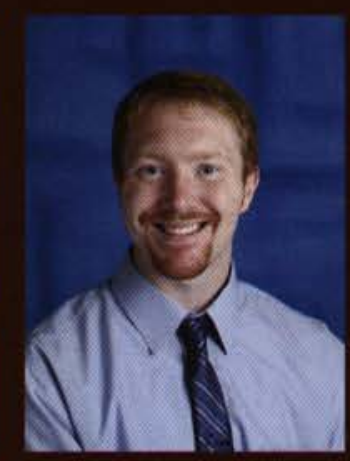

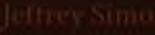

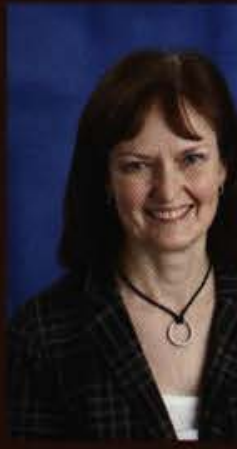

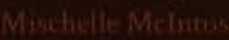

\section{Charles Elliot}

Chain, Modia and Applied Communications 


\section{College of Professions}

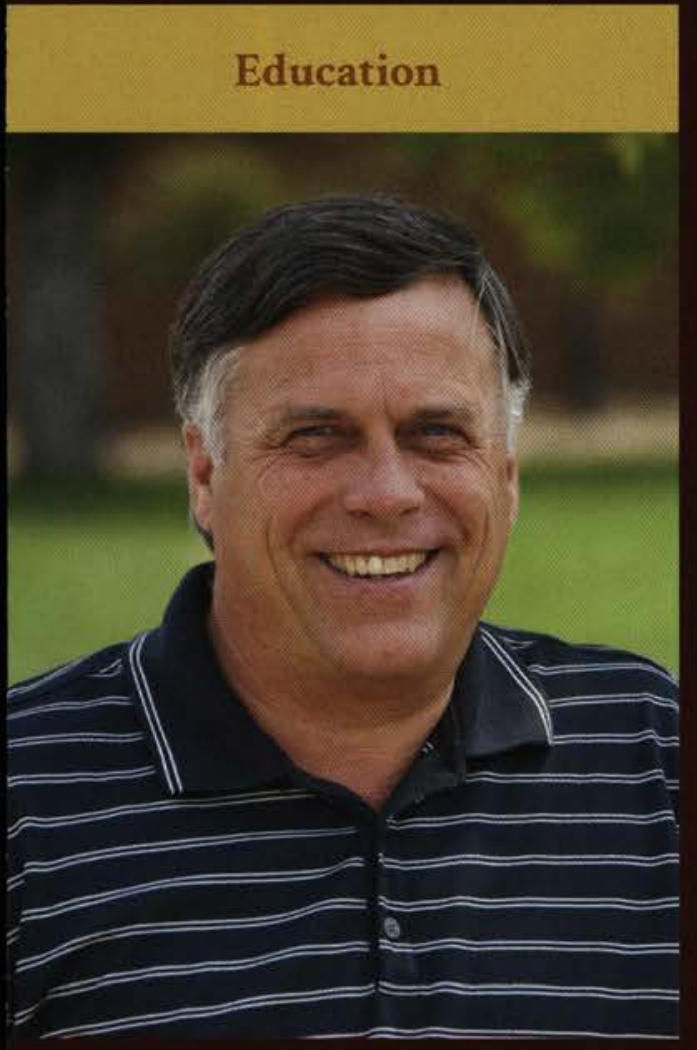

Stephen Gruber

Shair, Edrication

Engineering and

Computer Science
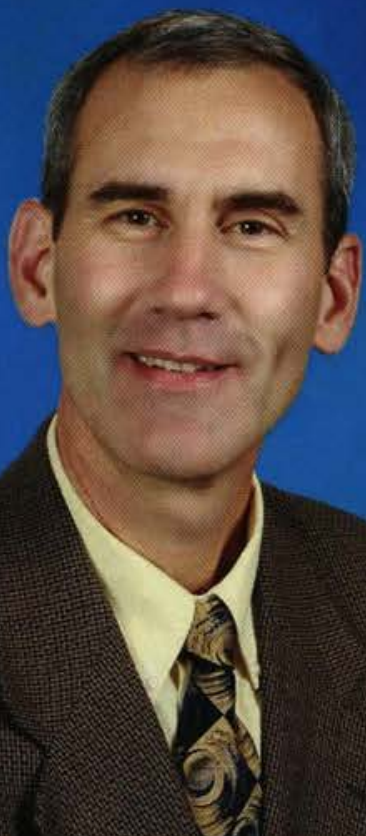

Samuel SanGregory

vair Fingincerins and Computer Sciente
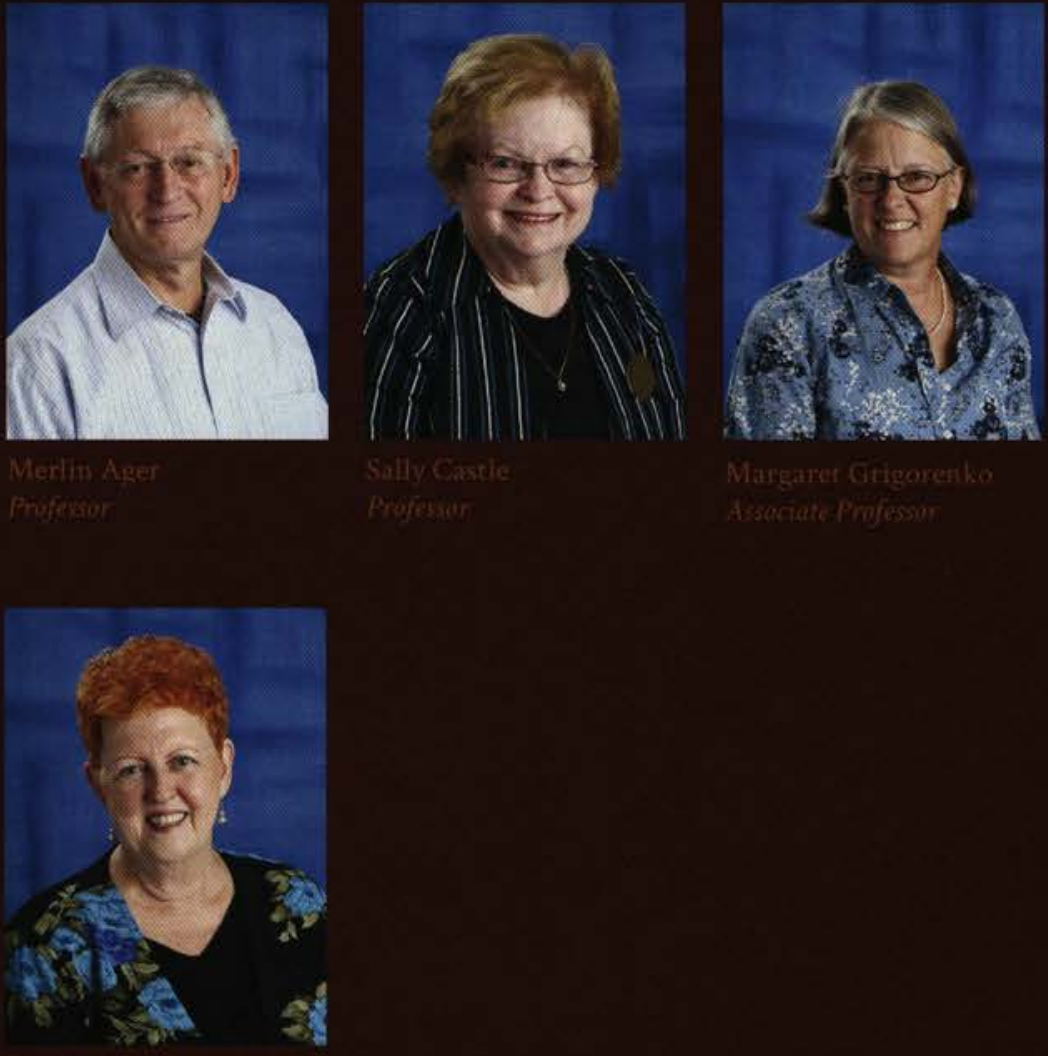

mant
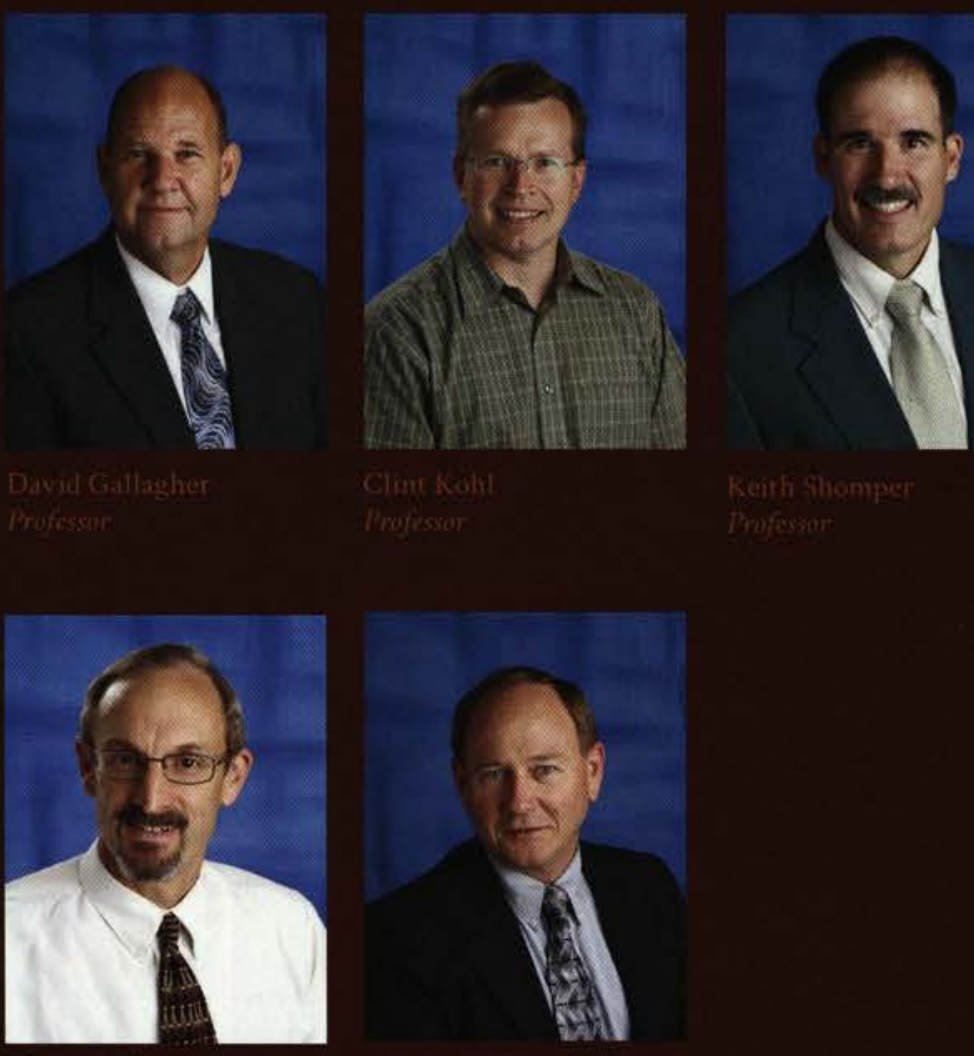


\section{College of Extended Learning}

\section{College of Extended Learning}

Andrew Runyan

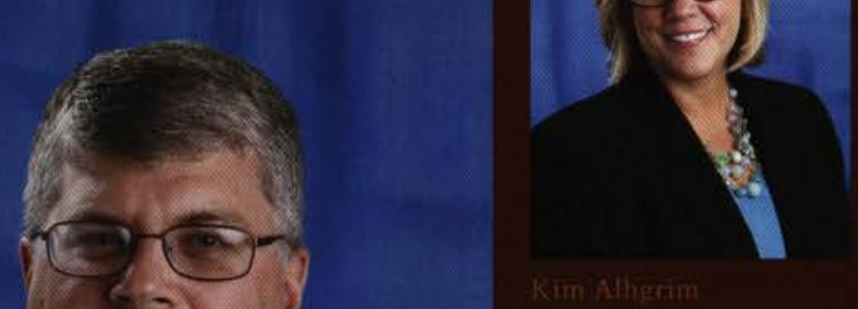

Semior Associate Academic Vice Presiden!

College of Exlended Learnins

\section{Library Services}
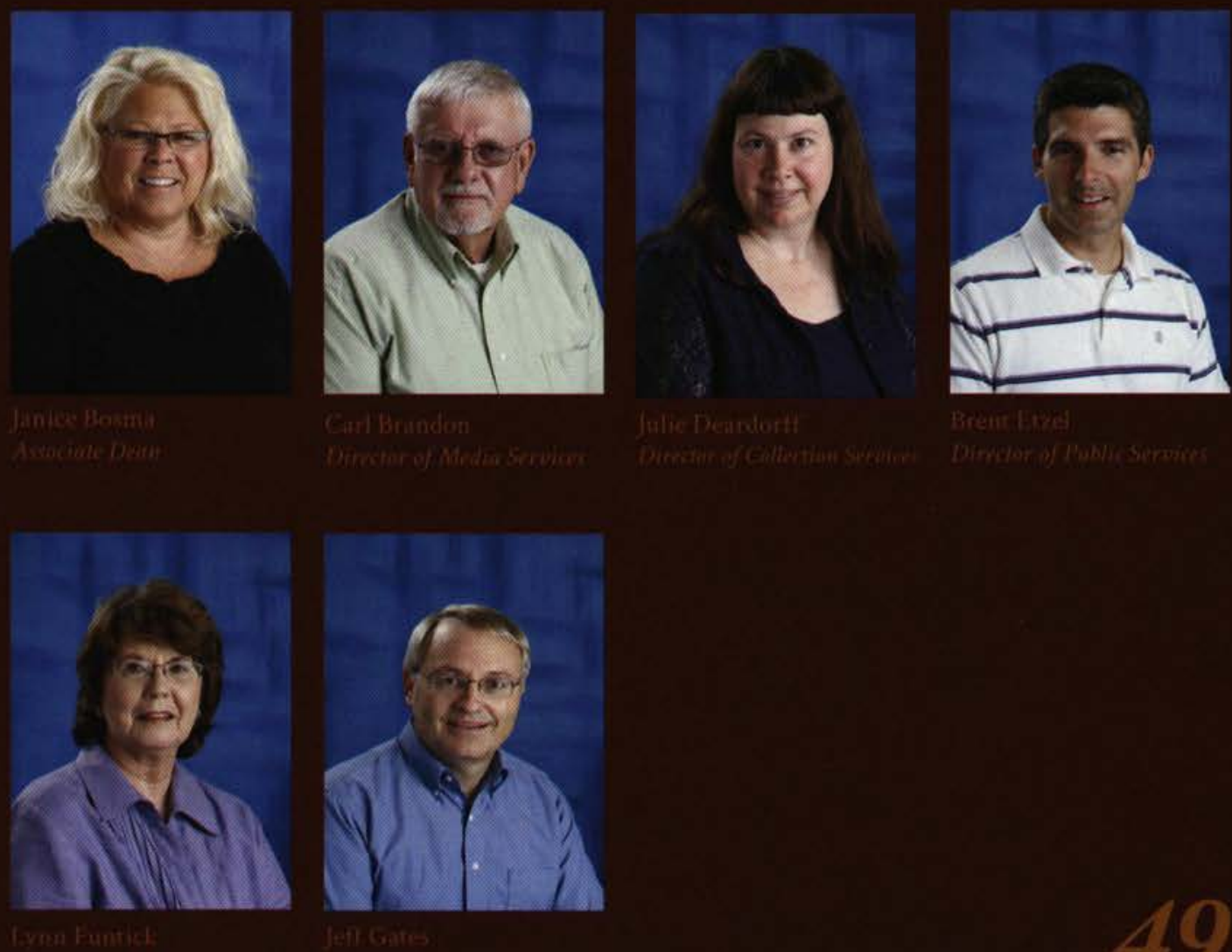


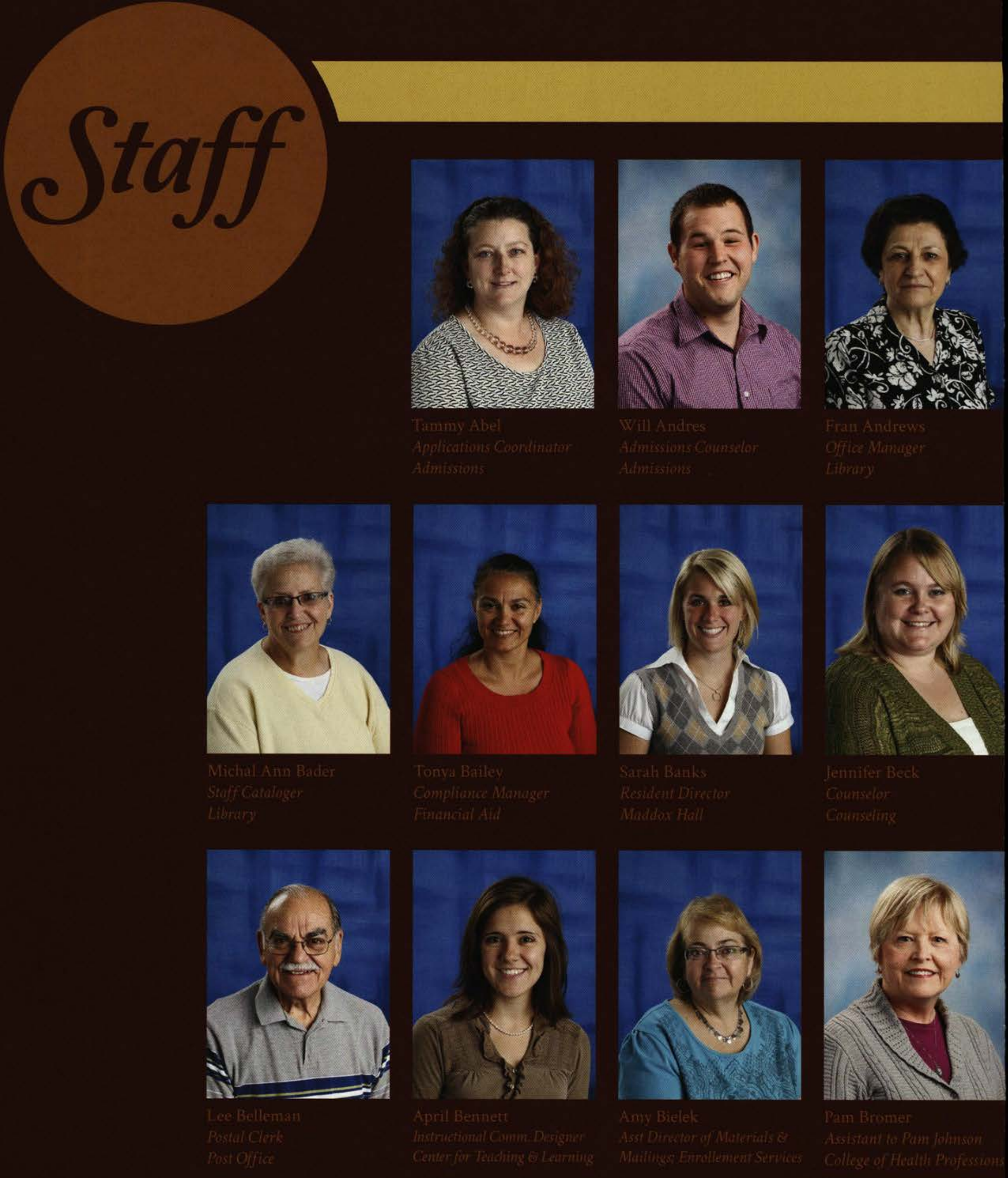



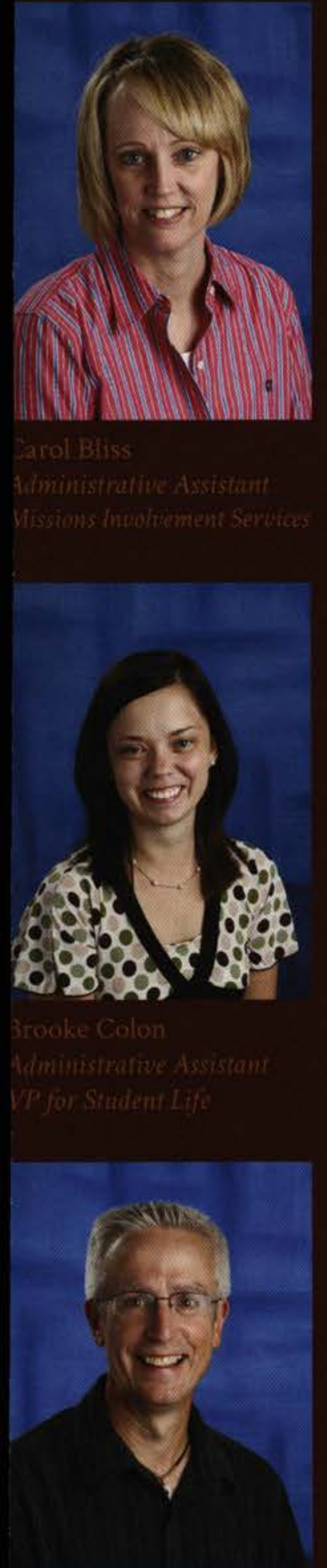
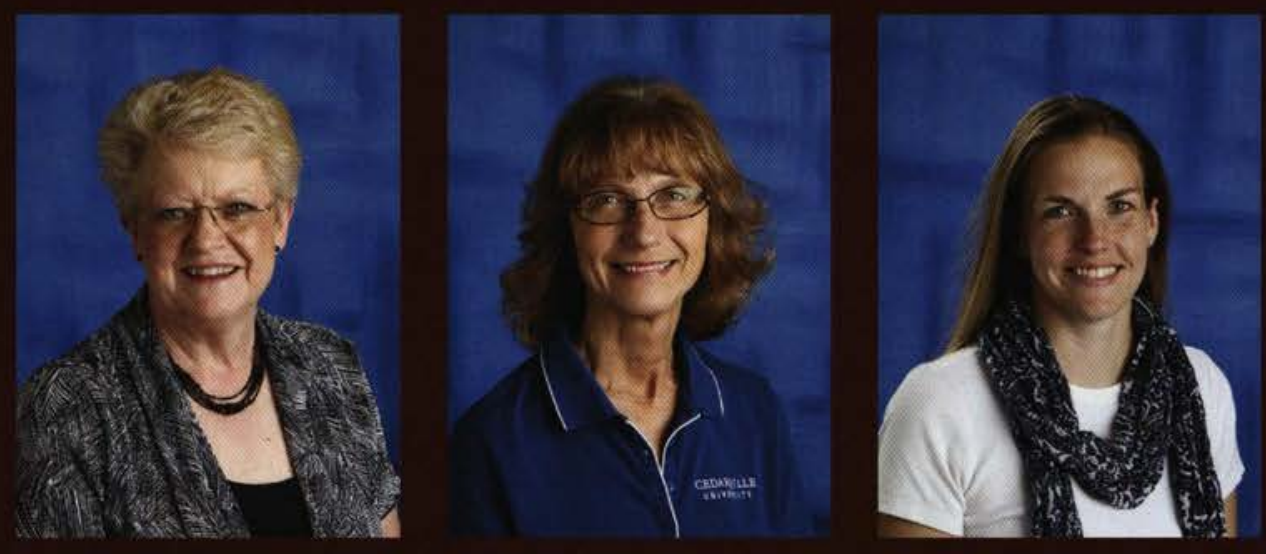

Fram Crimphel
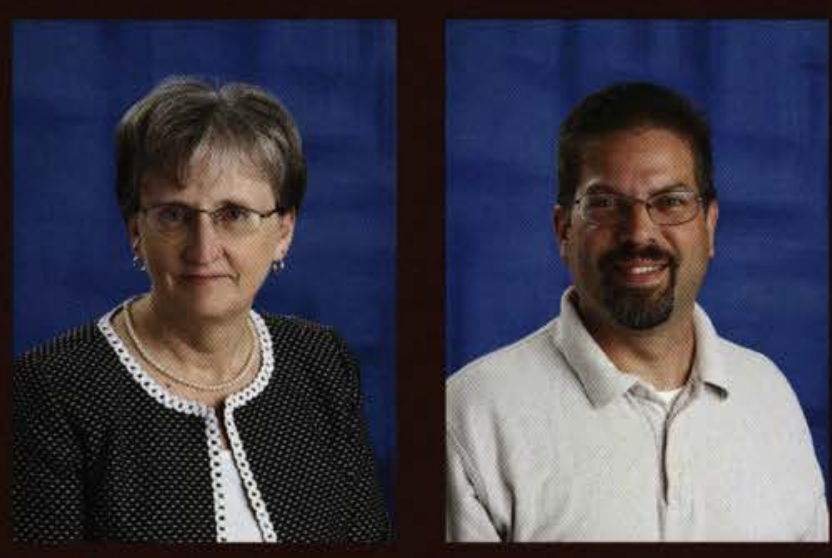

\section{Sरomat Drear}

Qrface the Registrar

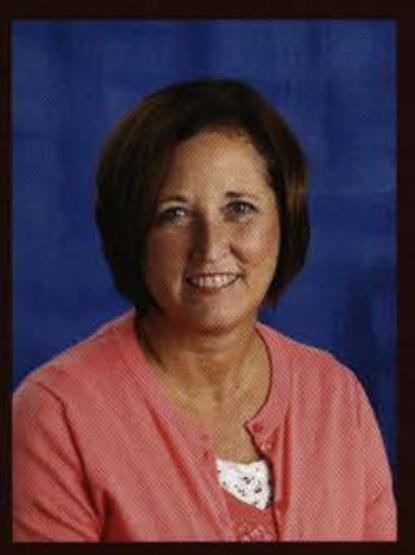

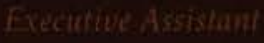

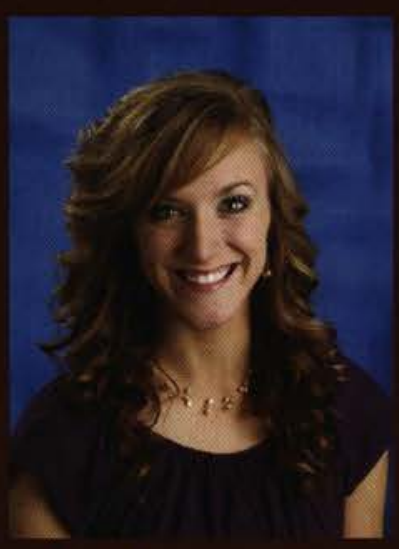

Melonglcato

Fitch Cirids

Techinal eocrdintor

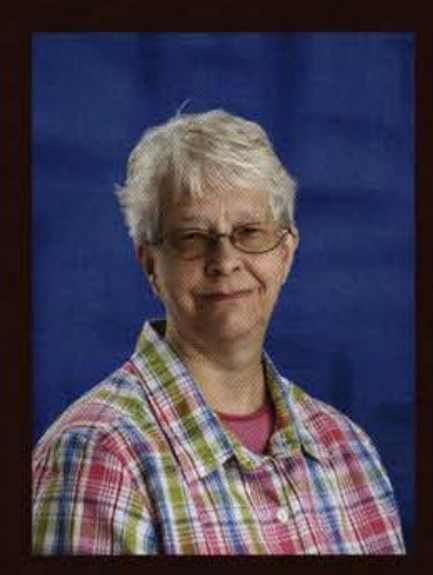

\section{Lasum}

Litbramy
Libana
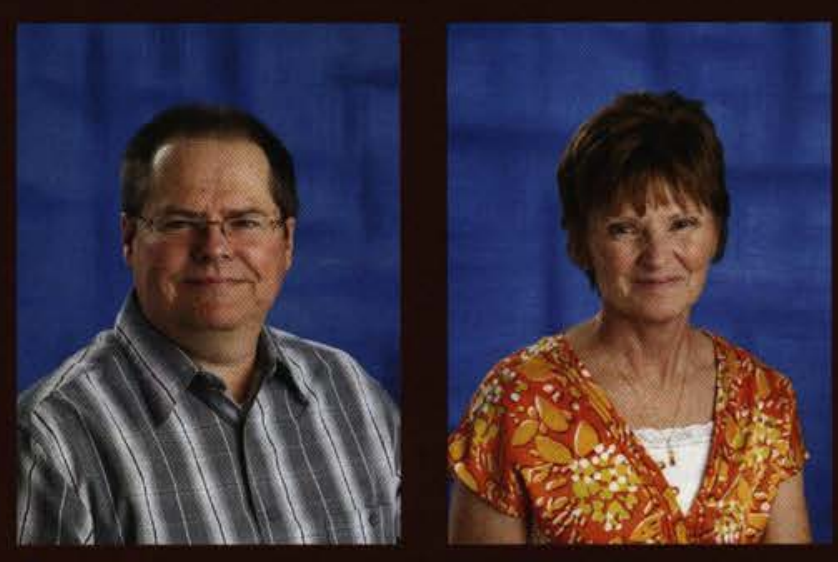


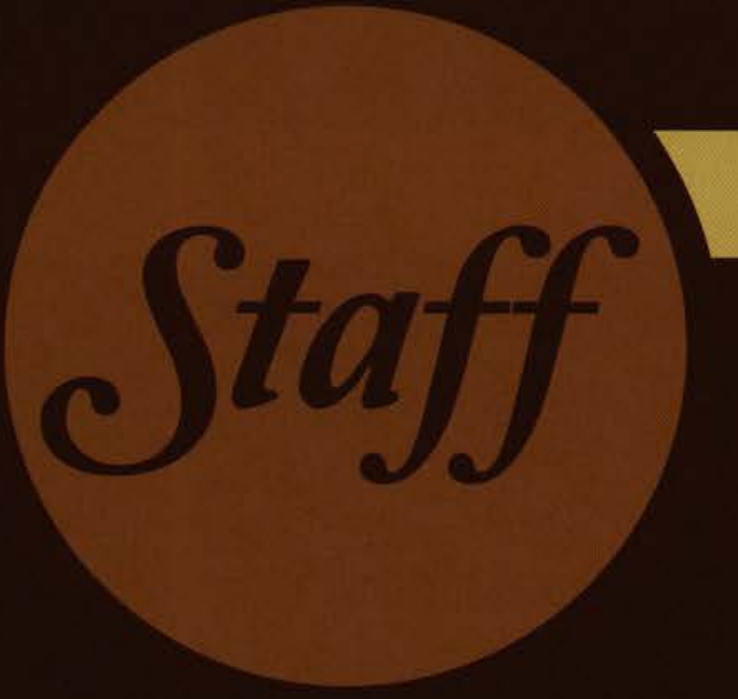

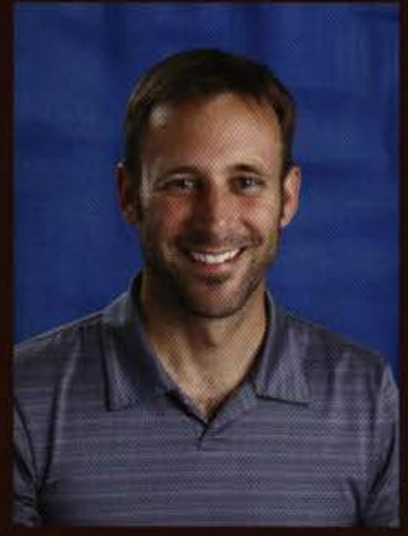

Mark lraving

Dinserer of Discipledip Min Disciplestip Ministrico

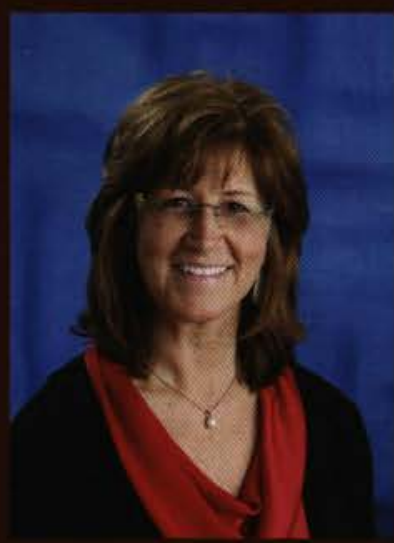

Btrine Keller

Almistratine Asstsiant

VP of Strudent Life

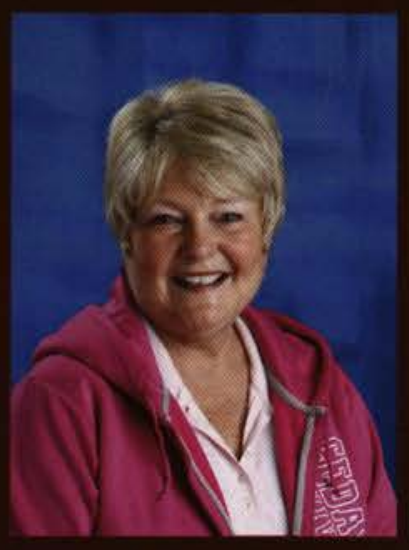

Jeante Leblans

Gifi and Card knys?

Rowarman:

Loren Kuhin

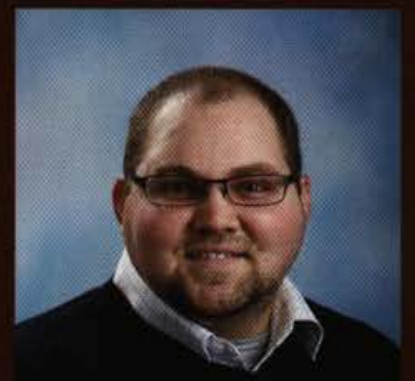

Eruent Coardinator

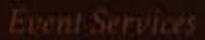

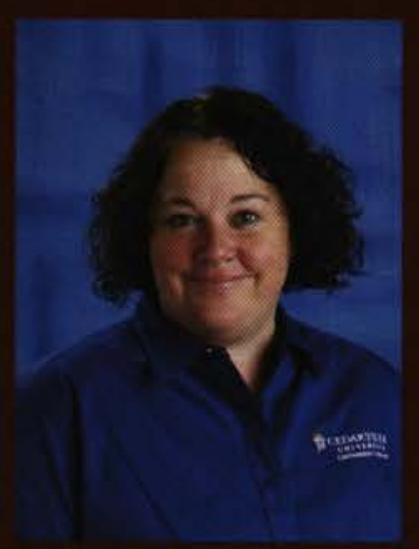

Laura LoMaster

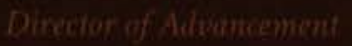

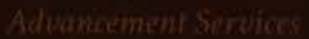
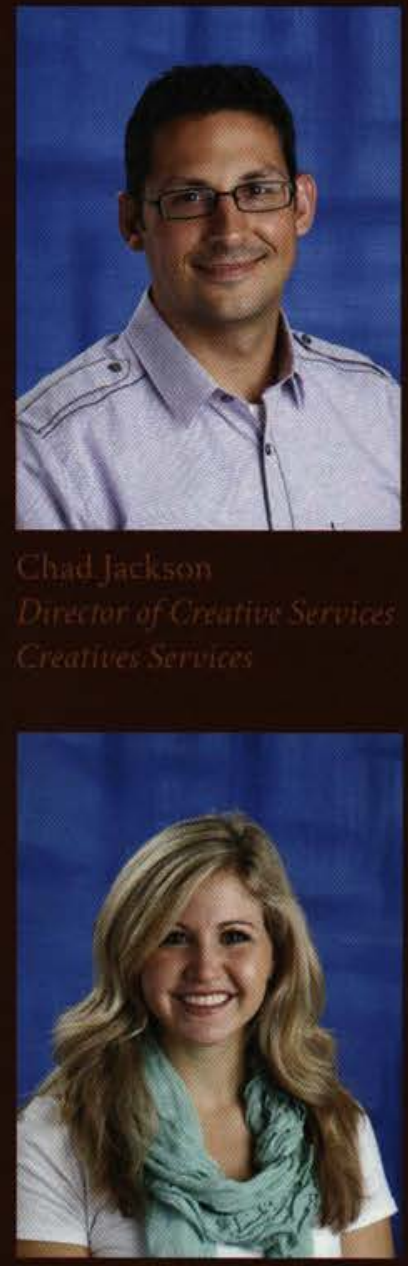

Chad fackson

Dinerker of Conatis

Cicatikessemicess

Mandir Larsey

Admosions Counastor

Admonsoms

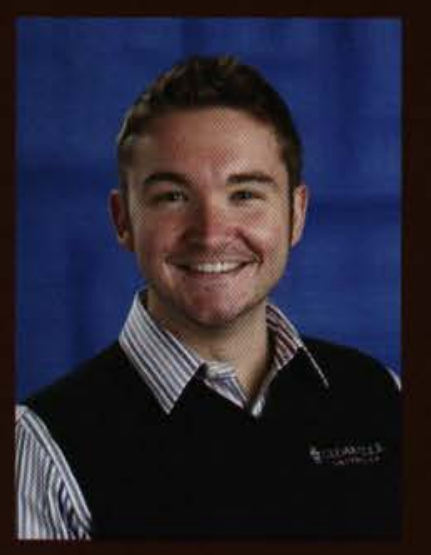

Matuhew Litule

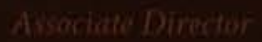

Adimissmits:

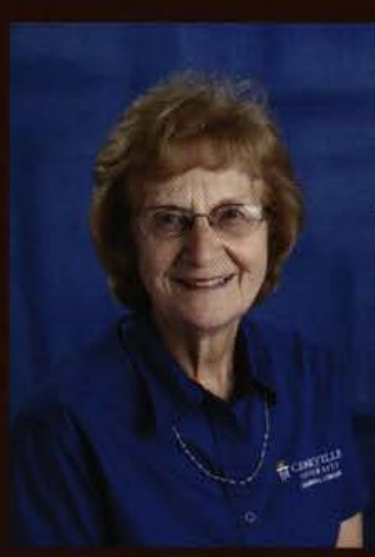

Rachel Johasion

collection simuices

bilmerny

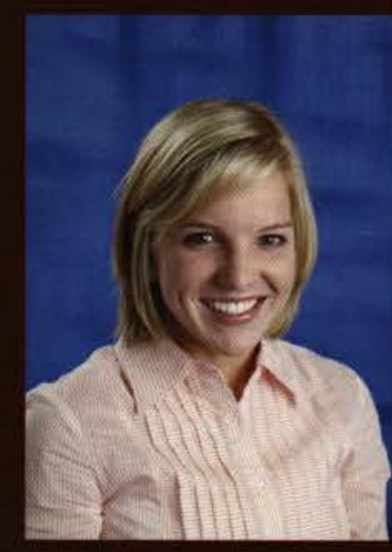

Kative Laustan

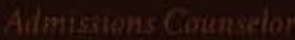

Achingions

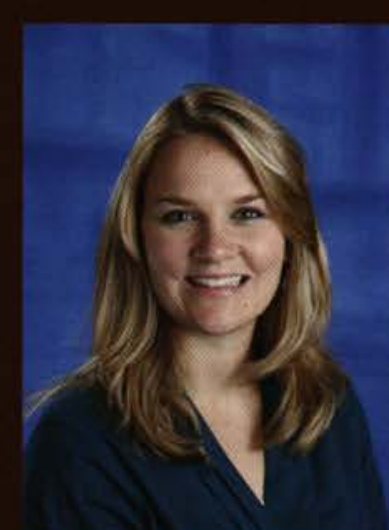

Golontinatary for Atumen Ahomi Pedaitions. 


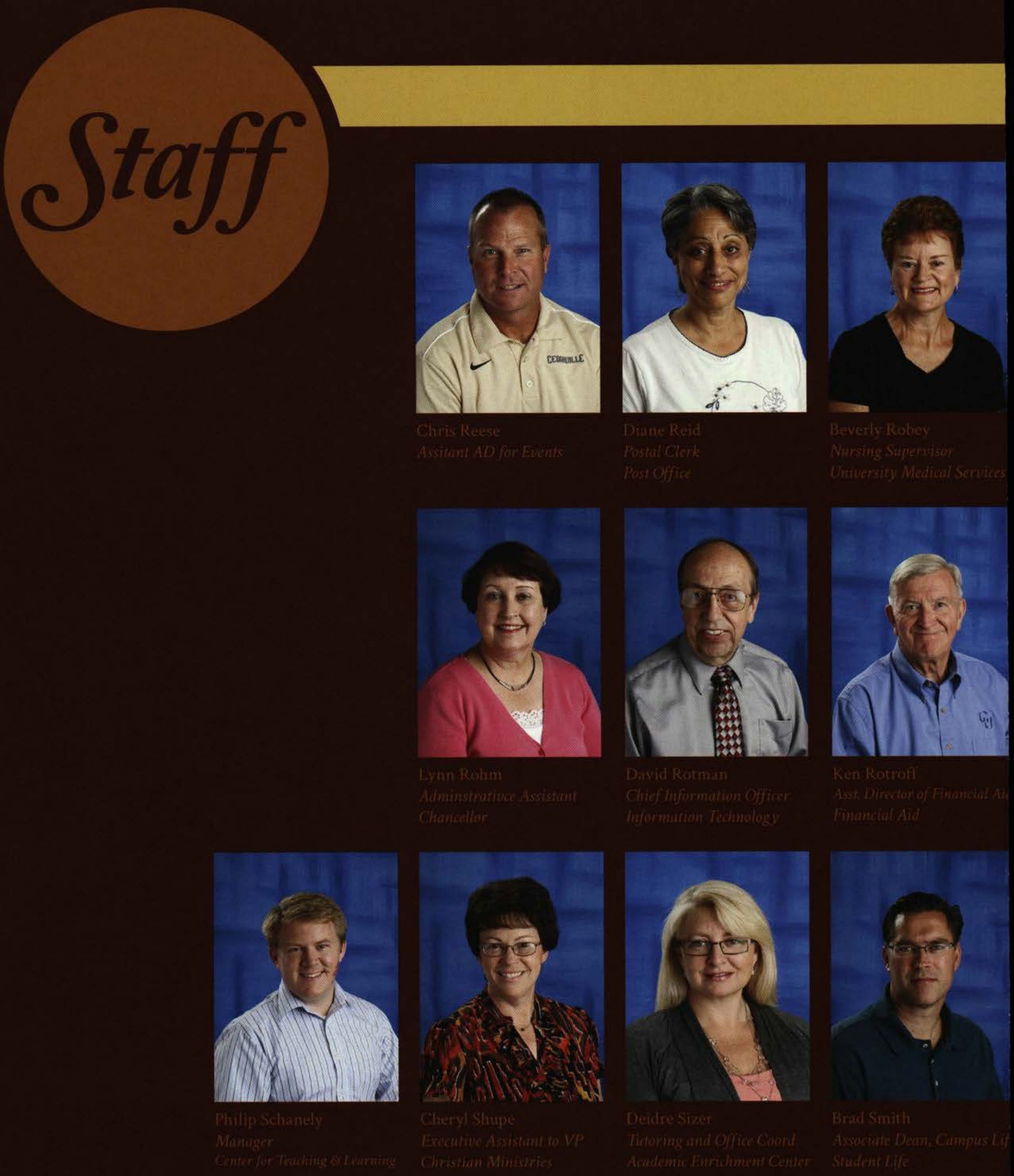



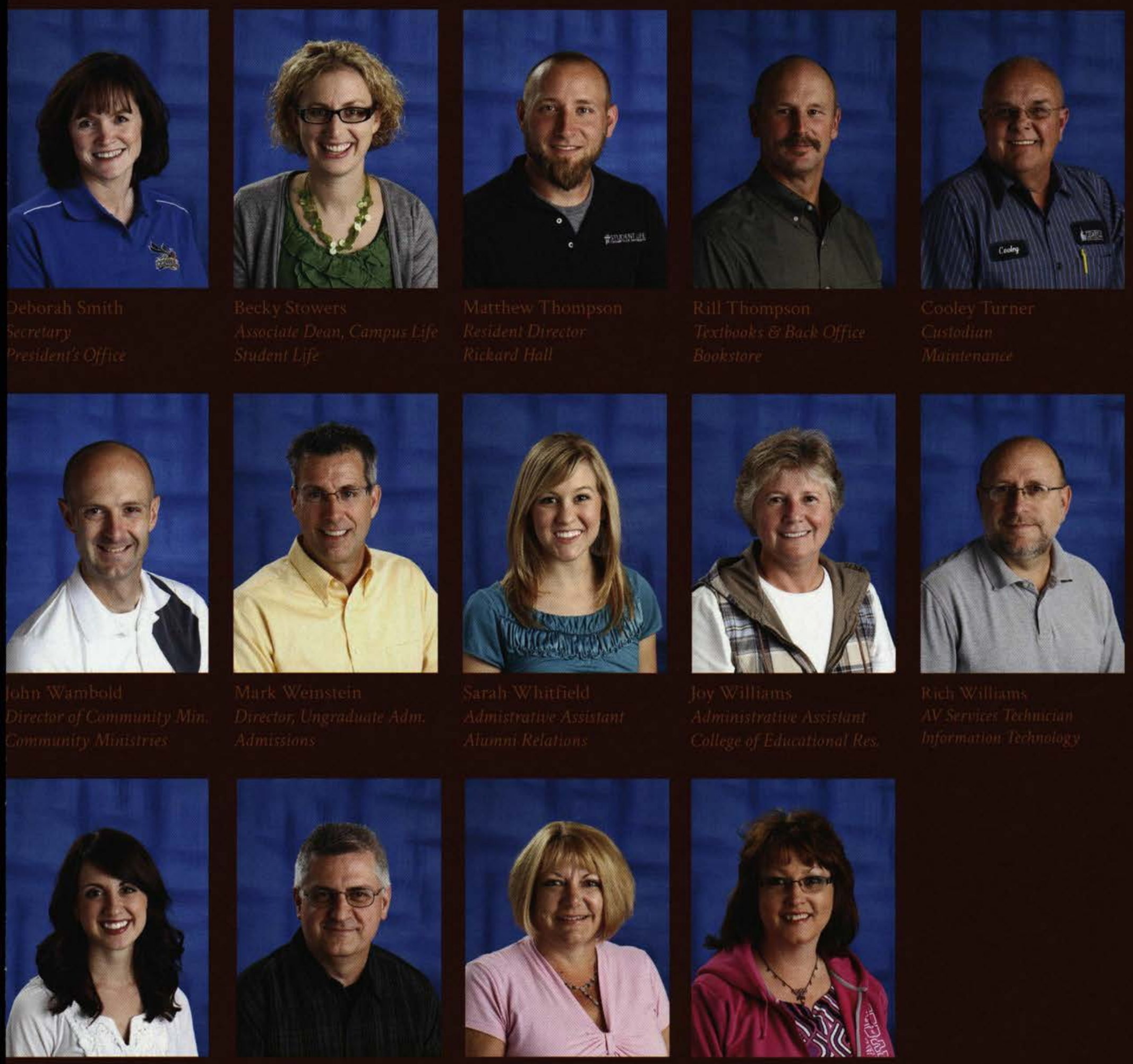


\section{Faculty E. Staff of the rear}

As student-elected honors, the Faculty and Staff of the Year awards are greatly appreciated.

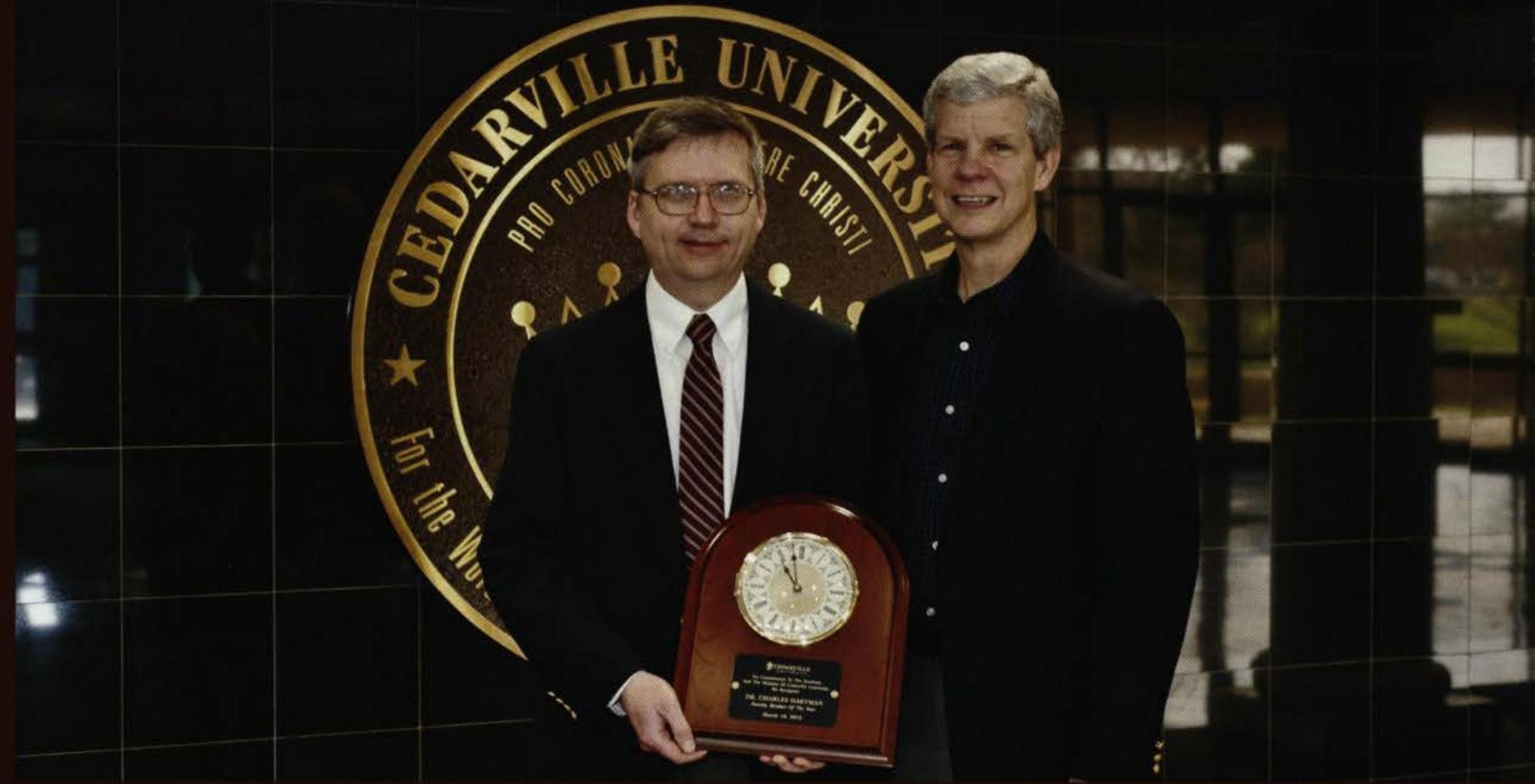

Charles Hartman, an associate professor of accounting, receives the award for Faculty of the Year.

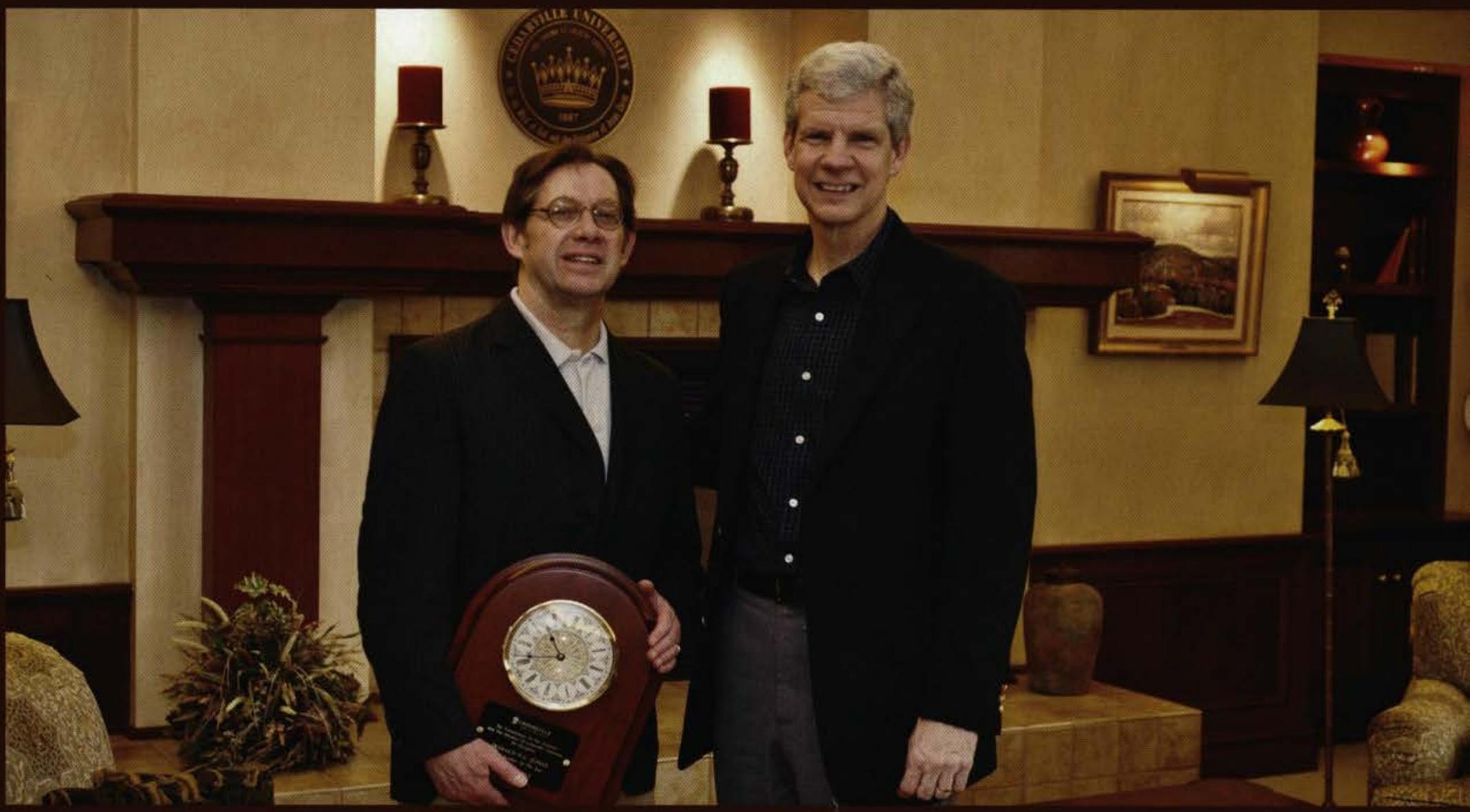


Charles Hartman and Donald Jones have invested their time and energy in ministering to our student body.

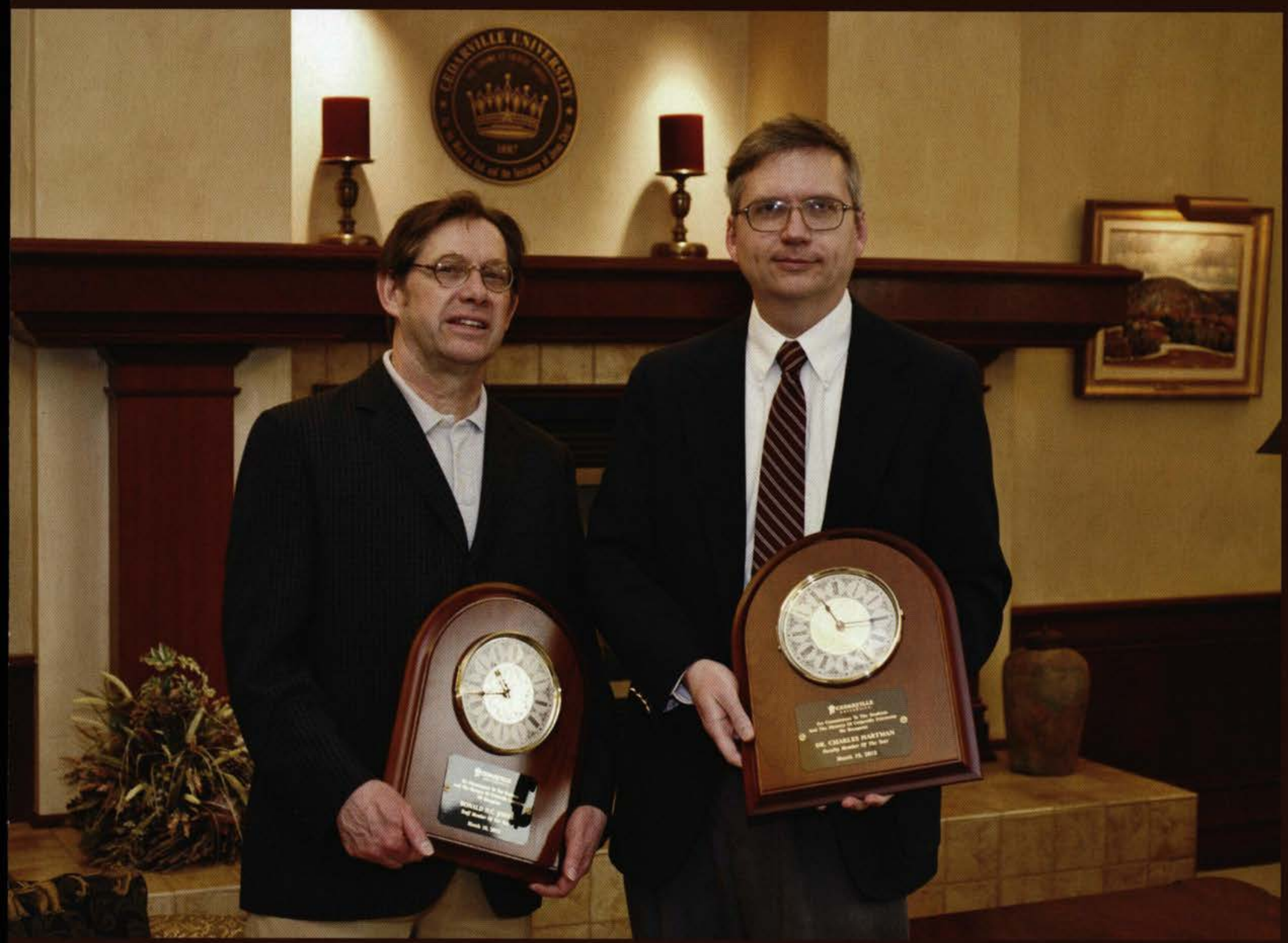

Donald Jones and Charles Hartman represent all of the staff and the faculty who contribute to student success at Cedarville. 


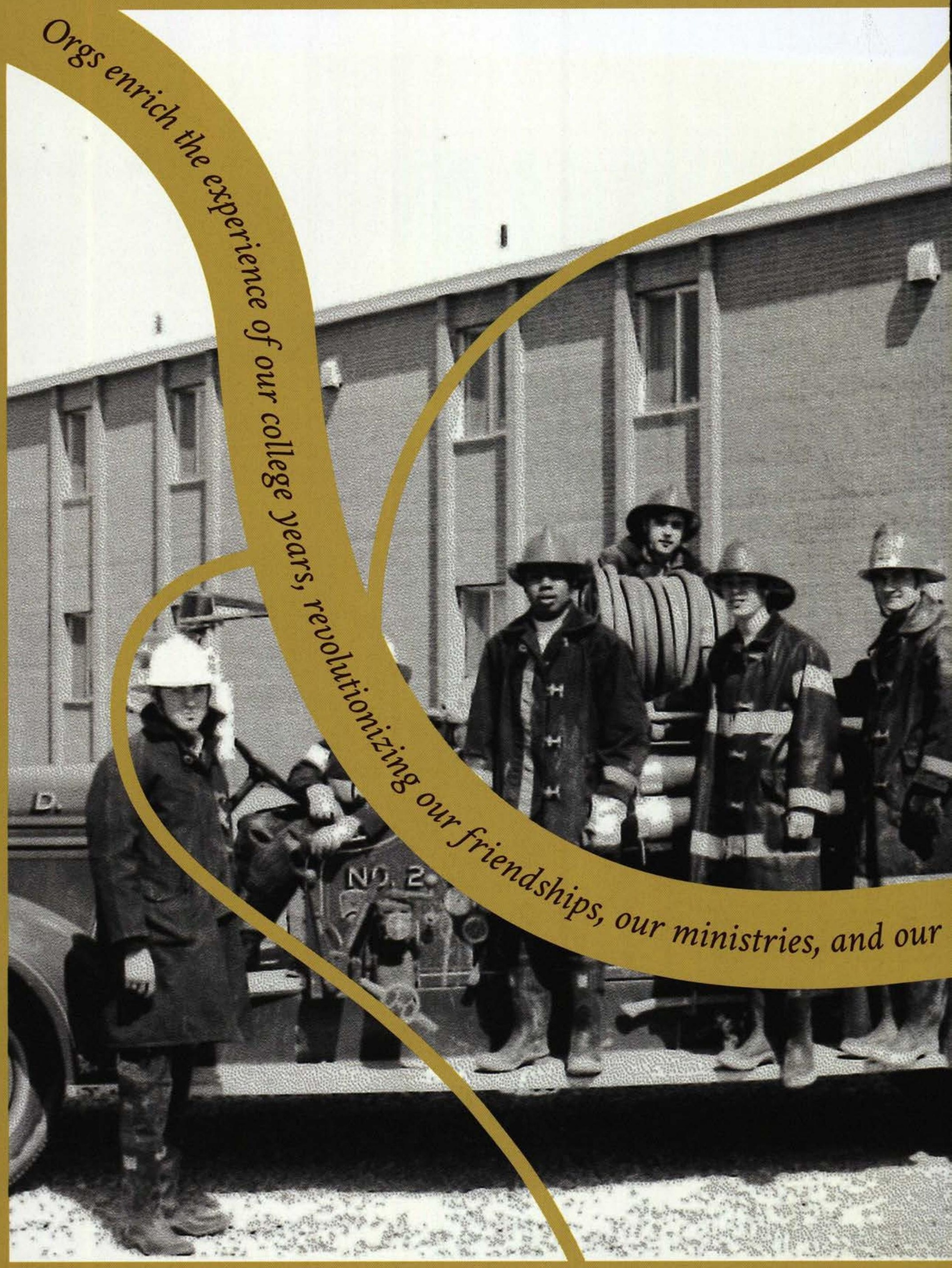



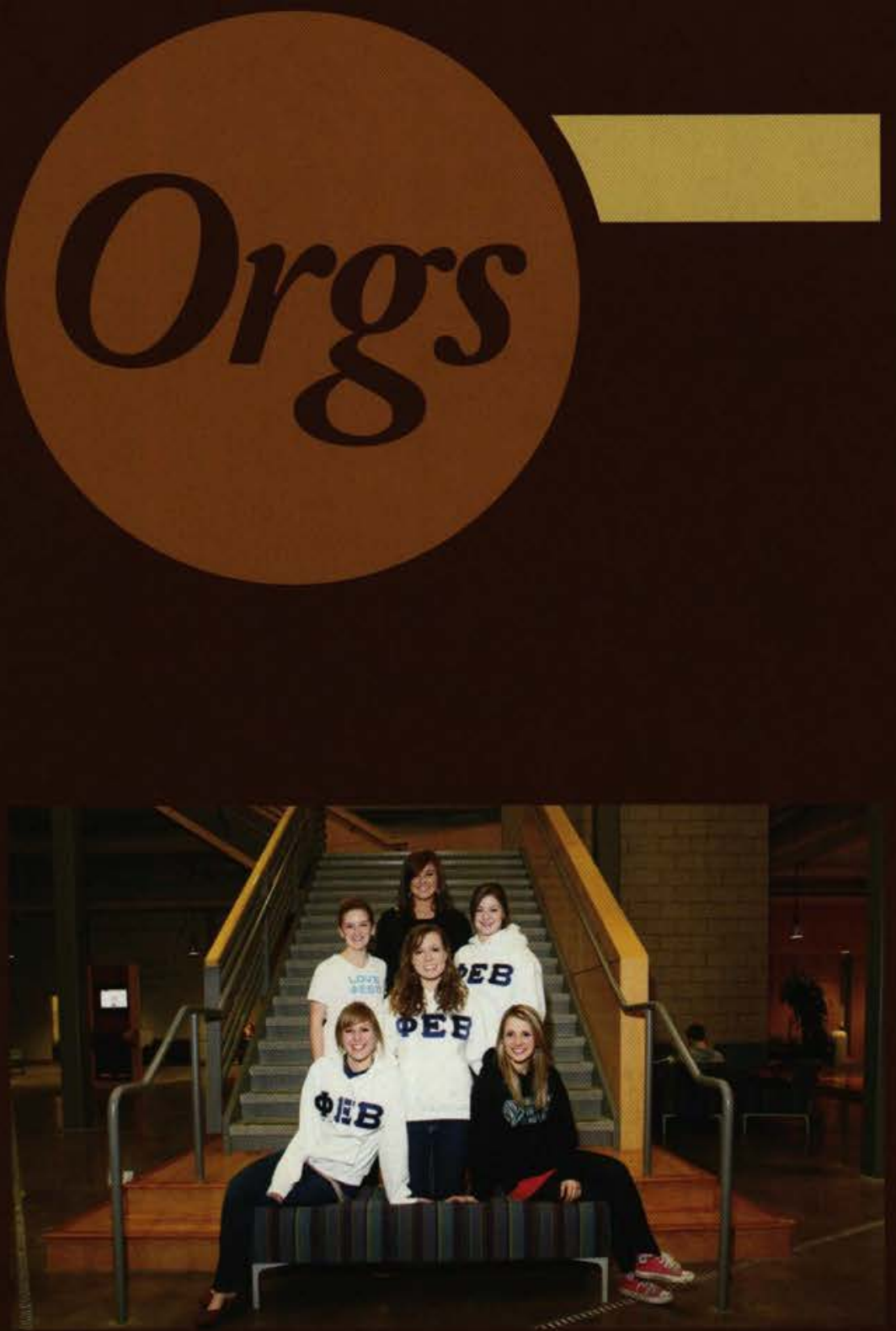

Pbi Epsilon Beta

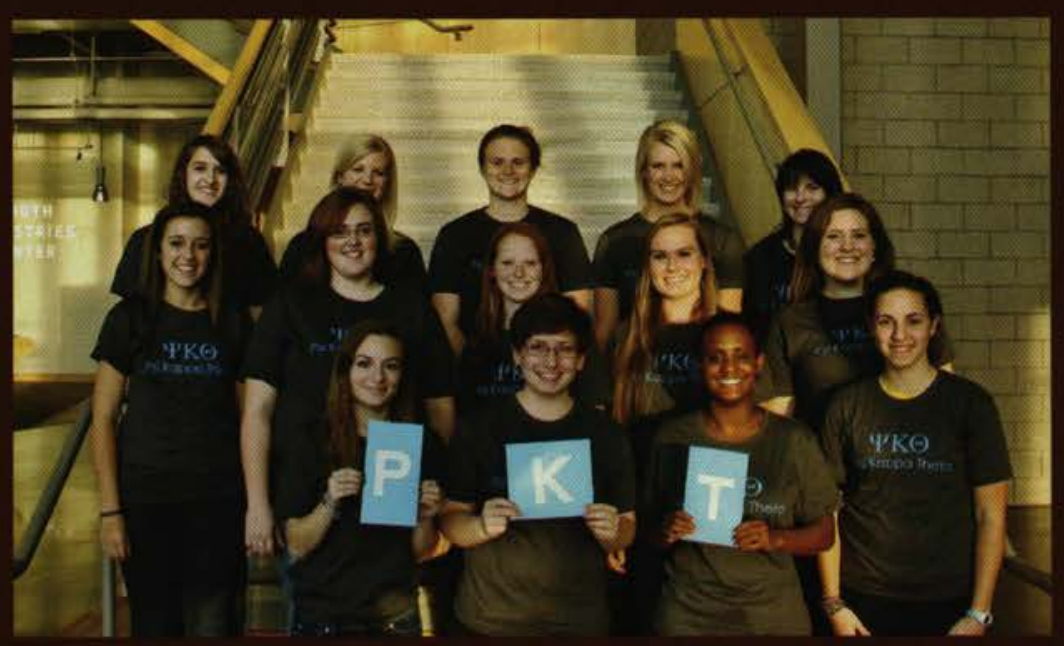

Psi Kappa Theta

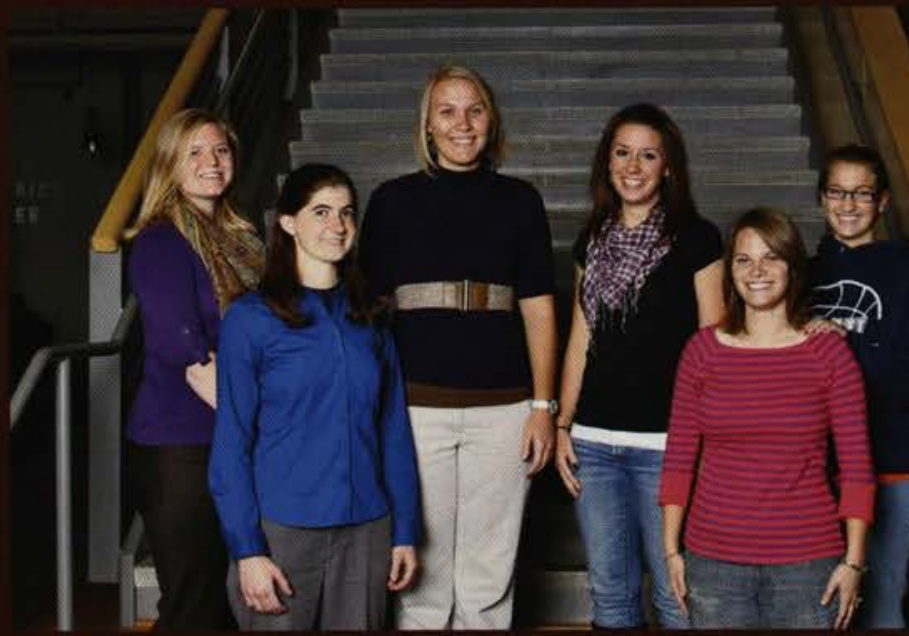

Epsilon Omega

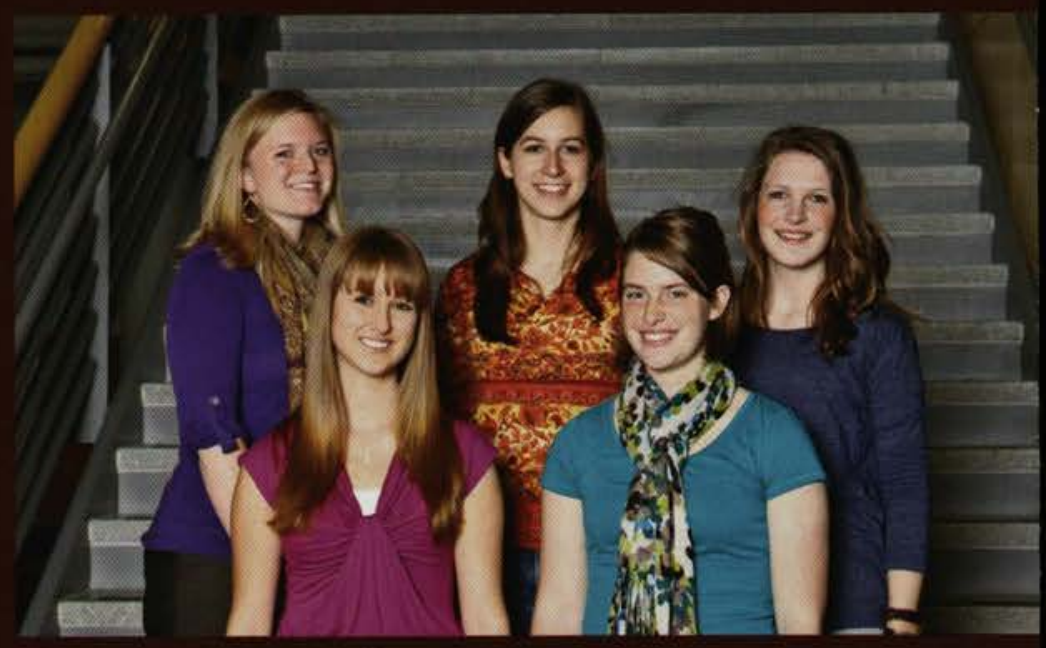

Pregnancy Resource Center

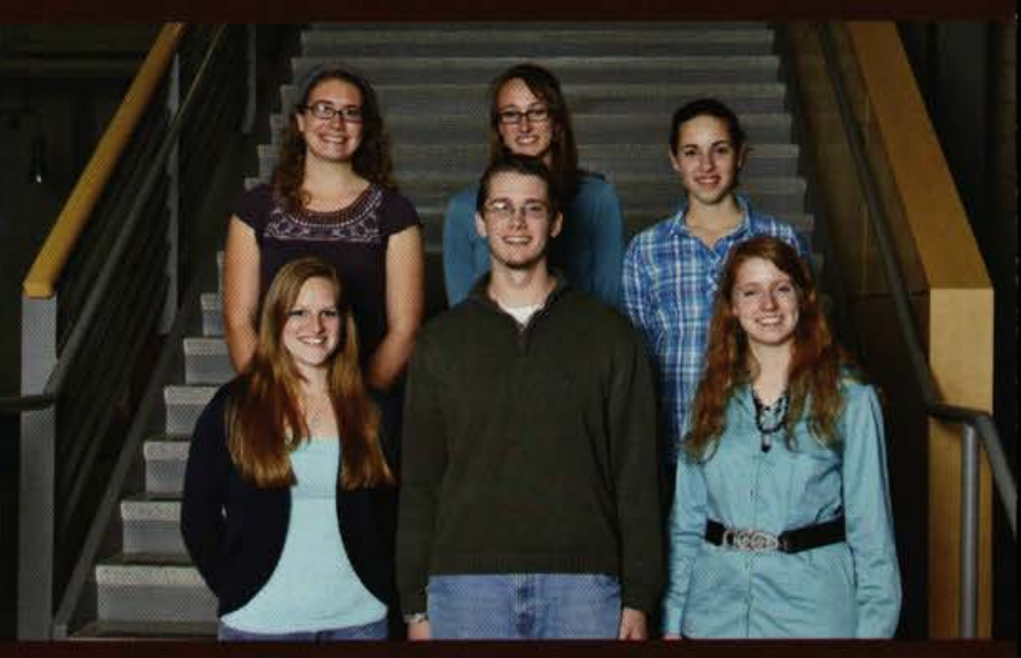

Tholography Club 


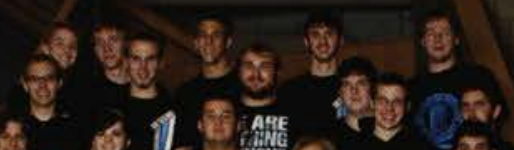

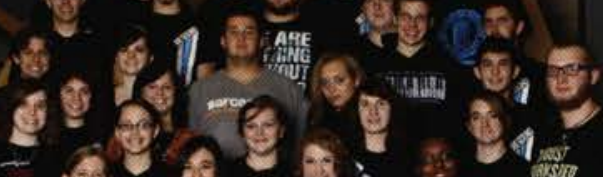

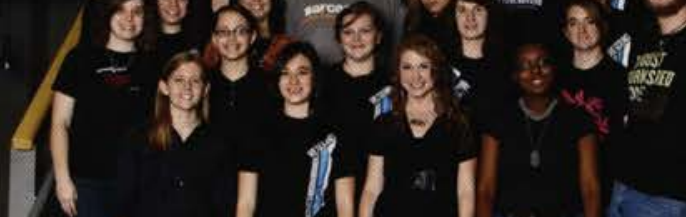

$1 / 1$

Resound Regdio

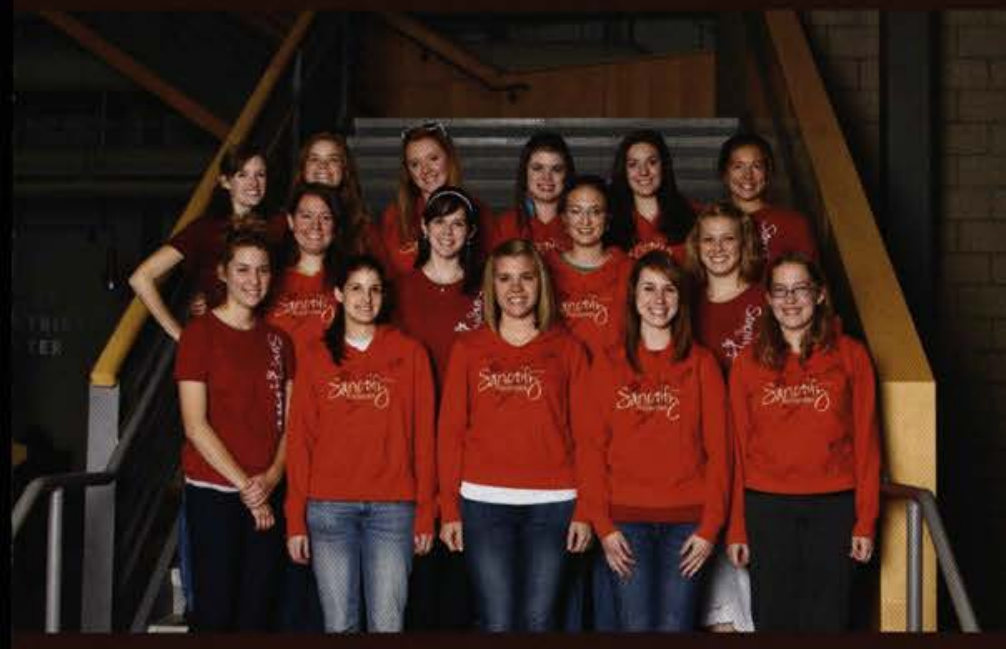

Sanctify Ministries

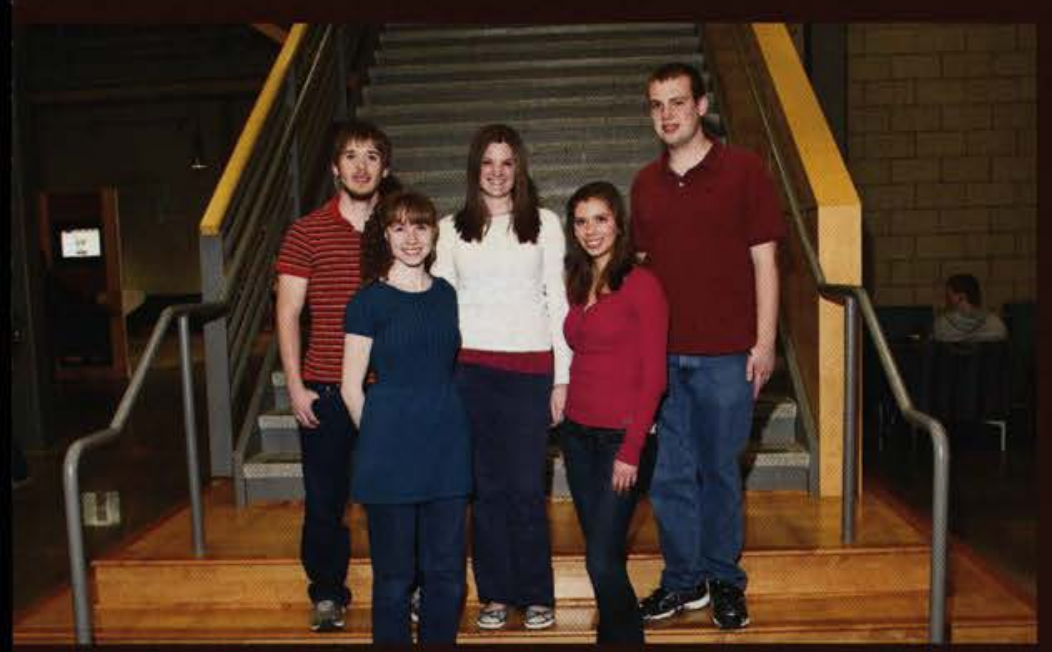

Students for Israel

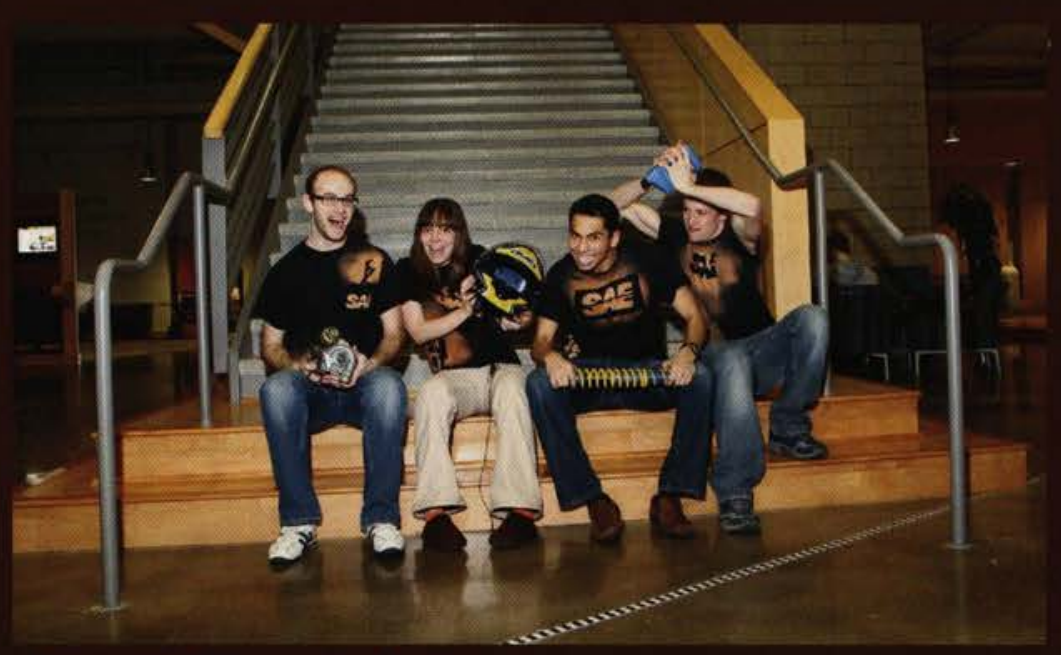

Society of CIntomotive Engineers

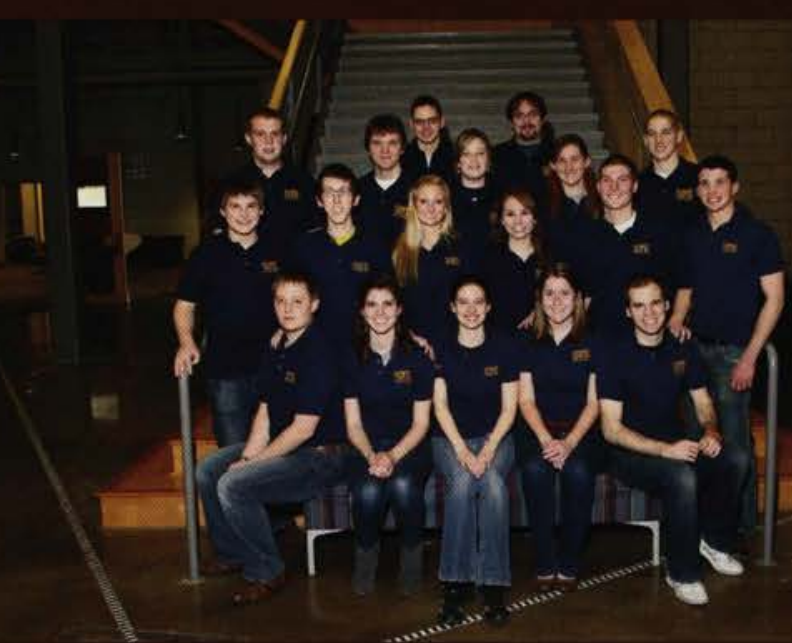

Students in Free Enterprise

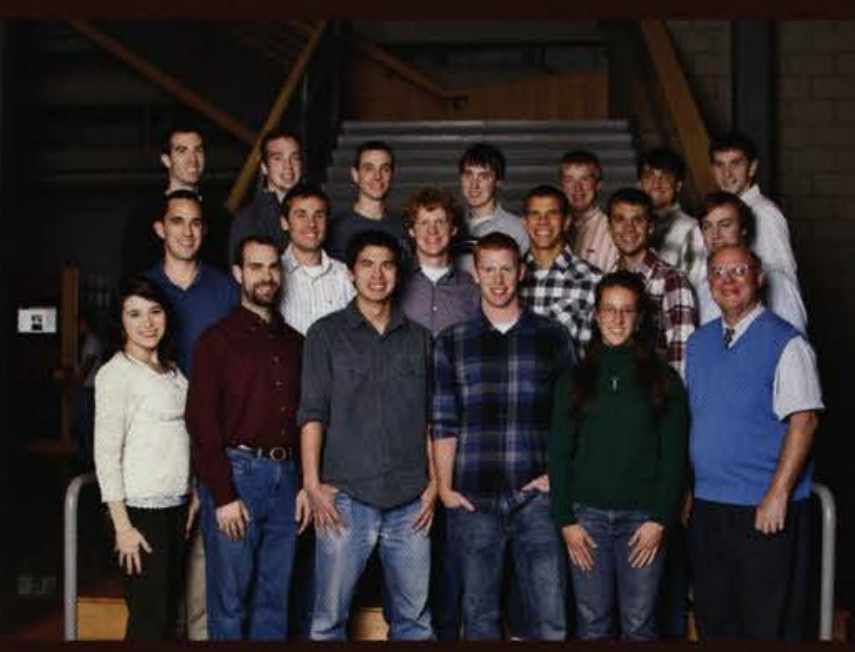

$T_{a u}{ }^{C B e t a}{ }^{P} i$ 


\section{Class Officers}

As elected leaders of their respective classes, these of ficers are also servants to their fellow classmates.

Freshman Class Officers: Phil Hord, Chad Smith, Casey Murphy, Allie Brown, Rebecca Davies, Chaney Isley

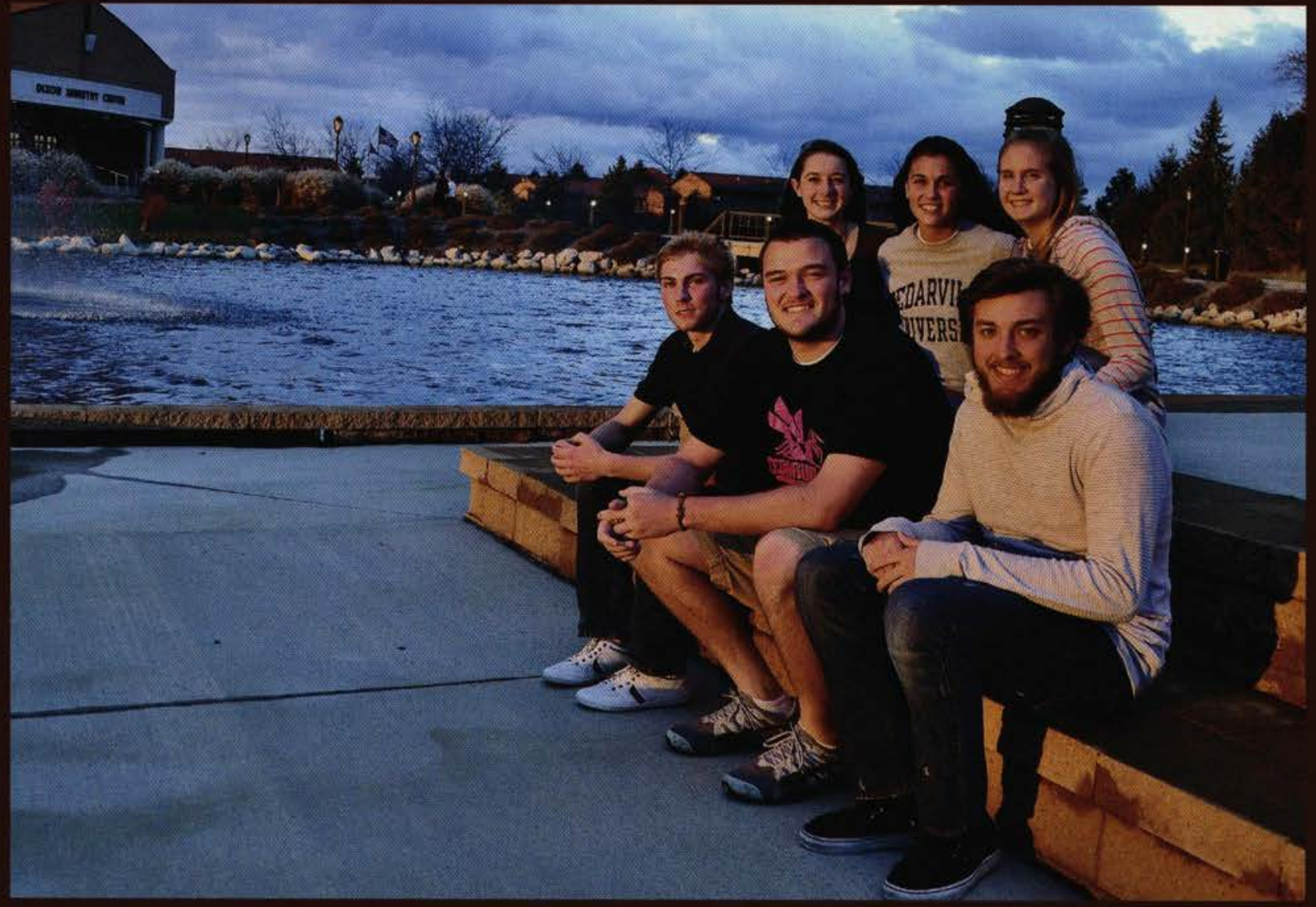

Vophomore Class Officers: Ryan Beach, Hannah Yelnik, Joel Israel, Brandon Ezzo, Galeb Nissley, Katherine Logsdon

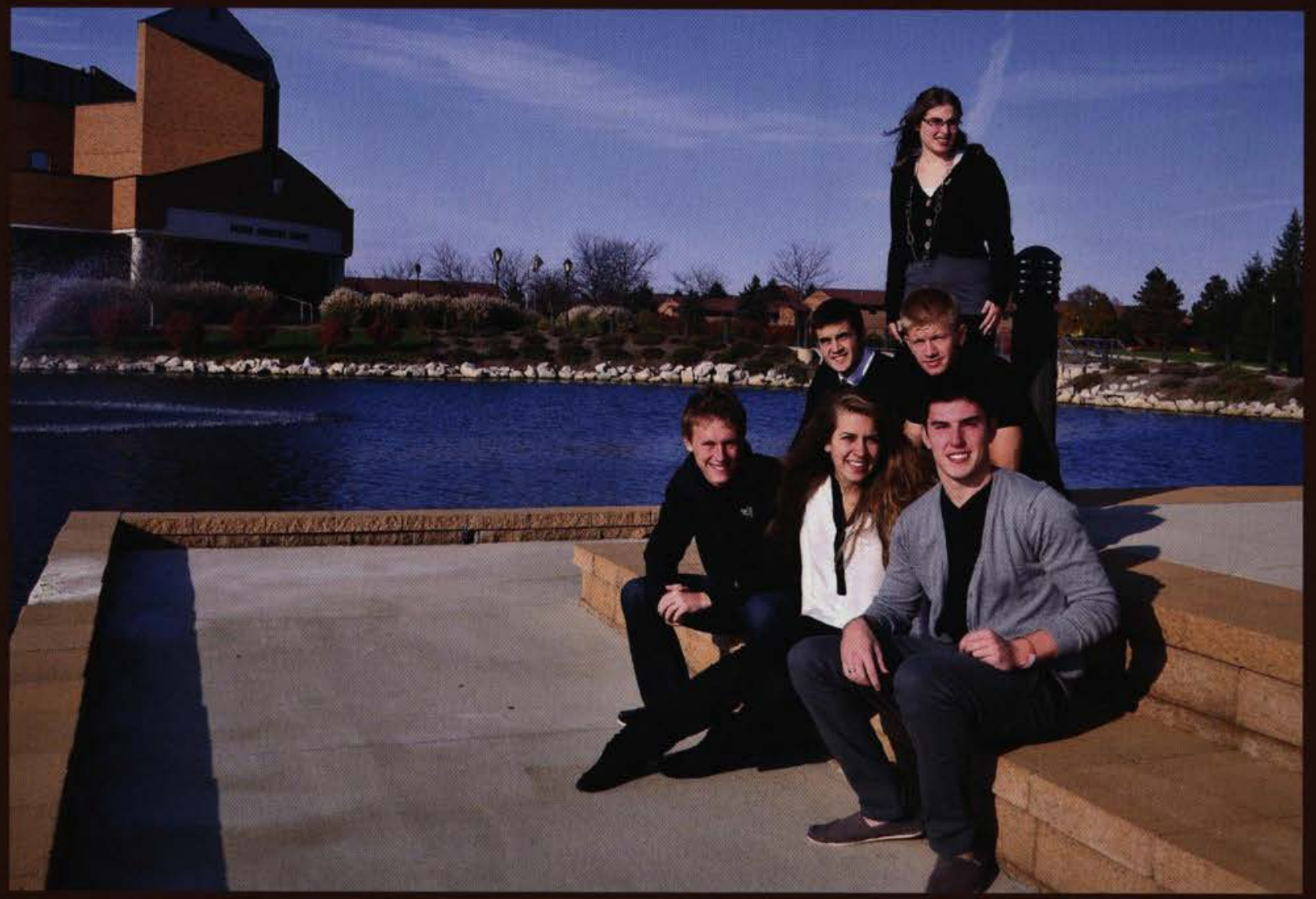


$\checkmark$ Junior Class Officers: Zachary Weston, Micah Moughon, Will Bush, Brooke Devereaux, Rebekah Brewer, Lauren Clark

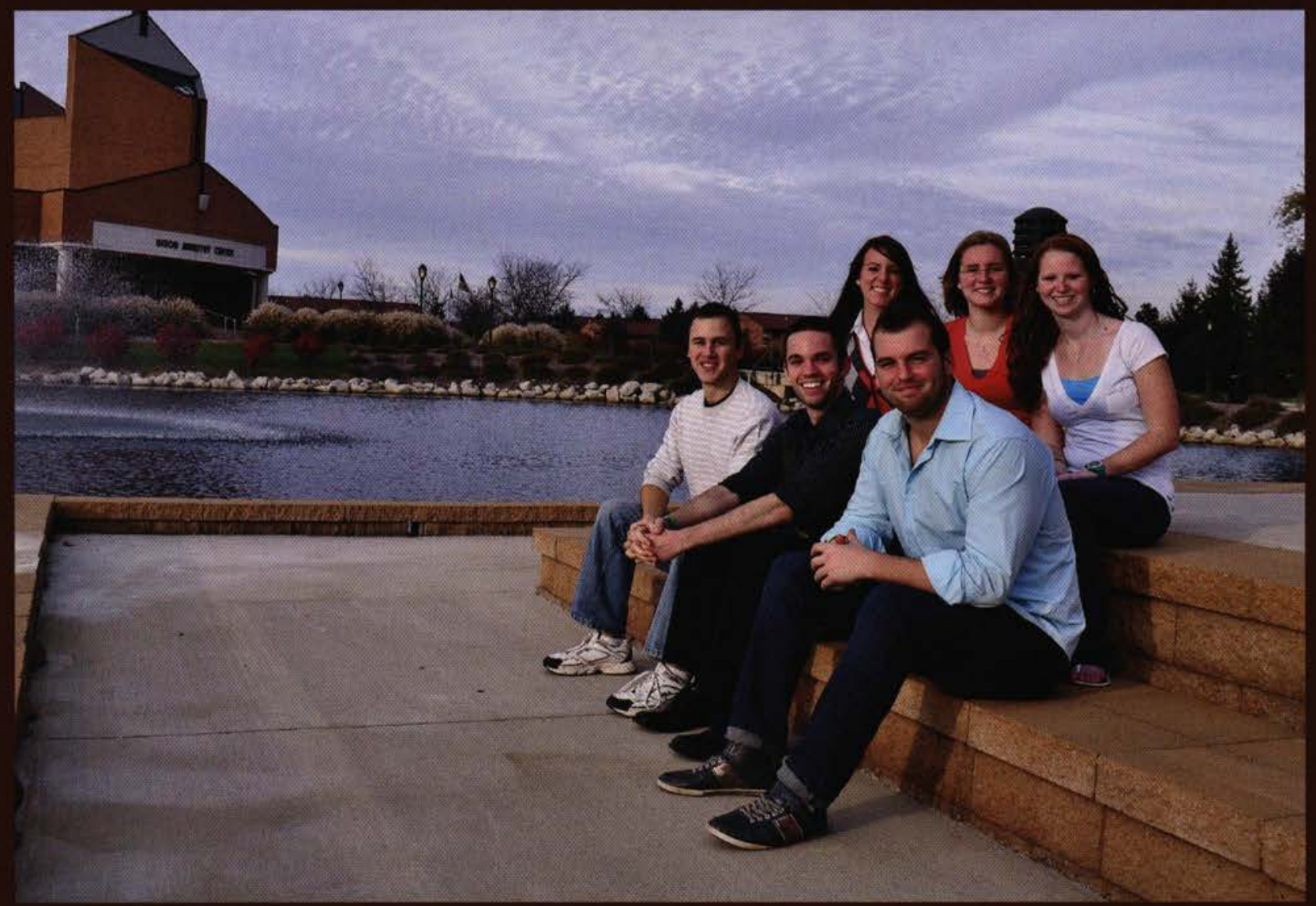

Venior Class Officers: Jane Covel, Gregory Davies, Hannah Rausch, Maggie Casillo, Matthew McDonald, Katie Hunt

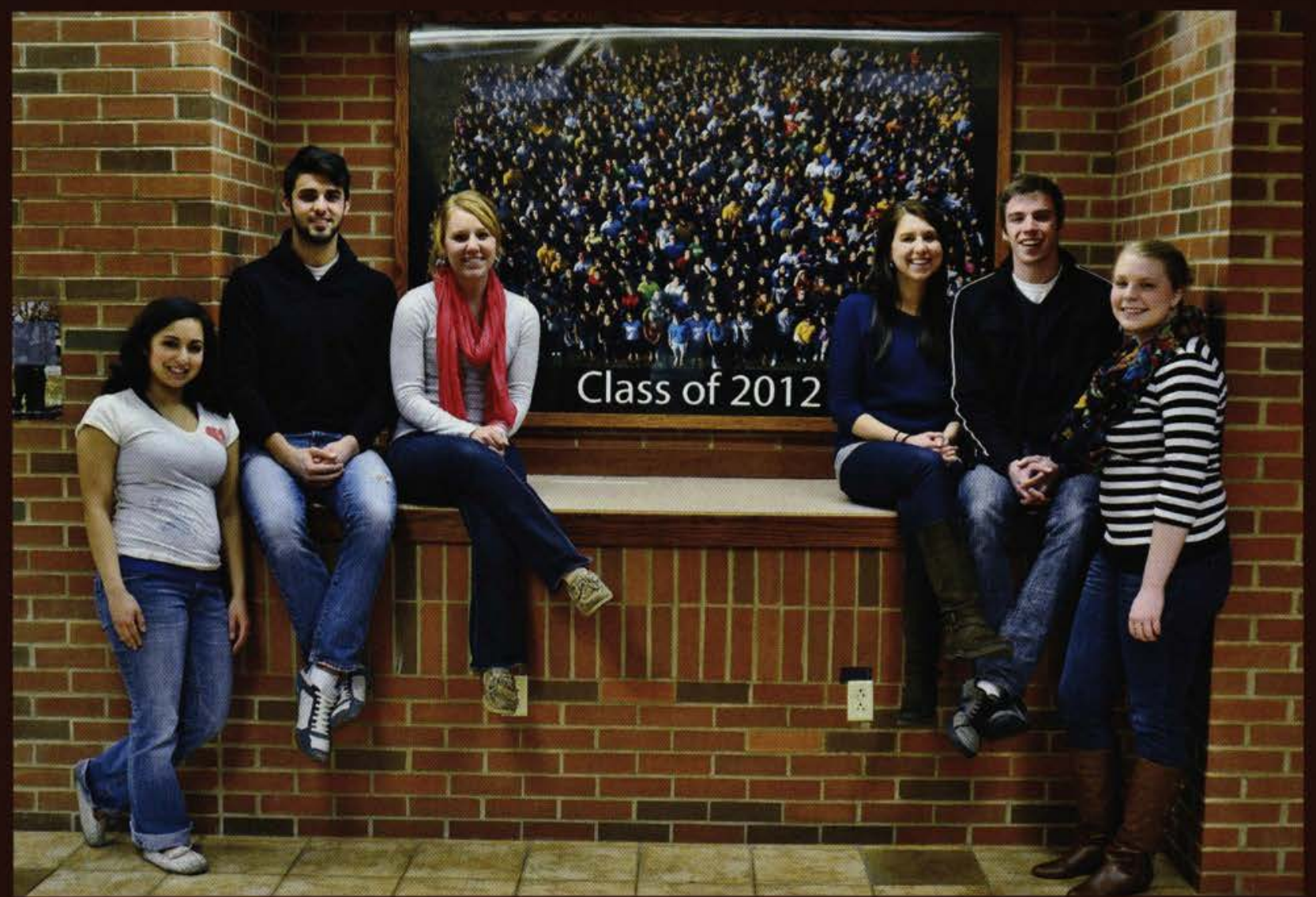




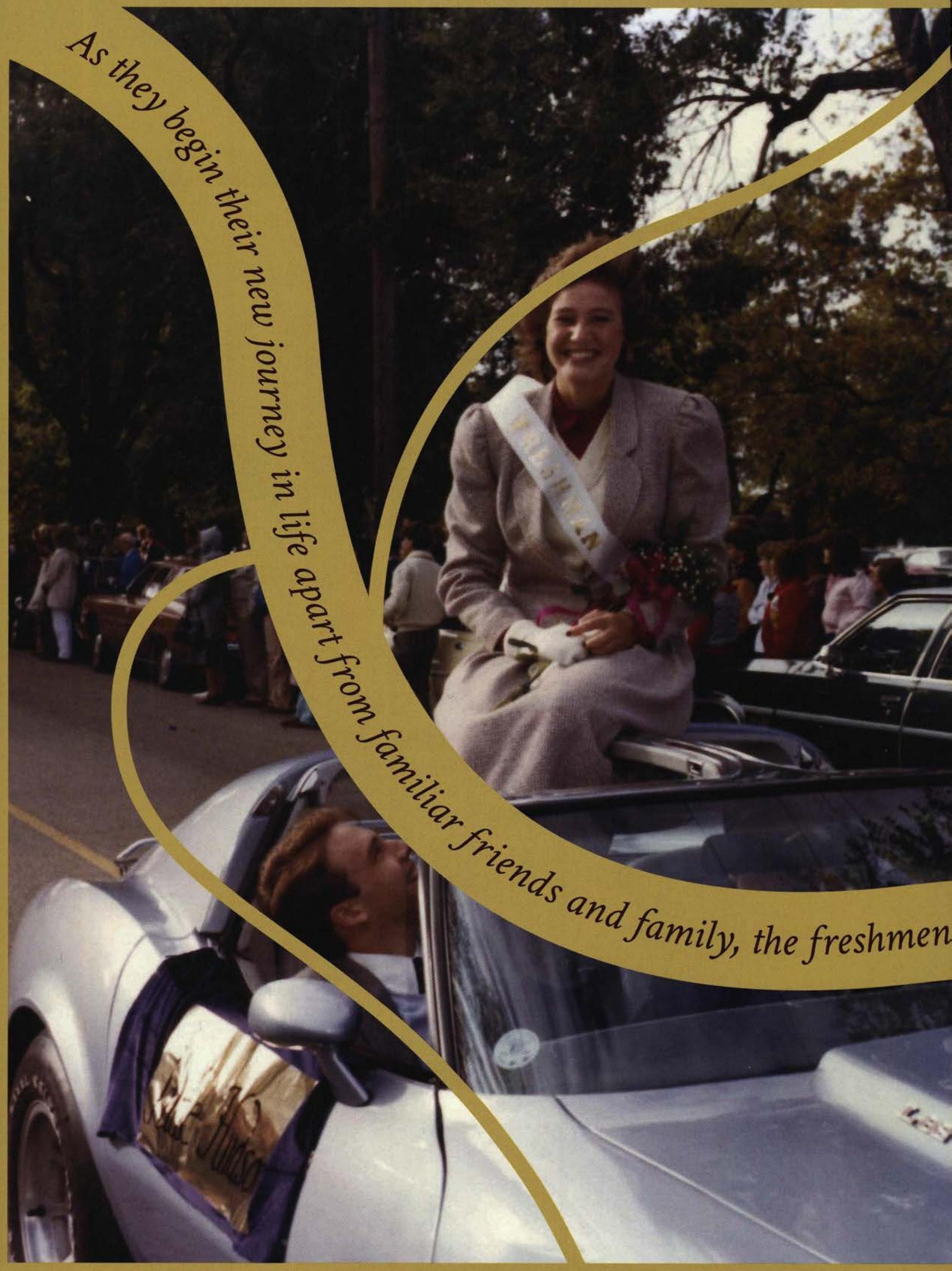




\section{Freshmen}
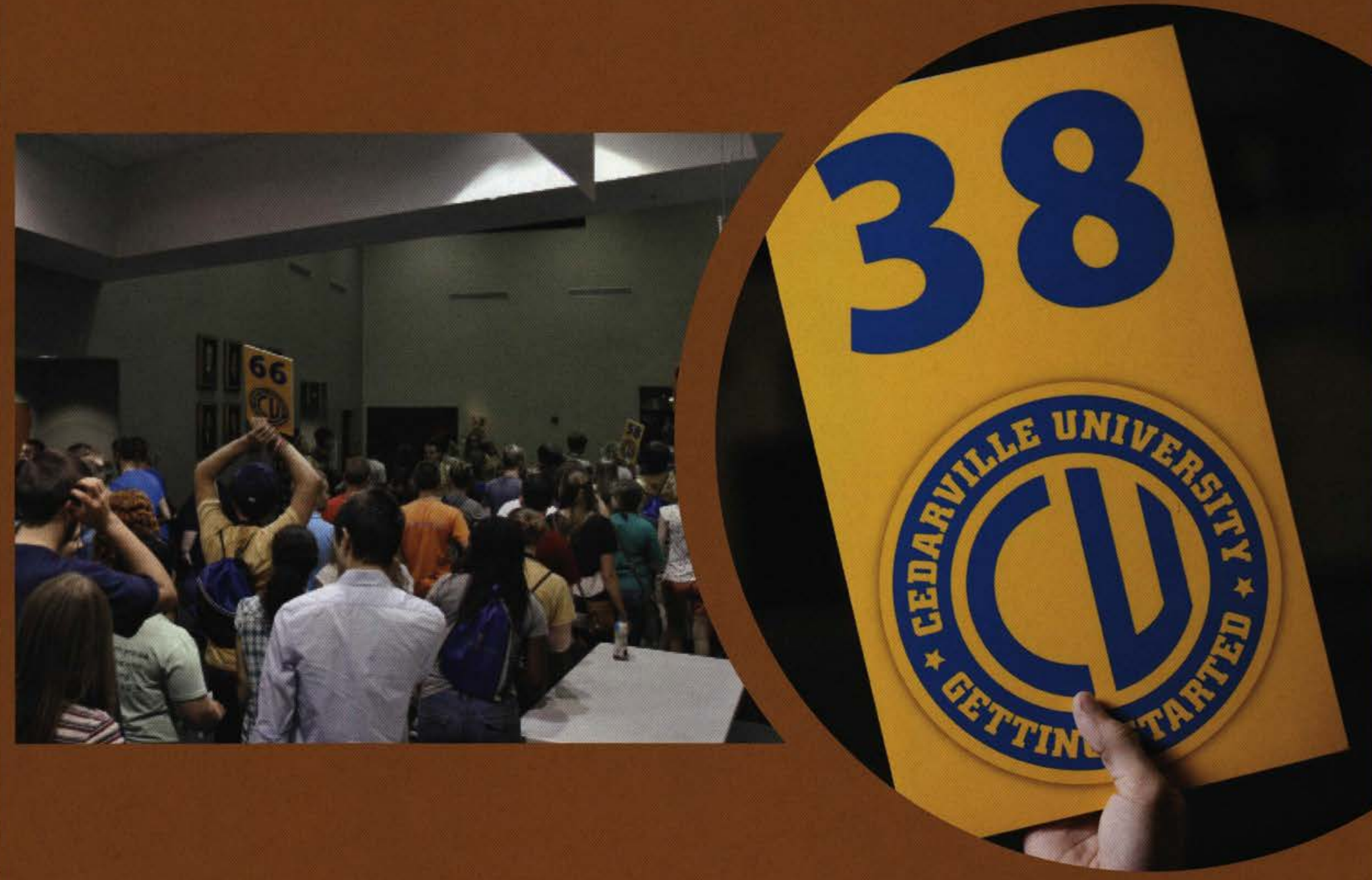

e 

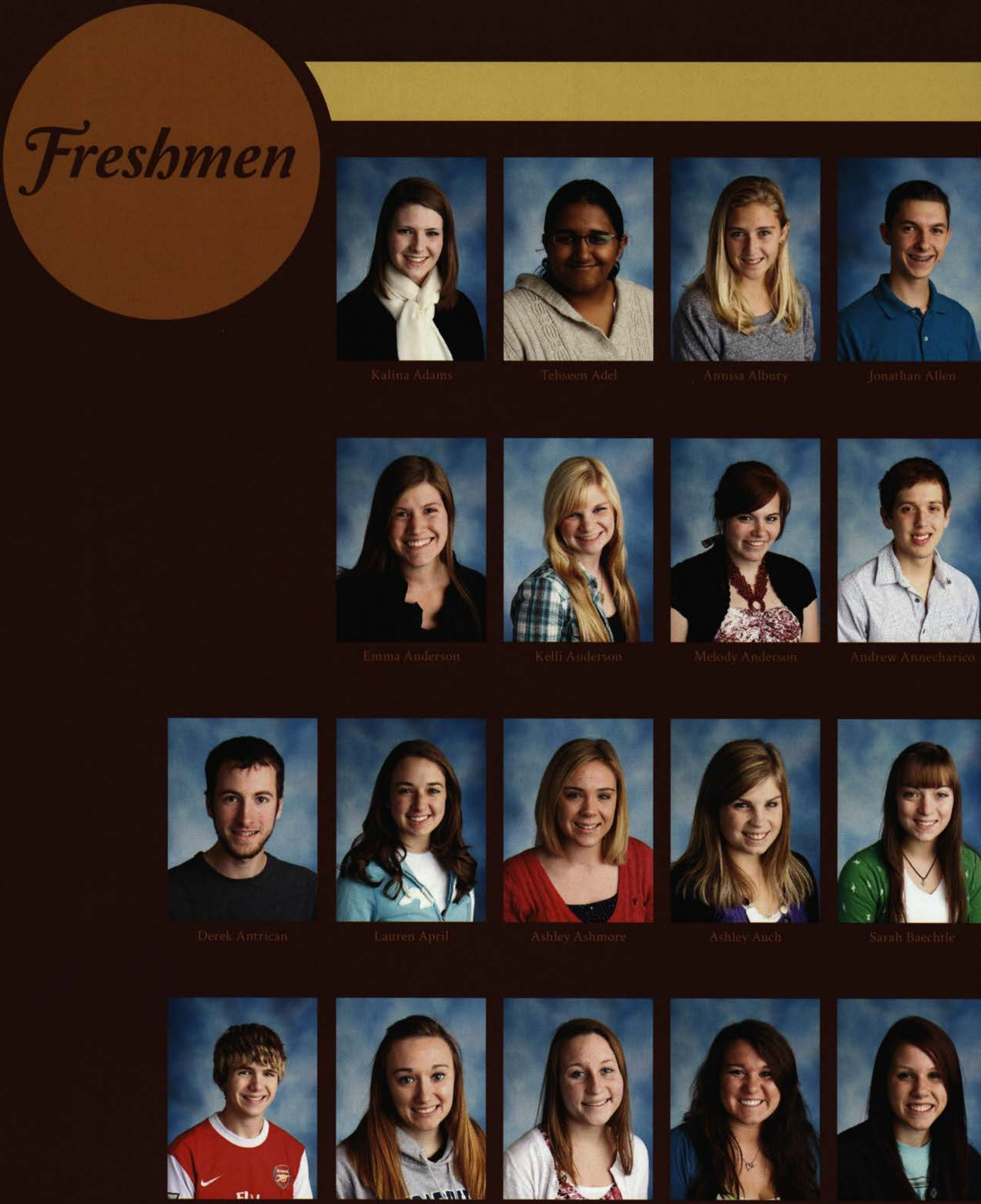


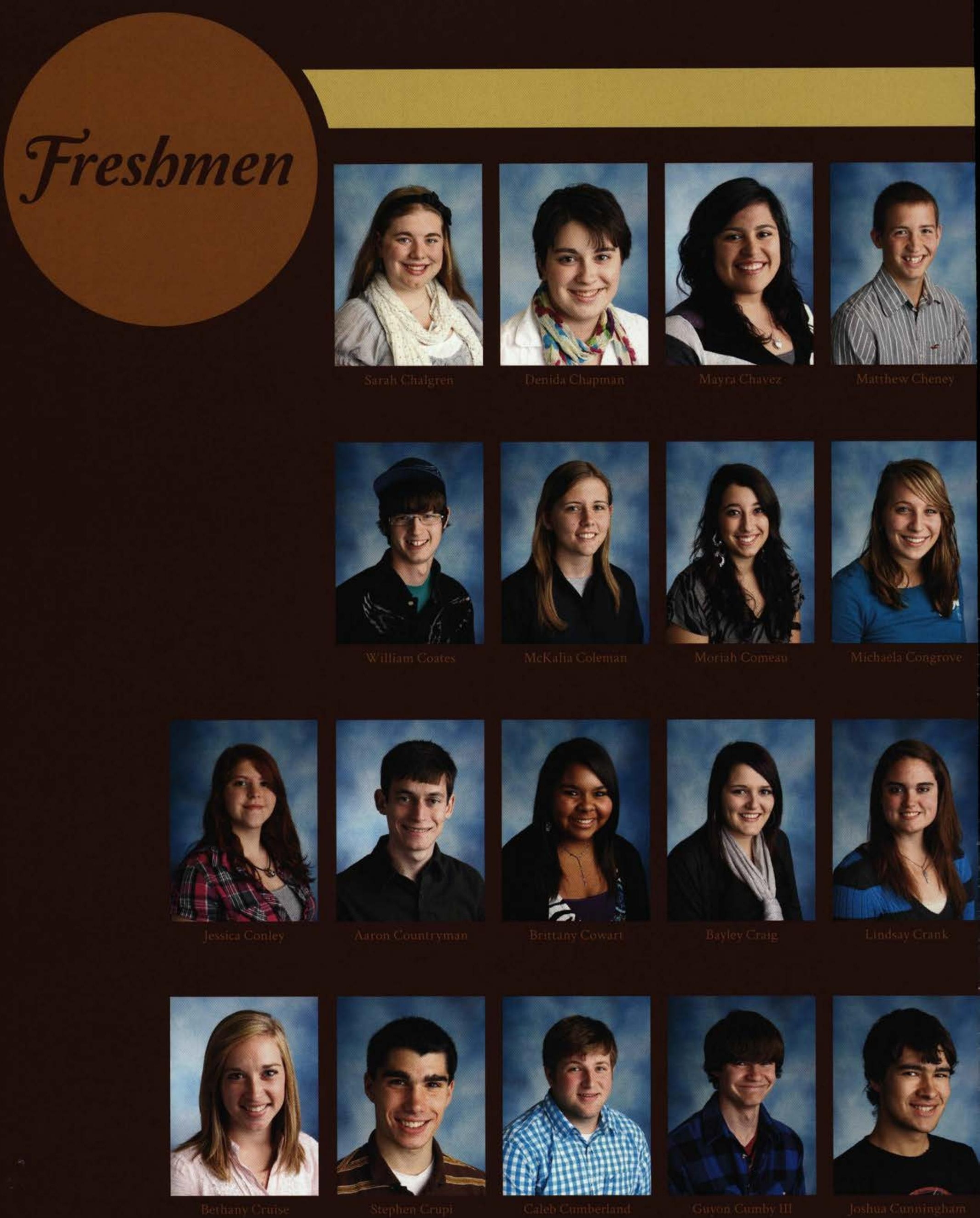




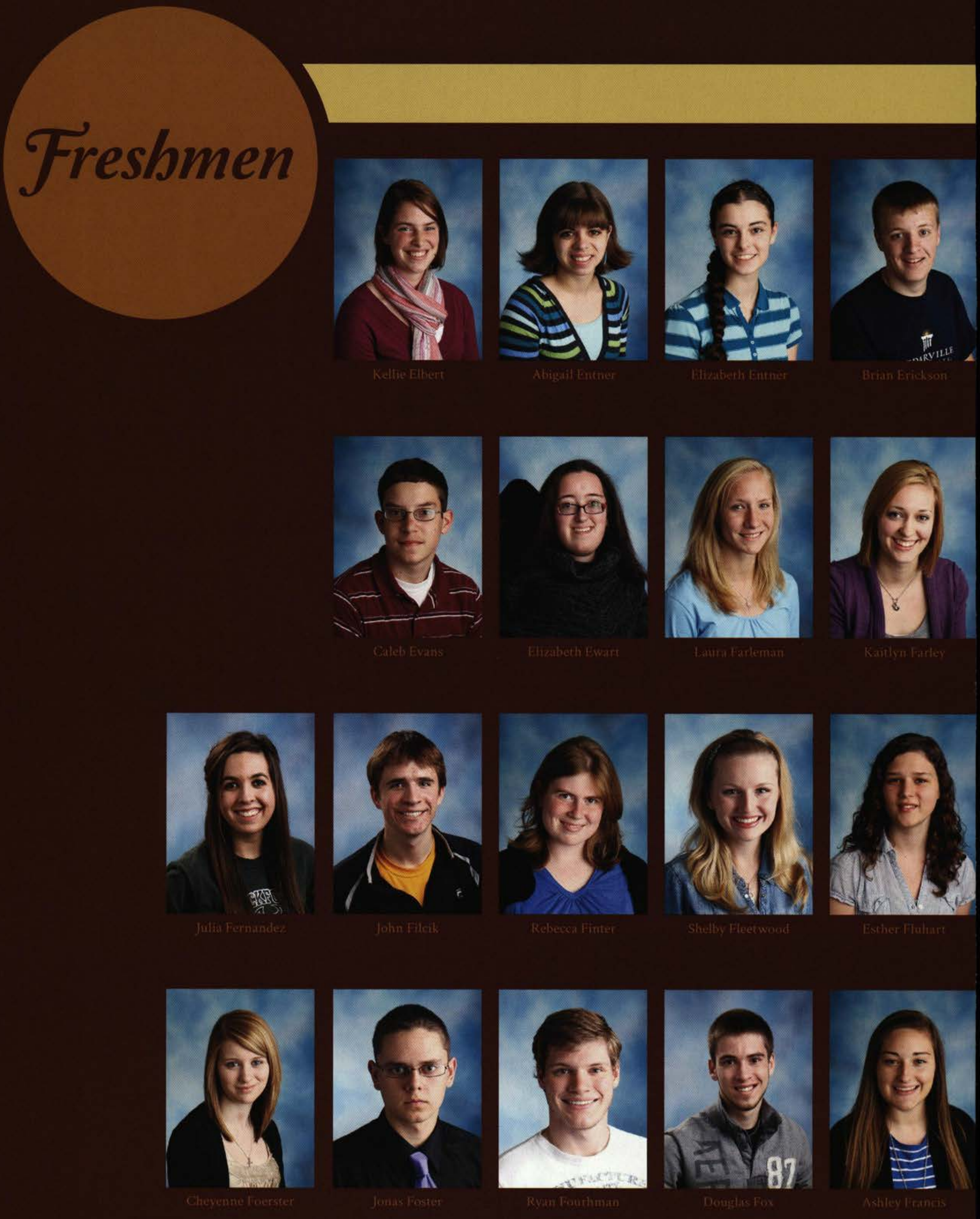



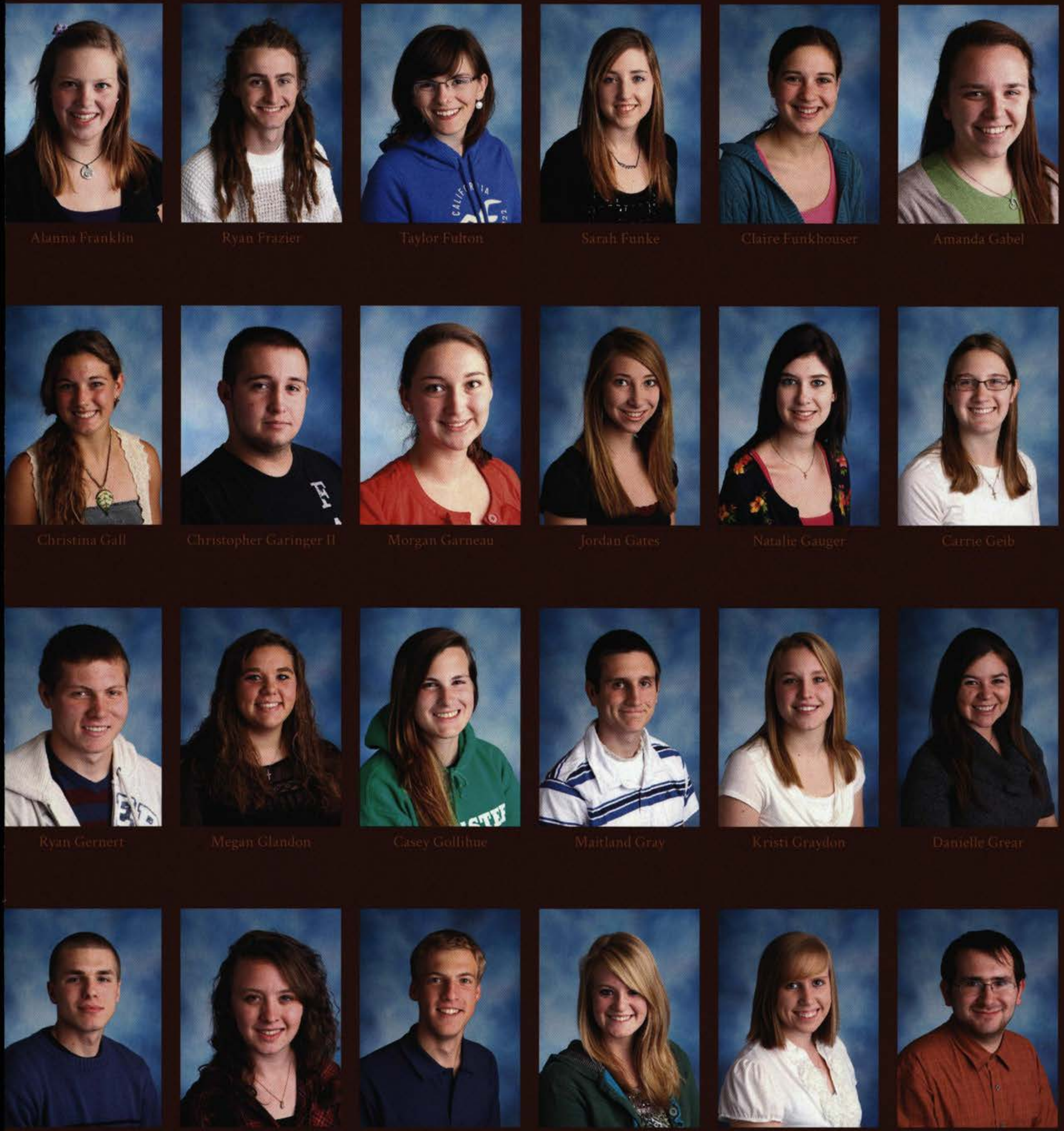


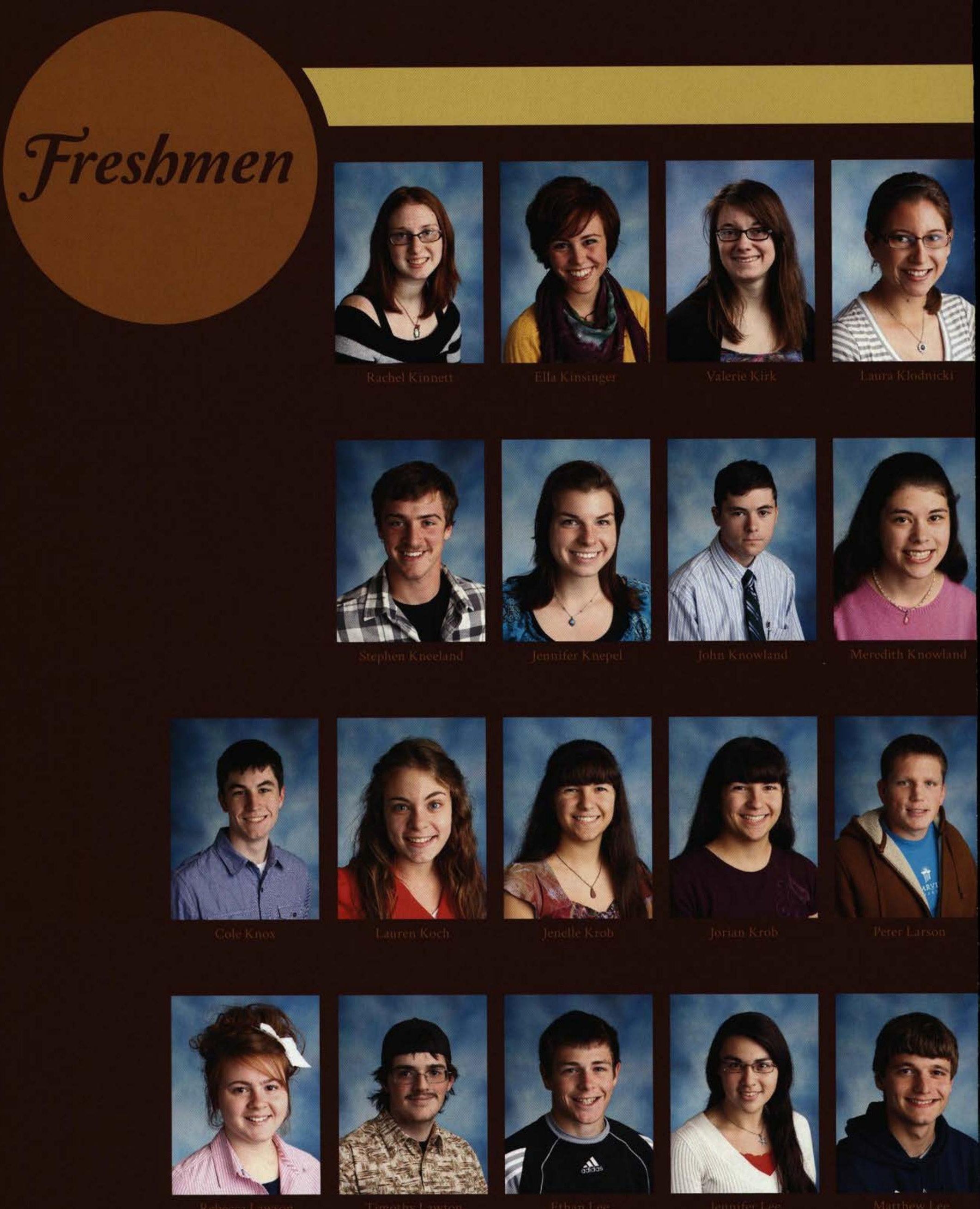



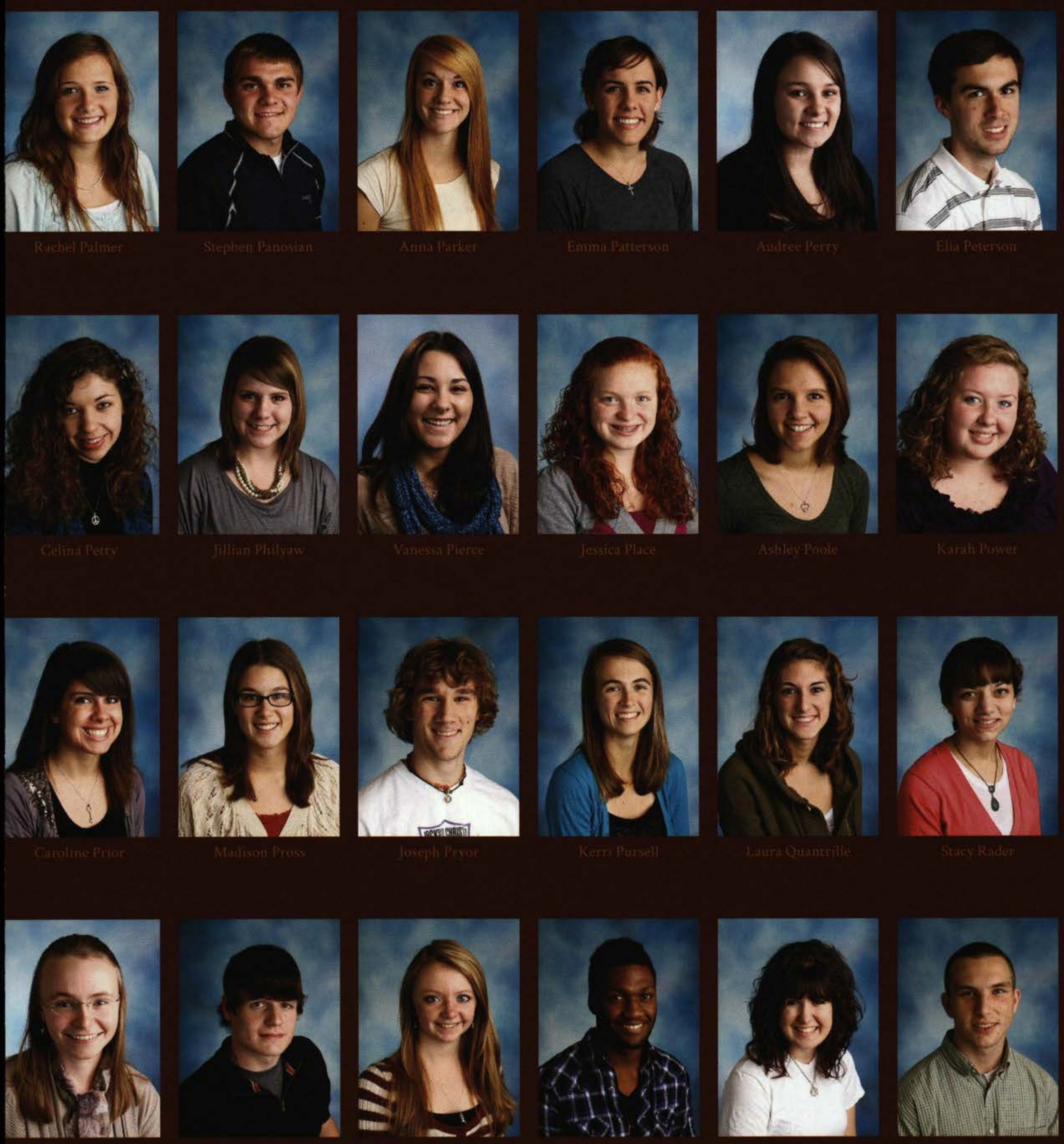

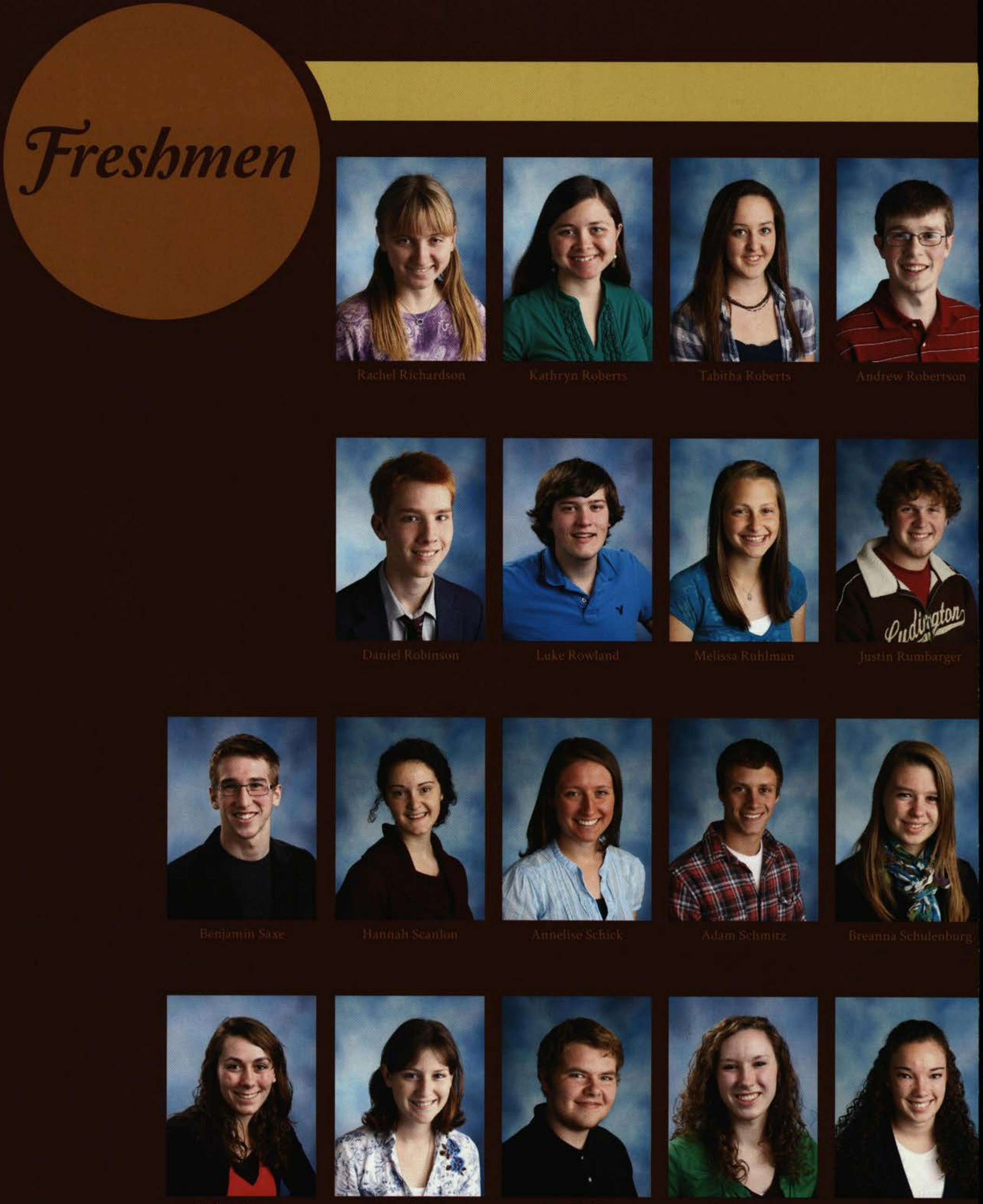


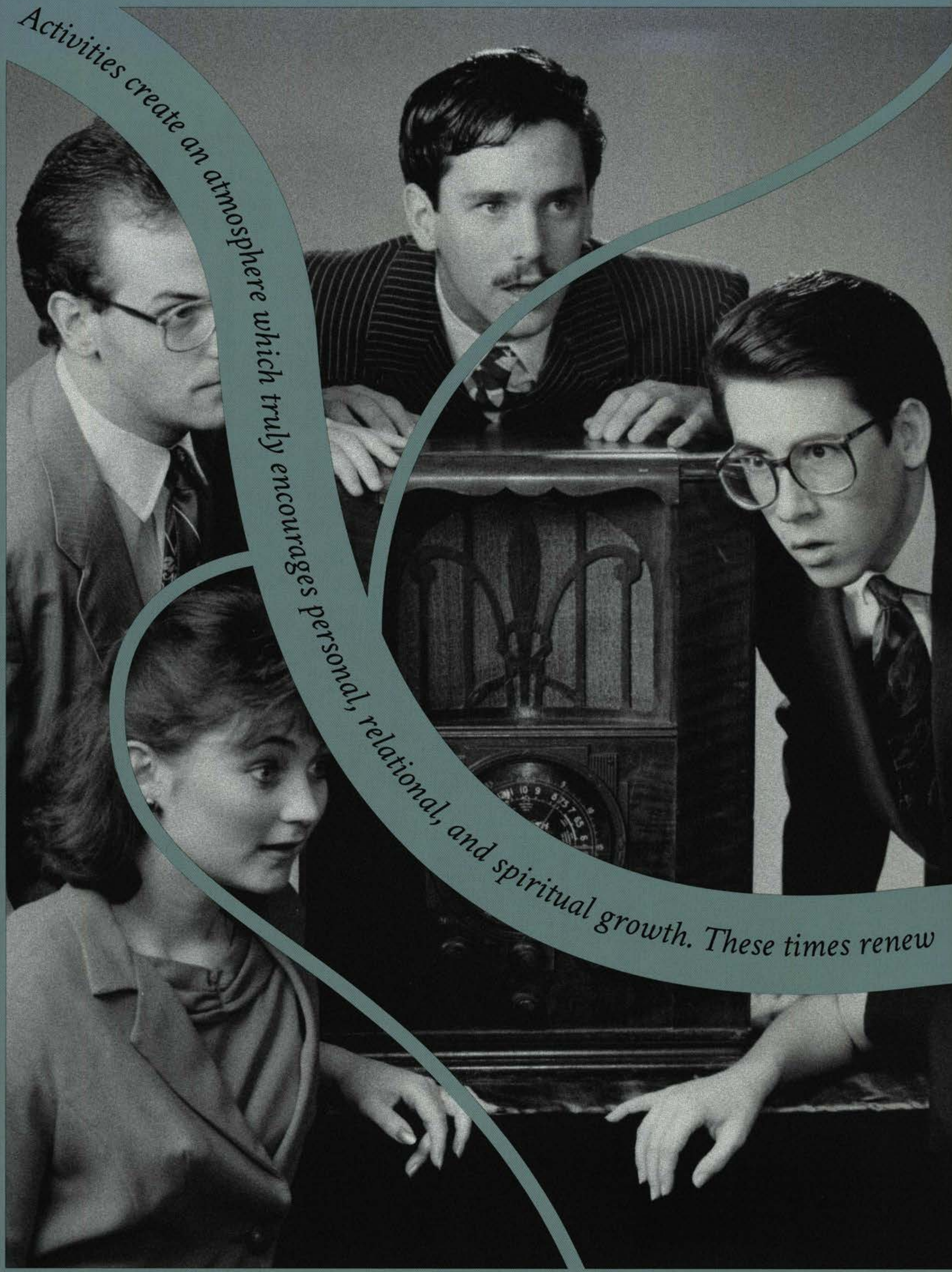




\section{Activities}

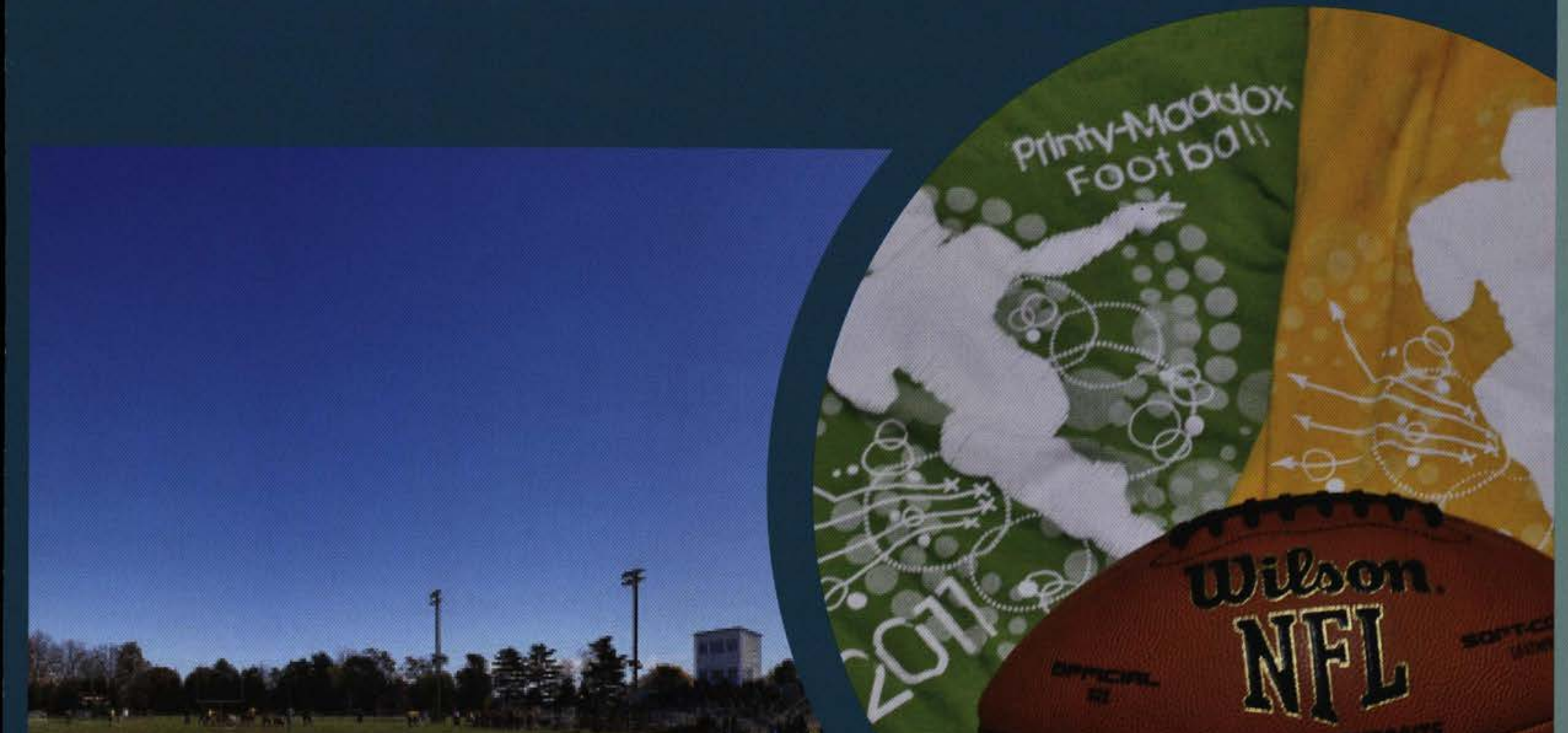

hearts with joy and create valuable

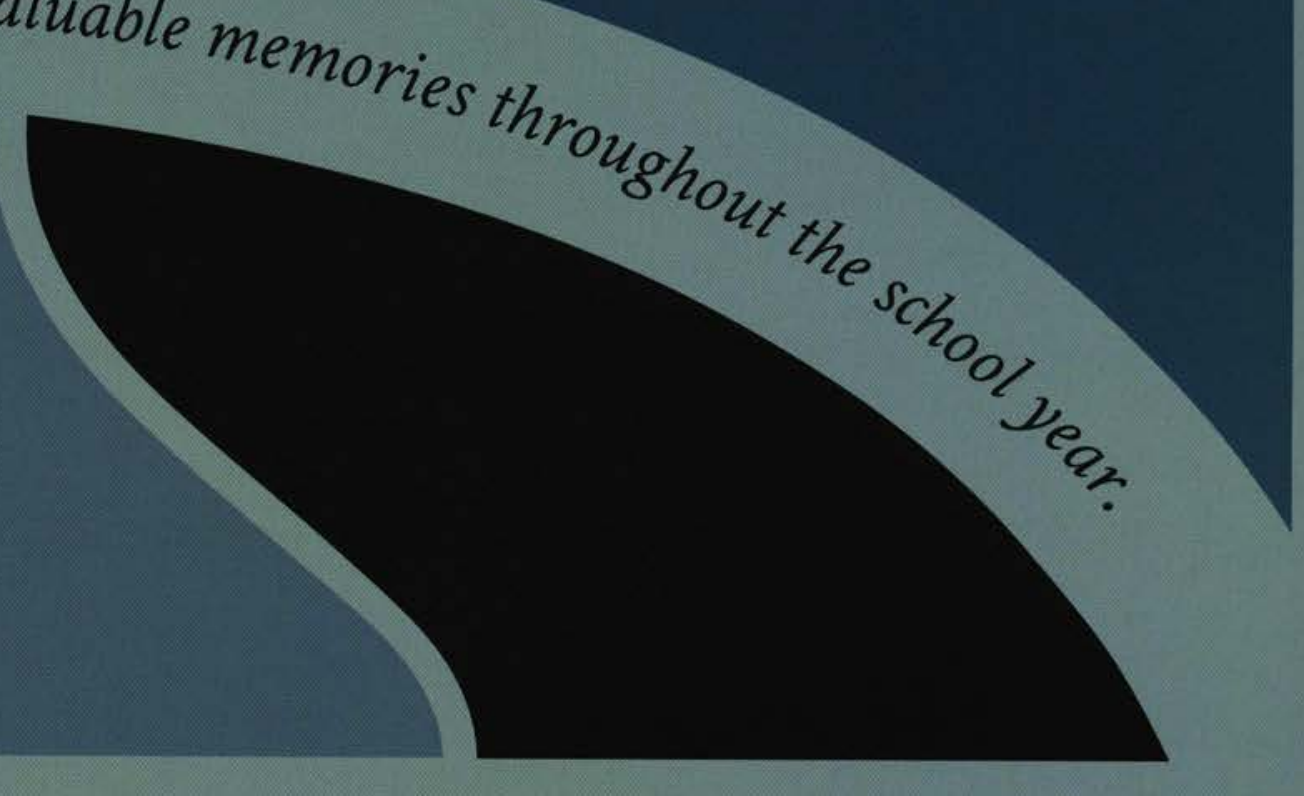


- Every Monday, Dr. Brown speaks in chapel, but occasionally, his wife, Lynne, joins him on stage.

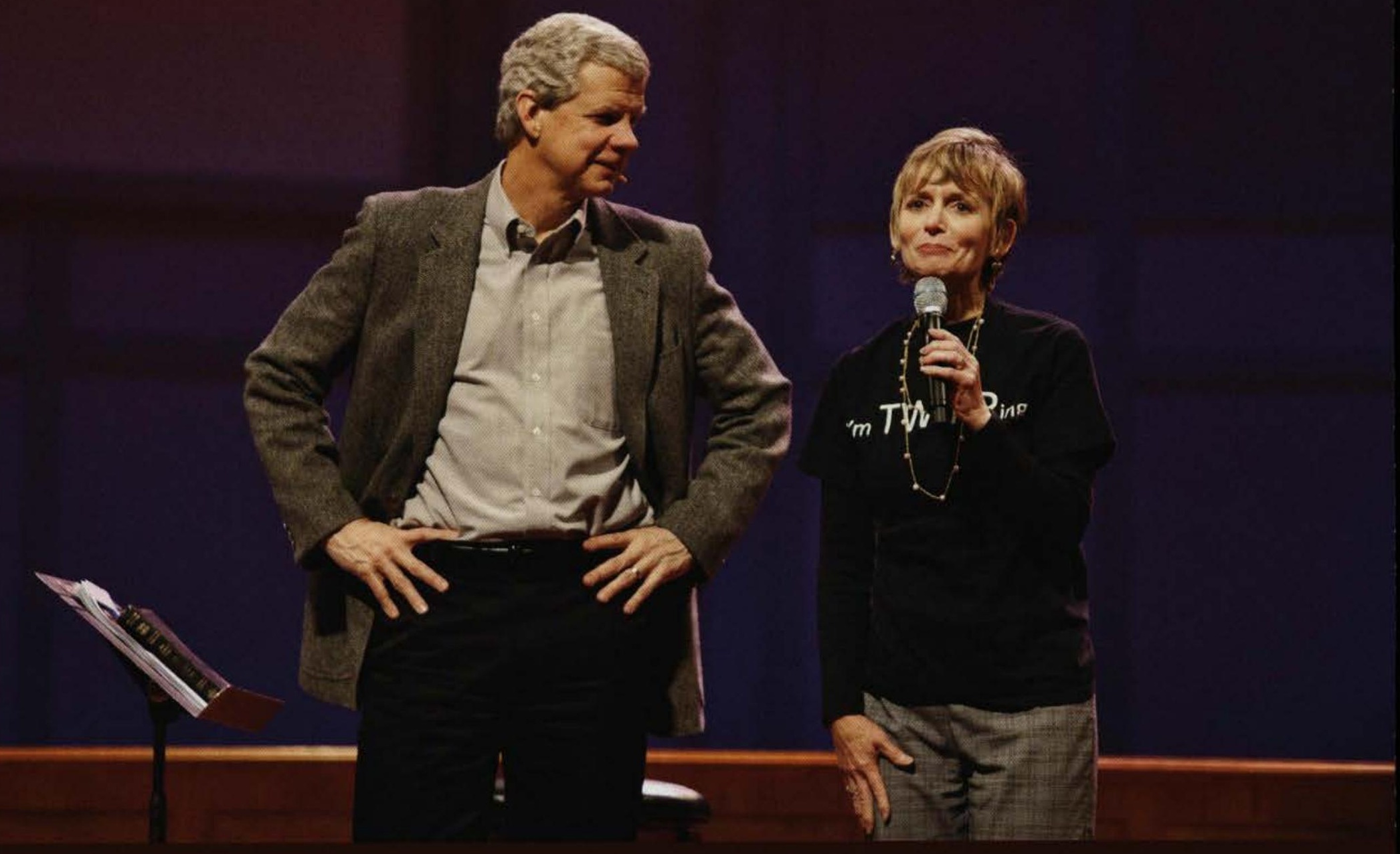

round 9:45 each weekday, a swarm
of college students flocked toward the Dixon Ministry Center, anticipating the upcoming chapel sermon. Though each hour consisted of a new message and offered the audience new perspectives on how to live a godly life, it was undeniable that weekly Monday and Friday chapels were perhaps some of the services which students enjoyed most. For the majority of students, the mere thought of waking up each Monday and starting the beginning of a new school week was quite dreadful. However, University President, Dr. Brown, never failed to encourage audience members through his deep and insightful messages. This school year, Dr. Brown delivered wisdom on "Sharpening the Christ-Centered Mind." Attendees at these chapels were challenged to persevere through trials related to their faith, stretched to develop a strong biblical worldview, persuaded to engage and assist those outside of God, and ultimately influenced to seek a deeper understanding of Christ. Friday chapels (also known as SGA chapels) were highly regarded for their amazing capability to combine both humor and meaning into their productions. Student leaders often incorporated a hilarious skit or video clip promoting upcoming campus events, guidance of the student body in an incredible worship time, and closure of the hour with an important message from SGA chaplain, Chris Voltz, who brought attention to serious issues regarding the Christian life and provided wisdom on how individuals could improve their walk with the Lord. These chapels were obviously well-spent, not only for their community-building aspect but most importantly for their ability to transform lives and refocus hearts on Christ. Even with lack of sleep, upcoming exams, or highstress moments, students had the opportunity to spend an hour in the morning reflecting on God's love and provision upon their lives. Truly, there could be no better way to begin each day. 

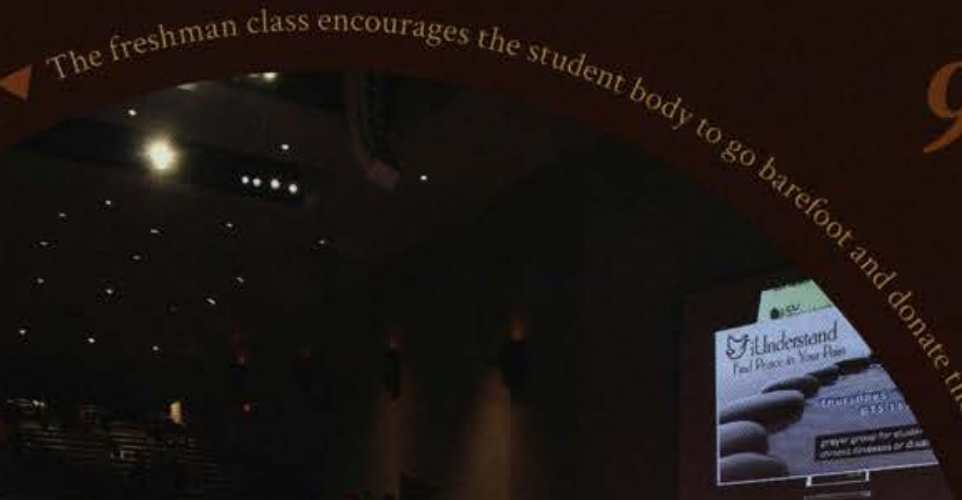
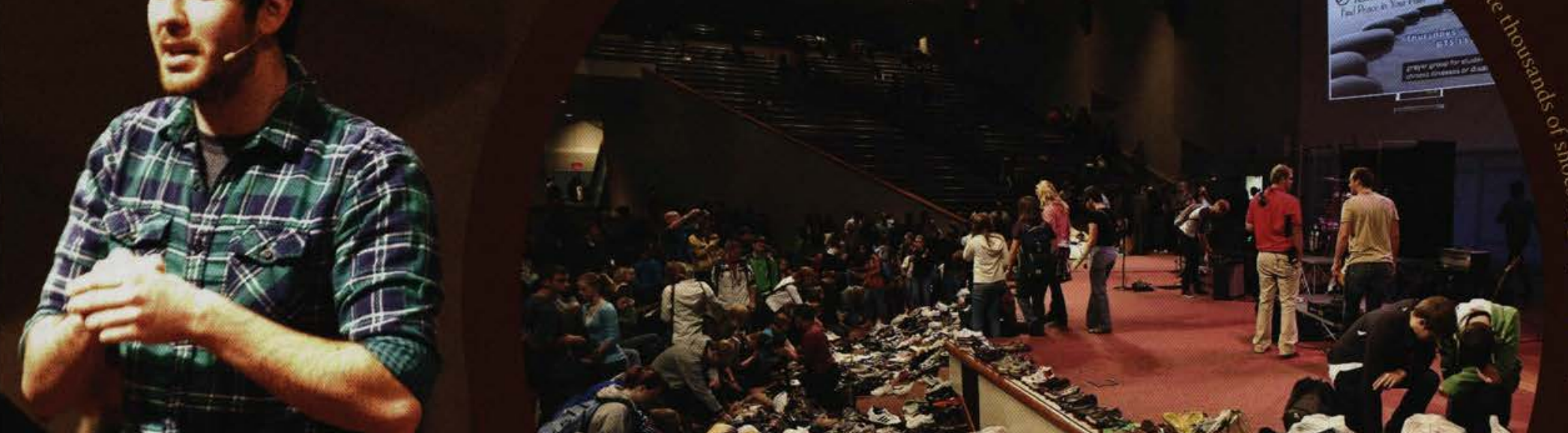

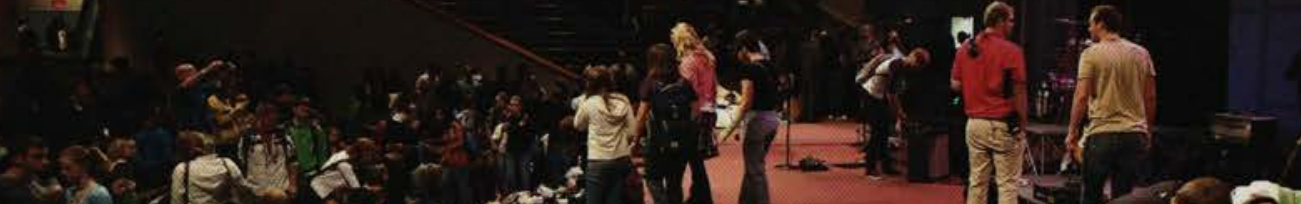
$\rightarrow$ mang $\cos ^{3}$. II 15: E NIT

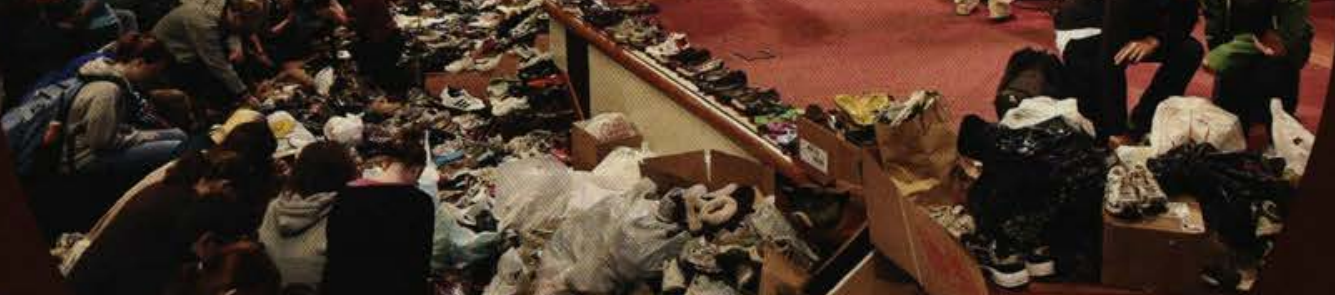
$\frac{0.11}{11}$
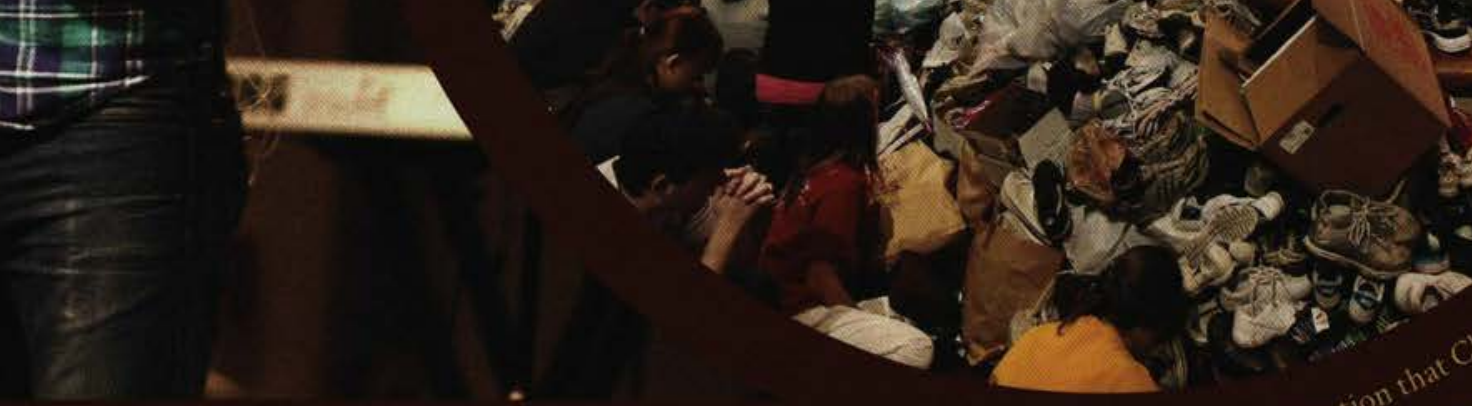


\section{Academics}

As a "Christ-centered learning community," Cedarville's focus and purpose is an education "marked by excellence.'

Chasing Innovations, an IBC company, gives an Annual Report to the professors and the investors for the Integrated Business Core class.

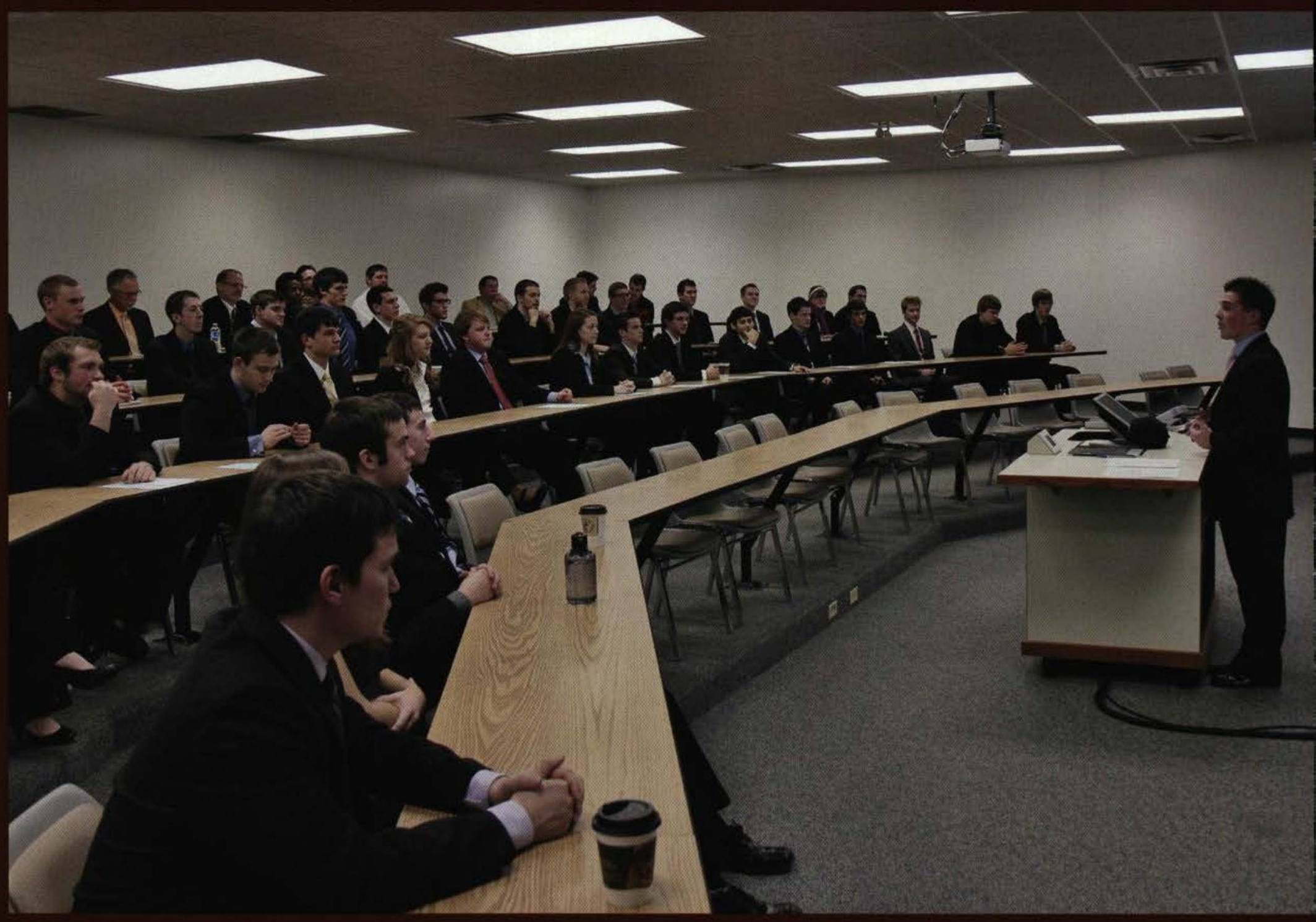

edarville University's mission statement speaks of the desire to provide an education that is "marked by excellence," and the university is continually striving to make sure that the students' academic experience is rewarding. In accordance with that mission statement, departments across campus added, modified, and enriched their offerings. Last spring, the art and design department introduced the Digital Photography minor. Classes in creative and studio photography, photojournalism, and digital imaging were designed not only to help students take better pictures but also to expose them to other methods that skilled photographers use. One class that recently grew in popularity was the Traditional Irish Music class, which was open to anyone who played an instrument and wanted to learn more about playing Irish folk music. The most visible academic change on campus came in the form of a new academic building. The Health Sciences Center, which was scheduled to be completed by the end of the summer, would house the growing number of nursing and pharmacy students who previously shared the ENS with the engineering and science students. This new building would contain classrooms and labs designed to provide students with hands-on training so that they could be successful in their particular fields. The addition of this building was a testament to the university's growth, as well as to its commitment to providing the best possible academic experience to all students. 

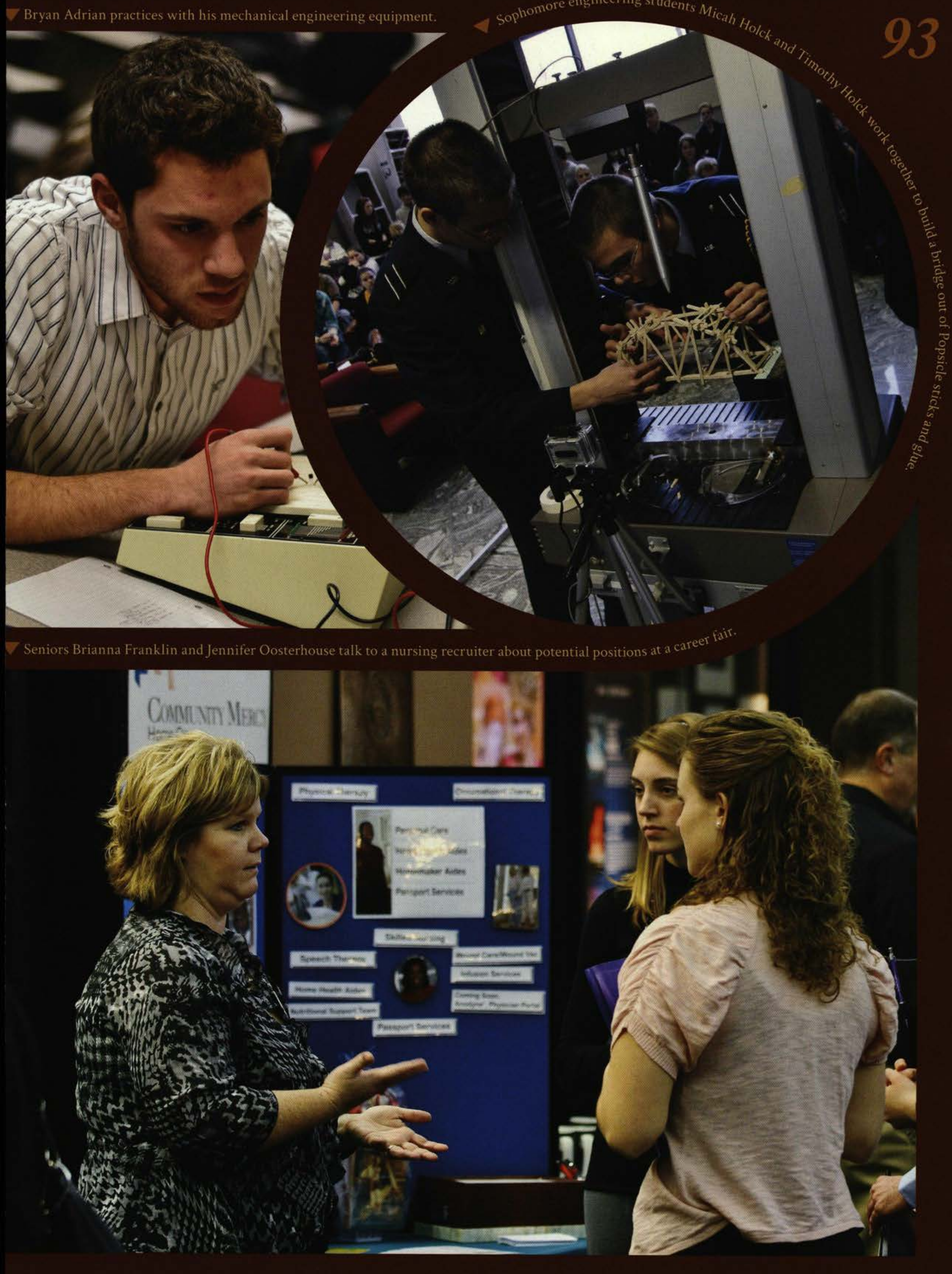


\section{Women's Residence Life}

The years of living shoulder to shoulder in a dorm forge strong bonds and life-long friendships.

The girls in units 14 and 16 show off their Rosie the Riveter costumes at Printy Wars.

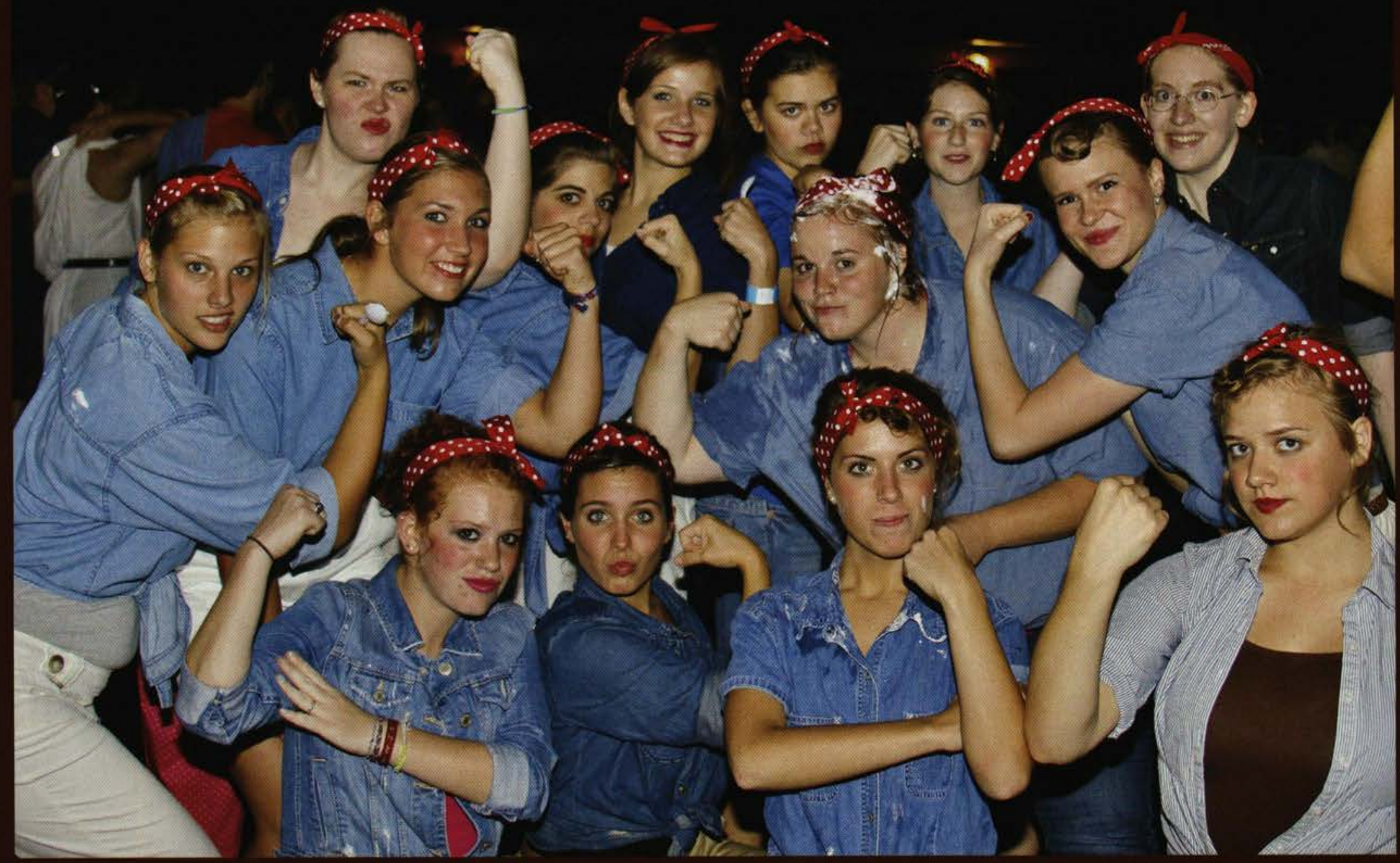

C

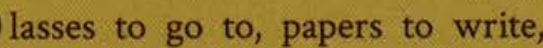
books to read -- academics consumed the hours of each week day. Then, students trudged though winter slush and spring rain back to their dorms. In Printy, a predominately freshman dorm, the girls became a kind of family, bonding together as they learned to navigate the college experience together. It was not unusual to go to someone's room and find five or six girls together. This kind of constant companionship fostered closenes as they told secrets or stayed up until 3 am talking together.
This year, a new Resident Director started on campus: Bri Dupree, who gathered the RAs and women of Faith Hall under her tutelage. This was a bond that came only with living together. The women at Cedarville learned each other's weaknesses, fears, and hopes as they prayed together, strengthening each other in Christ. Living together was at times difficult, but the bond of friendship and love overcame petty arguments. Unit meetings were times of silliness and food, but also seriousness as the girls shared their struggles and fears with each other. The RAs sometimes filled the role of older sisters or little mothers, comforting, praying, and having fun with their girls. They were immediately and easily accessible, helping the girls navigate the campus The experience of living together in a dorm could forge bonds unlike any others, especially during the first year of college. To live with other girls, many who were learning and experiencing similar lessons, made dorm life one of the most memorable parts of the Cedarville Experience. 


\section{Men's Residence Life}

Brock to the Rock, Lawlorpalooza, and Man Week -- all ways for Cedarville guys to be "men" and build friendships.

7 The men of Lawlor Hall battle in a tug-o-war contest while spectators-mainly women from Printy-cheer them on during Lawlorpalooza.

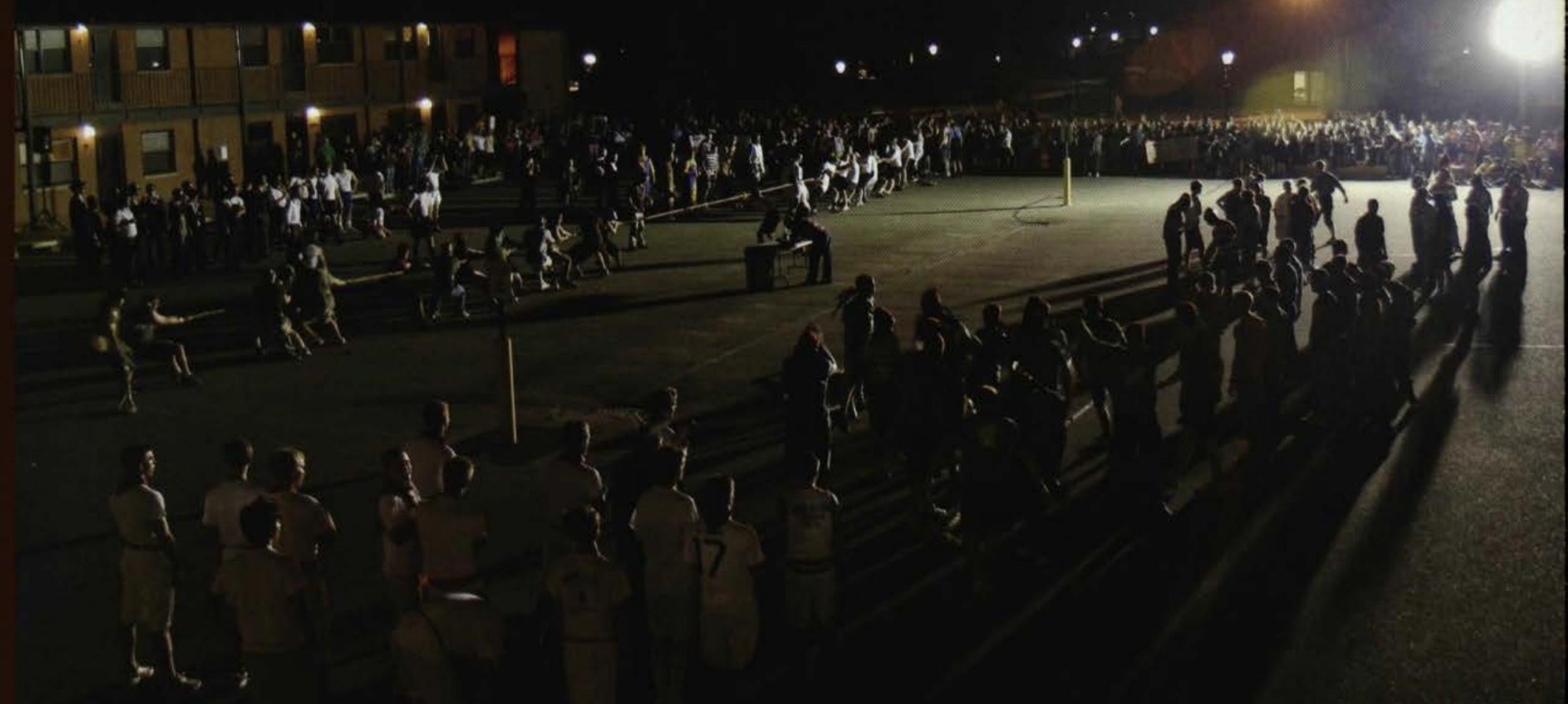

$\omega$ hat do you get when you mix video games, caffeine, and a couple hundred young men together in one large building? Nothing other than Cedarville University's men's residence halls, of course. That's not to say that the men's halls were composed only of these elements. Men's residence life at Cedarville also had everything a guy needed to succeed holistically in college. A quick trip through campus would show any observant visitor this fact. In Lawlor, one would find units full of tight-knit groups of sixteen guys, unified under a strong resident assistant. A trip to
Brock would yield some upperclassmen of the university, arranged in a hall style. At McChesney, St. Clair, Rickard, the Hill, and more, one would encounter men of Christ working and playing-living life together in community. "Men's residence life is very strong overall," reminisced Jon Musser, a 2011 Pre-Seminary graduate and former RA. "I think the most important thing that can be done is to develop real relationships in a genuine community. The tendency to over-spiritualize is not a bad thing, but it's more important to be real." Real relationships in genuine community were the goal.
The Student Life Deans, Resident Directors, Assistants, and students lived up to that goal consistently. One event held every year that epitomized the community of the residence halls was Man Week in Rickard. During this week, men were challenged physically (multiple Chipotle burritos, anyone?), but they were also taught how to be godly men. Life and relationship building events like this one demonstrated the efforts of RAs and RDs to help the men of Cedarville grow in more ways than one. 

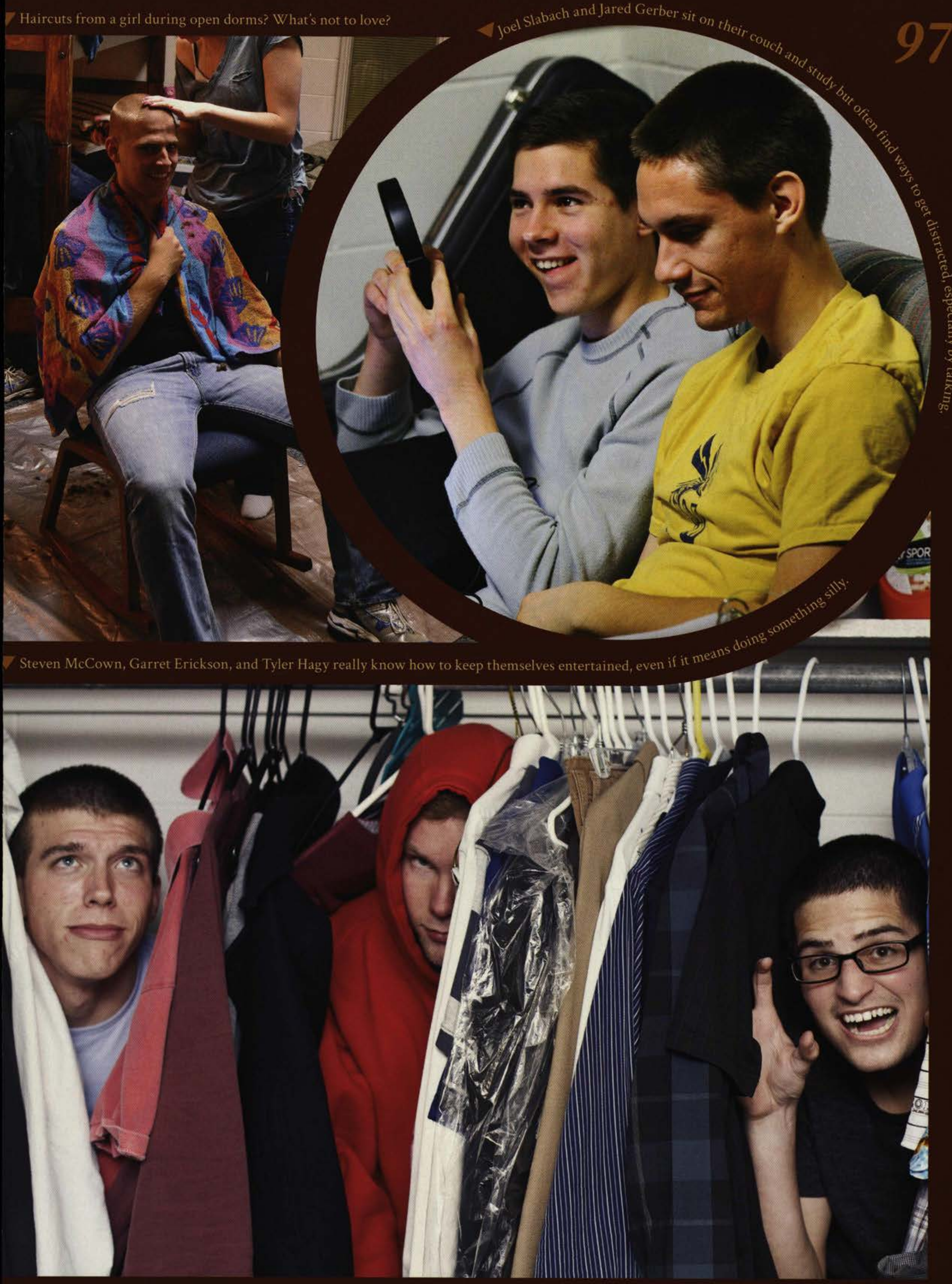


\section{Chuck's

Between the university cafeteria and the student-run coffee shop, students are sure to be well fed and fully caffeinated.

Students often find the tables outside the Hive and Rinnova a pefect place to balance studying and socializing.

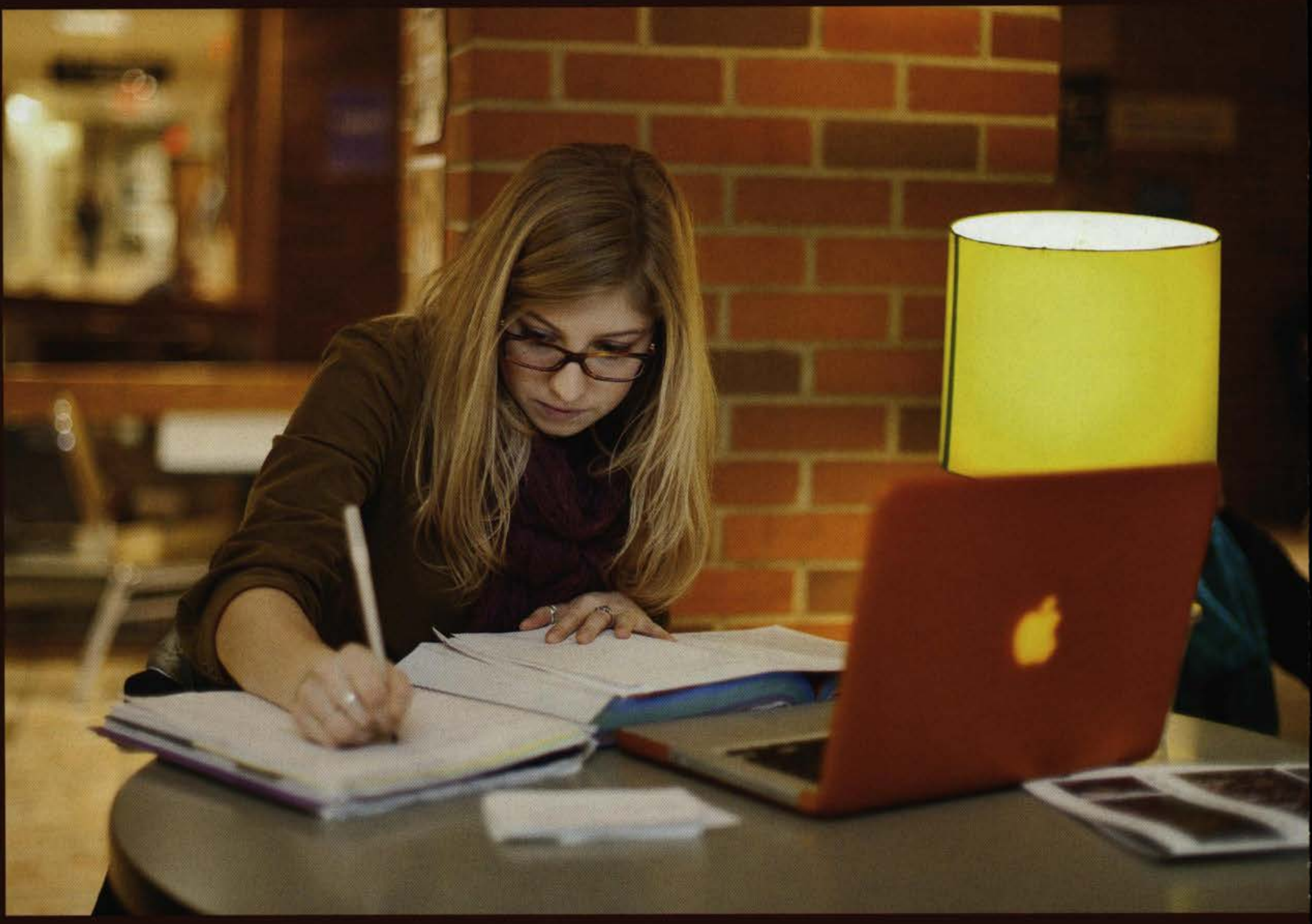

he Cedarville University cafeteria
was a popular place. So popular, in fact, that it even had its own name. Chuck's, located in the Stevens Student Center, was full of activity whenever mealtimes arrived. Chuck's offered a variety of food options for students - taco and pizza bars, a salad and fruit station, and breakfast all day. There were also grill stations where students could create their own dishes, and, of course, the sandwich smasher. But Chuck's offered more than food. The cafeteria transformsed into a center of festivities around major holidays like Thanksgiving, Christmas (when Christmas music was played during dinner) and Valentine's Day (when the tables were decorated and special theme dinners were prepared). College life and cafeteria food may become monotonous at times, but students all counted Chuck's among Cedarville's many blessings. What was the the cure for that sluggish, can't-keep-your-eyes-openduring-class feeling? That's easy. It was a cup of quality coffee from Cedarville's own coffee kiosk: Rinnova. Staffed and run by student baristas, Rinnova was a great place to purchase many varieties of coffee, plenty of flavors, and even noncoffee beverages like hot chocolate and chai. Monthly specials, the "Drink of the Month," just added further variety to the drinks Rinnova offered. Rinnova was also the perfect place to catch up with friends over a cup of coffee, enjoy a pleasant atmosphere for working on homework or even, let's face it, an ideal inexpensive date destination. This little coffee shop was certainly an important part of college life at Cedarville. 
The Hive opens itself for students all day, a place to eat, study, or relax: a nice change of scenery from Chuck's.

Students enjoy the atmosphere of the Hive, allowing them to multitask by listening to great music and getting homework done.

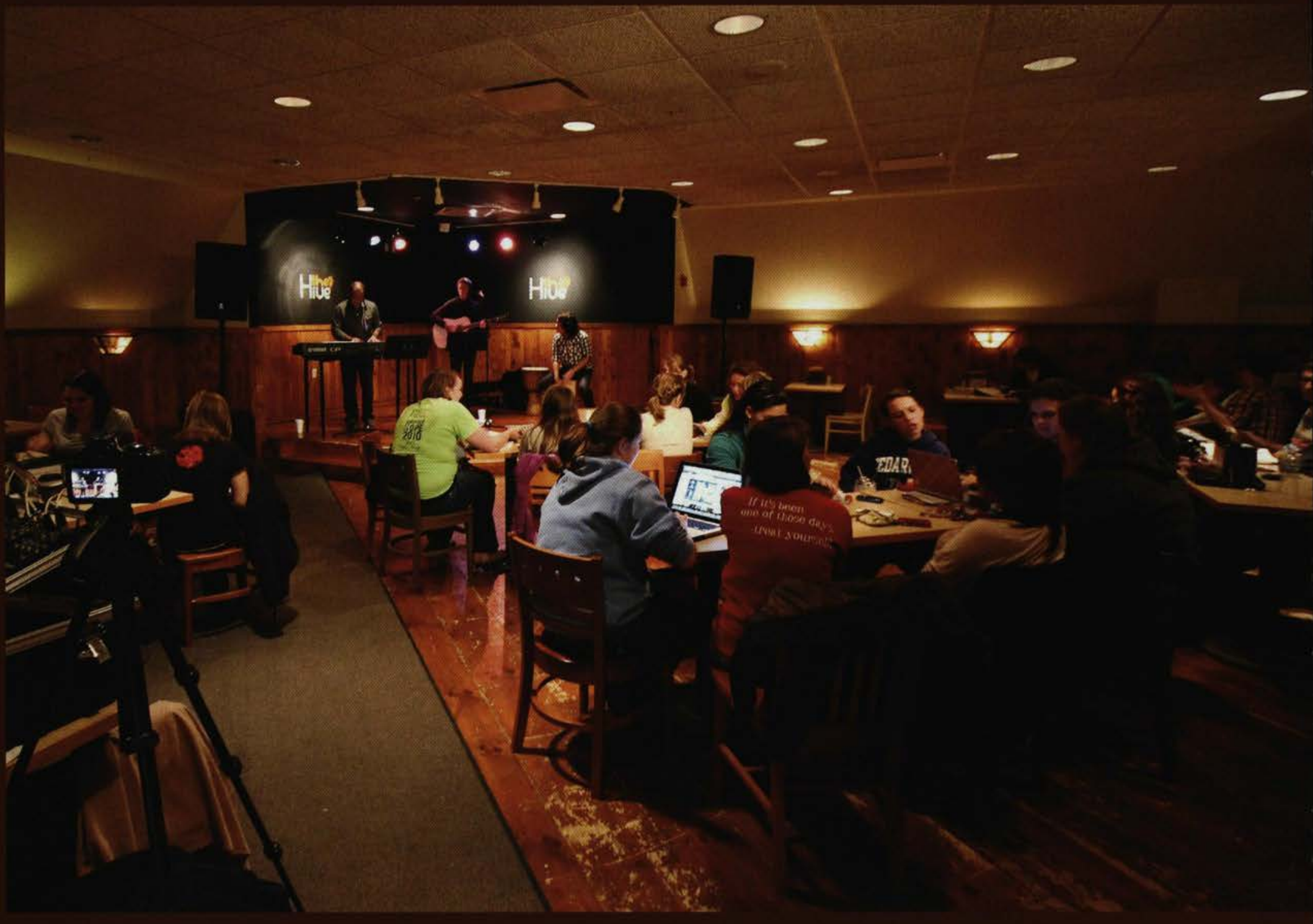

\section{he collection of artists and musi-
cians that make up the Cedarville} student body thrived in the opportunities Cedarville offered to showcase their talents. Chapel worship teams, Heartsong Ministries, and other ways of portraying musical talent were available, but some of Cedarville's unnamed musicians were able to let the rest of the student body see the musical gifts and abilities that might otherwise have gone unnoticed. Interruptions were a part of the Cedarville Experience, open for anyone to audition and available for everyone to enjoy. This concert series occurred in the Hive every Thursday night, offering a way for the students to showcase their talents. Students were invited to audition and could perform with up to five people in a set. An Interruption often had that special moment when a student presented an original song, for the very first time. Other times, students would perform the cover of a popular song or one of their favorites. Each Thursday night, the audience could hear the strumming of a guitar and the voice of Cedarville's artistic and talented students throughout the SSC. A new addition to Thursday nights was
Thursday Night Trivia. Students could earn a gift card by winning trivia rounds based on various topics. Students could also enjoy doing homework with friends or playing games. The Hive doubled as an alternative to Chuck's, featuring the traditional hamburger and fries but also carrying a Cedarville favorite, the stinger wrap. No matter the day, night, or reason, the Hive was a great place to eat, relax, do homework, and hang out. 


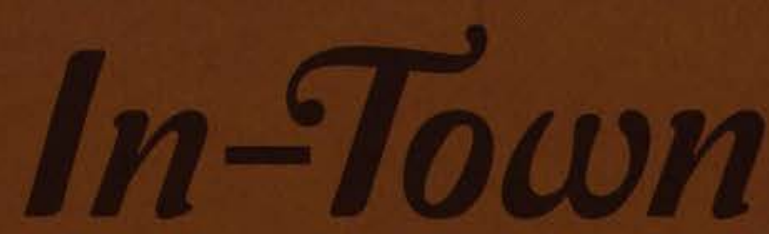

The village offers a place for students to step away from campus and enjoy our friendly community.

Town residents and students help with the annual CedarFest, a celebration on Labor Day Weekend that takes place every year

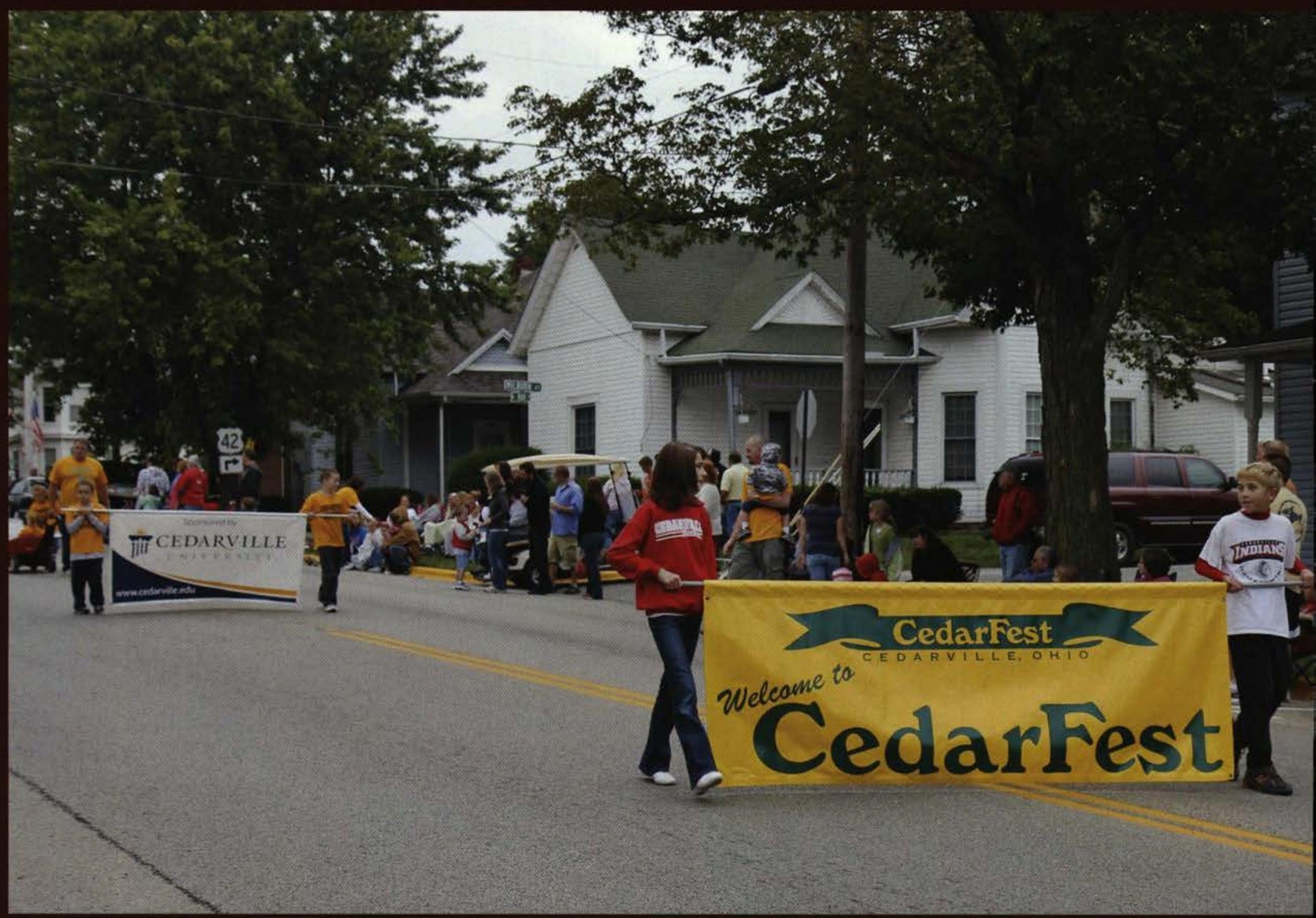

he sidewalks that led down Main
Street, Cedarville, were worn and cracked, but so well traveled. It was on these sidewalks that countless feet had walked, run, and trudged through snow, where innumerable conversations had taken place, some good and others bad. The sidewalks led to some of Cedarville students' favorite places: Beans N' Cream, Stoney Creek Roasters, Colonials Pizza. In these memorable locales, students could finish conversations that had begun on the sidewalks. The store windows lining Main Street reflected not just Cedarville students, who come and go, but also the locals who faithfully call this town home. The annual event of Cedar Fest brought many students down the four blocks from campus. Labor Day weekend included a parade, pancake breakfast, and fair that took place at the Cedarville Community Park. This annual event celebrated Cedarville's own James $\mathrm{H}$ Kyle (the "father" of Labor Day"). The Little Town of Lights, held every year on the first weekend of December, allowed residents to show off their Christmas lights. There were also hay rides, photo opportunities with Santa Claus, outdoor caroling, and samples of local cuisine. There was a live Nativity scene complete with live animals located outside of Grace Baptist Church, where they also offered homemade cookies. Musical events and plays were also often held in the Cedarville Opera House, a Cedarville landmark. The community of Cedarville wasn't just about being in the same geographic area; what made the town of Cedarville so special was the people present and willing to devote their time. 


\section{Intramurals}

While they may not wear the official Cedarville jerseys, these teams exhibit the same drive and passion for the game.

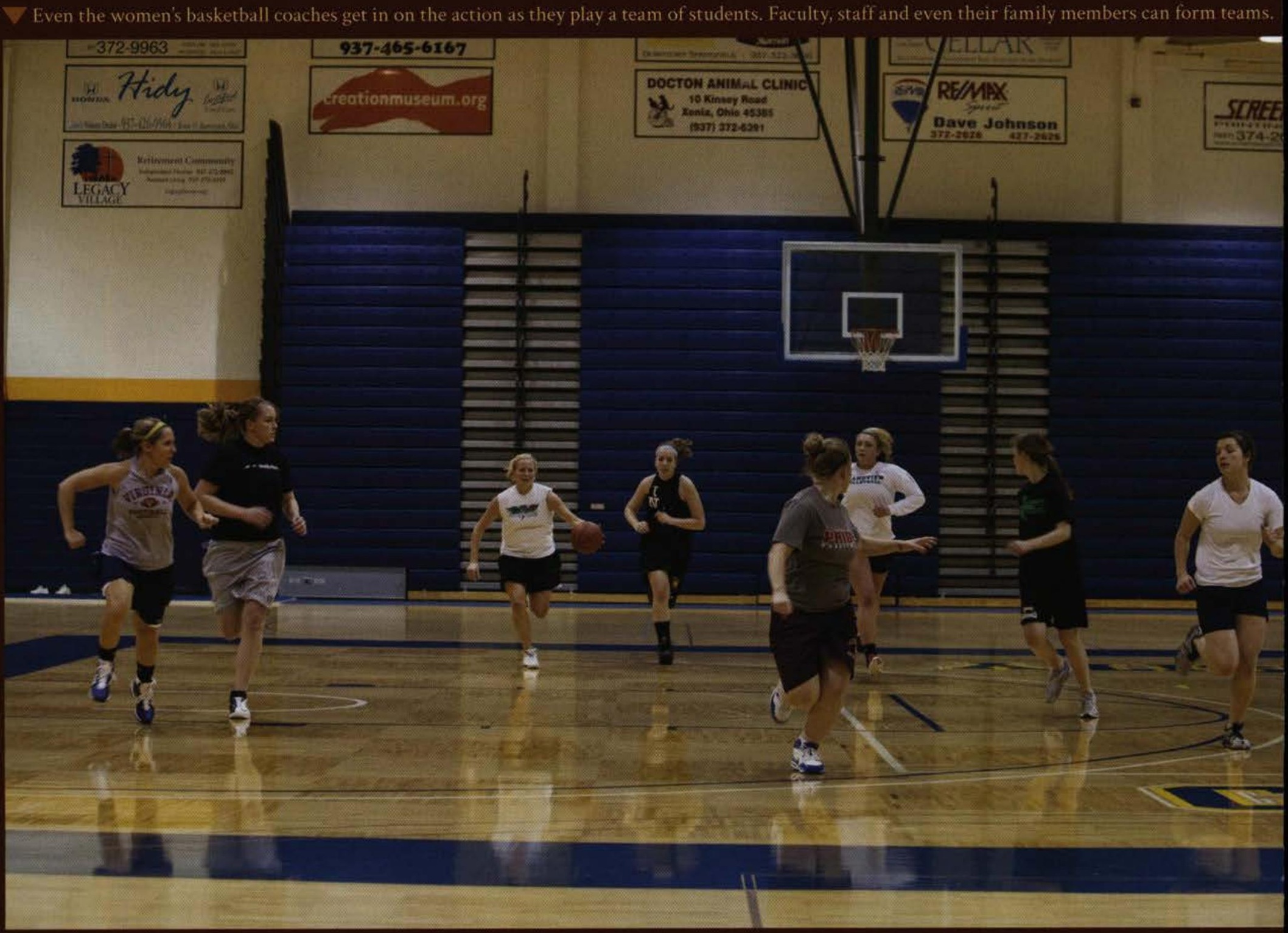

$\omega$ allyball. A little volleyball, a little racquetball, and a lot of manpower. For those who wanted more than an occasional game between friends, they could look no further than the Cedarville University intramural team. Students on intramural teams found not only fun in the sports they played, but they also found participation rewarding and enjoyed the motivating competition. For freshmen, intramurals provided another tool for meeting new friends. The sports offered at Cedarville included singles and doubles table tennis, mixed doubles racquetball, dodgeball, ultimate Frisbee, and yes, Walleyball. In the warmer weather, a walk by the sand volleyball courts just behind St. Clair would mean a sprinkling of sand as an intense player kicked up a storm. The Printy RAs even started an intramural team this year. The elusive CUIC t-shirts (Cedarville University Intramural Champions) held the same value for many intramural players as, say, those bi-annual 4.0 mugs -- usually so close but so far away. Intramurals also offered leagues in volleyball, soccer, softball, indoor soccer, and basketball. During the winter months, most of the student body would hang out in the field house or gym where they were either participating in a league or supporting their friends. With the many sports offered by Cedarville University, anyone could find a niche in the intramural options. Maybe competitive collegiate sports would be too much-too much time, too much pressure, too much competition-and friendly games just weren't enough. That was when intramurals were the perfect fit. 
Jenna Green tries to block Deanne Heffernan from passing the ball.

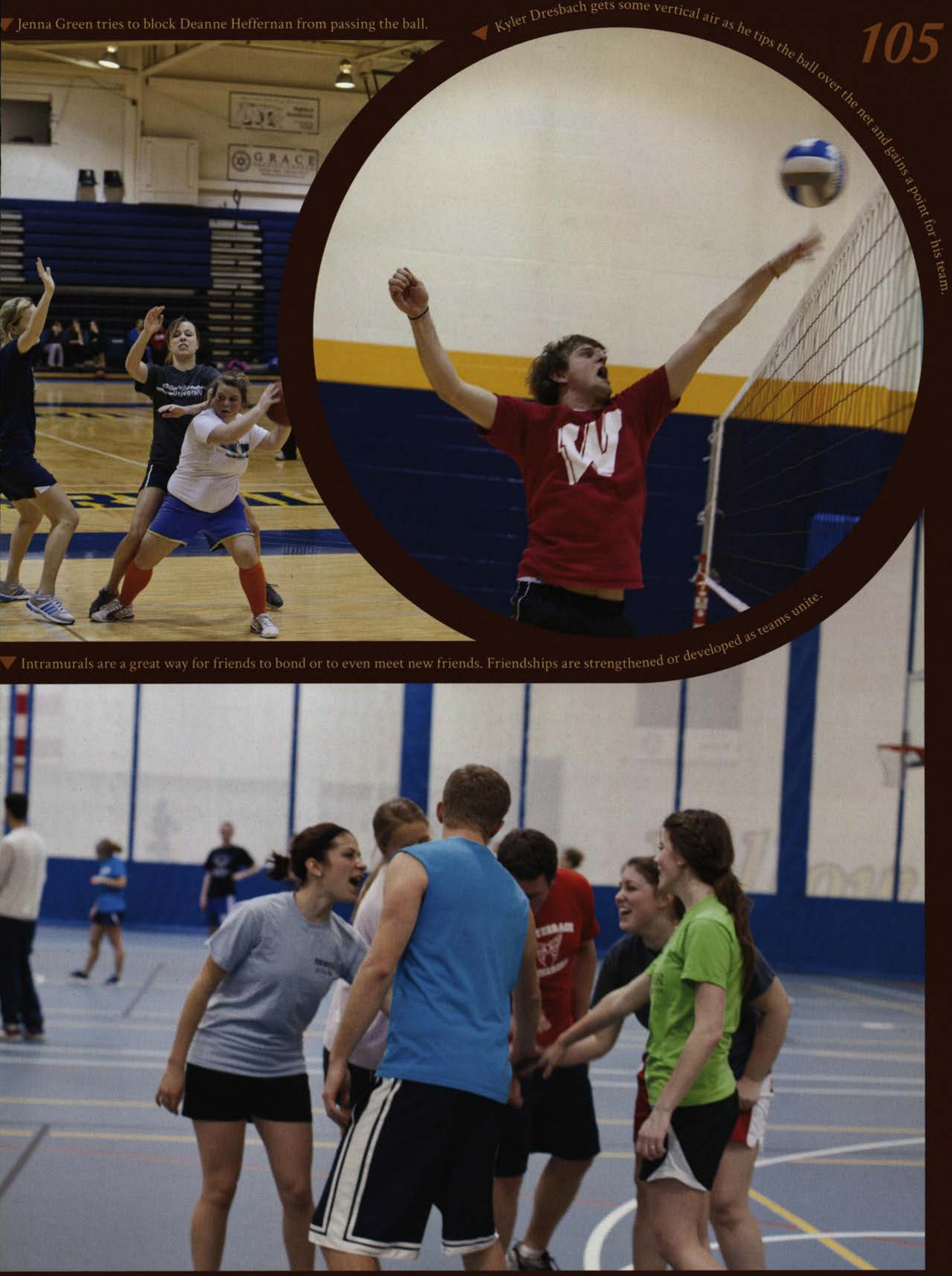




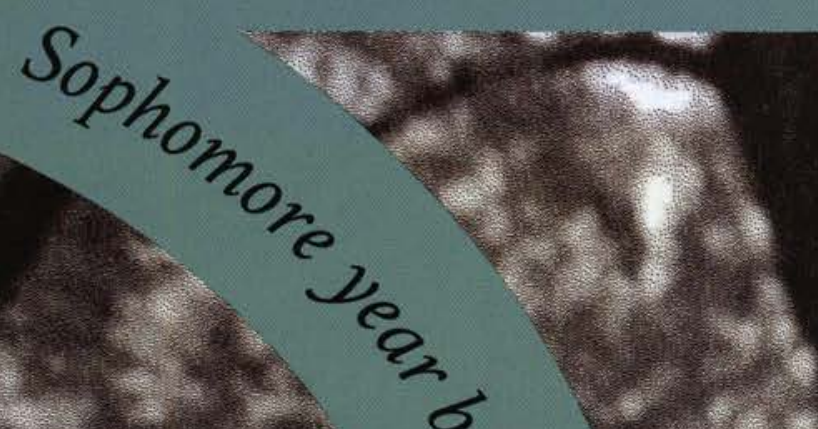

164 ex

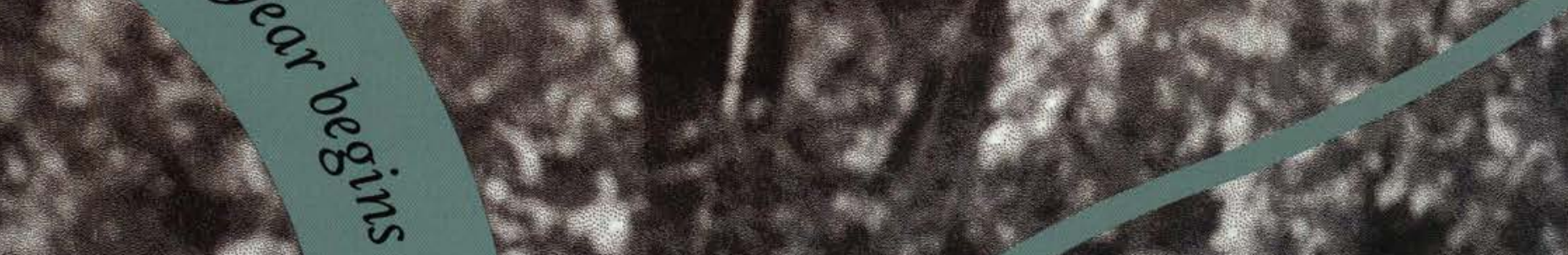

$x+25=$

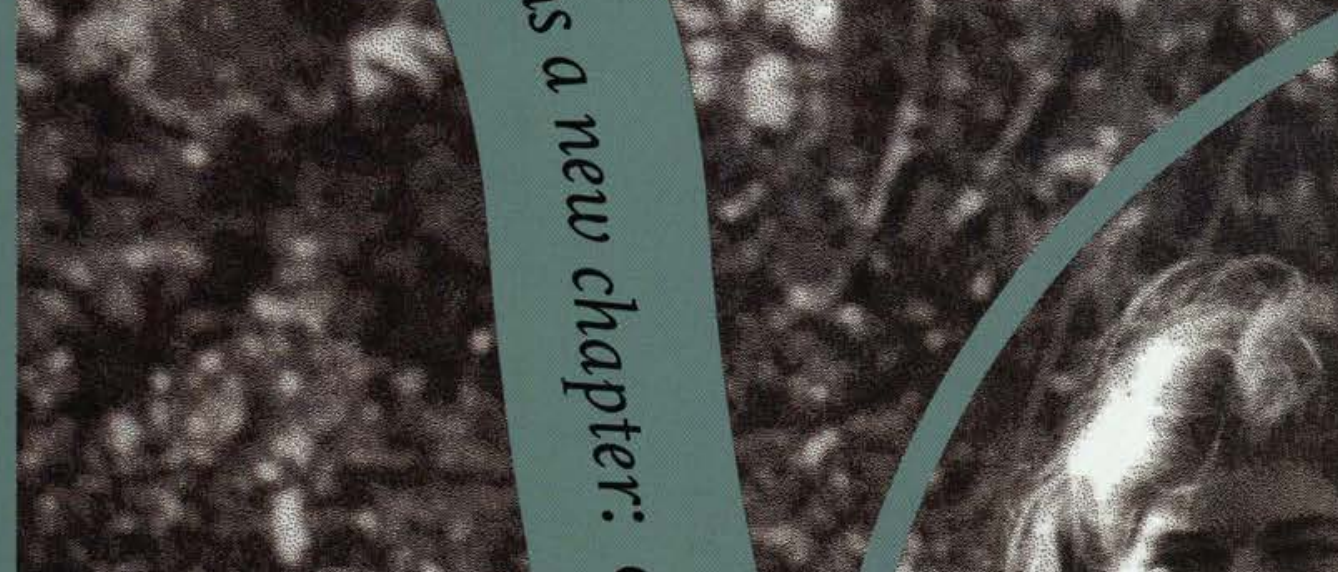

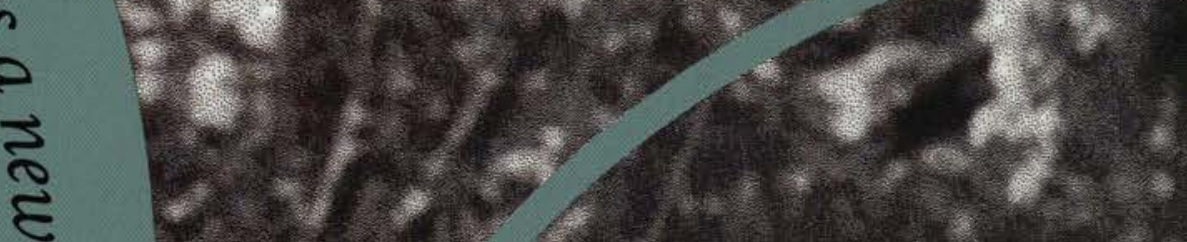

cosen = vis.

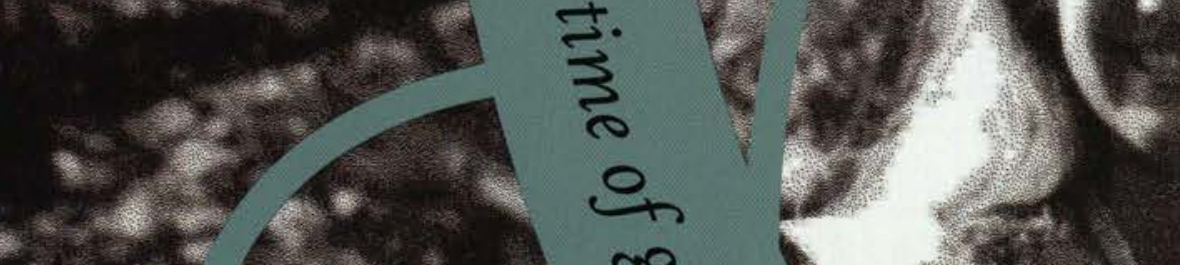

Q8:

xo

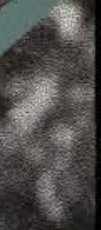

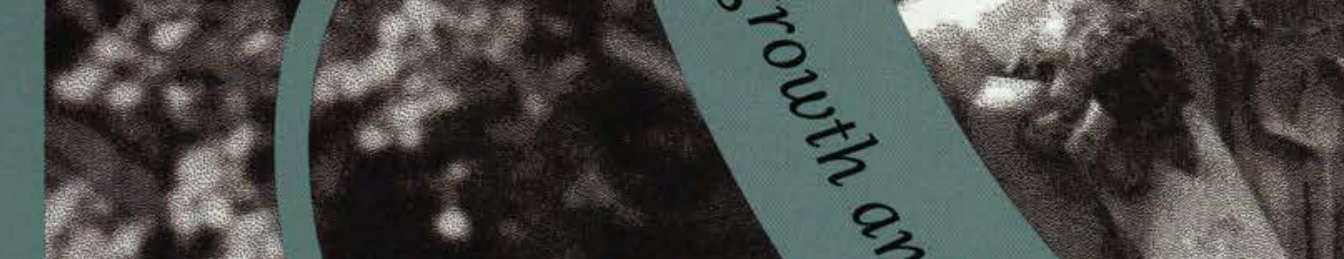

$x^{2}=$

race?

30

6. $0 \times 9$

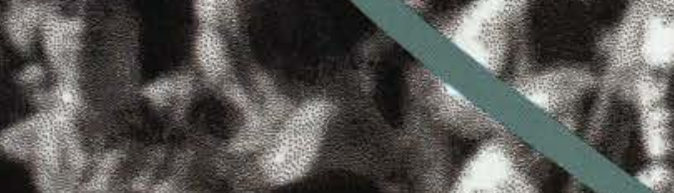

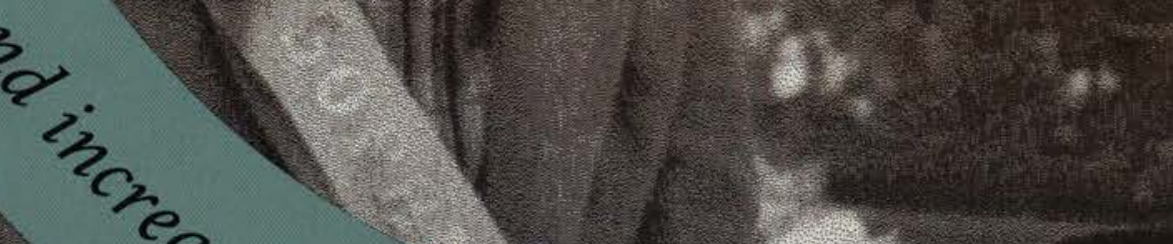

(5)

(2)

(1)

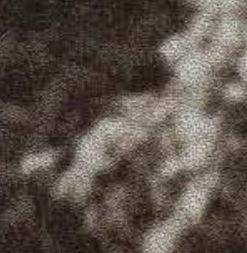

2. 

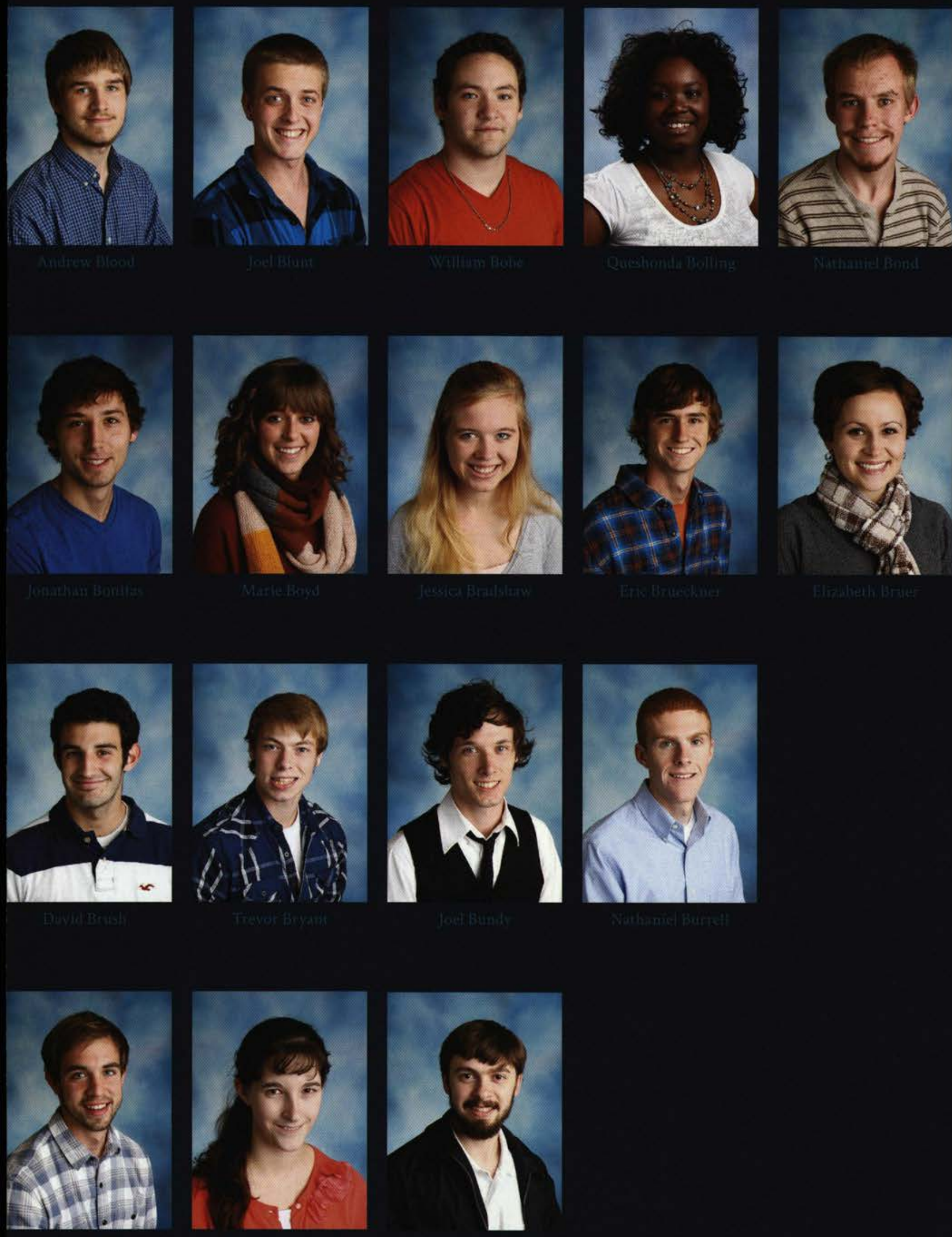

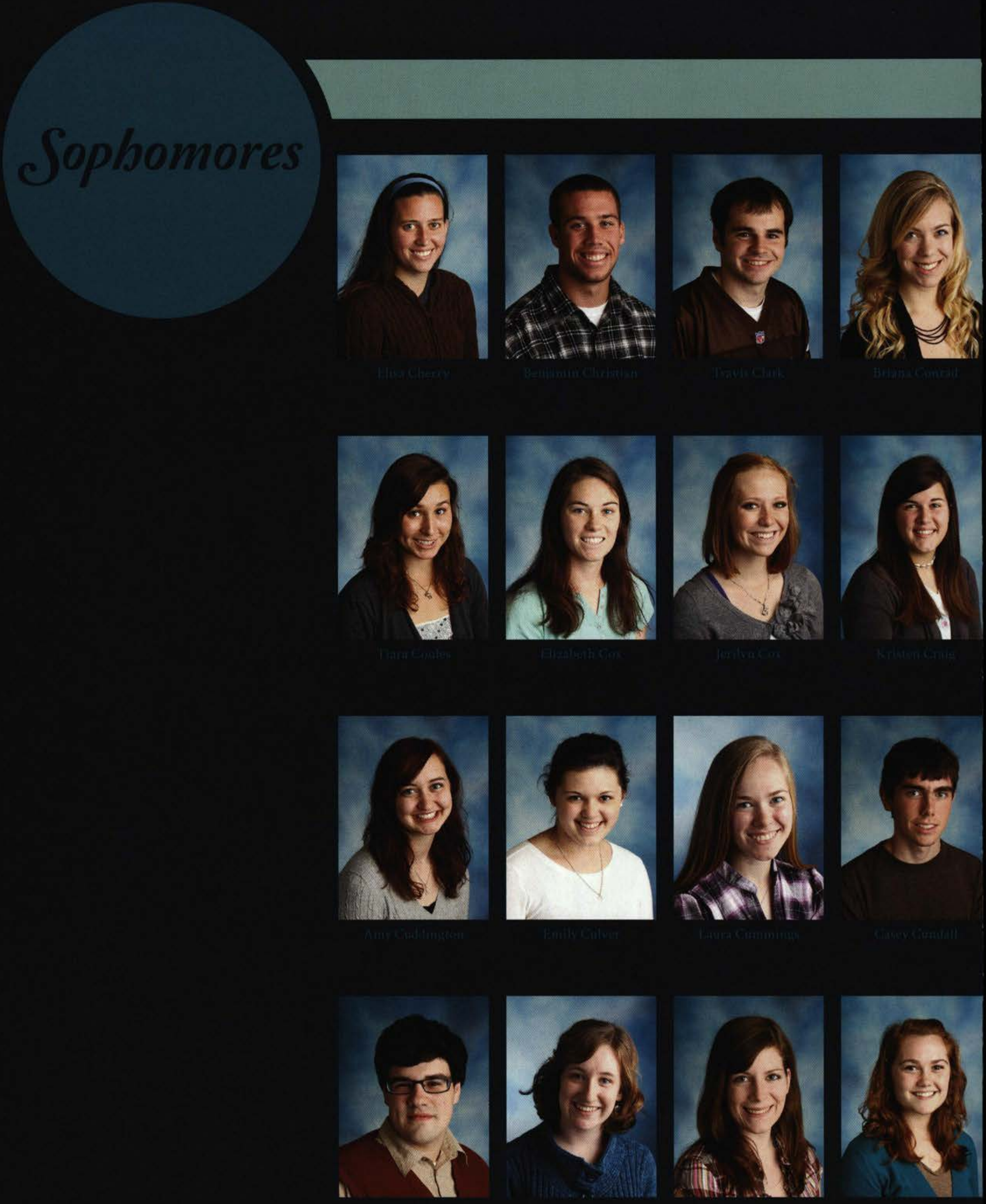

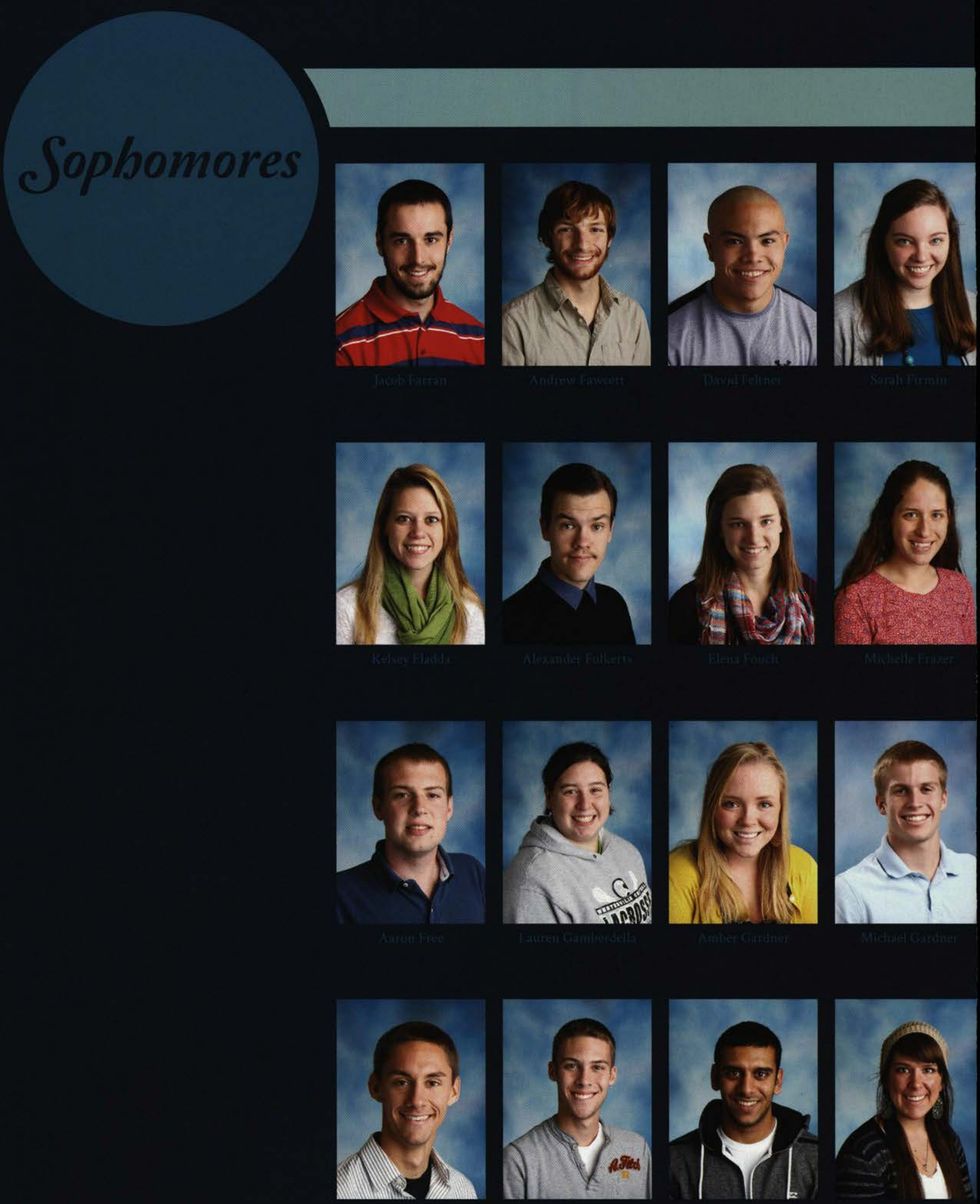

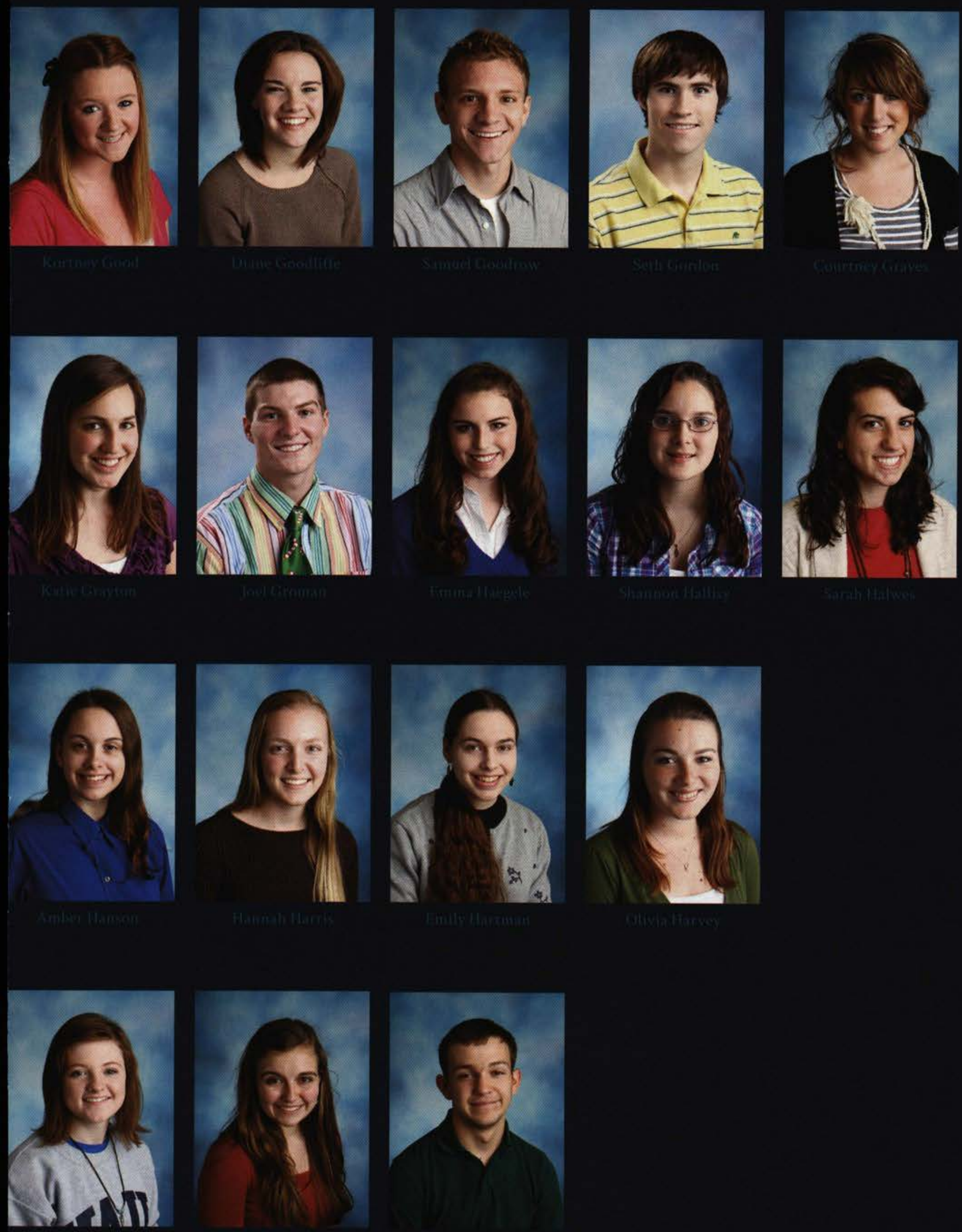

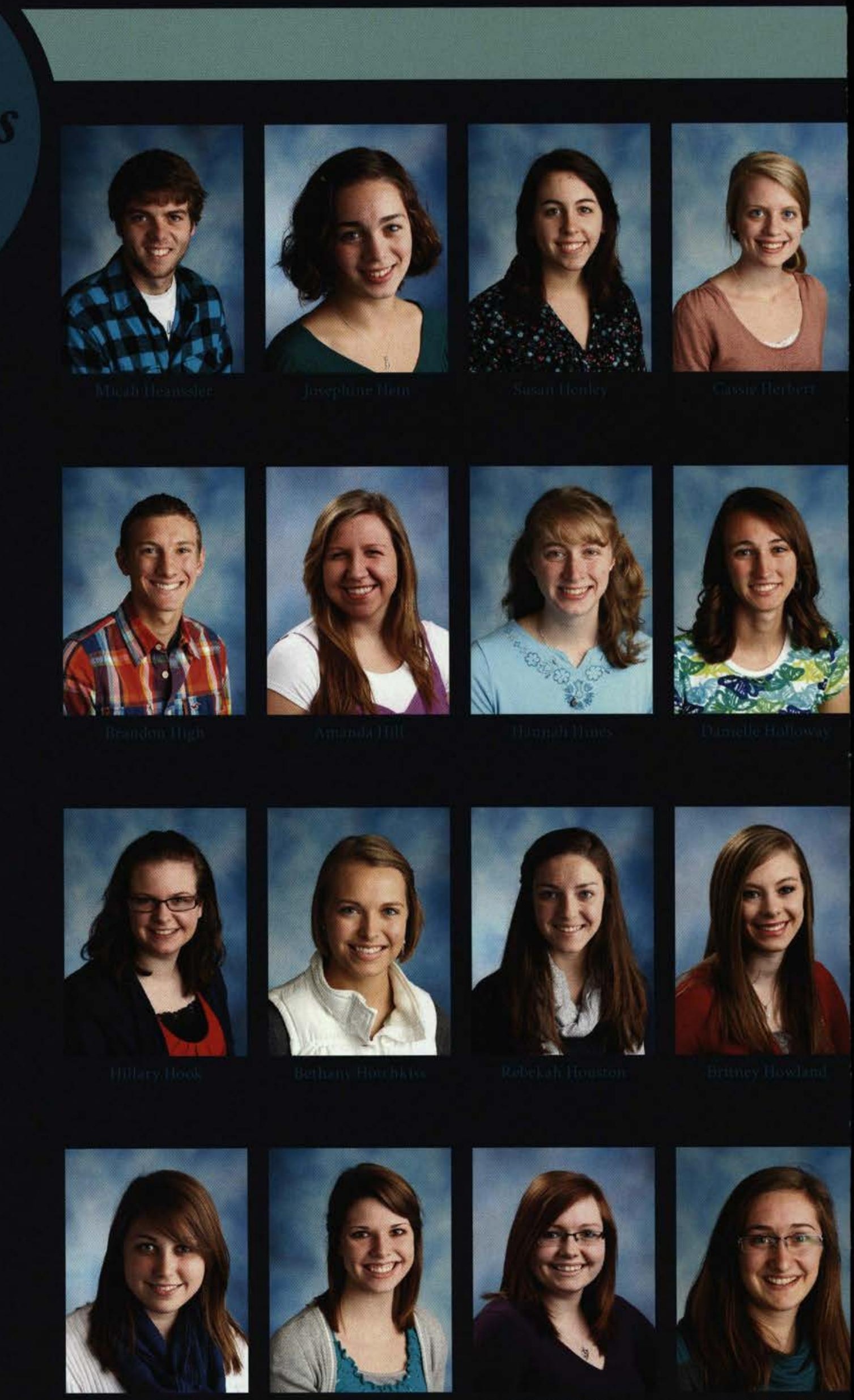


\section{Sophomores}
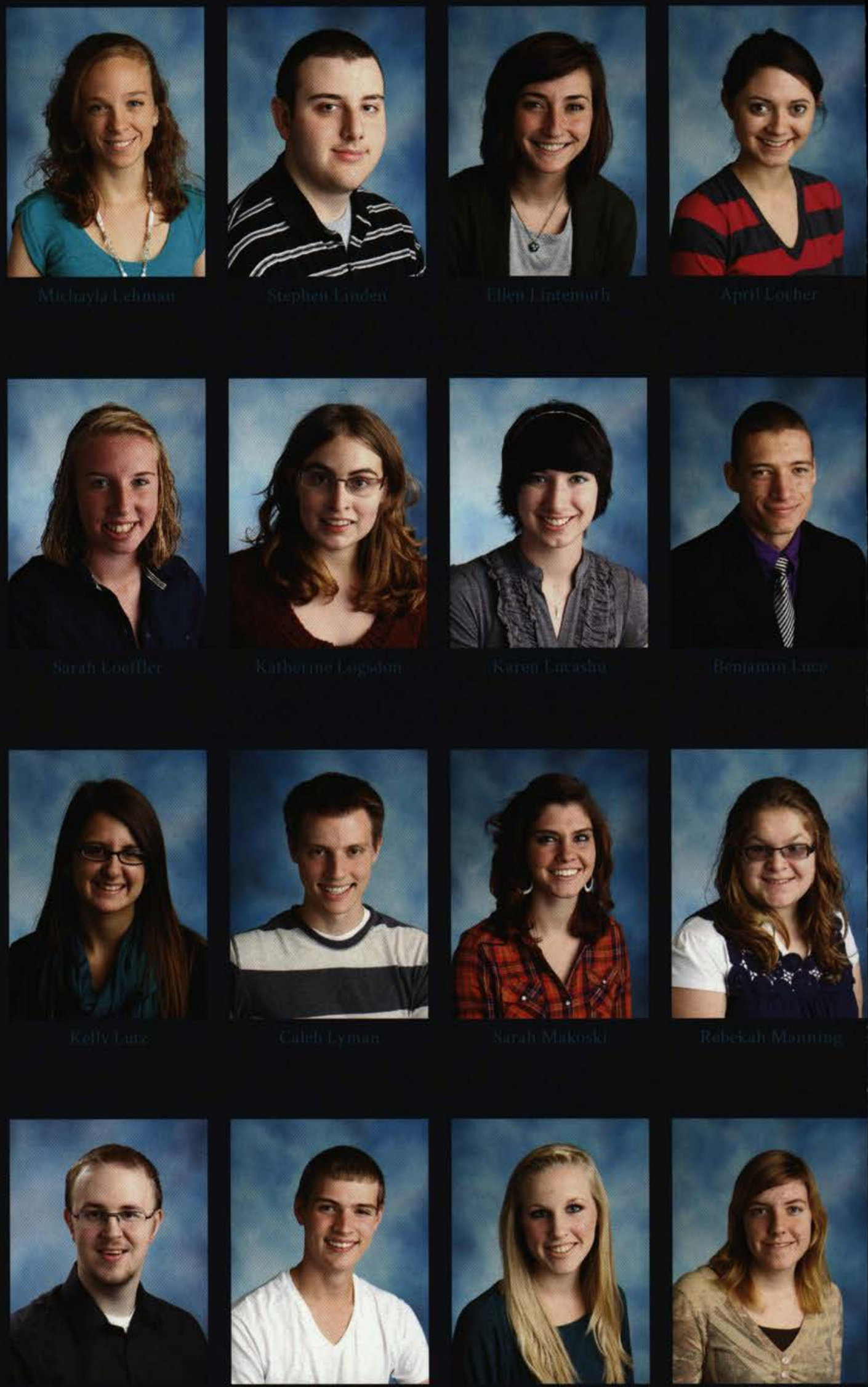

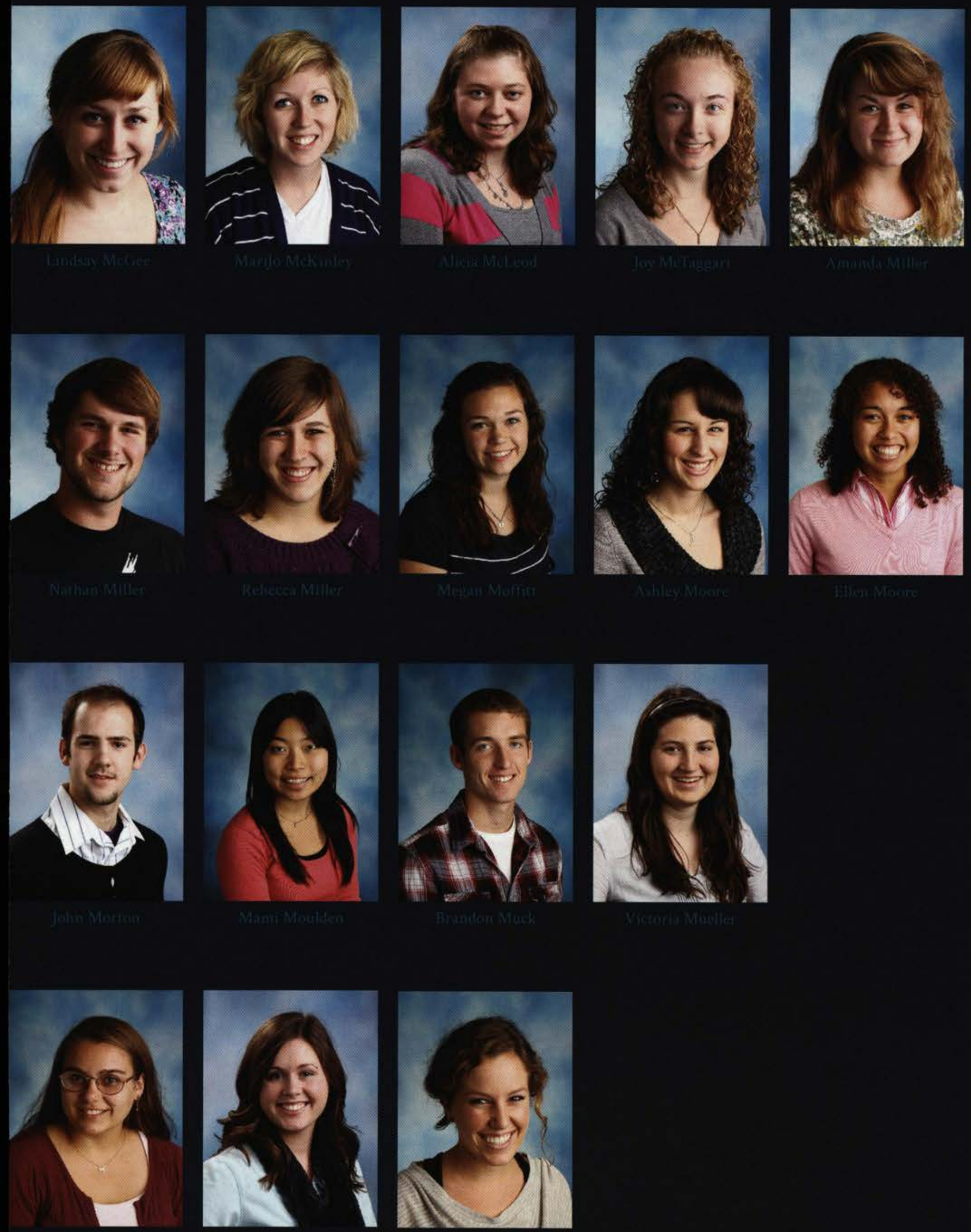


\section{Sophomores}
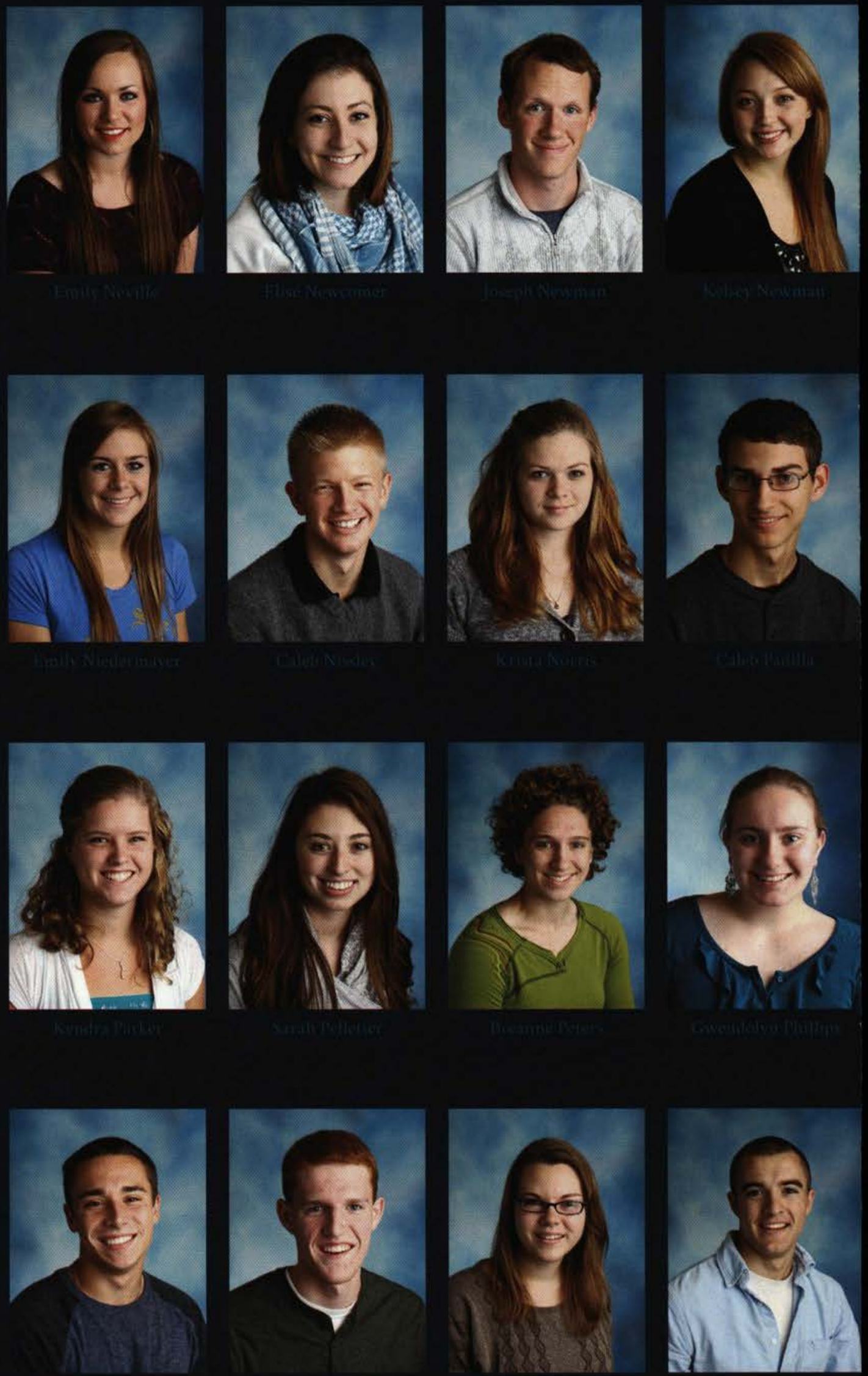


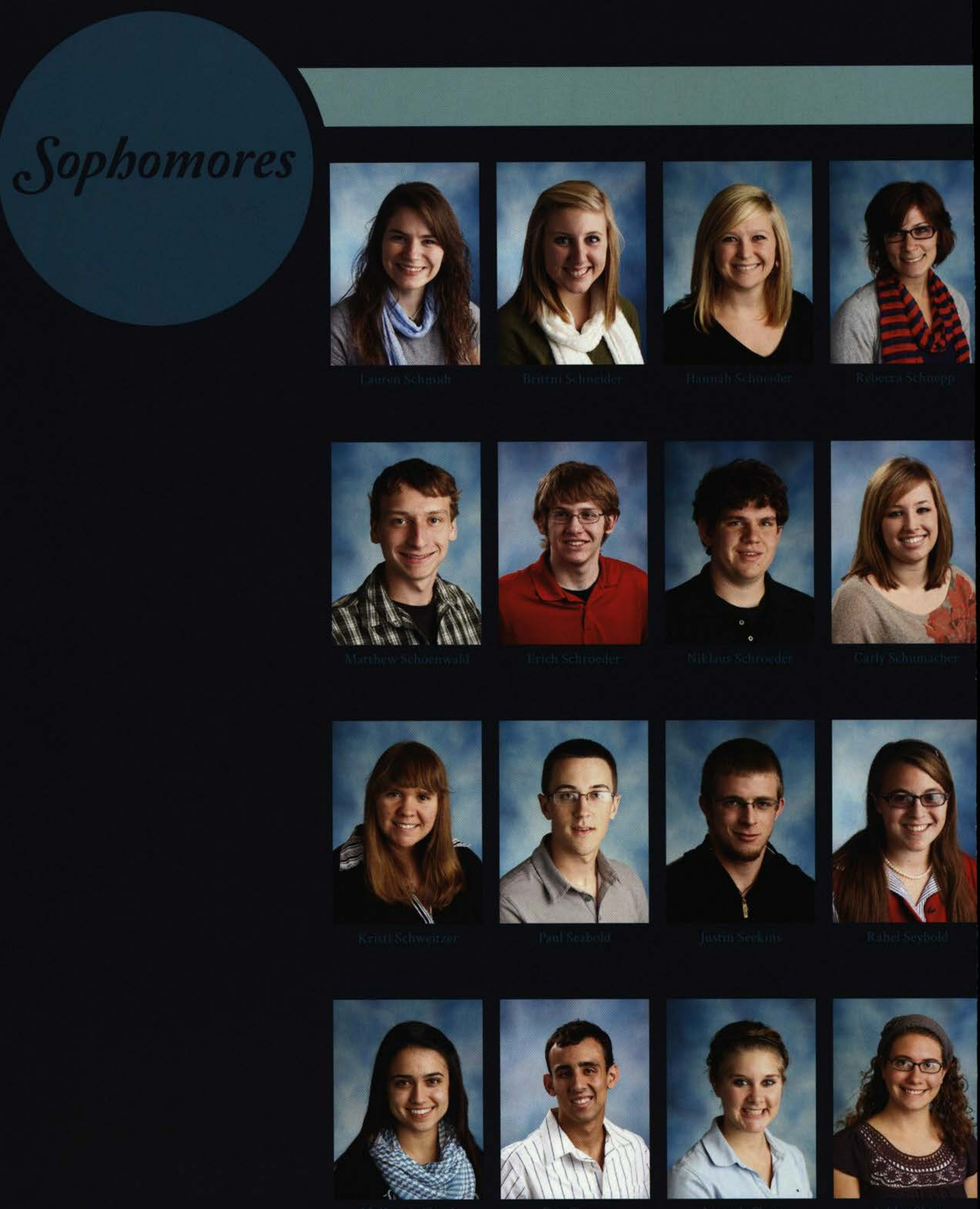



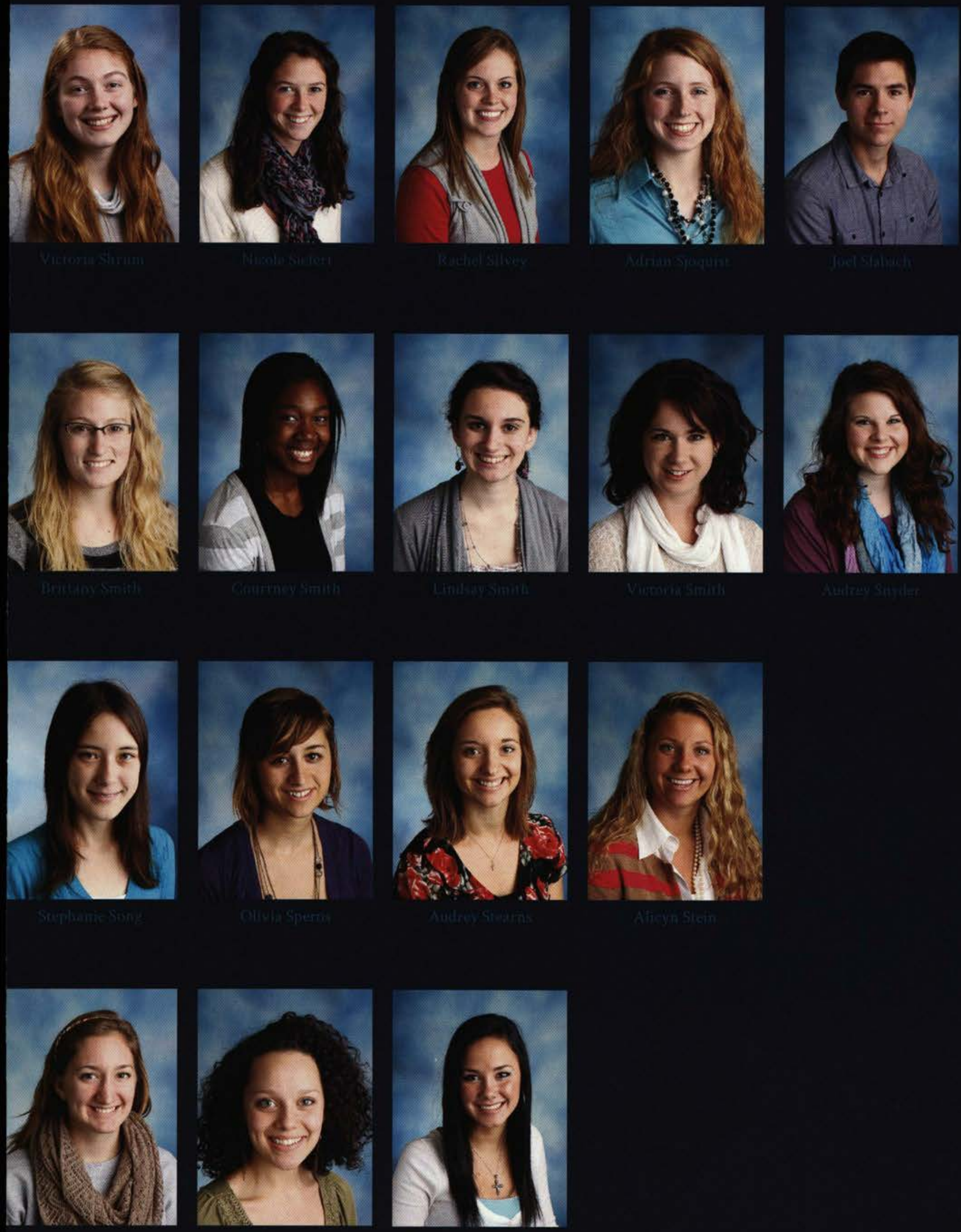


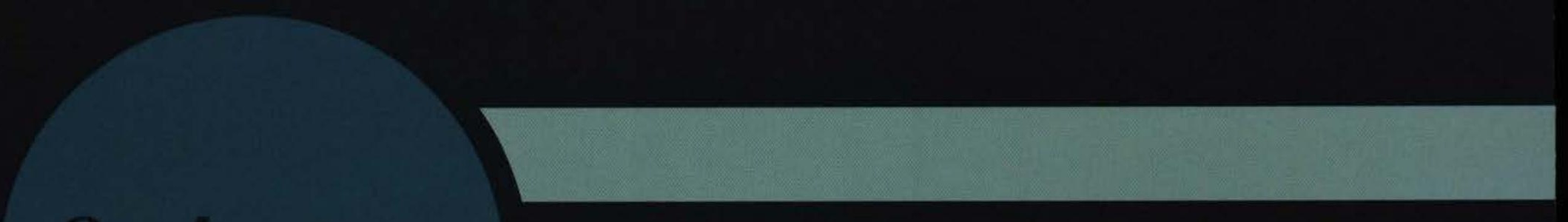
Sophomores
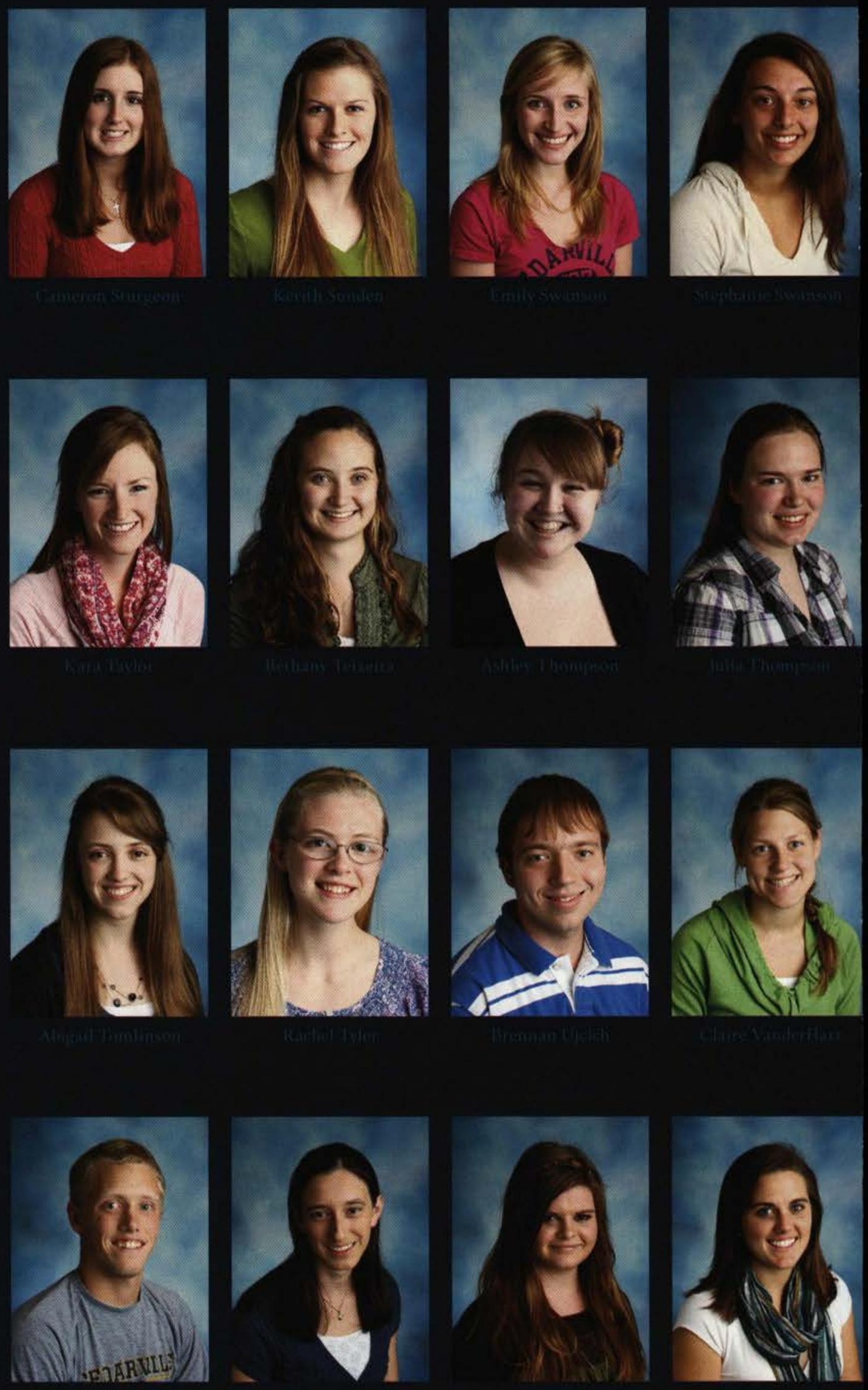

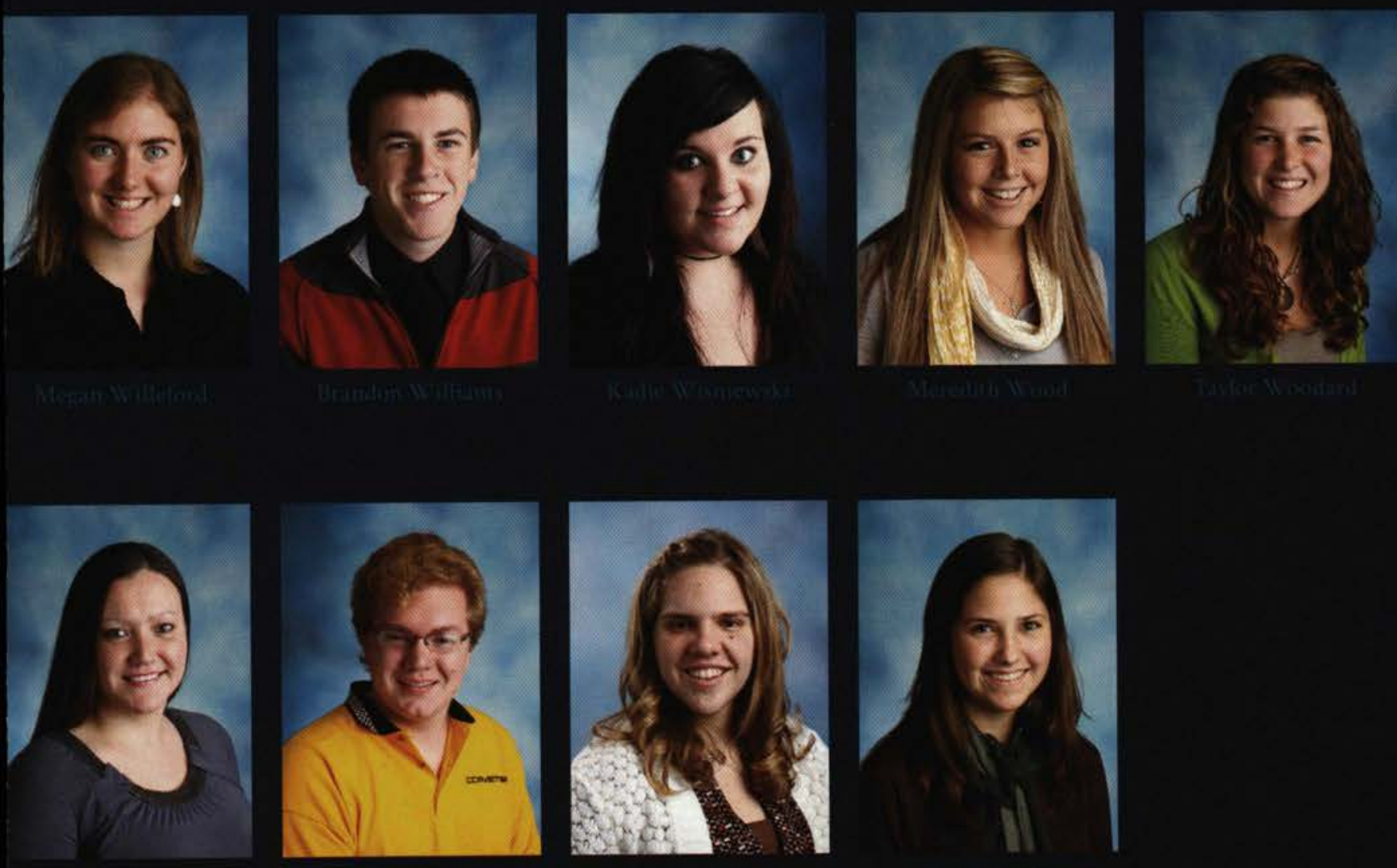


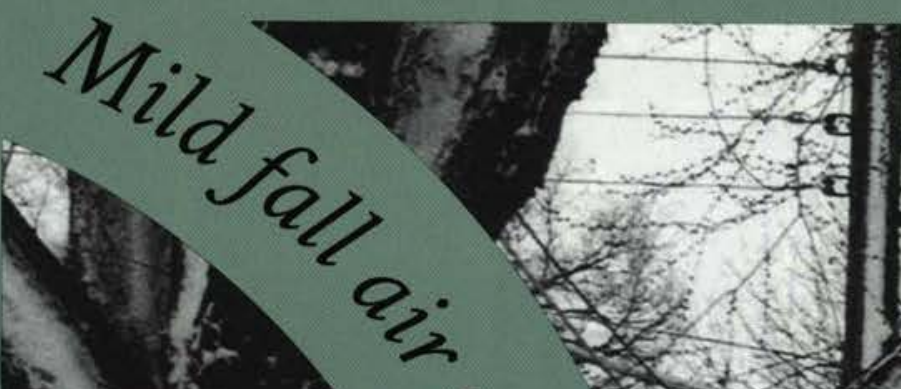

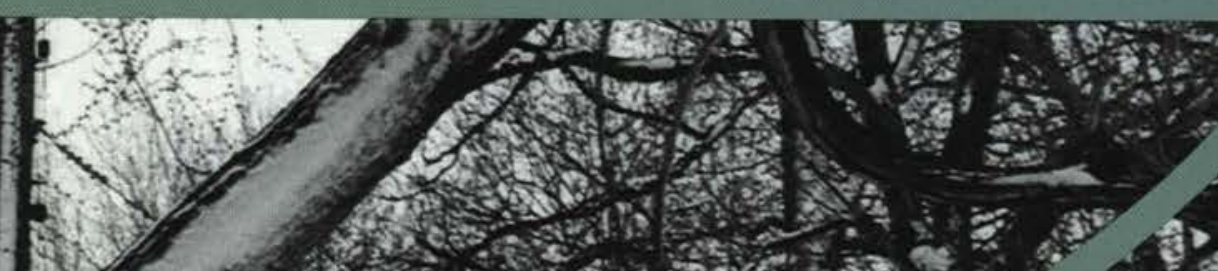

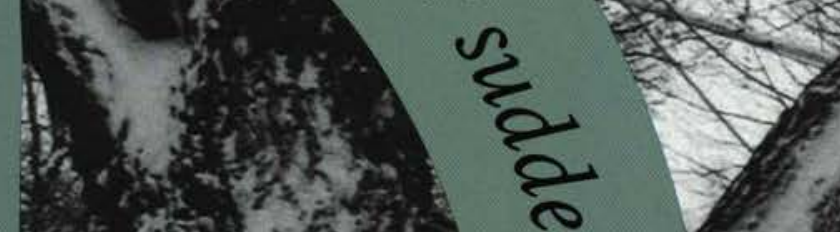

ot 10 .

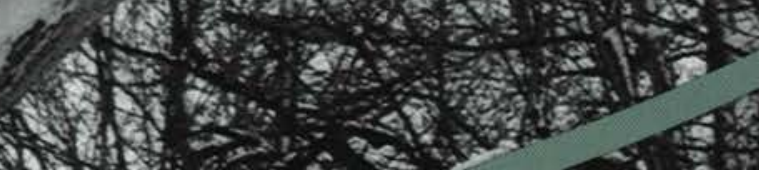

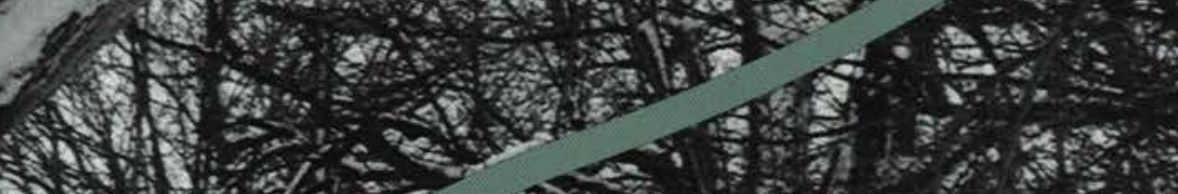

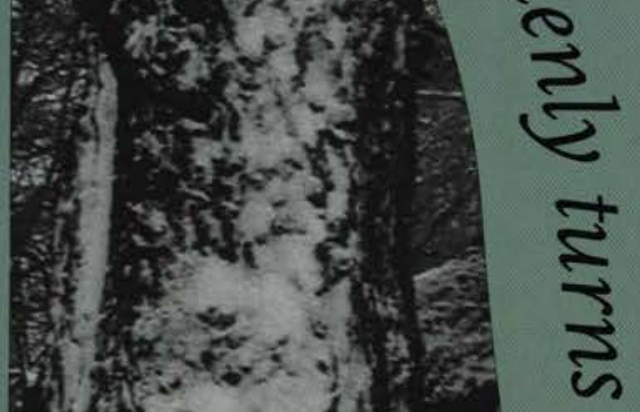

(1) 1 . 2

f)

- 1

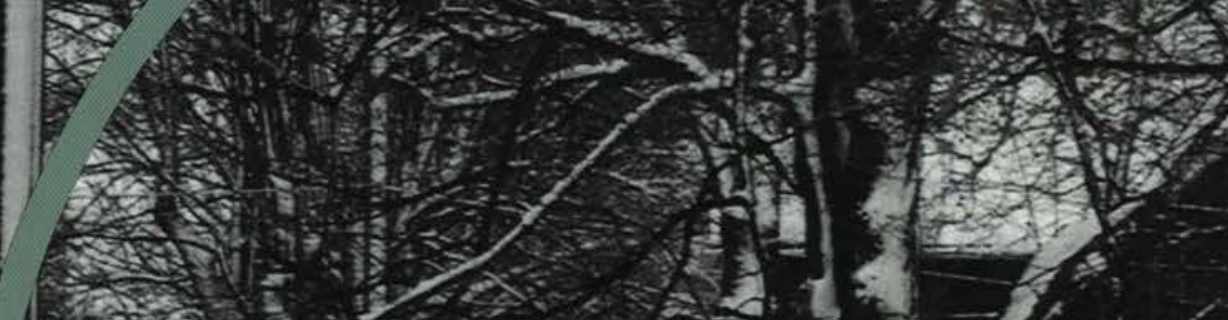

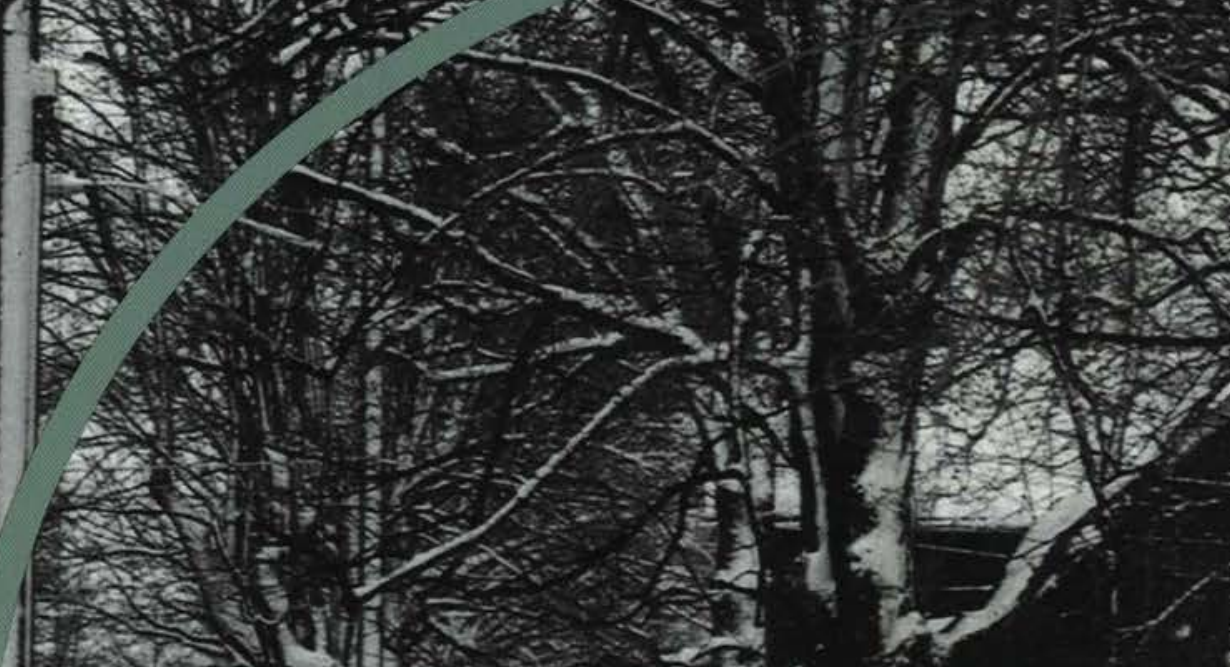

5.1 i

1.

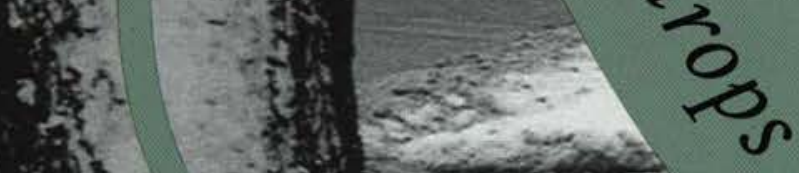

t)
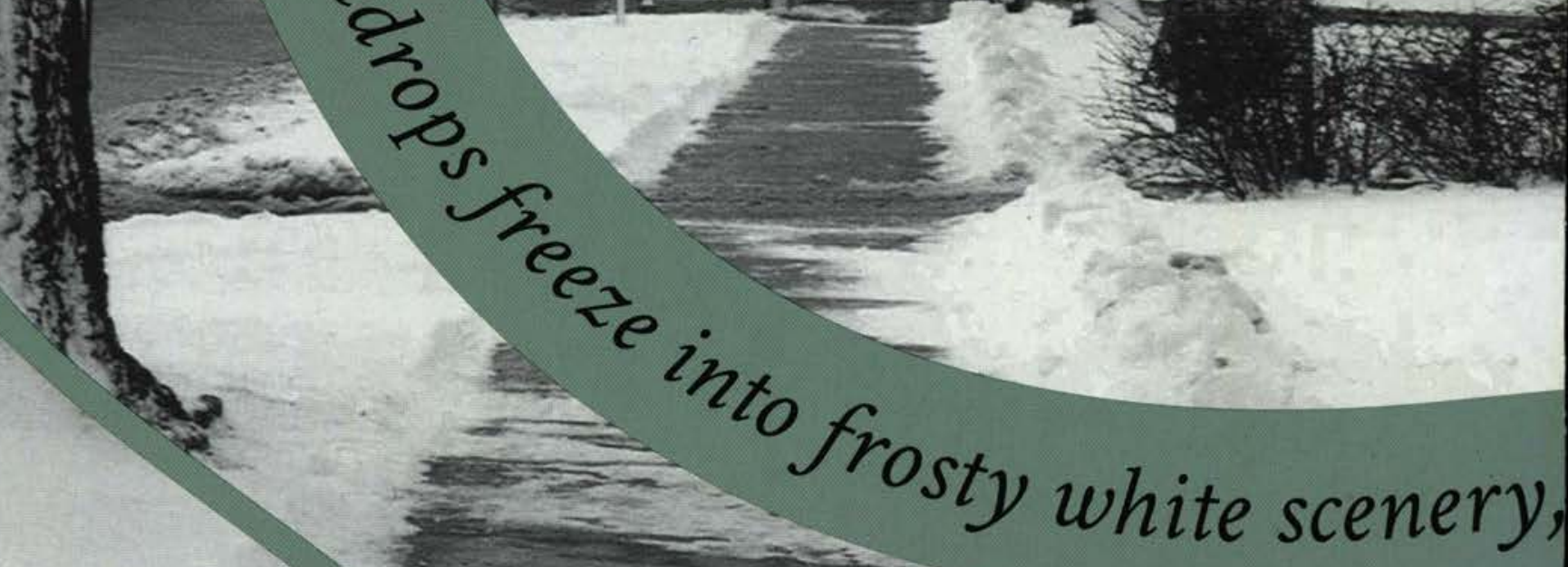


\section{Winter}

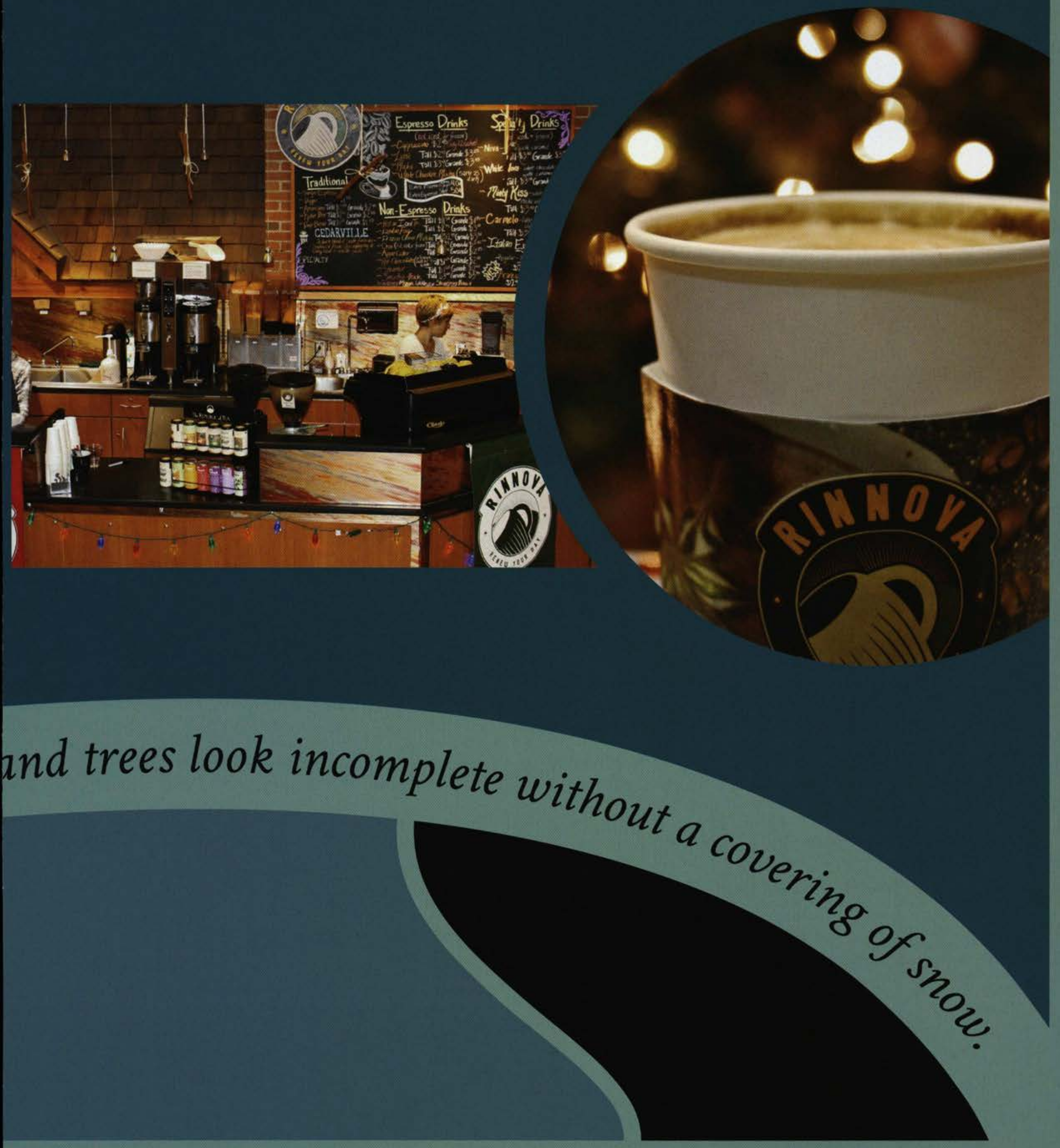




\section{Winter Play}

Through The Crucible, audience members are forced to consider deep issues of morality and mortality.

Betty Parris (Alexandra Hulfman) and Abigail Williams (Grace Pilet) expose the women who practice witcheraft to horrified friends and family.

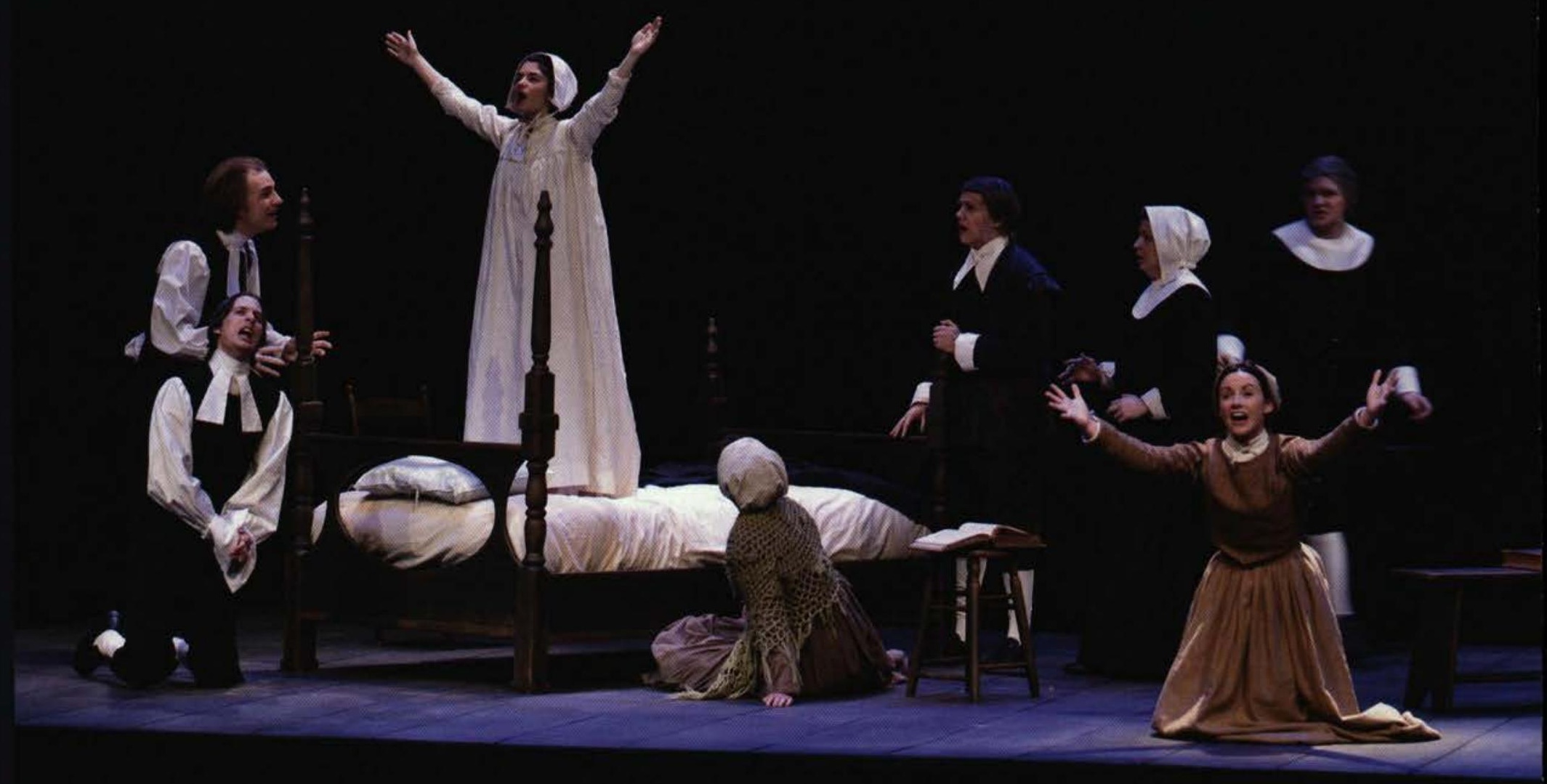

darville features a more serious play for its winter showcase, The Crucible. The story takes place in Salem, Massachusetts, during the 17 th century, at a time when the mention of witchcraft sparked terror and women could be tried and hanged as witches on the unprovable testimonies of their alleged victims. In The Crucible, Abigail Williams, played by Grace Pilet, uproots Salem by accusing upright Christian women of witchcraft. She hopes to have Elizabeth Proctor tried and hanged as a witch so that John Proctor will marry her. In Cedarville's rendition, the stage was separated into three sections, and the dark sharpness of the stage and backdrop added to the weightiness of the play. The play opened with the cast singing "A Mighty Fortress is Our God" a capella, the lights silhouetting their forms but obscuring their faces. It was haunting, indicating the heaviness of the play. The play forced the audiece to wonder: What will you give up to live? What are you willing to die for? Throughout the play, character after character is forced to choose, confessing to fictitious conversations with the devil or choosing death by hanging. Even Giles Corey, who delivers most of the play's witty one-liners, chooses death. Others prefer life. Mary, the Protors' hired help, confesses the ruse that she has not seen any ghosts, but when faced with perjury, she recants. The play ends soberly as John Proctor and Rebecca Nurse are wheeled in a cart to the gallows, refusing to confess a lie to live. It is not a humorously entertaining play, but a necessary one, forcing its audience to consider what they stand for. 
$e^{8}$
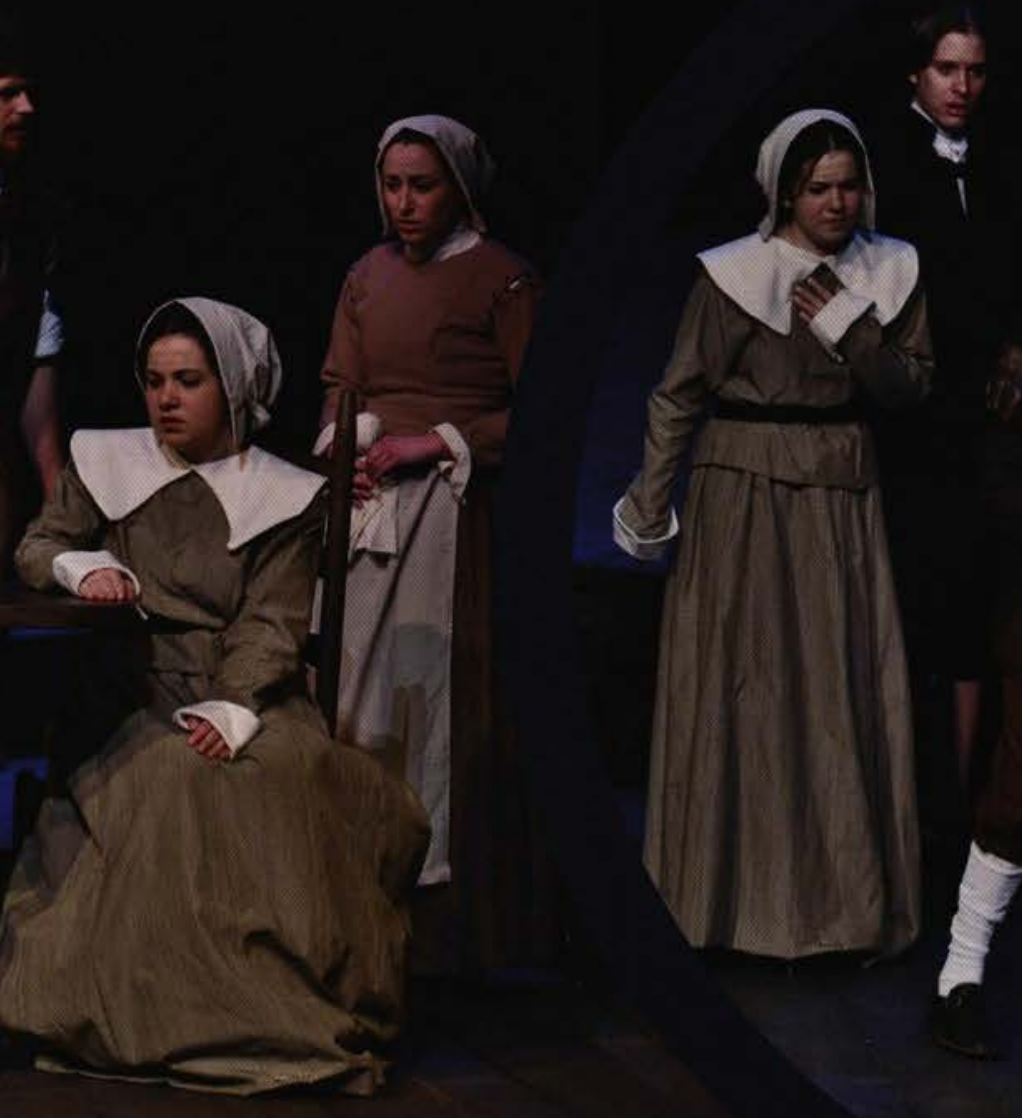

Giles Corey (Josiah Hutchings) mournsth
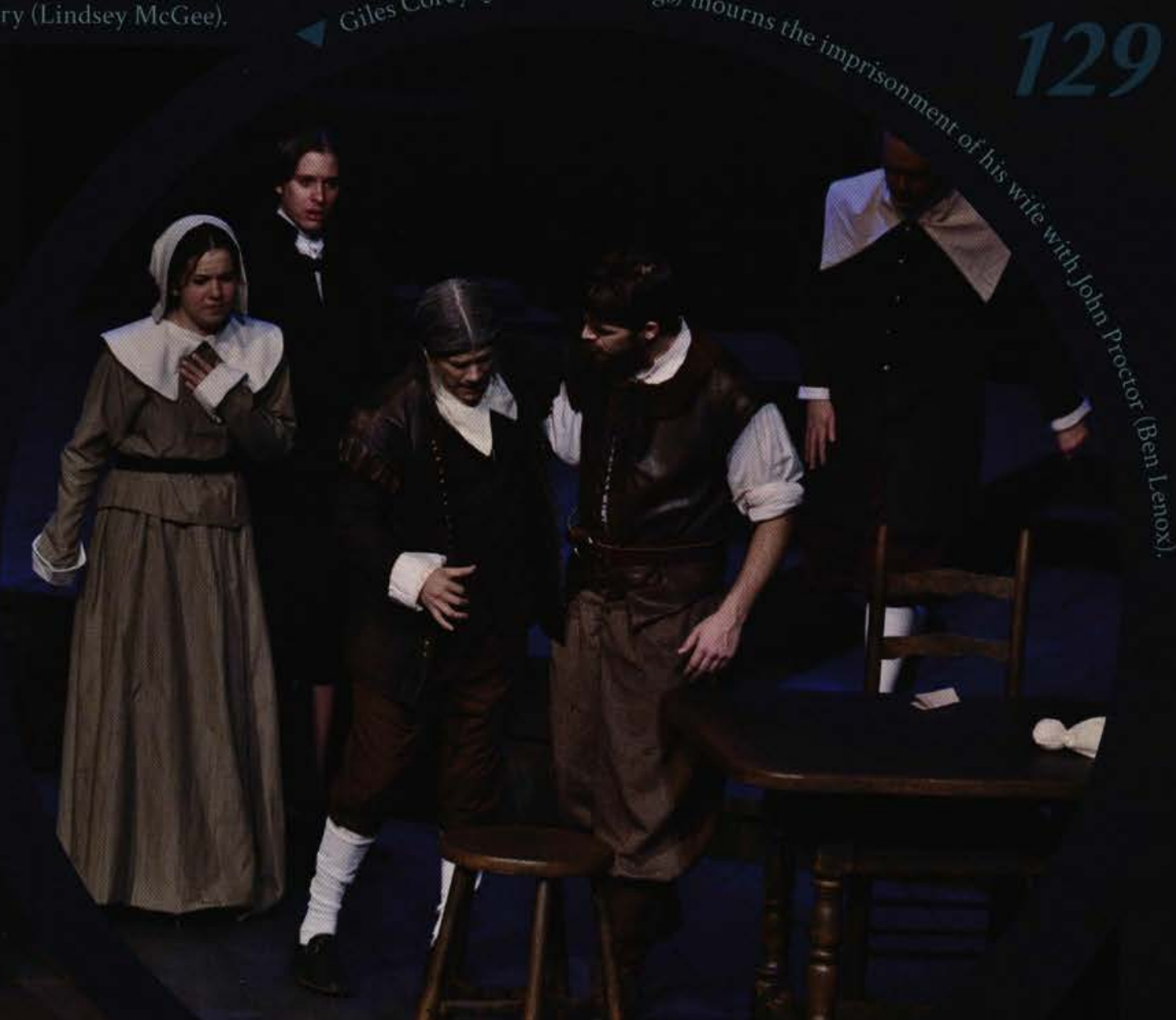

हो $\Rightarrow$
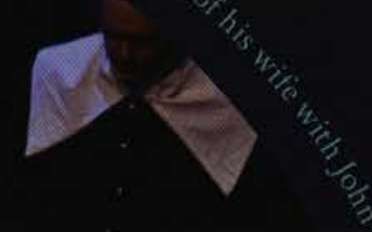

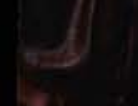

$\sqrt{3}$

4
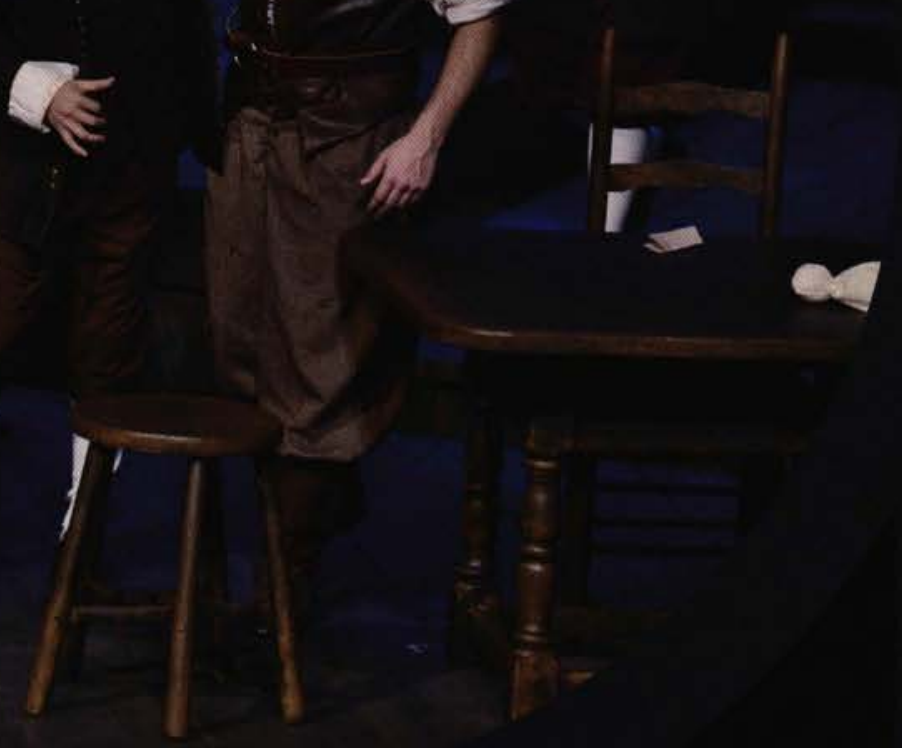

Reverend John Hale (James Lane) frees Tit uba (Stephanie Anderson) from her bondage to witcheraft.

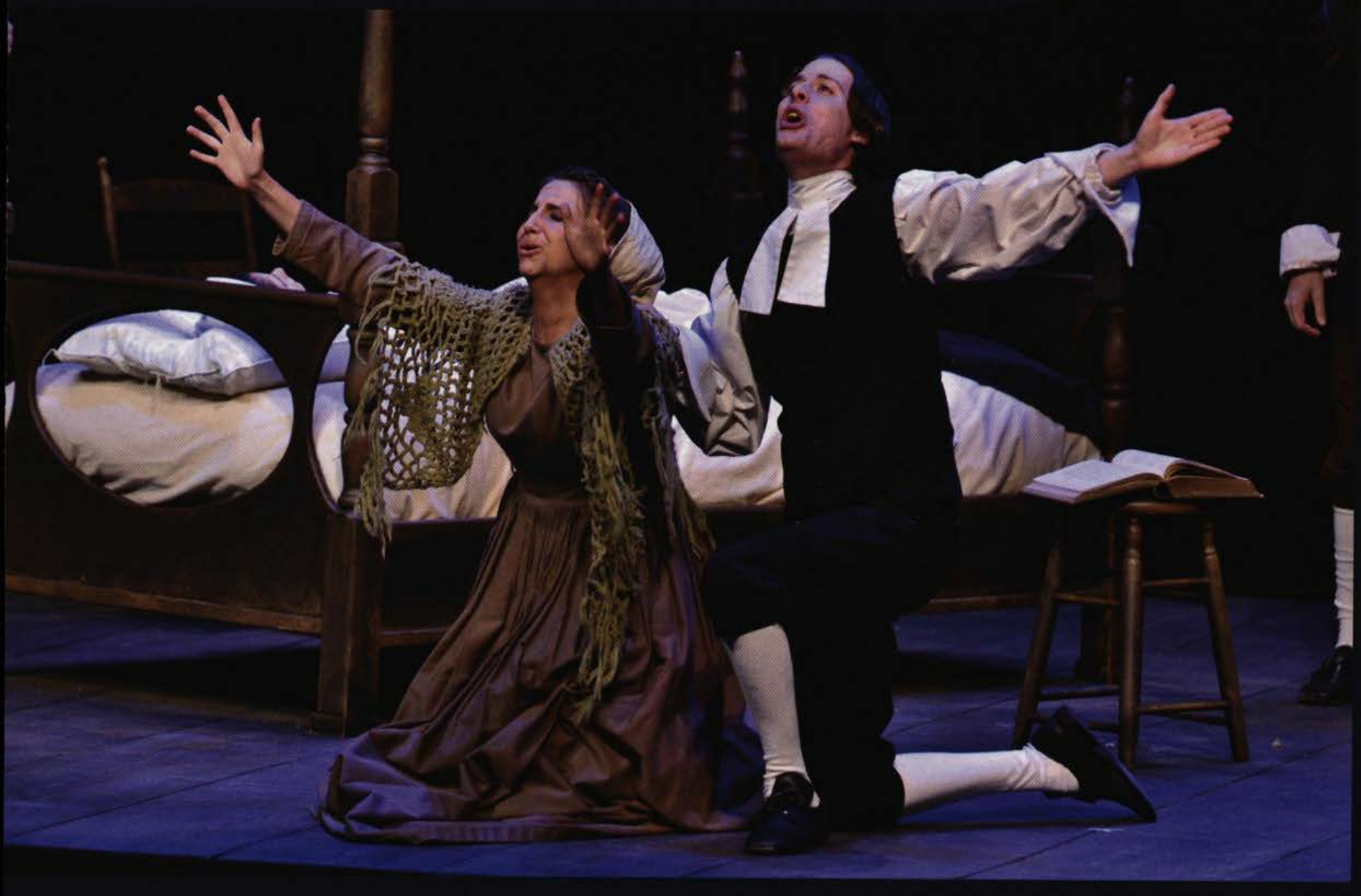




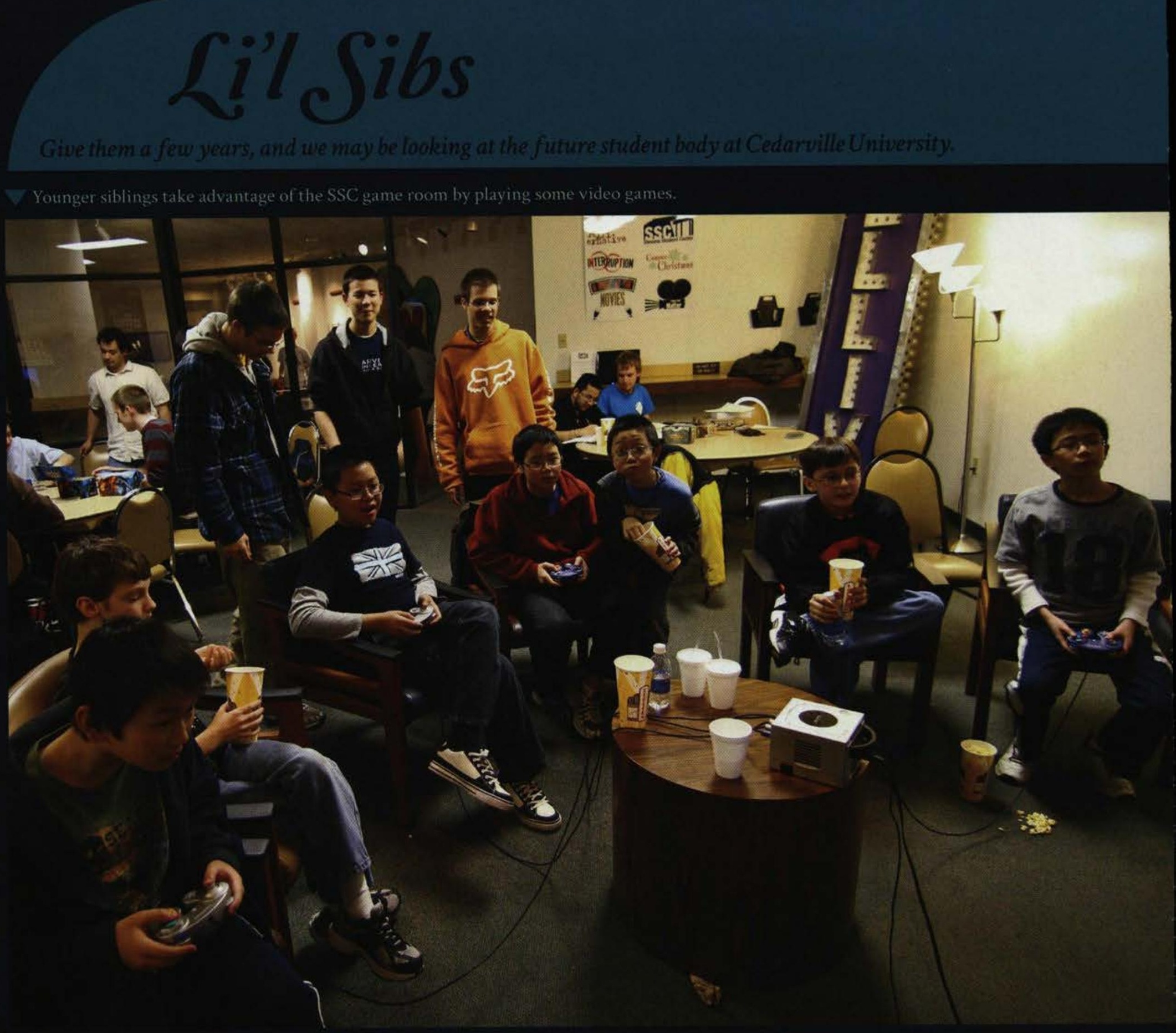

t's no secret that little siblings miss
their big brothers and sisters when August rolls around and school starts up again, so Cedarville University opened its facilities and dorms annually to these longing younger siblings with Lill Sibs Weekend, held every February. While the younger siblings were at Cedarville, SCAB provided campus-wide events that anyone could enjoy. This year, the weekend started on Friday night with a live Heartsong concert-a concert that was recorded for a CD. Next, students and siblings could join in some Laser Tag, Just Dance 2, or The
Muppets movie. Finally, they could end Friday night (and exhaust those under 10) with some Late Night Bowling. On Saturday, the morning started with a chance to climb the rock wall (parental consent required). Later on in the afternoon, Tanya Crevier, the World's Best Female Basketball Handler, delighted fans during the time between the female and male basketball games. For Tanya, ball handling was a lot more than balancing a basketball on one finger; it was balancing that basketball on her elbow, her knee, or doing pushups with a ball spinning on each hand. For a small price, students and their siblings could watch both games and Tayna... who showed up all four teams with her skills. Saturday night ended with a DTR. The comedy show, that is. Li'l sibs had to bid farewell to their older sibs on Sunday when mom and dad returned for pick-up. Fortunately, spring break wasn't far away. 


\section{$\omega_{i}$}

What an atypical Ohio winter - rain rather than snow and $\$ 5$ degree days in January - and unpredictable as usuall

- A chapel worship team leads high school students in worship during the annual High School Leadership Conference.

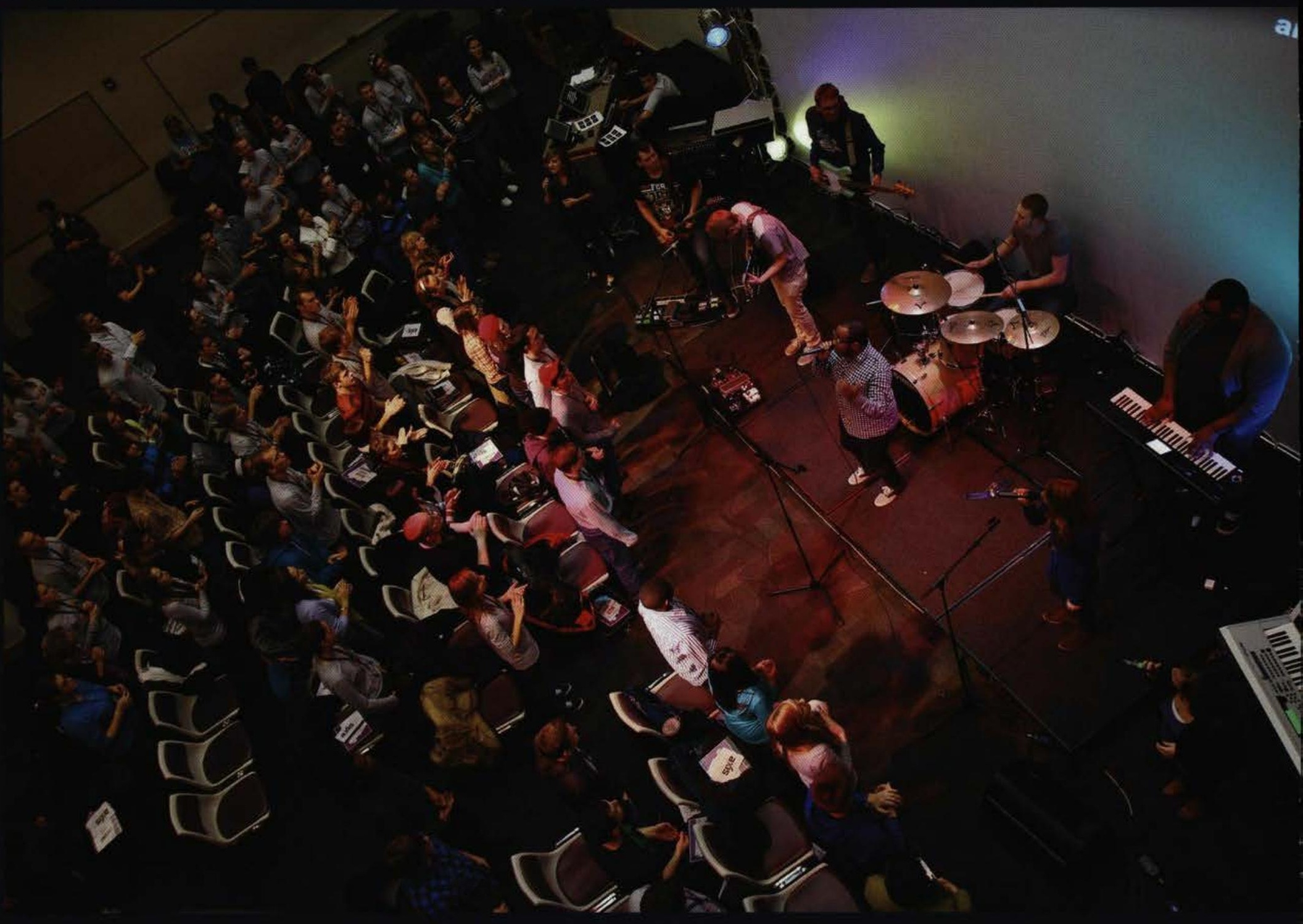

Dain. Lots of rain. This winter could
be described in one word by most be described in one word by most Cedarville University students, the word would be wet. Though winter temperatures were mild, the students engaged in their typical winter activities. Campus Christmas was again a hit, both men's and women's residence halls going all out for the event. Winning themes included "A Pilgrim Christmas" and "The Twelve Days of Christmas, Cedarville Style." SCAB put on the annual Winter Blast that kicked off the Spring semester by providing games, a movie, and more. Every year, Student
Life puts on a certain event to educate the students on Martin Luther King, Jr. Valentine's Day at Cedarville opened up the lower SSC to as many organizations as could cram into the space, selling cards, candy, honeybuns, and even a photo-booth this year. An old tradition returned to the university: TWIRP week. Women demonstrated their appreciation for their male friends by paying for a latte, donuts, or dinner. And then, there was Chuck's Speed Dating. Few words could express the experience of watching male students scoot from seat to seat at the sound of a pot banging. ALT night and Li'l Sibs were also events that occurred over the course of the winter. In order to raise money and awareness for sexual slavery, the members of IJM planned and executed the 3 rd annual Possible Impossibilities 10K. This year, money was donated to the Red Thread Movement. Though the winter was warm by Ohio standards, and no classes were cancelled, annual Cedarville traditions lived up to their promises of making the winter seem just a little shorter. 


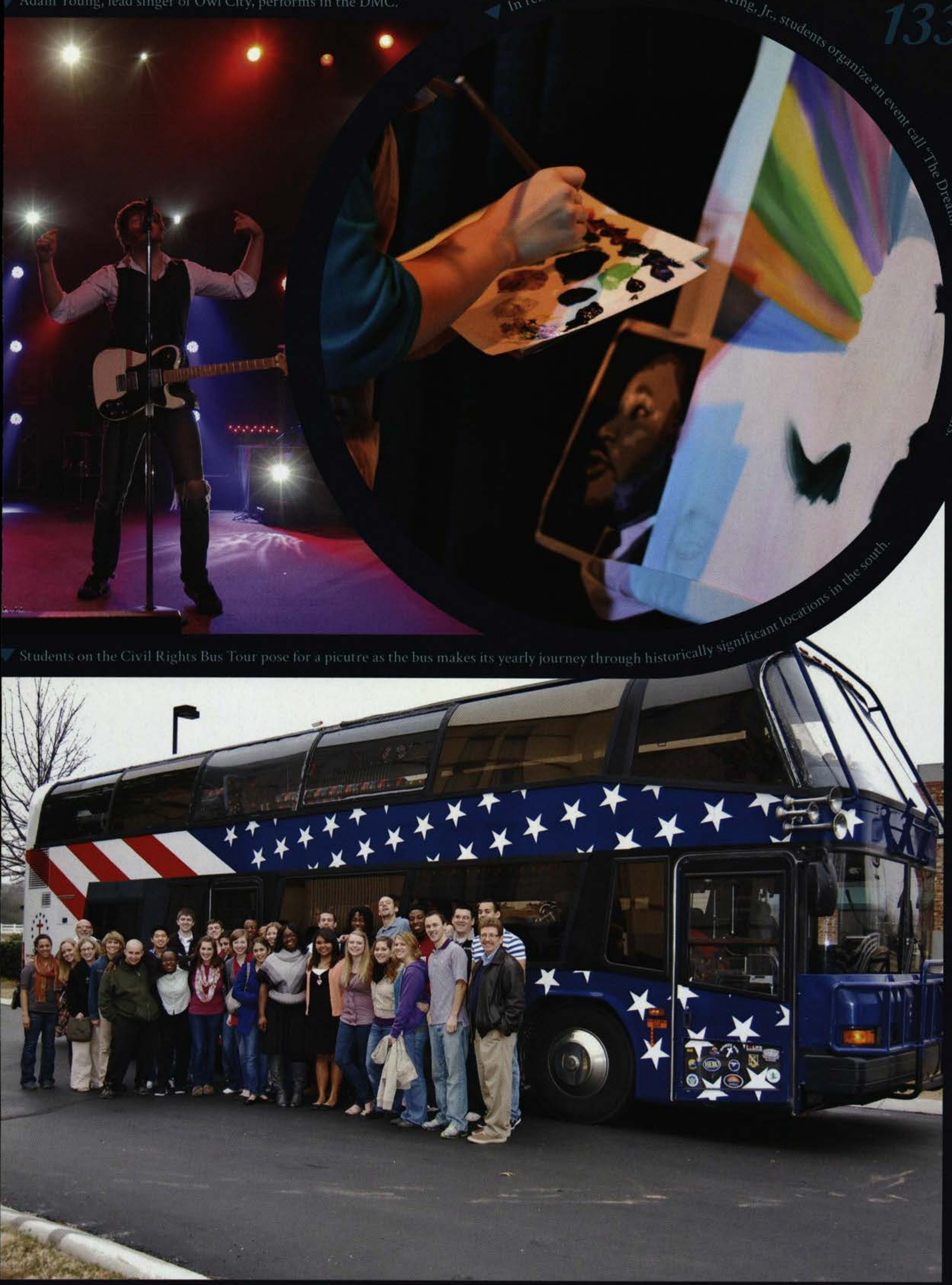


Tho $40 \%$

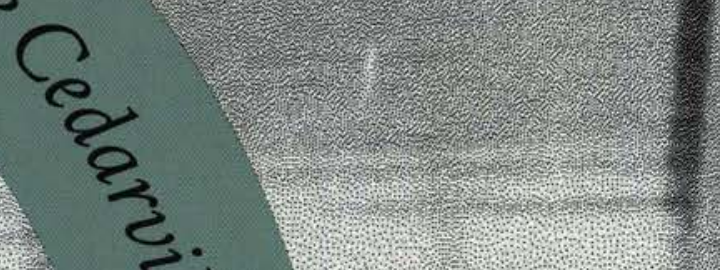



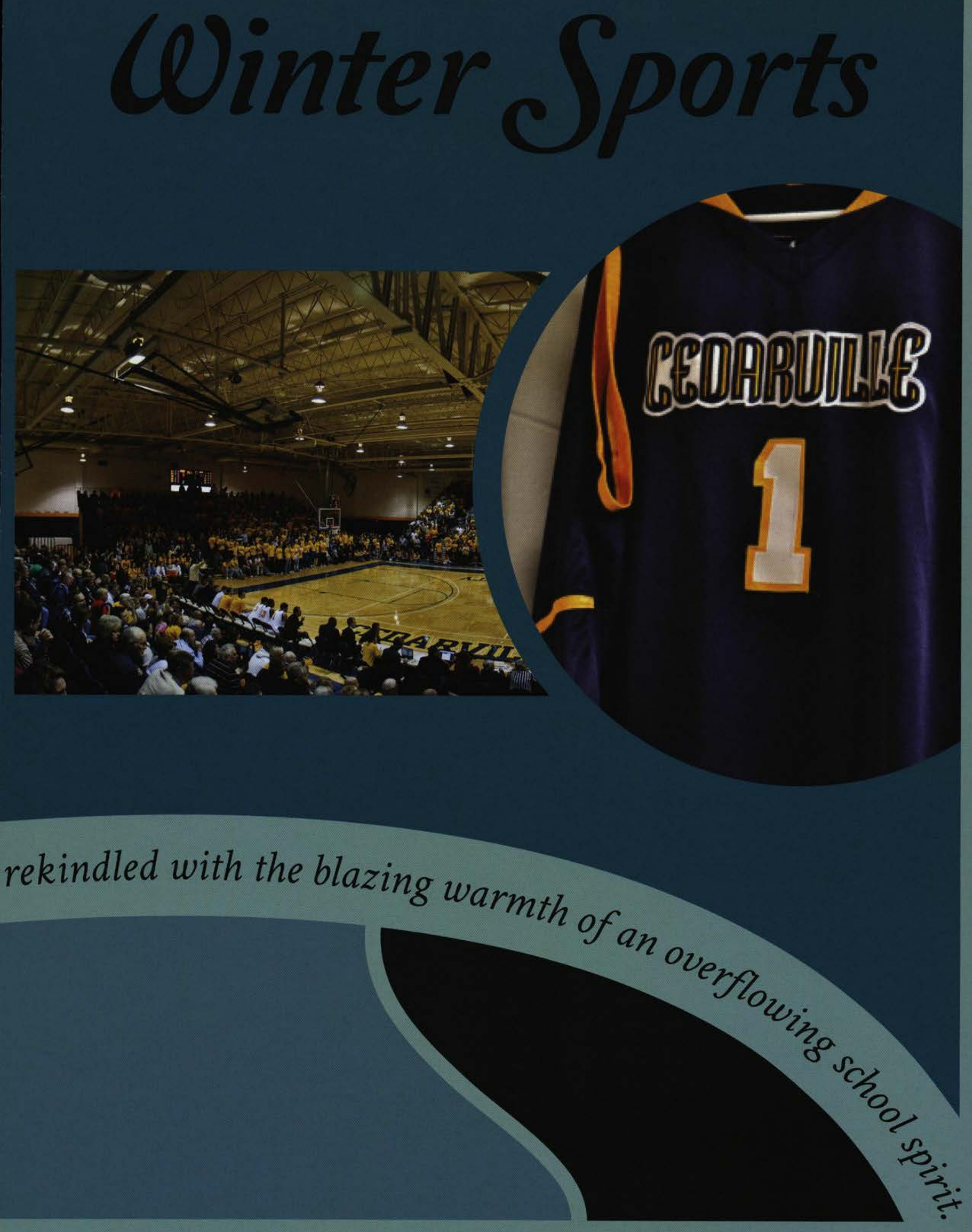

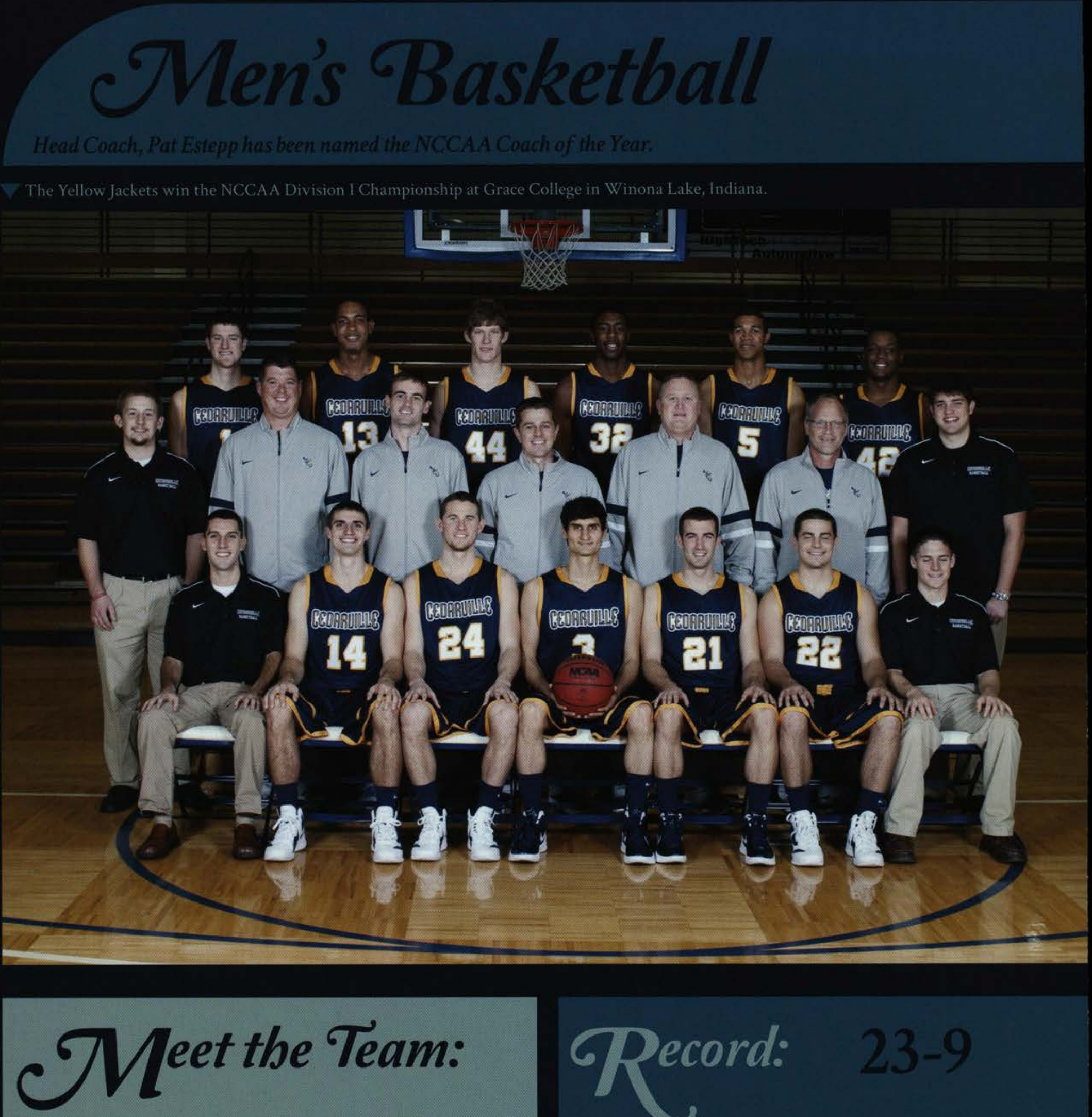

First-row: Student Assistant John Leonzo, Daniel Hickman, Zach Brown, Daniel Kohavi, Austin Foote, Marcus Reineke, Student Assistant Nathaniel Hughes

Second-row: Brian Cheney (Student Athletic Trainer), Chris Cross (Head Athletic Trainer), Assistant Coach Ryan Neises, Head Coach Pat Estepp, Assistant Coach Brett Newman, Team Chaplain Dr. Scott Dixon, Student Assistant Kyle Wright.

Back-row: Brian Hecker, Brian Grant, Caleb Maxwell, Zimmy Nwogbo, Leighton Smith, Bryan Redic. 
The Gady Jackets score both on the court and in the classroom; the Cedarville athletic teams have maintained a cumulative gpa of 3.0 or better.

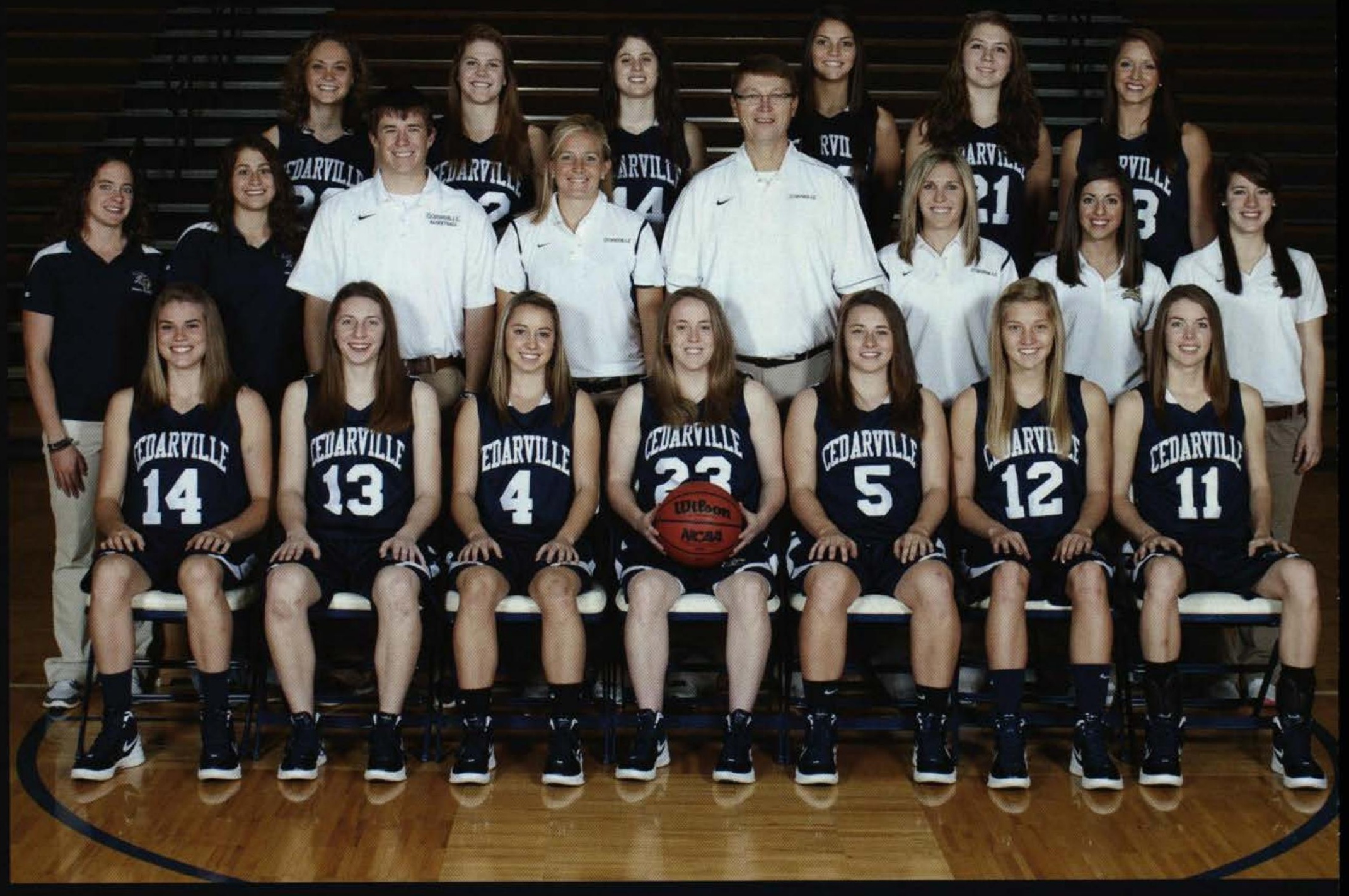

Weet the Team:

First-row: Heidi Ansiel, Kaysie Brittenham, Kayla Jenerette,

Kara Cayton, Raegan Ryan, Payton Strawser, Becky Orchard.

Second-row: Hannah Haynes (Assistant Athletic Trainer), Jill

Carroll (Student Athletic Trainer), Kyler Ludlow (Assistant

Coach), Kari Flunker (Assistant Coach), Kirk Martin (Head

Coach), Stacie Travis (Assistant Coach), Becca Roberts (Student

Assistant), Caroline MacKenzie (Student Assistant)

Back-row: Kathy Jakucki, Deborah Gordon, Danielle Spiliotis,

Lauryn Robinson, Keilah Ketron, Deborah Chandler. 


\section{Cheerleading}

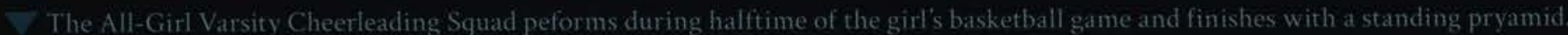

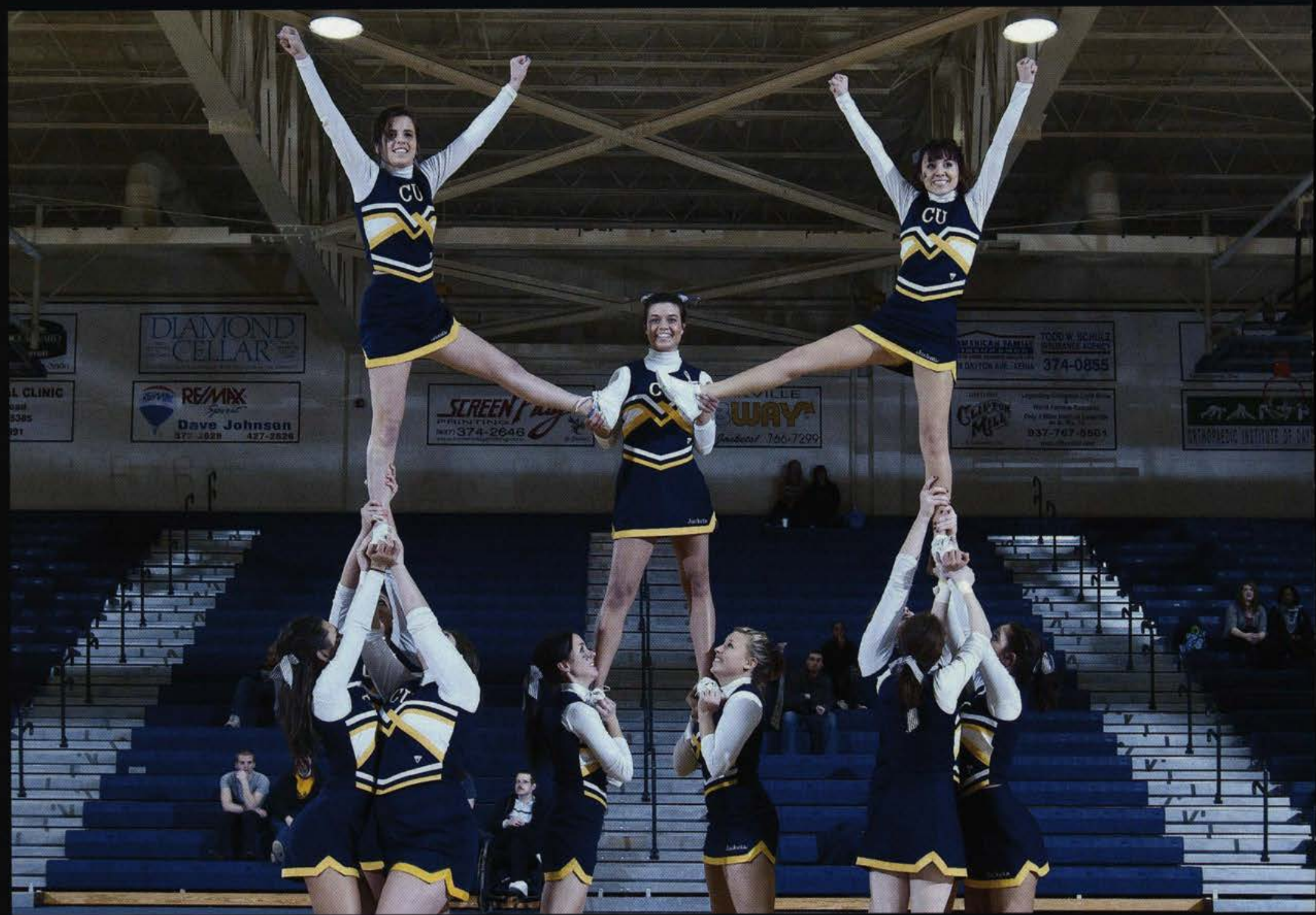

erhaps the best way to describe
the foundation of Cheerleading at Cedarville University is "The body that is united stands." This reflects not only the group's striving for strength through athleticism but is also a metaphor for the sport itself. The body must be strong and united in order to stand firm and succeed at what they do. At Cedarville, cheerleading was a vehicle to impress upon the athletes the vital importance of unity as the body of Christ, by learning unity in technique, mounts, jumps, and more. When support was strong, the athletes would inevitably form an unbreakable chain that most of them could attest to: a chain of strong relationships, strong bodies, and strong skills and talents as a strong squad. Cheerleading was a lot of work. Mentally, each member needed constantly to strive to pull together as a collective team. Physically, often times there would be a game the day after a tough practice, causing the members of the squad to be tired and sore, yet they offered their all and pulled off great performances to get Jackets' fans "Fired up!" Haley Studebaker, a sophomore on the All-Girl Varsity cheerleading squad, explained how being a part of the squad enriched her college experience: "It's been a wonderful time getting to know the girls on the squad and seeing how much we all have improved since day one. A lot of the girls have had very little cheerleading experience, but we've all pushed ourselves, and it's great to look back and see what we've accomplished." The Cheerleading Squad of Cedarville University not only represented unity through strength when they stood before the fans at every event, they also represented progress, growth, and accomplishment through Christ. 


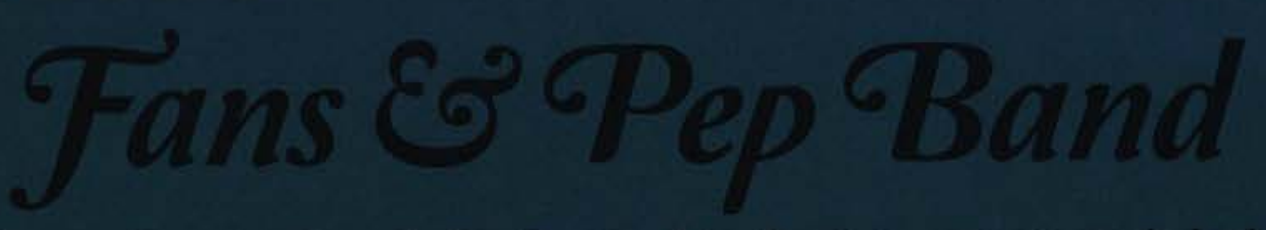

The enthusiasm and supporf from the Pep Band and the fans brings passion fo the bas

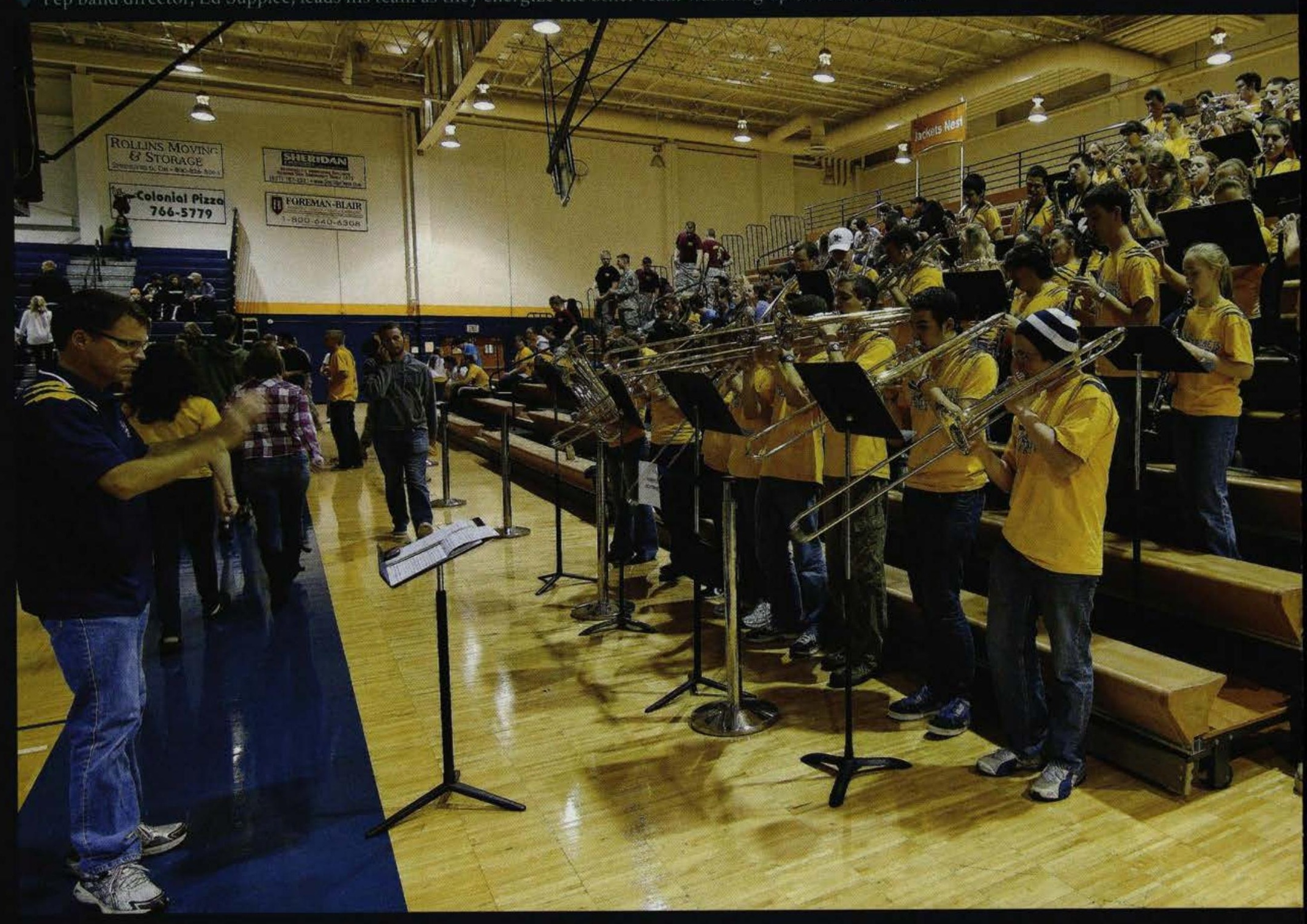

he crowd rocked and swelled. The
life-sized Yellow Jacket pumped up the crowd as a unifying symbol. The music crescendoed as the Pep Band harmonized in a song of triumph. This was the typical Cedarville University basketball game, home to the famed Yellow Jackets of NCAA Division II. The Yellow Jackets fans were committed to their team. It was common to find, upon entering the Callan Athletic Center at game time, a sea of blue and gold rippling in the stands exuding support for the Yellow Jackets' domination on the court. A tradition that had developed at Cedarville was the practice of jingling one's keys immediately before tip-off (some theorists claim this is a mimicking of the yellow jacket's buzz). It was a sense experience indeed to see the mass of gold and hear the victory roar, while seeing one's team crush the opposition! The music behind the Jackets was also very important. "Pep Band is a large part of the athletics atmosphere at Cedarville. It provides a lot of the energy and leads the fans in excitement," said student Seth Kark, who played his drums for Pep Band. "I would definitely recommend Pep Band to anyone who plays an instrument and is interested in the success of Cedarville's sports teams." Pep Band members and fans alike committed to "Back the Jackets All the Way" all year long. Their enthusiasm and support brought passion to the gymnasium, creating an unforgettable atmosphere and experience for all who supported our athletic teams. 


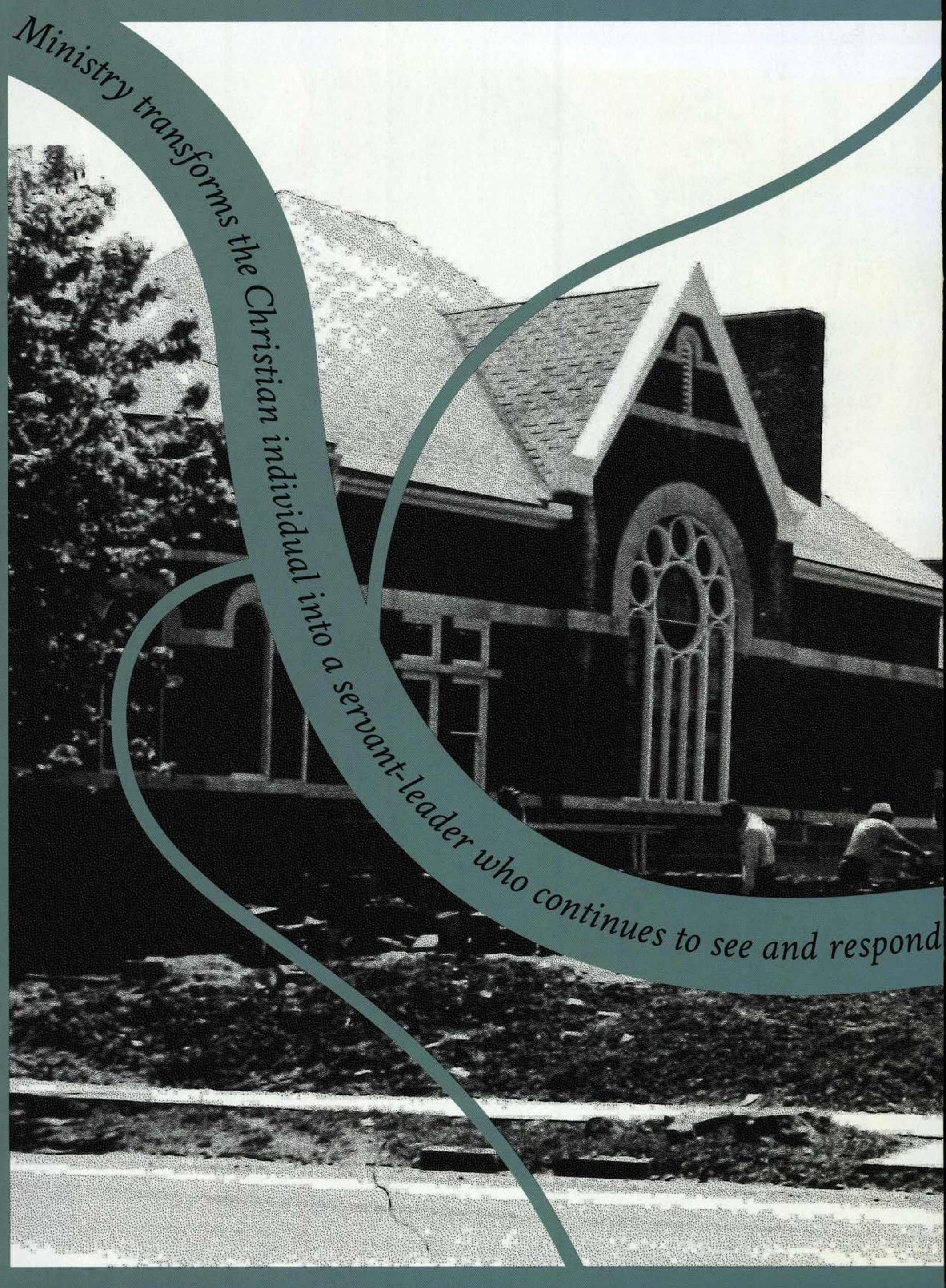




\section{$\checkmark$ Ministries}

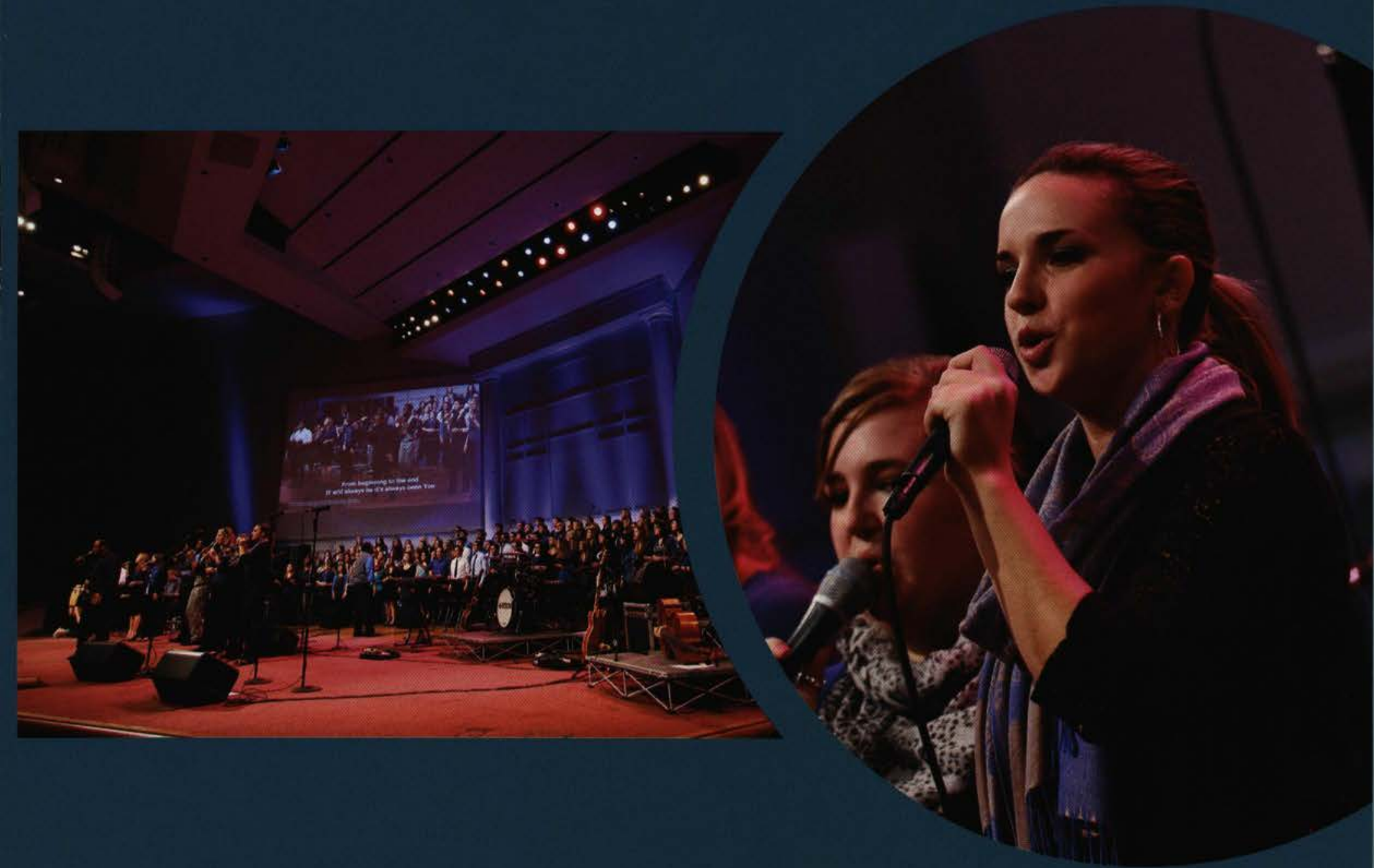

to 


\section{Community Ministries}

Students go into our own "Jerusalem" to preach the gospel, serve the community, and share the love of Christ.

Megan Helmbrecht and Micah Holck help Chinese students write letters during the Agape's ESL tutoring program minstry.

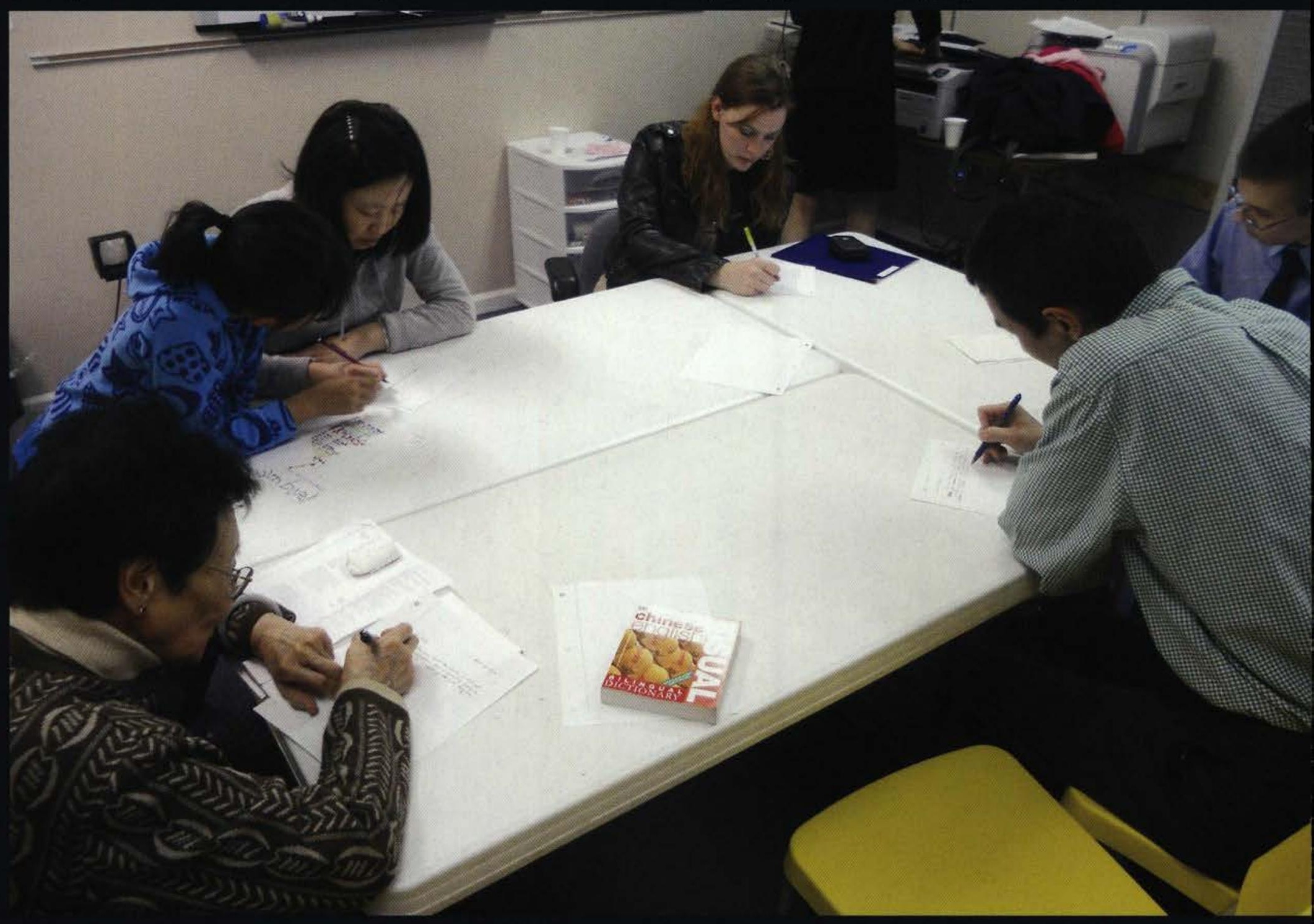

"ove God, Love Others," was
a popular slogan at Cedarville, a brand across University literature and sometimes clothing. Student ministries urged students to live up to the call of the Gospel not only to be a vertical climb but also a horizontal outreach, an attempt to show the love of Christ to the members of the nearby communities. A category of ministries that was common among students was church ministry. Worship teams, youth group leaders, and Sunday School teachers were easy to find on the campus, students answering the request for workers in the church. Other ministries students got involved in often were jail ministries or juvenile detention center ministries. In these outreaches, university students could practically extend Christ's love through their interactions with others. Perhaps one of the most radical ministries to overtake Cedarville students was Doors of Hope with Changing Lives Now ministries in Springfield. A Friday night team roamed the streets of Springfield searching for the lost and broken, the crack-addicted and the prostitutes, sharing the Gospel and a message of peace, pulling their name and ministry charge from Hosea 2:15. Youth community outreach was another pull for Cedarville. Cedarville students weren't very far removed from high school students and could easily relate to them. The Cliff, S.T.A.R.S., and Young Life all asked for some crazy college students to relate to some crazy high school kids, and there usually wasn't a shortage. Cedarville offered so many opportunities to enact the "Love God, Love Others" motto, something for everyone's passions, desires, and talents. 

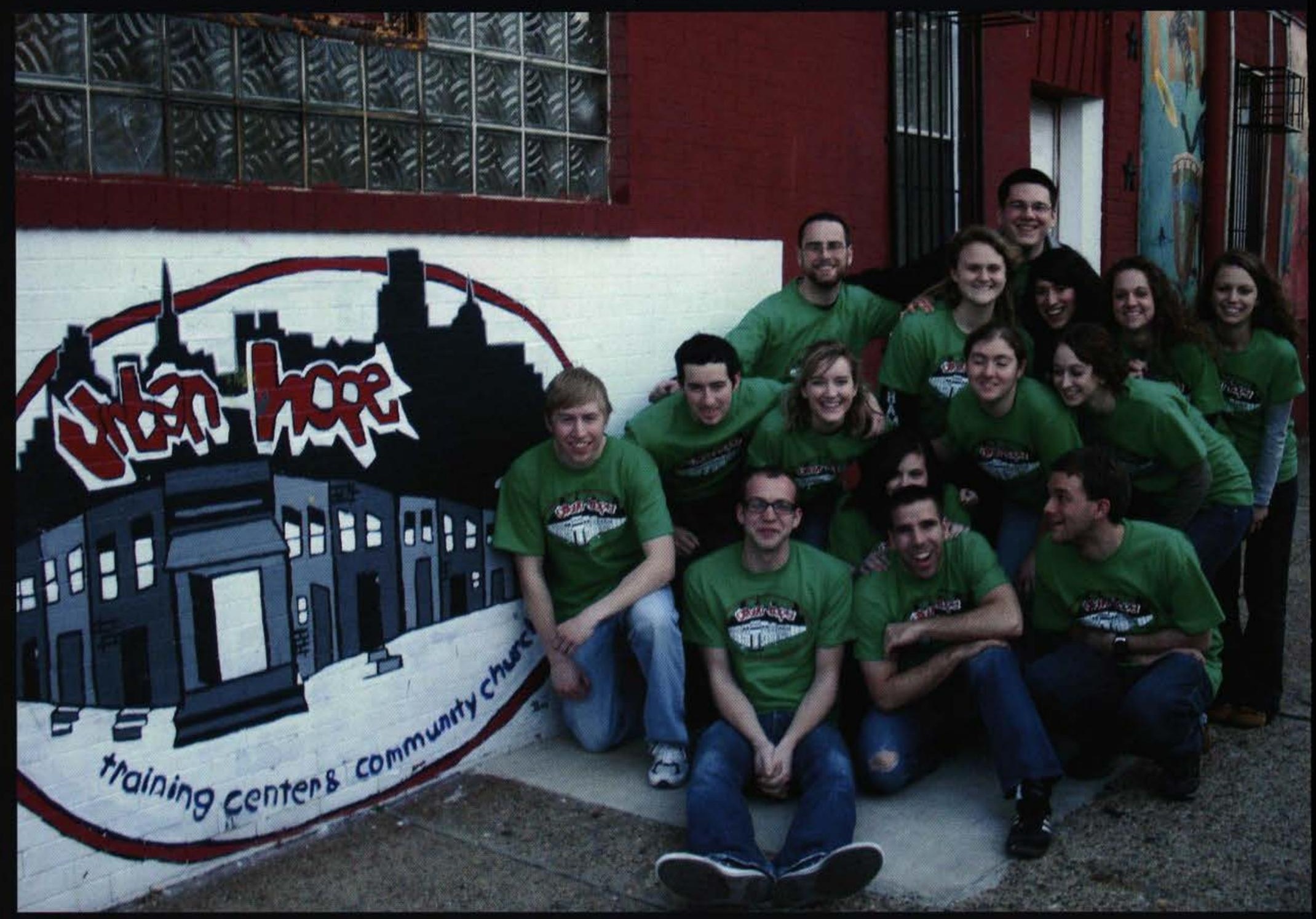

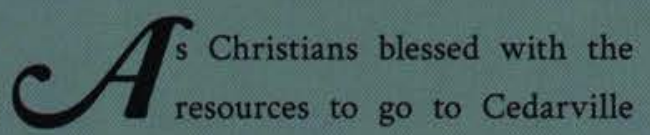

University, it can be easy to forget about reaching out to the unsaved in the world. Missions Involvement Services (MIS) provided opportunities for students to reach out to others. Some were general trips, open to all students with the desire to serve Christ by helping people in other parts of the world. Other trips were geared towards specific majors. Last year, nursing majors traveled to Togo, Africa, and engineering majors went to Liberia. Tasks could be basic, repairing and painting facilities or catered toward a specific need. These trips taught students how to adapt to other cultures and relate to other people. It also cultivated a heart for missions and confirmed for many that they were where God wanted them to be. MIS had been in existence for forty years, and in that span of time, it sent more than six thousand participants to ninetyone countries, including Jamaica, Bahamas, Honduras, Mexico, Australia, England, Germany, Hungary, Indonesia, Israel, Kosovo, Liberia, Middle East, South Africa, Rwanda, Thailand, Togo, and Ukraine. Teams were sent during breaks and in the summertime. Because students had to raise their own funds, it helped them learn to rely on God. They learned that if He wants them to go, He will provide the money. MIS trips also taught the students to work together and to support and encourage each other as they seek to glorify God together. The bonds that were formed on these trips were unlike any others. Students worked together, served God, together, and built memories with each other through MIS trips. 
Discipleship Ministries
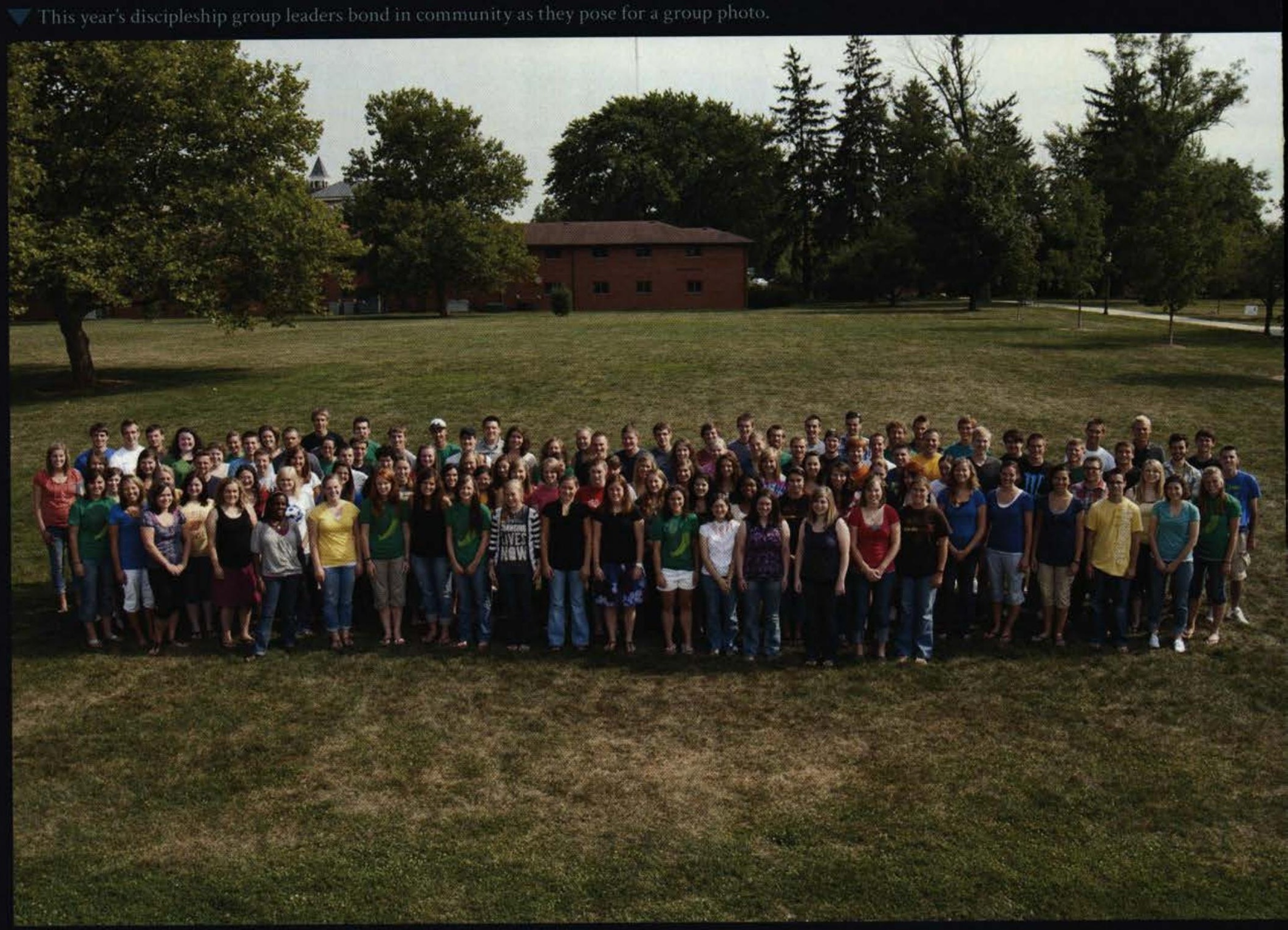

0 ne relatively unique aspect of Cedarville among universities was the often overlooked area of Discipleship Ministries. Led by Director of Discipleship Ministries, Mark Irving, this communityfocused ministry emphasized genuine discipleship and relationships with real results, taking a cue from the way Christ interacted with his disciples and others with whom He came into contact. A Discipleship Council of a very few students, along with Irving, decided the direction Discipleship Ministries was going to go that year. The Discipleship Council divided up a small group of student leaders and gave them each a responsibility to a particular discipleship group that met throughout the school year. Participation in a discipleship group was optional, but encouraged by the University. A weekly highlight for many alumni and upperclassmen who participated in a discipleship group for much of their time at Cedarville was the group meeting. What took place during the group meeting varied with the desires of the leader and group in general. While some form of Bible and/or other book study was usually present, other activities such as service to the community, sharing life maps with one another, and eating meals together were frequent as well This year's discipleship groups saw many students, new and old, grow in service to Christ and community among fellow believers. Some men's discipleship groups read and discussed What Ticks God Off, a study of God in the Minor Prophets, and Radical, a call to live fearlessly in an apathetic Christian America. Some women's discipleship groups also went through Radical together, as well as Authentic Faith a look at God's use of trials to forge a strong faith in Him. 


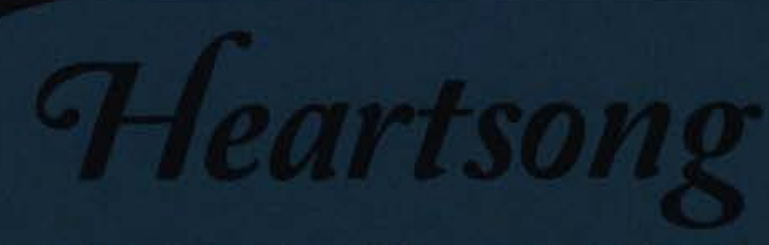

These talented musicians travel the counitry to share their gifts with local churches, leading others in worship.

While Heartsong generally travels to churches, here they take the time to lead our own student body in a time of worship.

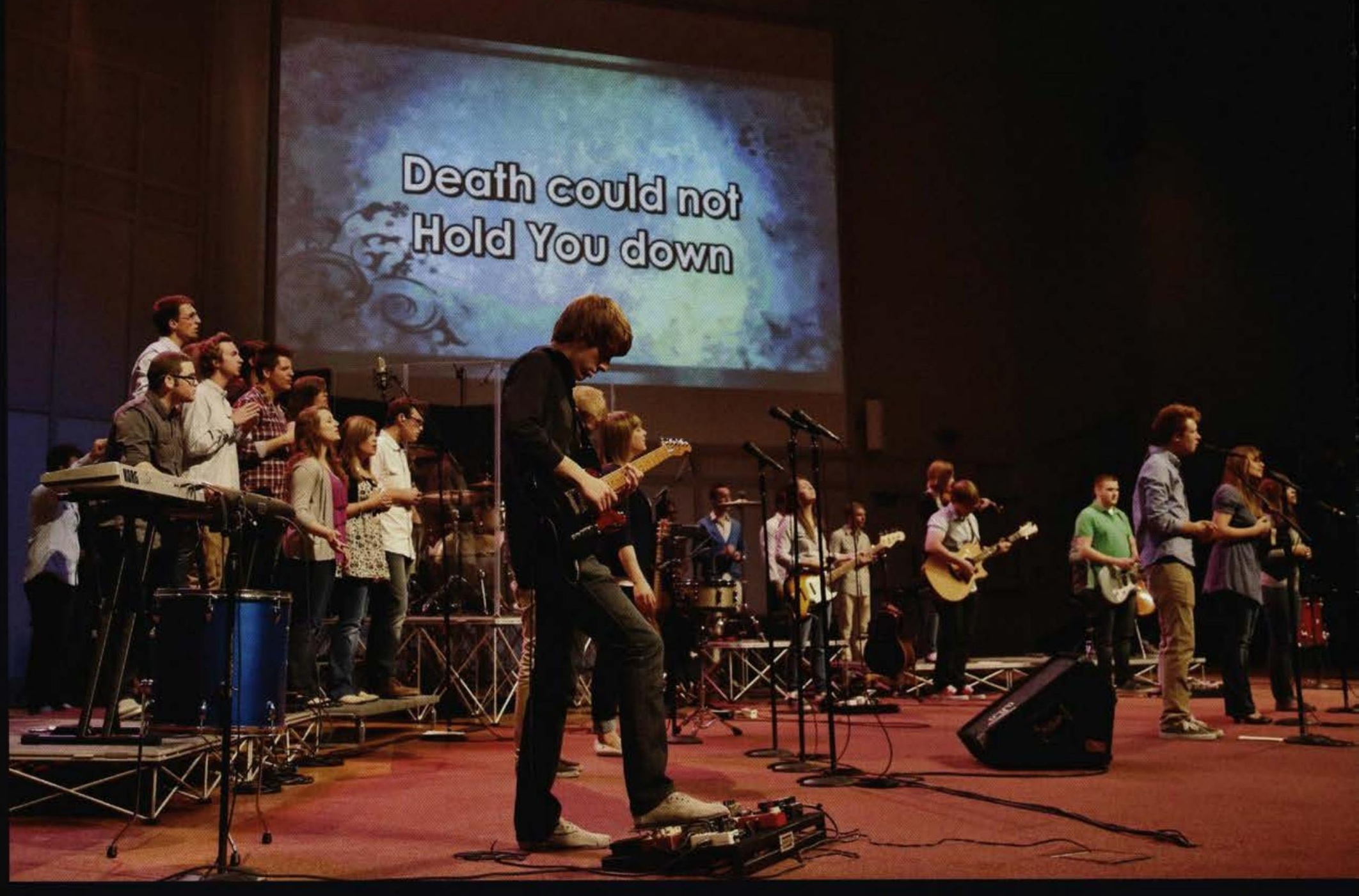

$\theta$ Dedarville University's main touring team is HeartSong. HeartSong is a music group comprised of three teams: the orange team, the green team, and the blue team. A spin-off of HeartSong is HeartSong Generation, also broken down into two smaller groups: the red team and the yellow team. The HeartSong groups blend music, Scripture, and life stories under the leadership of Jim Cato. The HeartSong teams travel constantly during the year, visiting churches on weekends during the semester. In the summer, HeartSong travels to camps throughout the United States, ministering through music to the camps. Team members stay in the homes of church members and have the opportunity to minister through their music and also through their personal interactions with the congregation. HeartSong Generation focuses their ministry more on students and on the youth, the "Next Generation." The music and content of HeartSong Generation's worship ministry is tailored more to a younger crowd, equipping them for service for Christ. This year, the HeartSong groups released their eighth album, entitled "HeartSong Live." The album was available through Cedarville's bookstore and through iTunes. To help promote their latest release, the HeartSong teams joined together in a chapel service. Jim Cato took a brief moment to encourage students to "let go of everything but God," providing a personal example of his own father's death and release of worldly pursuits. Through this special chapel service, Cedarville students saw the ministry of HeartSong in action. As the teams headed off for their summer engagements, students were asked to pray for everyone that would come into contact with the touring teams. 


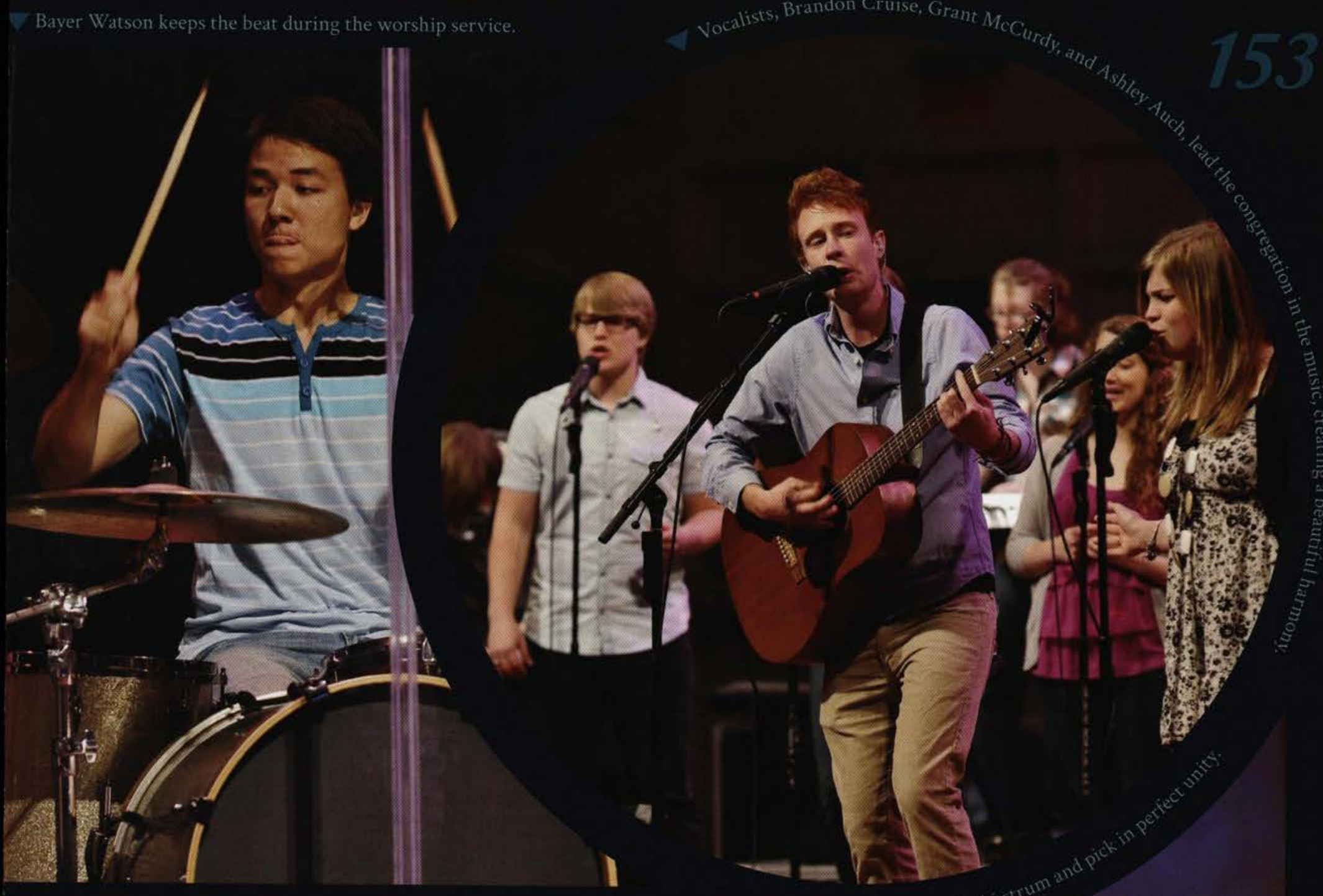




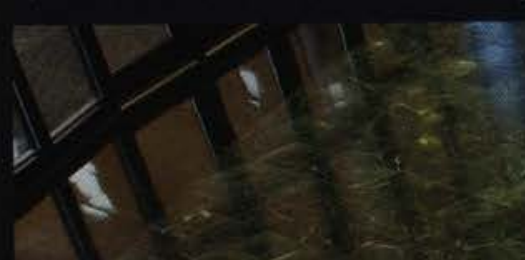

$\frac{5}{2} 5 x-2 y$

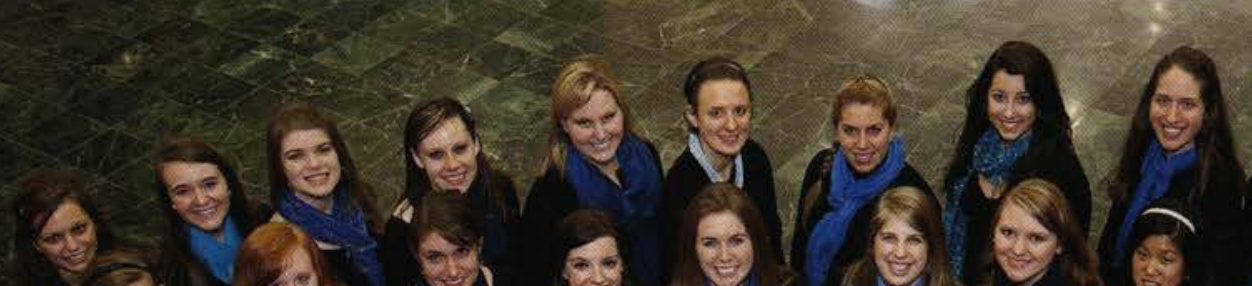

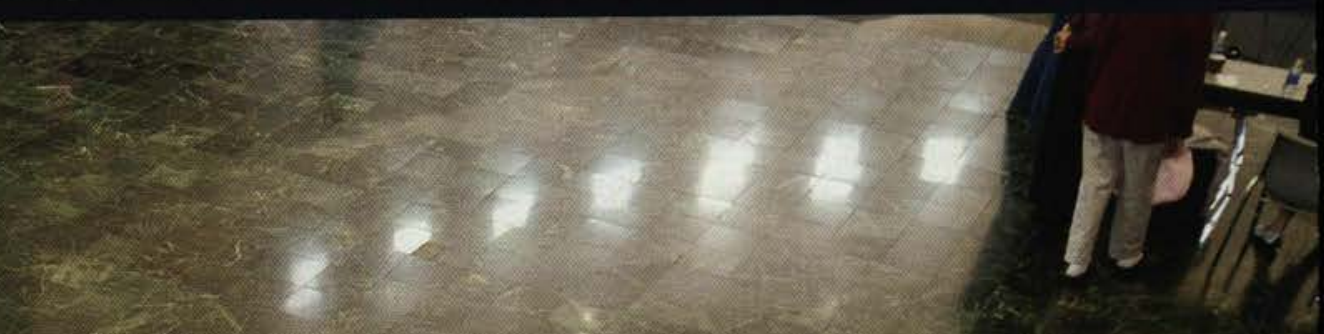
$3+2003$

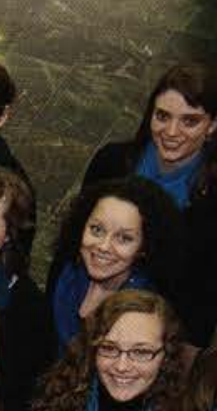

- 5,2 . - 5 ?

$\infty$
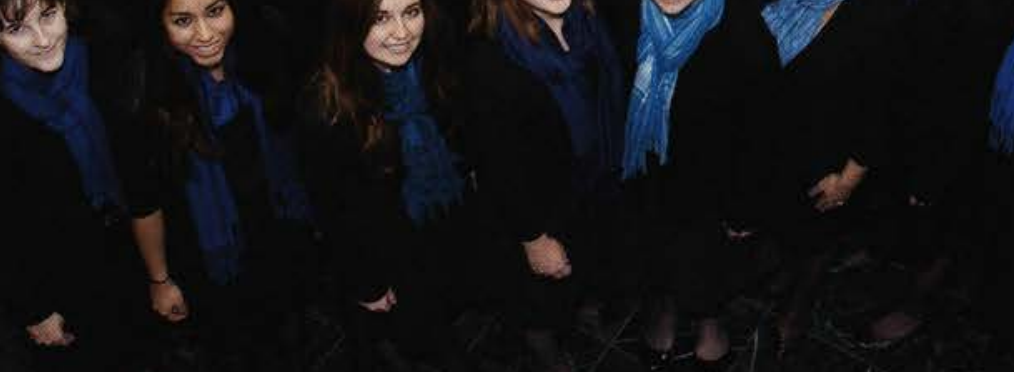


\section{Musical Groups}

Groups tike One Voice, Symphonic Band, and Men's Choir allow many students to usetheir mustical talents.

The voices of One Voice back up Alison Patton as she takes the melody.

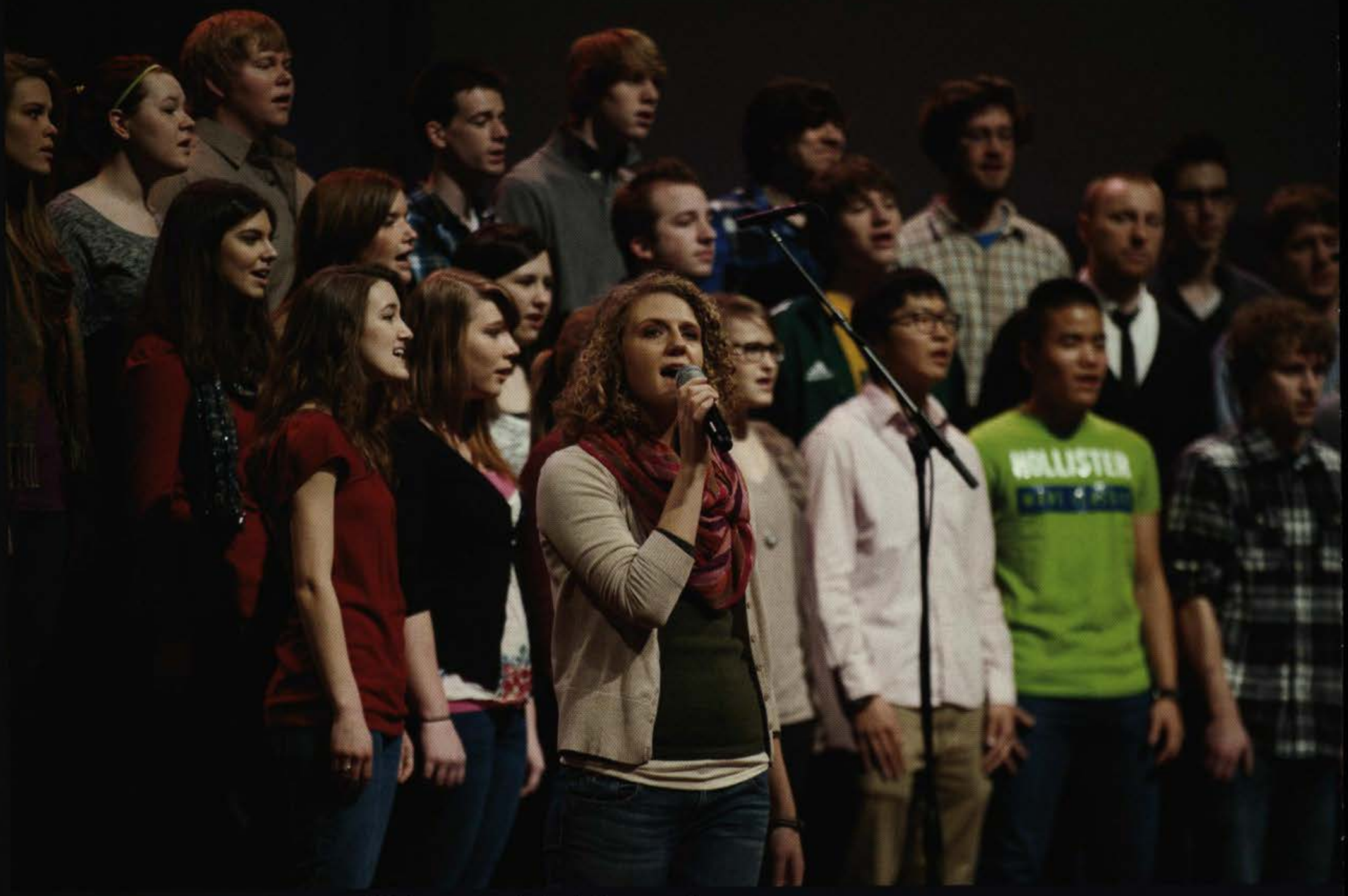

The members of the Symphonic Band fill the stage, ready for their next performance

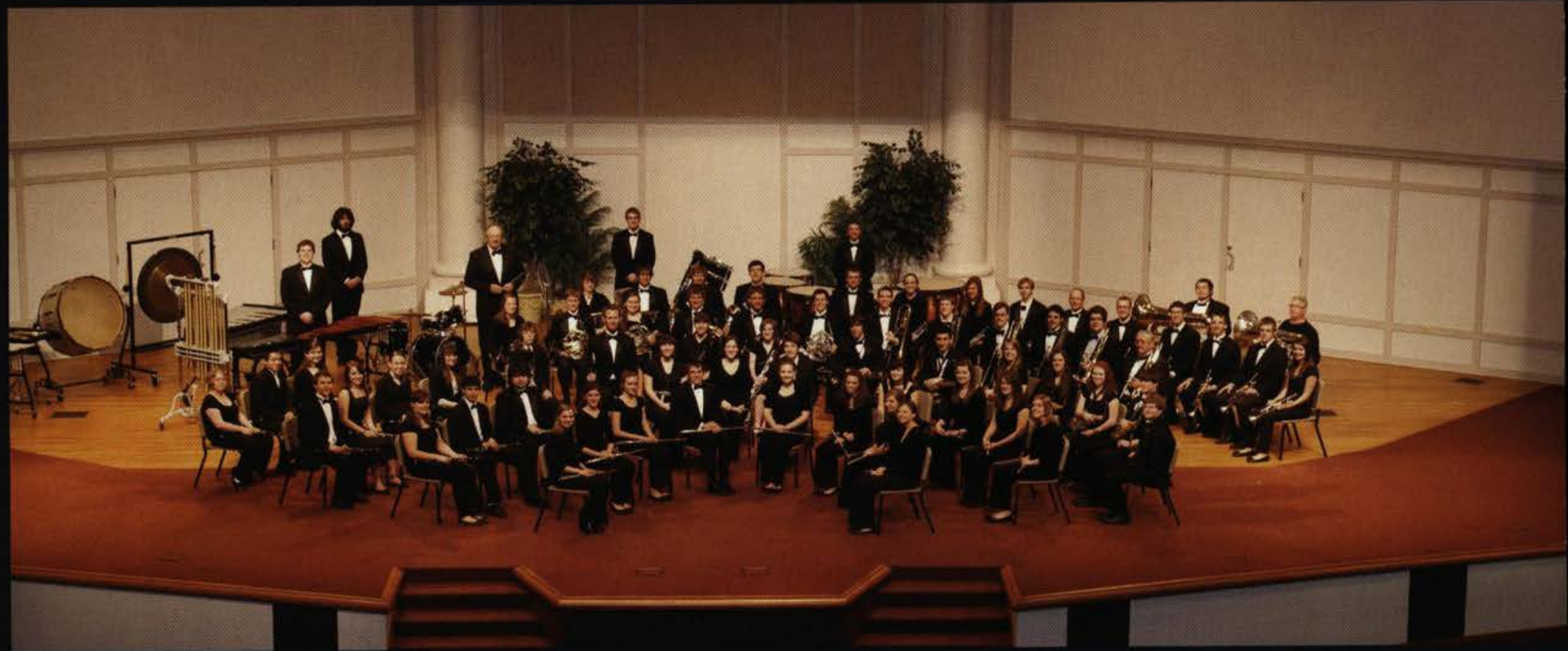




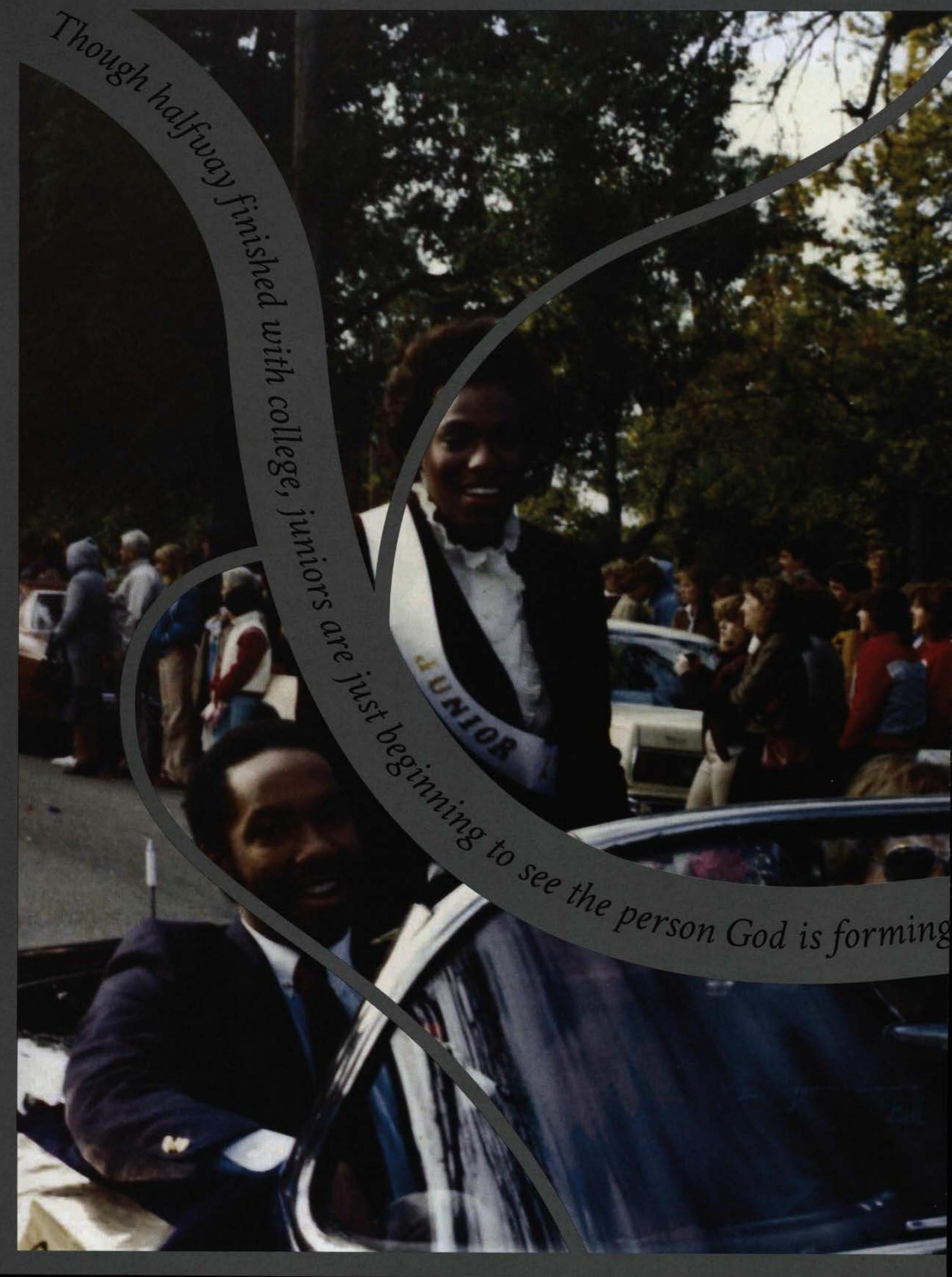




\section{Juniors}

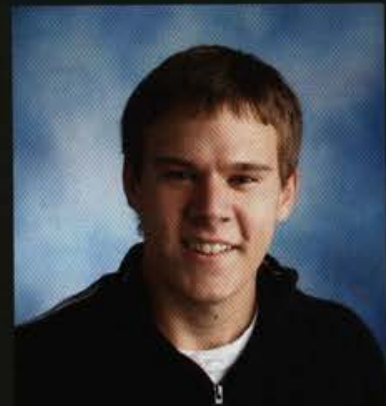

Eric Aho

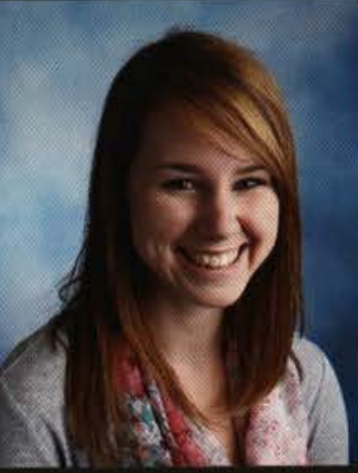

Sarah Arn

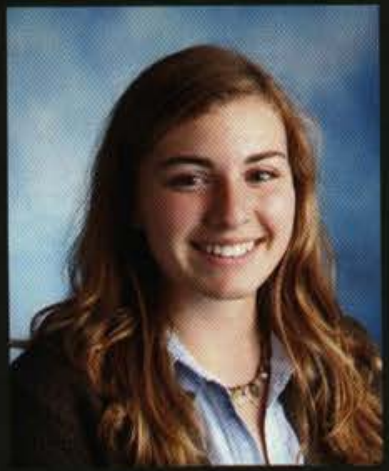

Moriah Bach

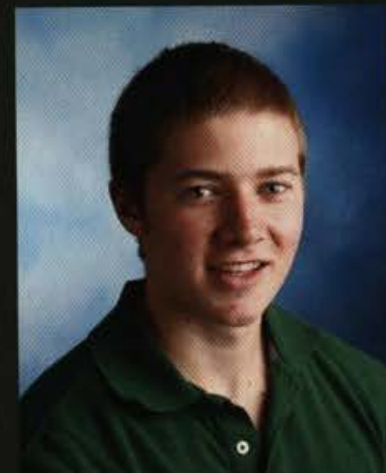

Daniel Adriansen

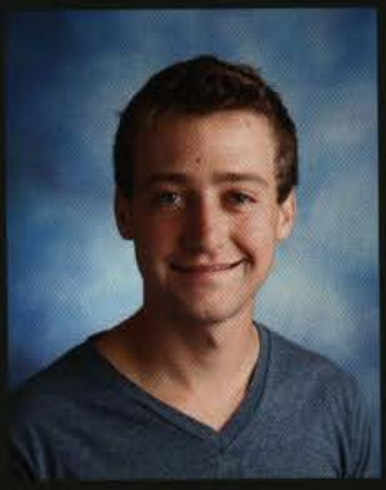

Caleb Alley

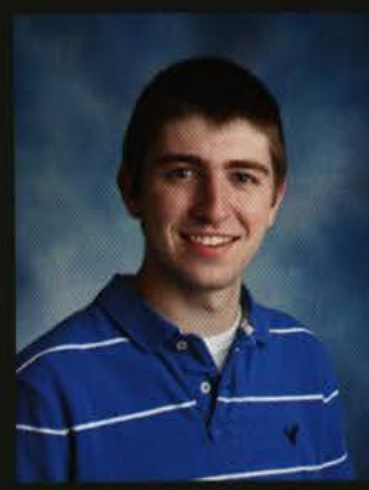

Joshus Arnold

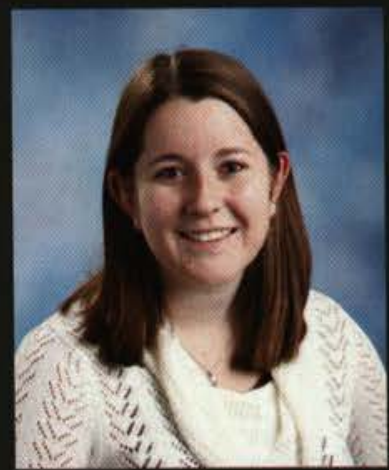

Alexandra Balkus

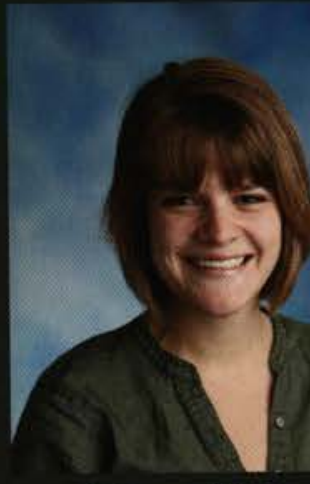

Brianna Ahlgrim

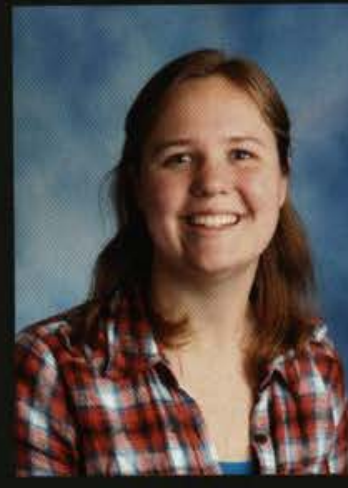

Malia Amling

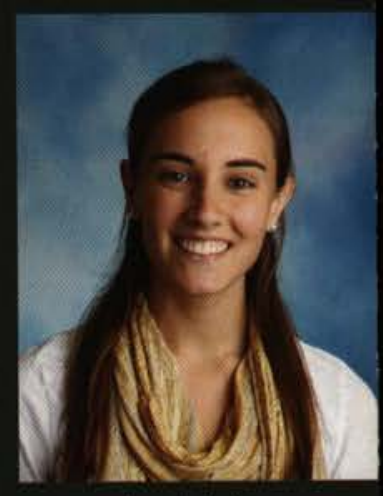

Jamie Arkins

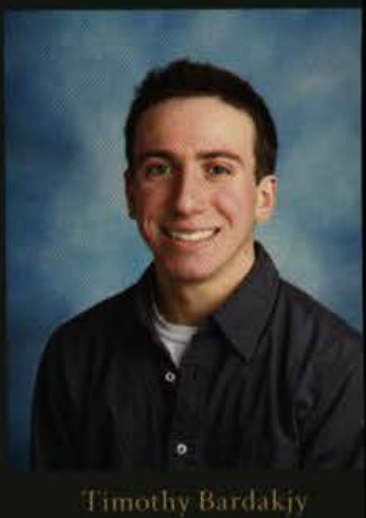




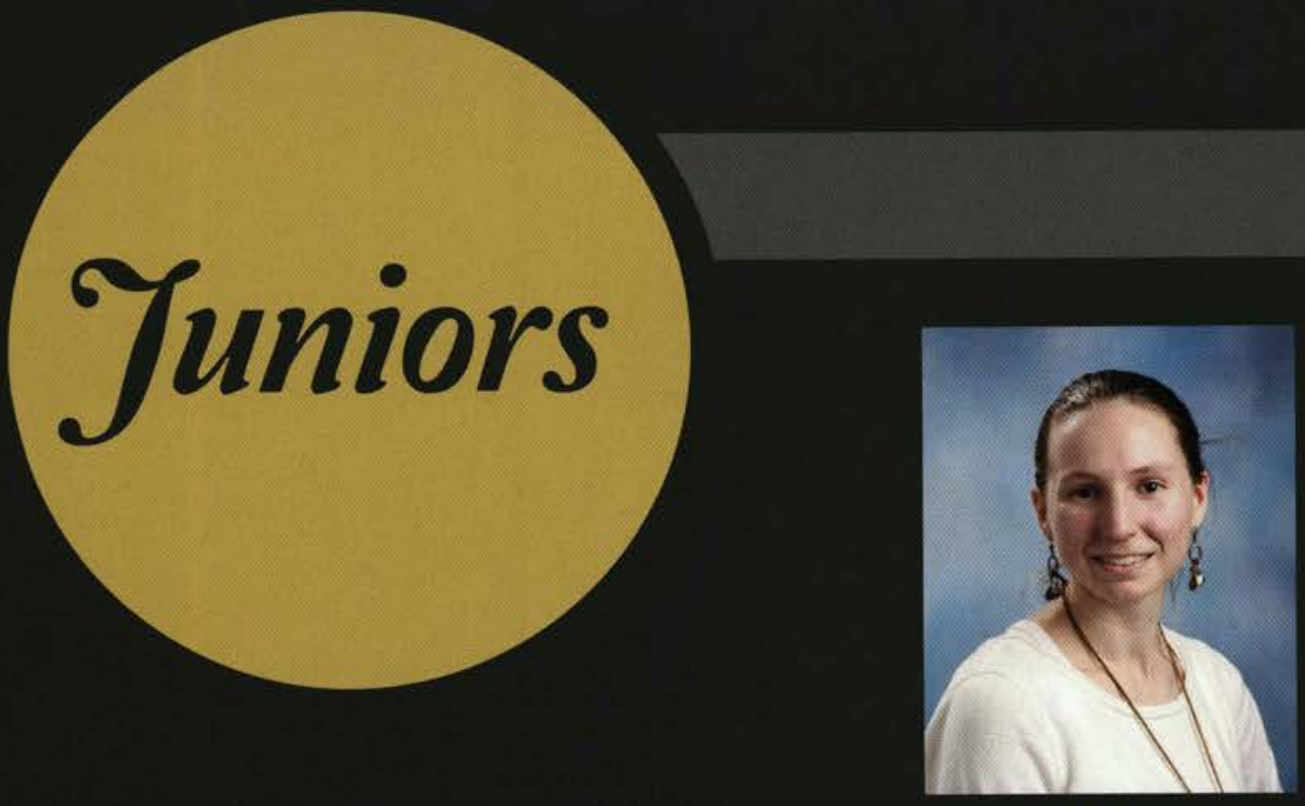

Rachel Burton

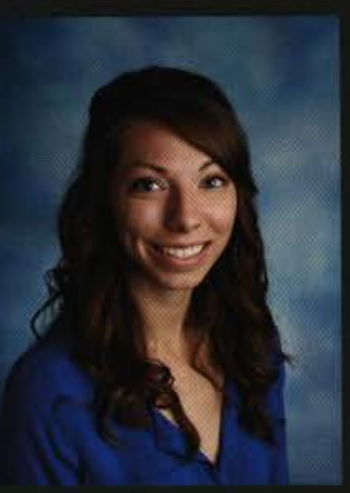

Chelsea Castillo

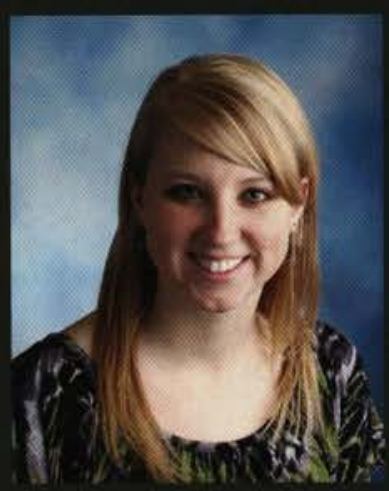

Amy Chase

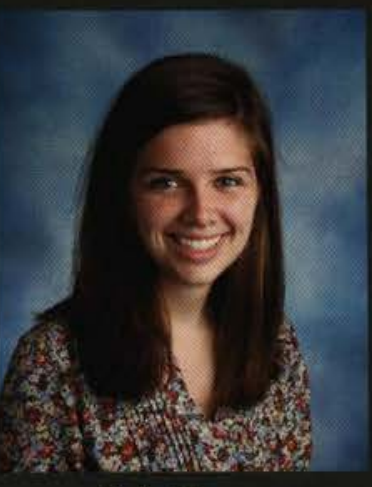

Kelly Classen

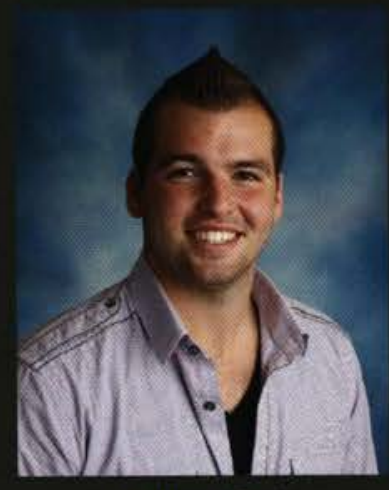

William Bush

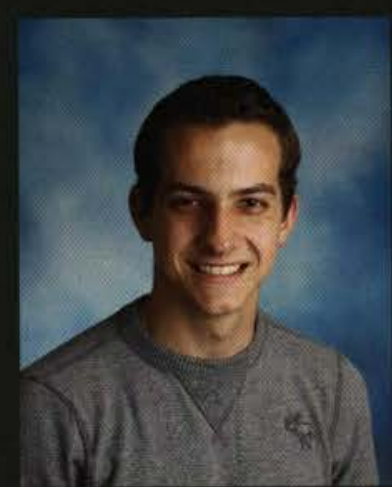

Brian Cates

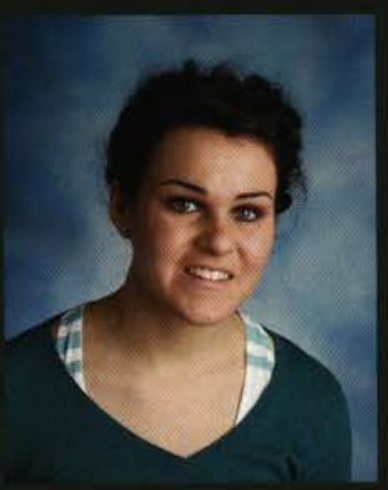

Julie Christiansen

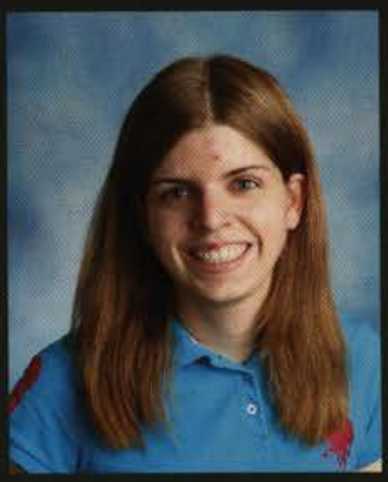

Hannah Cochran

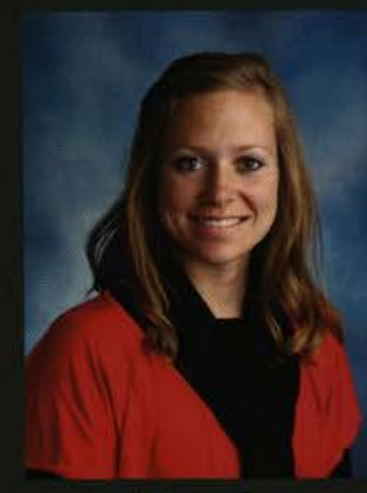

Dianna Cass

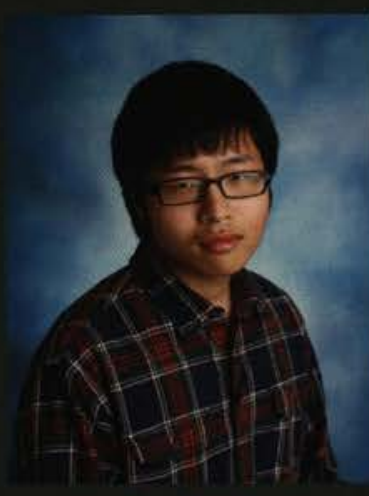

Eunho Cha

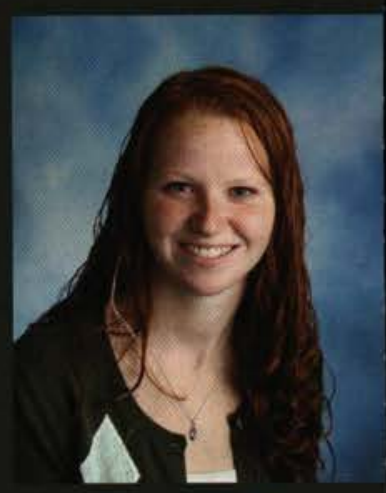

Lauren Clark

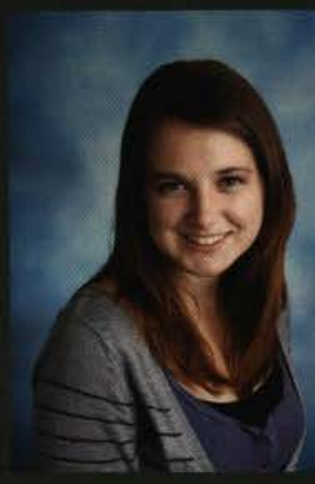

Juliana Goleman 


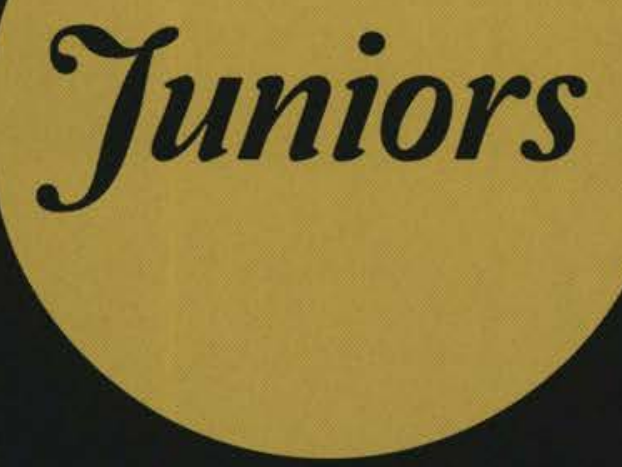

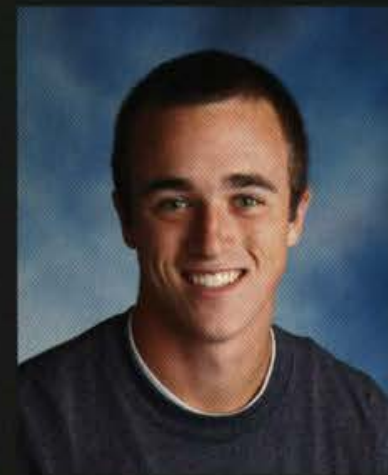

Stephen Ellis

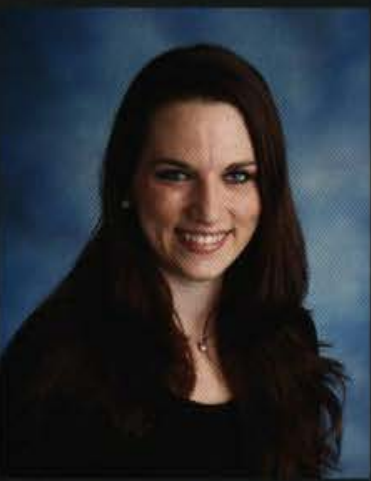

Allison Esbenshade

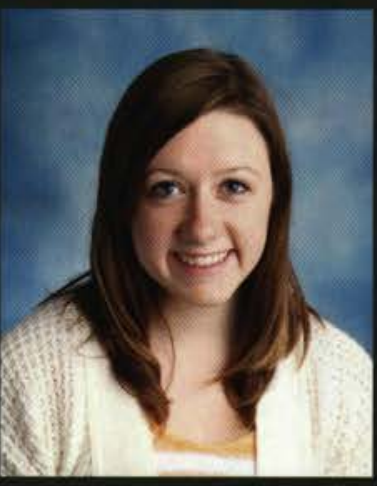

Hannah Fleming

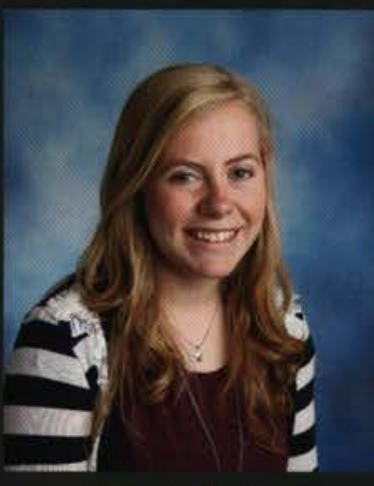

Nikalee Foster

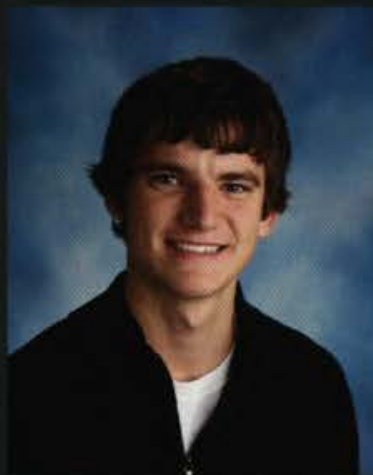

Caleb Enderle

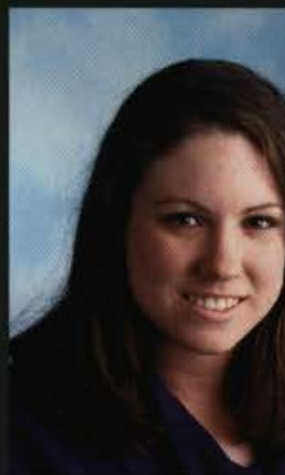

Stacia Firebaugb

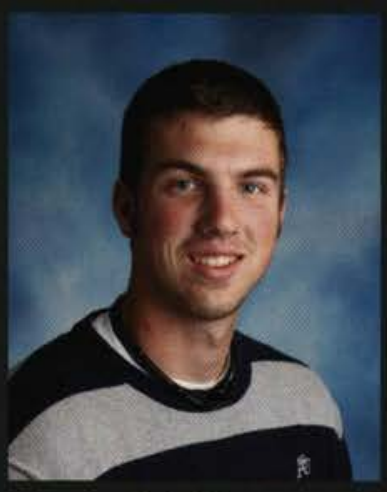

Eric Foley

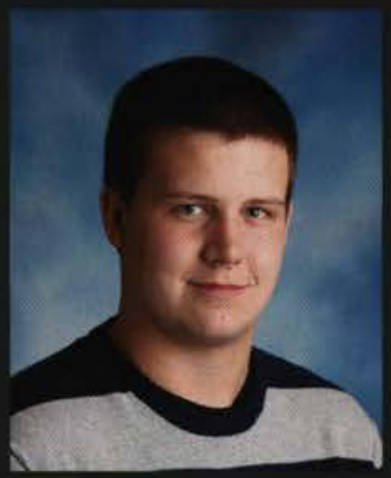

Zachary Franklin

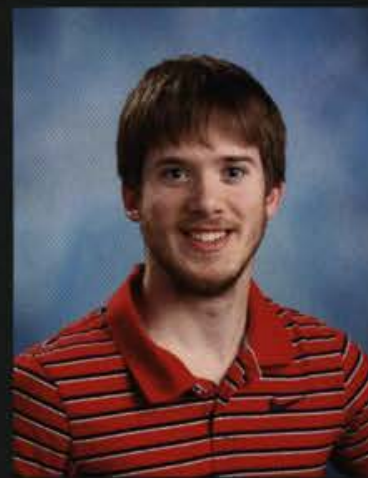

Clifton Ervin

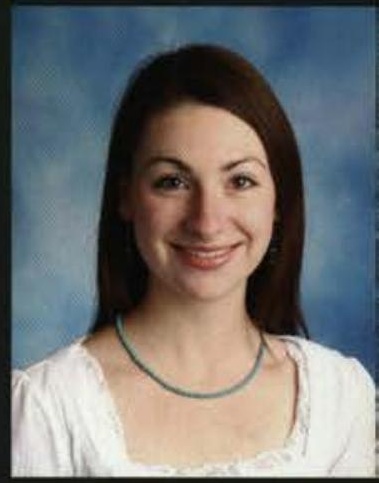

Anna Fitzpatricks

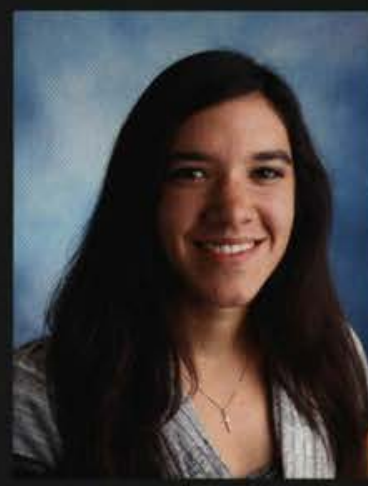

Rachel Fonseca

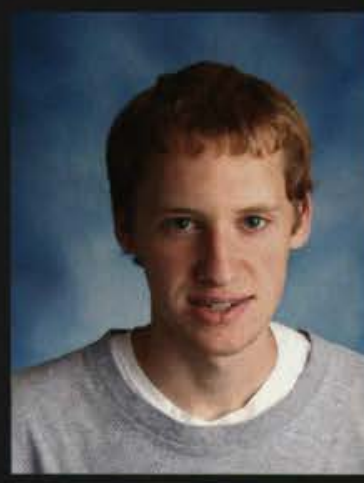

Samuel Freda 


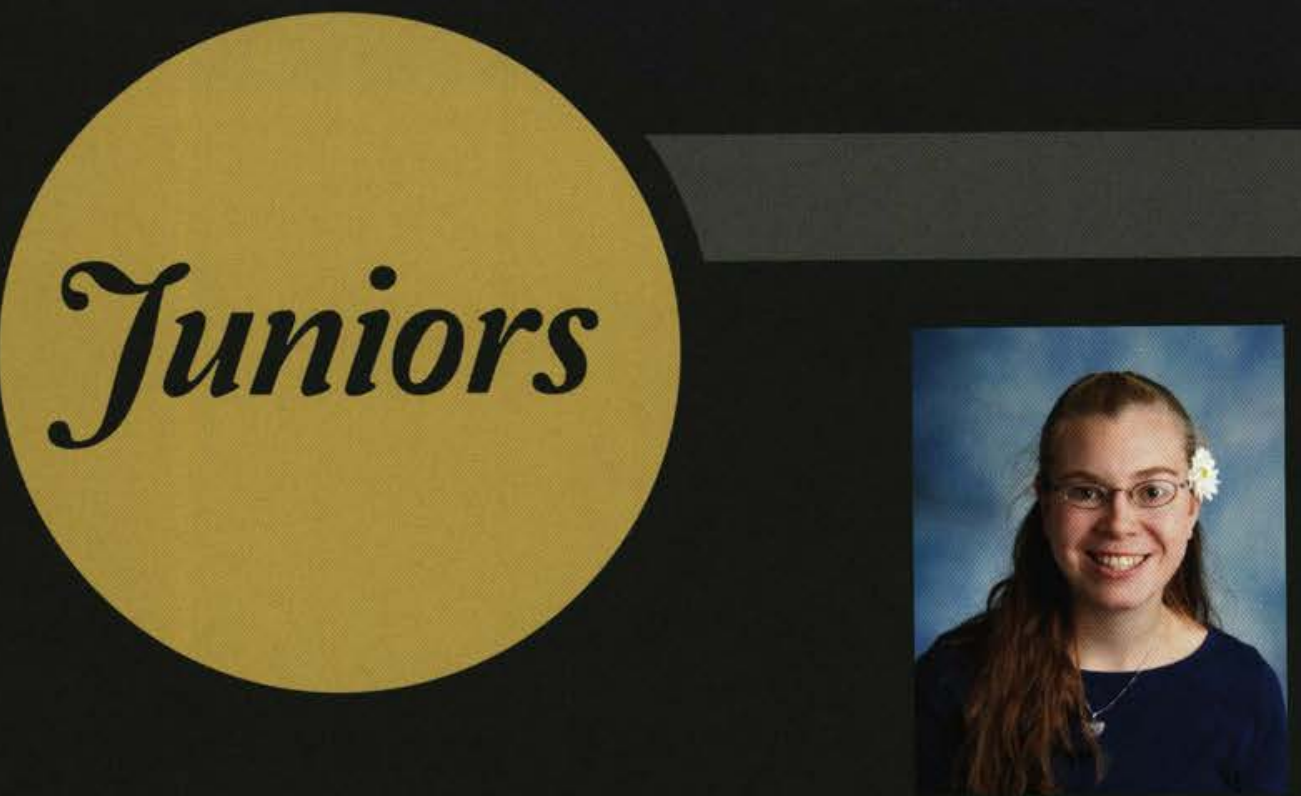

Robin Hrdina

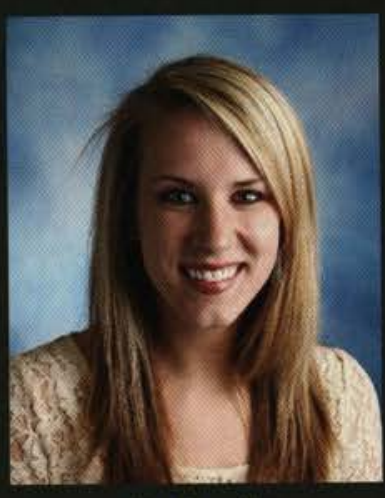

Allie Hundley

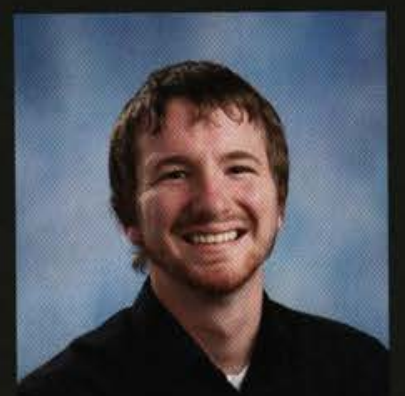

Martin Jellison

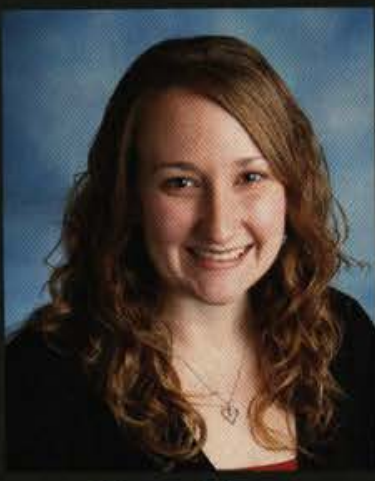

Kirsten Johnson

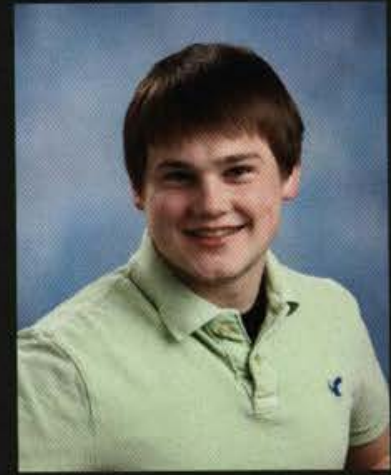

Joshua Hric

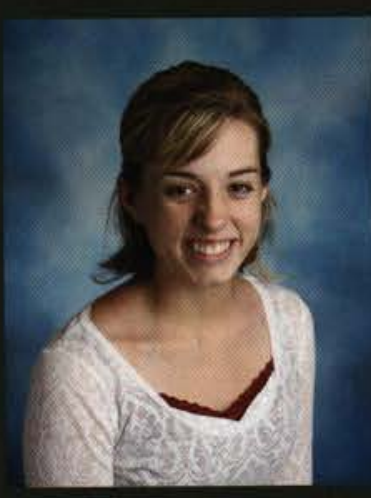

Rebekah Isaac

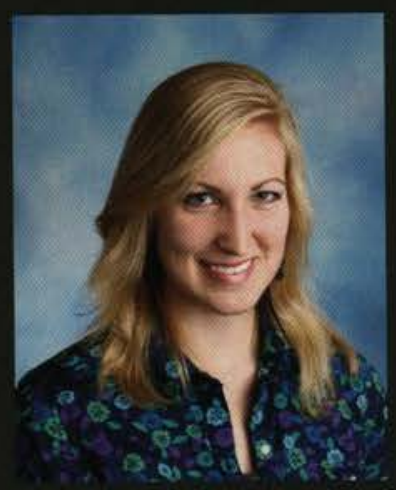

Brooke Johnson

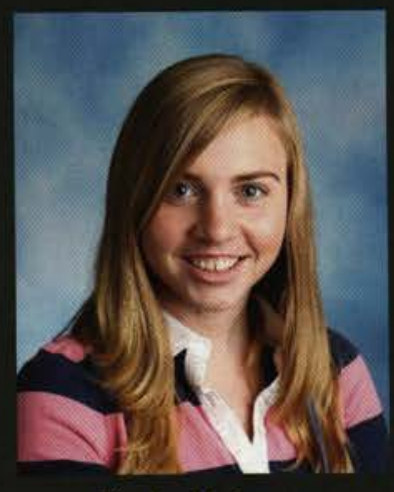

Rachael Johnson

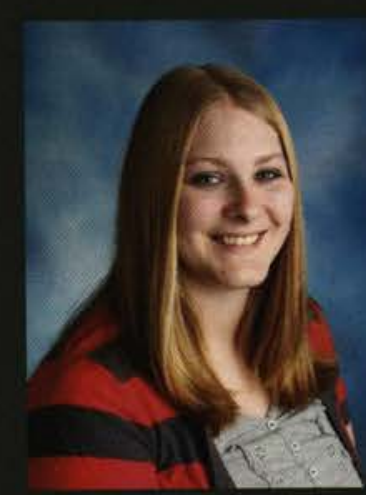

Roxanne Hulbert

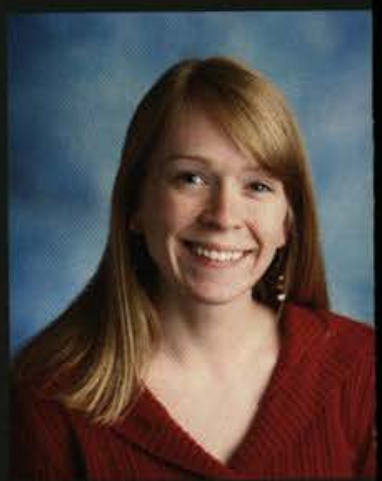

Megan Jahnke

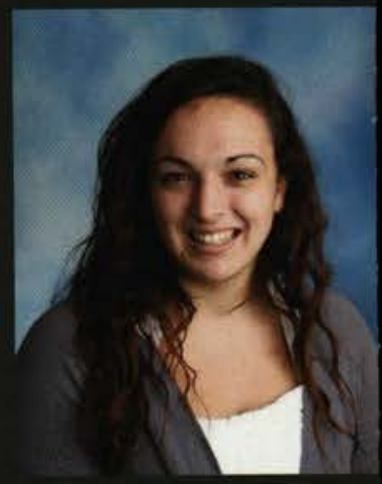

Chloe Johnson

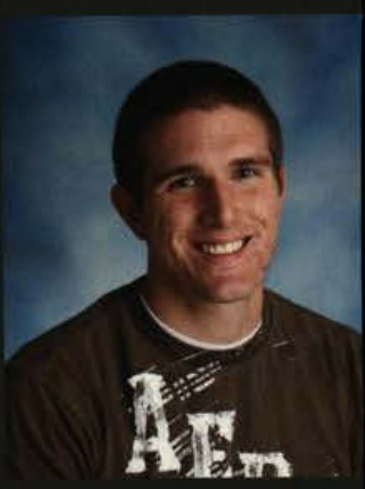




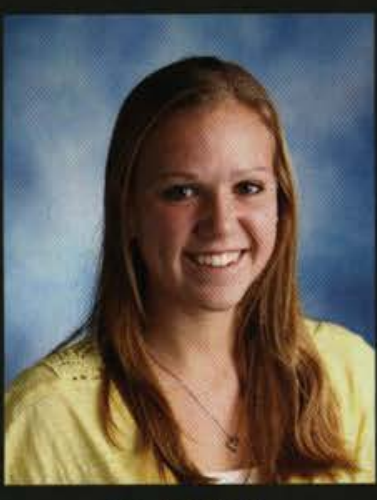

Rachel Kark

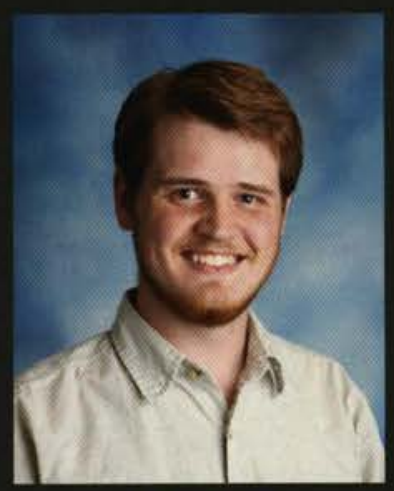

Jeffrey Kee

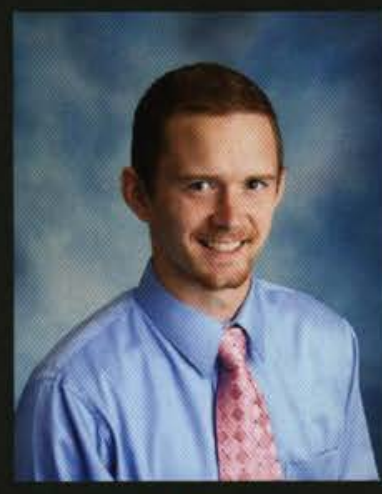

David Kemmenøe

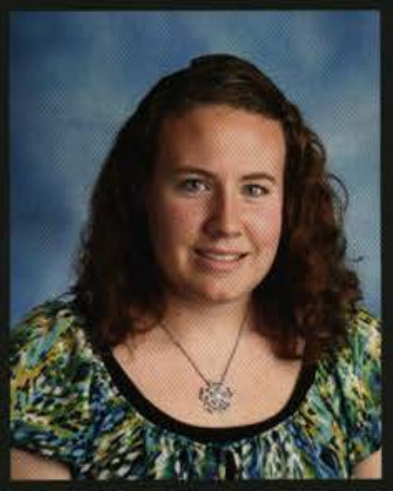

Caroline Kostreva

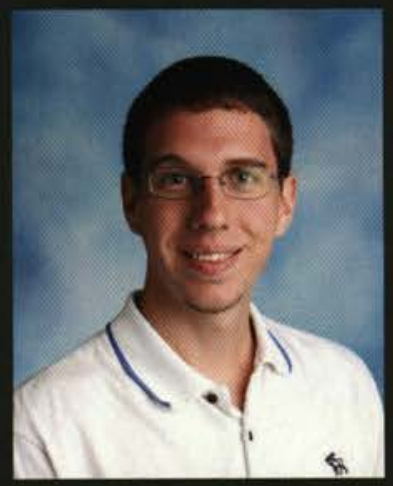

Tieg Laskowske

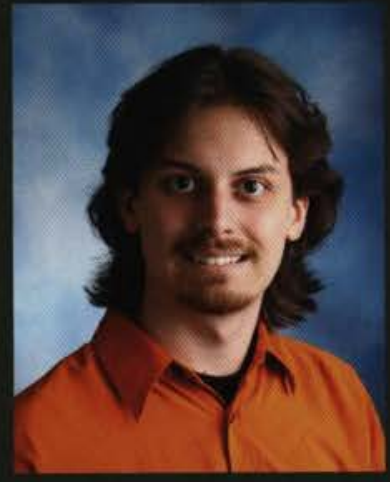

Joseph Lamy

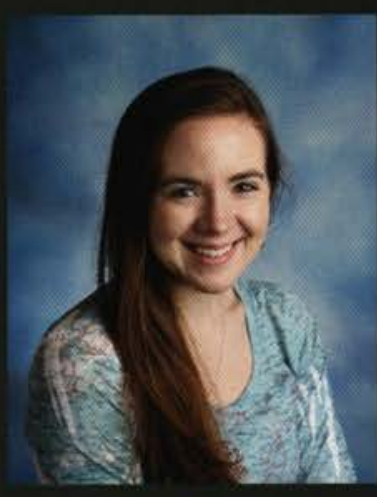

Heather Kirkpatrick

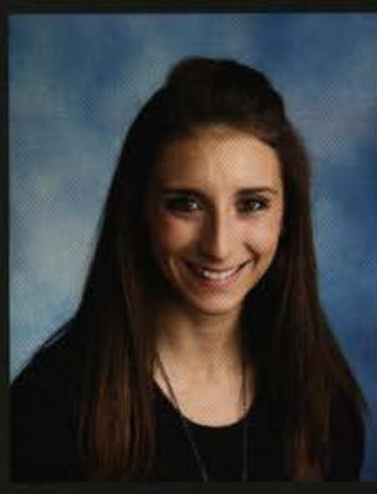

Christine Krapohd

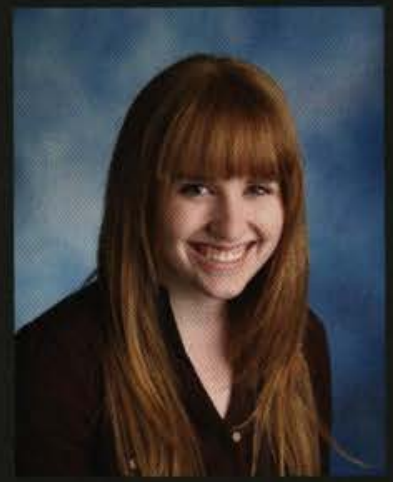

Jemna Lawhead

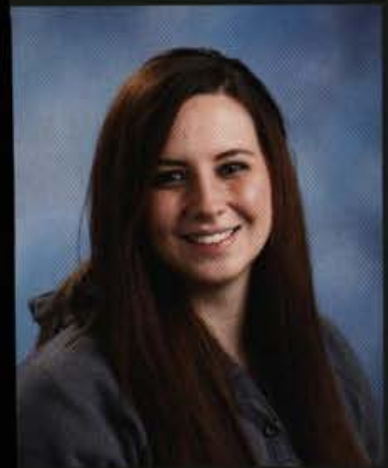

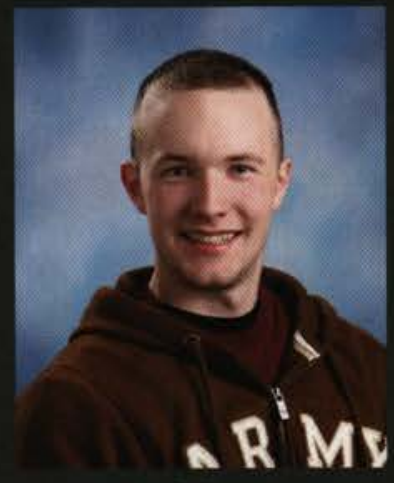

Jacob Layer

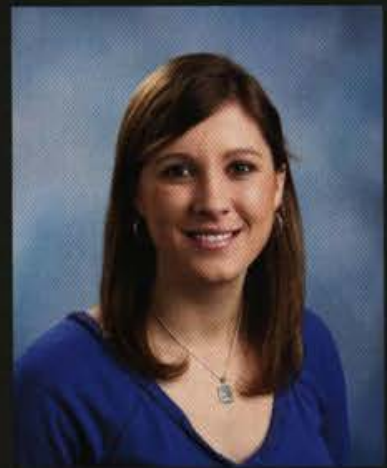

Elizabeth Lears

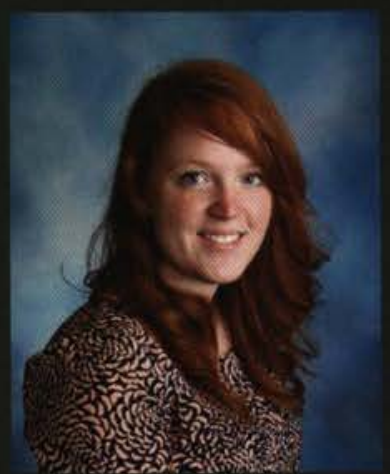

Hilary Leese 


\section{Yuniors}

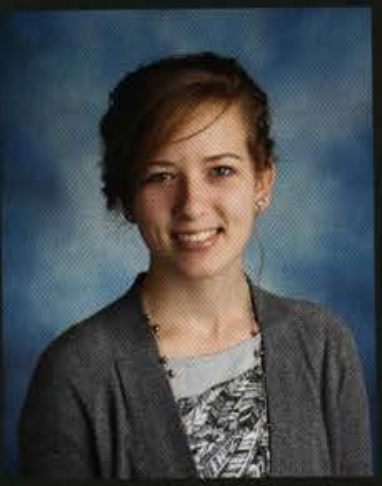

Natalie Linder

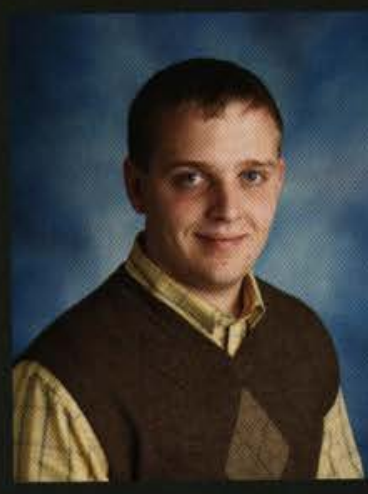

Alan Lockwood

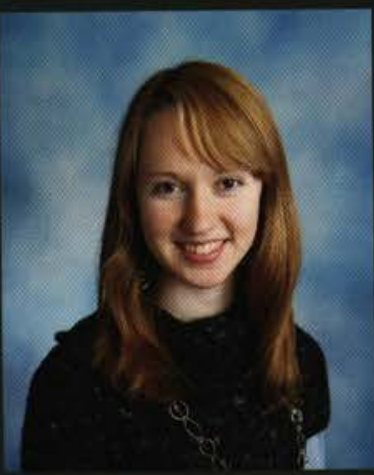

Rachel Lowrance

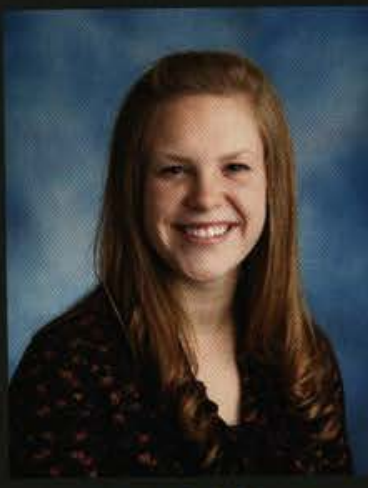

Meredith LePage

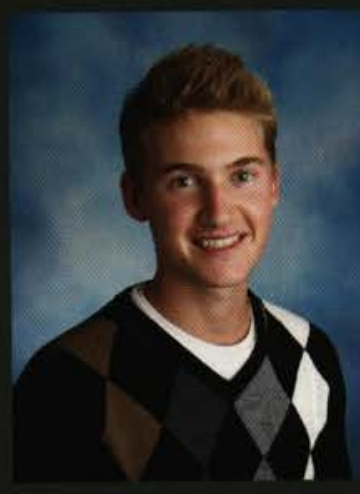

Kenneth Littrell

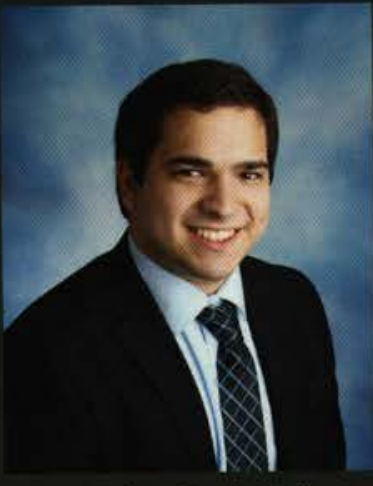

Zachary Lorenzini

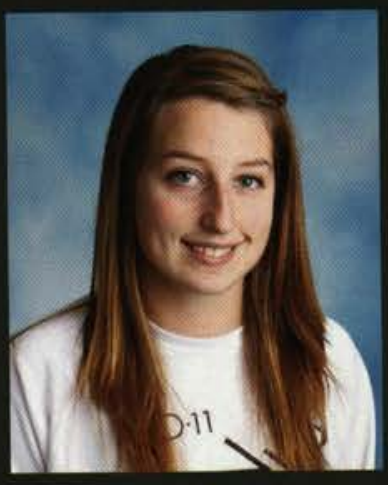

Amelia Lyons

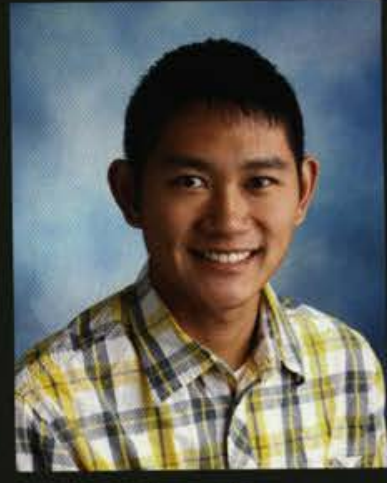

Stuart Li

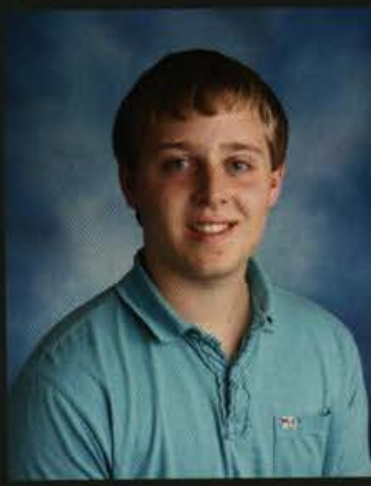

Adam Lockwood

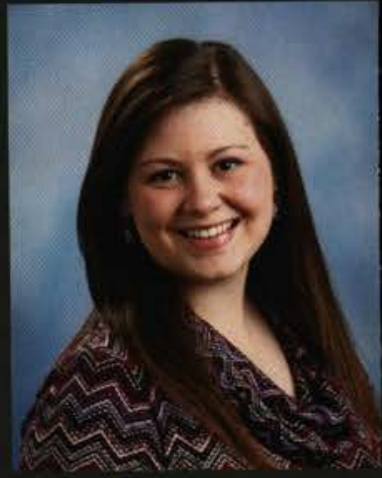

Megan Lowe

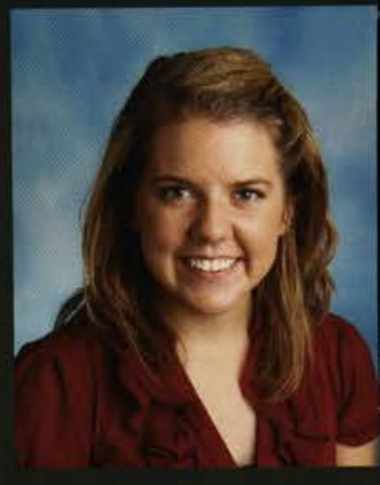

Laura Martin 


\section{Juniors}
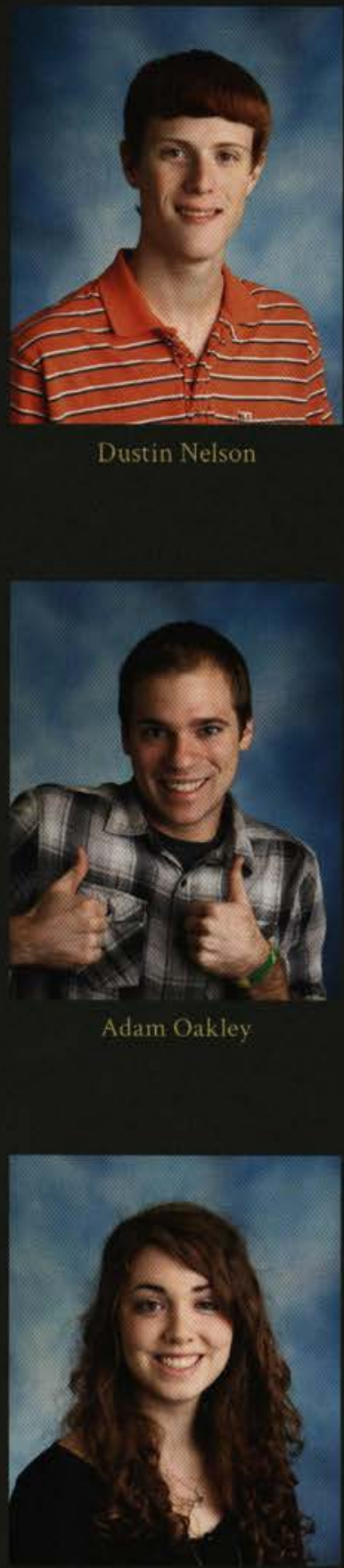

Elizabeth Patterson

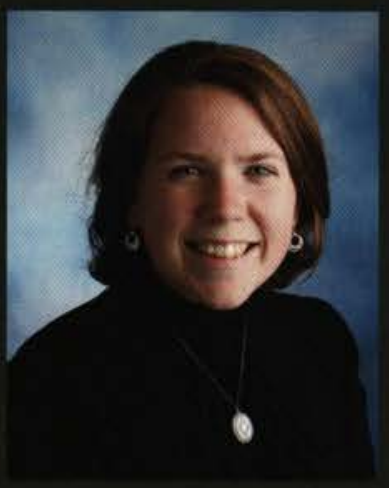

Adrienne Nesbitt

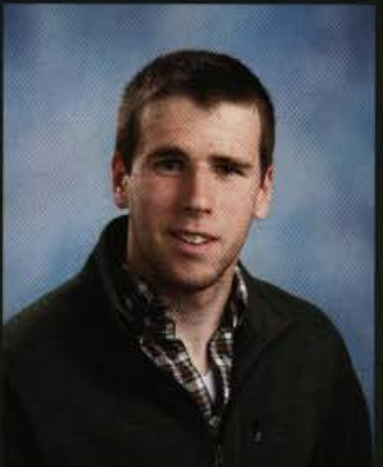

Andrew Orton

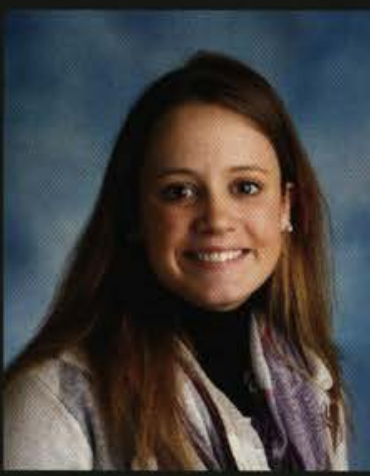

Sandra Patton

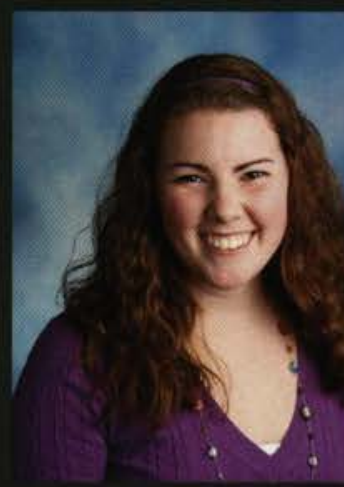

Laura Nagelkirk

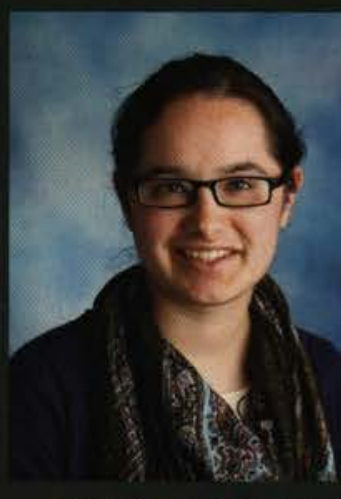

DeLora Neuschwander

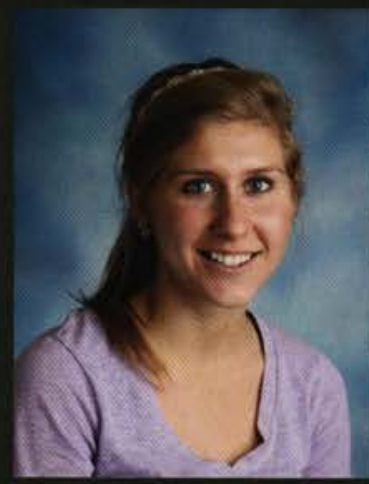

Danae Patrick

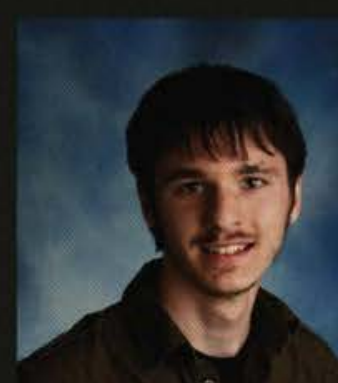

Ryan Patznick 


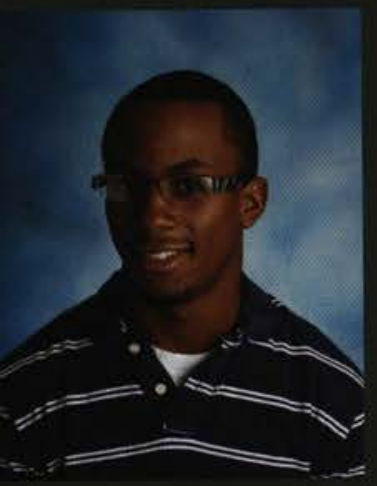

Quinton Paul

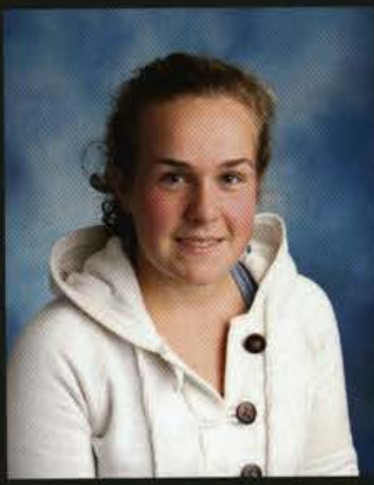

Rachel Pauling

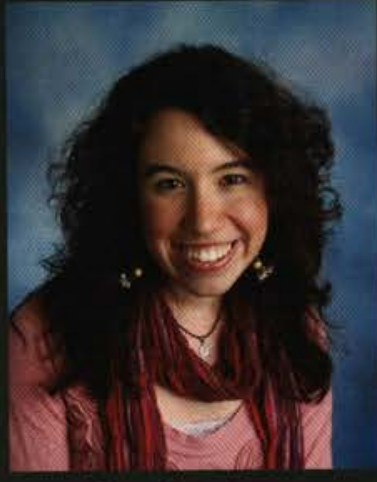

Kara Pernicano

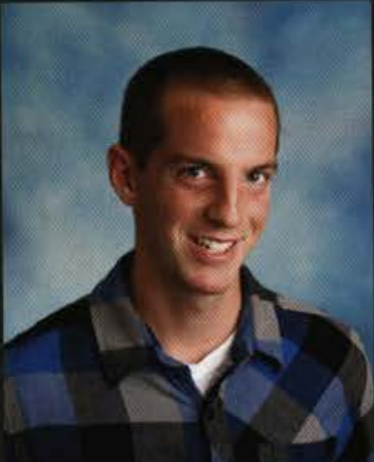

Joel Pfahler

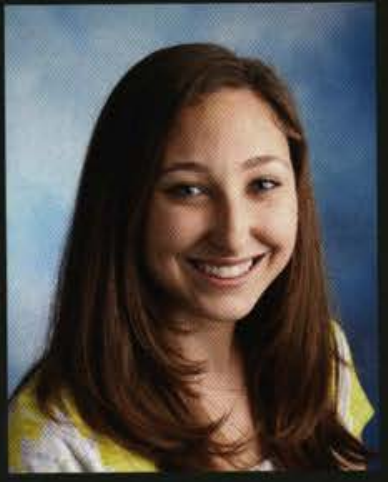

Ruthie Ray

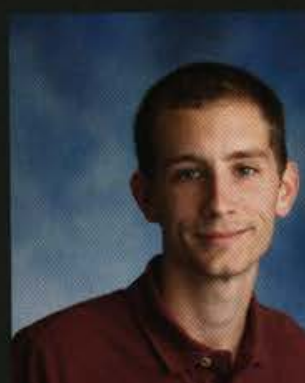

Nathan Reed

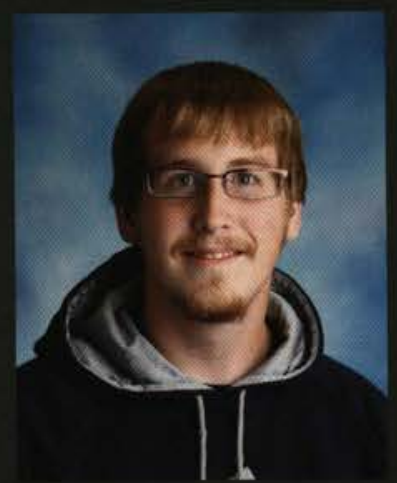

Cory Richardso:

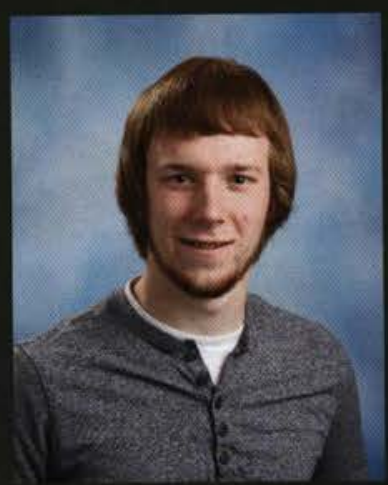

Kyle Ripperger

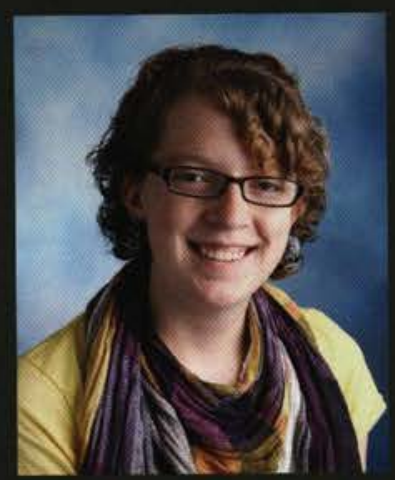

Deanna Ruman

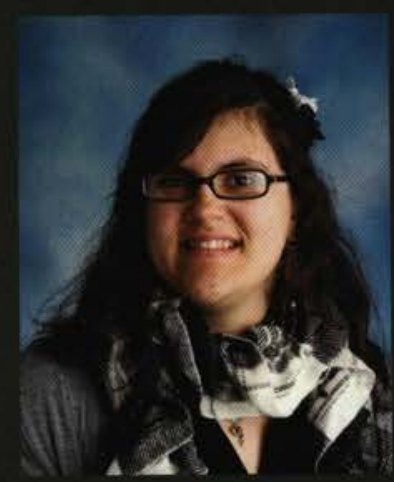

Maria Salas

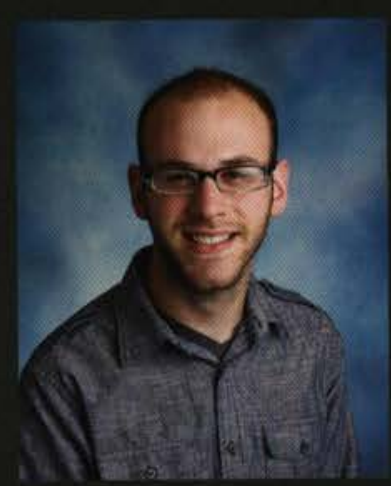

Daniel Santiso 


\section{Juniors}

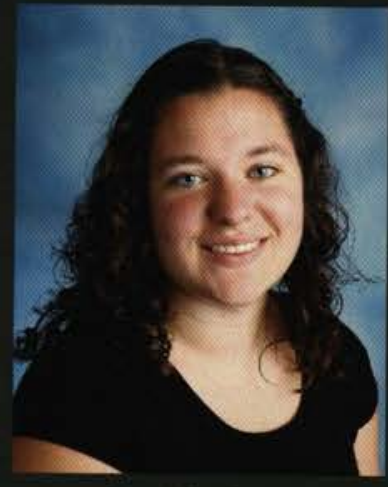

Danielle Sauer

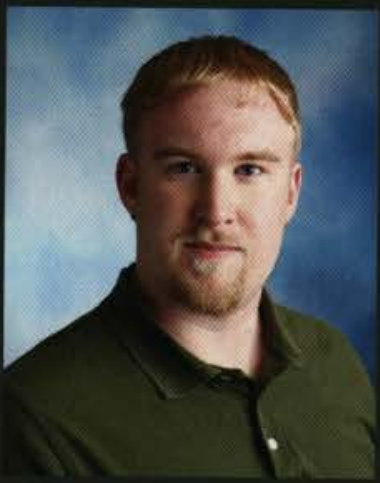

Timothy Schlabach

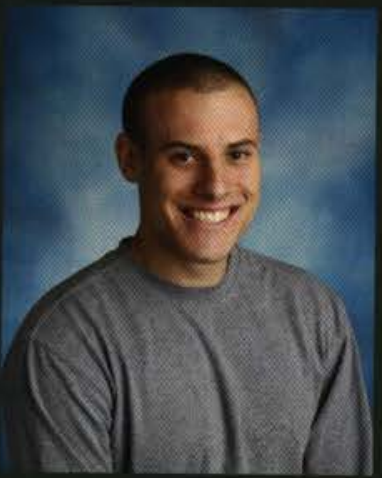

Alexander Shepherd

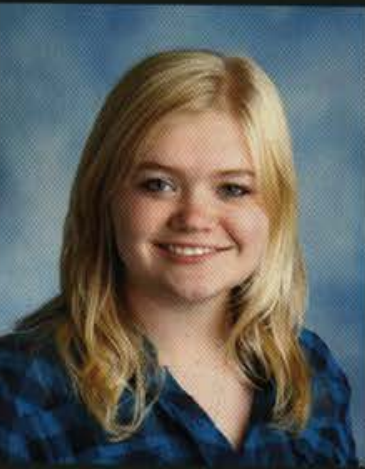

Shayla Shuck

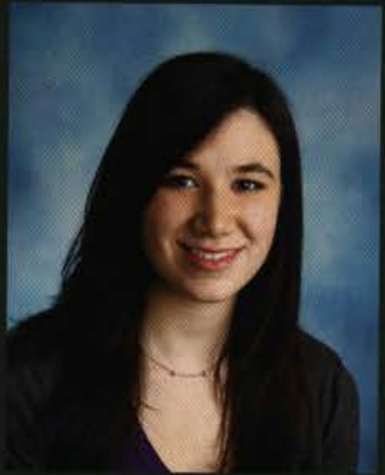

Rebecca Scarpone

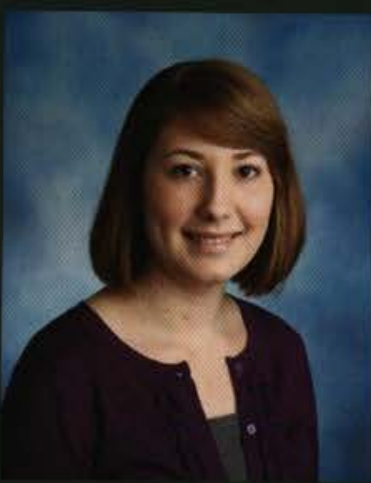

Kirsten Setzkorn

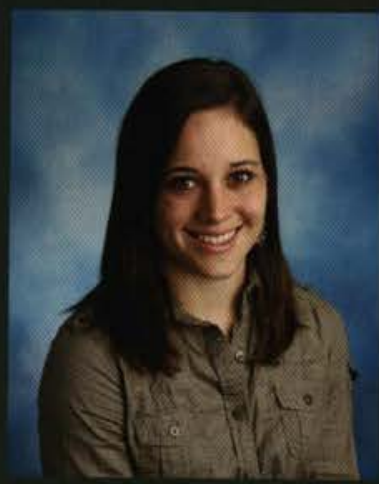

Alexandra Shiff

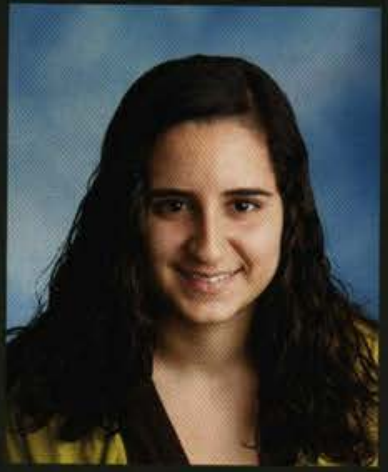

Rose Silbak

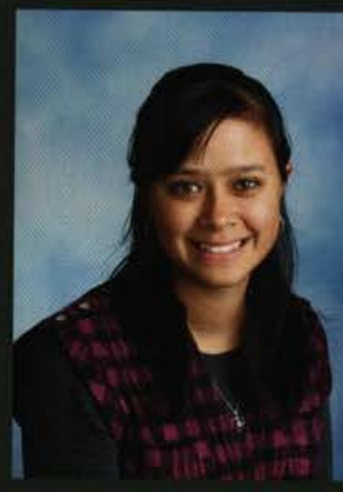

Rebekah Scarpuzzi

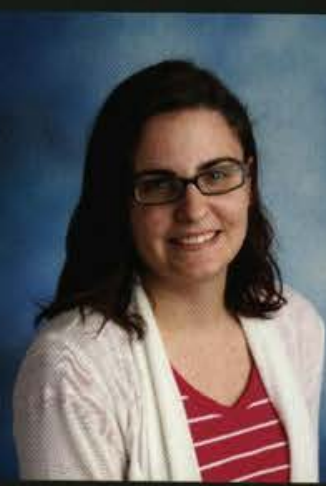

Lauren Shaw

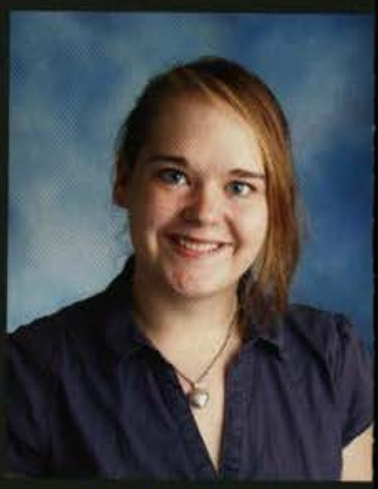

Caroline Shimeall

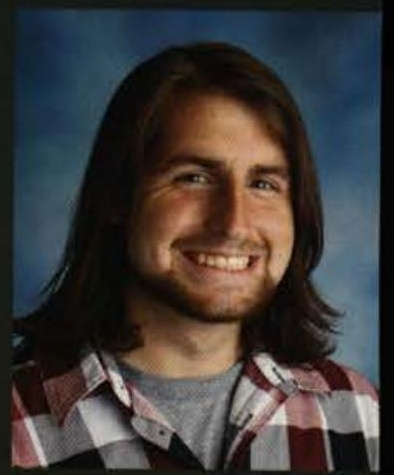

Ryan Sjoquist 


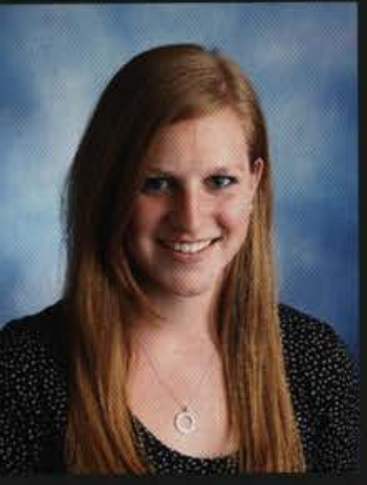

Laura Smith

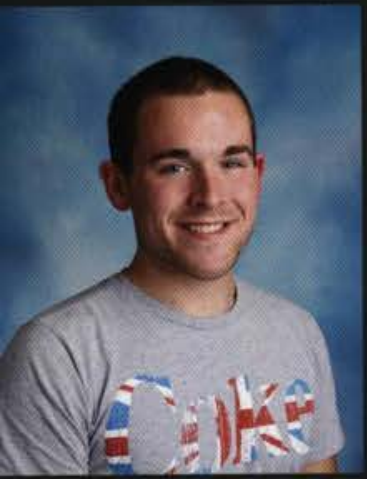

Joshua Steele

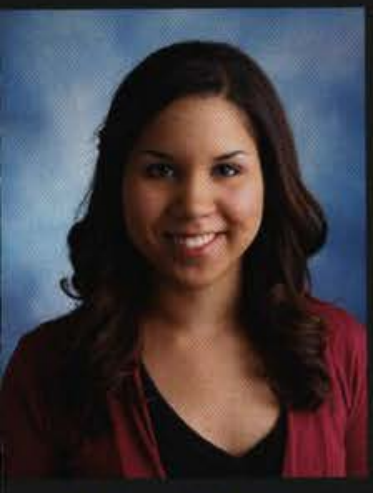

Michelle Strickland

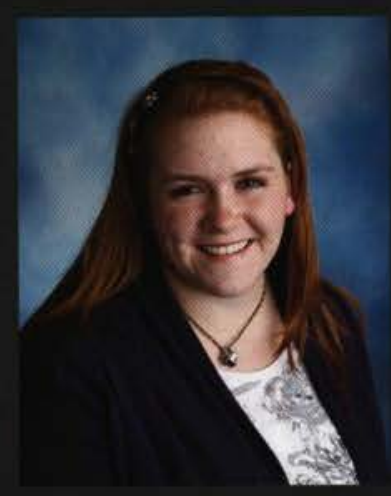

Abigail Stitzinger

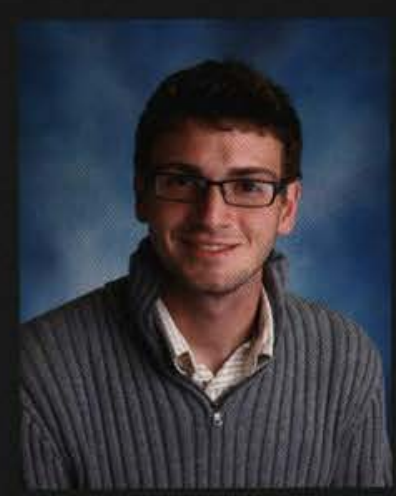

Faylor Swayze

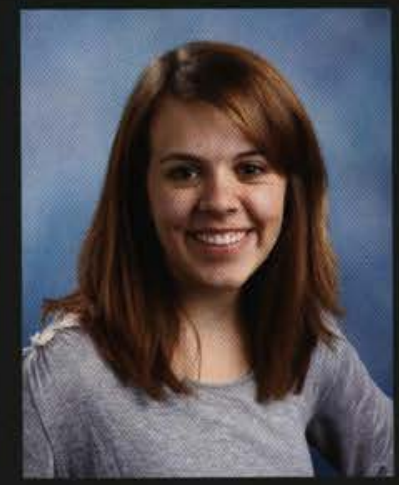

Karyn Straw

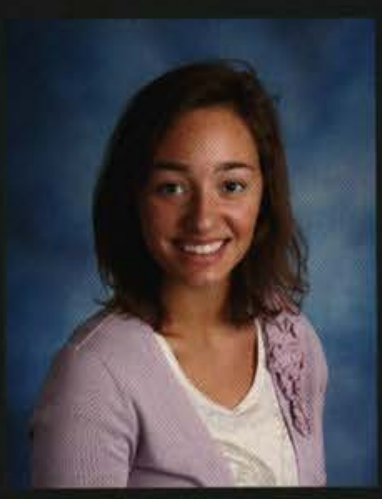

Emily Sweet

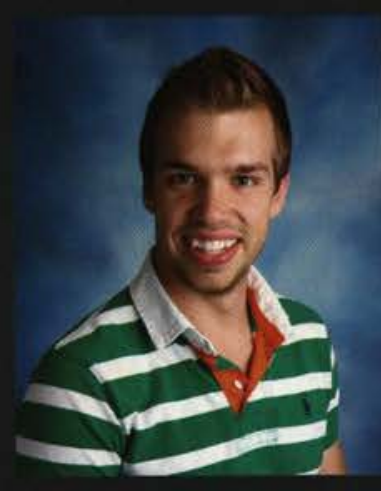

Rockwell Taylor II

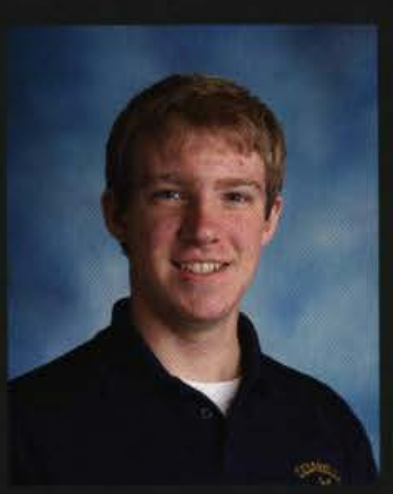

Bernardus TerreBlanche

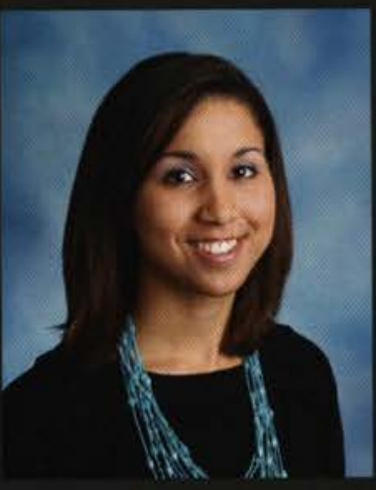

A mber Strickland

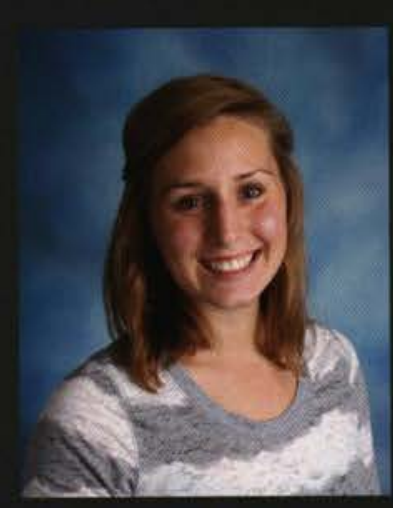

Sheila Talbott

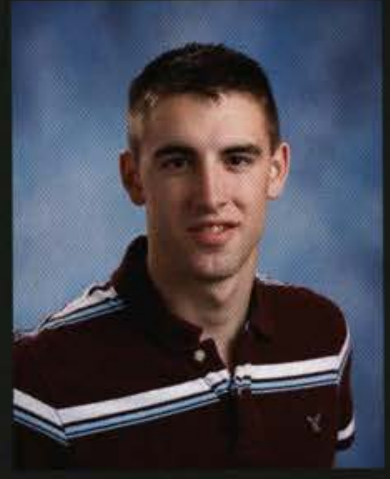

Gerrit Start

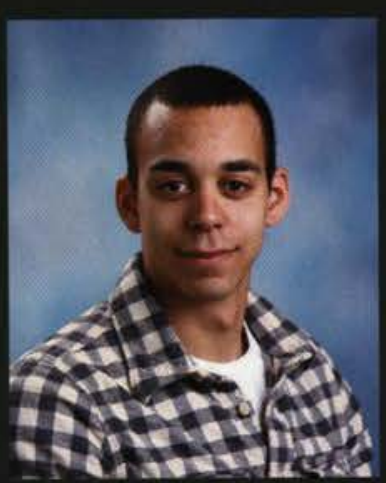

Greggory Thorpe 

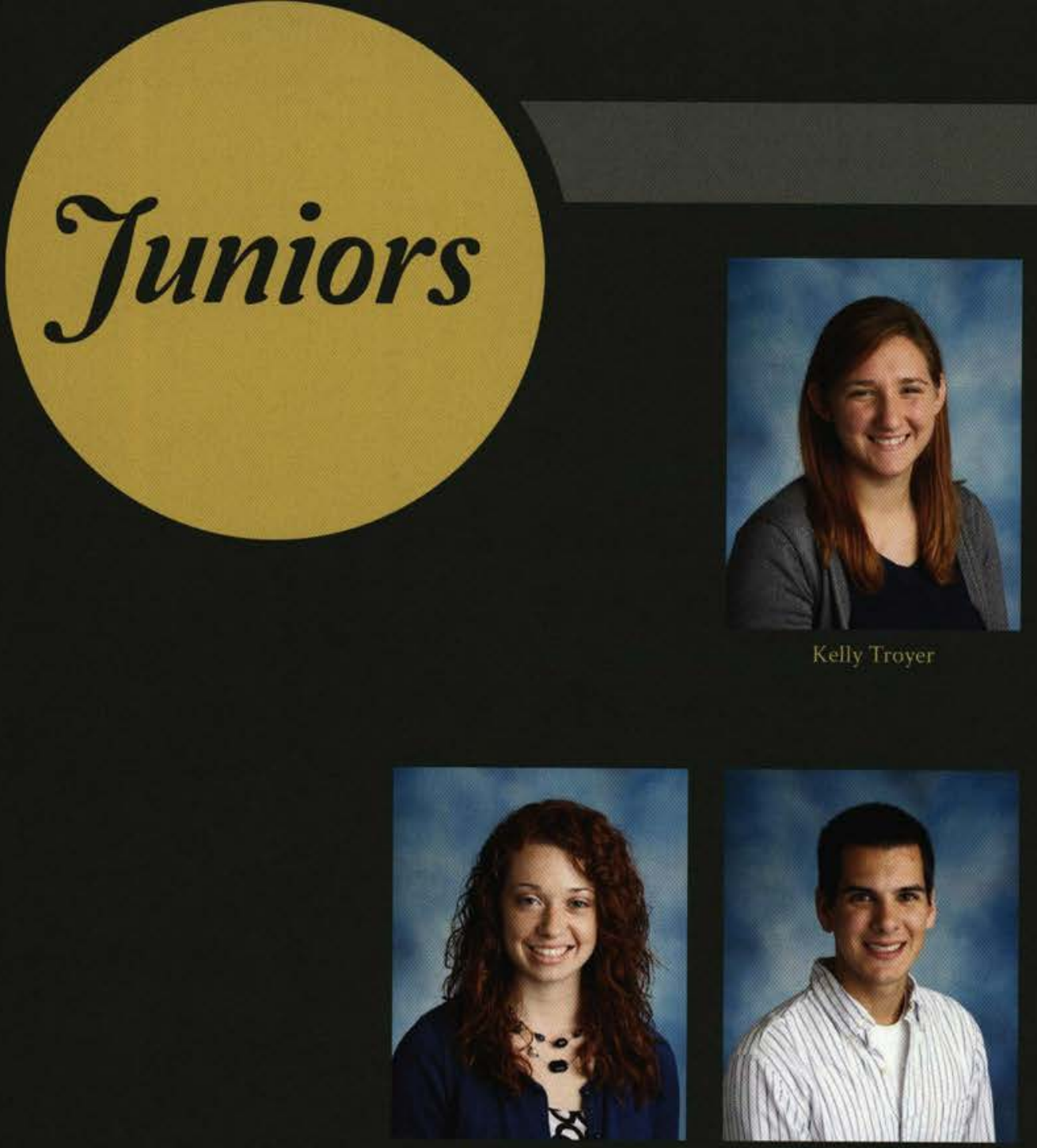

Amanda Turbett

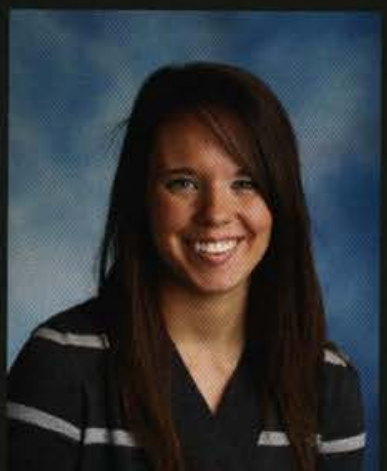

Andrea Van Meter

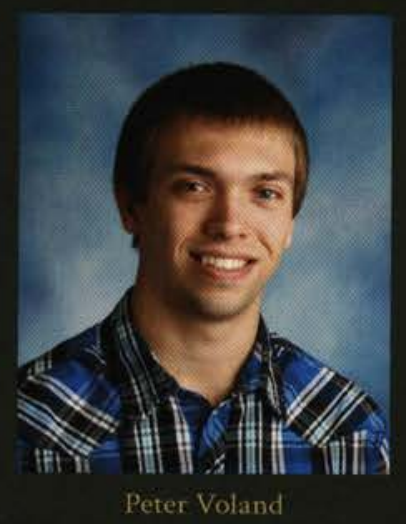

Kelly Troyer

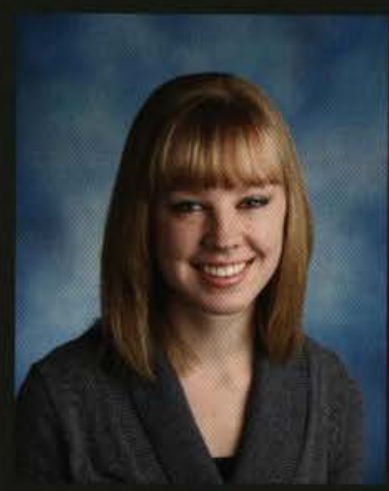

Colleen Tucker

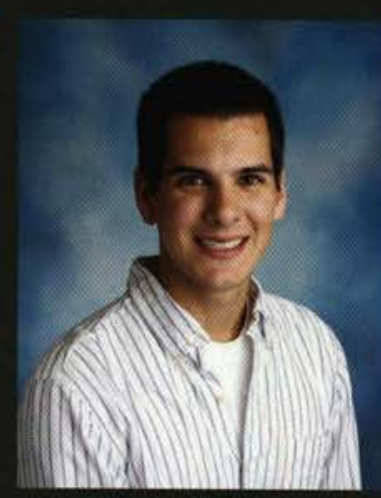

Matthew Turing

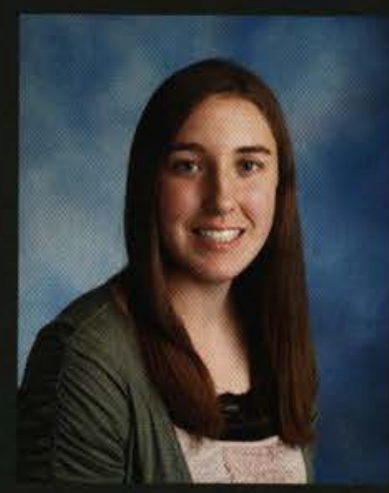

Melinda Vasser

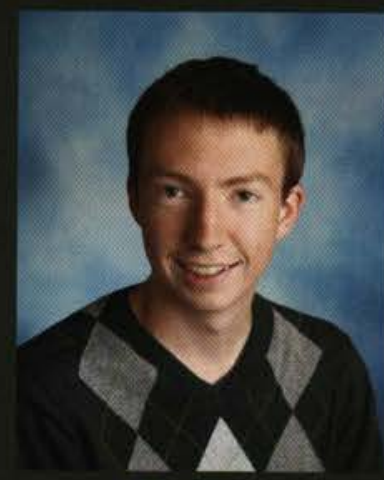

Caleb Wagner

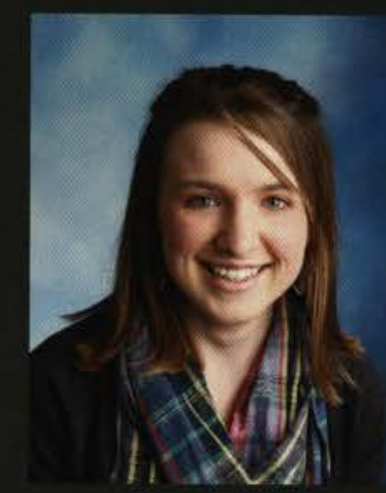

Molly Turner

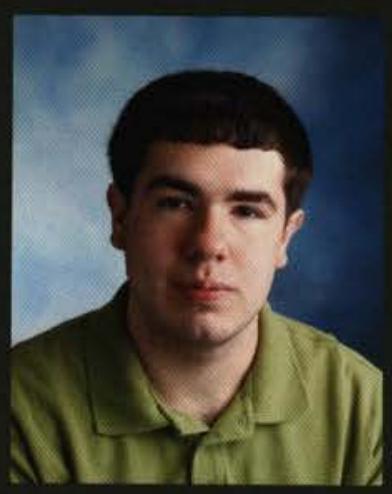

Jonathan Veith

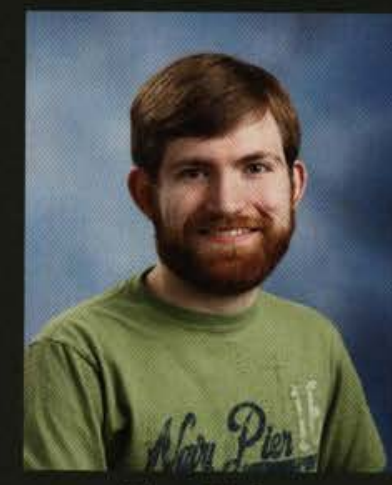

Ethan Walker

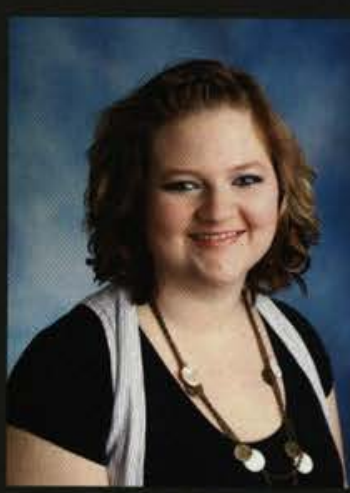

Hannah Tucker

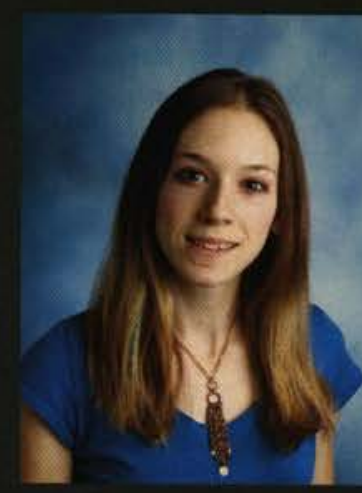

Elise Vachino

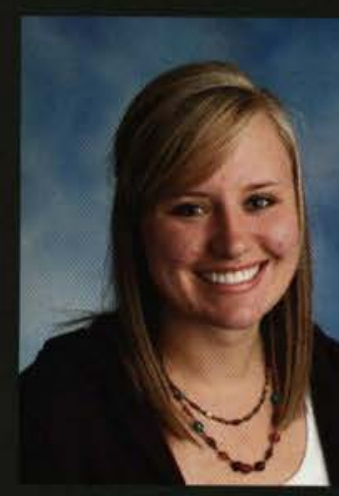

Anna Vendl

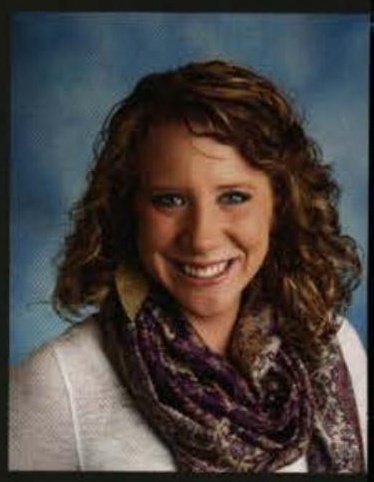

Jennifer Ward 


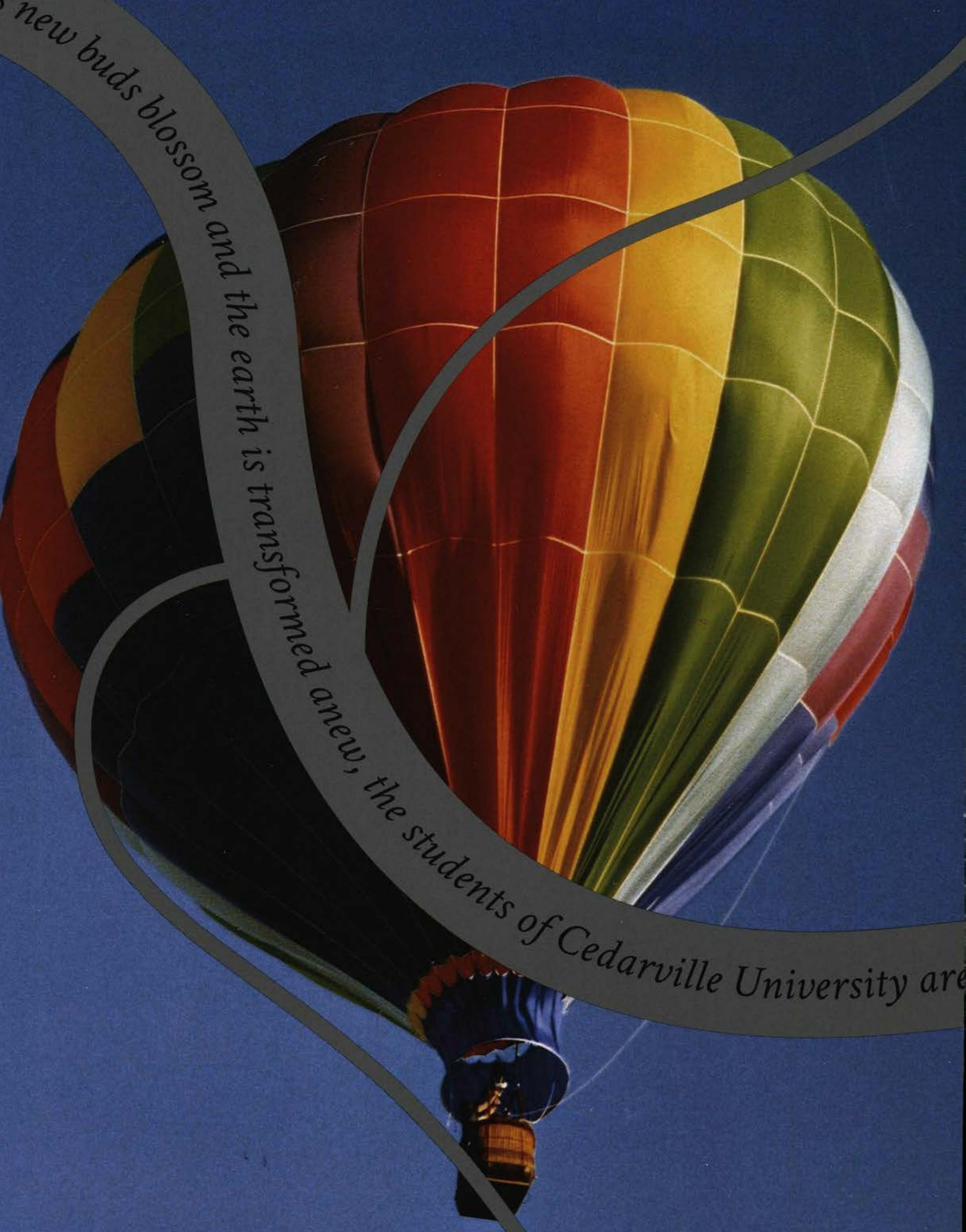




\section{Cpring}
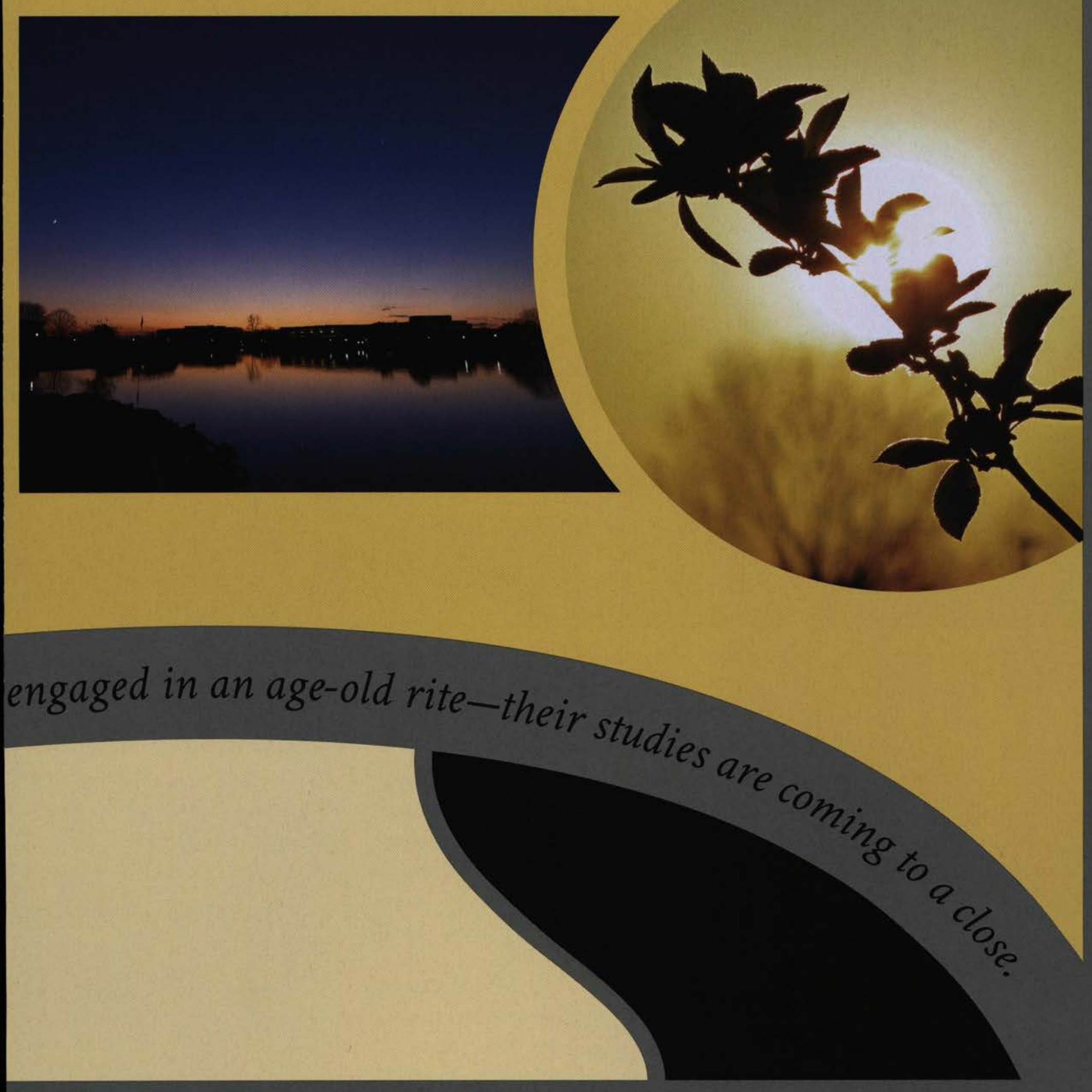


\section{Spring Play}

With The Star Spangled Girl the theater department pulls off another great performance.

$\checkmark$ Gast and crew come together withdirector, Mischelle Mclntosh, and set designer. Bob Clements, forkagroup photo.

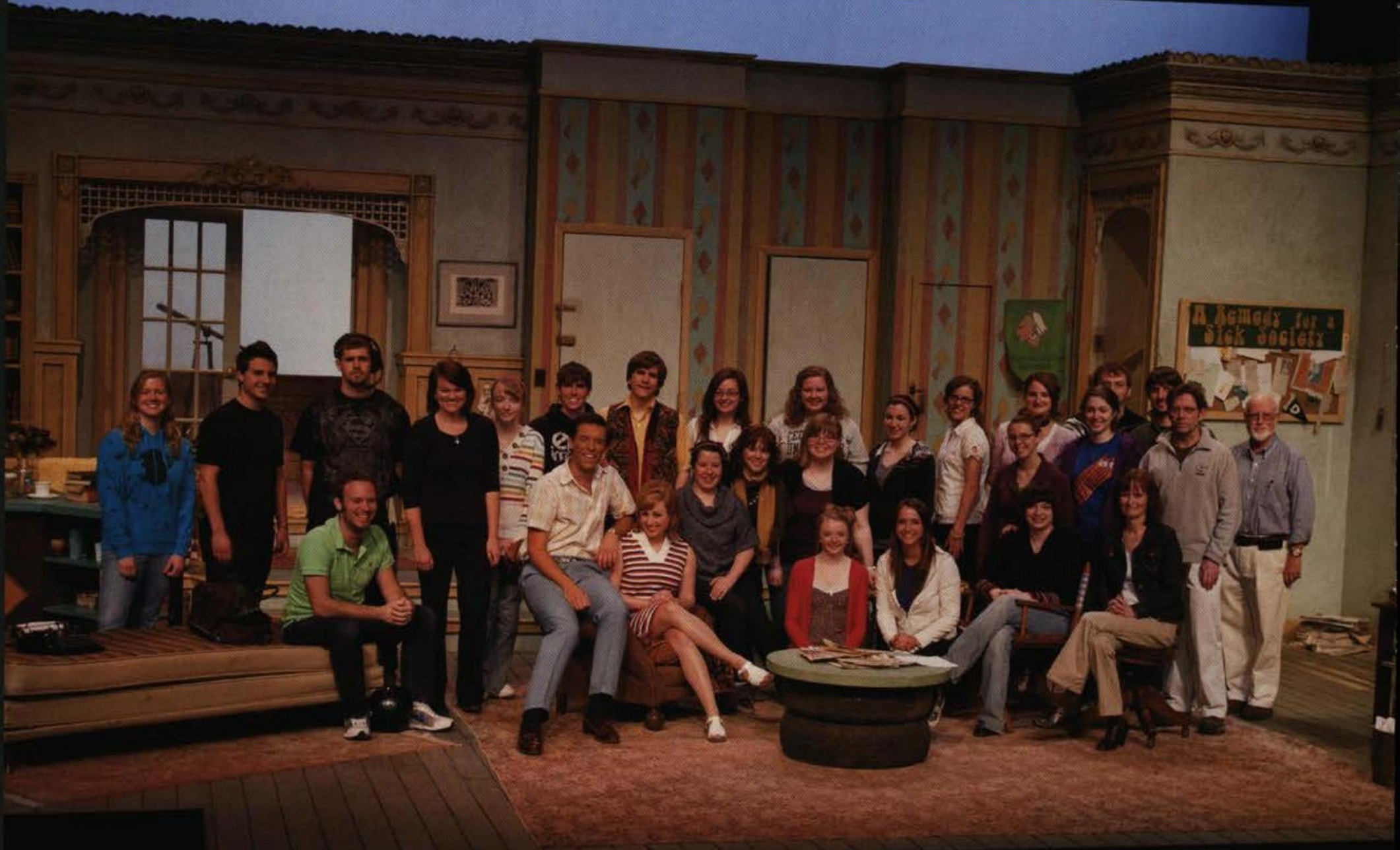

$\omega$ hat is love? That is, what is it that causes two people to fall in love? Is it physical attraction? Political opinons? Both? Neil Simon's comedy, The StarSpangled Girl, is the story of three quirky people who encounter all these questions when they find themselves caught up in an unlikely love triangle. Sophie, an allAmerican girl from the South, moves to California and finds herself next door to Norman and Andy, two radical liberals trying to produce their own anti-establishment magazine. Norman is smitten as soon as he lays eyes on Sophie, but, unfortunately, she doesn't feel the same way. In fact, Sophie can't stand Norman, and she especially can't stand his and Andy's "antiAmerican" political views. In the words of Dramaturg Samantha Sumler, "It's not only a fight for love, but a fight to prove who the true American really is." When the show came to the stage of Cedarville University's De Vries Theatre, the three-person cast put on an exceptional performance, keeping the action lively and the comedy escalating right up to the very end. Sumler called the show a "delightful blend of love and politics that results in all sorts of funny happenings."
Just as the show provided an escape from the realities of the Vietnam War to its original 1966 audience, Cedarville's performance of The Star-Spangled Girl allowed student audiences a chance to take break from the coming realities of final projects and exams, and simply laugh. 


\section{Elliv}

Students spend precious time and money preparing for this show-stopping break from the final push toward exams.

A nna Zavodney and Brian Johnson perform a cover of "Turning Tables" by Adele during the show:

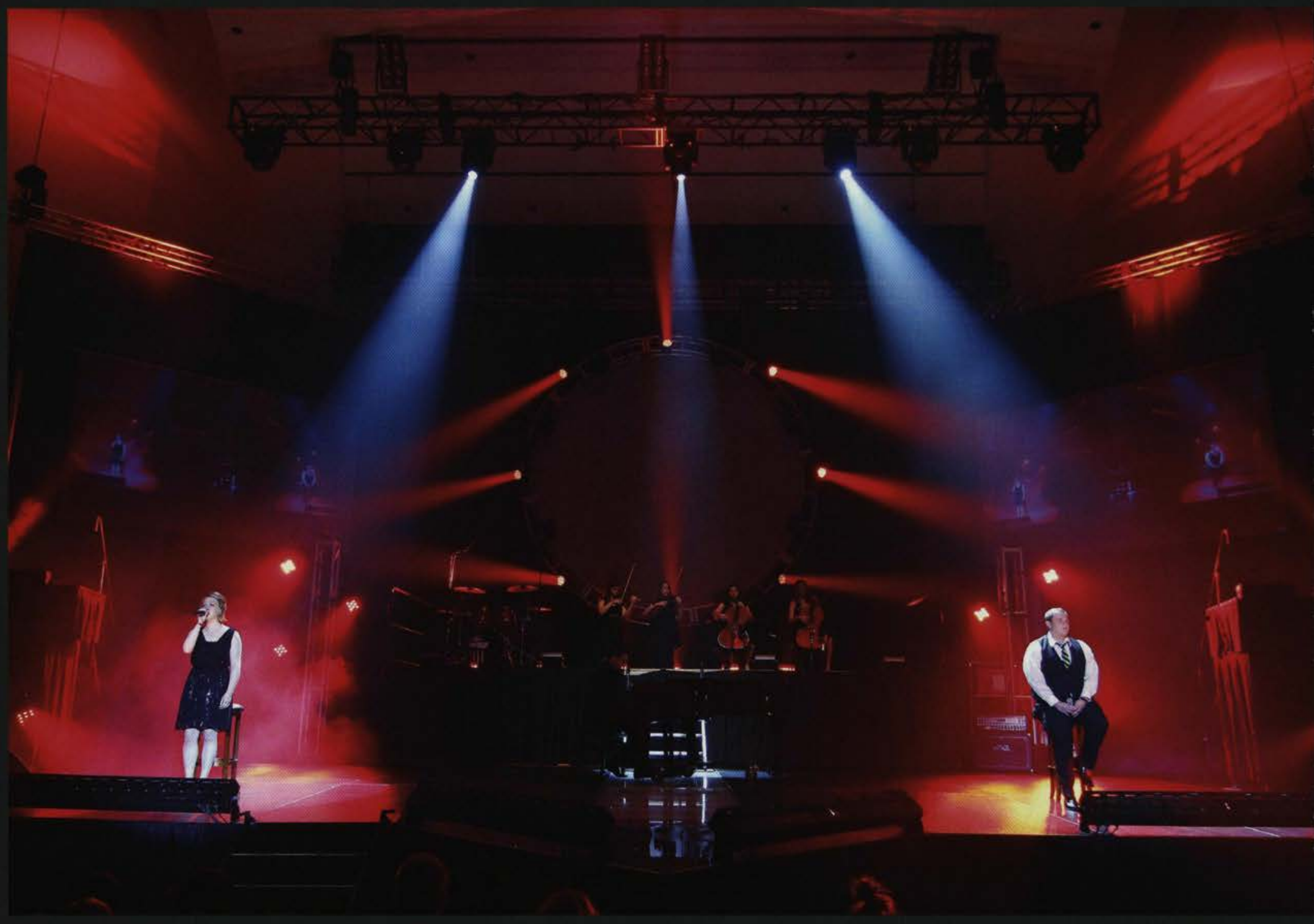

here is a theory that after the teaser
video for this year's Elliv was shown in chapel, iTunes downloads and YouTube plays of AWOLNATION's song "Sail" increased exponentially. At least, they did on Cedarville's campus. A video of Chris Voltz wearing a white morph suit and being splattered with multiple colors of paint might do that to a song. The theme of Elliv this year was "Color Me Loud" and pulled heavily from a rave concept: glow sticks and loud music, a dance floor in the DMC Alumni Hall, paint splatter. Some attendants were hoping for more of a rave vibe with strobe lights. In past years, Elliv had used one distinct theatrical element. This year, it was the light show. The musical acts started with Florence and the Machine's "Dog Days are Over," touched on Adele's "Turning Tables," and wowed the crowd with two favorite Queen hits, "We Will Rock You" and "We Are the Champions" (the show favorite). A new addition to the show this year-perhaps a permanent addition-was real-time voting. Instead of voting for award nominees before the big show, hosts Allie Hundley and Seth Trautman would announce the nominees, and the audience could vote by texting their choice during an act. The winner would then be announced and would receive a Rock as their award. Definitely voter powered! The show was loud. It was colorful. It was Color Me Loud! 

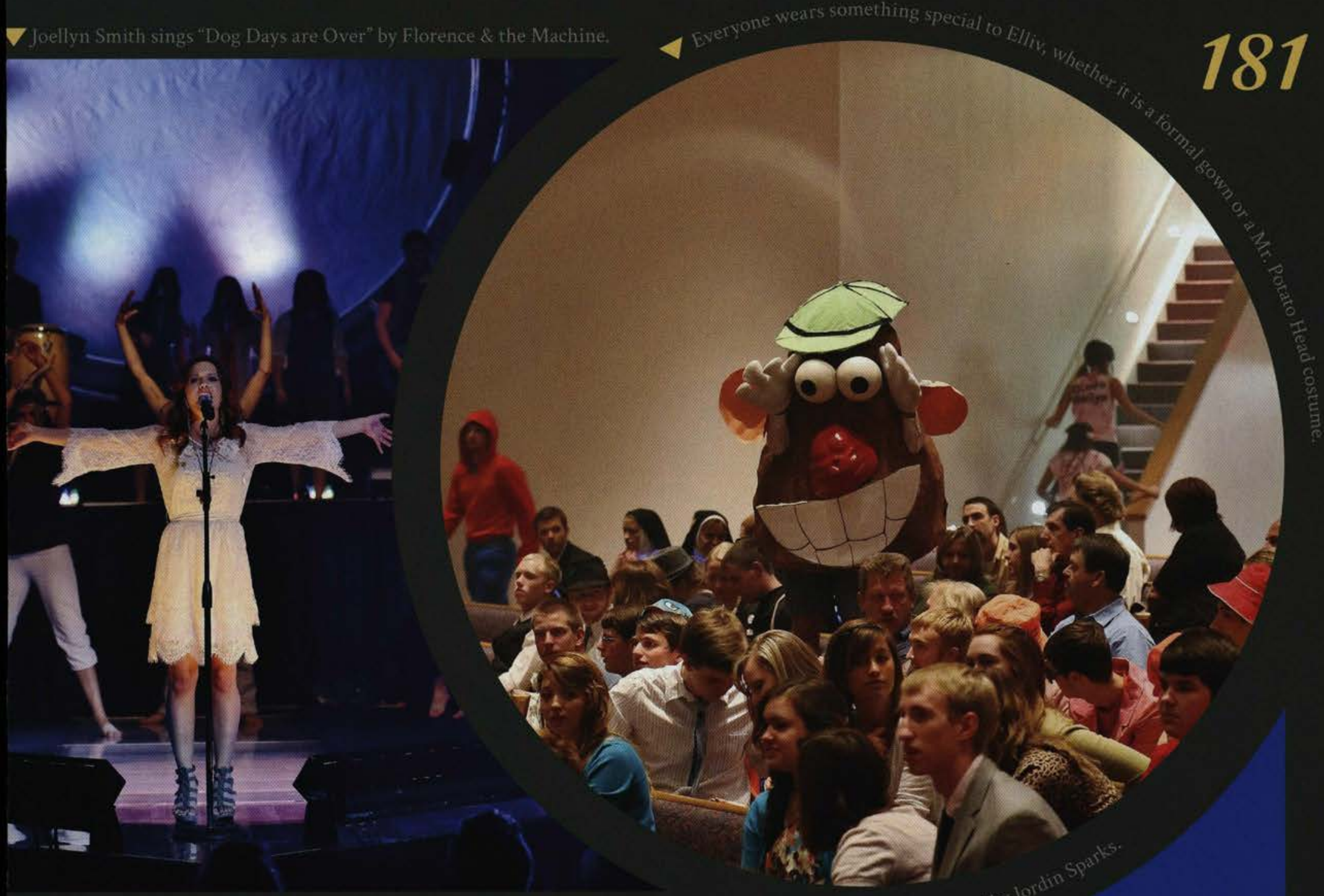

7
9

. 25 - it

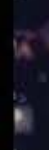

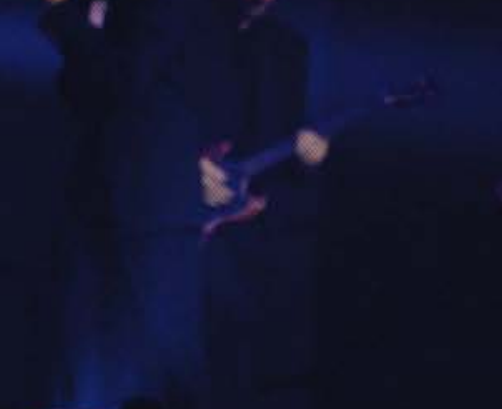

$+205+i=$

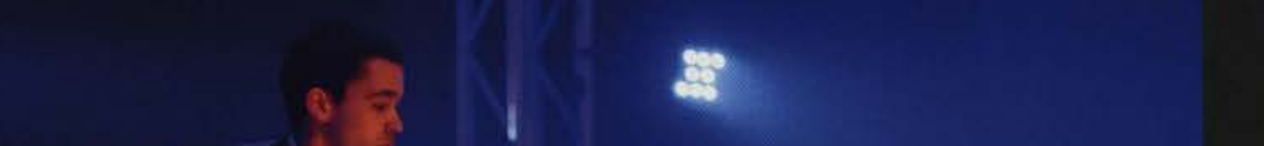




\section{Junior/Senior Banquet}

The Junior class J/S Committee create another memorable evening to celebrate and commemorate this year's Seniors.

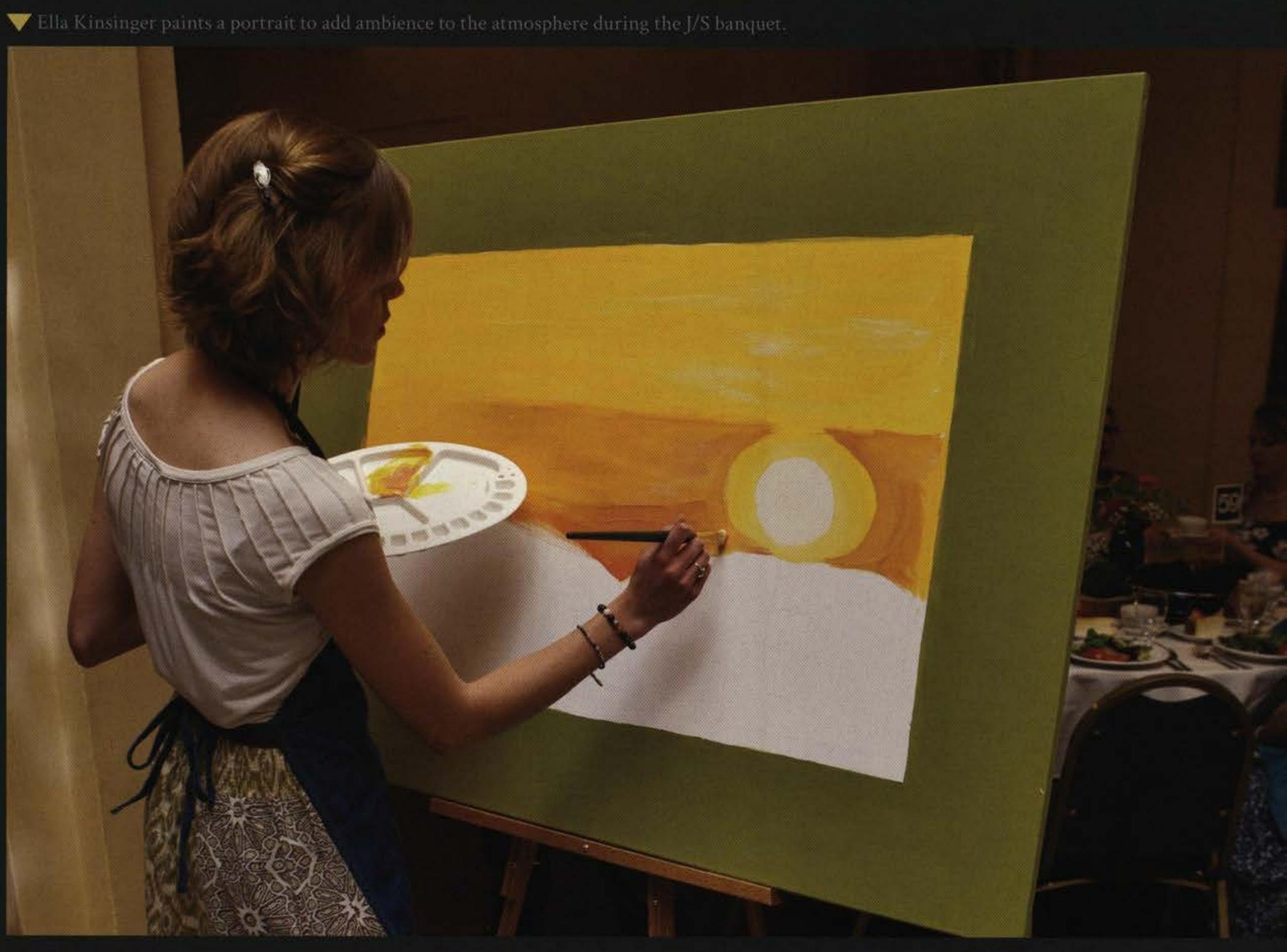

\section{6 he Junior/Senior Banquet was held at the Athenaeum, a banquet facility} located in Columbus. The students who attended stepped into a Grecian-style ballroom from the Columbus streets. The theme was Simple Recollections, a folksy, artistic décor covering the tables and walls. After dinner and a nostalgic message from Dr. Brown, the juniors and seniors journeyed upstairs to a theater for the evening's entertainment. Senior and SGA Chaplain, Chris Voltz, hosted the show Simple Recollections Live (SRL), a take on Saturday Night Live. With video skits poking fun at stereotypical Cedarville culture and a performance by "The Band," SRL gave students a laugh ... but then turned serious. Seniors were asked to video tape a recollection from their four years at Cedarville. Some recollections were humorous, some were inside jokes that few would understand, and some reminded seniors that they were moving on and their time at Cedarville was drawing to a close. Finally, to bring back even more memories, seniors were asked to step out into the center of the theater for a picture reminiscent of the infamous freshman group shot. After multiple photos-just in case-Chris Voltz said some exciting words, with a typical Chris Voltz face: "If you notice, you're all standing on a floor. A dance floor." To top off the night, songs like the Cupid Shuffle, the Cha-Cha Slide, and the original Slide played over the speakers. There wasn't much room on the floor, so people just shuffled back and forth to the music. The DJ even threw in some swing music for those dancing fans. The Junior/ Senior Banquet gave students a chance to remember their time at Cedarville andperhaps with some sadness-to spend the evening one more time with their friends. 


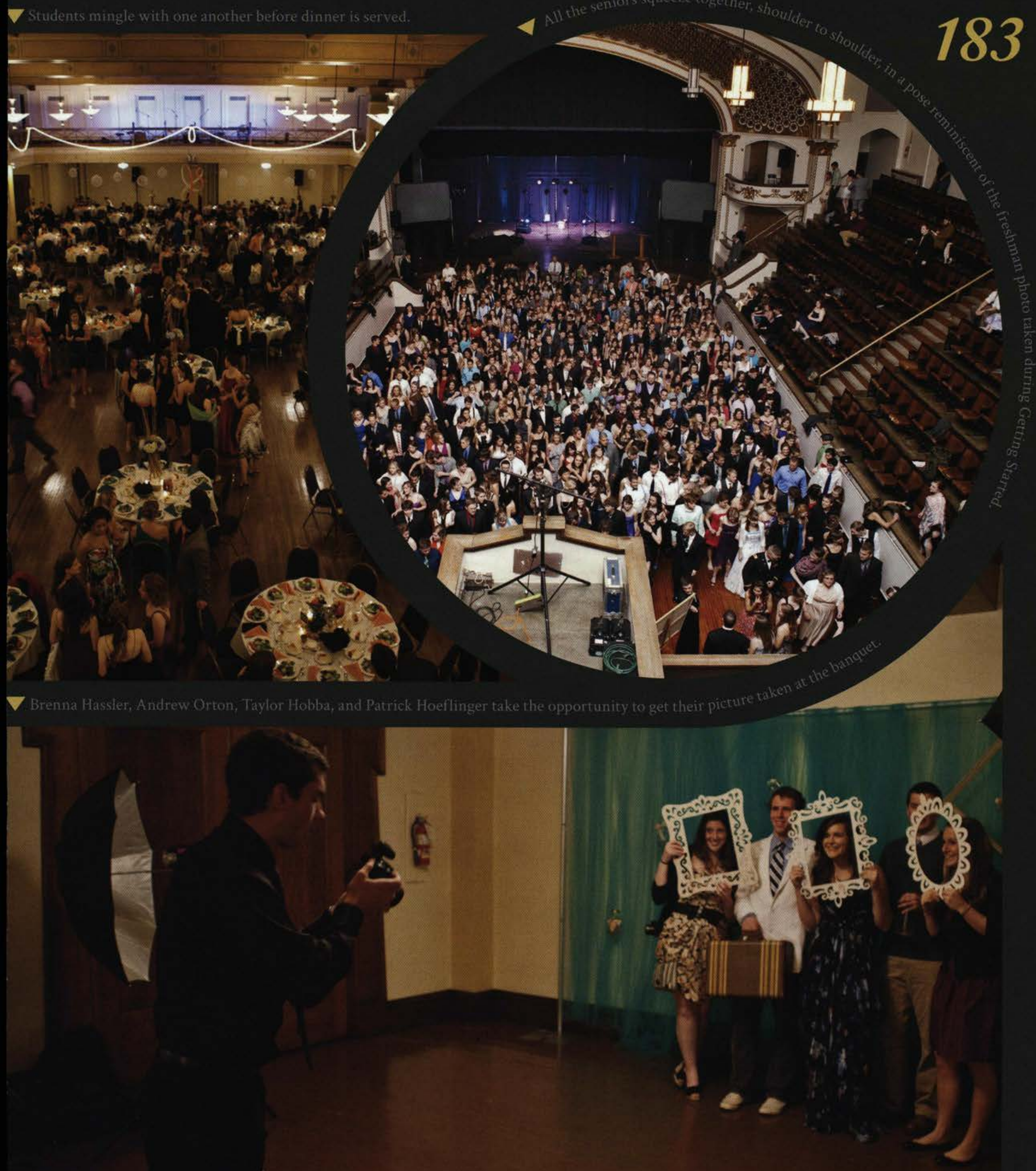




\section{Spring Events}

Along with the anticipated change in temperatures, the Spring weather also brings a slew of activities to the campus.

$\checkmark$ Rebecca DeRose, Shaun Frazier, Anna Edwards, and Cameron Hill pose foria picture during the Preemptive Love Coalition campagin to raise S30,000.

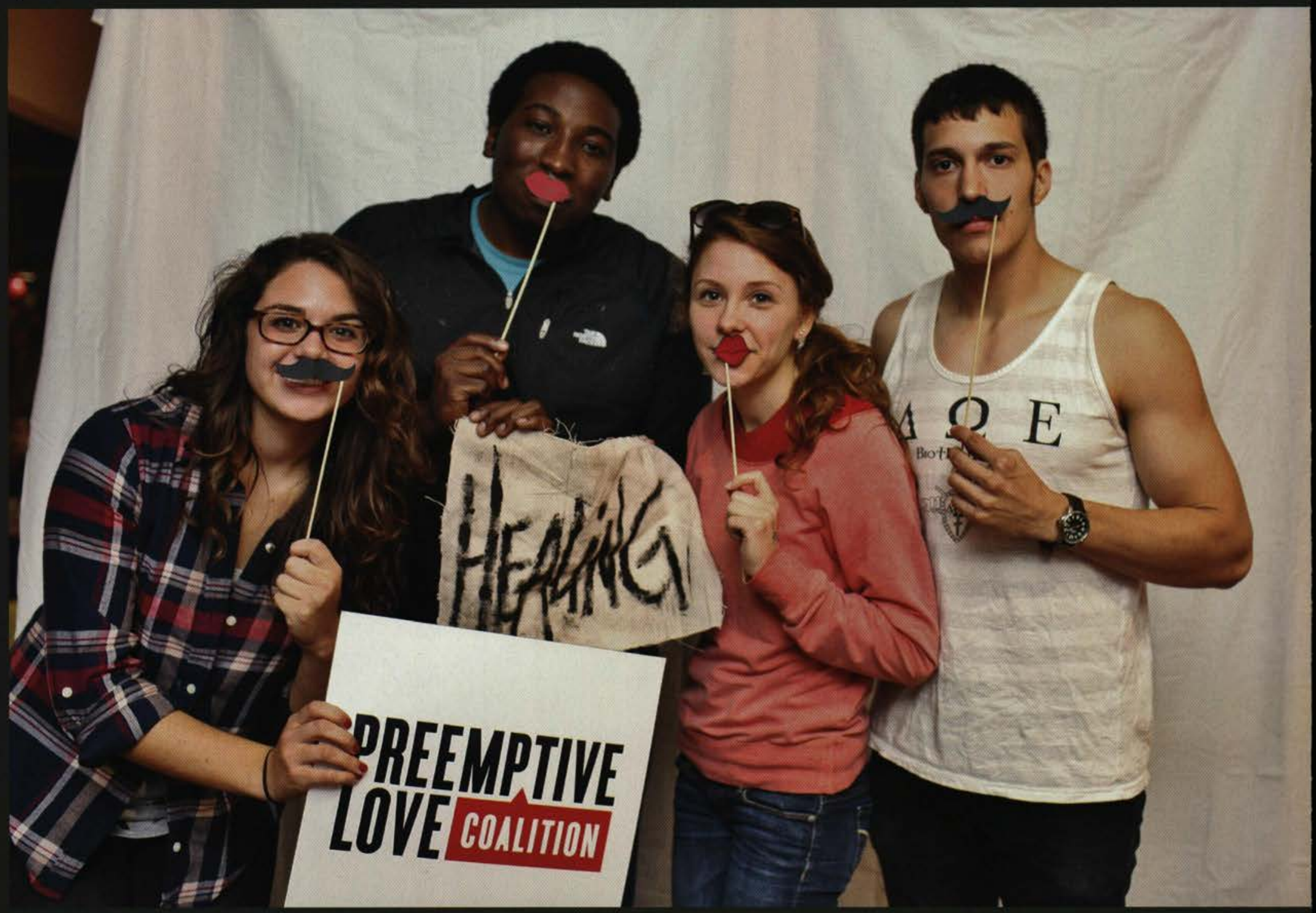

his was perhaps the warmest spring
on record! Countless days in a row broke temperature records, hitting temperatures like 70 degrees in February, but the people of windy Cedarville weren't complaining too much-except for those snow fans. As always, the spring semester flew by, seeming to go faster than fall semester. In January, elite high school students visited the campus for two days for the high school leadership conference, gaining wisdom in how to lead both the world and their own high school in a godly, impactful way. The International Justice Mission held their third annual Possible Impossibilities 10K Race in collaboration with the Red Thread Movement. The Red Thread Movement fights to end human trafficking, exactly what IJM and the $10 \mathrm{~K}$ stand for. This year Cedarville moved from doing Junior Jam twice a year to only doing it once: in the spring. The event for elementary-age children was held in March, and the campus was overrun with children for a Saturday. That was a day many students were careful where they chose to go because they knew it would be crowded with children. On the other hand, the screaming outside our windows all night was CedarMania, a night-long event for middle school students. Both events provide a mixture of fun activities and an encouraging message for youth. With Spring Break and Easter Break to cut up the semester, students often found themselves asking at the end of April, "Where did the year go?" 


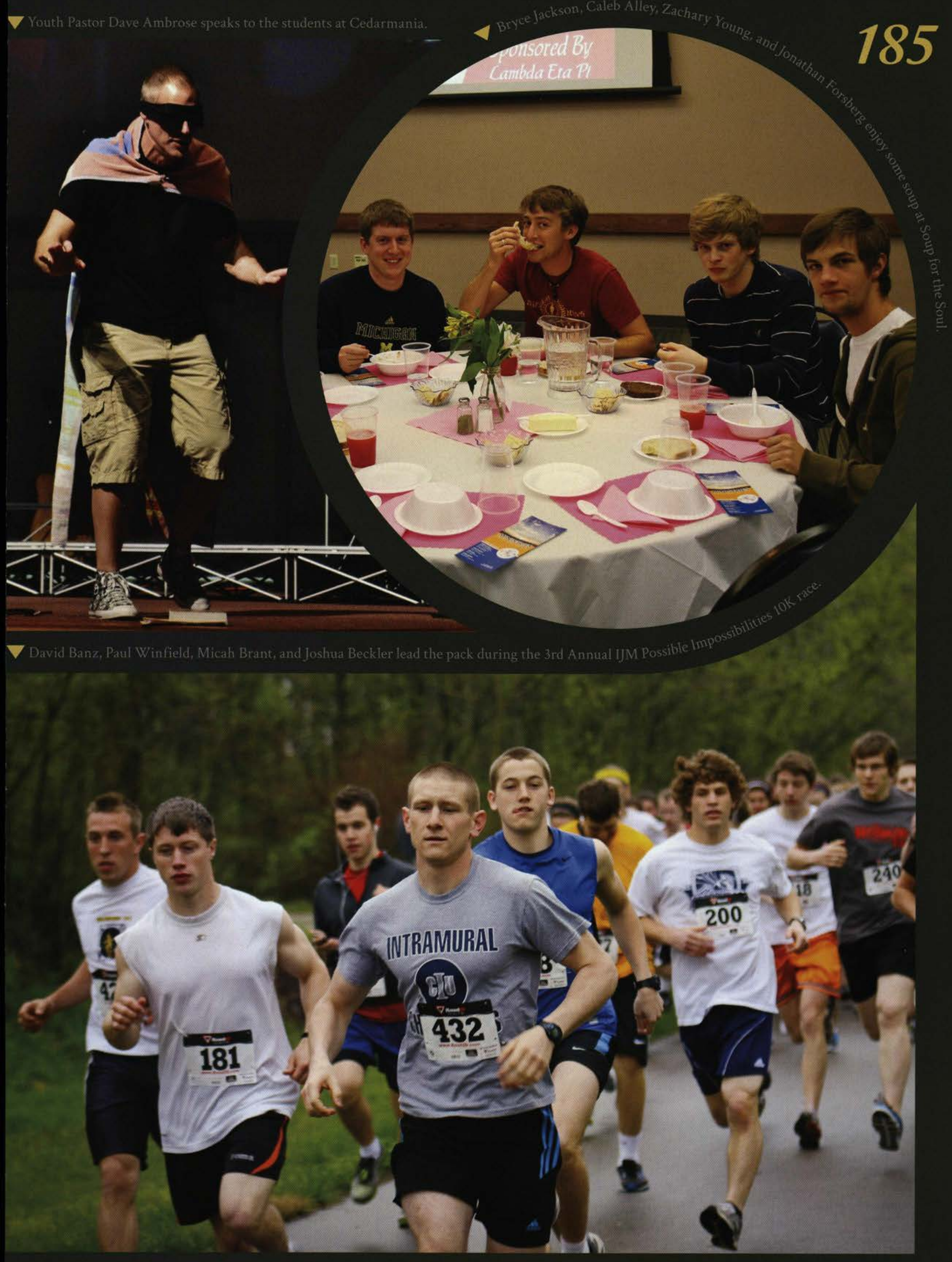




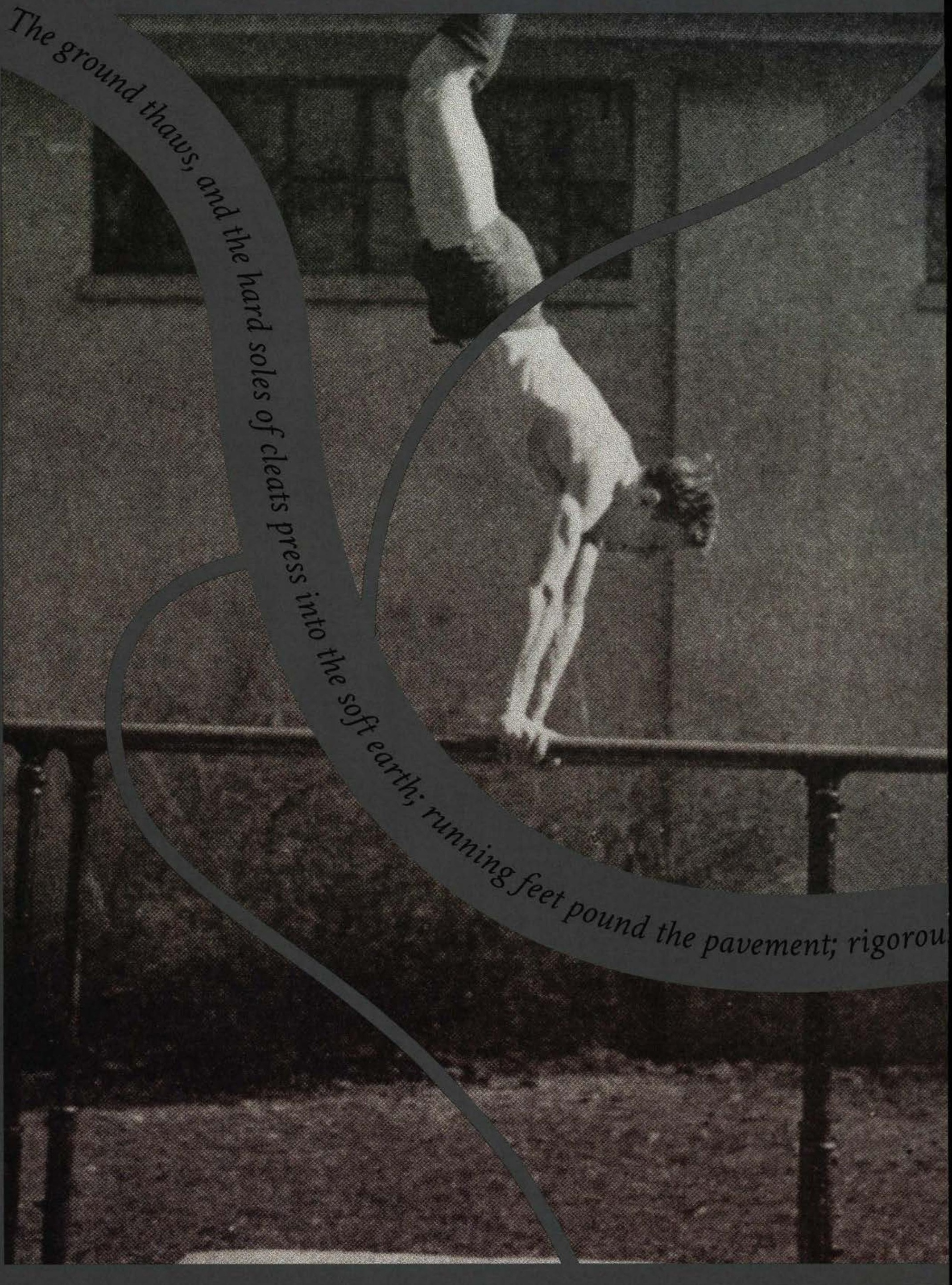




\section{Cpring Cports}
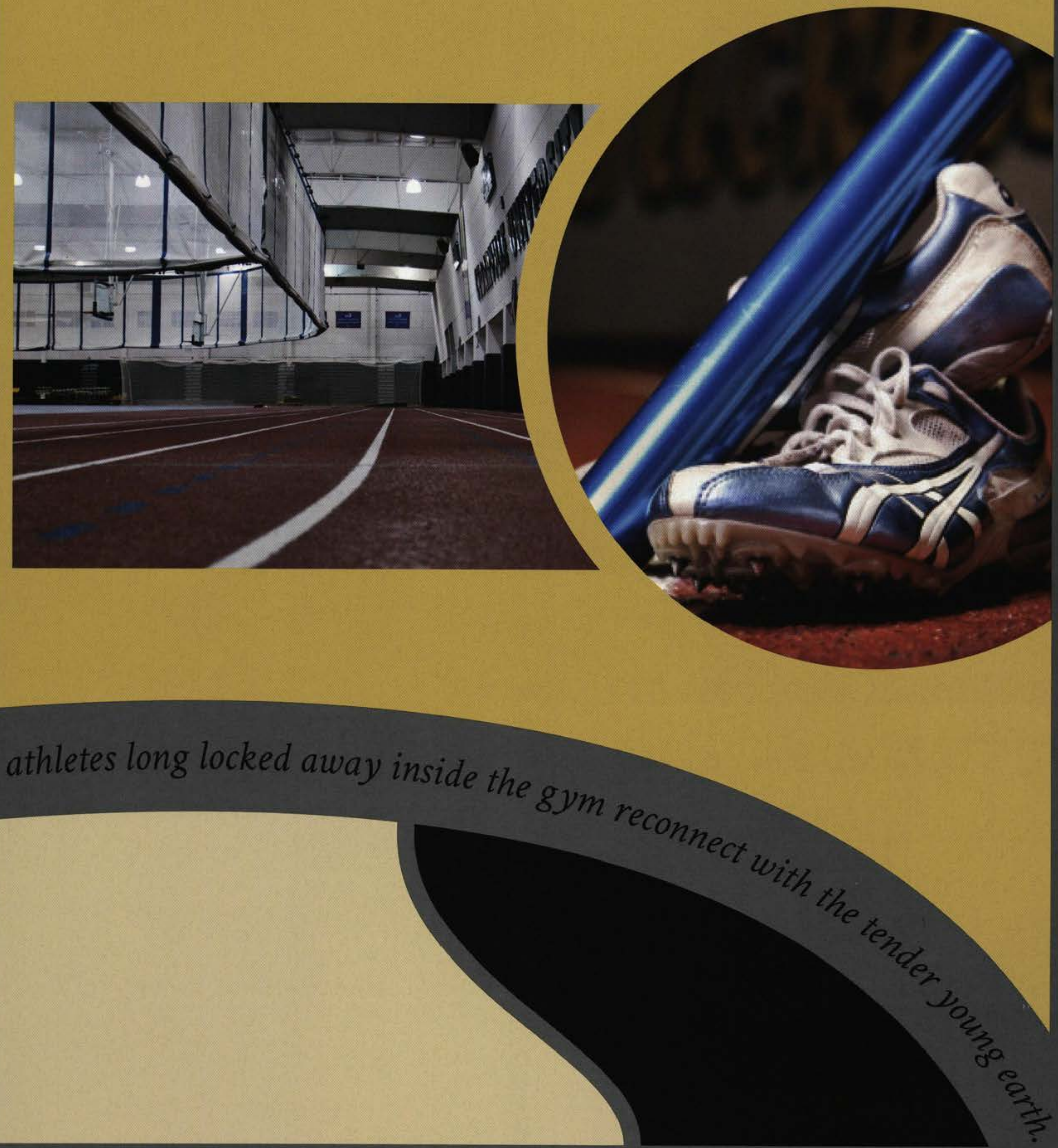


\section{Golf}

Cedarville's men's golf team rallies to win third at the Taylor Invitational.

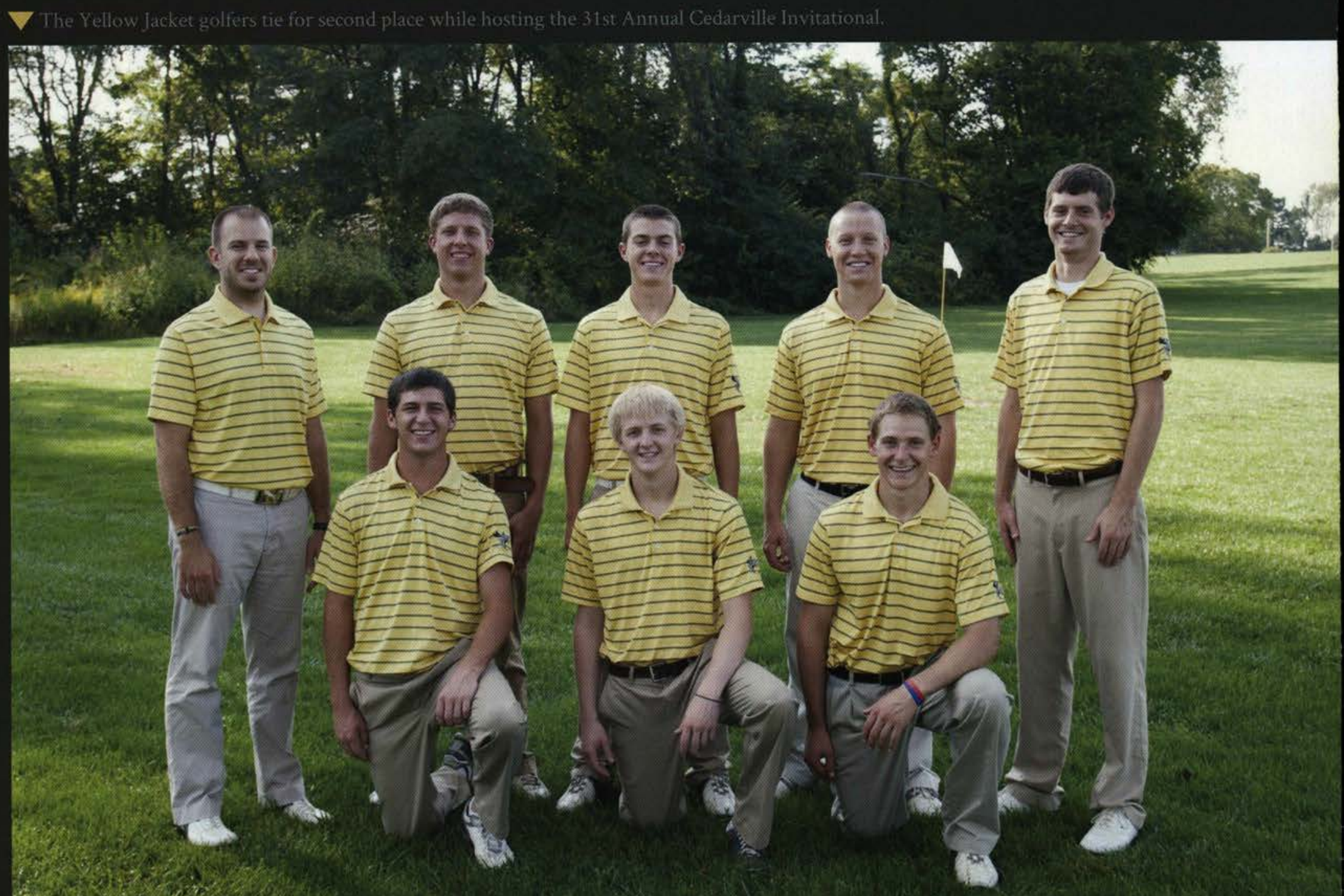

\section{Weet the Team:}

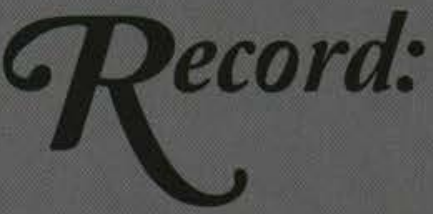

First-row: T.J Pancake, Trayton Ojala, Jacob Forsythe.

Second-row: Head Coach Joe Poelzer, John Stonkus, Jacob Nafziger, Brigham Michaud, Chris Bennington. 3rd of 7-Ohio Dominican Classic 9th of 16- Atlantic Region Invitational Itth of 15-Midwest Regional Ist of 5- Yellow Jacket Fall Invitational 10th of 18- NCCA A Championship 1st of 7-Shawnee State Invitational 8 th of 13- Trevecca Nazarene Invitational $3 \mathrm{rd}$ of 9- Taylor Invitational 2nd of 7-31st Annual Cedarville Invitational 2nd of 4-Ohio Independent Championship 

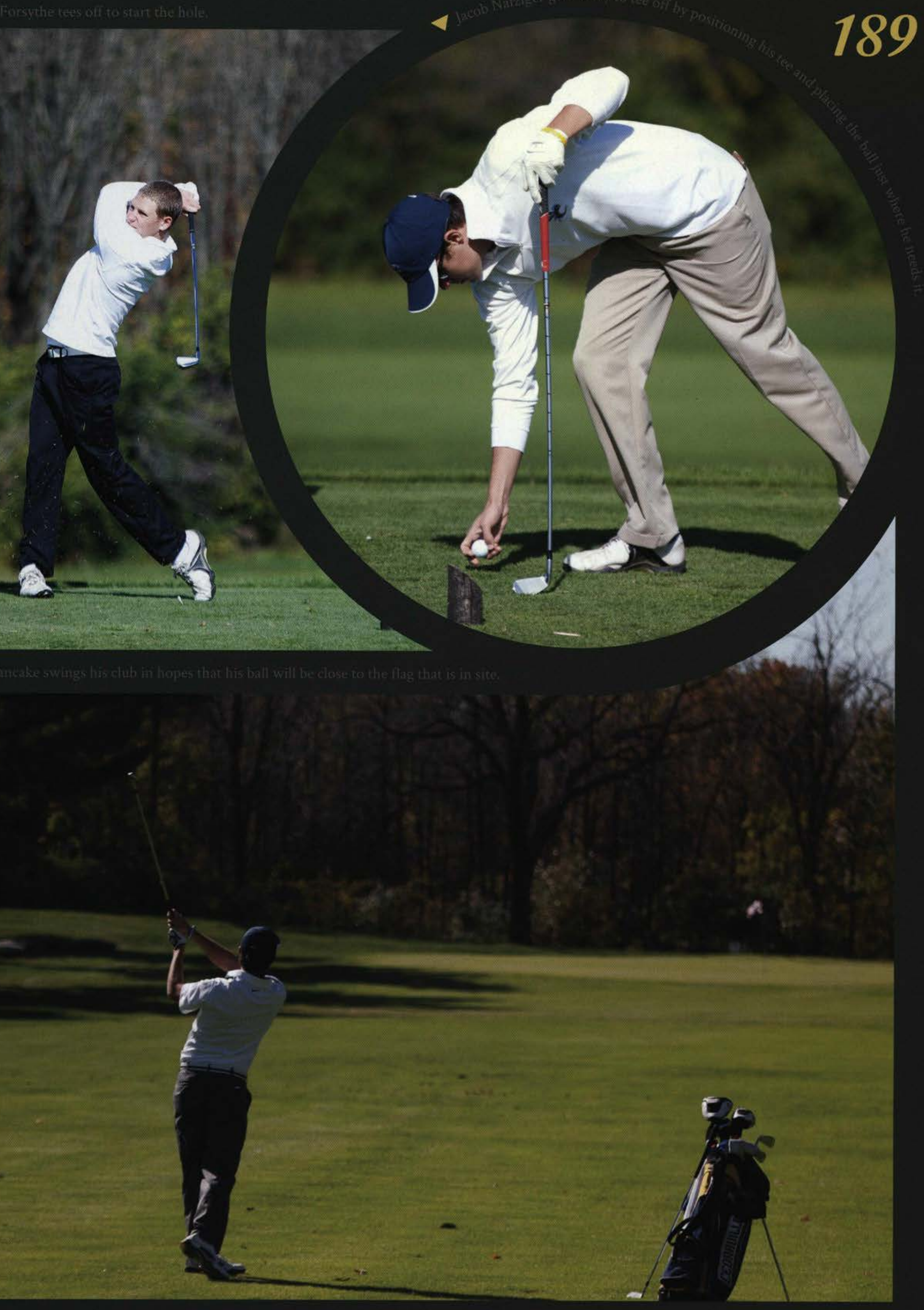


\section{Men's Track Eण Field}

The Men's Track \& Field team placed 2nd at the NCCAA Outdoor Championship in Joliet, IL.

$\checkmark$ Distancerunner Evan Thaver received the Cedarville University's Male Athlete of the Year:

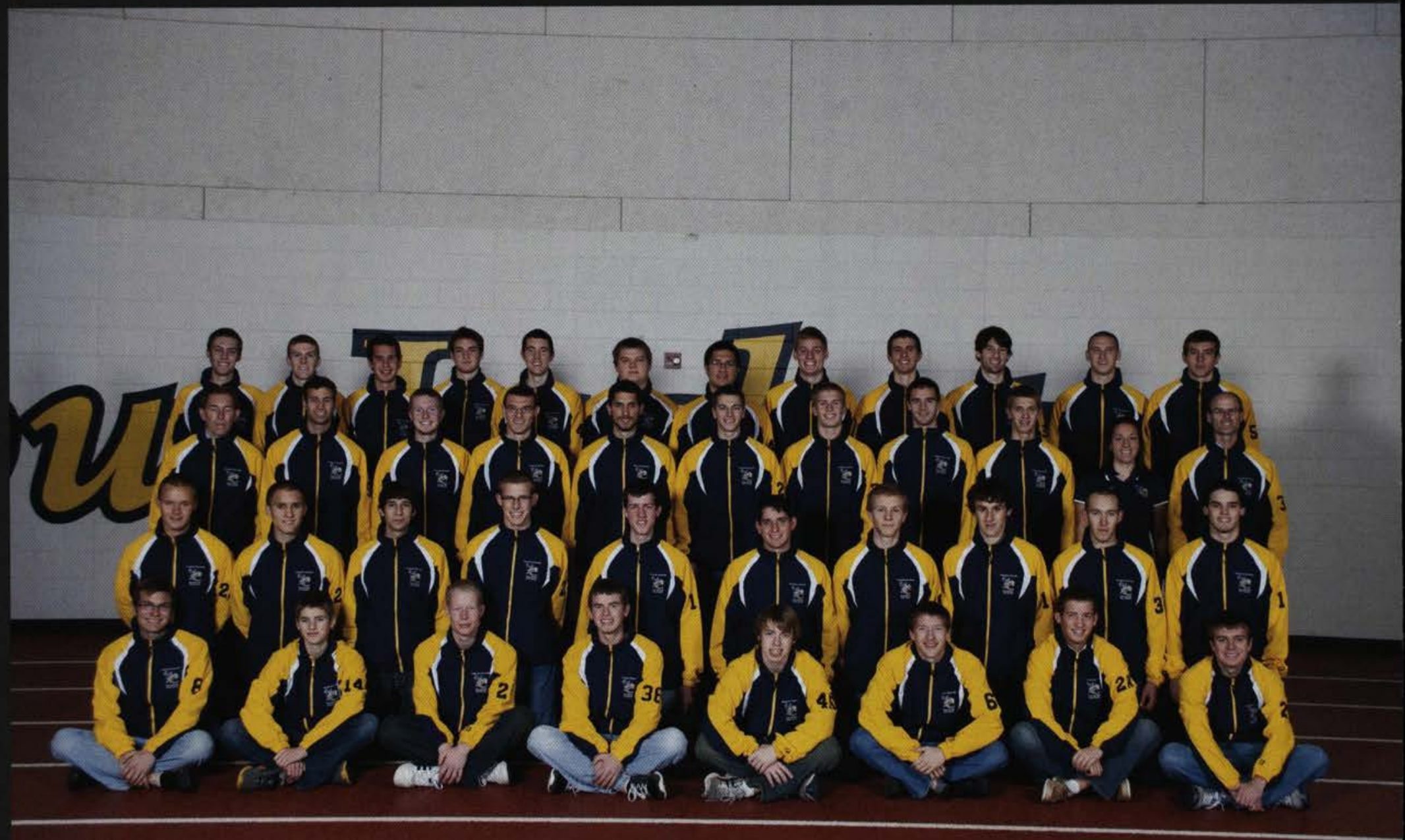

\section{Weet the Team:}

First-row: Greg Johnson, Benjamin Tuttle, Eli Pyles, Erik Johnson, Trevor Bryant, Josiah Clemons, Matt Chaney, Dusty Dalton.

Second-row: Clay Watson, Ryan Gustafson, Joseph Cathey, Joe Niemiec, Jacob Walter, Nathan Wright, Josiah Bragg, Samuel Rice, Dylan McKevitt, Ryan Baker.

Third-row: Assistant Coach Paul Orchard, Curtis Meyer, Scott Gardner, Neil Klinger, Stephen Port, Mark Farris, Michael Gardner, Andrew Richard, Landon Stapleton, Assistant Athletic Trainer Leyna Hebert, Head Coach Jeff Bolender.

Back-row: Drew Gilliland, Nathaniel Burrell, Evan Thayer, Landon Bundenthal, Jacob Dubie, Sam LeMaster, Mike Herrera, James Blackwell, David Yoder, Joshua Lusk, Beau Michaud, Corey Caldwell.

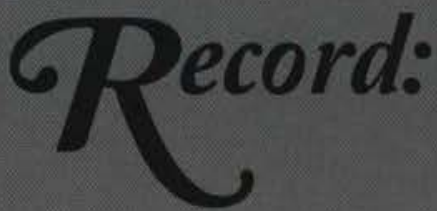

3rd of 17-Cedar ville Collegiate Invitational 3 rd of 20-NCCAA Indoor Championship 3 rd of 12-Cincinnati Relays 3rd of 14- Emory Invitational Ist of 12- Yellow Jacket Collegiate Open 7th of 14-Miami Invitational 1st of 5-Ohio Independent Championship 2nd of 19-NCCAA Outdoor Championship 


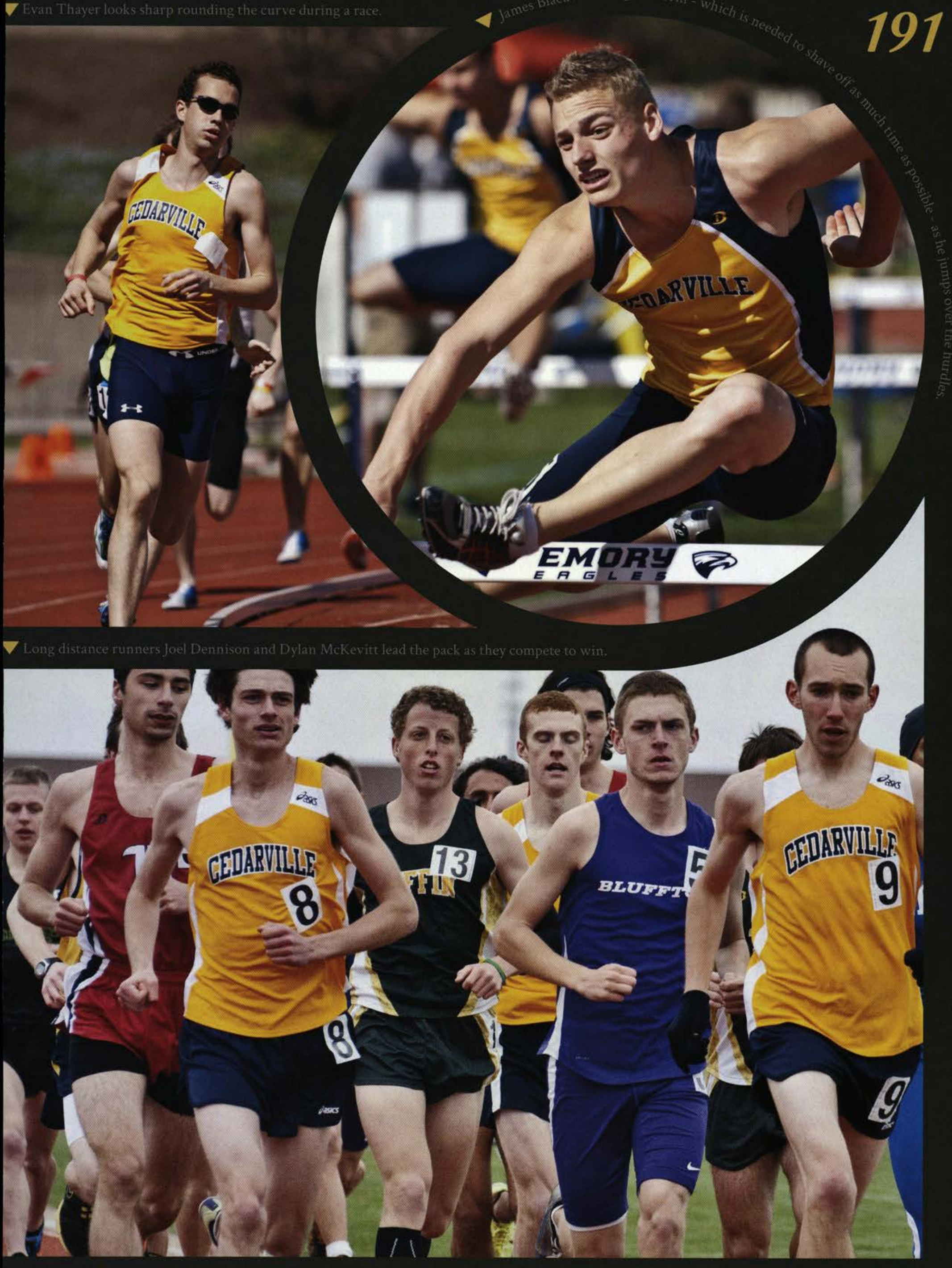




\section{Women's Track E。 Field}

The Women's Track \& Field Team had 8 All American athletes at the NCCAA Outdoor Championship in Joliet, IL.
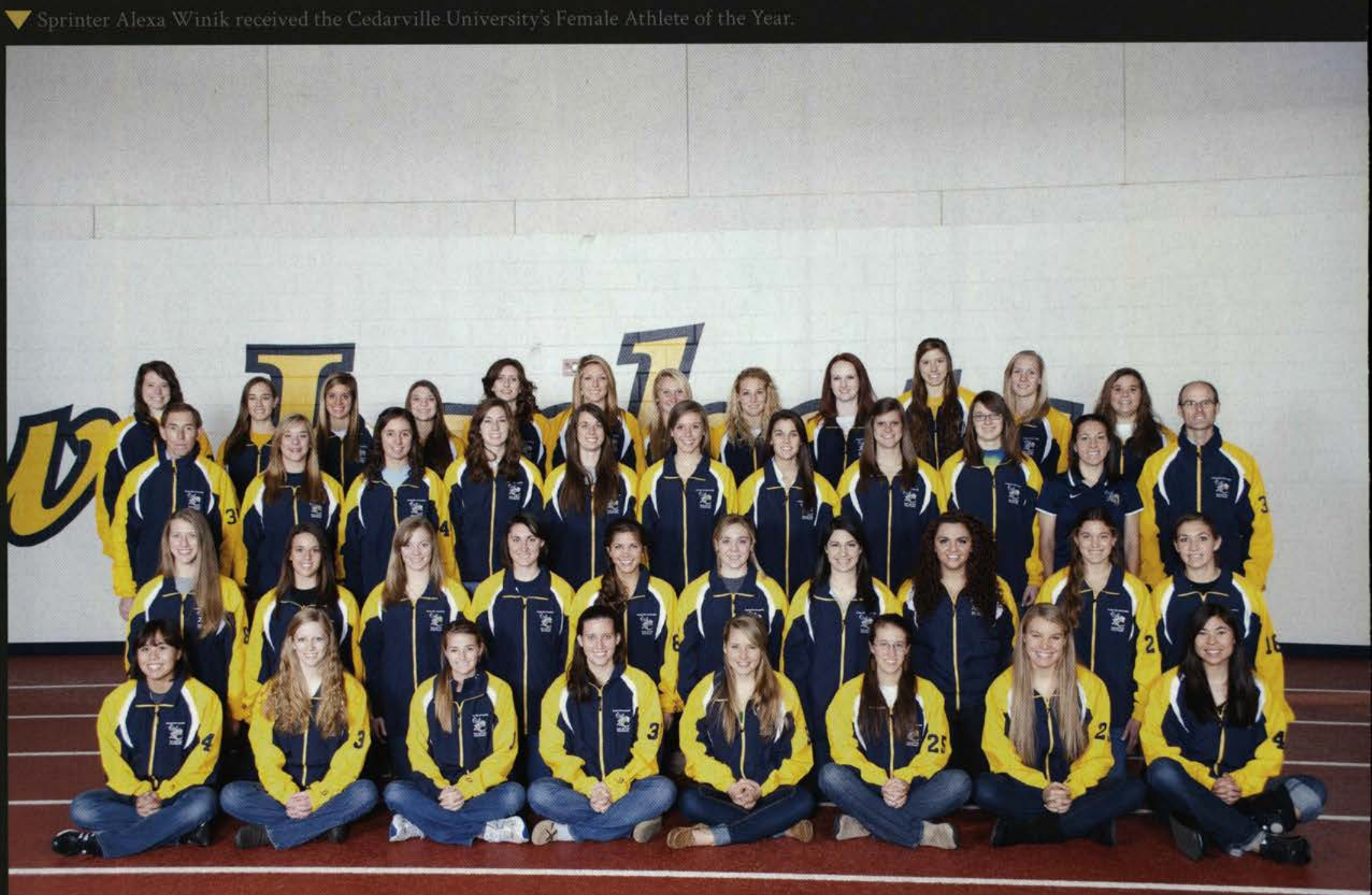

\section{Weet the Team:}

First-row: Abby Wong, Rachel Herrera, Tabby Moore, Elisa Cherry, Carolyn Case, Neola Putnam, Tabitha DeHart, and Rachel Wong.

Second-row: Kara Yutzy, Rachel McKinley, Krista Johnson, Grace Campbell, Jennifer Hollander, Ashley Ashmore, Hannah Lamos, Kelsey Wilson, Christina Gall, Karlee Mater.

Third-row: Assistant Coach Paul Orchard, Alyssa Mathis, Anna Schmid, Mackenzie McMahan, Michelle Mead, Katie Lanphier, Becca Davis, Beth Jones, Valerie Kirk, Assistant Athletic Trainer Leyna Hebert, Head Coach Jeff Bolander.

Back-row: Jo Sharp, Jamie Atkins, Meghan Terrell, Gina Mattes, Lauren Callahan, Carolyn Cann, Jasmin Banachowski, Chelsea Gruet, Jessica Dahnke, Nicole Deneseus, Laura Farleman, Megan Glandon.

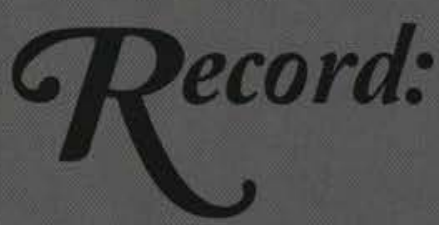

2nd of 15-Cedarville Collegiate Invitational Ist of 20-NCCAA Indoor Championship 3 rd of 15 - Cincinnati Relays 4th of 14-Emory Invitational 1st of 15- Yellow Jacket Collegiate Open 11th of 18- Miami Invitational Ist of 6-Ohio Independent Championship 4th of 18- NCCAA Outdoor Championship 


\section{Men's Tennis}

The \#2 doubles team, Bobby Eberhard and Jared Gerber beat the \#2 doubles team from Walsh in the OIC at home.

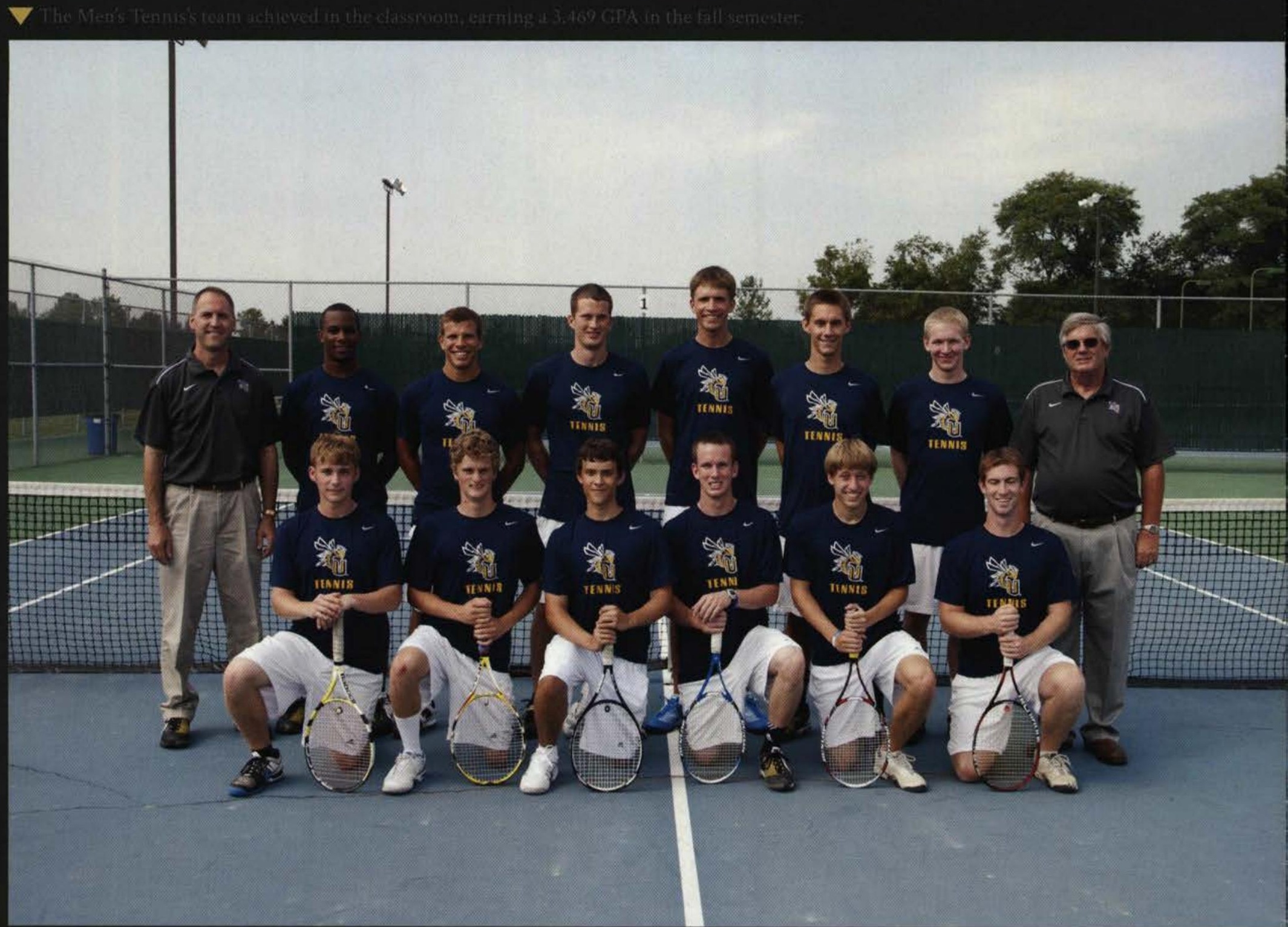

\section{Weet the Team:}

First-row: Corey Whitlock, Adam Levesque, Josh Van Zandt, Bobby Eberhard, Drew Steinhart, Mike Clark.

Second-row: Team Chaplain Jeff Lewis, Quinton Paul, Aaron Niemiec, David Barton, John Filcik, Jared Gerber, Jake Miller, Head Coach Alan Edlund.

\begin{tabular}{|c|c|c|c|}
\hline Taylor & L $3-6$ & Tiffin & L. 3-6: \\
\hline Wittenberg & L $2-7$ & Capital & W $8-1$ \\
\hline Findlay & L. 3-6 & Anderson & W 9.0 \\
\hline Otterbein & W $8-1$ & West Liberty & L $3: 6$ \\
\hline Wilmington & W 9-0 & Indiana East & W 9-0 \\
\hline Indianapolis & L. $1-8$ & Central State & W $8-1$ \\
\hline Southern Ind. & L $0-9$ & Aquinas: & L 0.9 \\
\hline Le Moyne & L. $4-5$ & Malone & W 9-0 \\
\hline Erskine: & L. $1-8$ & Walsh & L. 1.8 \\
\hline Carson-Newman & L. $0-9$ & Bethel (IN) & W 9-0 \\
\hline Central State & W 9-0 & Malone & W $5-0$ \\
\hline Indiana Wesleyan & L. $3-6$ & Walsh & L $1-8$ \\
\hline
\end{tabular}




\section{Women's Tennis}

In the fall, the Lady Jackets opened their season playing on courts that were 114 degrees against Geneva.

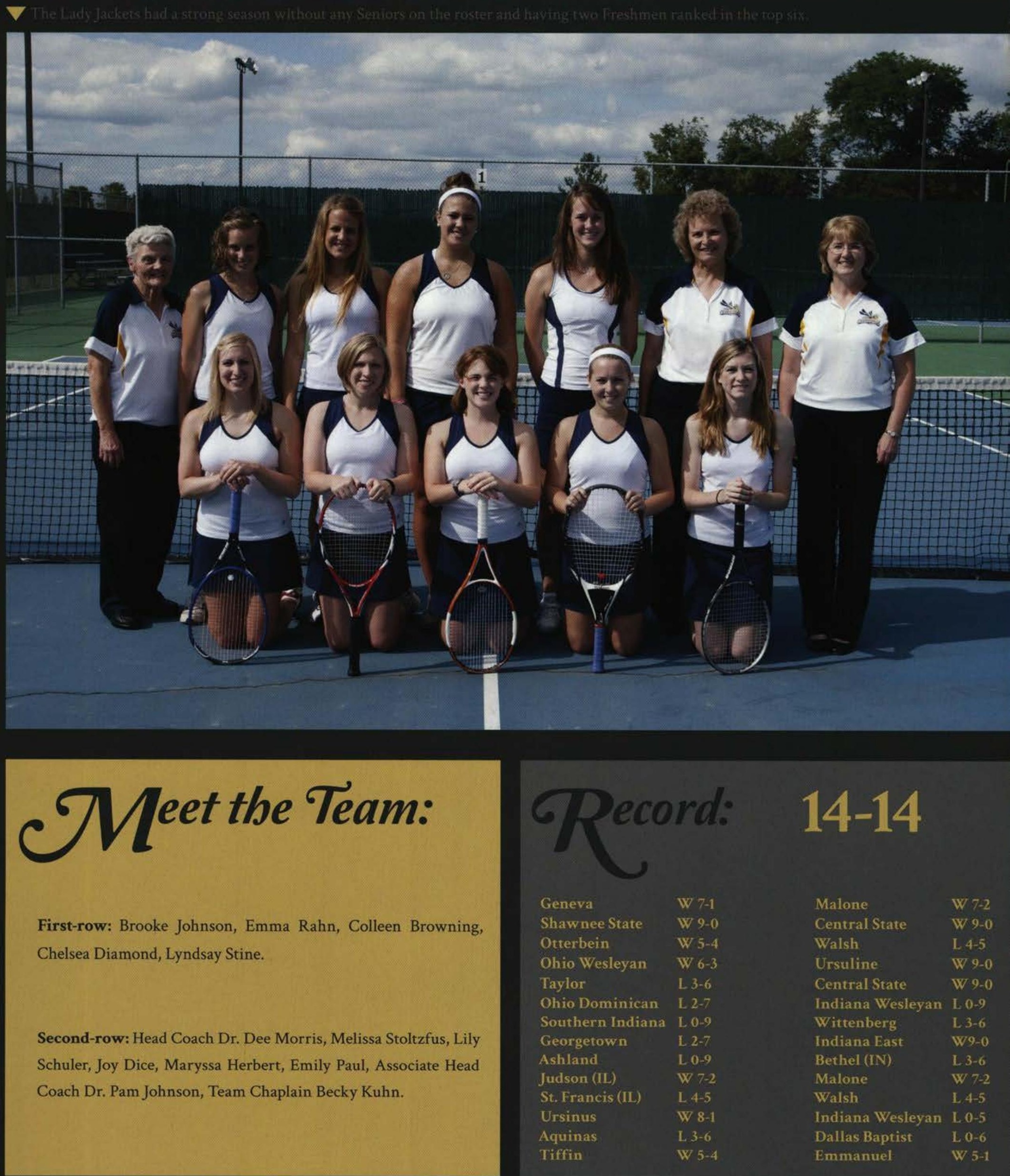




\section{Men's 'Baseball}

The Yellow Jackets earned the \#1 seed at the NCCAA Division I Baseball Championship in Mason, $\mathrm{OH}$.

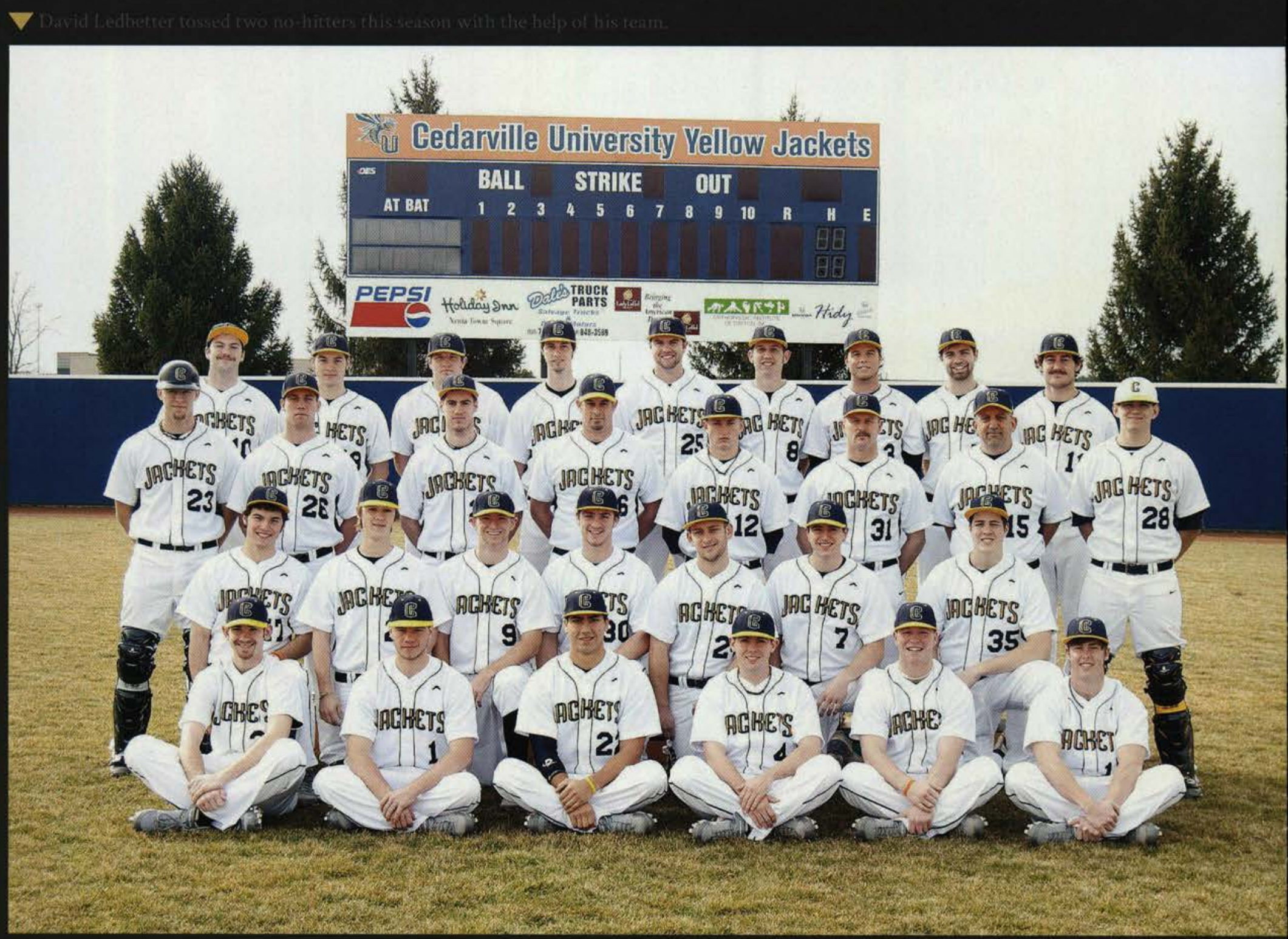

\section{. \\ Meet the Team:}

First-row: John Mark Edwards, Parker Brown, Jordan Chapman, Zach Huskey, Sam Summerlin, Shane Johnson

Second-row: Ryan Ledbetter, Cam McWilliams, Alex Beelen, Stephen Kneeland, Chris Ward, Paul Hembekides, Peter Martin

Third-row: Chris Fox, Ben Christian, Dan Larkin, Asst. Coach Ben Galbreath, Asst. Coach Tyler Rost, Asst. Coach Rill Thompson, Head Coach Mike Manes, Dan Petke

Back-row: Zach Lardy, David Ledbetter, Steve Cardwell, Sean Larkin, Nate Davenport, Jordan Ammon, Michael Roe, Derek Ogle, Logan Kassabian

Record: $38-13$

Clearwater $\quad 6-0,13-1$

Southeastern L. 4-12

Neumann L9-11

Upper Iowa $\quad$ W/ $3-1$

Florida Christian W 9-7

Upper lowa W/ $8-3$

Oakland City W16-1

East Stroudsburg W 12-9

Miami-Hamilton 2-3, 11-4

Hiwassee W 5-0

Ohio Christian $\quad 9-2,3-2$

Tiffin

Oakland City

Walsh

Salem Int'
L. $0-4$

$-3,10-8,13-4$

$16-0,7=0$
UC-Clermont

$10-0,10-6$

Notre Dame (OH) 0-1, 8-2

Walsh

Salem Int I

Malone

Oakland City

Wilmington

Urbana

Malone

Urbana.

Spring Arbor

Emmanuel

Southeastern

Nyack

Olivet Nazarene I 5-6
2-7, 8-11

11- $0,5-4$

$5-2,0-5$

$3=3,4-1,18=-3$

W 19-9

$4-7,6.5$

W 4-2

$4=0,6=0$

$4-2,2-3,3-0$

W $5-4$

W $1-0$ 


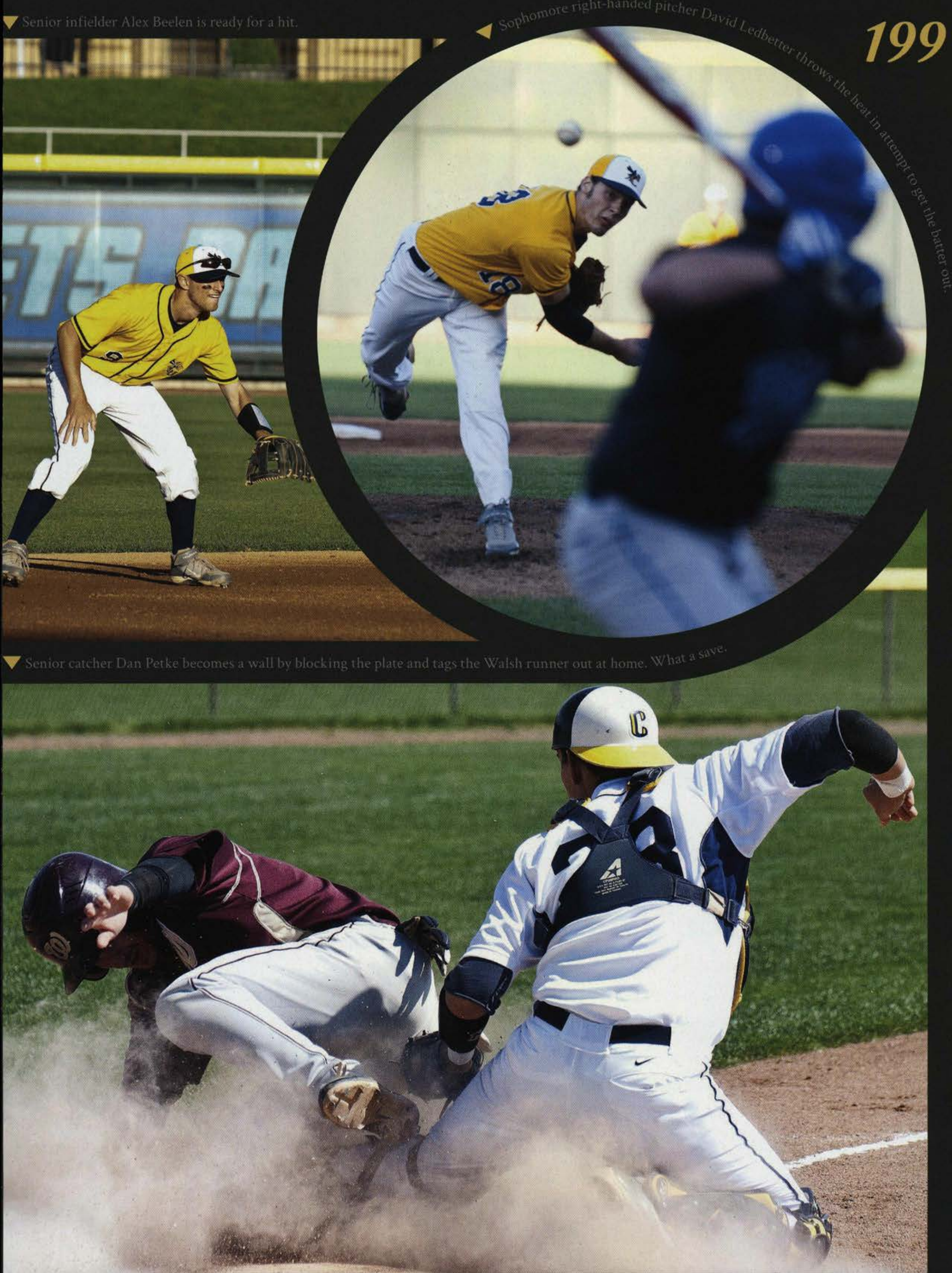




\section{Women's Softball}

The Lady Jackets made their second straight appearance at the NCCAA national tournament in Troutville, VA.

$\nabla$

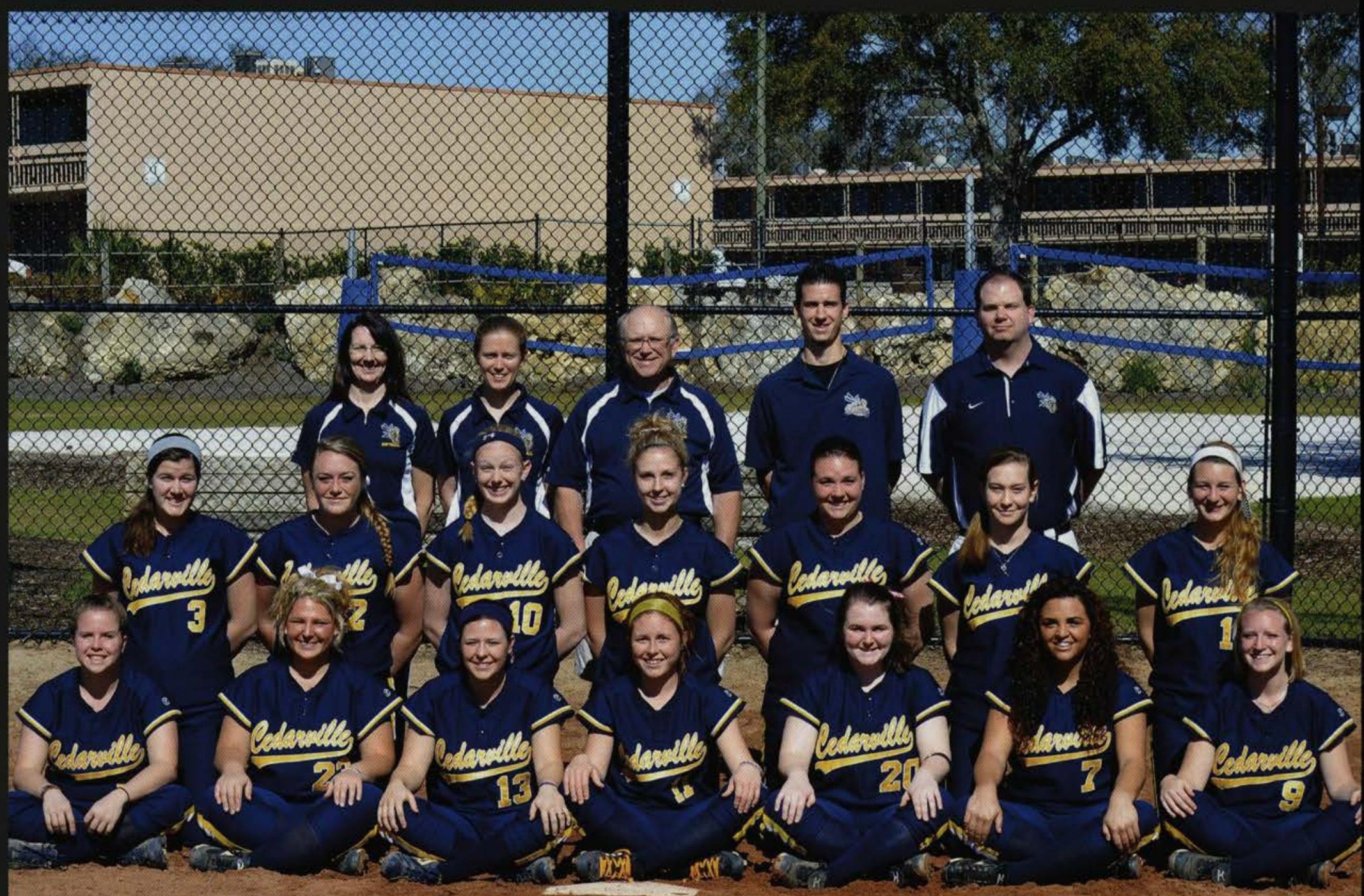
Meet the Team: 
Wo, $1 \mathrm{e}$

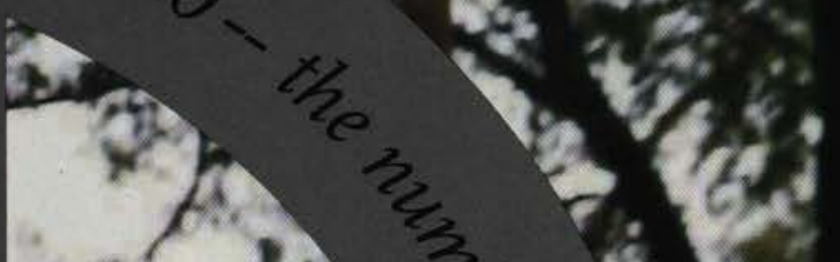
01 . 3 x $x=20$ vitid $\approx 21$ worese

cos and s.

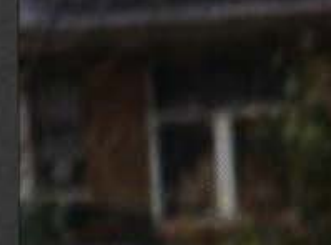

6

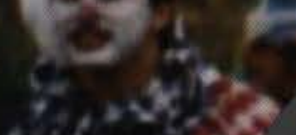

3.t)

C11 다요

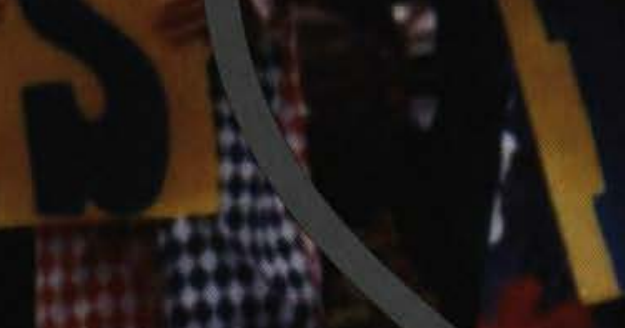

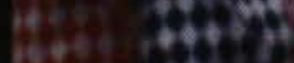

196

wet:

now

21 $\sum^{2} \quad 26$

o $\quad(x, y)$

r

है

Q

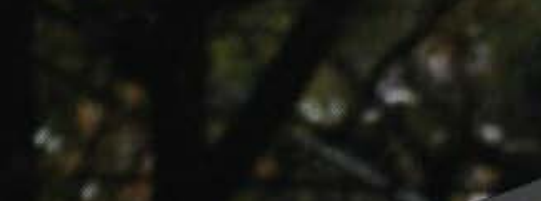
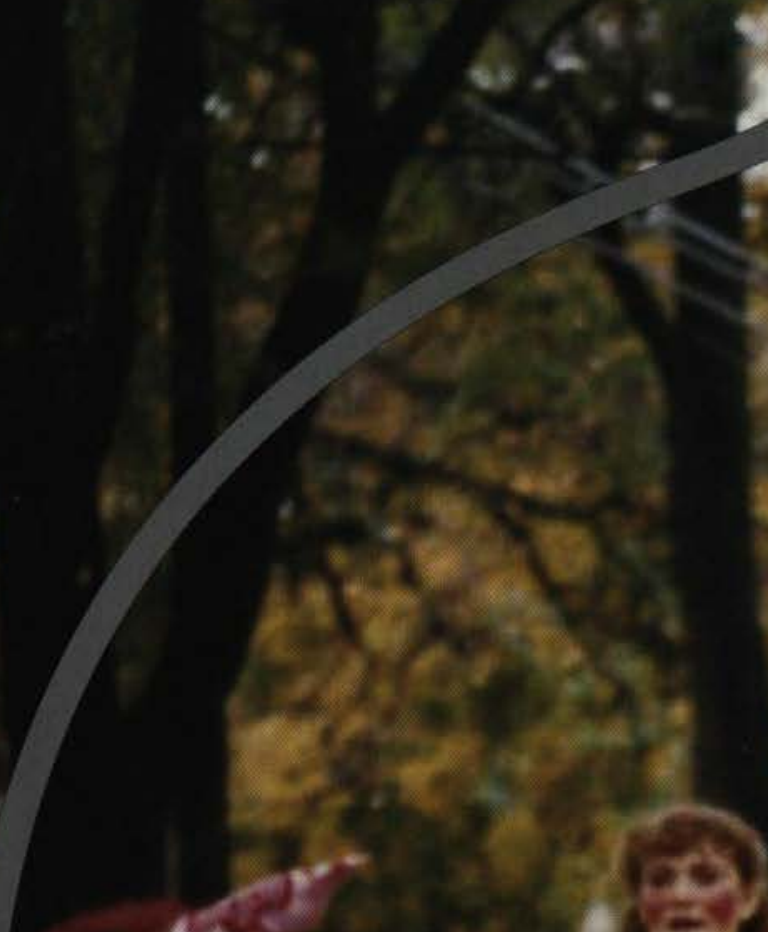

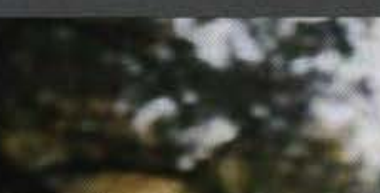

$\frac{92}{4}$

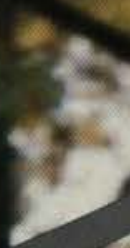

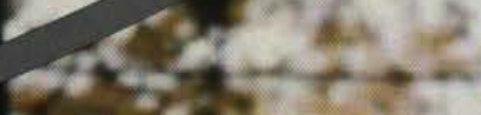

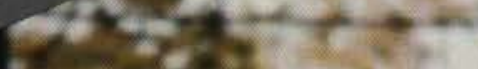

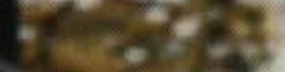
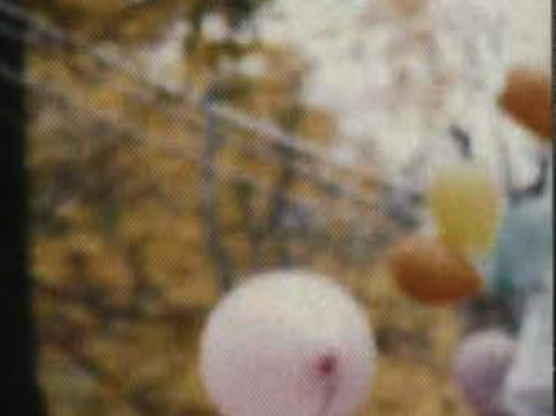

atis

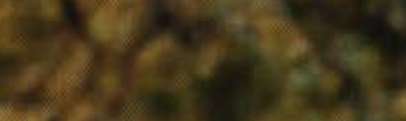

ind $x$
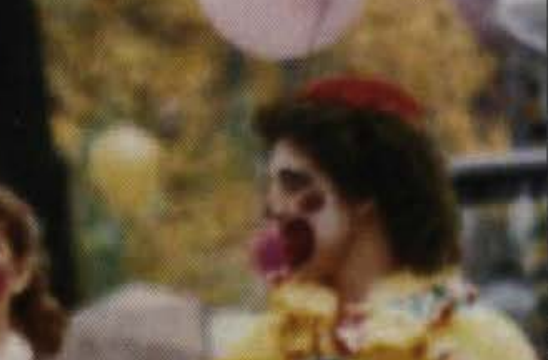
$y-1$

$\cot ^{2}+x^{2}$

in के $\checkmark$ h.

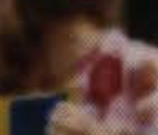

$\left(\begin{array}{l}3 \\ (2)\end{array}\right.$

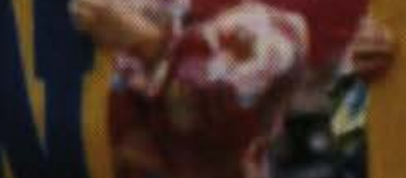
हैं 1. 3

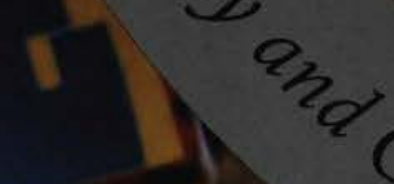

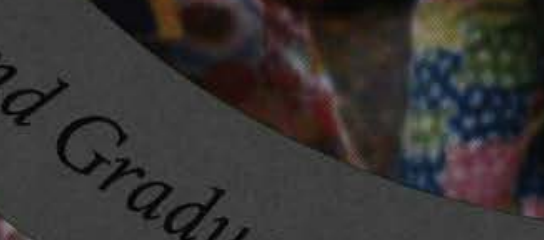

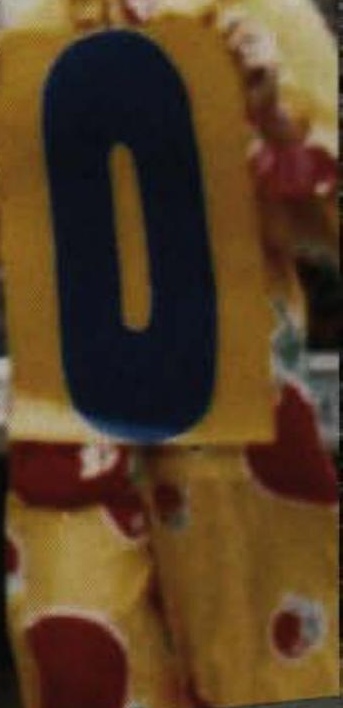




\section{Ceniors}

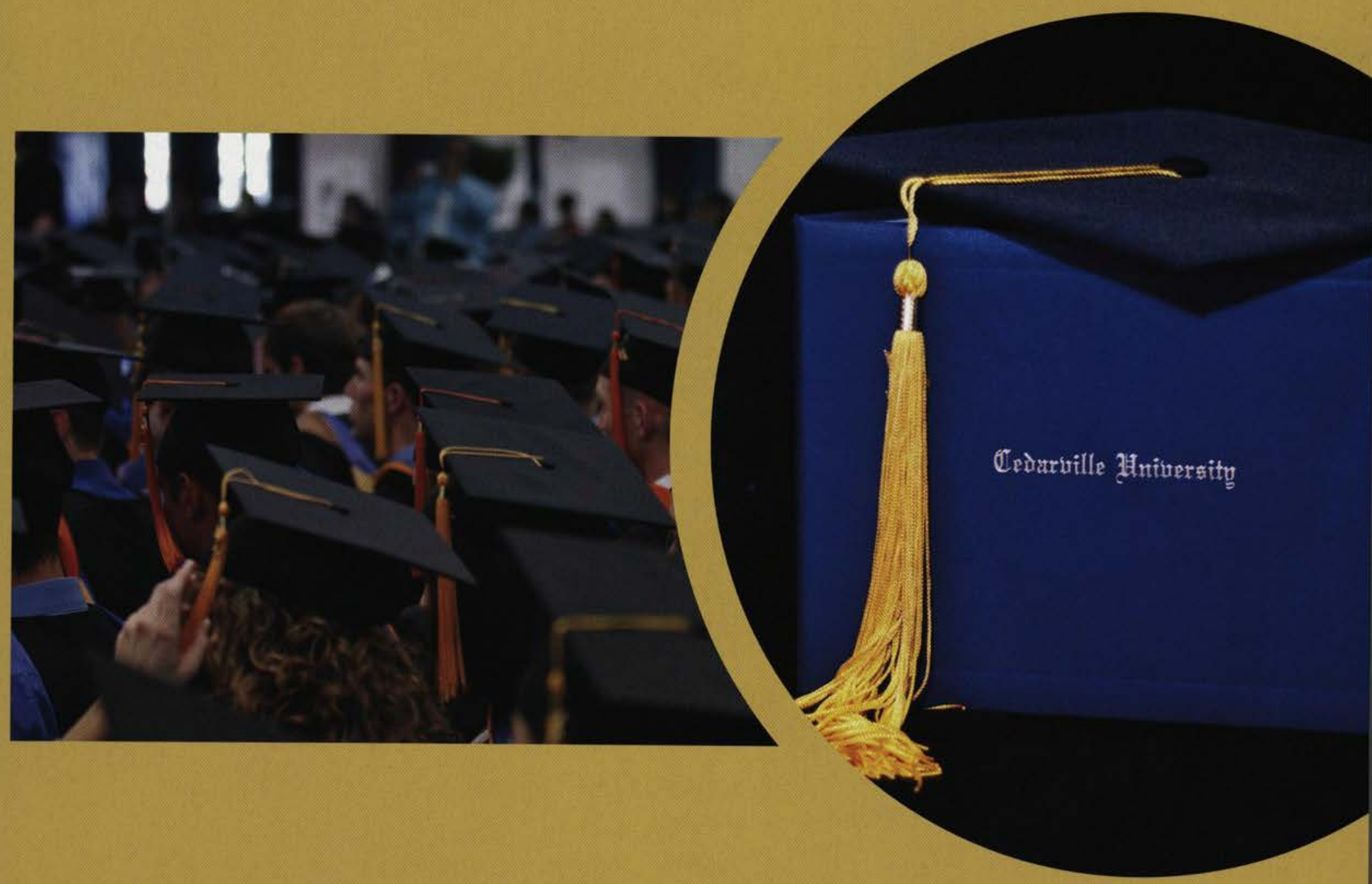

than four years, we are 


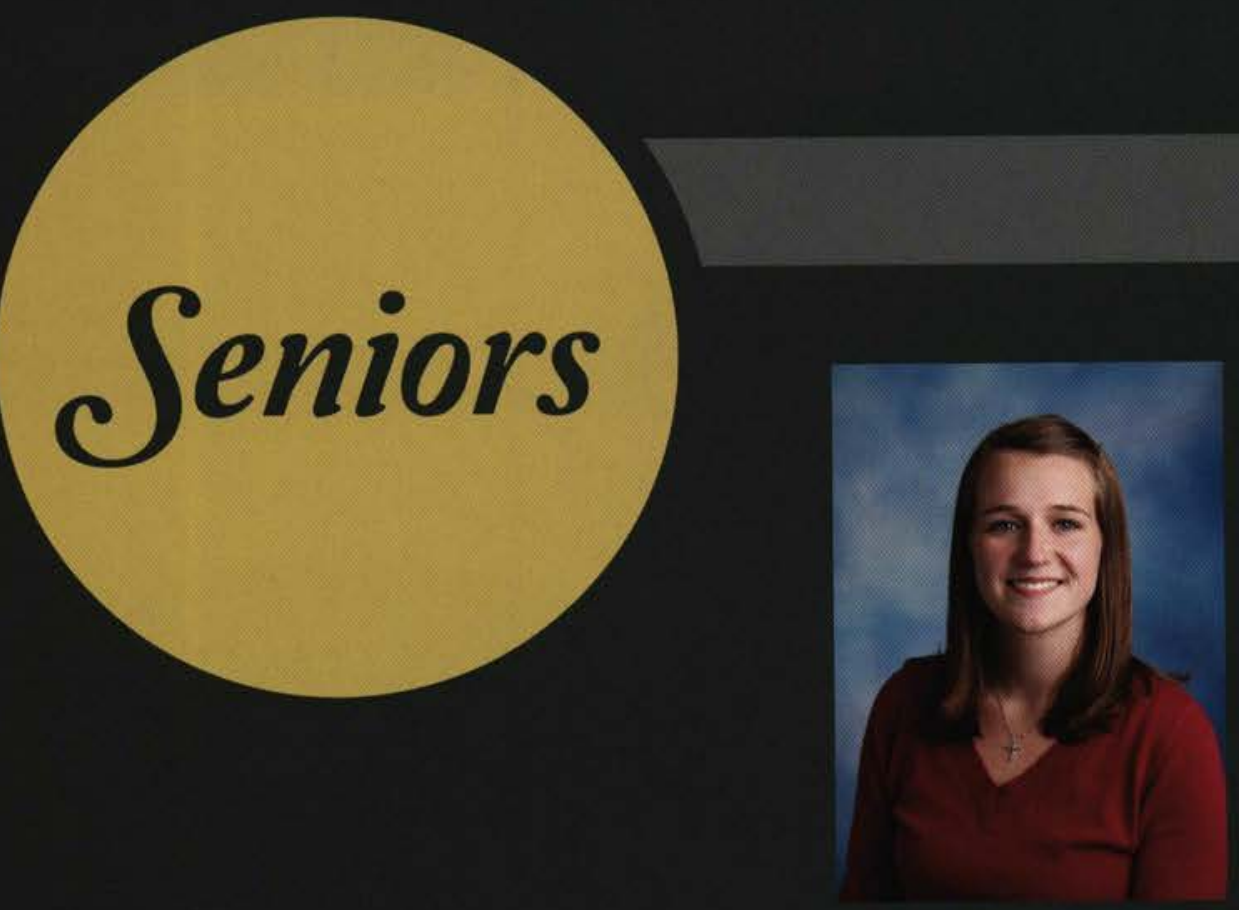

Elizabeth Ahrens

Longmeadow, MA

Nursing

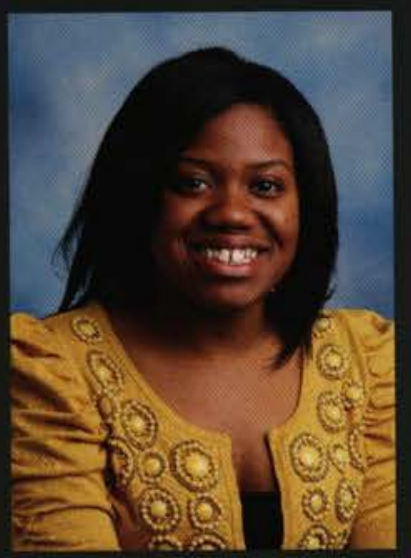

Rachel Arthur

Romulus, MI

Organizational Comm.

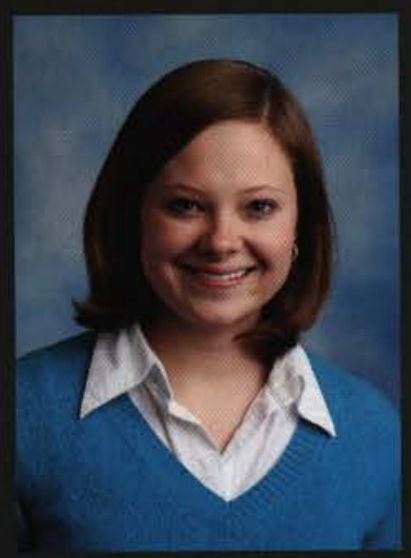

Kristen Baechtle

Vestal, NY

Geology

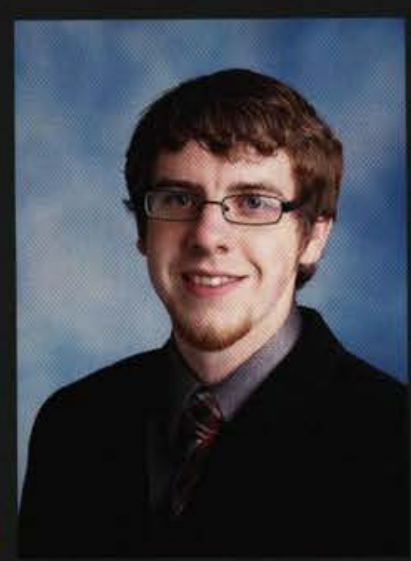

Joel Ashley

Northfield, $\mathrm{OH}$

Christian Education

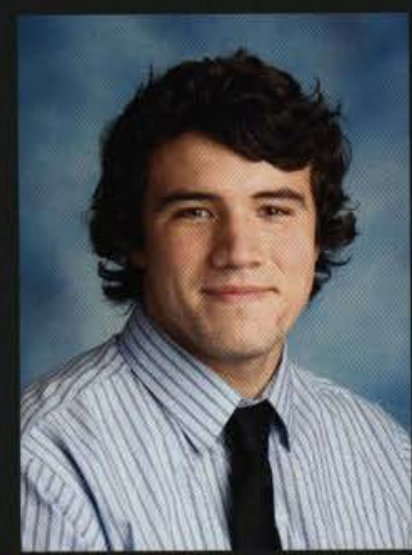

Nathan Baird

Broadabin, NY

Graphic Design

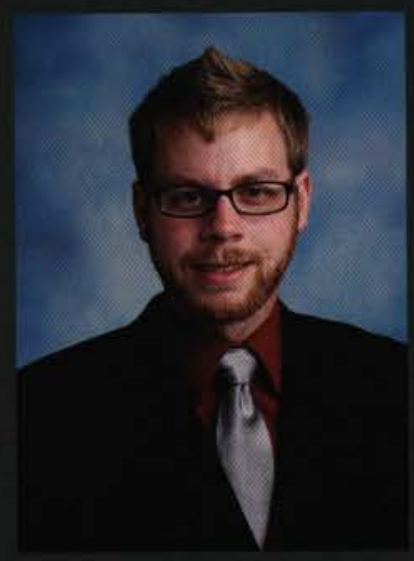

Jonathan Ashley

Northfield, $\mathrm{OH}$

Youth Ministry

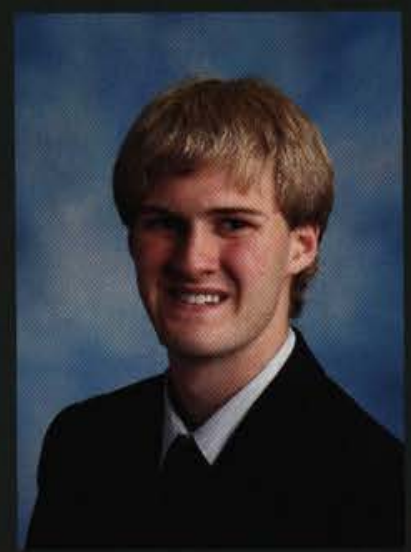

Dane Baldwin

Plain City, $\mathrm{OH}$

Computer Science

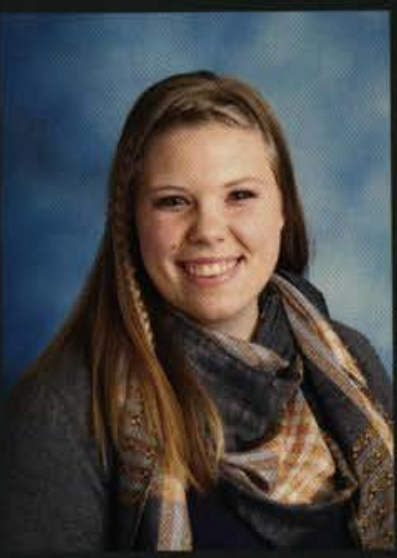

Angela Allen

Toledo, $\mathrm{OH}$

History \& Political Science

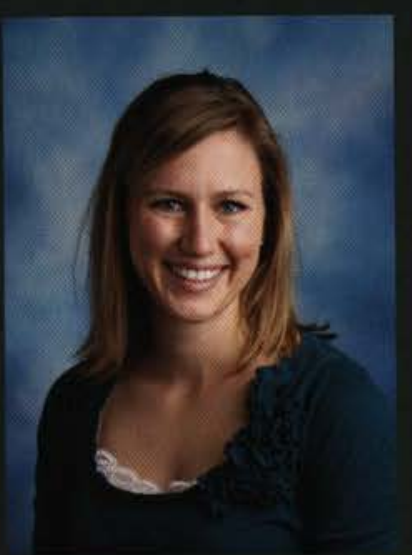

Laura Backer

Columbus, $\mathrm{OH}$

Industrial \& Innov Design

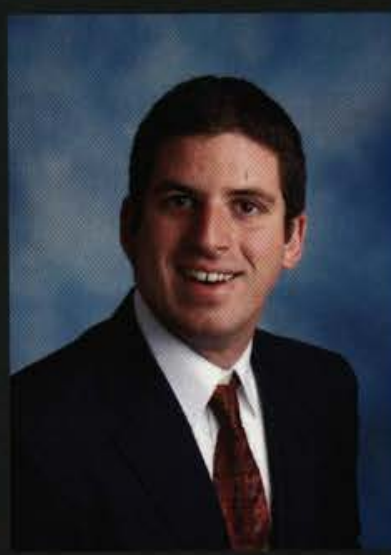

John Baldwin

Jackson, MI

Middle Childhood Edu.

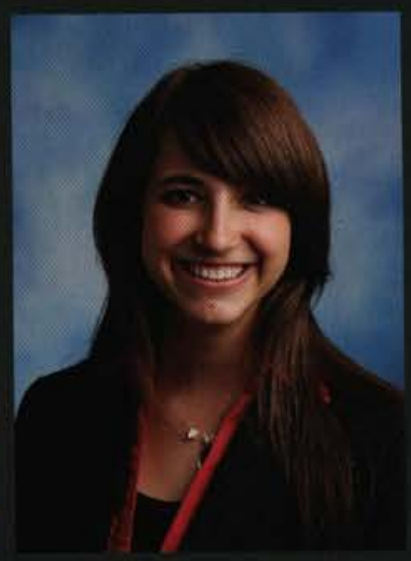

Stephanie Anderson

Rockford, IL

Theatre

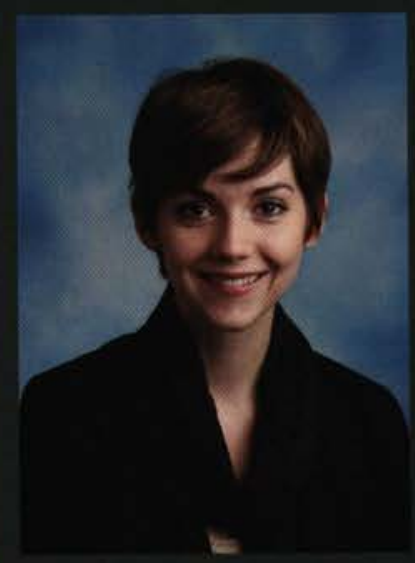

Ariel Bacon

Bellbrook, $\mathrm{OH}$

Music

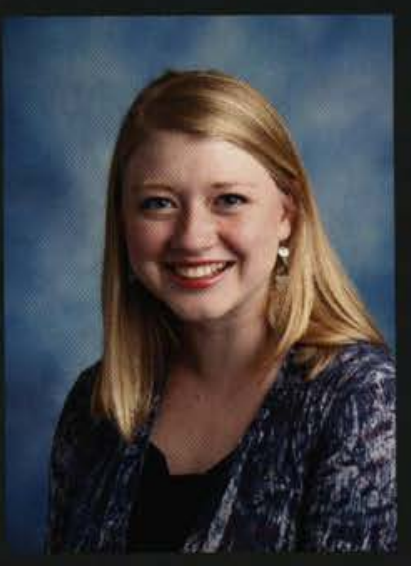

Geneva Banz

Telford, PA

Nursing 


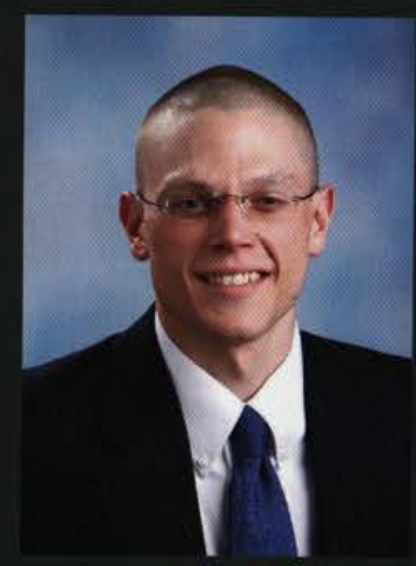

Jacob Bapst

Lucasville, $\mathrm{OH}$

Mechanical Engineering

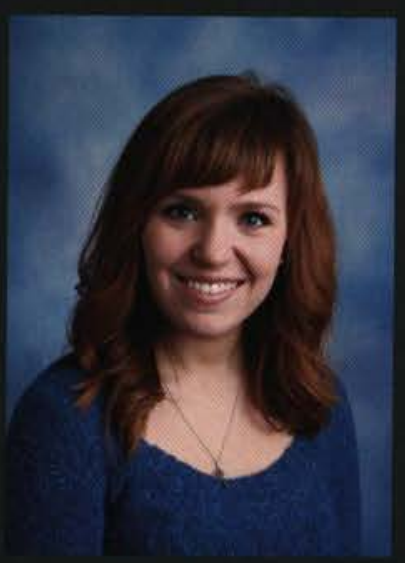

Erin Bartley

Rio Grande, $\mathrm{OH}$

Tech \& Prof Comm.

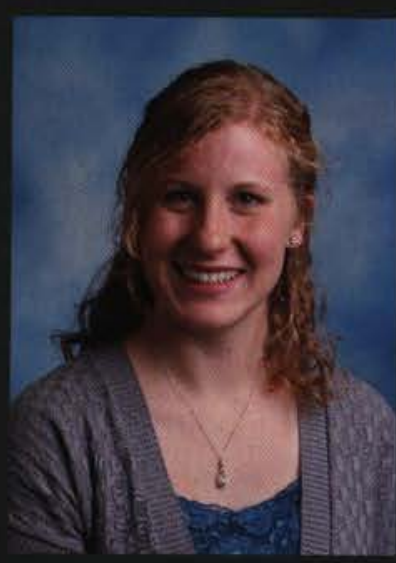

Molly Bearden

Sheridan, WY

Early Childhood Education

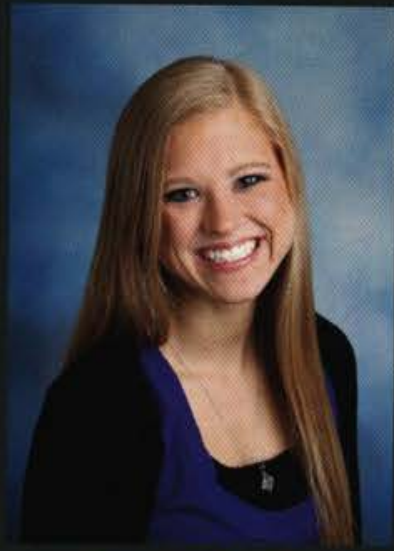

Samantha Barclay

Berlin Heights, OH

Biology

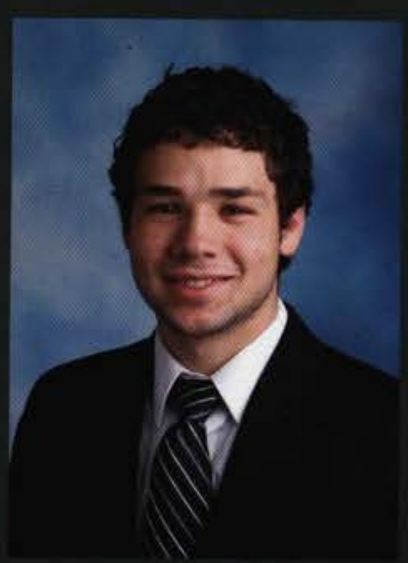

Andrew Bash

Jamestown, OH

Graphic Design

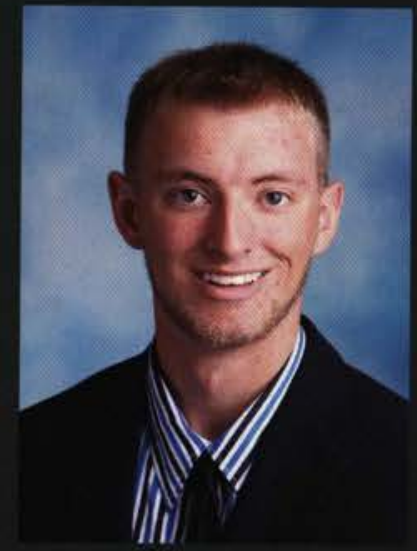

Alexander Beelen

Bidwell, $\mathrm{OH}$

Allied Health

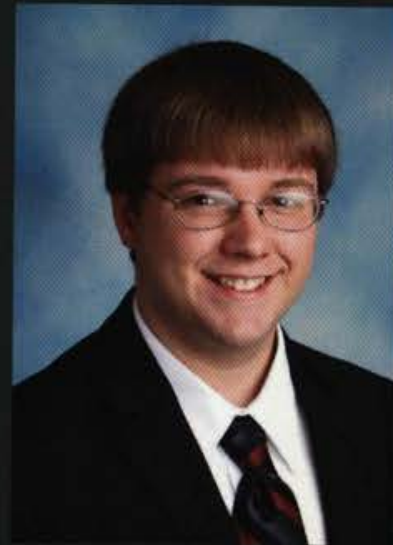

Jacob Barker

Franklin, $\mathrm{OH}$

Computer Engineering

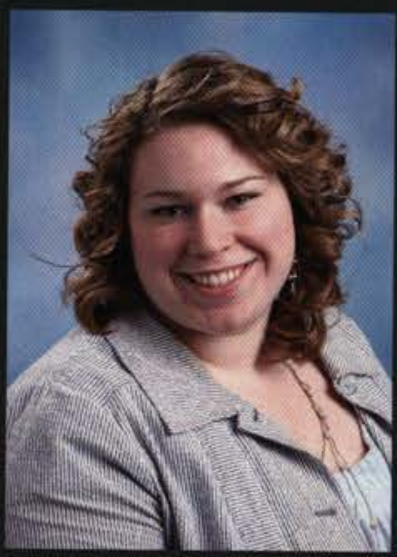

Sarah Bates

Montague, NJ

Language Arts Education

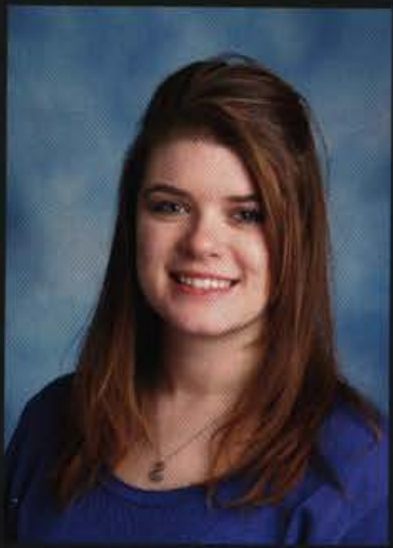

Lauren Bell

Lucasville, $\mathrm{OH}$

Organizational Comm.

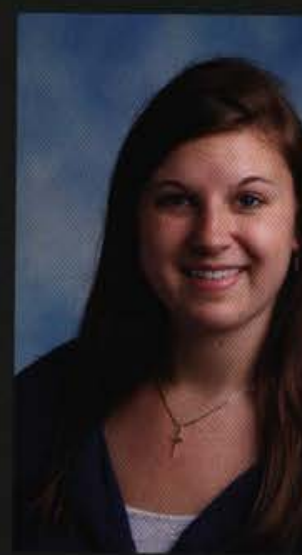

Rebekah Baron

Maineville, $\mathrm{OH}$

Nursing

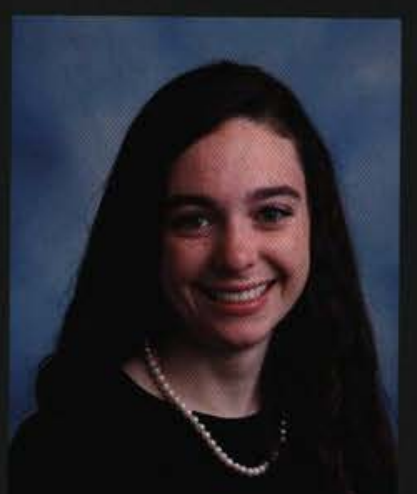

Christine Battis

Chanhassen, MN

Biology

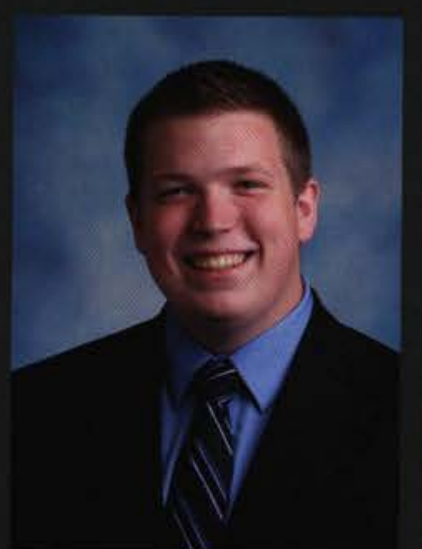

Ryan Belton

Union Grove, WI

Graphic Design

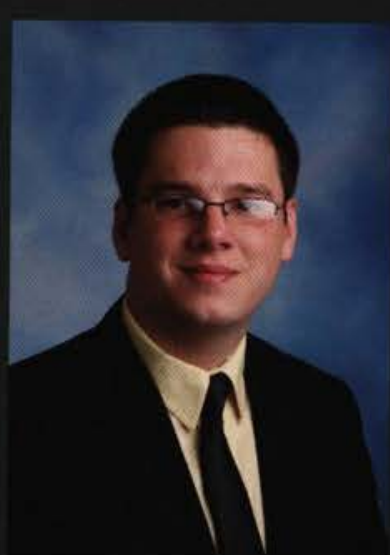

Collin Barrett

Kalamazoo, MI

Computer Engineering

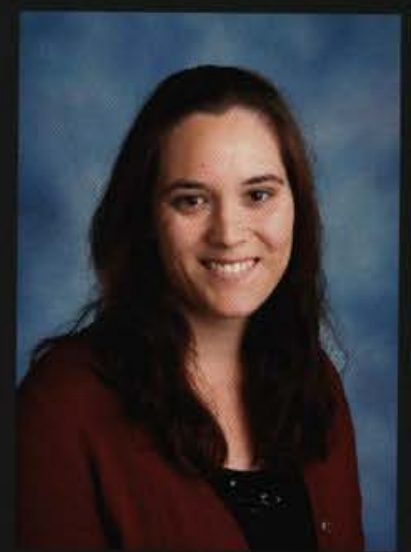

Rachel Beachy

Sutton, AK

Tech \& Prof Comm.

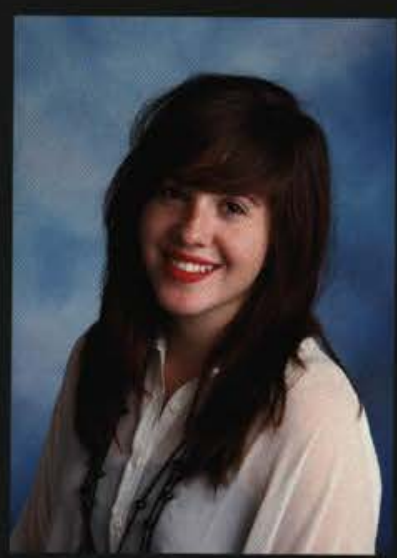

Kathleen Bernard Magnolia, DE

Special Education 


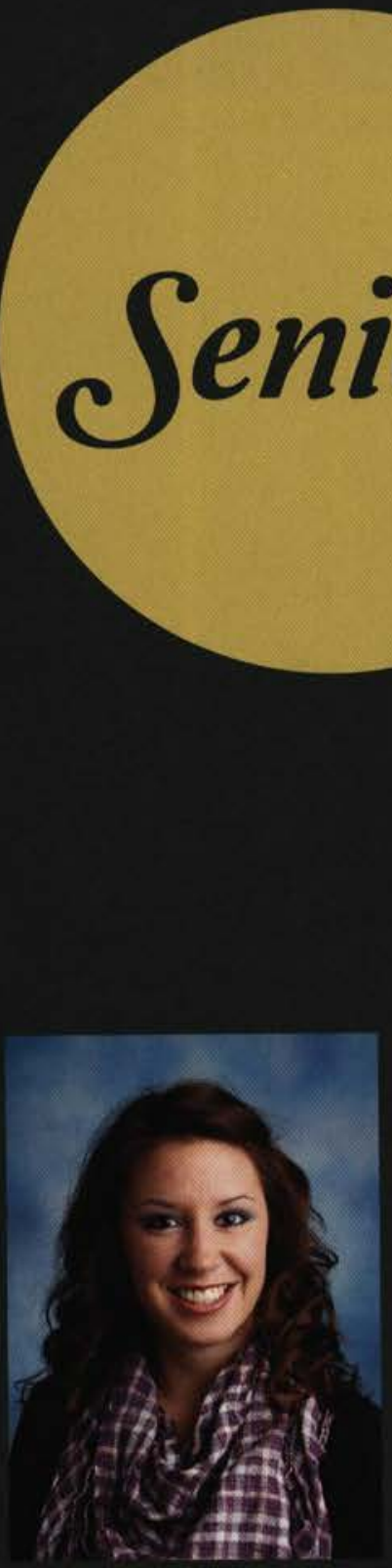

Vawny Blackburn Minneapolis, $\mathrm{MN}$ Social Work

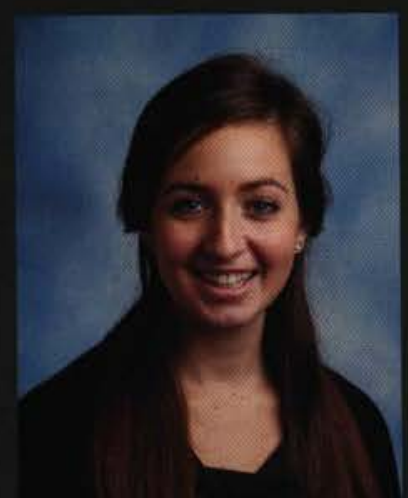

Rachel Bowman

Plainwell, MI

Criminal Justice

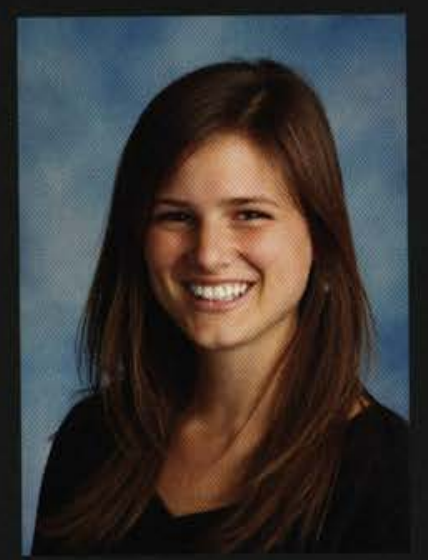

Michelle Blackstone Independence, $\mathrm{KY}$ Graphic Design

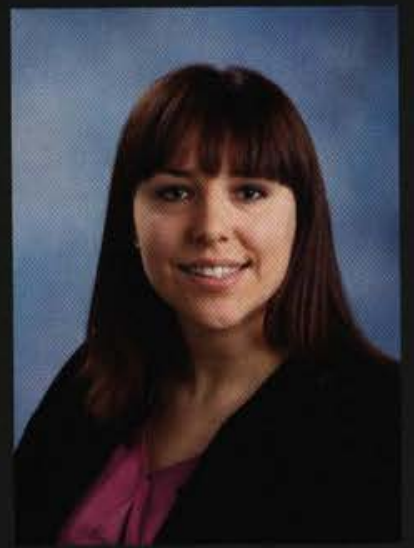

Heather Boyd Chantily, VA Marketing

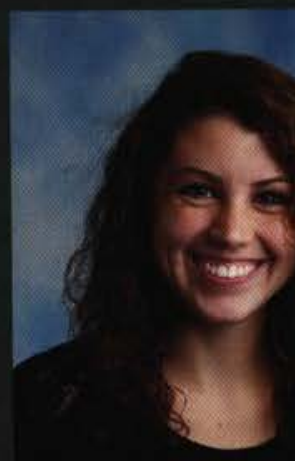

Molly Bewley

Cincinnati, $\mathrm{OH}$

Nursing

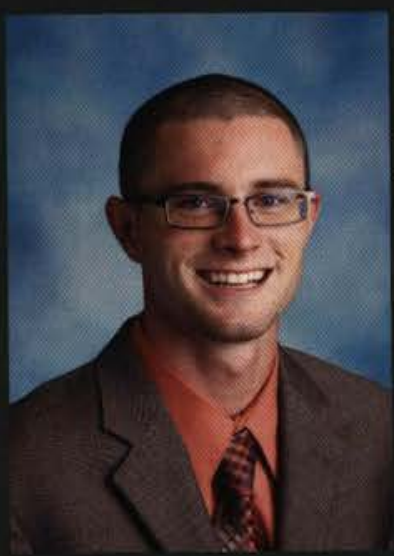

Ethan Blagg

Marshalltown, IA

Exercise Science

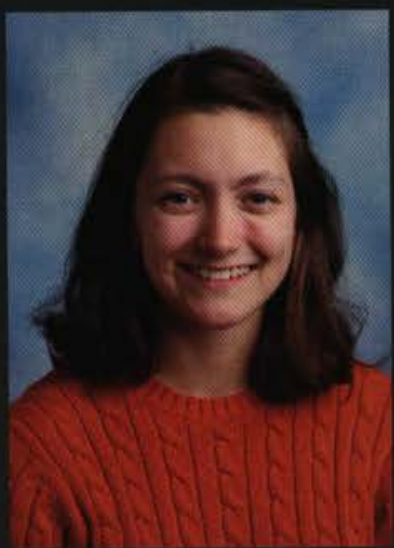

Amanda Brindley

Thomasville, NC

Preseminary Bible

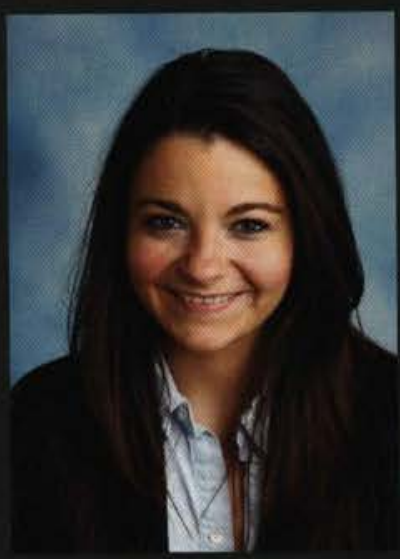

Emily Bielek Jamestown, $\mathrm{OH}$

History

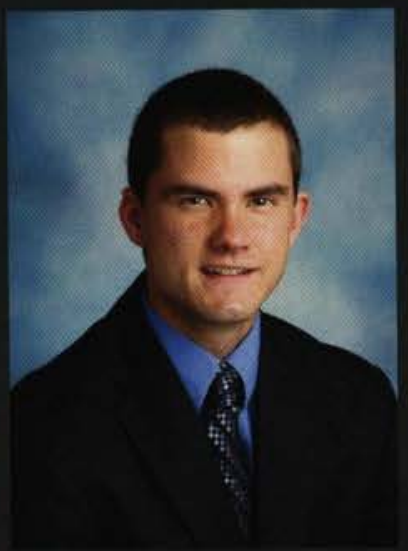

David Boltz Indianapolis, IN

Marketing

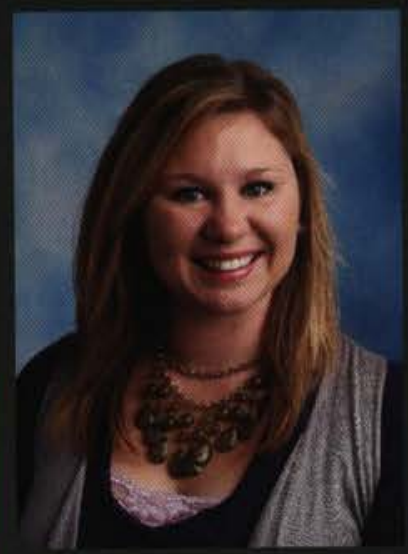

Sarah Brittan

Mattawan, MI

Middle Childhood Edu.

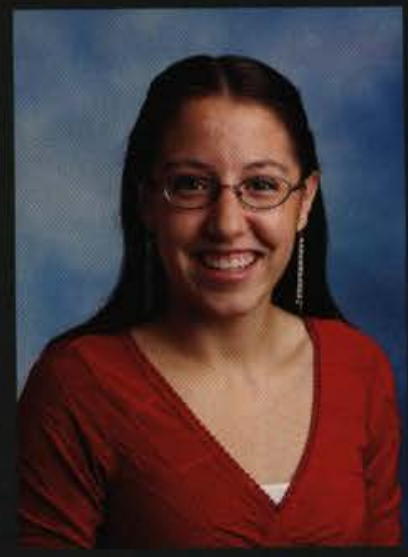

Valentina Blackburn Minneapolis, $\mathrm{MN}$ Christian Education

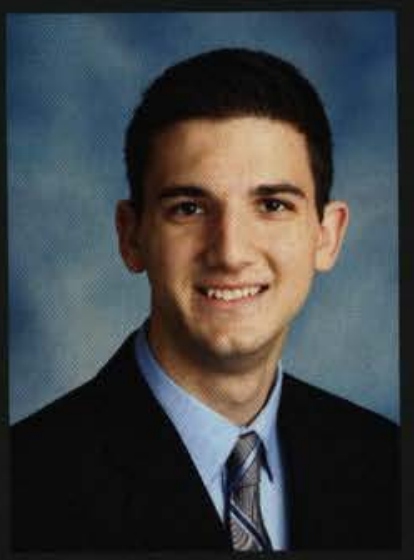

David Bonifas

Bronx, NY

Excercise Science

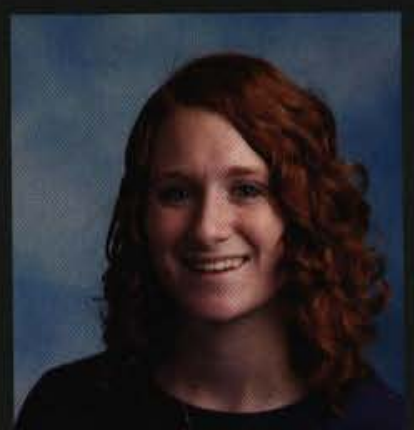

Andrea Brown

Portland, MI

Mathematics 


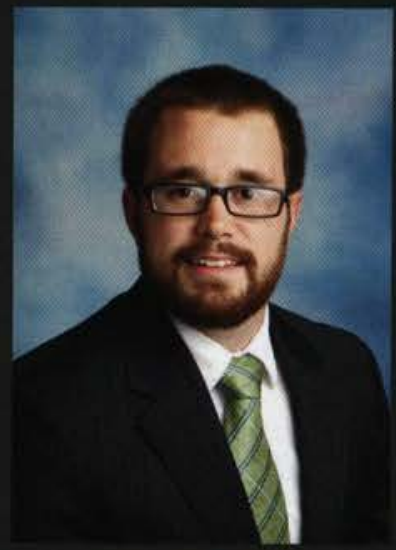

Douglas Brown

Lake Stevens, WA

Organizational Comm.

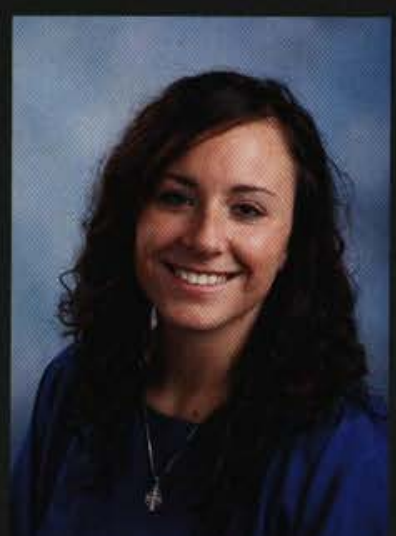

Sarah Brownfield

Dublin, $\mathrm{OH}$

Nursing

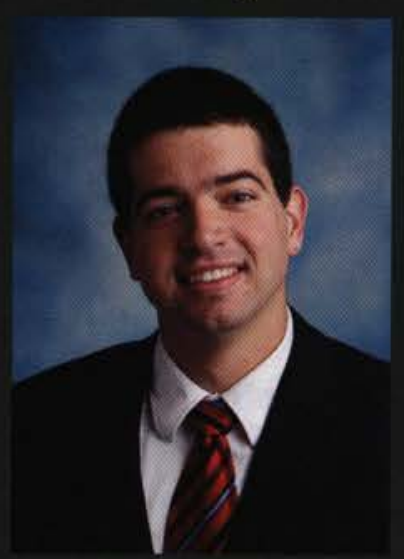

Zachary Burt

Westerville, $\mathrm{OH}$

Chemistry

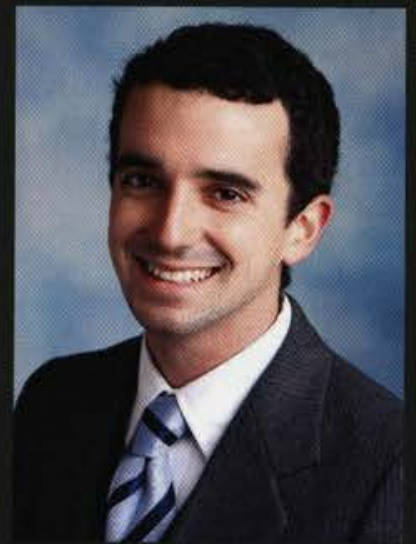

Jacob Brown

Landsdale, PA

Nursing

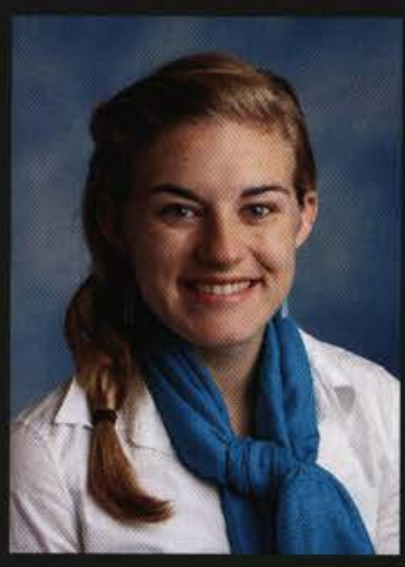

Hannah Bryan

Manns Choice, PA

Tech \& Prof Comm.

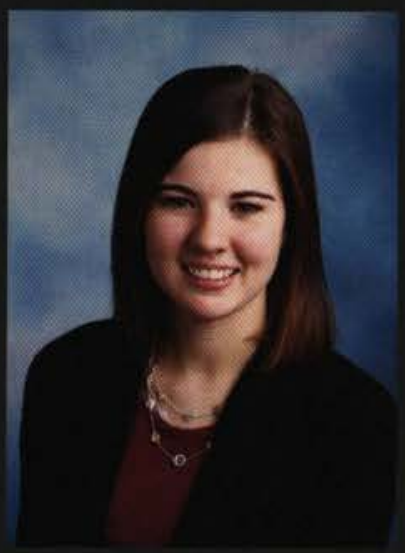

Hannah Campbell

Baberton, $\mathrm{OH}$

Early Childhood Education

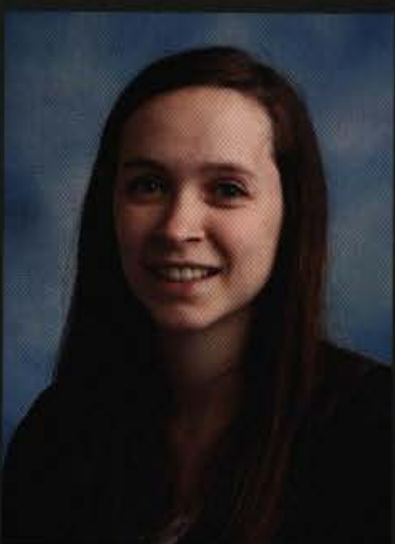

Kara Brown

Cedarville, $\mathrm{OH}$

Mathematics Education

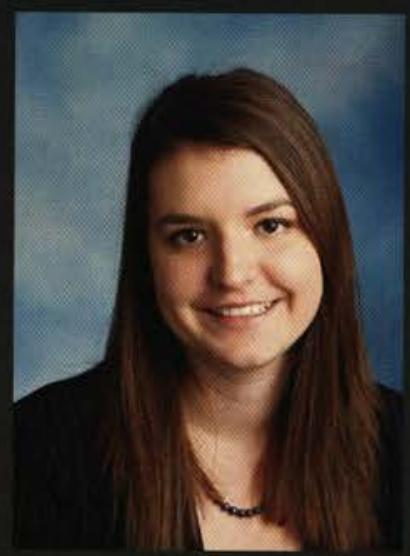

Tiffany Buehler

Naples, FL

Business Management

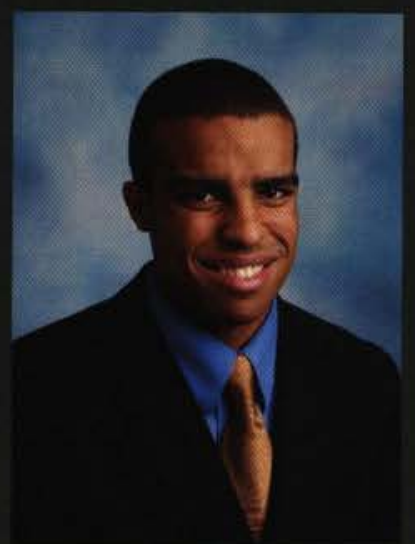

Stephen Campbell

Windermere, FL

History \& Political Science

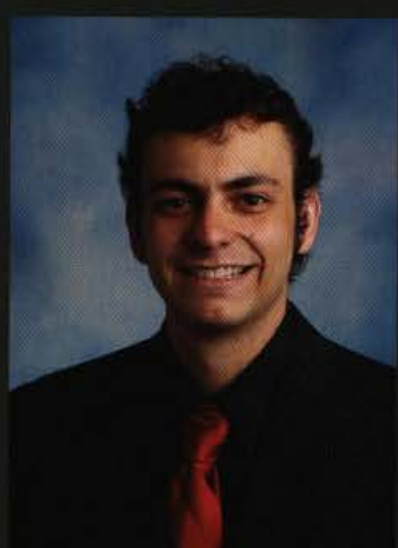

Nathan Brown

Moorpark, CA

Computer Science

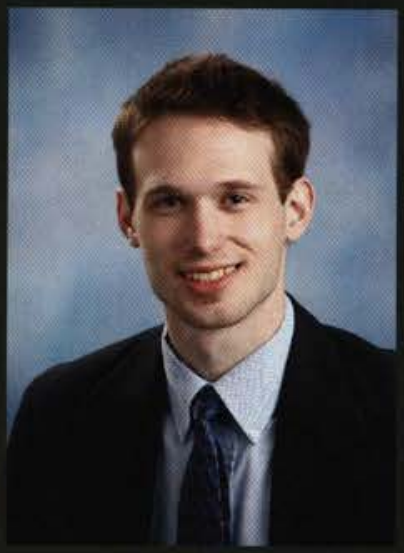

Jonathan Bundy

Columbus, $\mathrm{OH}$

Journalism

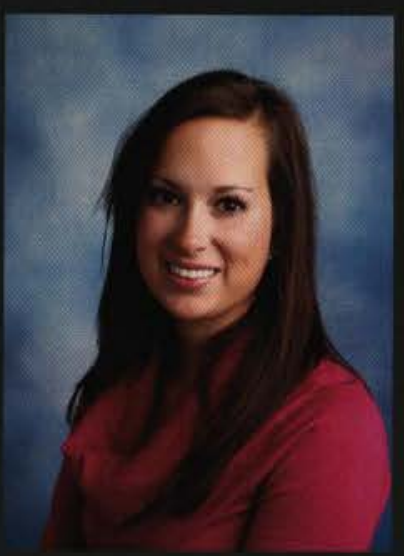

Abigail Carlson

Urbandale, IA

Nursing

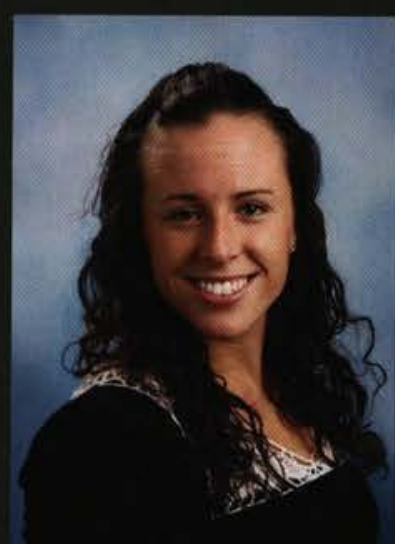

Rachel Brownfield

Dublin, $\mathrm{OH}$

Biology

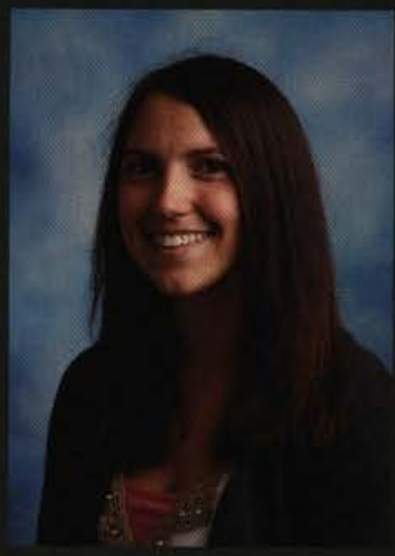

Brittany Burkholder

Springfield, $\mathrm{OH}$

Early Childhood Education

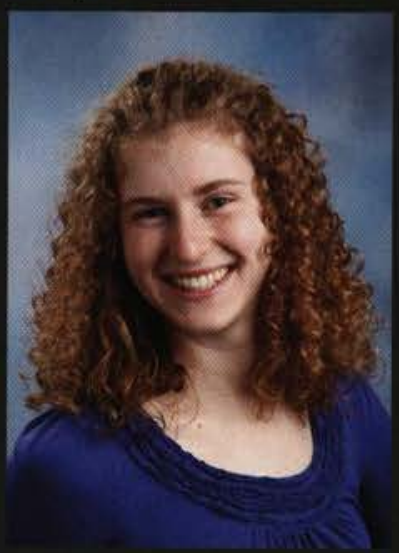

Meagan Carns

Sierra Vista, AZ

Early Childhood Education 


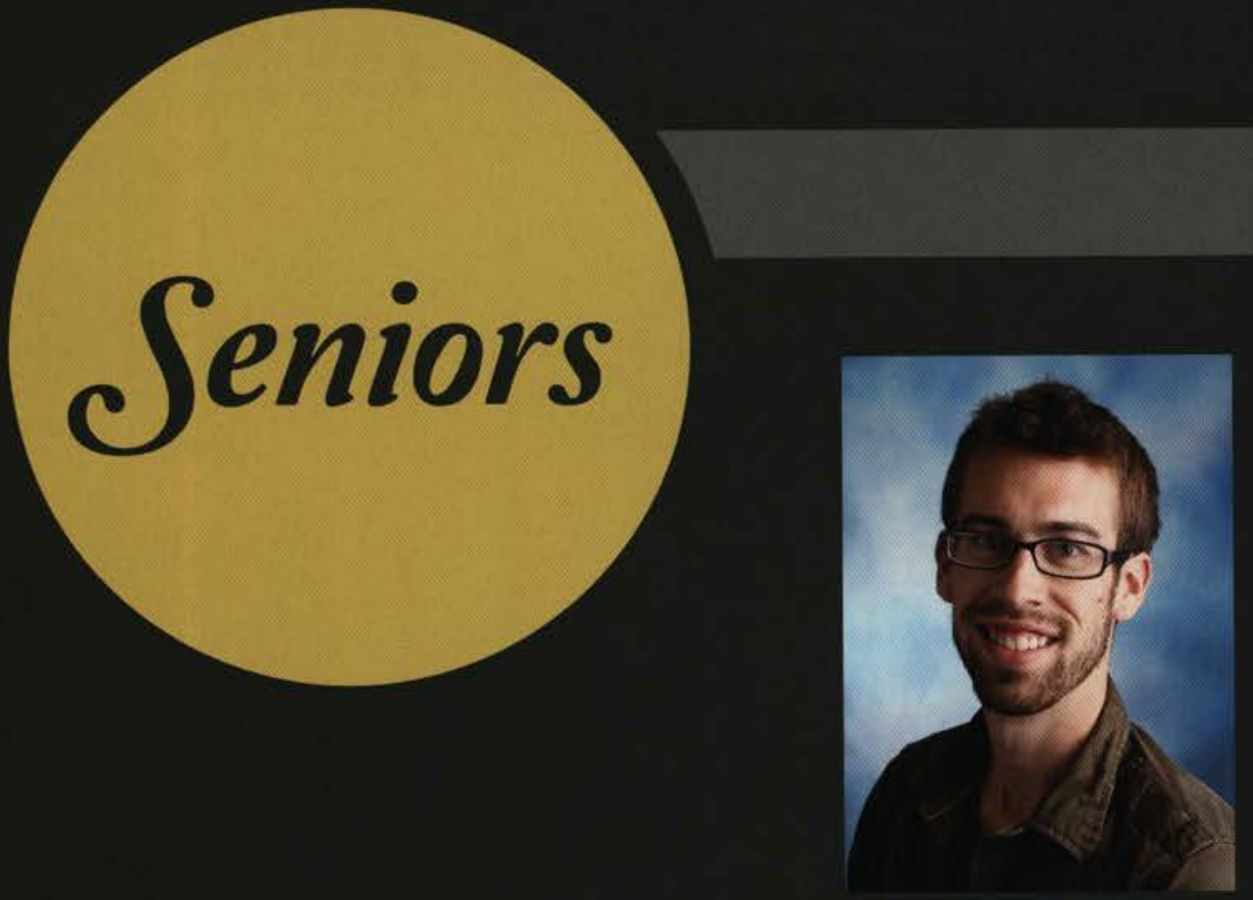

Robbie Carter

Pittsboro, IN

Comprehensive Bible

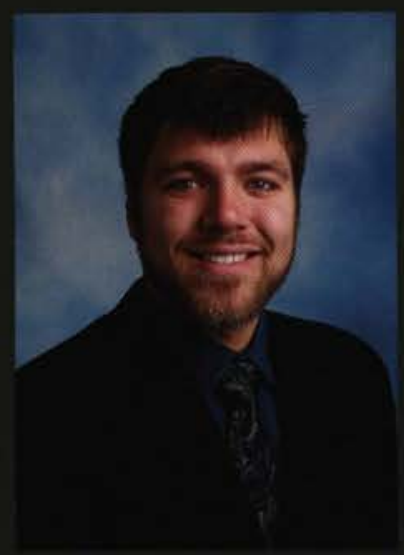

Grayson Gato

Cedarville, $\mathrm{OH}$

Comprehensive Bible

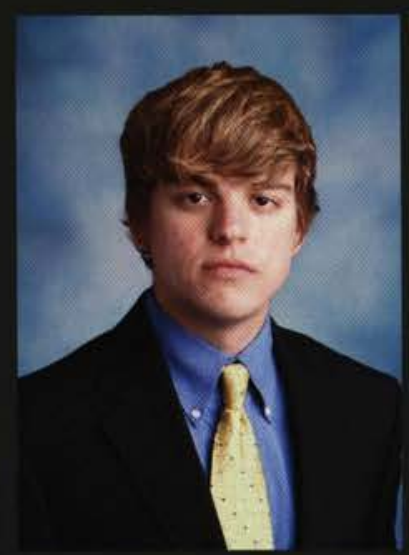

Anthony Chester

Springboro, $\mathrm{OH}$

Prelaw

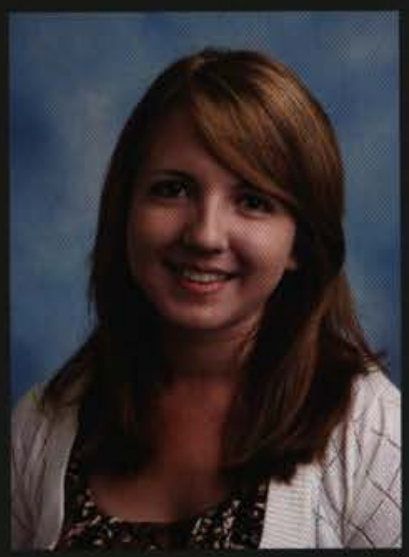

Samantha Cazzell

Centerville, $\mathrm{OH}$

Pyschology

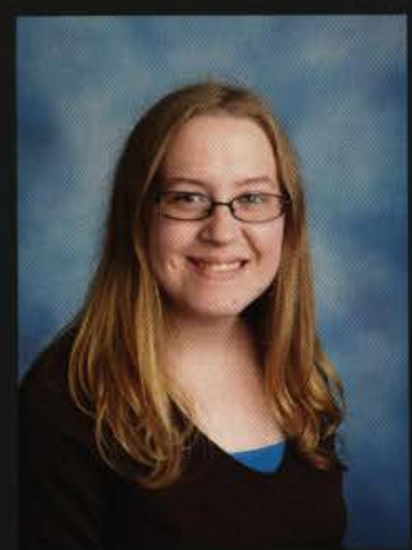

Brenna Christiansen

Northwood, $\mathrm{OH}$ History

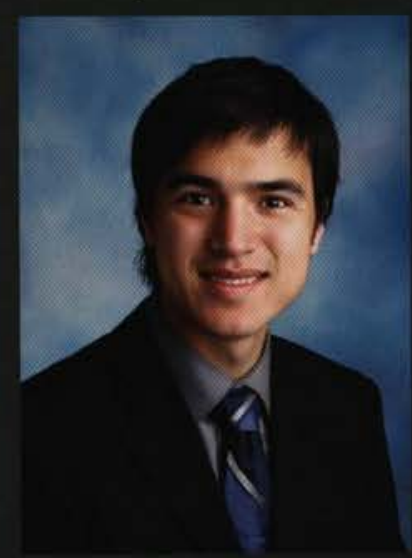

Tyler Chan

Las Vegas, NV

Electrical Engineering

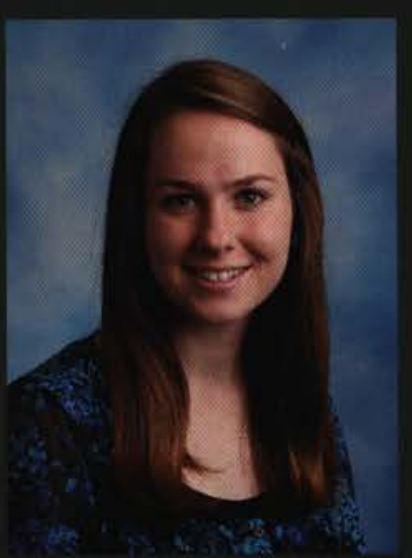

Ruth Christiansen

Wauconda, IL

Allied Health

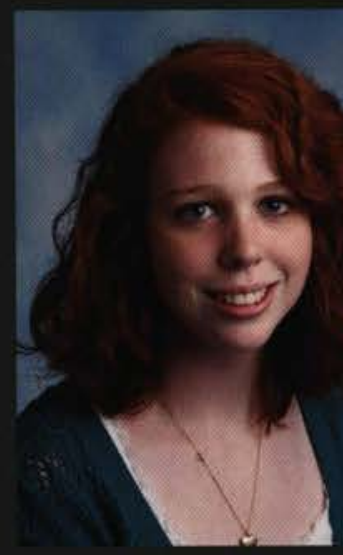

Sarah Cash

Duncannon, PA

Nursing

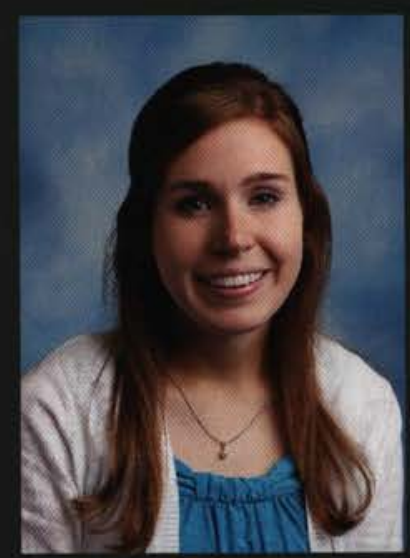

Kimberly Cheeseman

Newtown Square, PA

Accounting

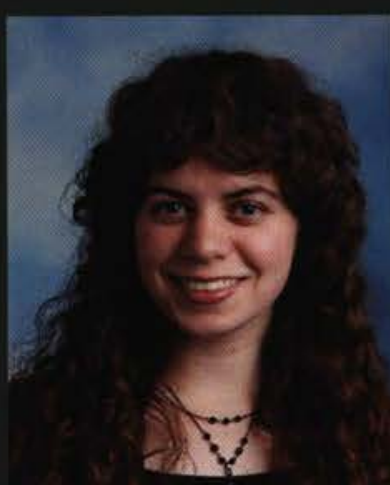

Stephanie Chrystal Xenia, $\mathrm{OH}$

Tech \& Prof Comm.

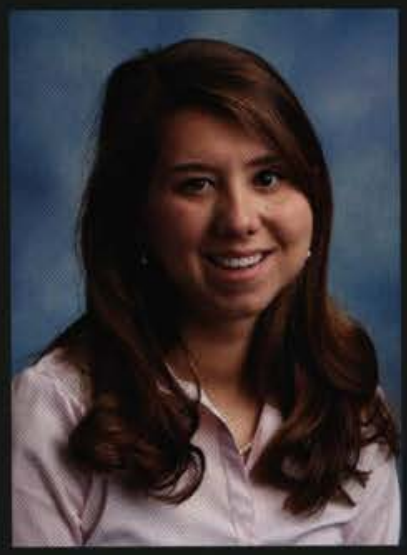

Margaret Casillo Lansdale, PA Pyschology

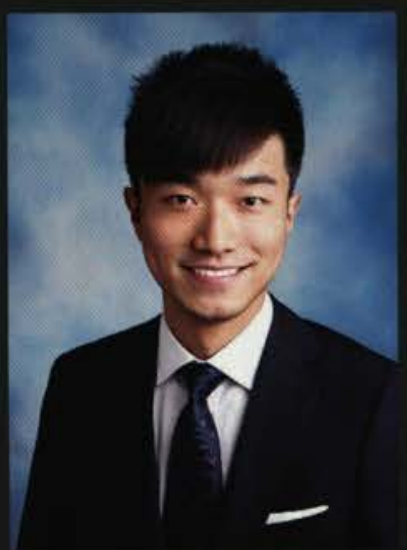

Qiudong Chen Jiangsu, China Chemistry

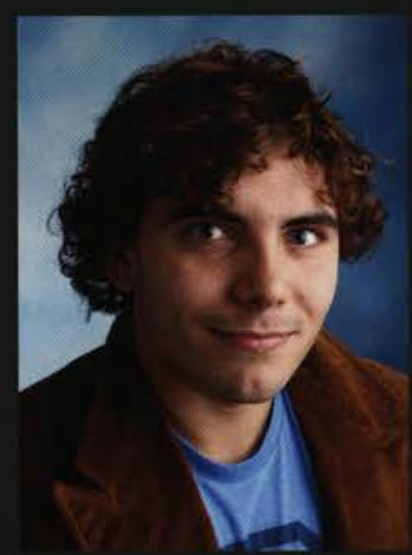

David Gianci

Mount Vernon, NH International Studies 


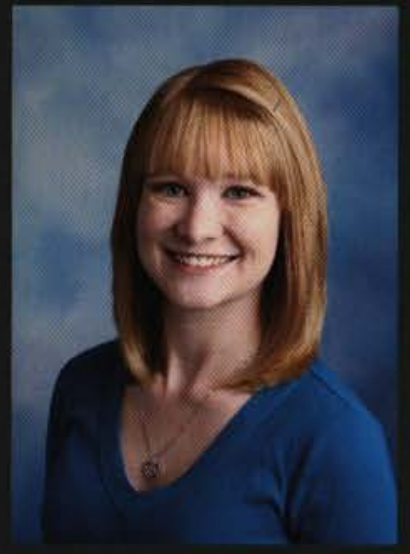

Heather Clark

Bethel, $\mathrm{OH}$

Chemistry

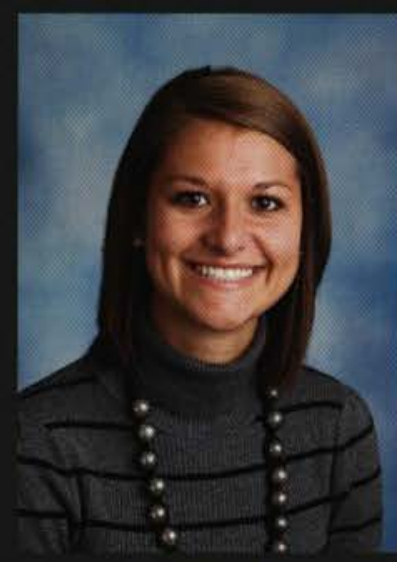

Laura Cook

Mason, $\mathrm{OH}$

Graphic Design

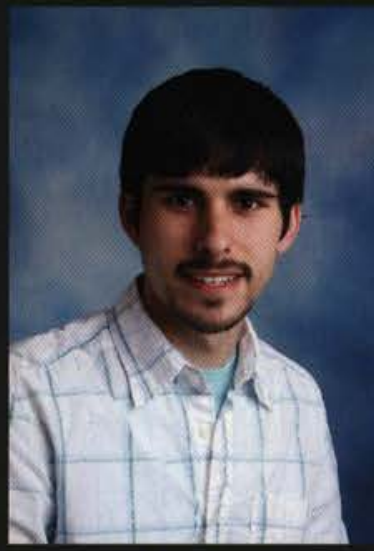

John Coules Apalachin, NY Youth Ministry

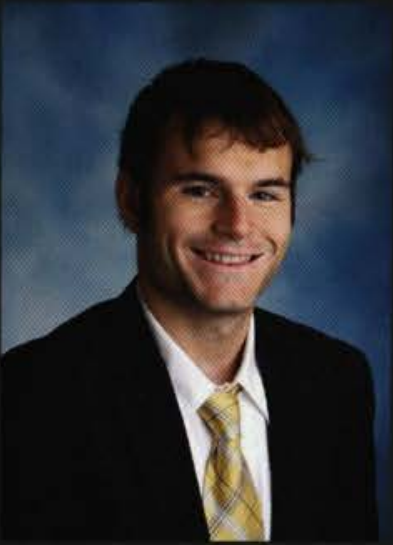

Jordan Clark

Medina, $\mathrm{OH}$

Int'l Business/Global Econ.

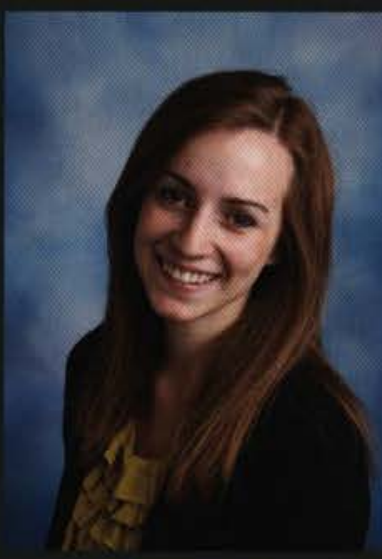

Julianne Cooper

Westfield, MA

Social Work
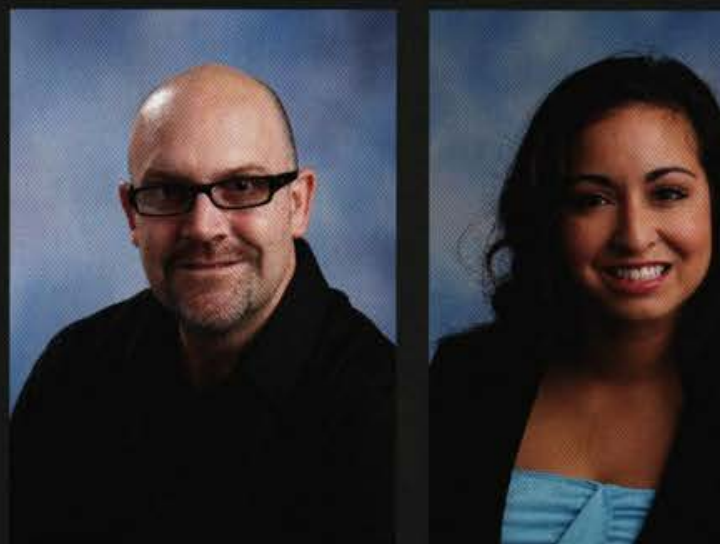

Kenneth Coulson

Brisbane, Australia

Geology

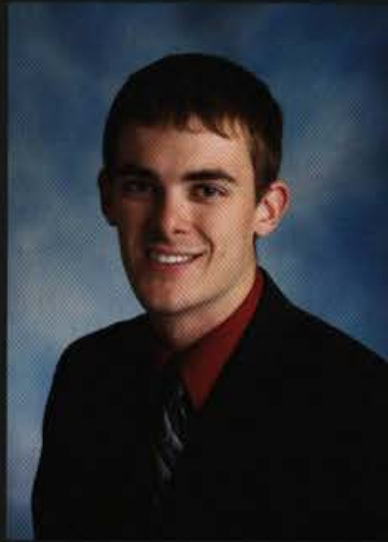

Luke Clore

Clarklake, MI

Biology

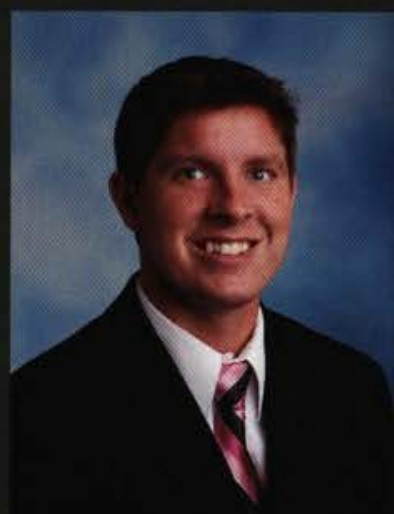

Matthew Coover

Henryville, PA

Marketing

Janemarie Covel Middletown, DE

Finance

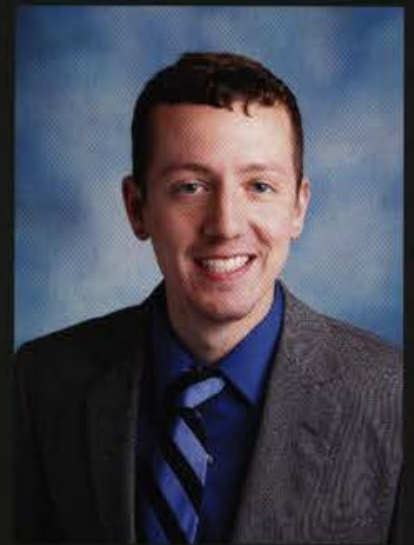

Andrew Comers

Columbus, $\mathrm{OH}$

Electronic Media

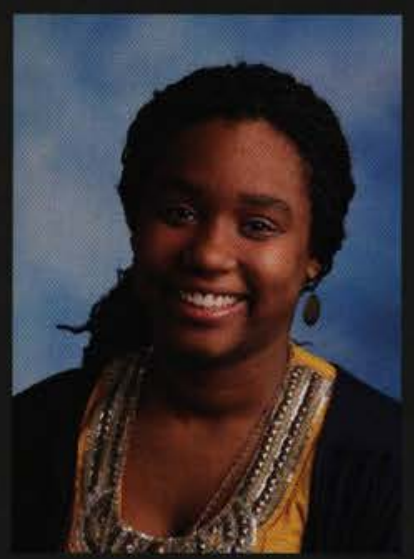

Hope Cornelius

Cheltentham, PA

Social Work

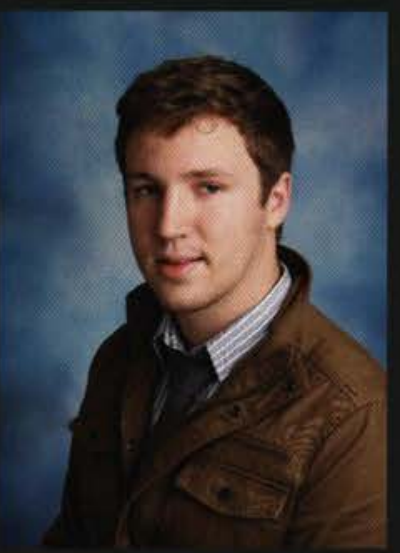

Samuel Cowden

Hickory, PA

Broadcasting/Digital Media

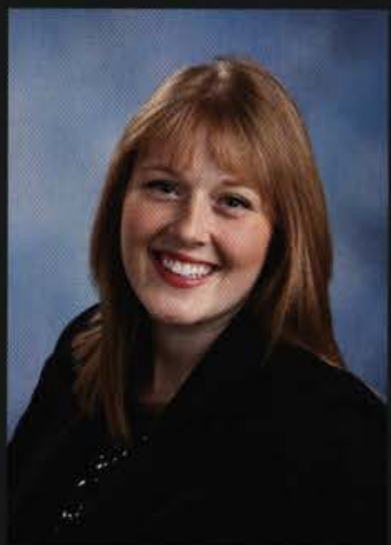

Stephanie Comley Miamisburg, $\mathrm{OH}$ Marketing

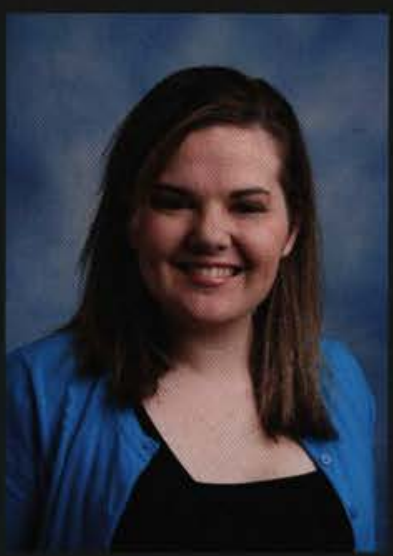

Lindsay Cornish

Venice, FL

Nursing

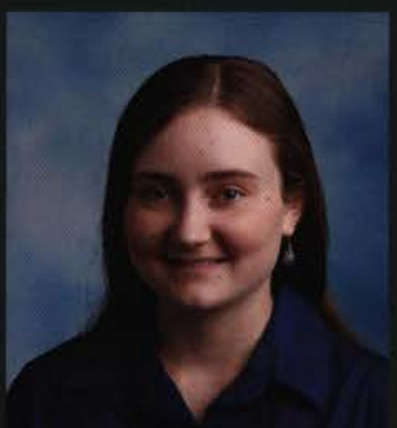

Miriam Crane

Richmond, IN

Exercise Science 


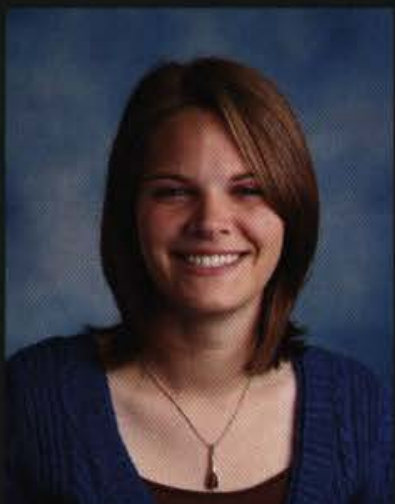

Jennifer Dixson

Berwick, PA

Social Work

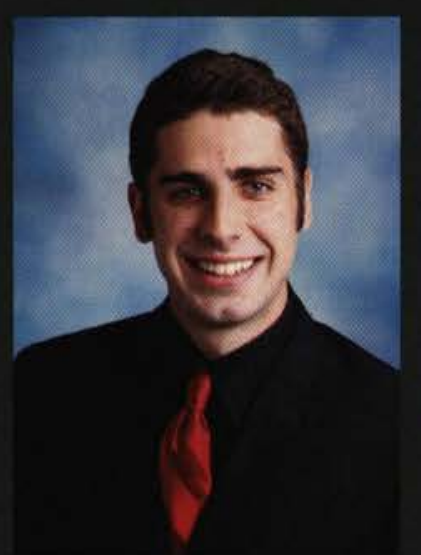

Christopher Durbin

Shaker Heights, $\mathrm{OH}$

Youth Ministry

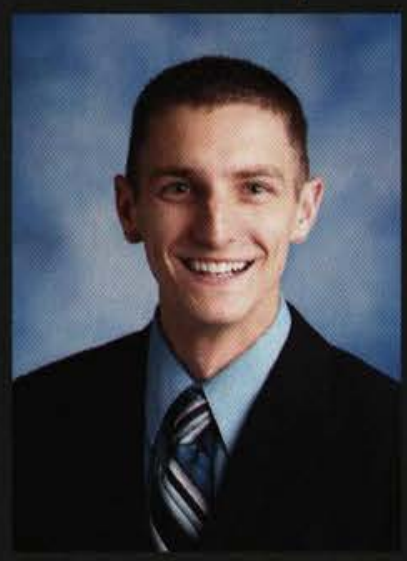

Andrew Englund

New Braunfels, TX

Chemistry

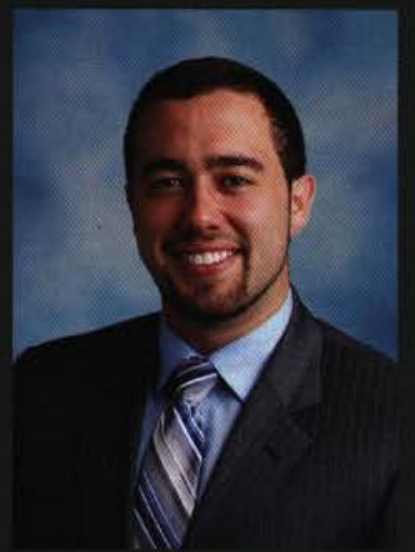

Jordan Doyle

North Rose, NY

Marketing

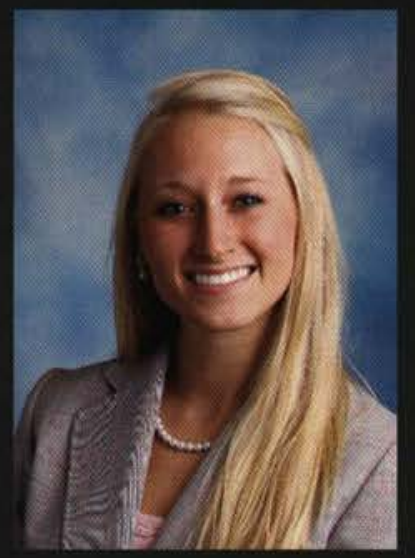

Felicia Dyksterhouse

Otsego, MI

Nursing

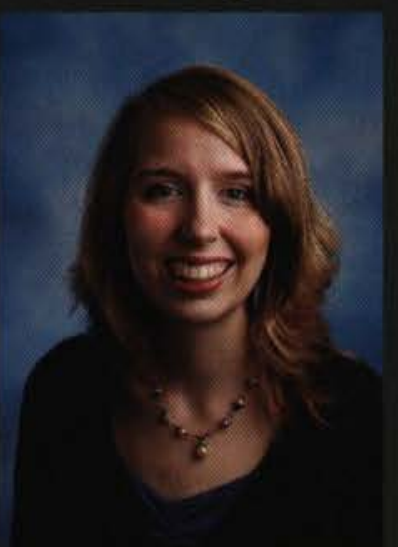

Abigail Eustace

Beavercreek, $\mathrm{OH}$

International Business

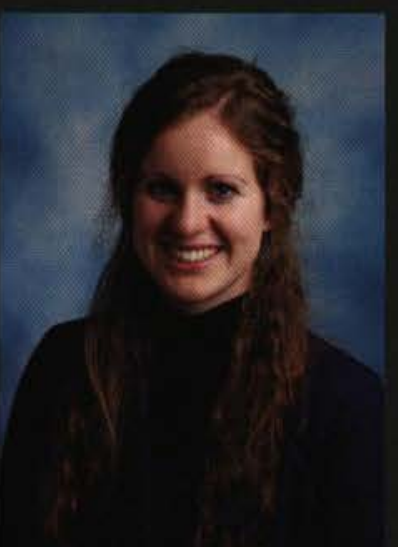

Michelle Doyle

Strongsville, $\mathrm{OH}$

Mechanical Engineering

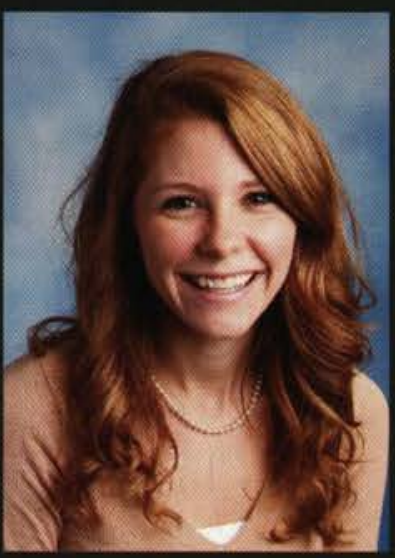

Anna Edwards

Zeeland, MI

Pyschology

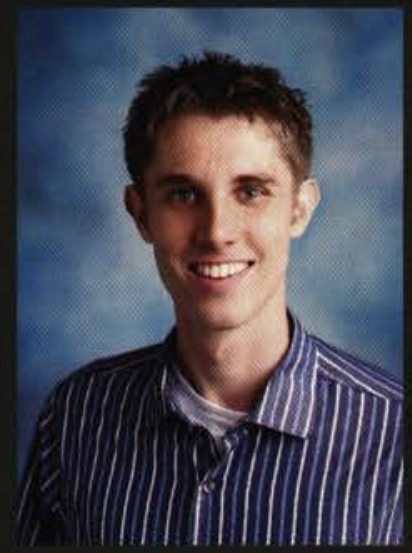

Jeffrey Evans

Naples, FL.

Business Management

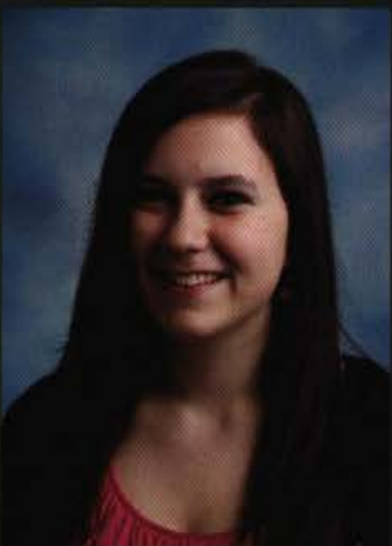

Hannah Dreisbach

Westerville, $\mathrm{OH}$

Preseminary Bible

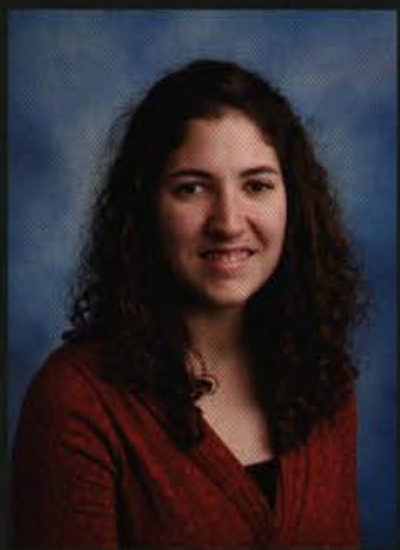

Heidi Edwards

Malta, OH

Environmental Science

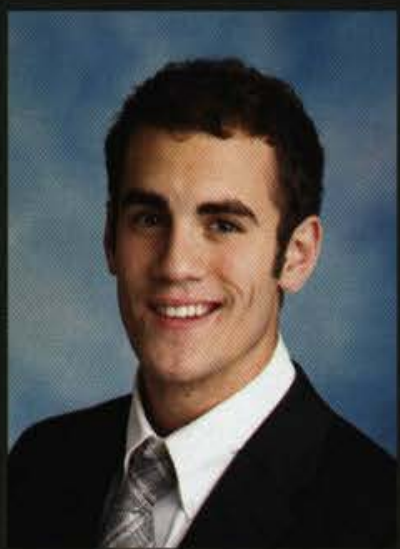

Matthew Ezzo

Merrimack, NH

Finance

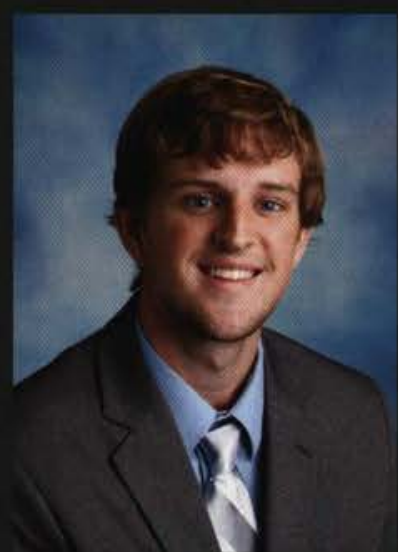

Kvler Dresbach

West Chester, $\mathrm{OH}$

Marketing

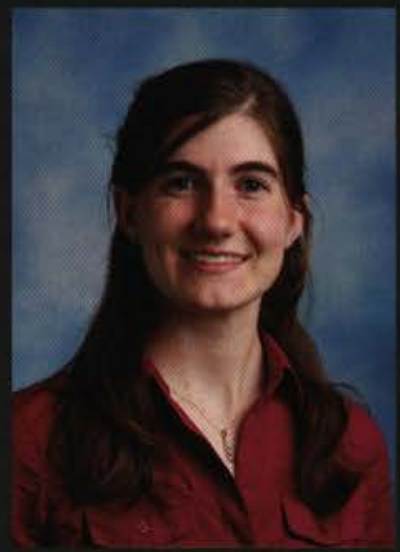

Sabrina Elgersma

Westminister, MD

Social Work

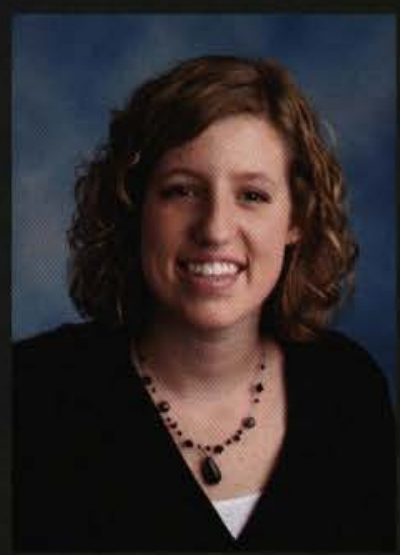

Sarah Fehl

Canonsburg, PA

Comprehensive Bible 


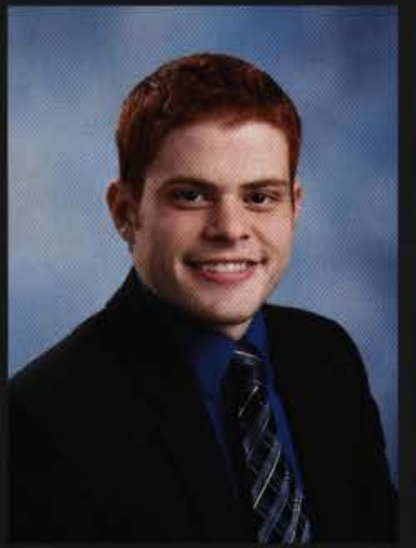

Joe Gallagher

Westerville, $\mathrm{OH}$

Finance

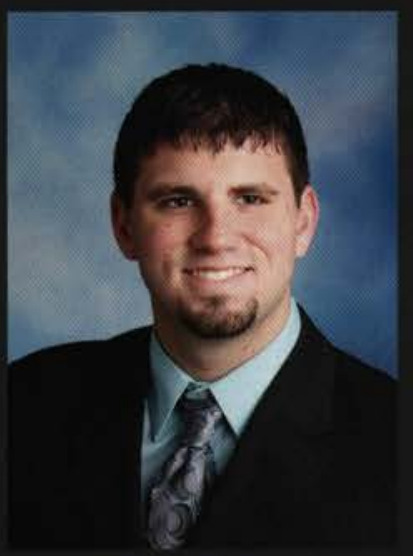

Dane Gordon

Needmore, PA

Electronic Media

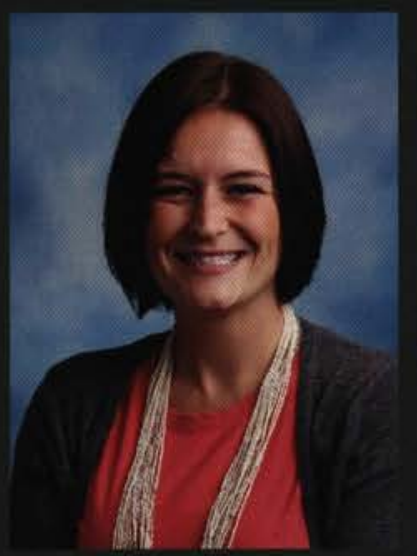

Stephanie Grant:

Westerville, $\mathrm{OH}$

Middle Childhood Edu.

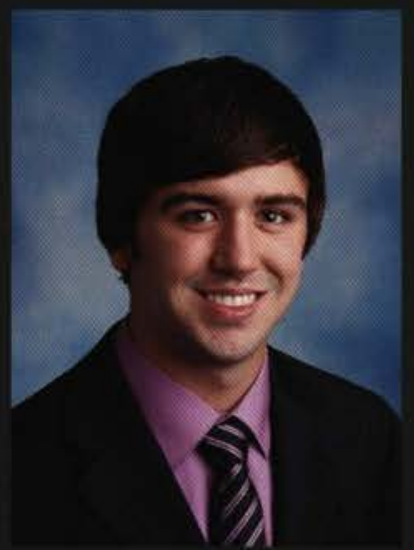

Jennings Gardner

Eastampton, NJ

Sport Management

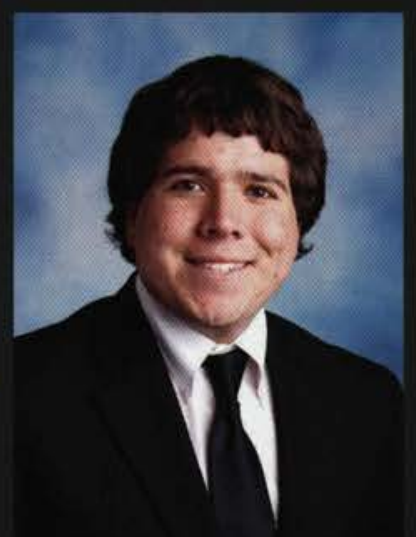

Joshua Gordon

Mechanicsburg, PA

Electronic Media

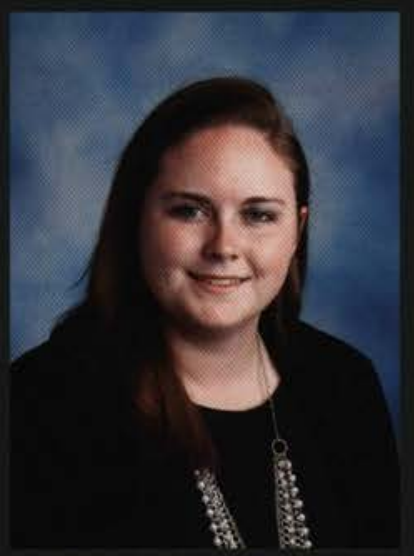

Mary Alyce Greener

Woodbridge, VA

Middle Childhood Edu.

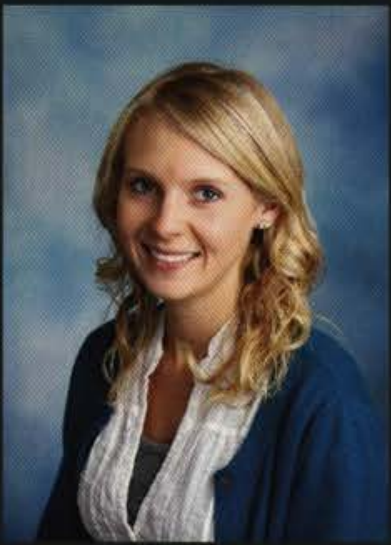

Breanne Gibson

Cambride, Ontario

Biology

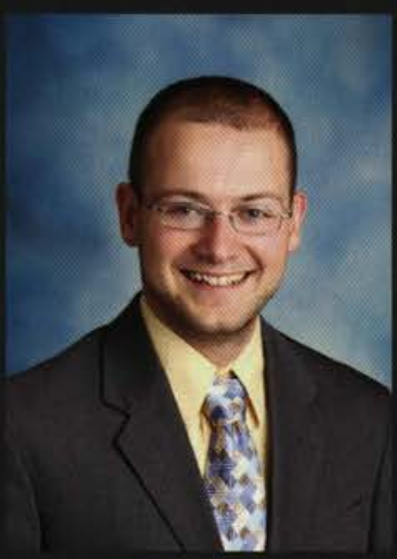

Paul Gordon

Normal, IL.

History

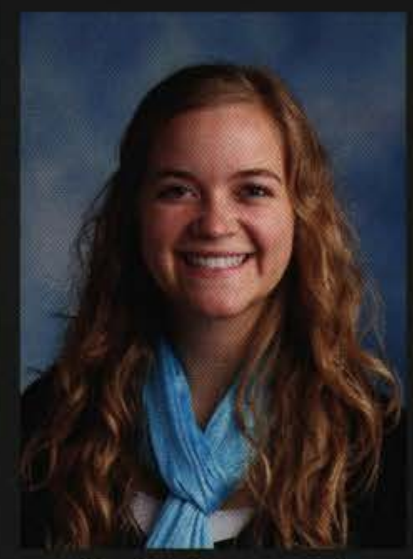

Rachel Greenwood

Alton, IL

Pyschology

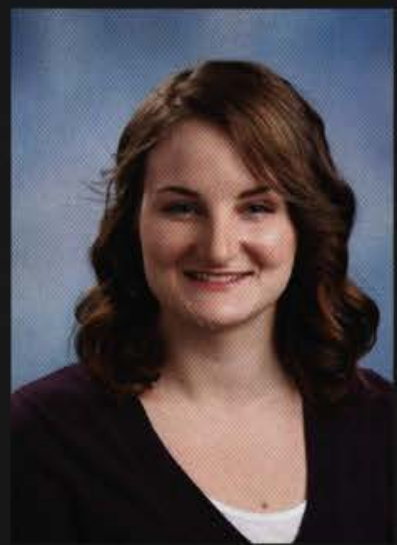

Kelly Gollihue

Erial, NJ

Graphic Design

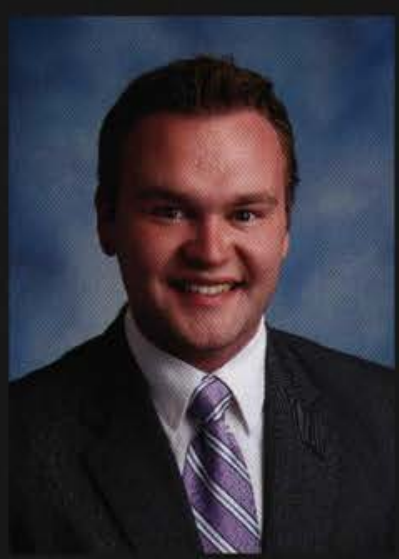

Sean Gowdy

Portsmouth, $\mathrm{OH}$

Electronic Media

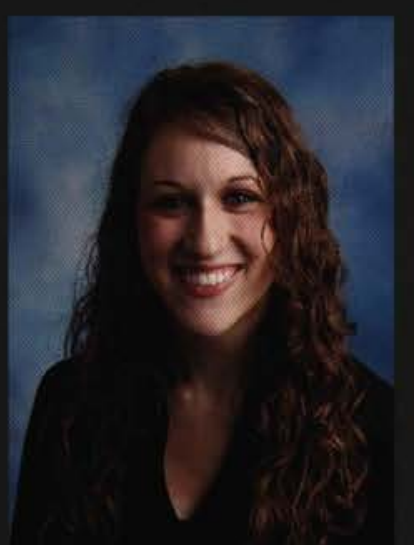

Samantha Grelen

Little Rock, AR

Music Performance

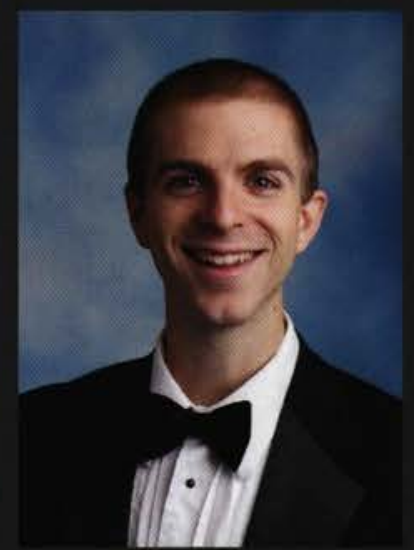

Steven Goodman

Mount Gilead, $\mathrm{OH}$

Mathematics

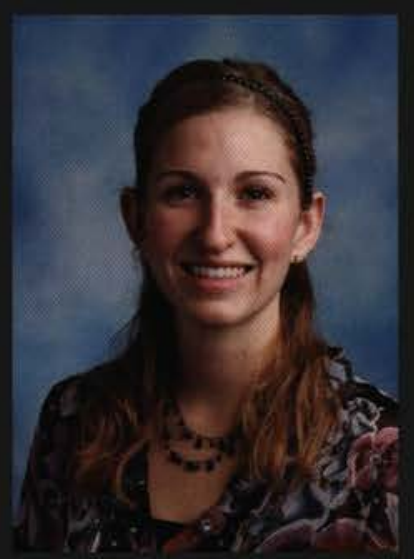

Amy Granger

Grand Ledge, MI

Chemistry

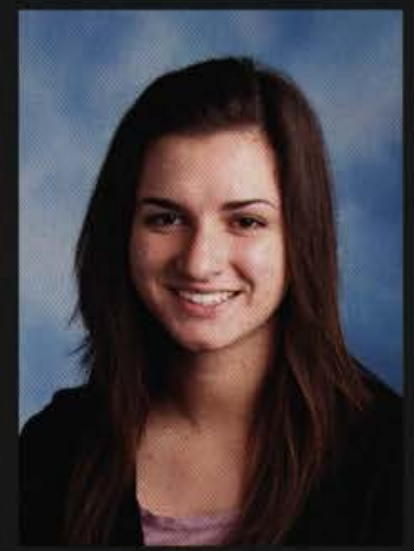

Sarah Grenier

West Chester, PA

Accounting 


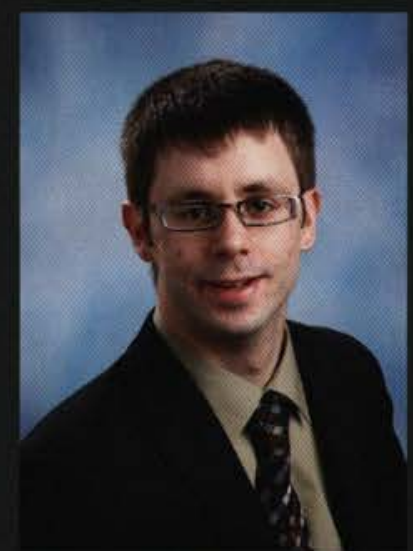

Carl Heinly

Mount Joy, PA

Mechancial Engineering

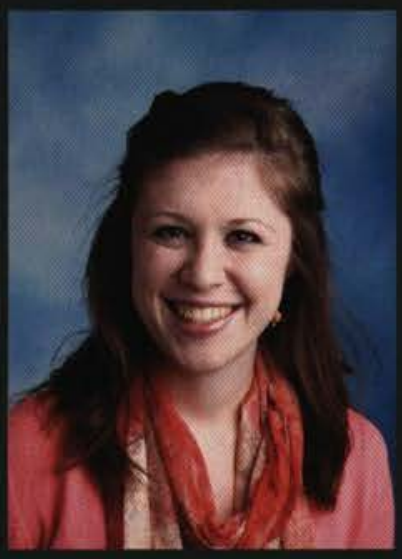

Ashley Herbert

Moon Township, PA

Christian Education

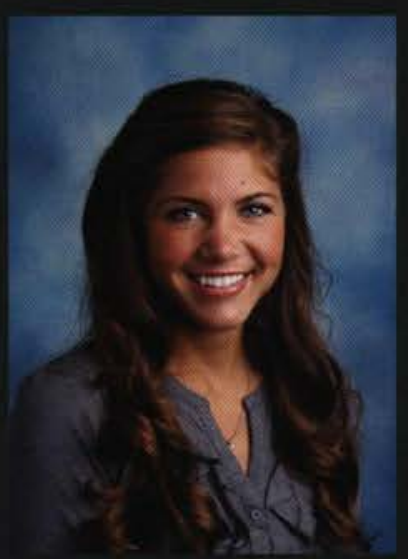

Jennifer Hollander Centerville, $\mathrm{OH}$ Nursing

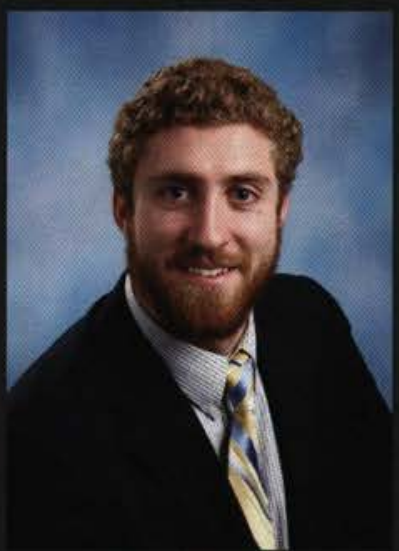

Brandon Hellwig

Lakewood, CO

International Studies

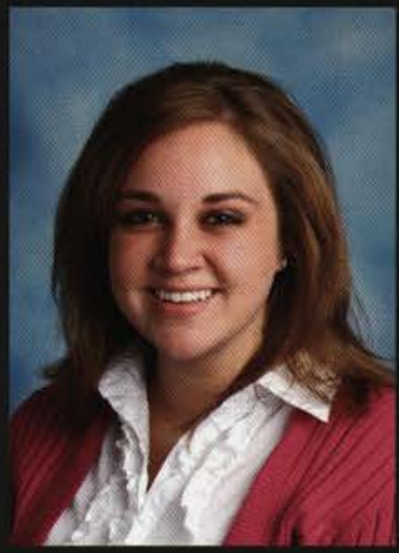

Jessica Hilderbrand Mount Pleasant, PA Early Childhood Education

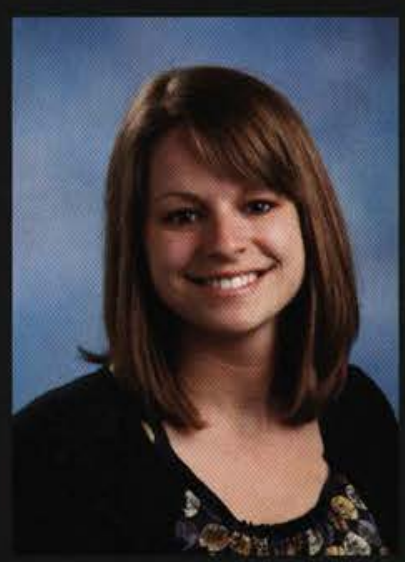

Rachel Horst

Lancaster, PA

Accounting

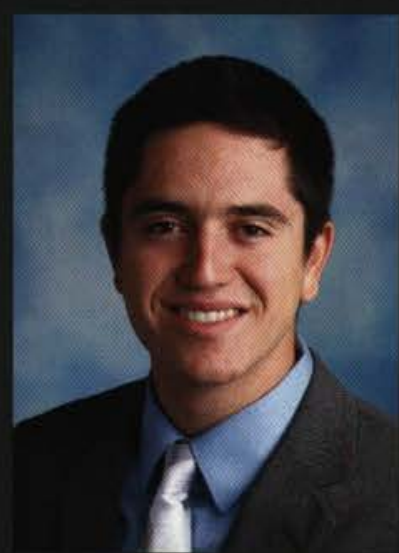

Paul Hembekides

West Chester, PA

Comprehensive Comm.

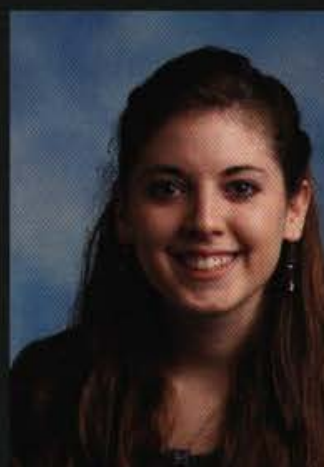

Jenna Hilditch

Wellington, $\mathrm{OH}$

Nursing

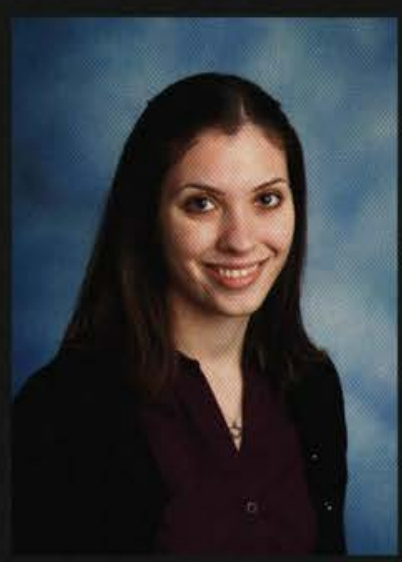

Kristen Hulsey

Lima, $\mathrm{OH}$

Worship

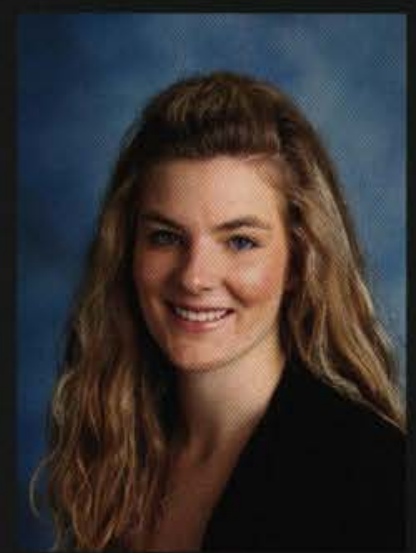

Tiffany Hendricks

North Port, FL

Comprehensive Bible

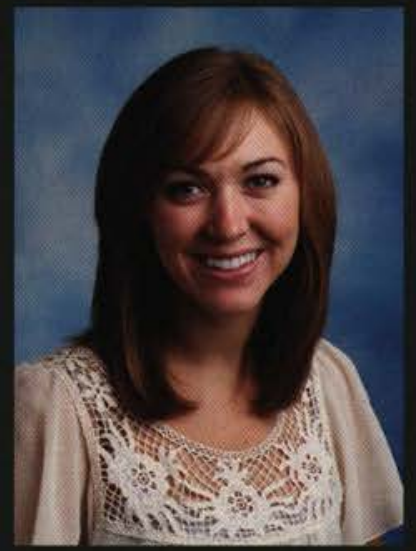

Stephanie Hill

Xenia, $\mathrm{OH}$

Social Work

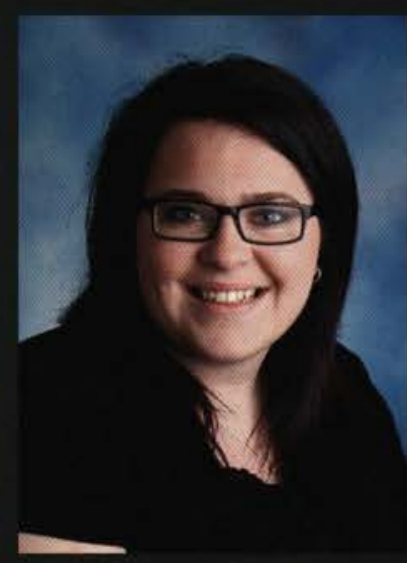

Lisa Humberson

Hinckley, $\mathrm{OH}$

Christian Education

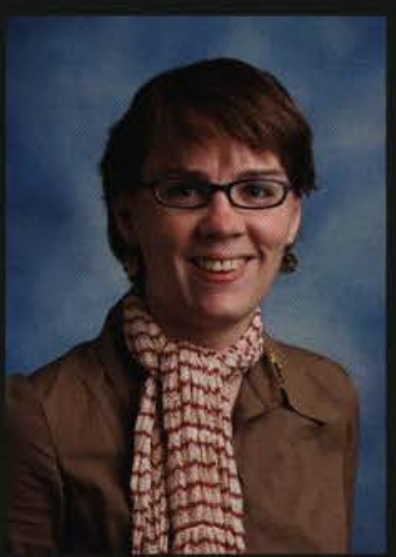

Karley Hepworth

Cedarville, $\mathrm{OH}$

Tech \& Prof Comm.

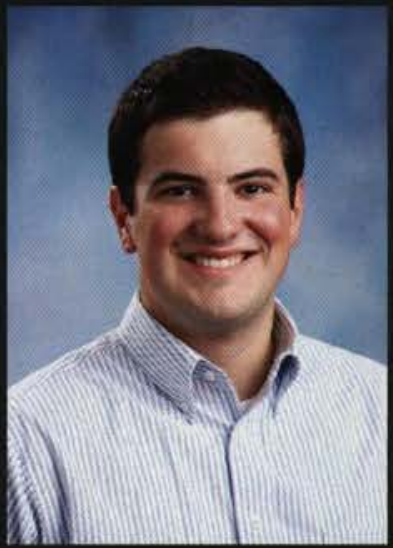

Patrick Hoeflinger Cement City, MI Molecular/Cellular Biology

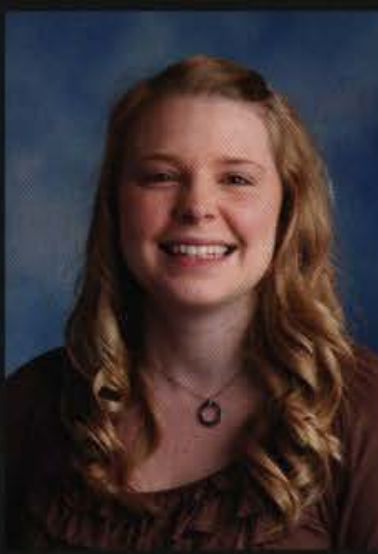

Katelyn Hunt Hixson, TN Chemistry 


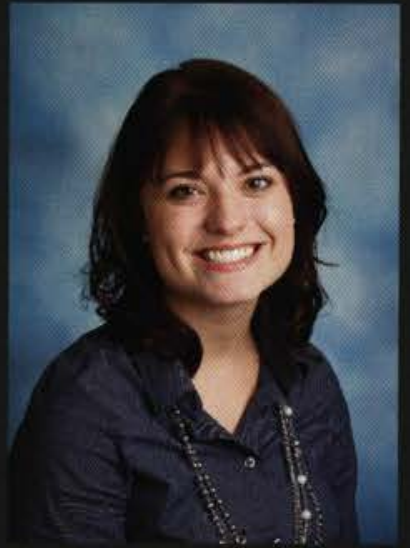

Amy Kelly

Kenosha, WI

Early Childhood Education

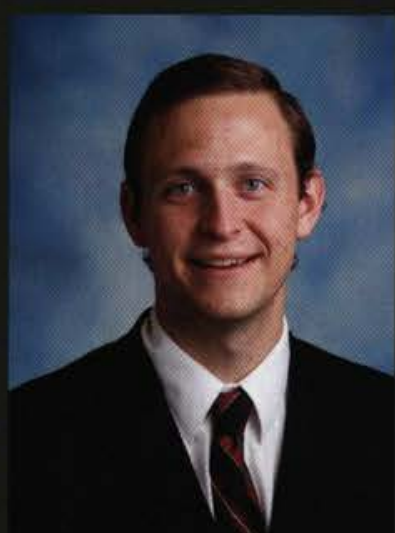

Matthew Koranek

Madison, VA

Biology

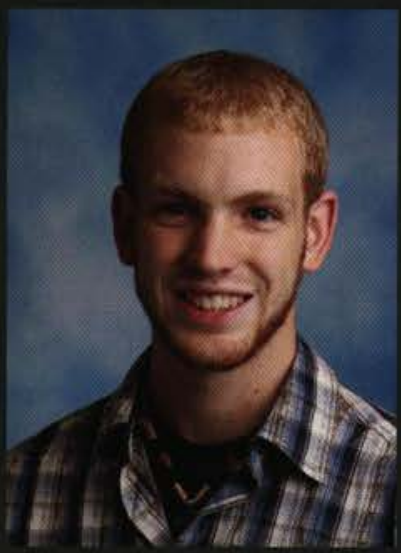

Jesse Kuiken

Franklin, N

Youth Ministry

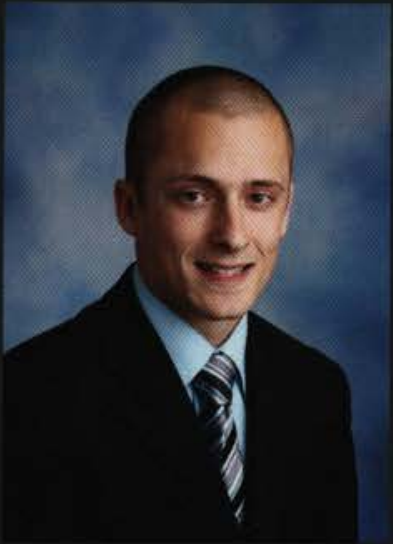

William Kelly Jr.

Rancho Santa Margarita, CA

History \& Political Science

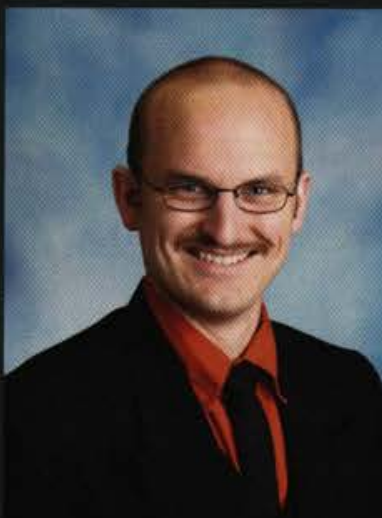

Steven Kostusyk

Winterport, ME

Nursing

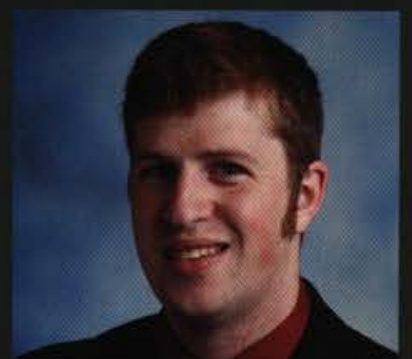

Eric Lamb

Damascus, $\mathrm{OR}$

Mechanical Engineering

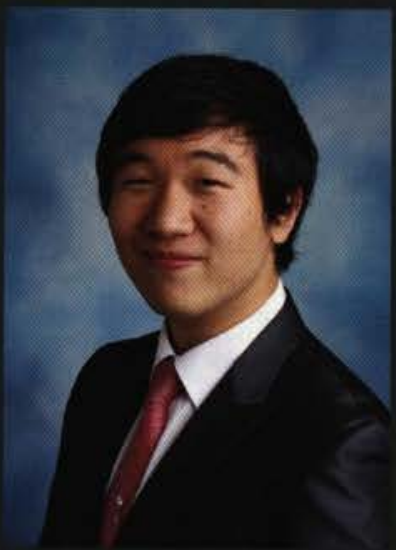

Seung Kim

Asuncion, Paraguay

Broadcasting/Digital Media

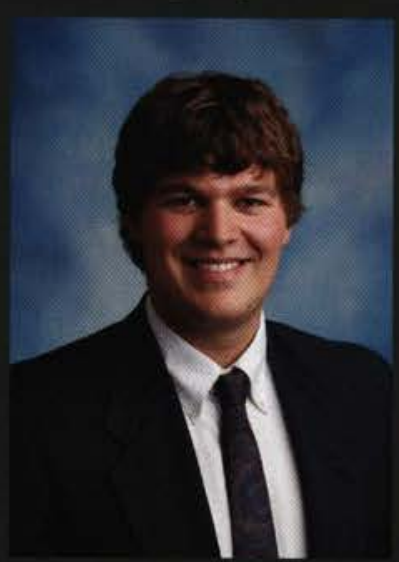

David Krimmel

Dillsburg, PA

Biology

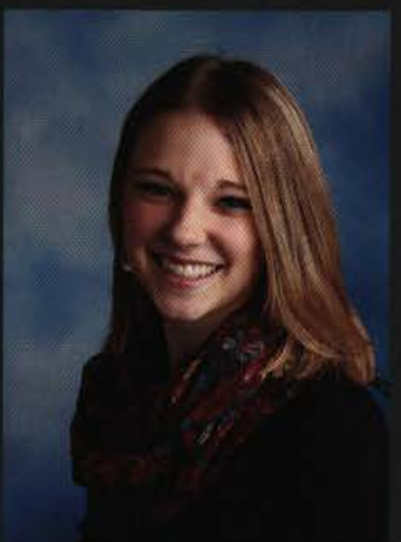

Lauren Lane

Bellbrook, $\mathrm{OH}$

Early Childhood Education

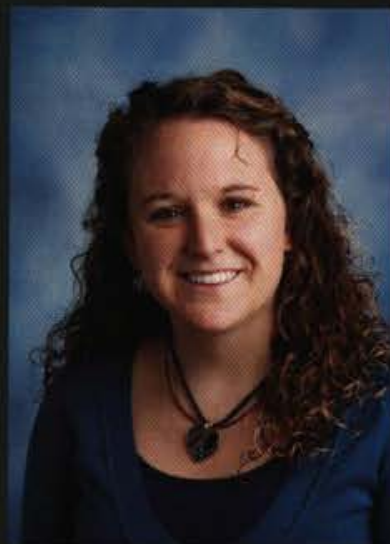

Laura Kirby

Lakeland, FL

Early Childhood Education

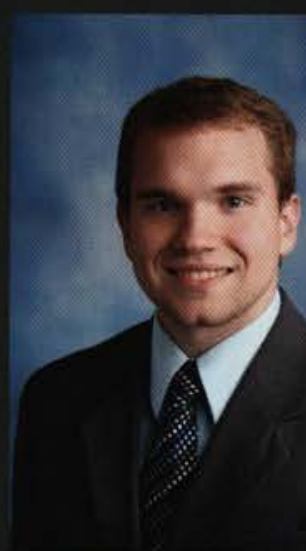

Matthew Kroening

Elizabethtown, KY

Electrical Engineering

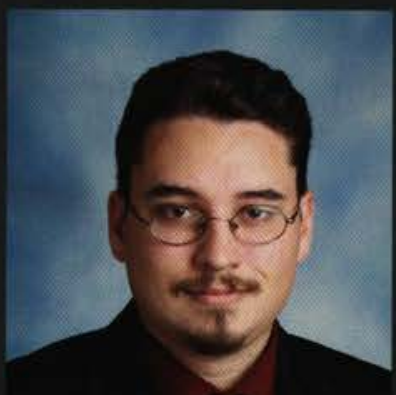

Robert Langan III

Medina, $\mathrm{OH}$

Criminal Justice

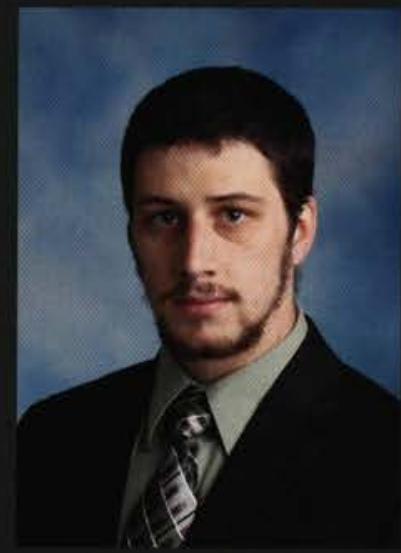

Zachary Klink

North Dighton, MA

Computer Science

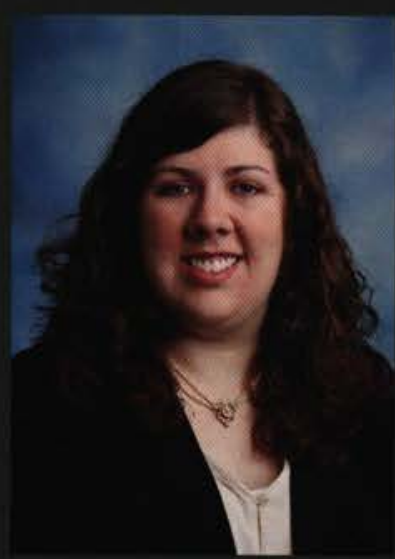

Krista Kroninger

Westerville, $\mathrm{OH}$

Electrical Engineering

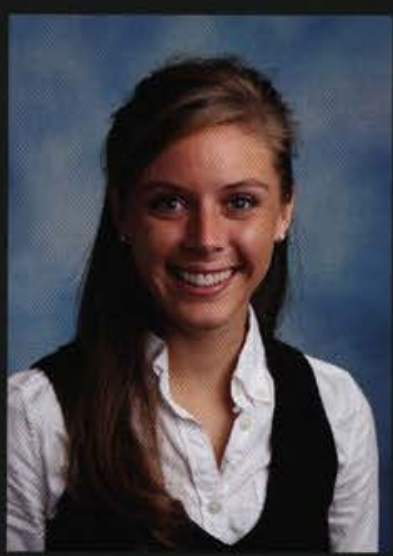

Katherine Lanphier Cincinnati, $\mathrm{OH}$

Nursing 


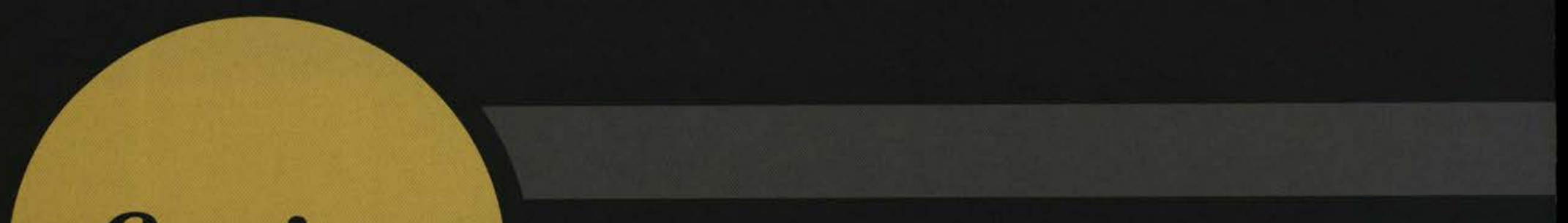

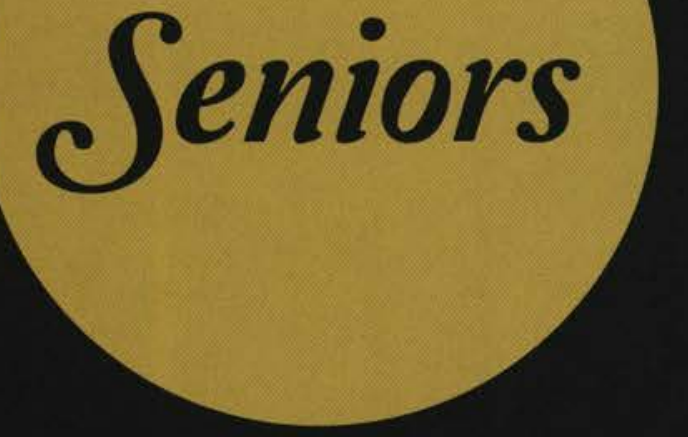

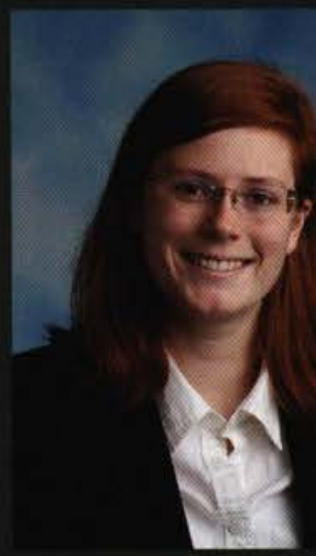

Gabrielle Lassetter

Middletown, $\mathrm{OH}$

Pyschology
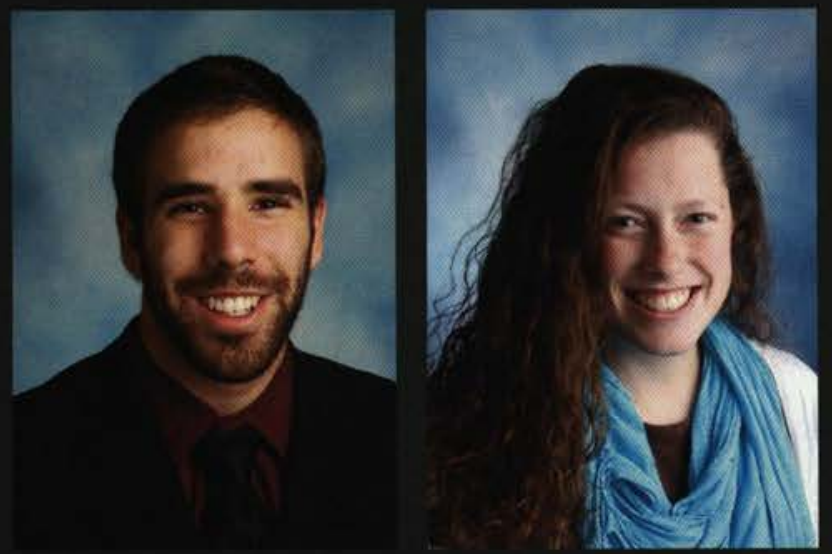

Daniel Lewis

Maynard, MA

Mechanical Engineering.

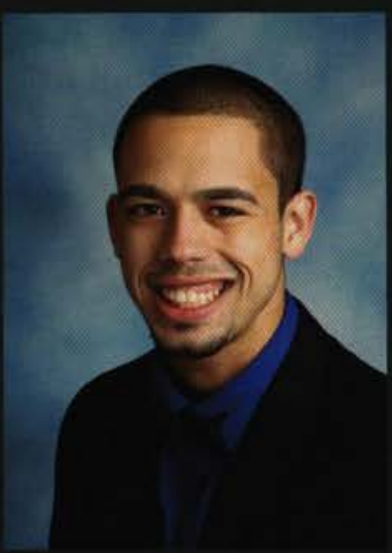

Richard Lozada

Bronx, NY

Early Childhood Edu.
Kristen Lewis

Joppa, MD

Early Childhood Education

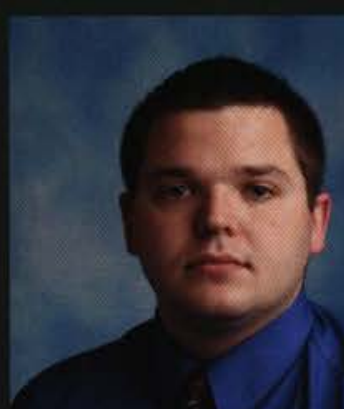

Jeffrey Lynch

Stonewood, WV

Pastoral Studies

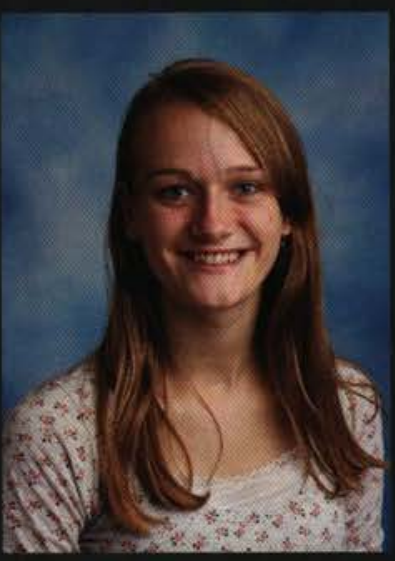

Melody Lightner

Mentor, $\mathrm{OH}$

Spanish Education

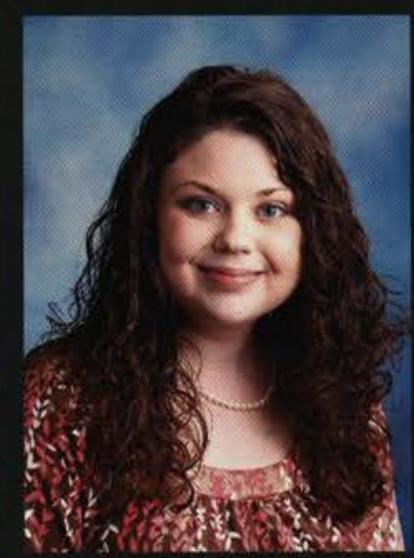

Rebekah Lynch

Stonewood, WV

Comprehensive Bible

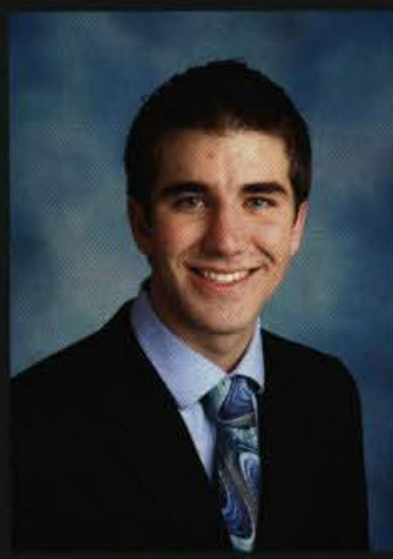

Jordan Lenz

Wadsworth, IL

Accounting

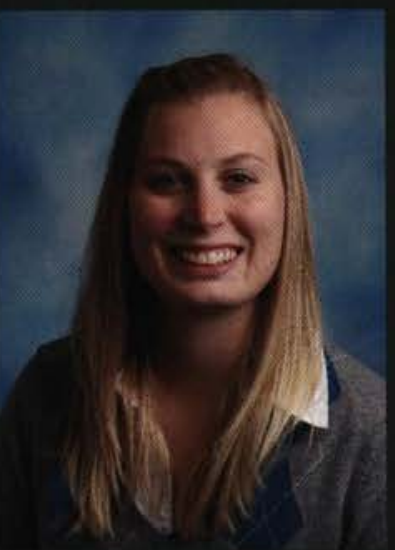

Erin Linnell

Bourbonnais, IL

Sport Management

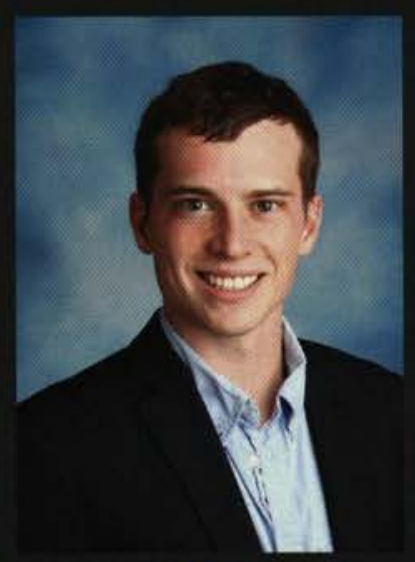

Daniel MacDougall

Bedford, $\mathrm{NH}$

Marketing

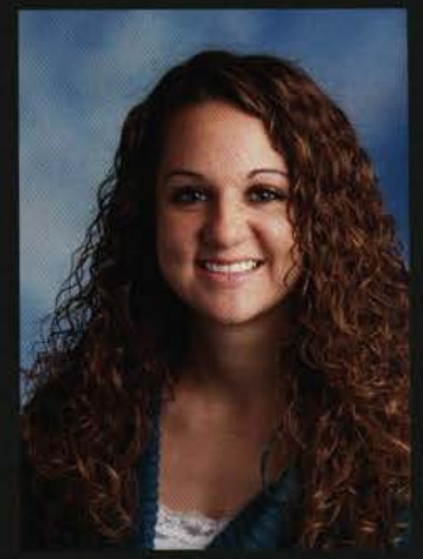

Joanna Leszczynski

Aurora, IL

Nursing

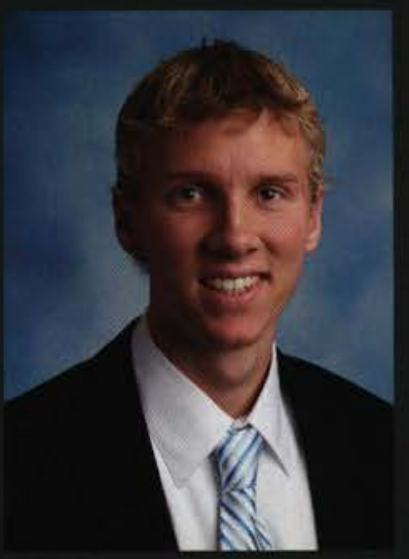

Nathan Losch

Kansas City, MO

Allied Health

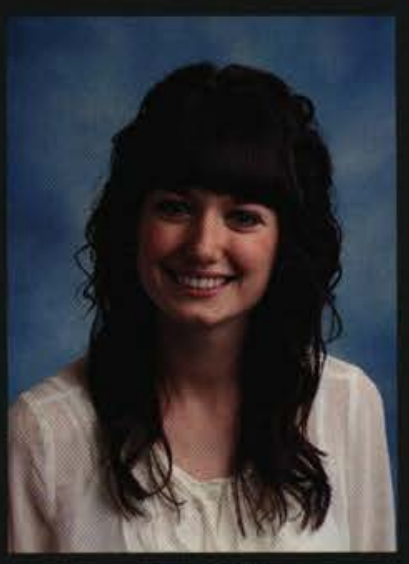

Jane MacGillivray Aurora, Ontario Nursing 


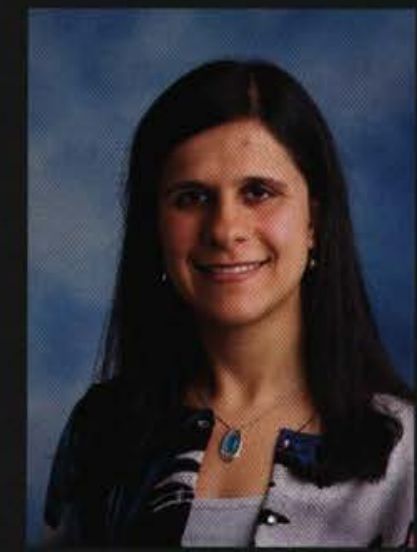

Sarah Maithe!

Bloomfield Hills, MI

Geology

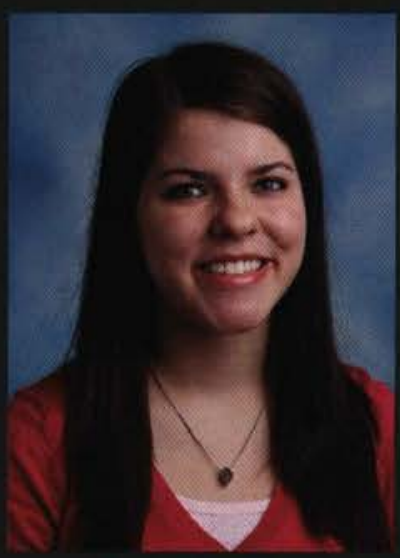

Alyssa McClure

Silverdale, WA

Electronic Media

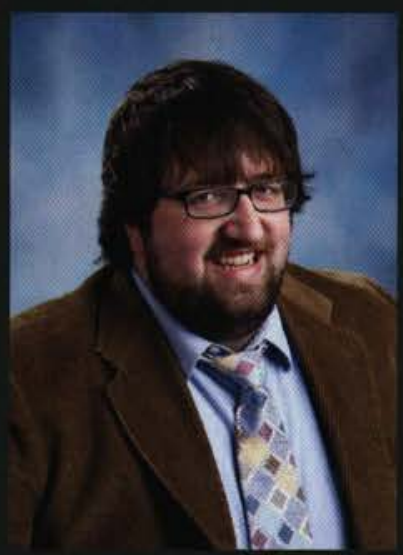

Craig McLeod

Belmont, $\mathrm{OH}$

Electronic Media

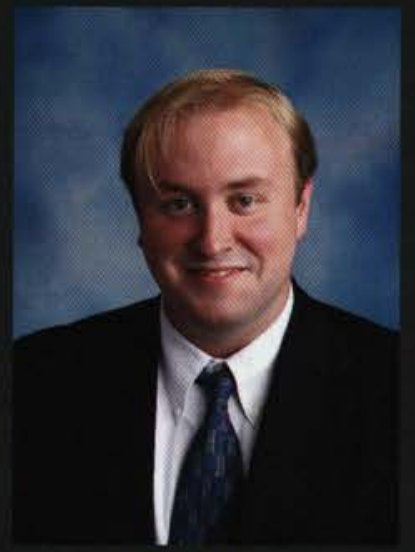

Luke Marot

King, NC

Electronic Media

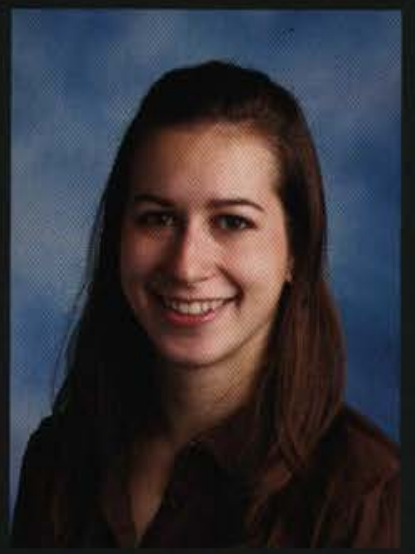

Sarah McEllhenney

Stevens, PA

Language Arts Education

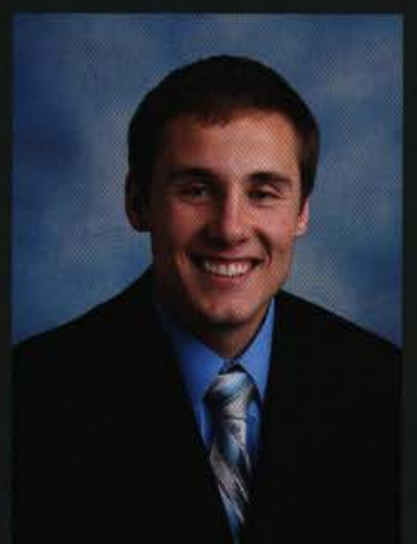

Samuel McLeod

Levant, ME

Mechanical Engineering

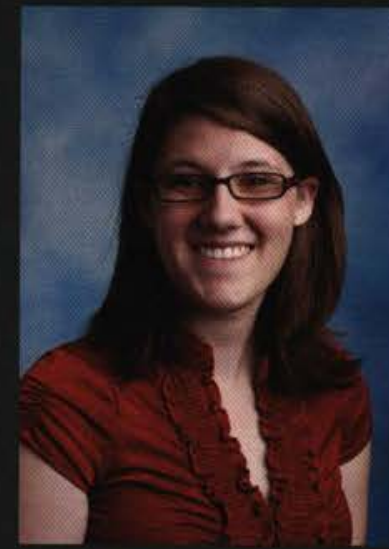

Catherine Martin Mechanicsburg, PA Tech \& Prof Comm.

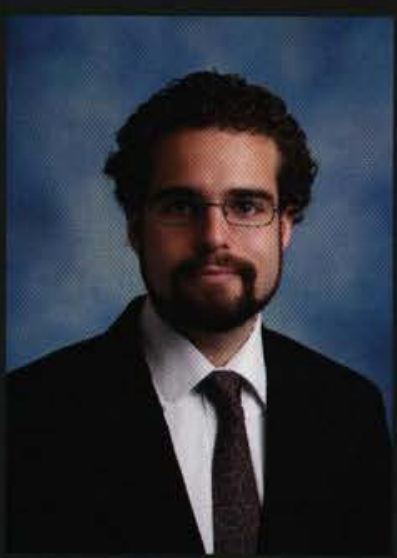

Mark McFarlane Enfield, CT Biology

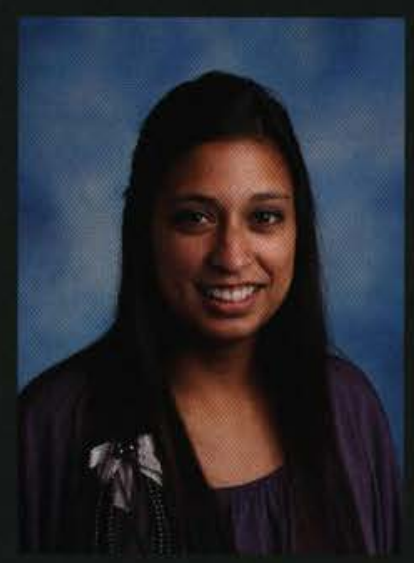

KaLee Medina Norwalk, IA

Nursing

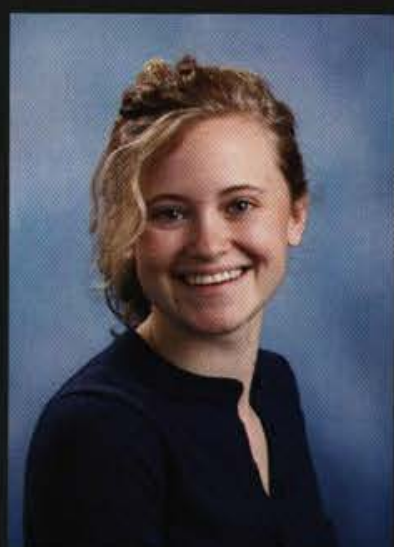

Krista Mast

Plain City, OH

Pyschology

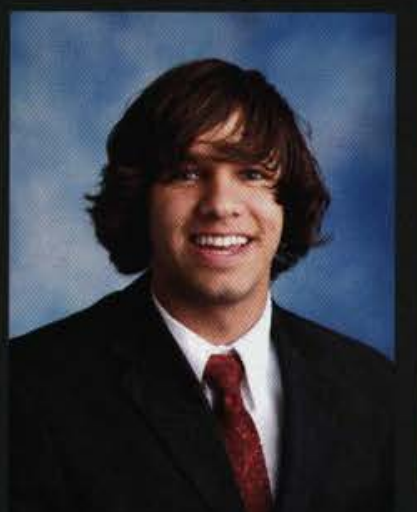

Stephen Mclver

Las Vegas, NV

Electrical Engineering

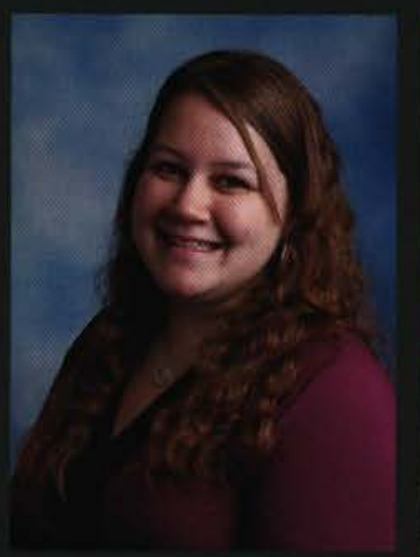

Sarah Medina Bloomfield, NJ Criminal Justice

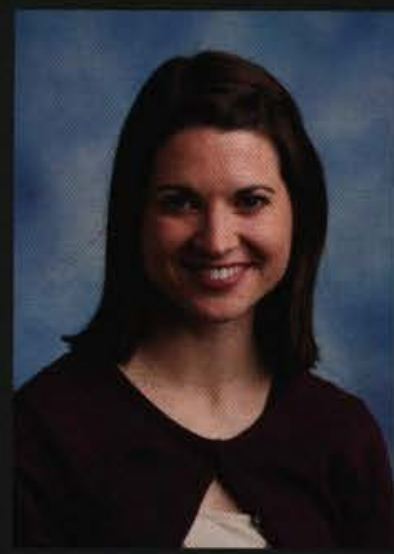

Gretchen Maver Lima, $\mathrm{OH}$

Keyboard Pedagogy

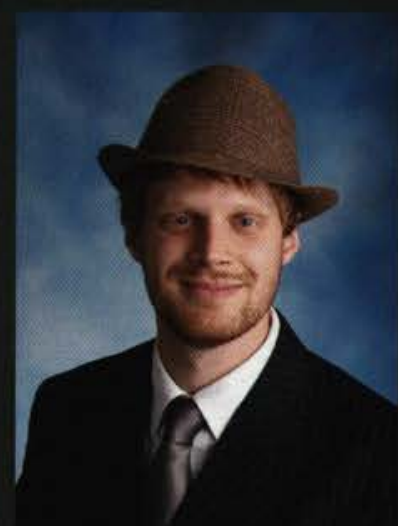

Matthew McLain

North Greek, NY

Geology

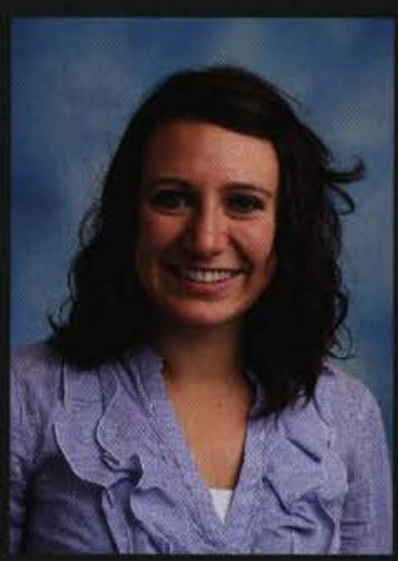

Rachel Miceli

Howell, MI

Exercise Science 

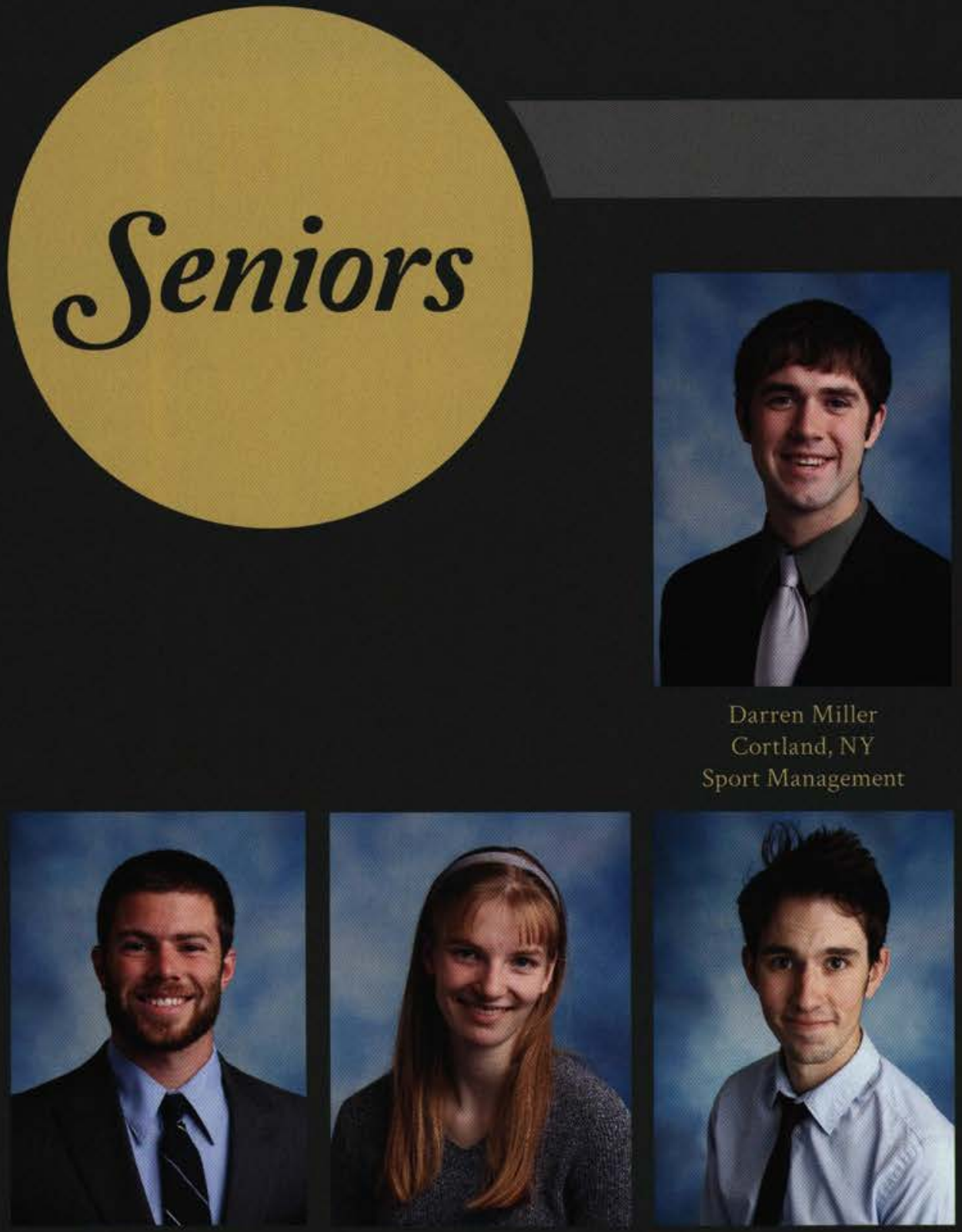

Collin Mitchell

Mason, $\mathrm{OH}$

Youth Ministry

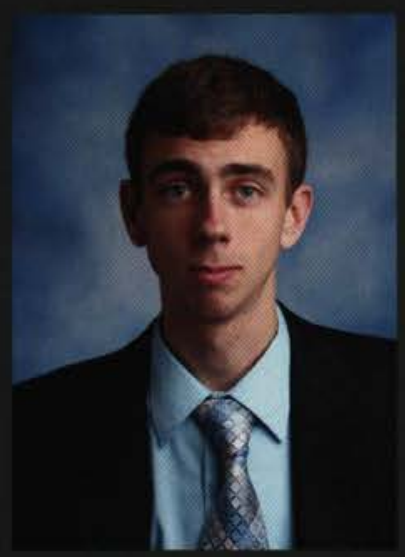

Bradley Morin

Glen Ellyn, IL

Finance

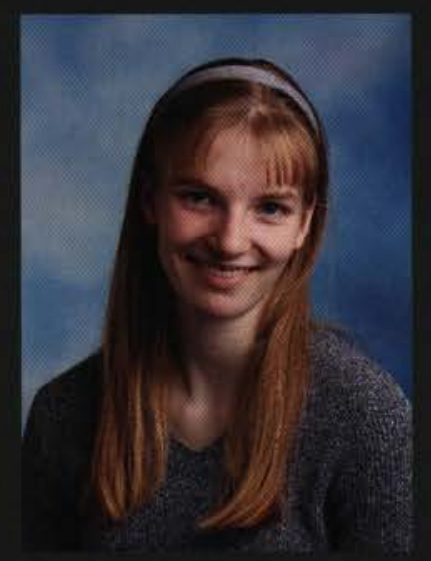

Michelle Mitchener

Troy, MI

Chemistry

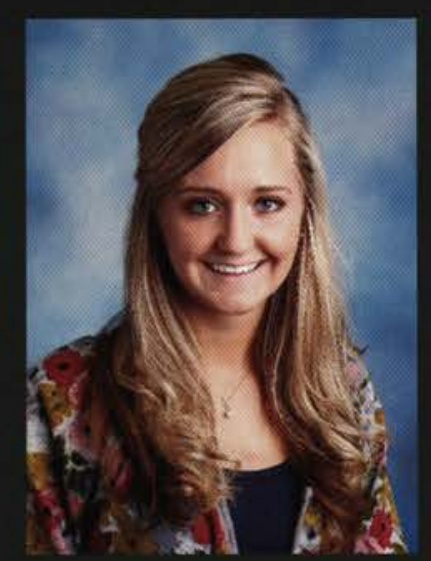

Abigail Morris

Tipp City, OH

Early Childhood Education
Darren Miller

Cortland, NY

Sport Management

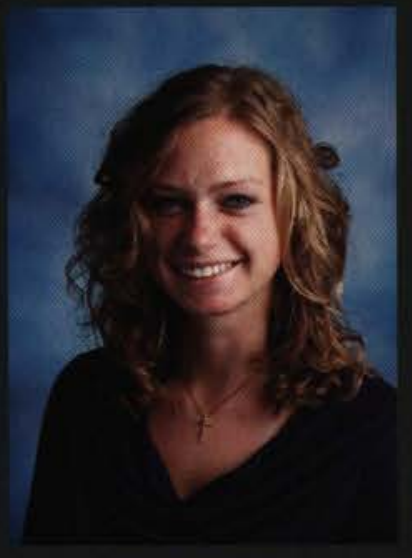

Emily Miller

Perkasie, PA

Nursing

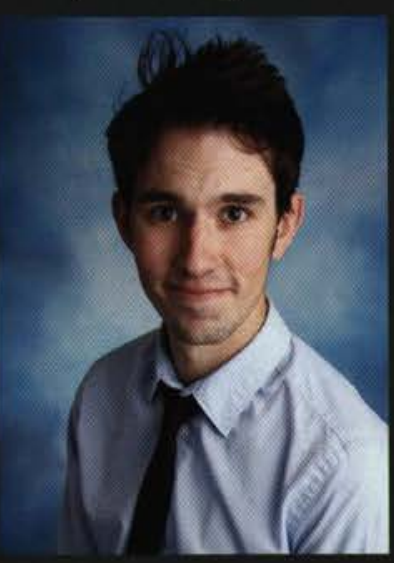

Jared Mittelo

Cedarville, $\mathrm{OH}$

Worship

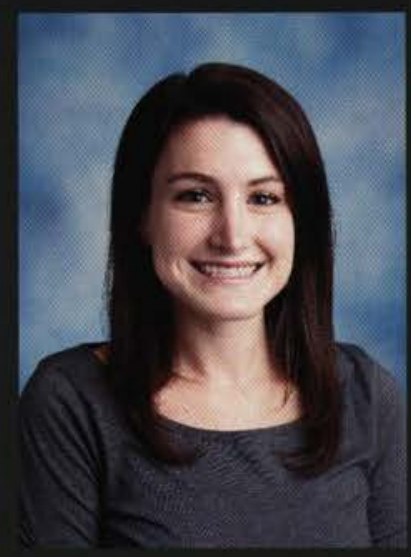

Kaitlyn Morris

Marlton, NJ

Nursing

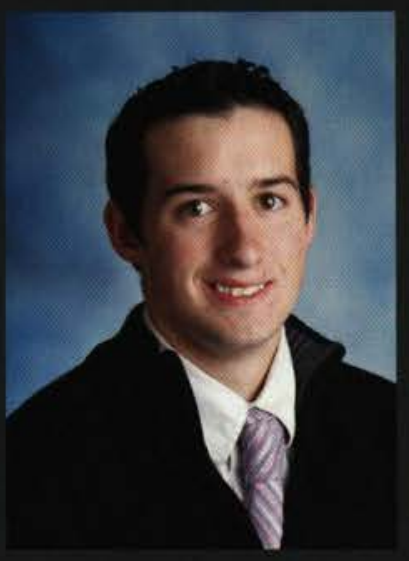

Michael Monroe Mexico, NY

Exercise Science

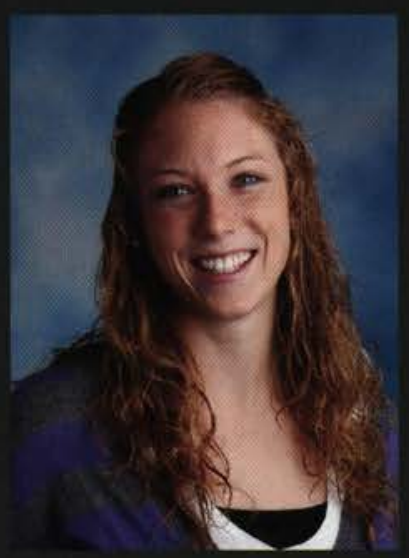

Emilie Morrison

Mount Vernon, IA

Early Childhood Education

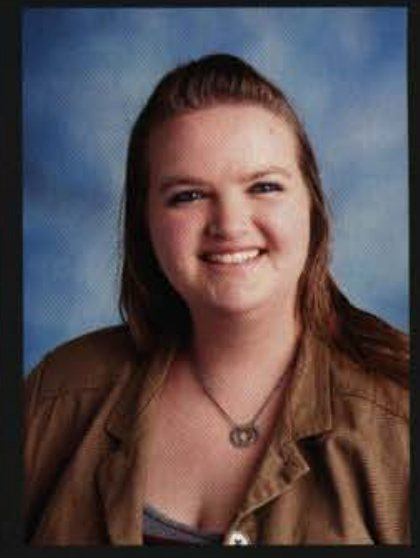

Sarah Mimbs

Palmetto, FL

Pyschology

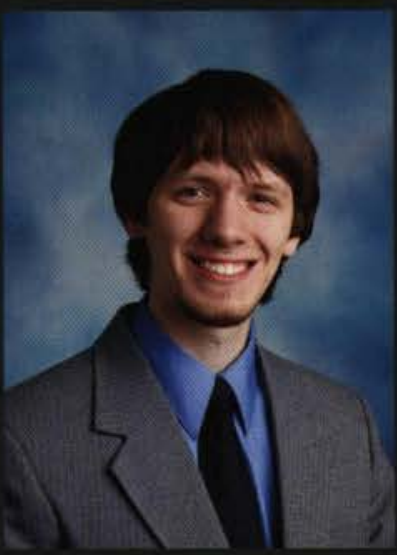

Joel Moore

Hebron, KY

Broadcasting/Digital Media

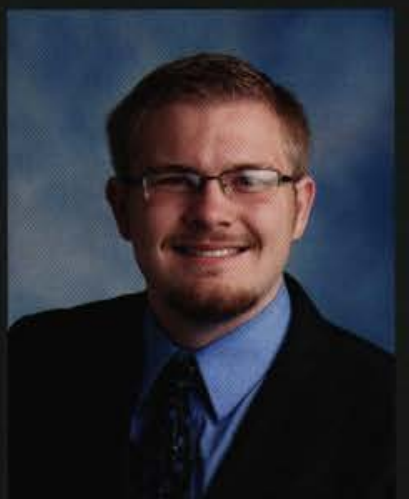

Mitchell Muhlenkamp

Coldwater, OH

Computer Engineering 


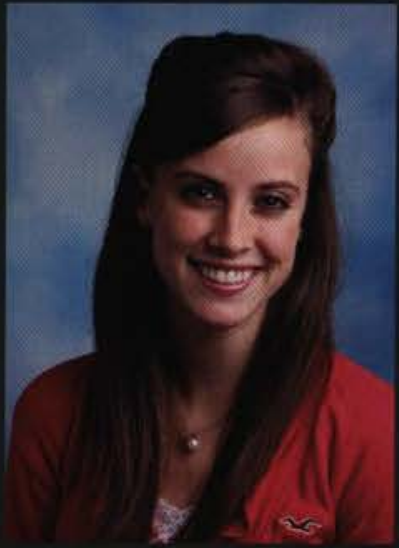

Brittany Muschott

Galena, $\mathrm{OH}$

Early Childhood Education

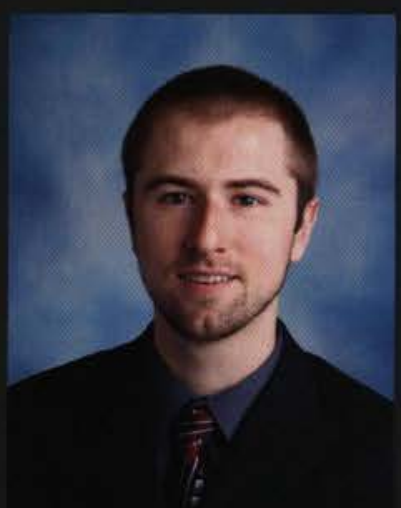

Craig Nichelson

Cedarville, $\mathrm{OH}$

Mechanical Engineering

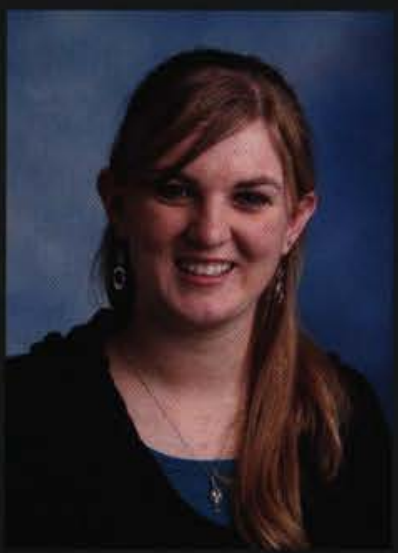

Sarah Norris

Gladwin, MI

Computer Engineering

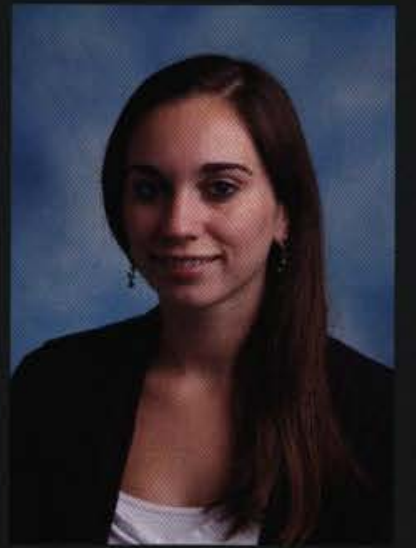

Cherice Musselman

Export, PA

Early Childhood Education

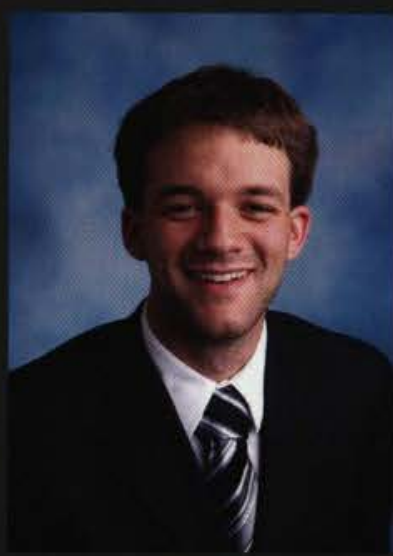

Josef Nick

Concord Township, $\mathrm{OH}$

Mechanical Engineering

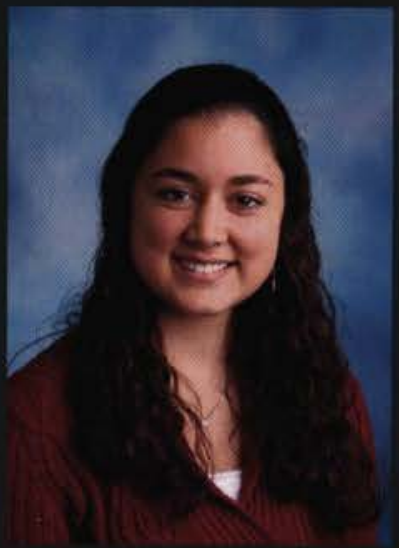

Cheryl Nugent

Royersford, PA

Molecular/Cellular Biology

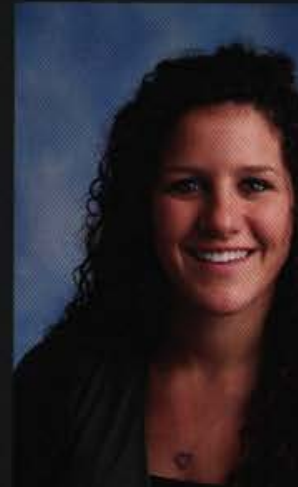

Ashley Musser

Dillsburg, PA

Nursing

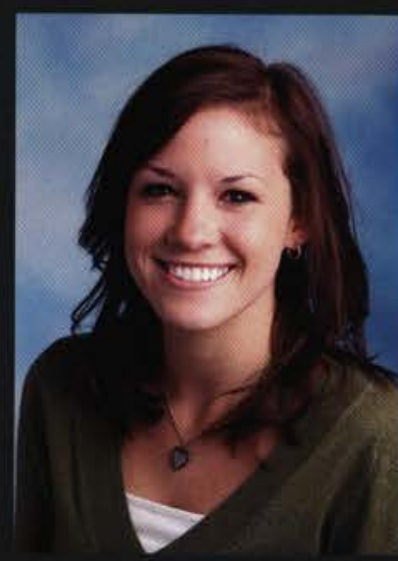

Anne Nicol

Maineville, $\mathrm{OH}$

Social Work

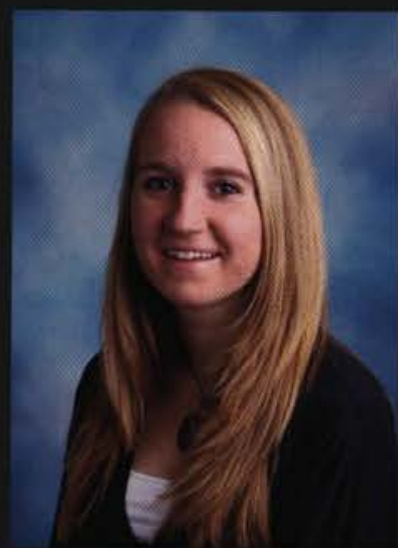

Ashley Nygren

Jamestown, NY

Social Studies Education

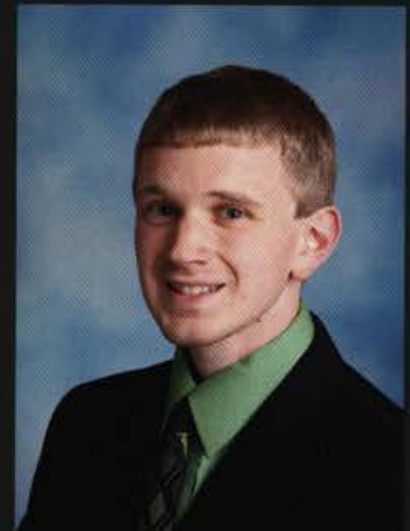

James Myers

Mount Pleasant, PA

Electrical Engineering

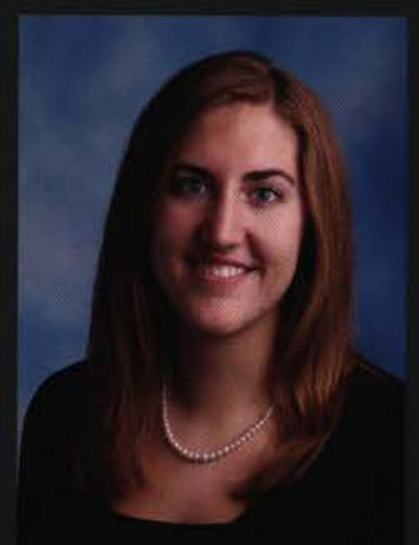

Kirsten Nicolaisen

Clifton Park, NY

Mechanical Engineering

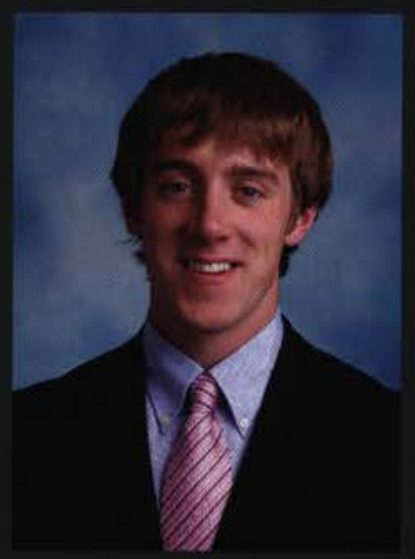

Jordan Oakes

Waukee, IA

Mechanical Engineering

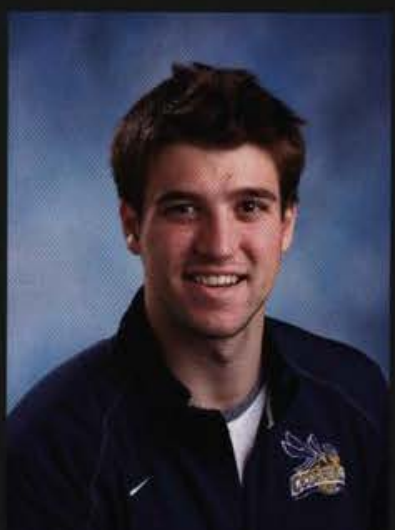

Eric Newman

Columbus, $\mathrm{OH}$

Accounting

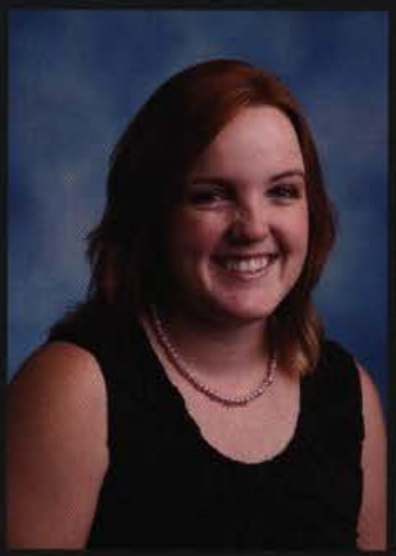

Jerilynn Nine

Canon City, $\mathrm{OH}$

Comprehensive Comm.

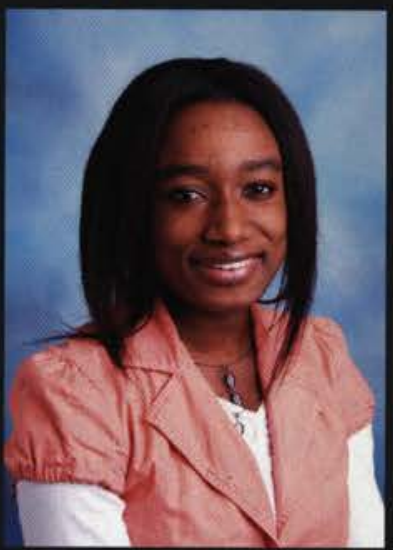

Mary Obielodan

Xenia, $\mathrm{OH}$

Allied Health 


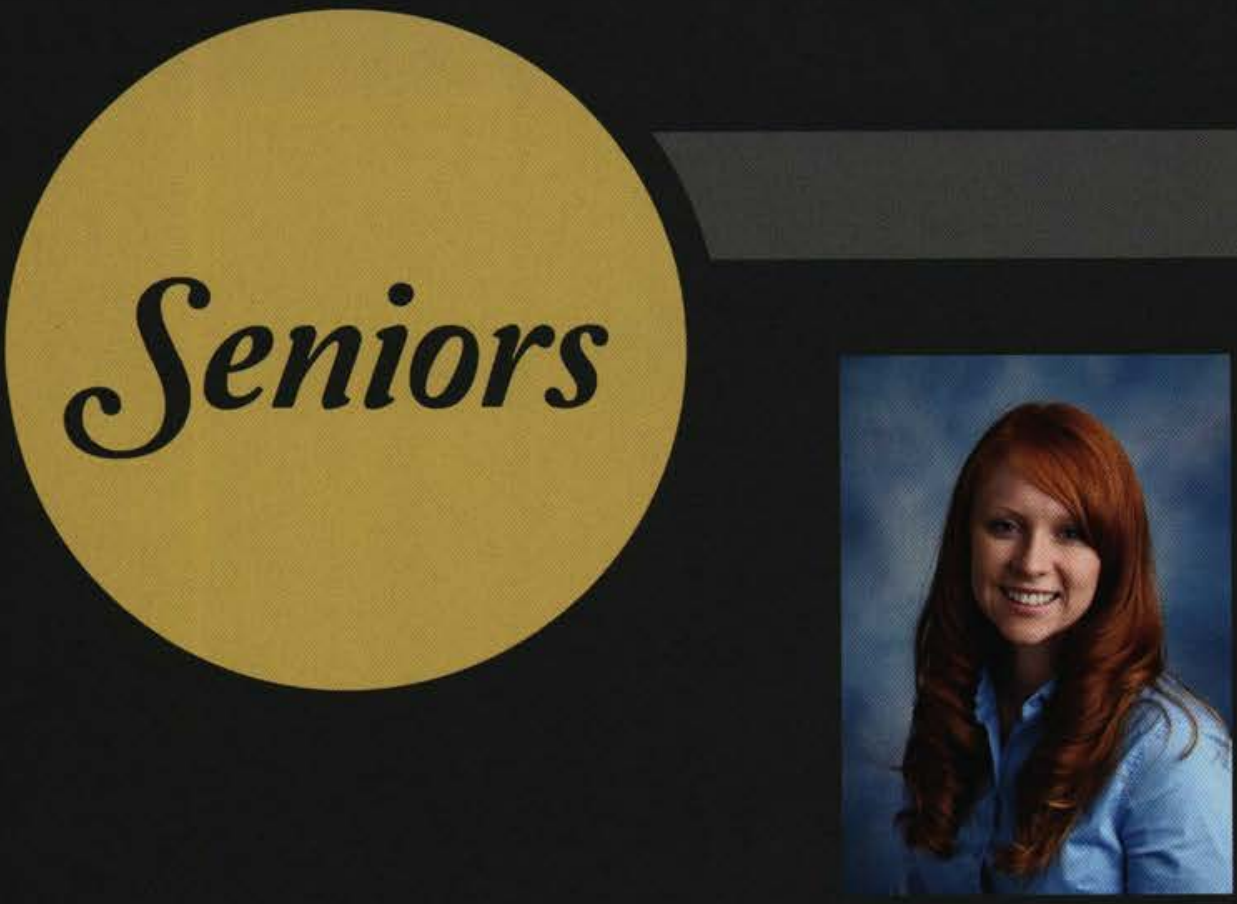

Kara Obuchowski

Dundee, IL

Nursing

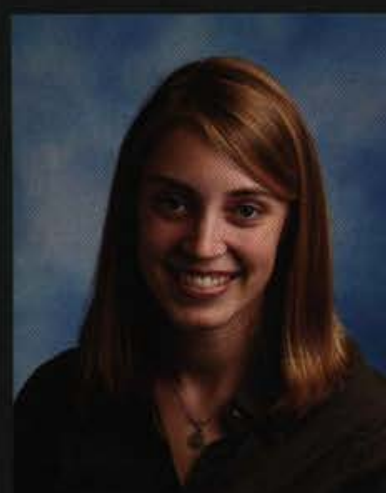

Jemnifer Oosterhouse

Wayland, MI

Nursing

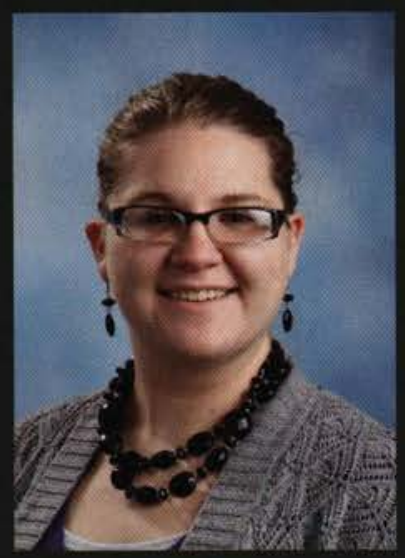

Jillian Payne

Xenia, $\mathrm{OH}$

Physical Science Education

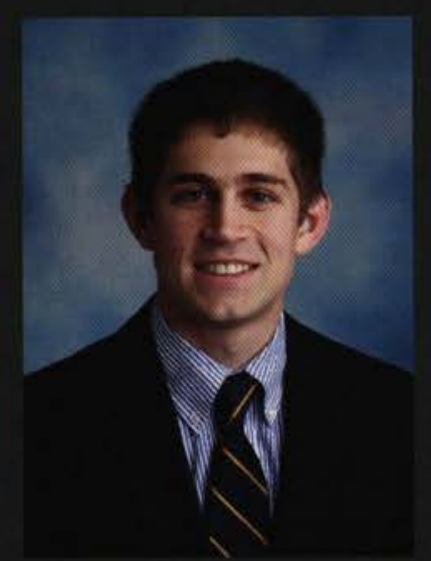

Paul Page

Lexington, $\mathrm{KY}$

Biology

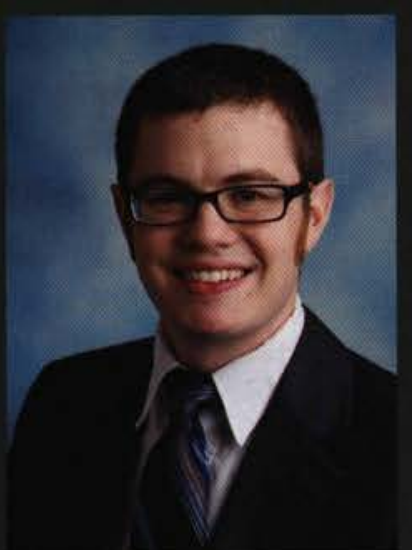

Brian Perhai

Port Huron, MI

Mechanical Engineering

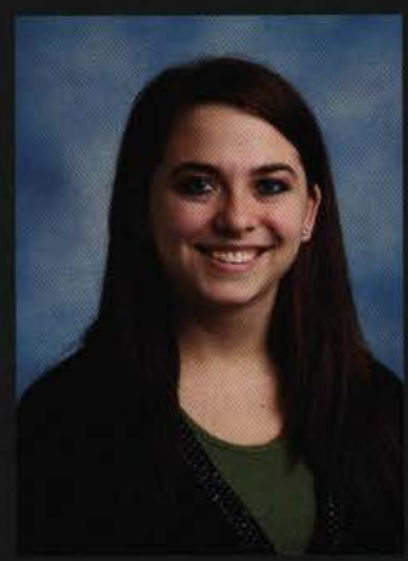

Rachel Parrott

Cedarville, $\mathrm{OH}$

Social Work

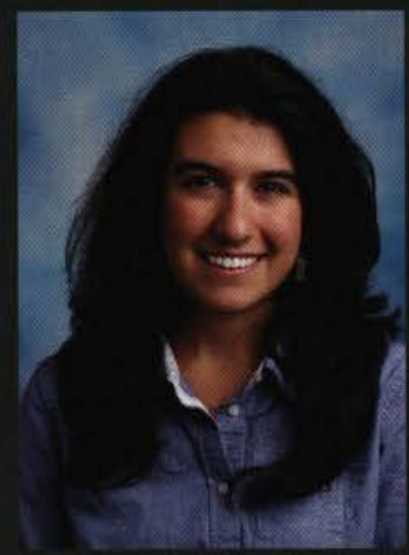

Leah Pernicano

Tampa, FL

Mechanical Engineering

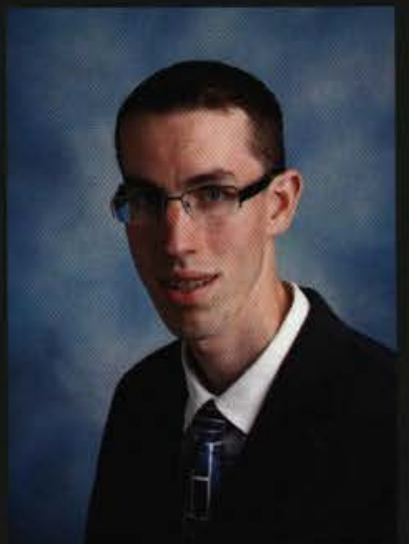

Matthew Oddis

Pittsburgh, PA

Undeclared

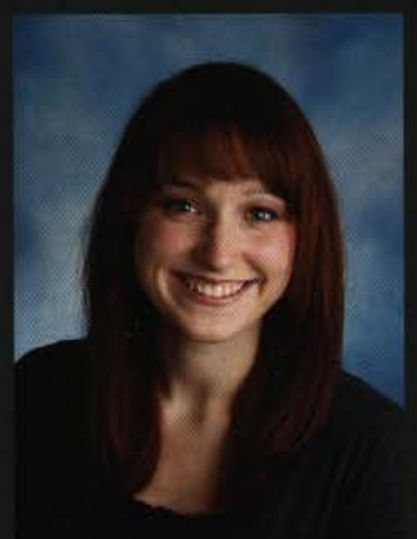

Alyssa Pasma

Centennial, CO

Graphic Design

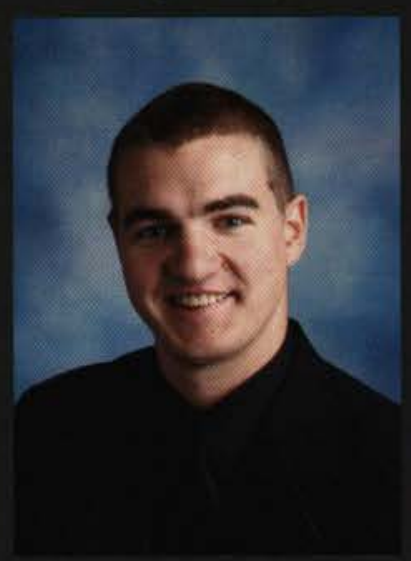

Jordan Petersen

Freeport, MI

Nursing

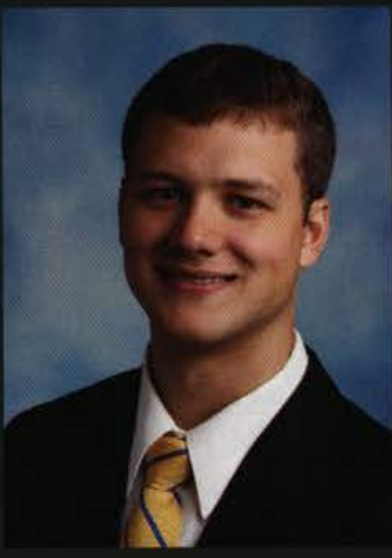

Corey Ommundsen

Hawthorne, NJ

Mechanical Engineering

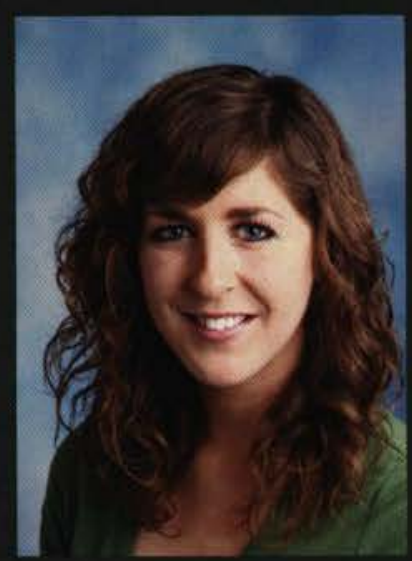

Diana Patrick

Chattanooga, TN

Nursing

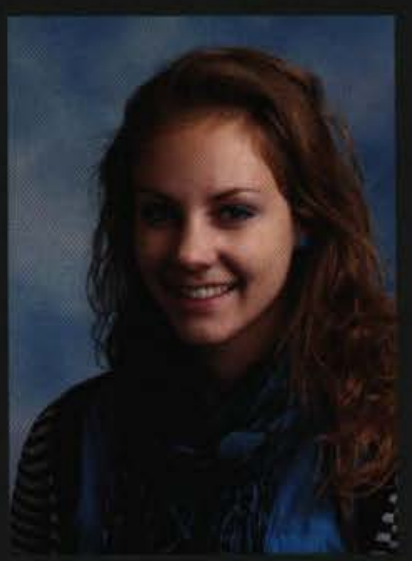

Christi Peterson

Minneapolis, MN

Graphic Design 


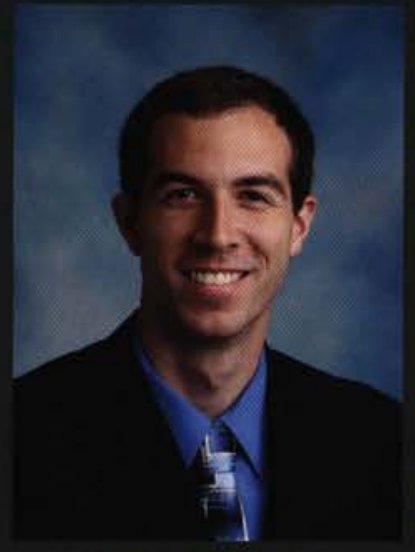

Ethan Peterson Hurricane, WVV

Computer Engineering

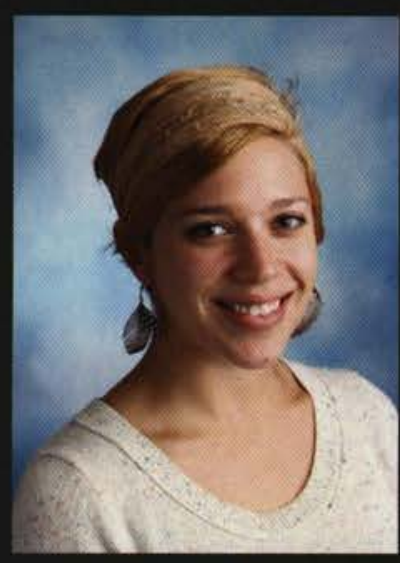

Suzanne Pitts

Xenia, $\mathrm{OH}$

Early Childhood Education

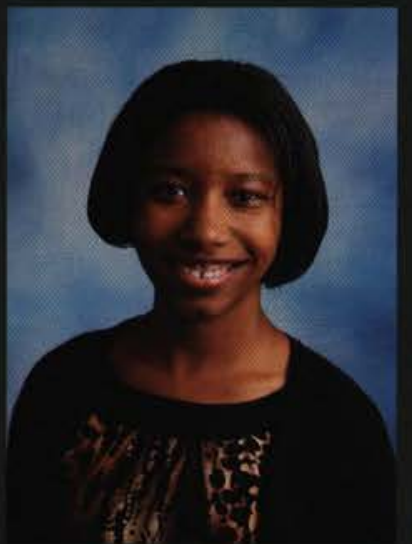

Danielle Price

Beavercreek, $\mathrm{OH}$ Nursing

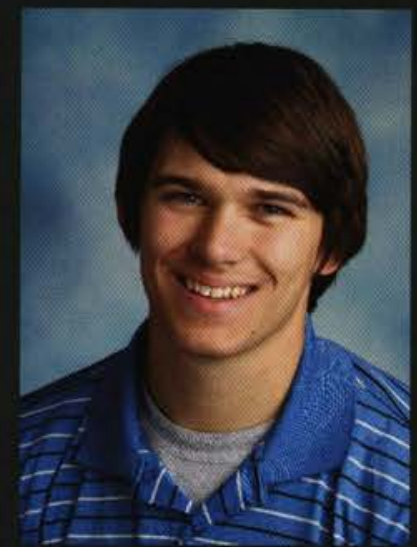

Daniel Petke

Columbus, $\mathrm{OH}$

Preseminary Bible

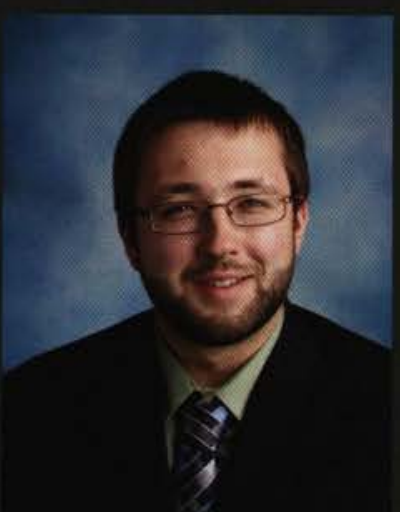

Thomas Poore

Mount Vernon, NH

Mechanical Engineering

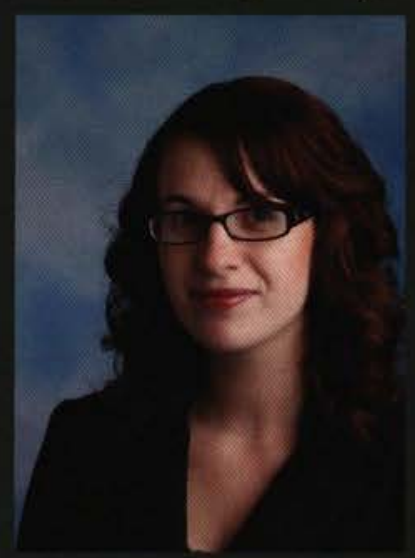

Nina Prozzo

Cedarville, $\mathrm{OH}$

Electronic Media

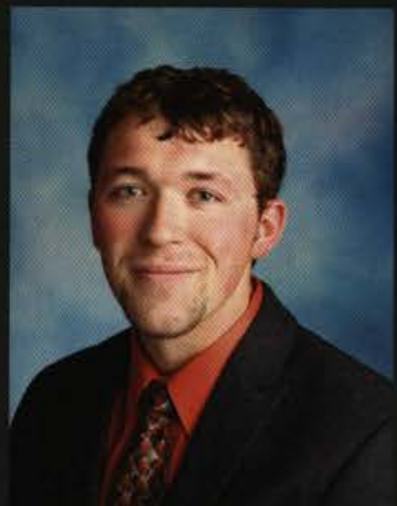

Roger Pettit III

Marysville, $\mathrm{OH}$

Allied Health

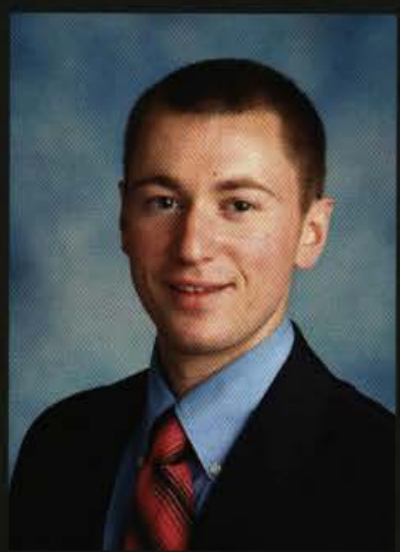

Matthew Porter

Hixson, TN

Business Management

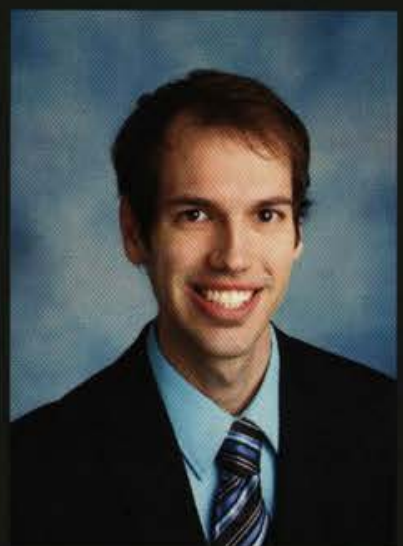

Brandon Rabb

Bowling Green, $\mathrm{OH}$

Information Systems

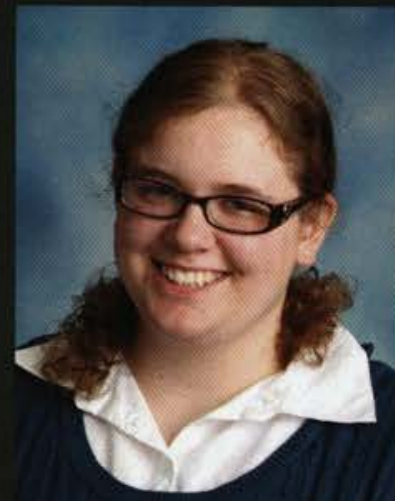

Alyssa Phillips

Ocoee, FL

Electronic Media

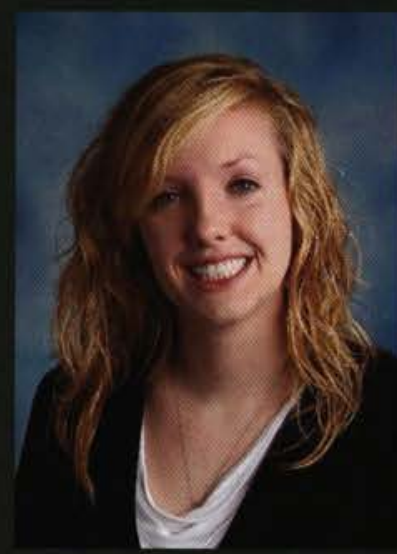

Candace Pratt

Scranton, PA

Business Management

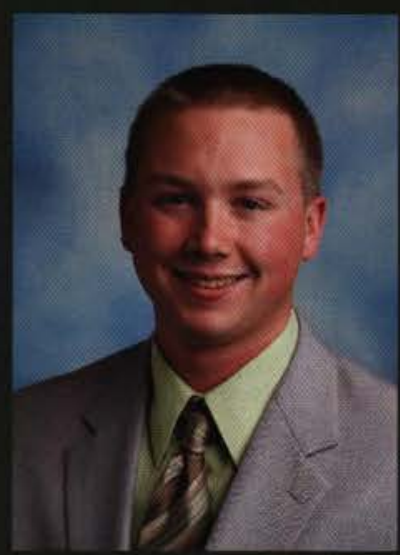

Robert Rabenstein

West Liberty, $\mathrm{OH}$

Electrical Engineering

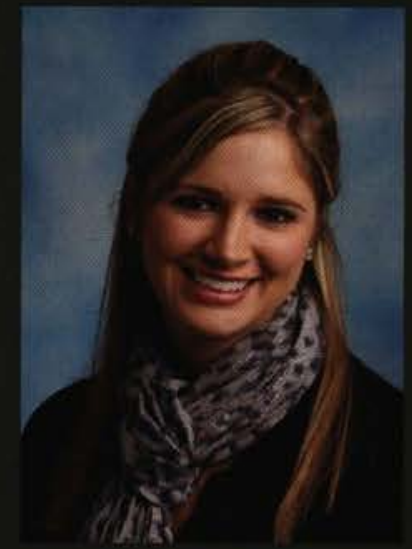

Samantha Phillis

Painesville, $\mathrm{OH}$

Biology

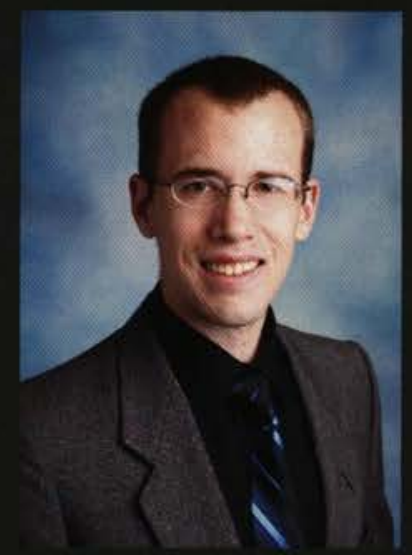

Andrew Price

Upper Darby, PA

Music

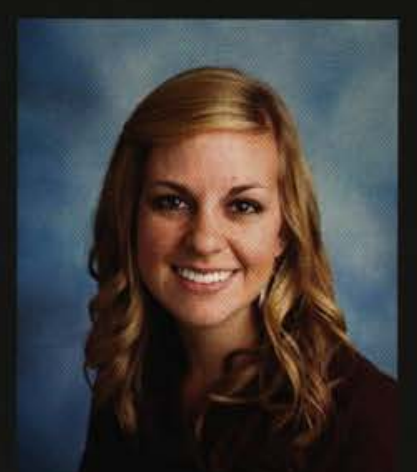

Lauren Radcliffe

Naples, FL

Nursing 


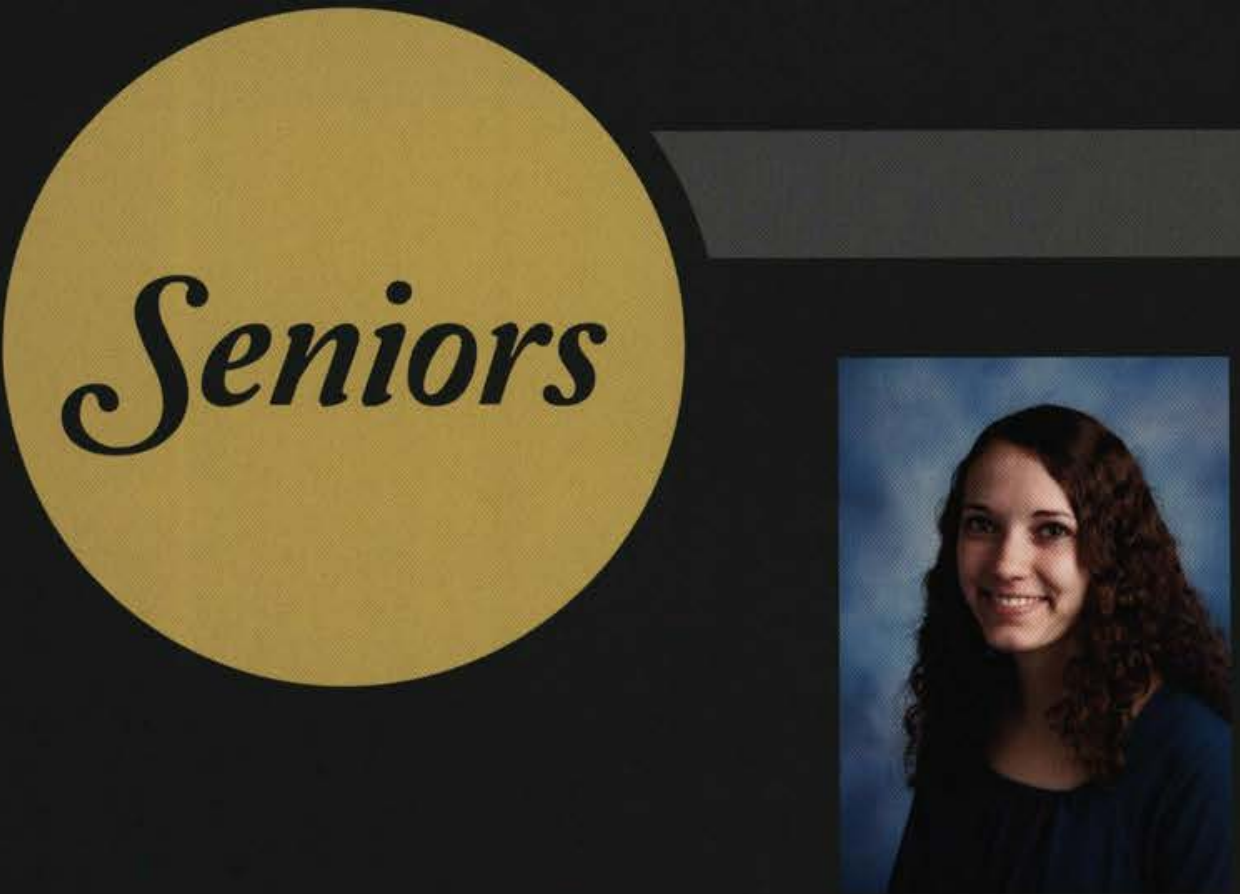

Sarah Rader

Springfield, IL

Nursing

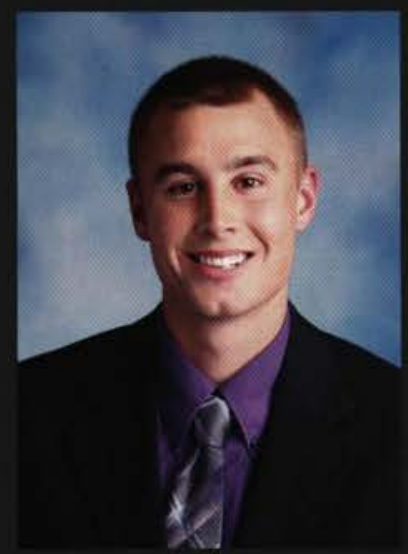

Tyler Rhodus

New Paris, $\mathrm{OH}$

Physical Education

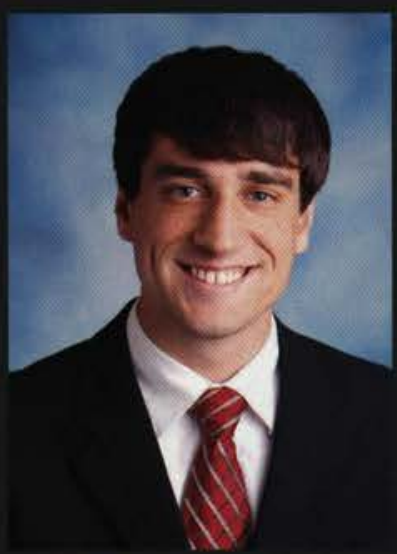

Timothy Ronco

Williston, VT

Mechanical Engineering

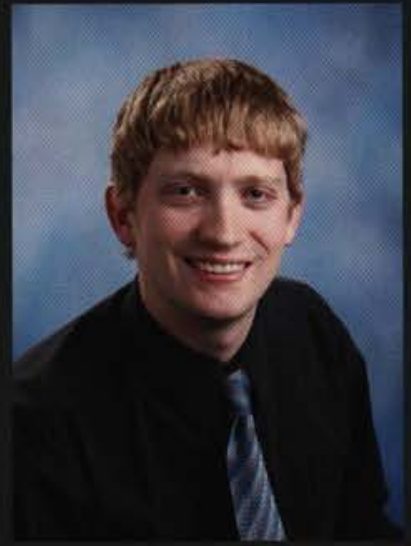

Shawn Rifner

Beavercreek, $\mathrm{OH}$

Broadcasting/Digital Media

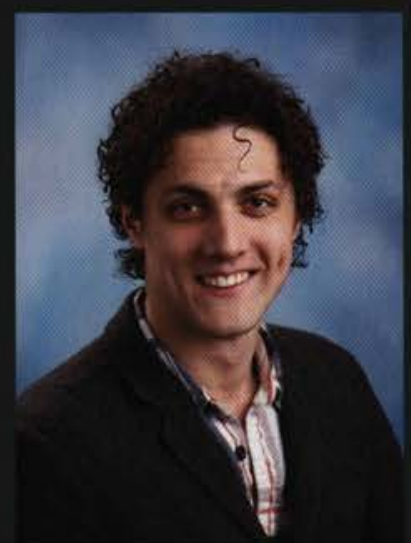

Joshua Roose

Tustin, MI

Biology

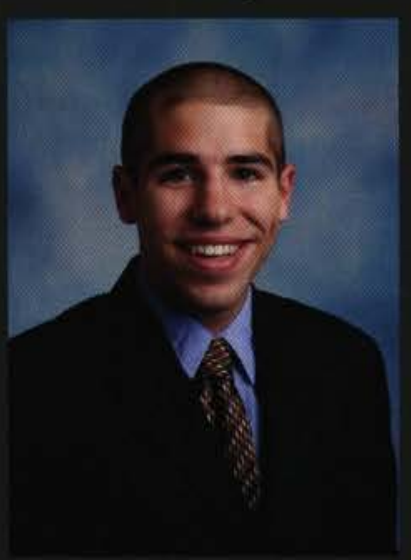

David Riggleman

Indianapolis, IN

Computer Science

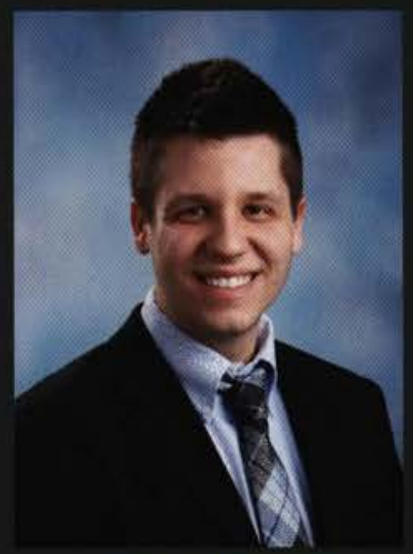

Michael Roten

Parkersburg, WV

Organizational Comm.

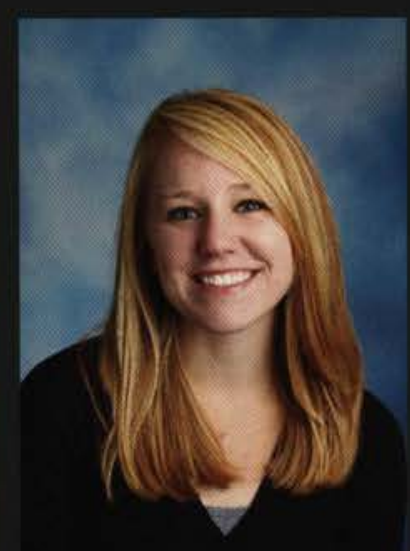

Hannah Rausch

Lafayette, IN

Early Childhood Education

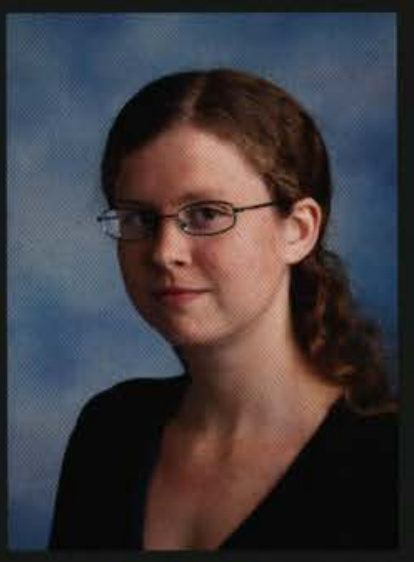

Leah Robertson

Columbia, CT

International Studies

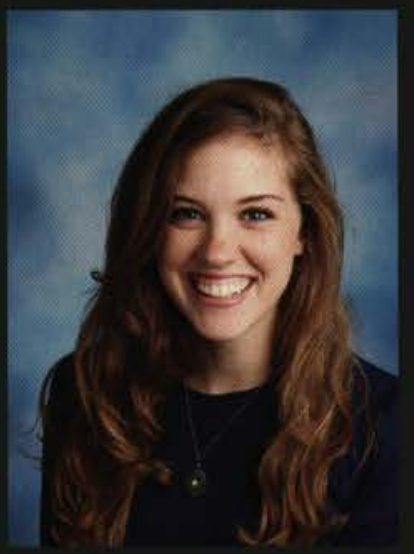

Sarah Rothhaar

Burlington, $\mathrm{KY}$

Studio Art

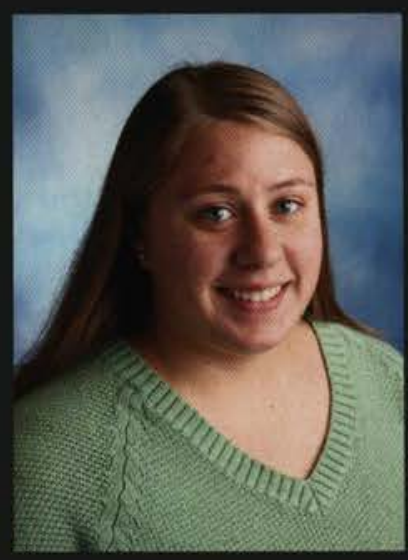

Eadie Rethmeier

Laurel, IA

International Studies

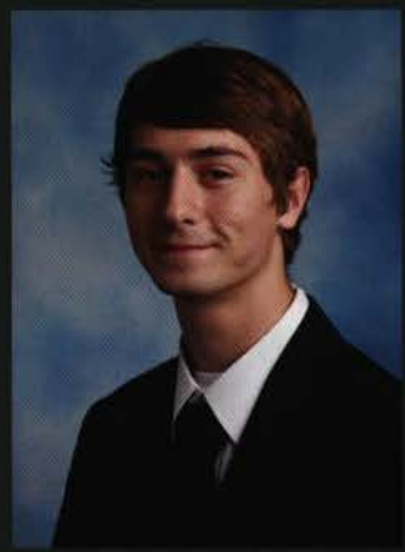

Chance Rollins

Glenburn, ME

Information Systems

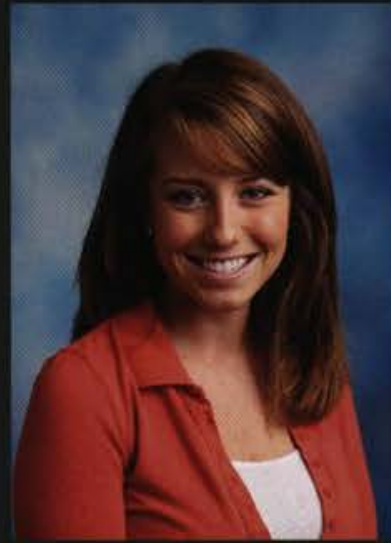

Meagan Ruby

South Charleston, $\mathrm{OH}$ Middle Childhood Edu. 


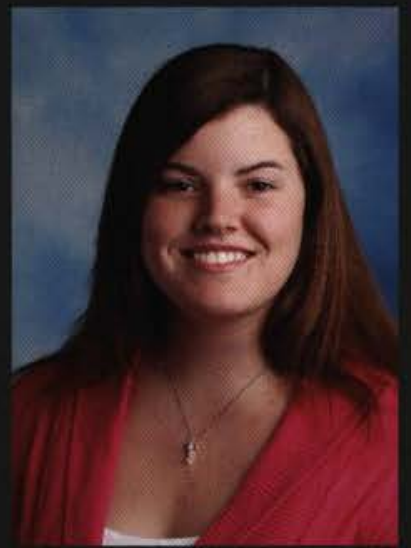

Bridget Russell

Edgewater, MD

Nursing

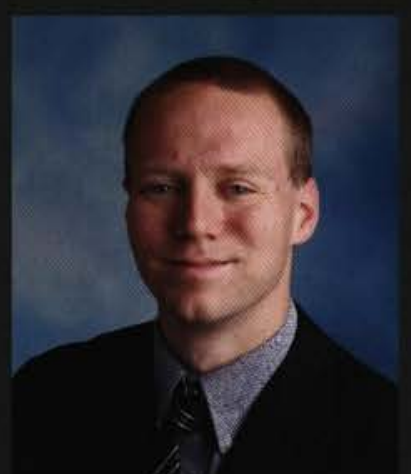

Erik Sanders

Massillon, $\mathrm{OH}$

Athletic Training

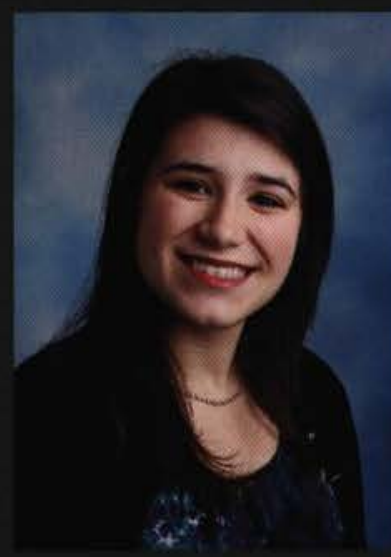

Danielle Scarpone

Bloomingdale, $\mathrm{OH}$

Electrical Engineering

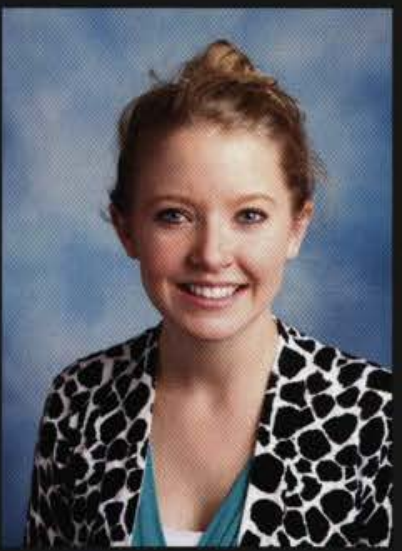

Stephanie Russell Butler, PA

Computer Science

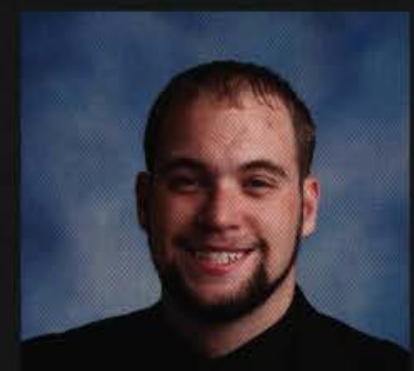

Larry Sanders Jr.

Genoa, $\mathrm{OH}$

Electrical Engineering

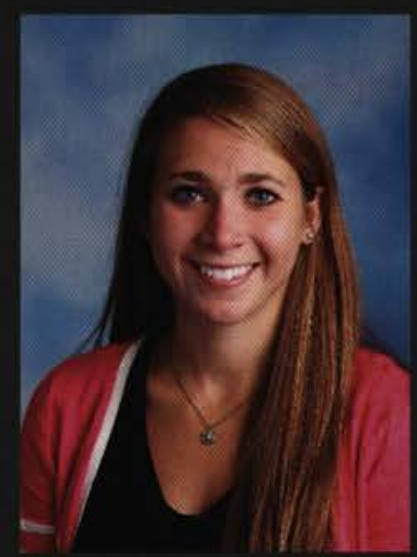

Alison Scharold

Hilton Head Island, SC

Early Childhood Education

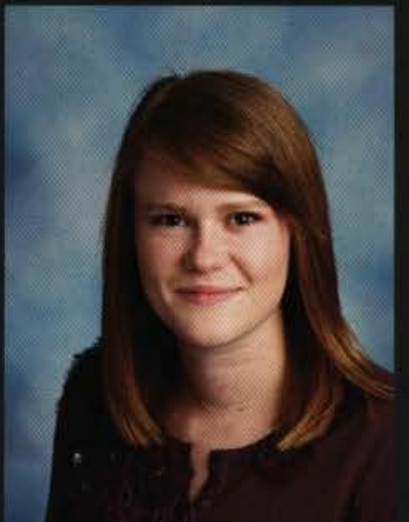

Sarah Ryker

Fort Wayne, IN

Allied Health

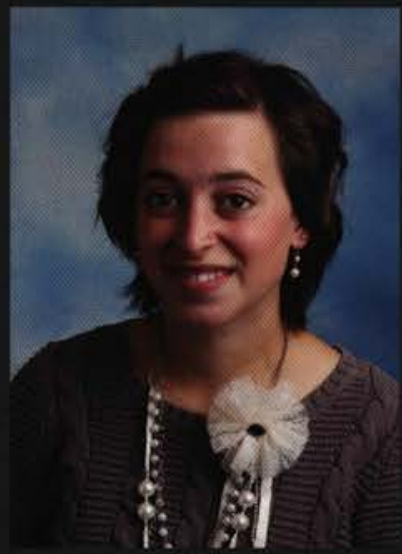

Gabrielle Sanfilippo

Lititz, PA

Music Education

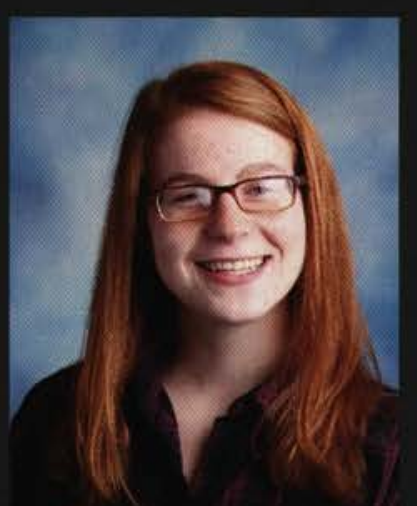

Katherine Schmidt Joliet, IL

Early Childhood Education

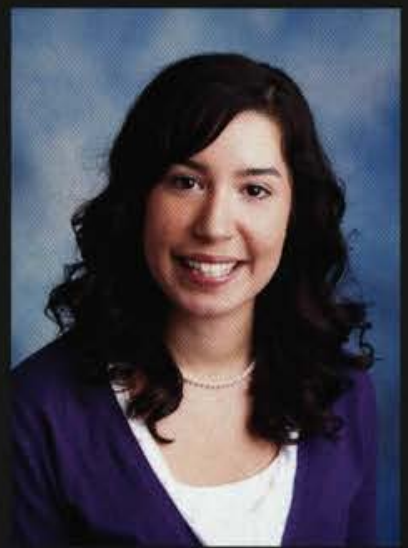

Sarah Sahulcik

Hammond, IN

Nursing

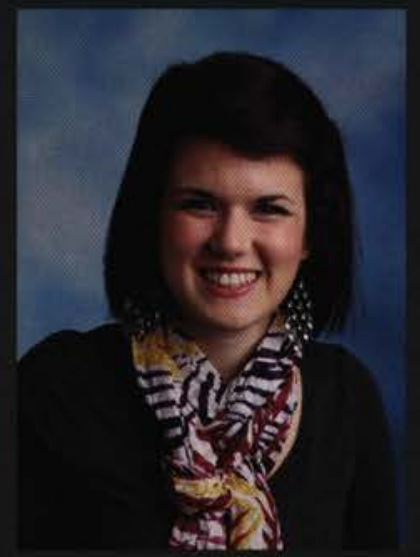

Samantha SanGregory

Xenia, $\mathrm{OH}$

Accounting

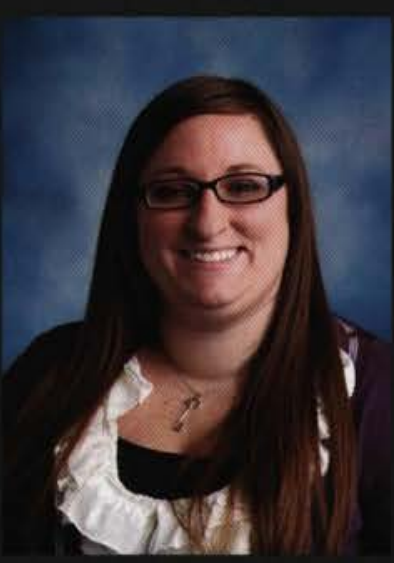

Sarah Schmidt

Prescott, MI

Nursing

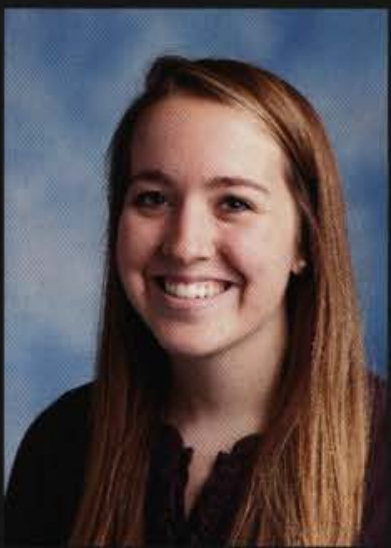

Stephanie Salzler

Plain City, OH

Social Studies Education

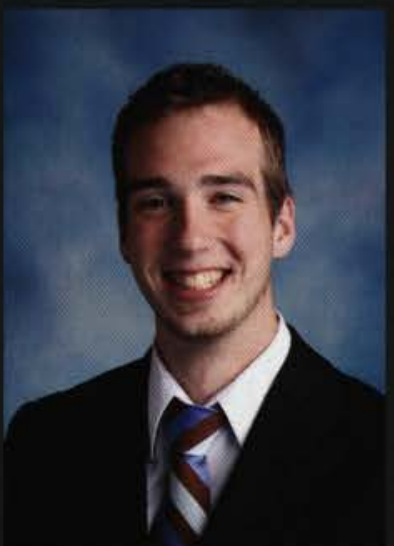

Jonathan Saxe

Dayton, $\mathrm{OH}$

Mechanical Engineering

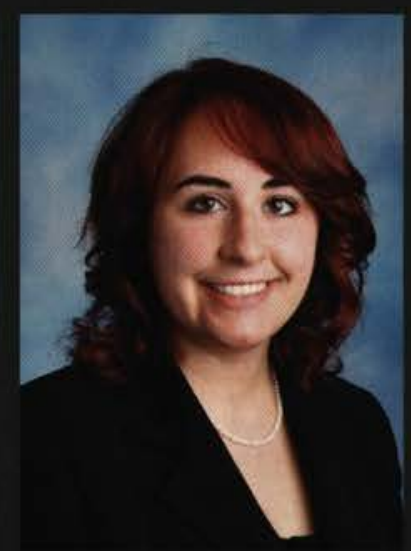

Megan Scott

Pinckney, MI

Graphic Design 


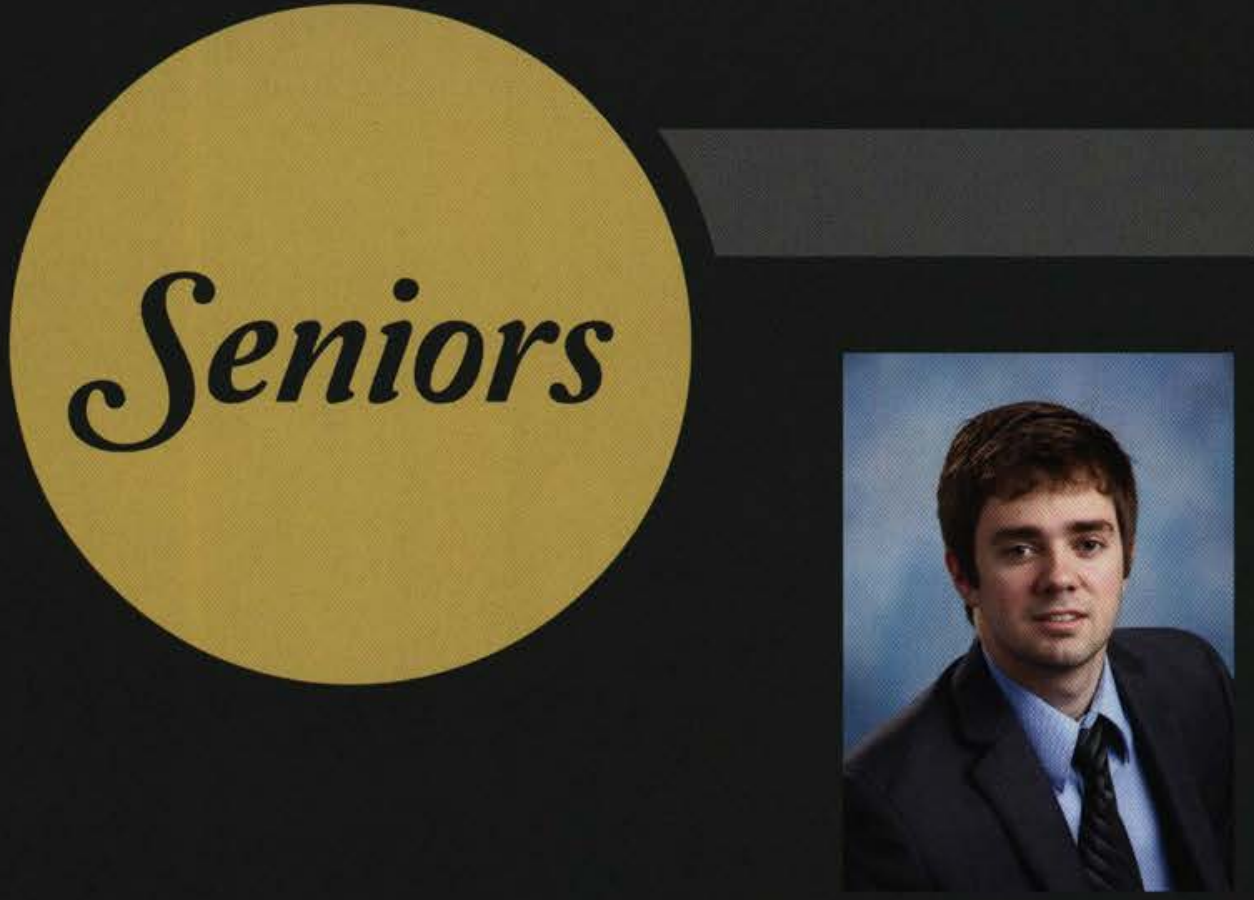

Seth Scott

Massillon, $\mathrm{OH}$

Accounting

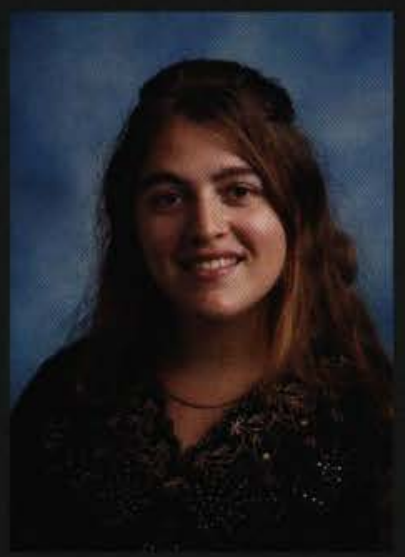

Susanne Seybold

Cedarville, $\mathrm{OH}$

Language Arts Education

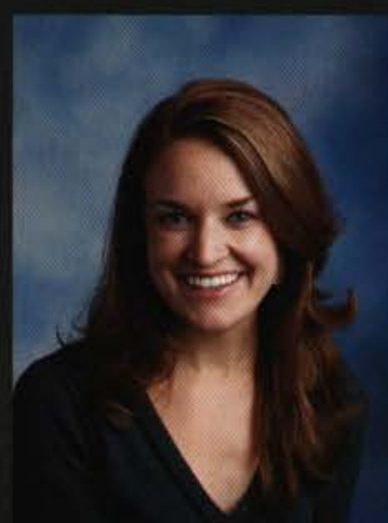

Lauren Simpson

Reading, PA

Pyschology

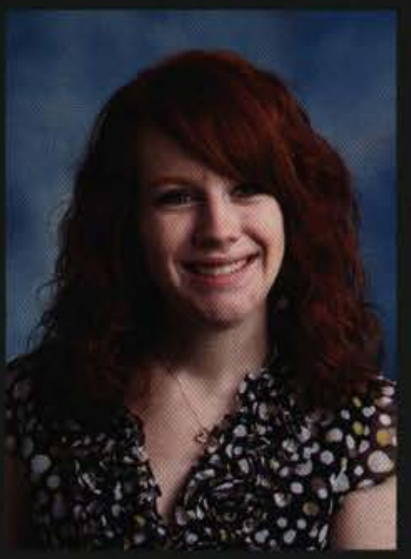

Jessica Sharp

Mount Laurel, NJ

Early Childhood Education

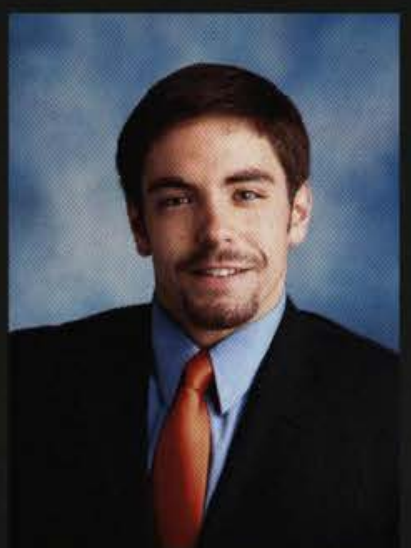

William Simpson

Westfield Center, OH

Comprehensive Bible

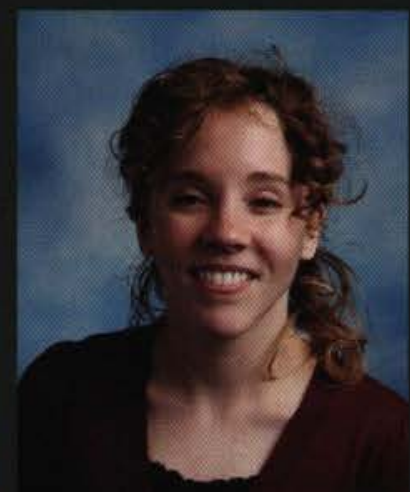

Erin Shockley

Vienna, WV

Chemistry

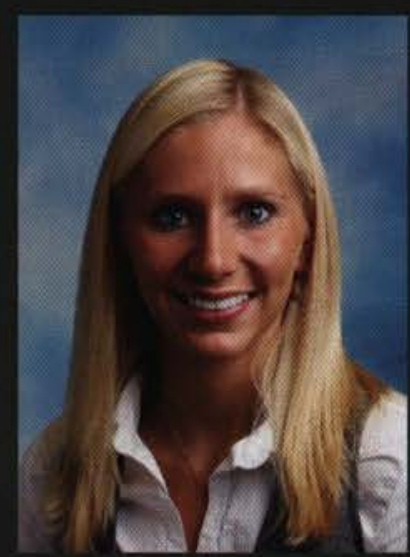

Jessica Smith

Ona, WV

Exercise Science

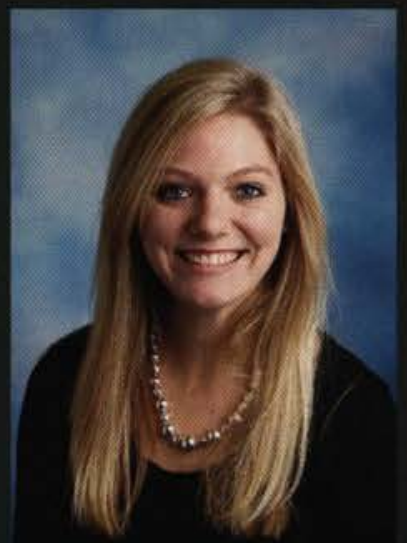

Bethany Servi

Neenah, WI

Nursing

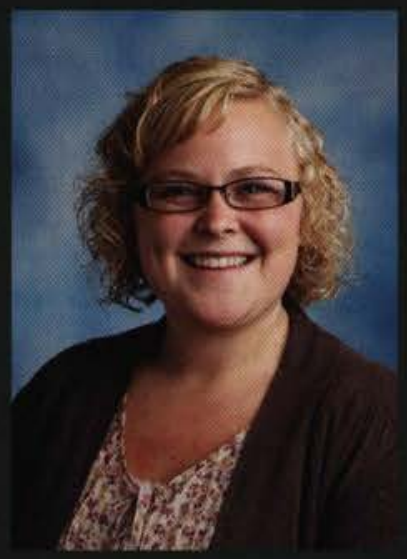

Melissa Sides

Grand Haven, MI

Nursing

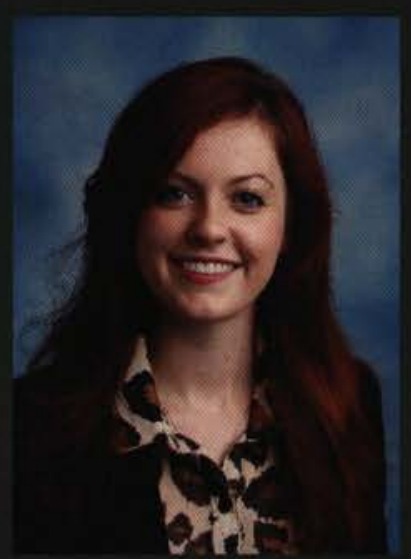

Jordan Smith

Winchester, VA

Intercultural Comm.

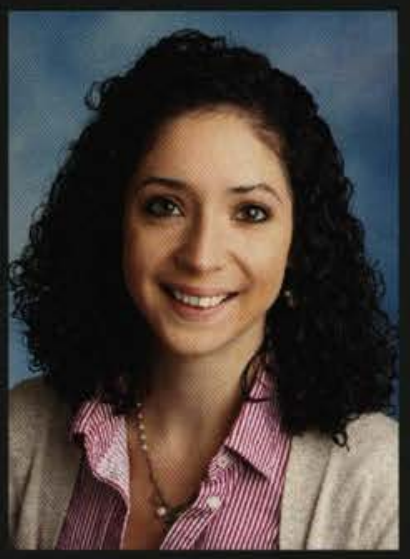

Emily Severance

Landsale, PA

Journalism

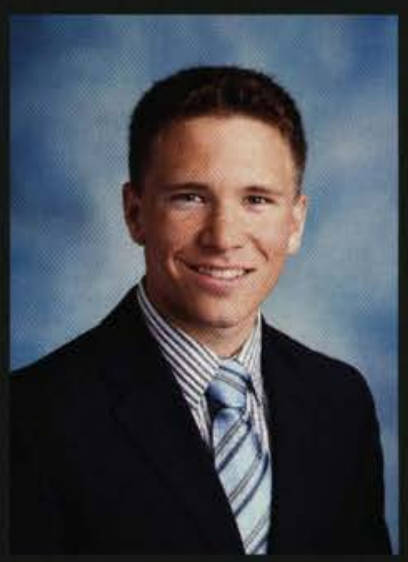

Daniel Sievert

Pewaukee, WII

History \& Political Science

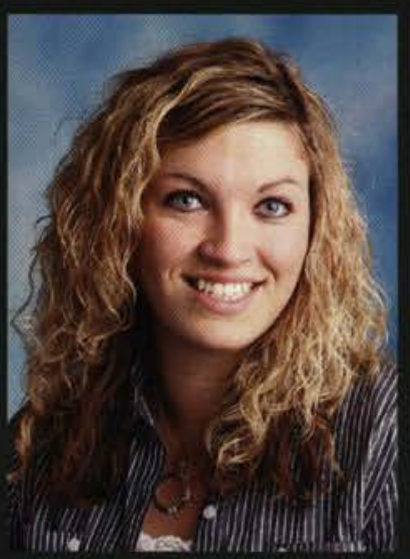

Kendra Smith

Lapeer, MI

Graphic Design 


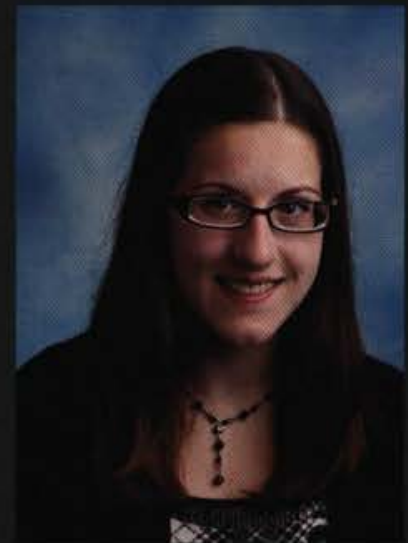

Meagan Smith

Duncansville, PA

Accounting

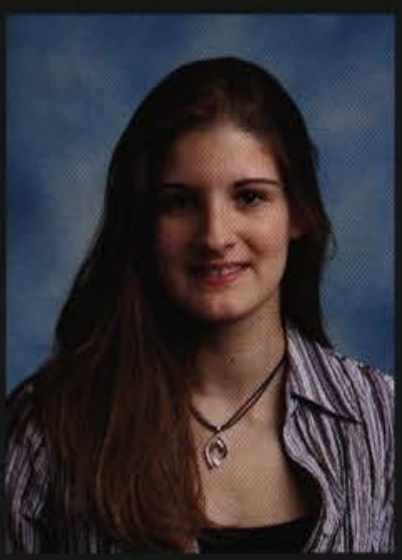

Grace Stearns

Beavercreek, $\mathrm{OH}$

Chemistry

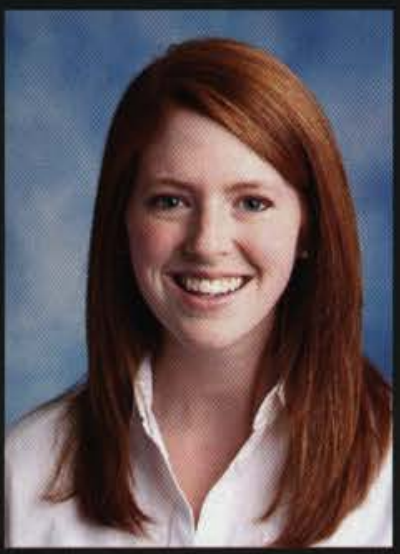

AliStrayhorn

Ada, MI

Nursing

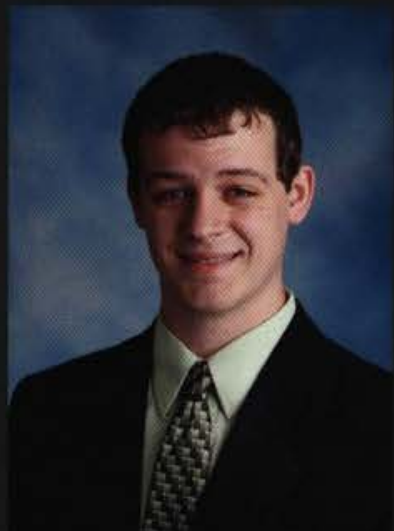

Zachary Smith

Springfield, $\mathrm{OH}$

Computer Engineering

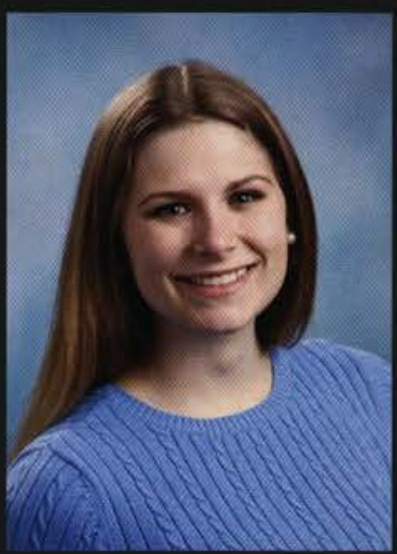

Rachel Steetle

Colbert, WA

Public Administration

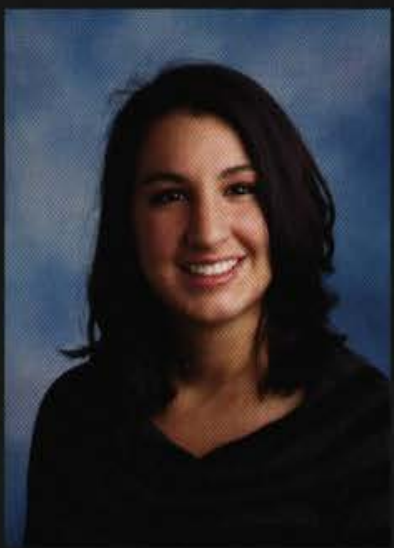

Stephanie Strejc

Elmhurst, II

Nursing

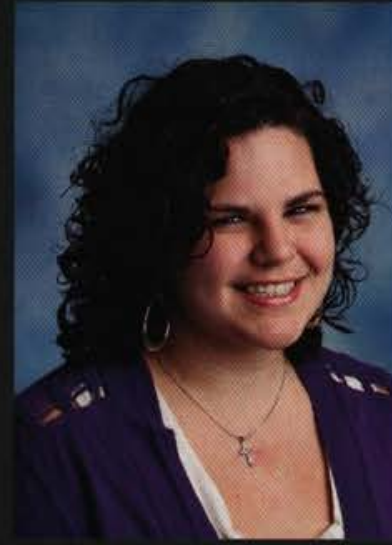

Apryl Sniffen

Peekskill, NY

Tech \& Prof Comm.

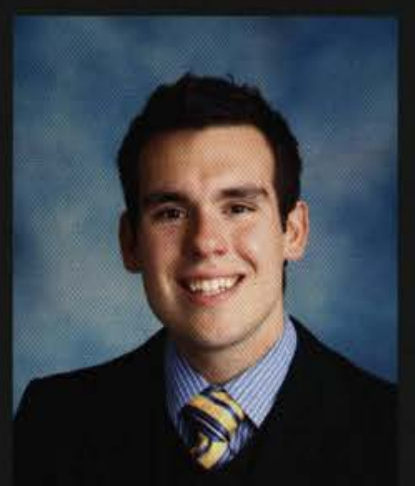

Scott Stephens

Whitley City, KY

Organizational Comm.

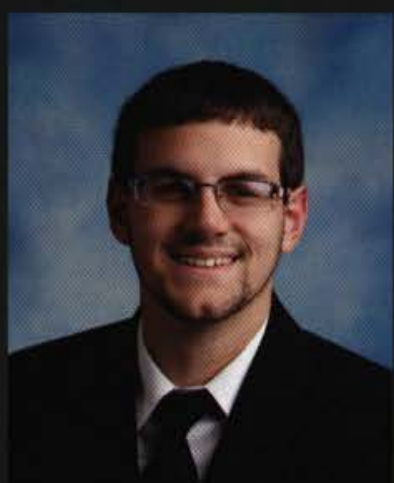

Alexander Struble

White Lake, MI

Geology

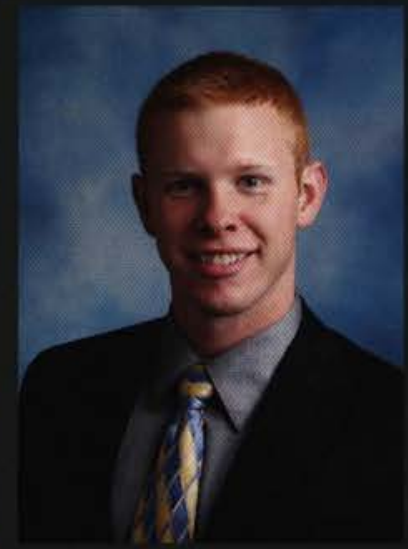

William Sorensen

Cologne, MN

Mechanical Engineering

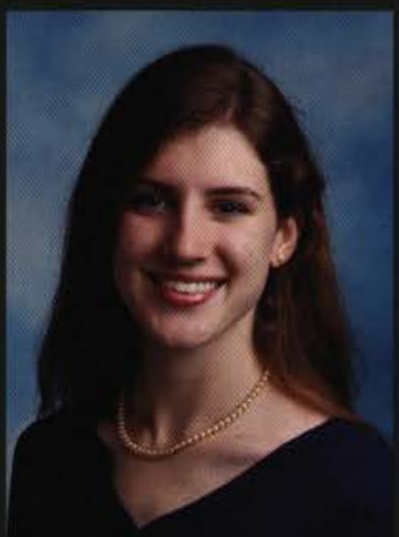

Lillian Stevens

Raleigh, NC

History

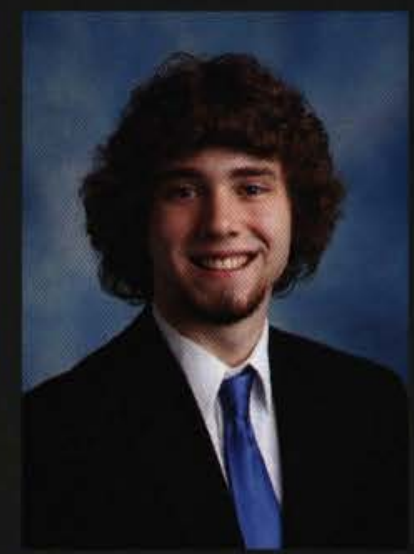

Timothy Studebaker Eaton, $\mathrm{OH}$

Physical Education

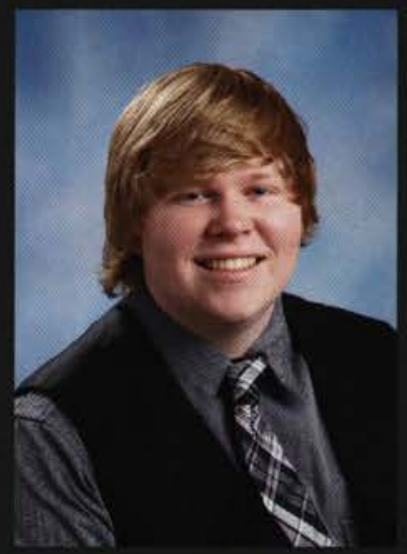

Joshua Staley

Lees Summit, MO

Worship

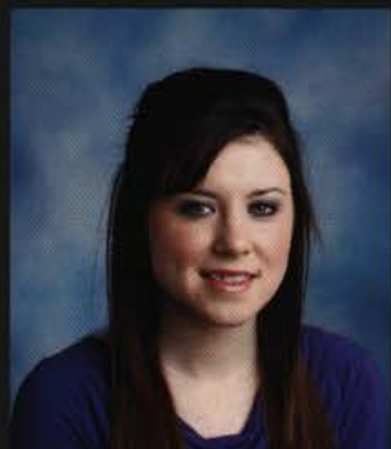

Grace Stearns

Beavercreek, $\mathrm{OH}$

Chemistry

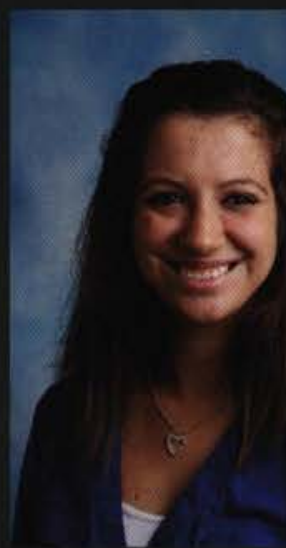

Meredith Sumner

Williamsport, MD

Organizational Comm 


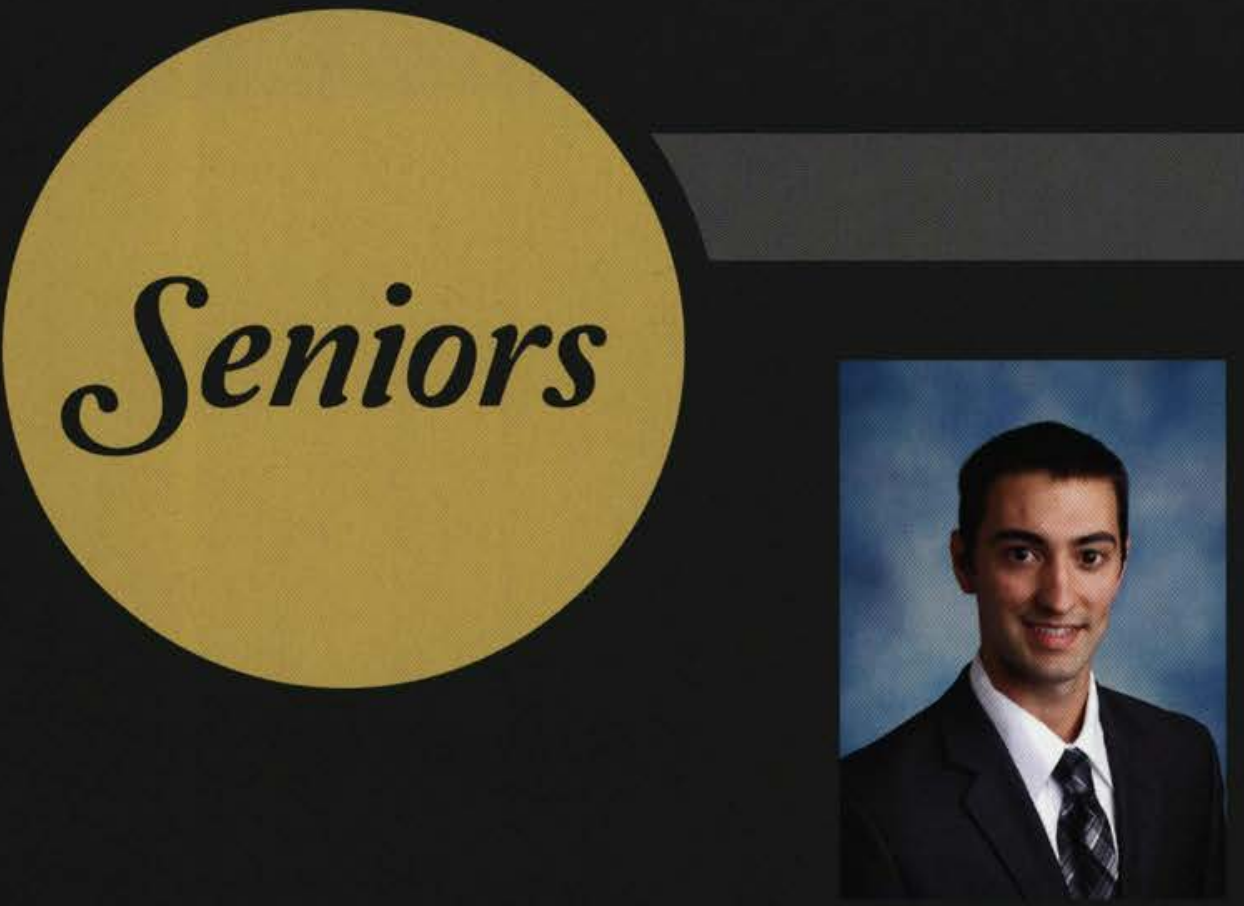

Timothy Swanson

Killingworth, CT

Electrical Engineering

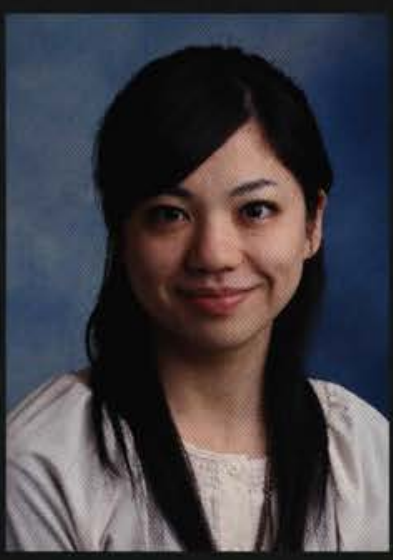

Miki Takeuchi

Tokoname, Japan

Nursing

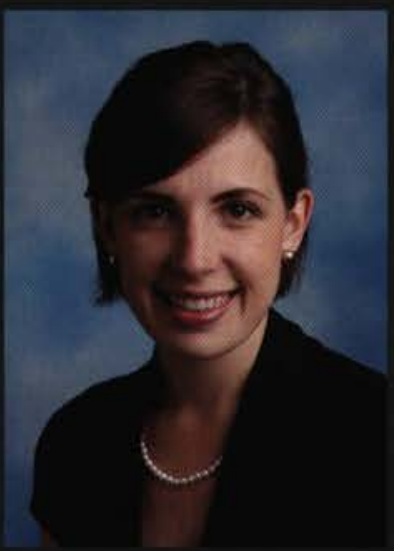

Rachel Thompson

Cypress, TX

Tech \& Prof Comm.

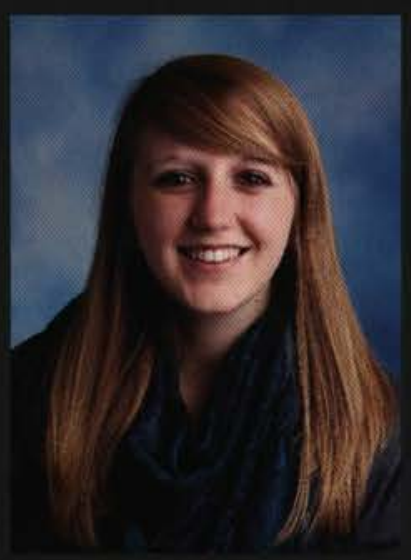

Rebecca Tervo

Flanders, NJ

International Studies

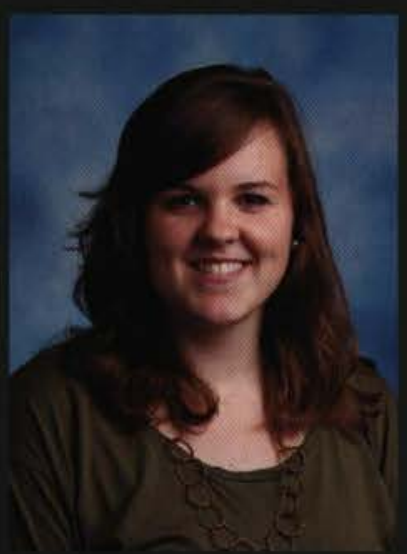

Sarah Thompson

Harleysville, PA

Music Education

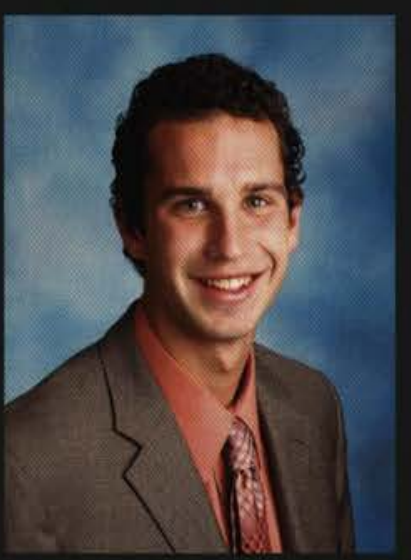

Evan Thayer

Naperville, IL Biology

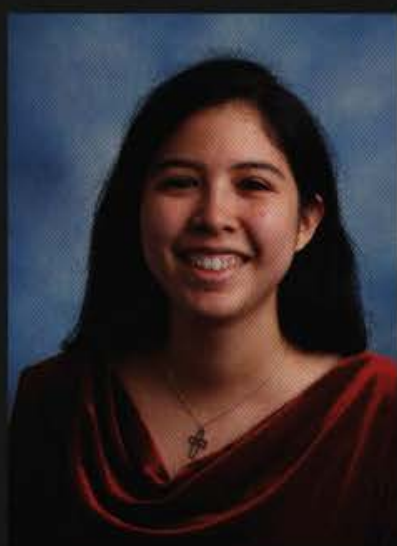

Charissa Thong

Newnan, GA

Graphic Design

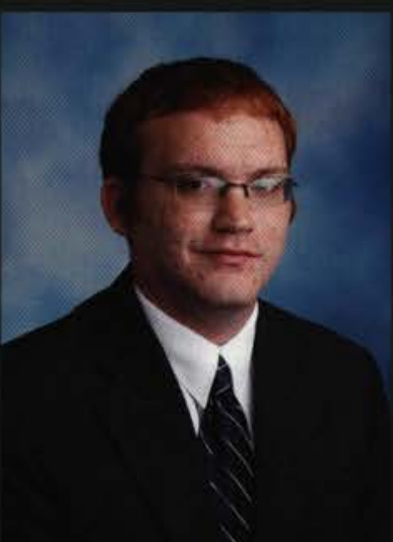

David Swick III

South Webster, $\mathrm{OH}$

Philosophy

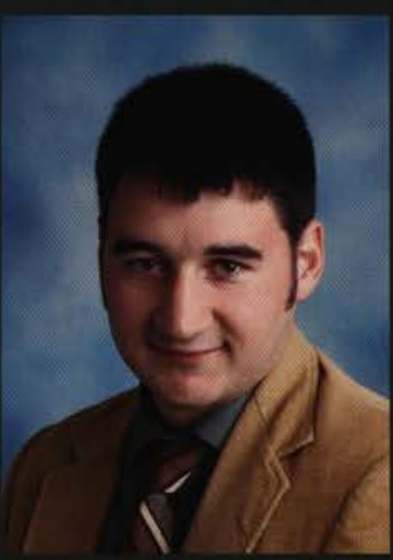

Jeremy Thomas

Colton, NY

Middle Childhood Edu.

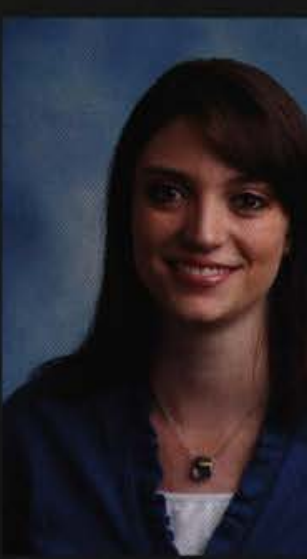

Emily Tomlinson

Morrow, $\mathrm{OH}$

History

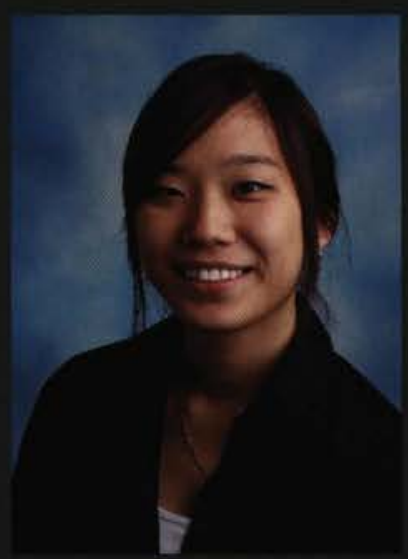

So Tak

NaeDaeji Village, S. Korea Nursing

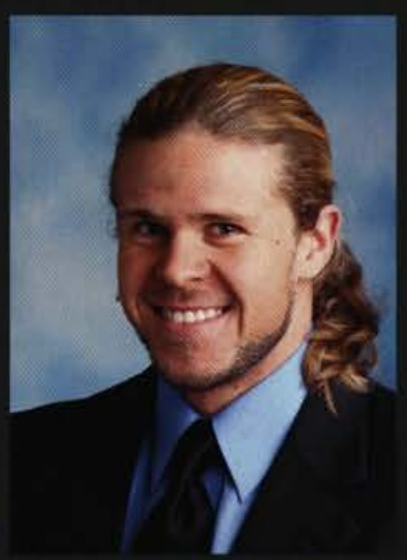

Eric Thompson

Columbus, $\mathrm{OH}$

Graphic Design

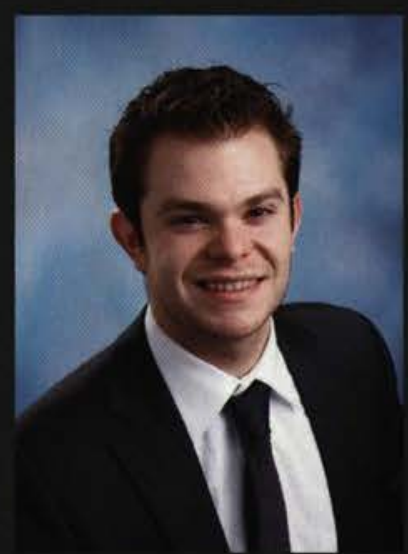

Seth Trautman

Powell, $\mathrm{OH}$

Business Management 


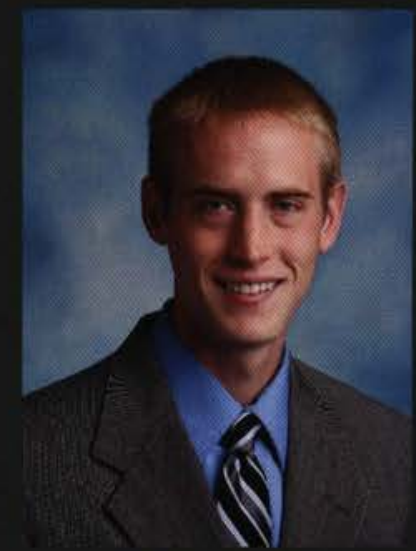

Jeffrey Travis

Yardley, PA

Youth Ministry

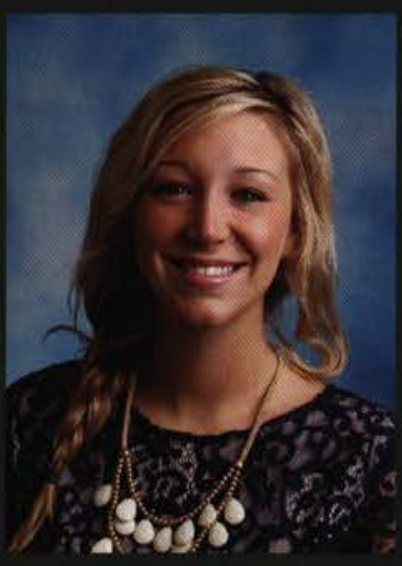

Rachel Valarik

Cincinnati, $\mathrm{OH}$

Comprehesive Comm.

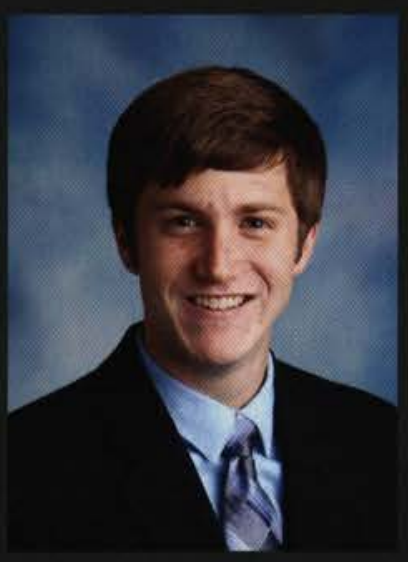

David Wagner

Upper Sandusky, $\mathrm{OH}$

Accounting

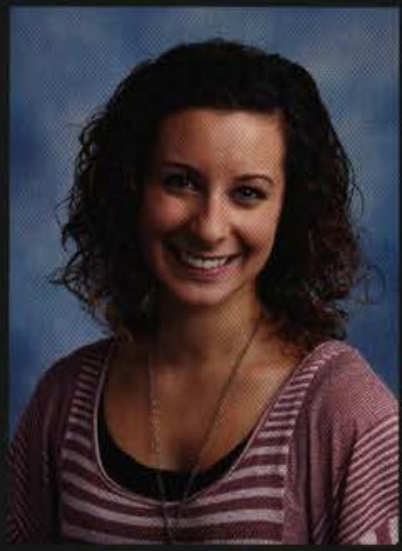

Vienna Trindal

De Pere, WI

Music

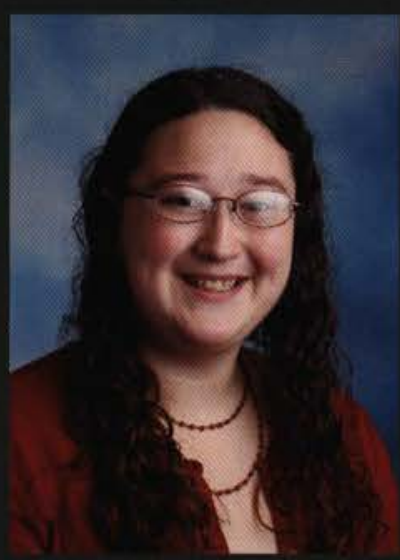

Hadassah Veldt

West Liberty, $\mathrm{OH}$

Business Management

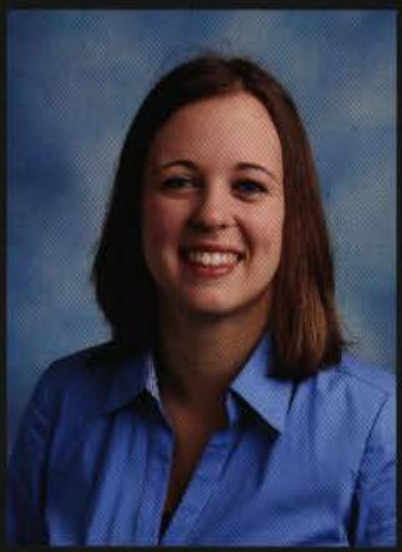

Maryann Wagner

Salineville, $\mathrm{OH}$

Finance

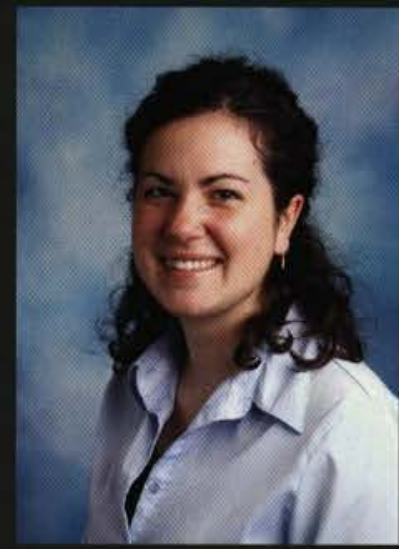

Kristin Trover

Elida, $\mathrm{OH}$

Theatre

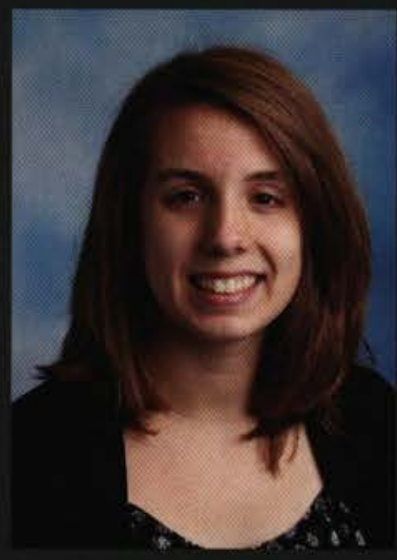

Jennifer Vinciguerra

New Britain, PA

Mathematics

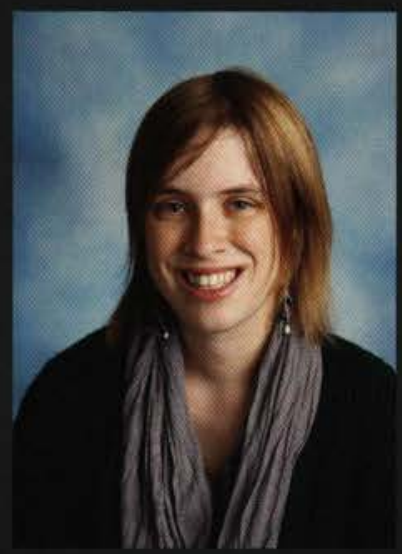

Rachel Waldrop

Sierra Vista, AZ

English

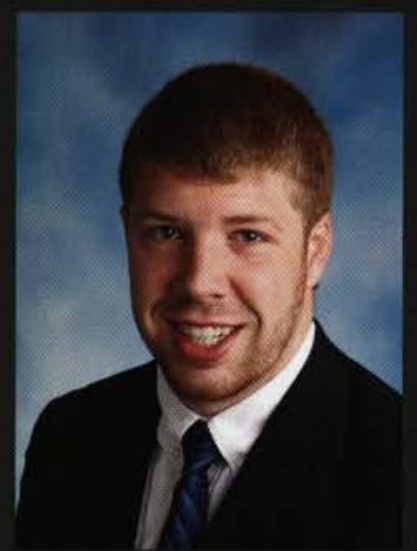

Jonathan Tucker

Cedarville, $\mathrm{OH}$

History

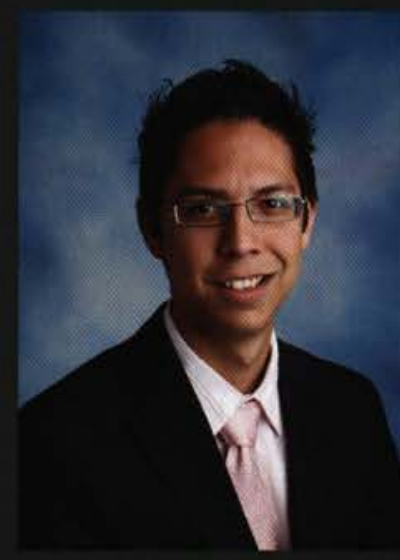

Abraham Vivas Aguilar

Columbus, IN

Computer Engineering

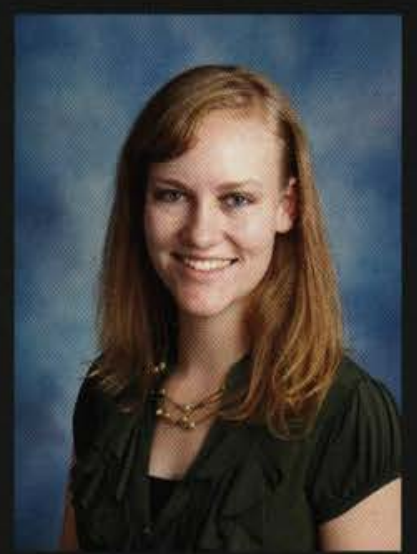

Rebekah Wallin

Torrance, CA

Criminal Justice

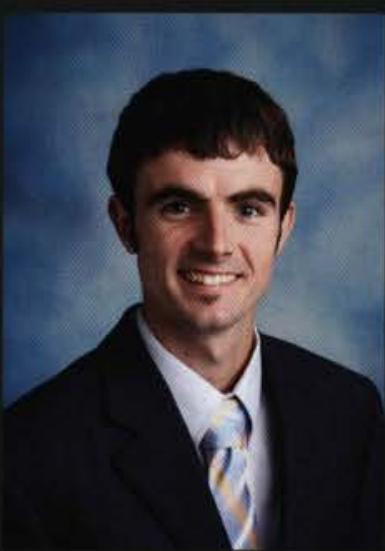

Thaddaeus Tuggle Butler, $\mathrm{OH}$

Environmental Science

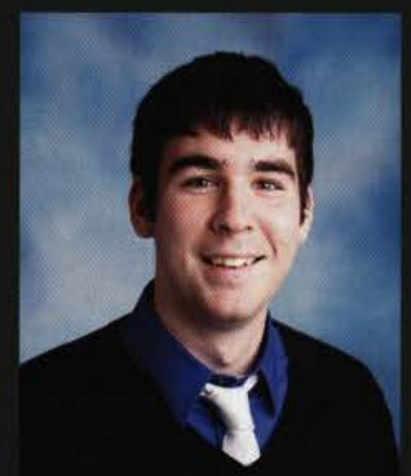

Christopher Voltz

Westfield, IN

Preseminary Bible

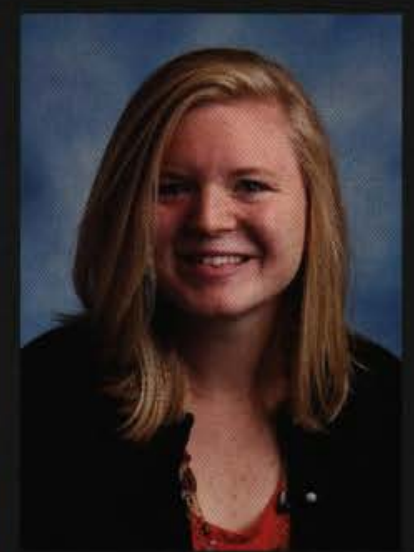

Elizabeth Walton

Jenera, $\mathrm{OH}$

Social Work 


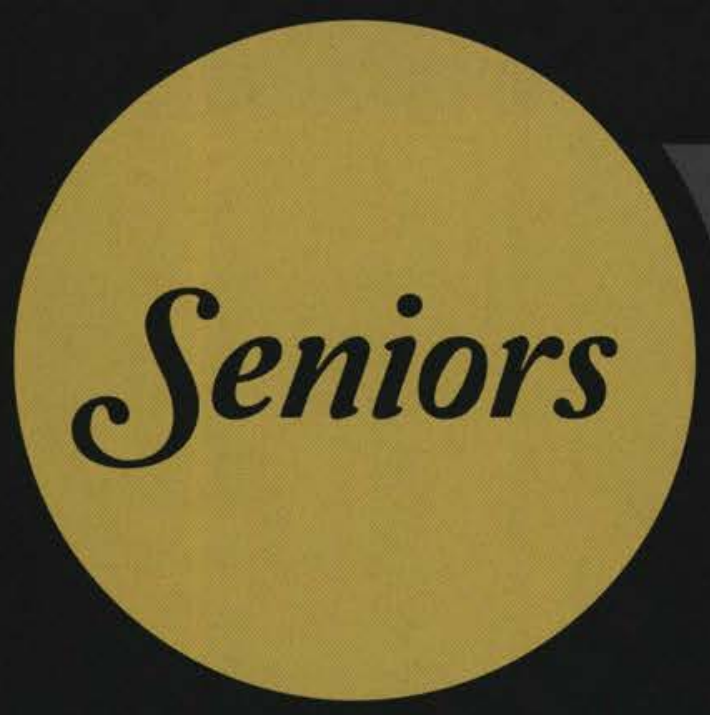

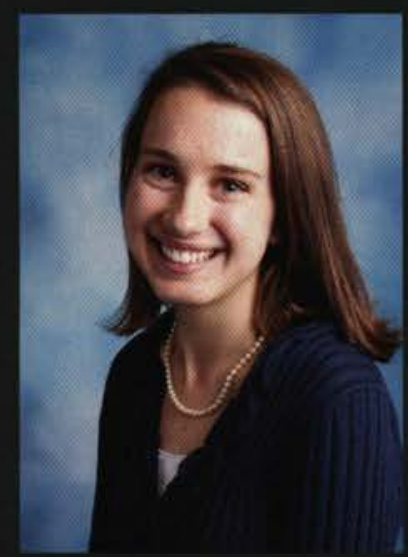

Elizabeth Weiser

Bethel Park, PA

Early Childhood Education

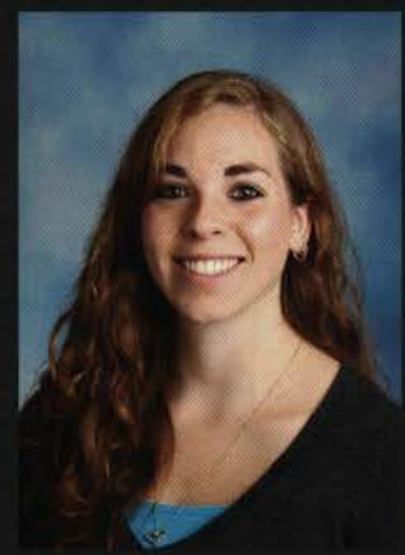

Alexandra White

Mount Vernon, $\mathrm{OH}$ Nursing

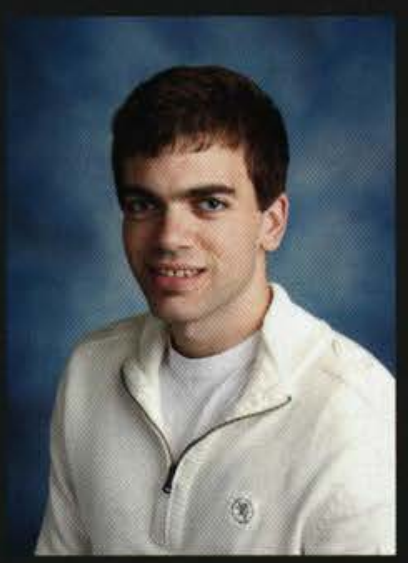

Lucas Wemple Bridgewater Corners, VT Mathematics

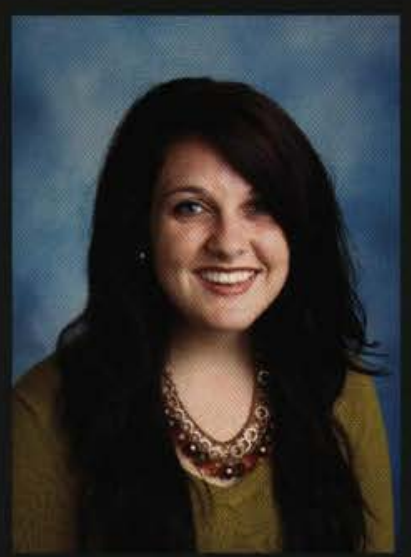

Allyson Wicker

Napels, FL

Early Childhood Education

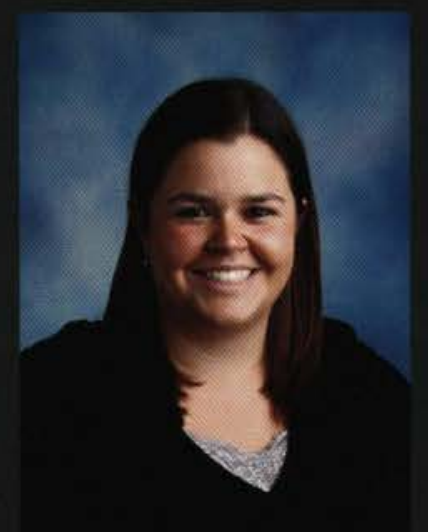

Amanda Wands Seaford, DE

Nursing

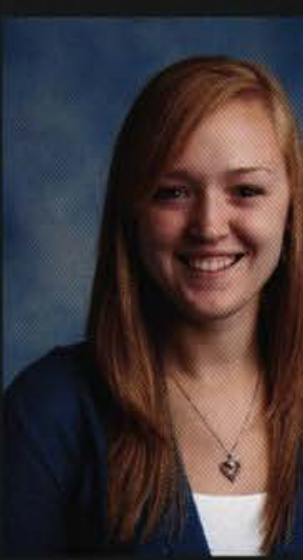

Jessica Wengerd

Uniontown, $\mathrm{OH}$

Nursing

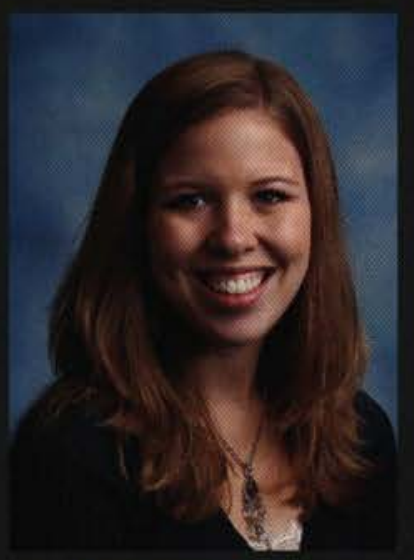

Rebecca Widder

Rocton, IL

Chemistry

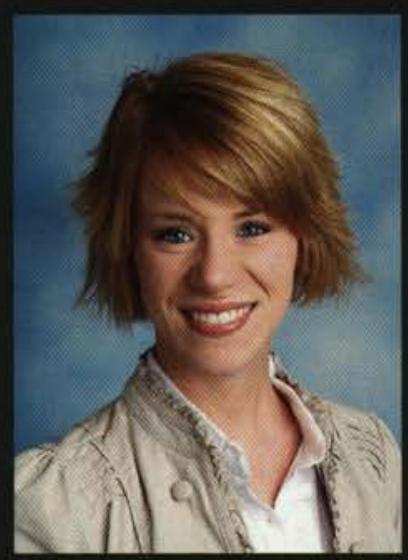

Laura Ward Scottsburg, IN Graphic Design

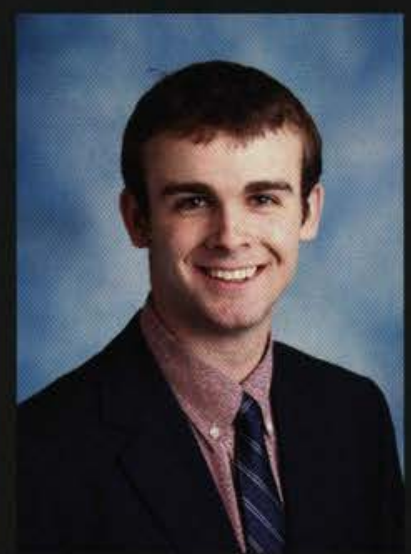

Matthew West

Valrico, FL

Accounting

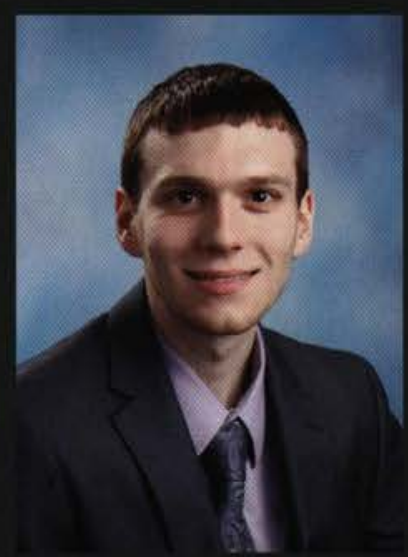

Kyle Wilcox

Anderson, IN

Social Studies Education

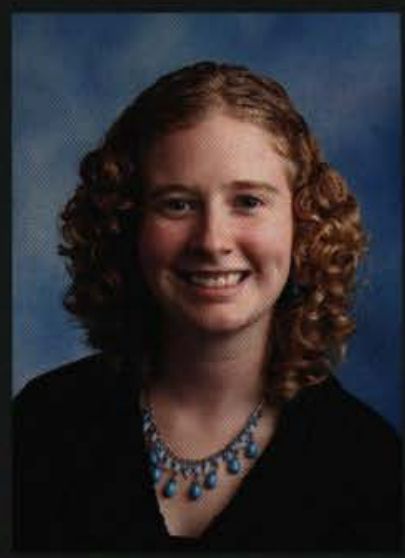

Diana Weaver Indianapolis, IN Nursing

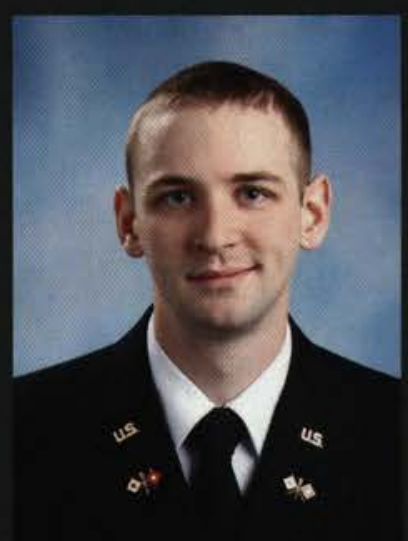

Barry Westefeld Little Egg Harbor, N Mechanical Engineering

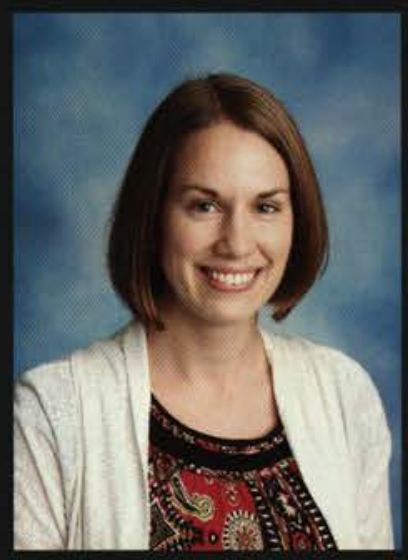

Jane Wildman

Warsaw, IN

Early Childhood Education 


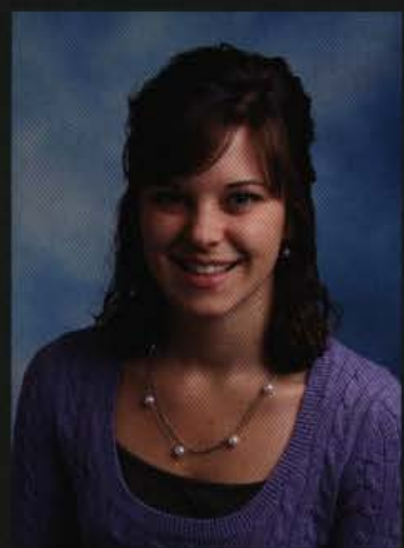

Krista Wiles

Skowhegan, ME

Music Education

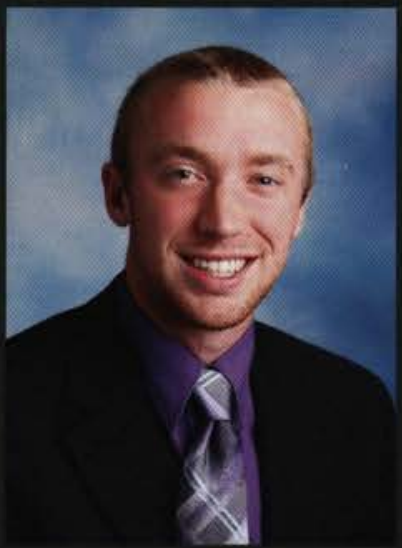

Ryan Worley

Elkton, MD

Sport Management

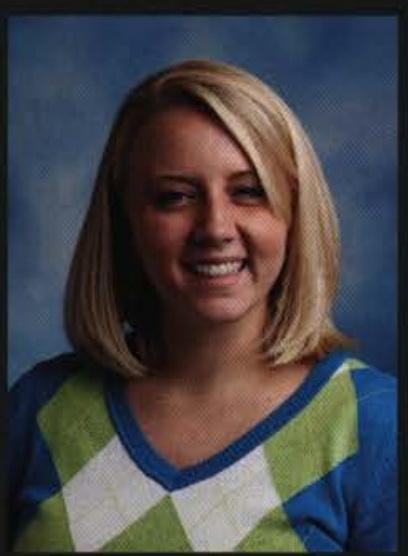

Lauren Young

Indianapolis, IN

Spanish Education

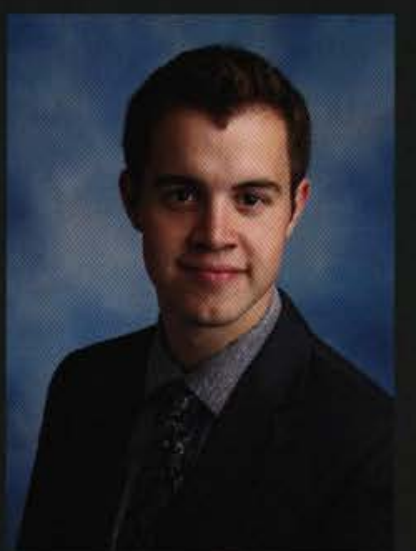

Alexander Williams

Clackamas, OR

Finance

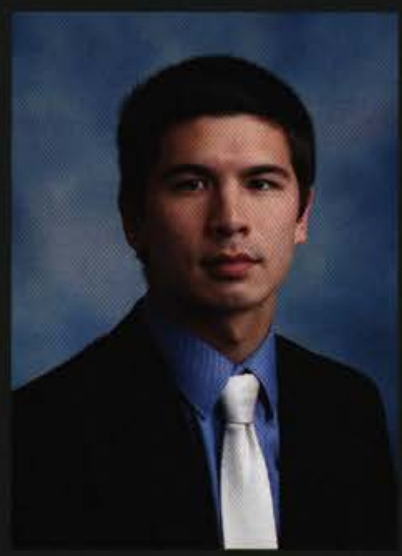

Benjamin Yeh

California, MD

Mechanical Engineering

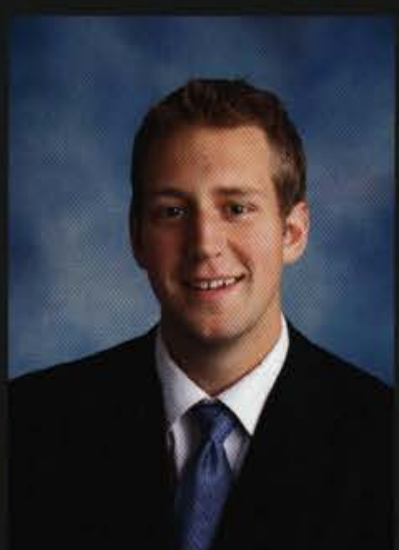

Wesley Young

Brussels, Belgium

Molecular/Cellular Biology

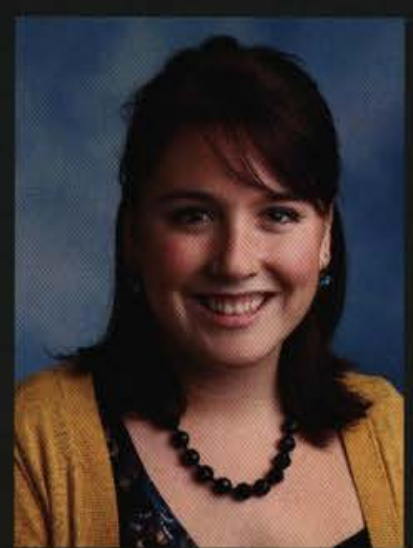

Lauren Williams

South Charleston, $\mathrm{OH}$

Social Work

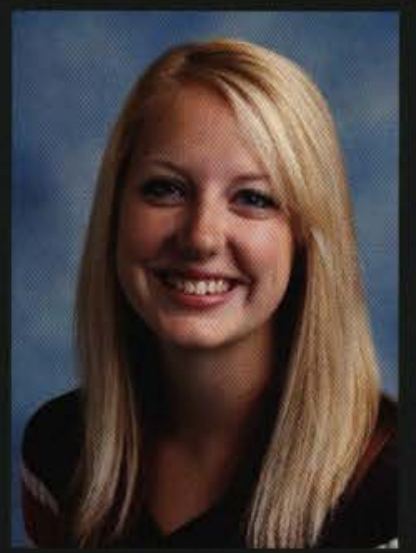

Caitlin Yoder

West Liberty, $\mathrm{OH}$

Social Work

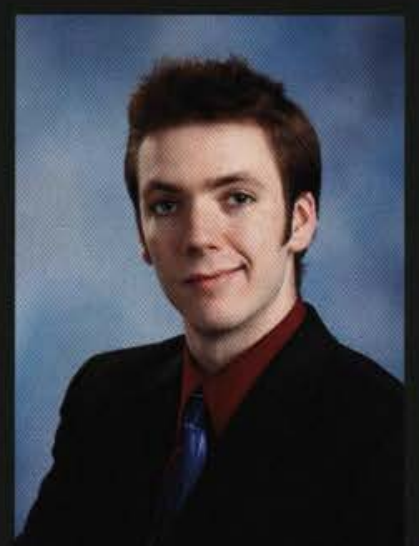

Lucas Zellers

Ashton, IL

Comprehensive Comm.

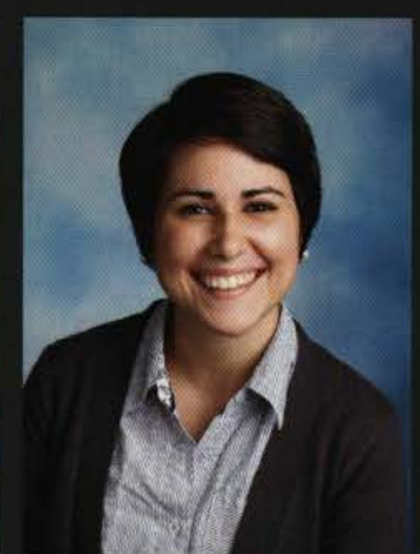

Chelsea Wolf

Columbus, $\mathrm{OH}$

Nursing

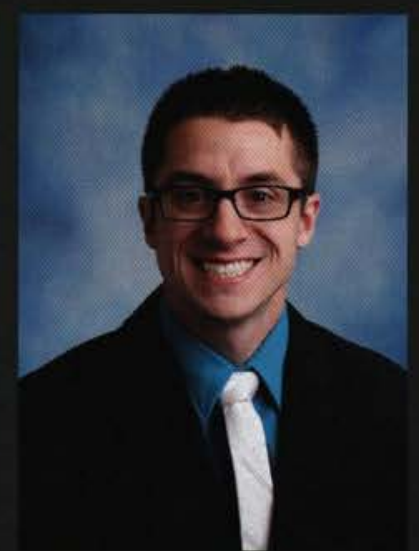

Zachary Yonek:

Huron, $\mathrm{OH}$

Youth Ministry

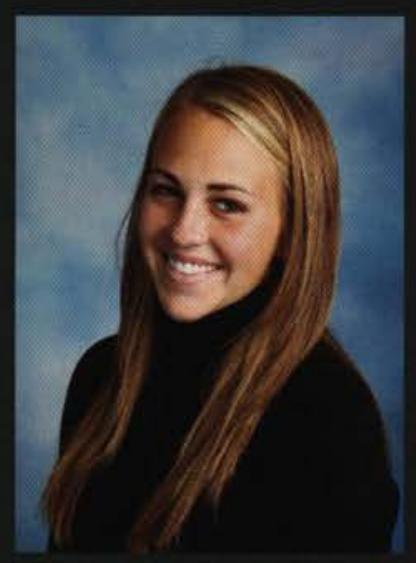

Morgan Ziegler

Wellington, $\mathrm{OH}$

Exercise Science

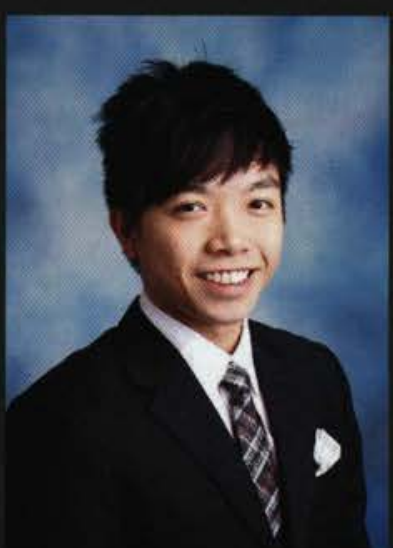

Luen Wong

Kowloon, Hong Kong

Accounting \& Finance

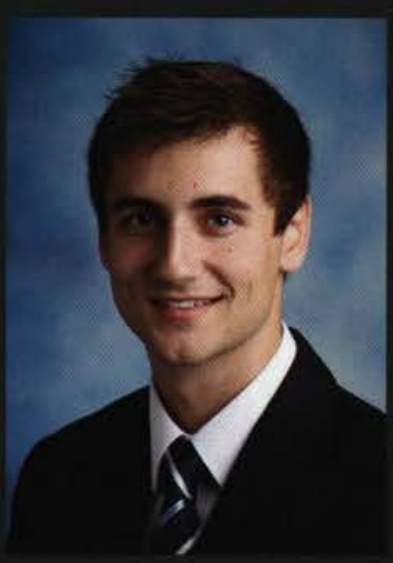

Cameron York

Mars Hill, ME

Exercise Science

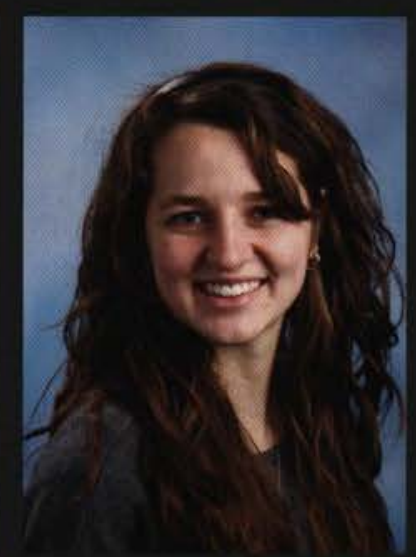

Tia Zirkle

York, PA

Biology 


\section{c

It seems like just yesterday that it was Getting Started 2008 and now we look back wondering where the time has gone.

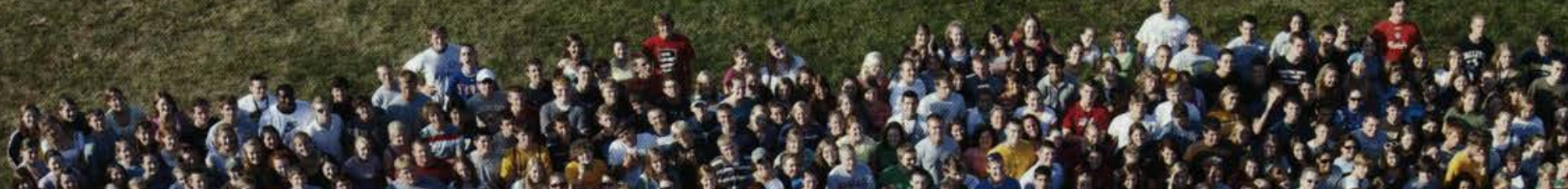

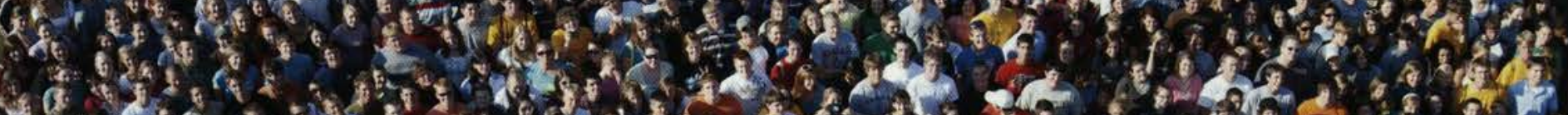

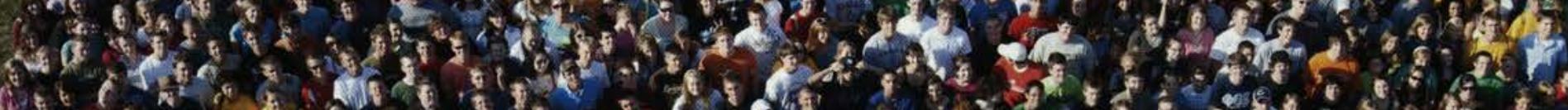

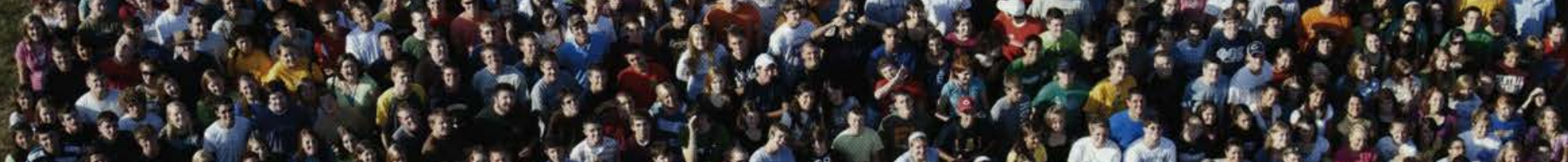

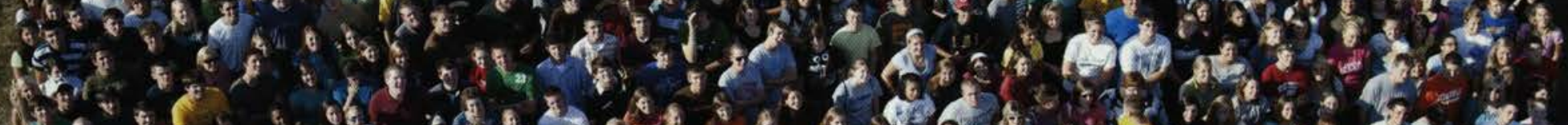

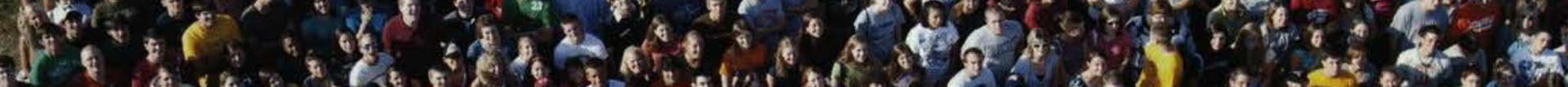

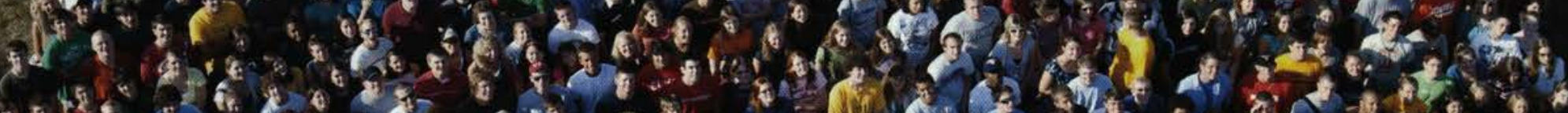

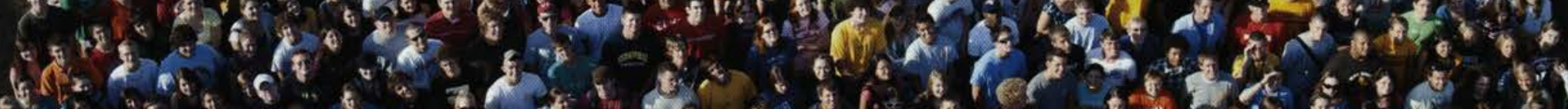

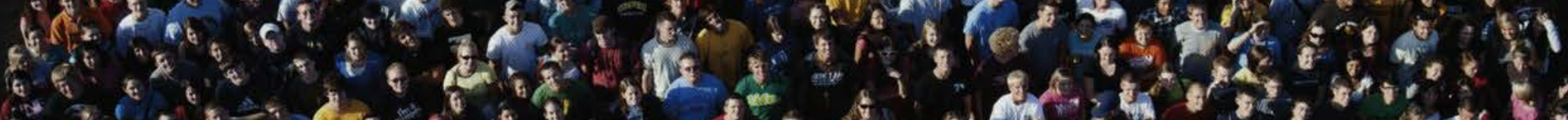

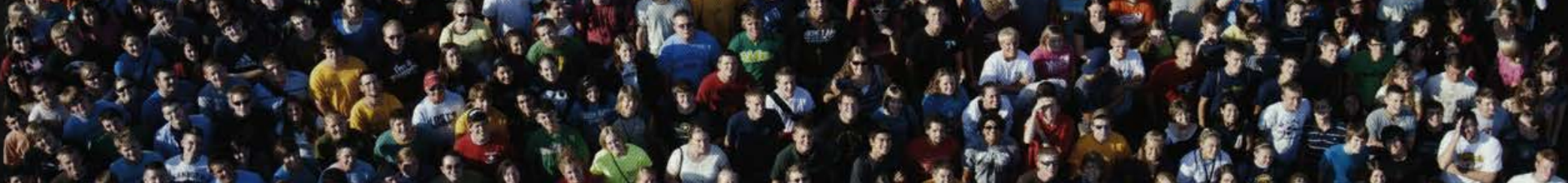

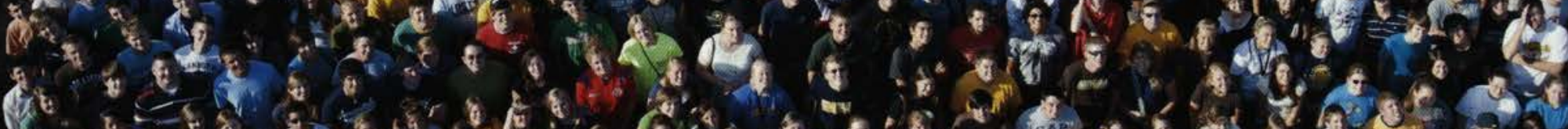

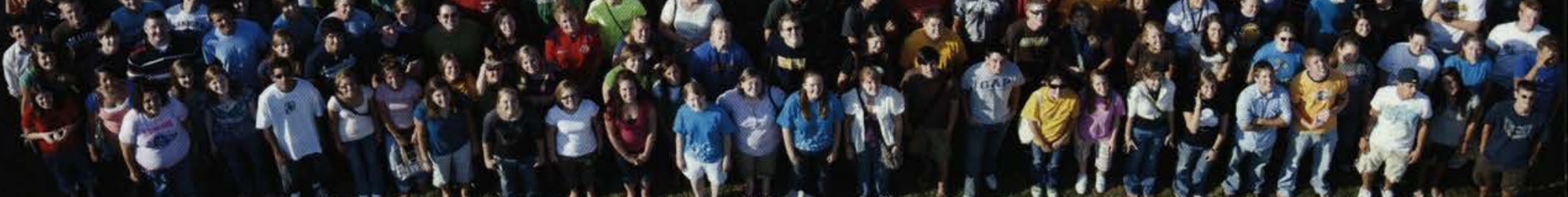

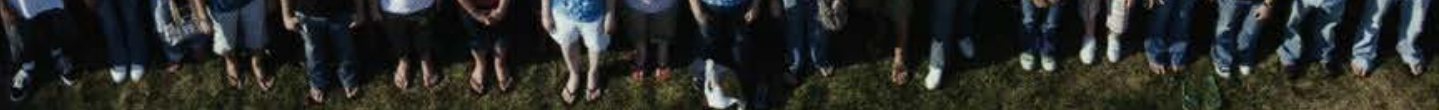
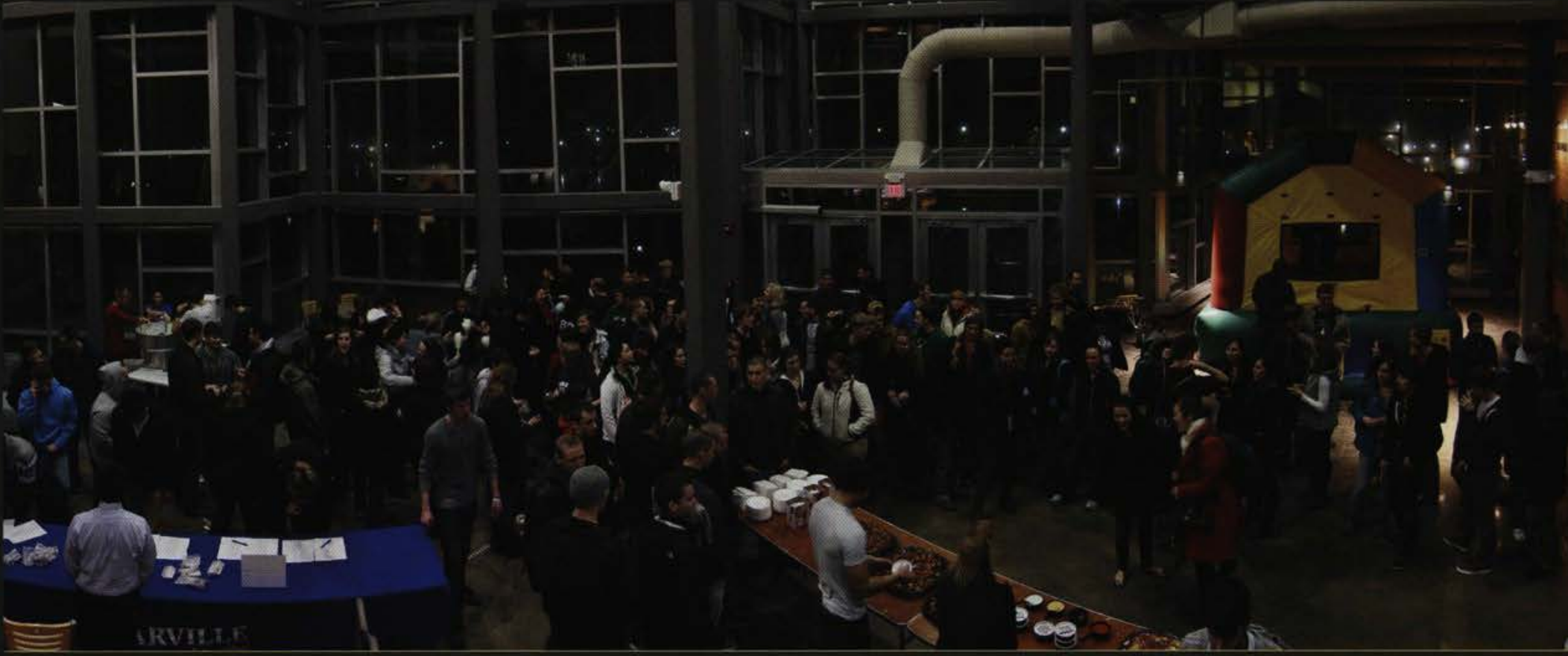


\section{Fonors \\ $\varepsilon \sigma^{2}$ \\ Convocation}

Four years of academic acheivement deserves a little bit of recognition.

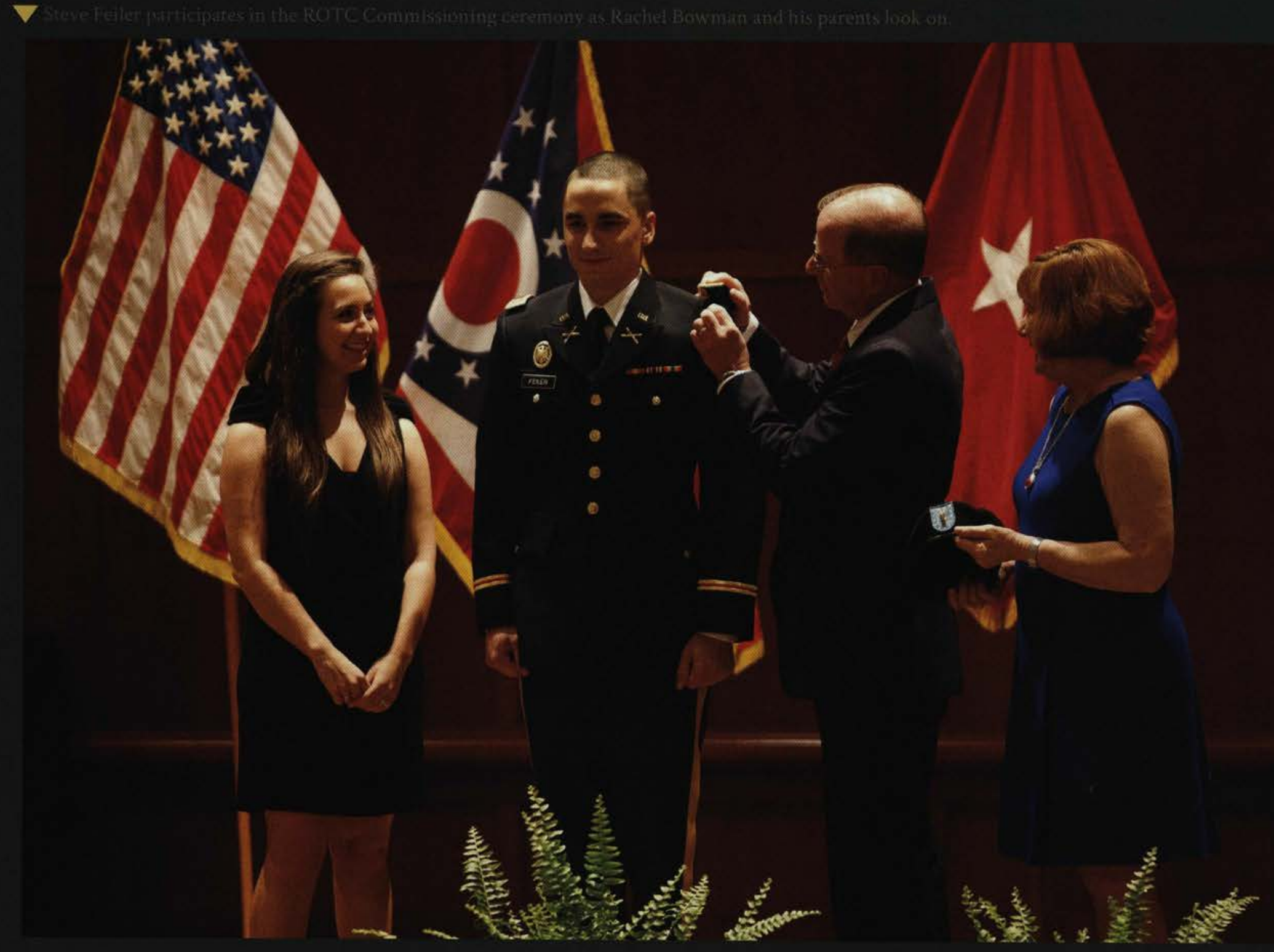

s a "Christ-centered learning
community, $C$ edarville University purposed to provide a quality education and emphasized academics as a means of growth in the whole person. Many students, from their first class as a freshman to their last exam as a senior, took this endeavor seriously and earned academic accolades for their hard work. During an honors-day chapel, several students received awards and scholarships for their academic performance. For seniors, academic performance was also demonstrated at commencement through honor cords. Students graduating with academic honors wore a gold cord with their cap and gown - one cord as "honor" for a grade point average of 3.5 or better, two cords as "high honor" for a grade point average of 3.75 or better, and three cords as "highest honor" for a grade point average of 3.9 or better. Some departments hosted special convocation ceremonies in addition to commencement to recognize and honor their graduates, of ten allowing for presentations of senior projects and a reception for friends and family. For those students pursuing a military career through ROTC as well as their Cedarville degree, a commissioning ceremony culminated the completion of their military training and marked their entry into the US Military Officer Corps. To attend one of these special ceremonies, receive an honors-day award, or wear honor cords at graduation proved the end of four years of hard work and a muchdeserved token of appreciation. 


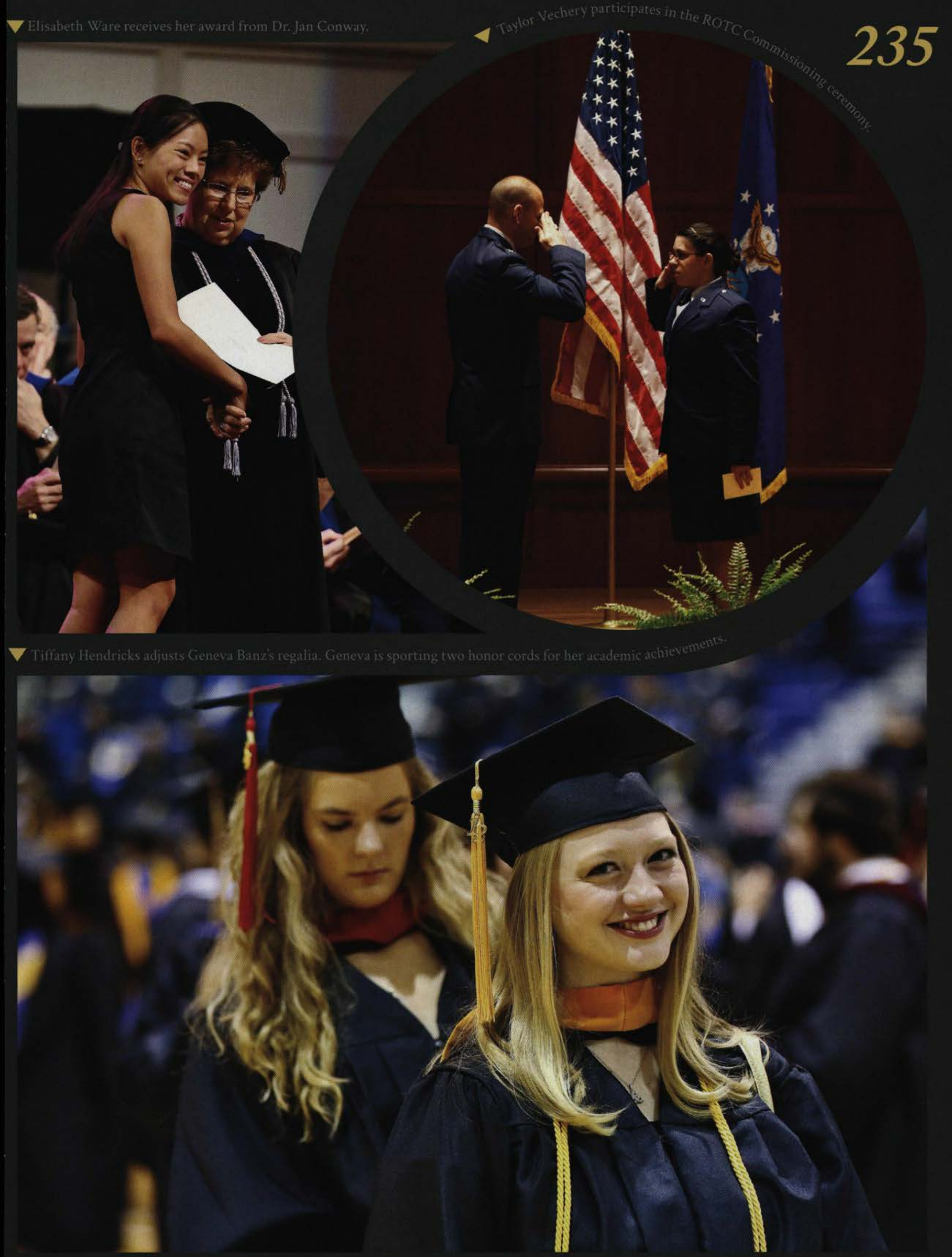




\section{Commencement}

The culmination of four years of learning and making friends, graduation is a bittersweet moment.

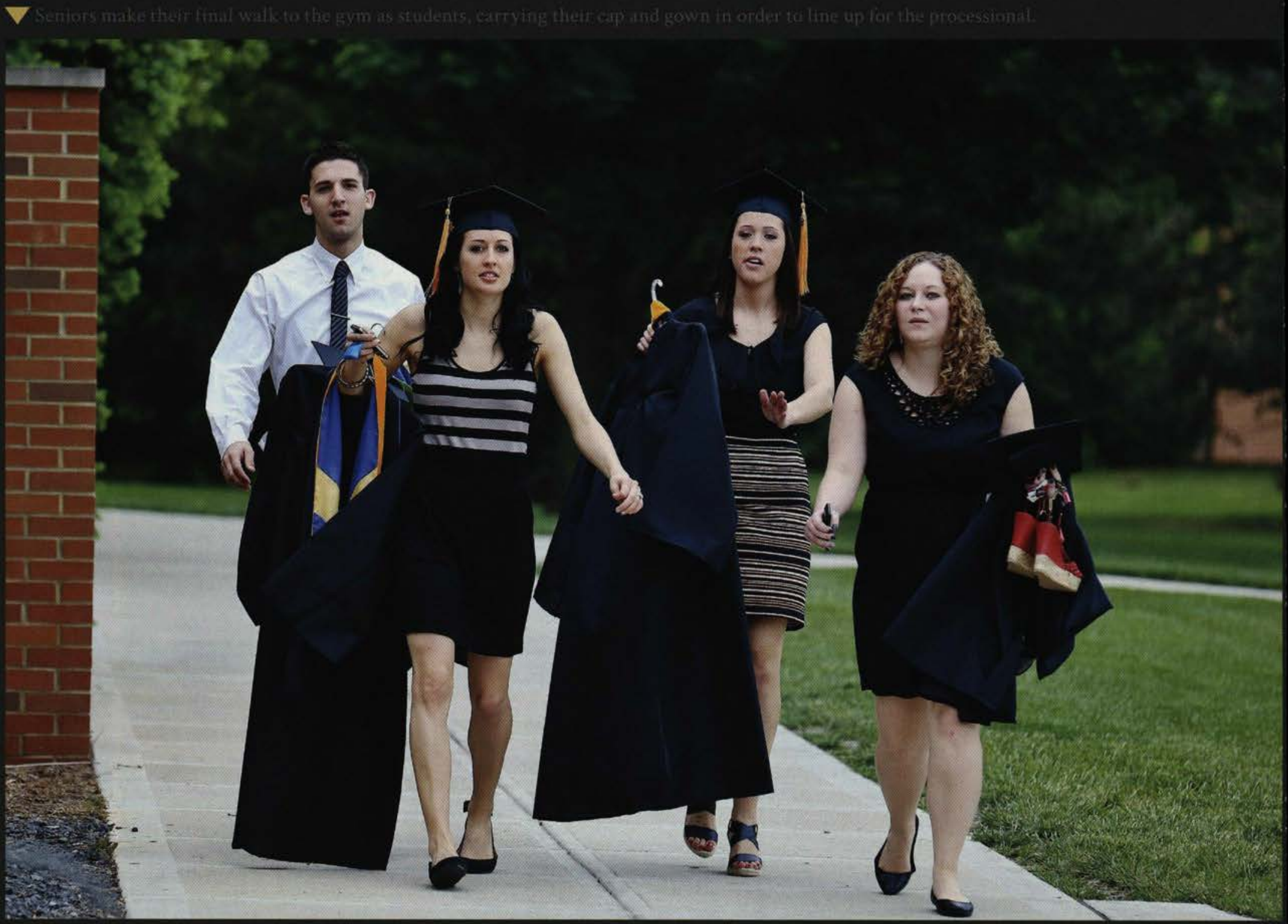

0 n the first Saturday of May a typical overcast and muggy spring morning - graduates, parents, grandparents, faculty, and alumni converged in the Dixon Ministry Center for another commencement ceremony. This year, over 650 graduates listened intently for their names to be called and then crossed the platform for that long-sought-after handshake, Bible, and well-earned diploma. For the keynote address, Reverend Frank Graham delivered the challenge to live a life unashamed of the gospel. Rev. Graham, the President and CEO of Samaritan's Purse and the Billy Graham Evangelistic Association, challenged everyone to "make it [life] count for the King of kings and the Lord of lords." Rev. Graham also received Cedarville University's Medal of Honor, one of only thirteen others who can claim this distinction. After presenting this award, Dr. Brown also addressed the graduating class, his last time to speak to this group as students rather than alumni. He then presented several awards to deserving graduates. Nathaniel Flack, Brandon Hellwig, and Samantha San Gregory received this year's President's Trophy, and Samantha Barclay, Samantha Cazzell, Michelle Mitchener, and David Riggleman received the Faculty Scholarship Award for earning a cumulative 4.0 grade point average. Whether with special awards or not, every graduate worked hard to achieve their degree. 


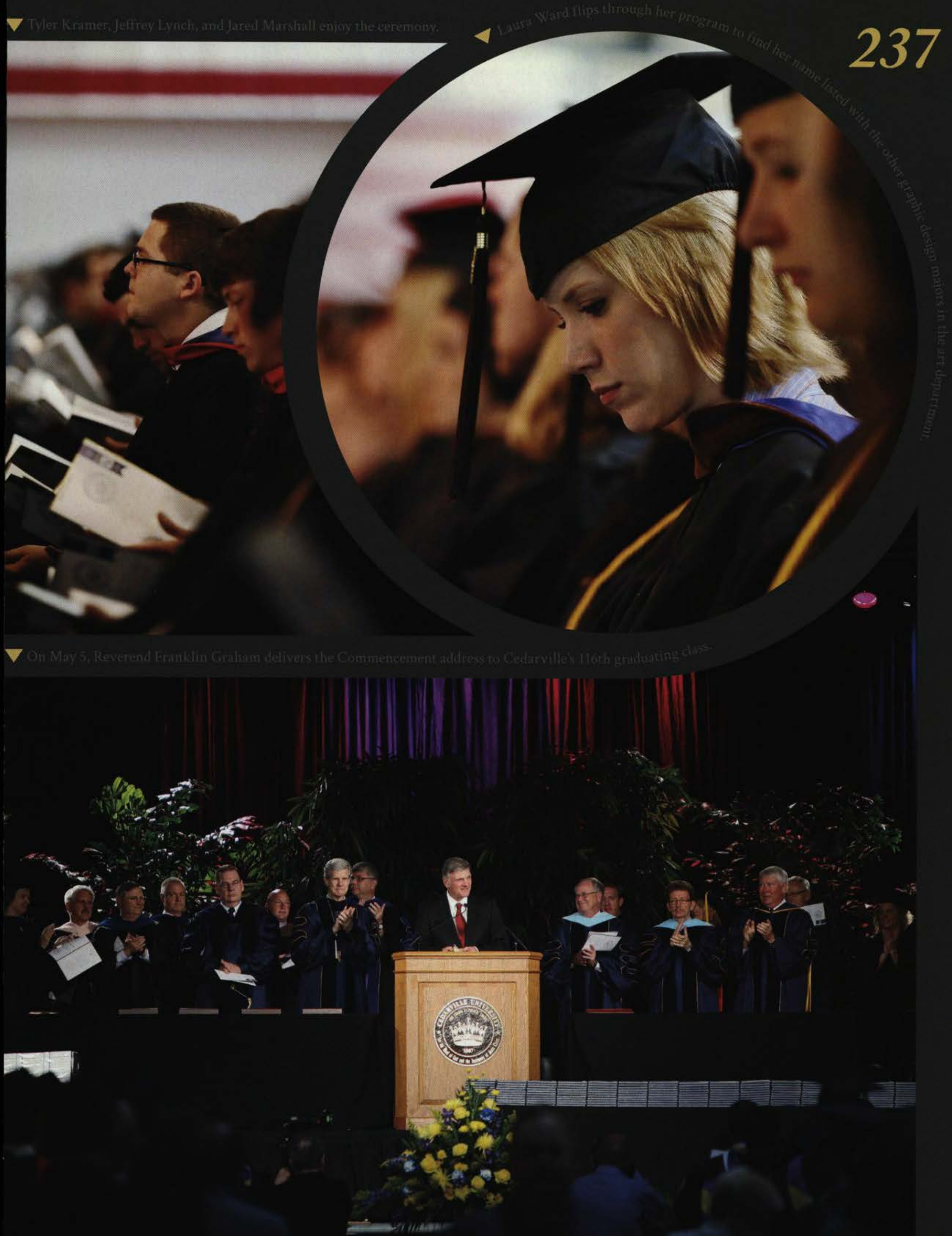




\section{Commencement}

Hats off to this year's graduating class! May God bless each graduate's future endeavors.
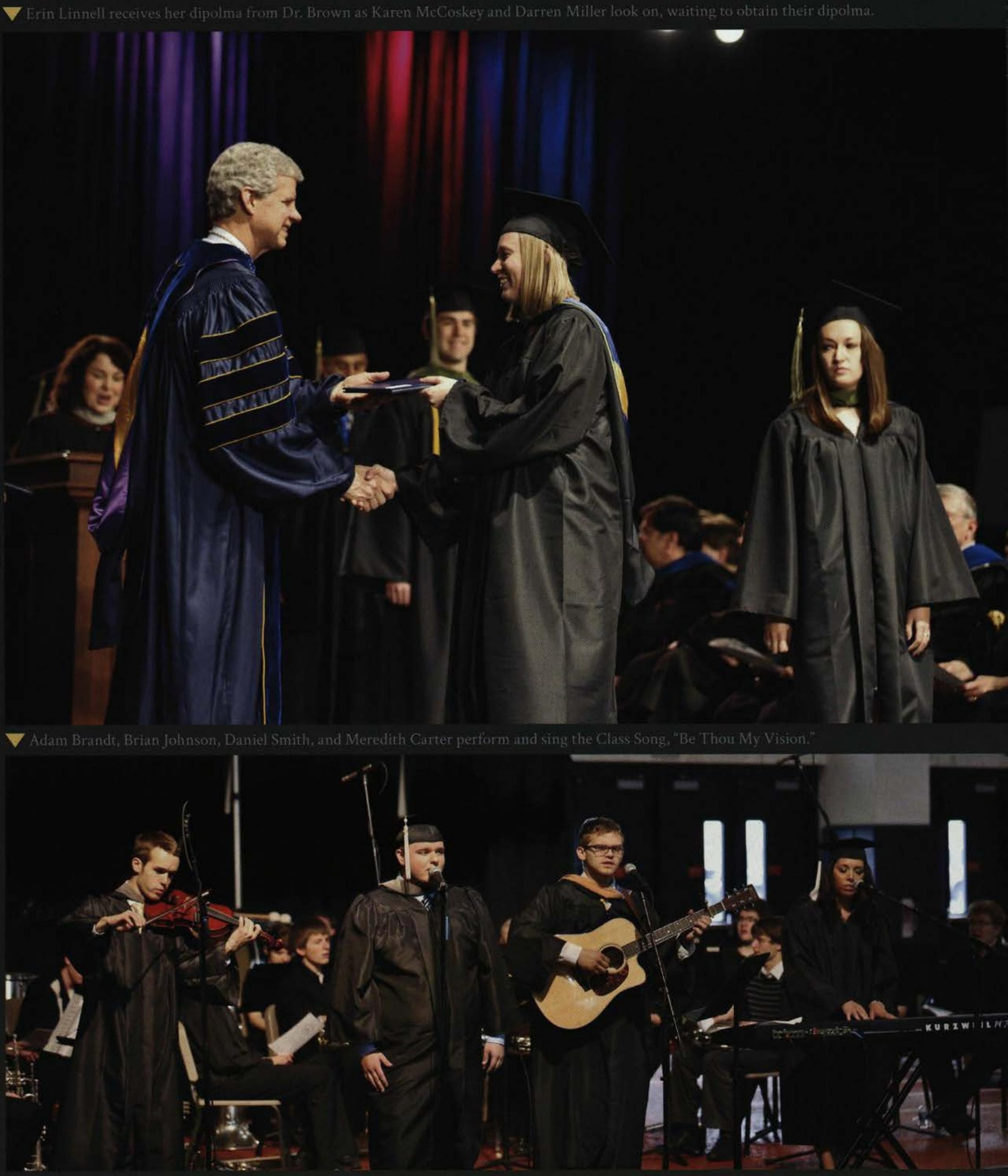


\section{Annual Editors}

Working for the yearbook is a time-consuming yet rewarding job on campus. Being an editor provides opportunities to
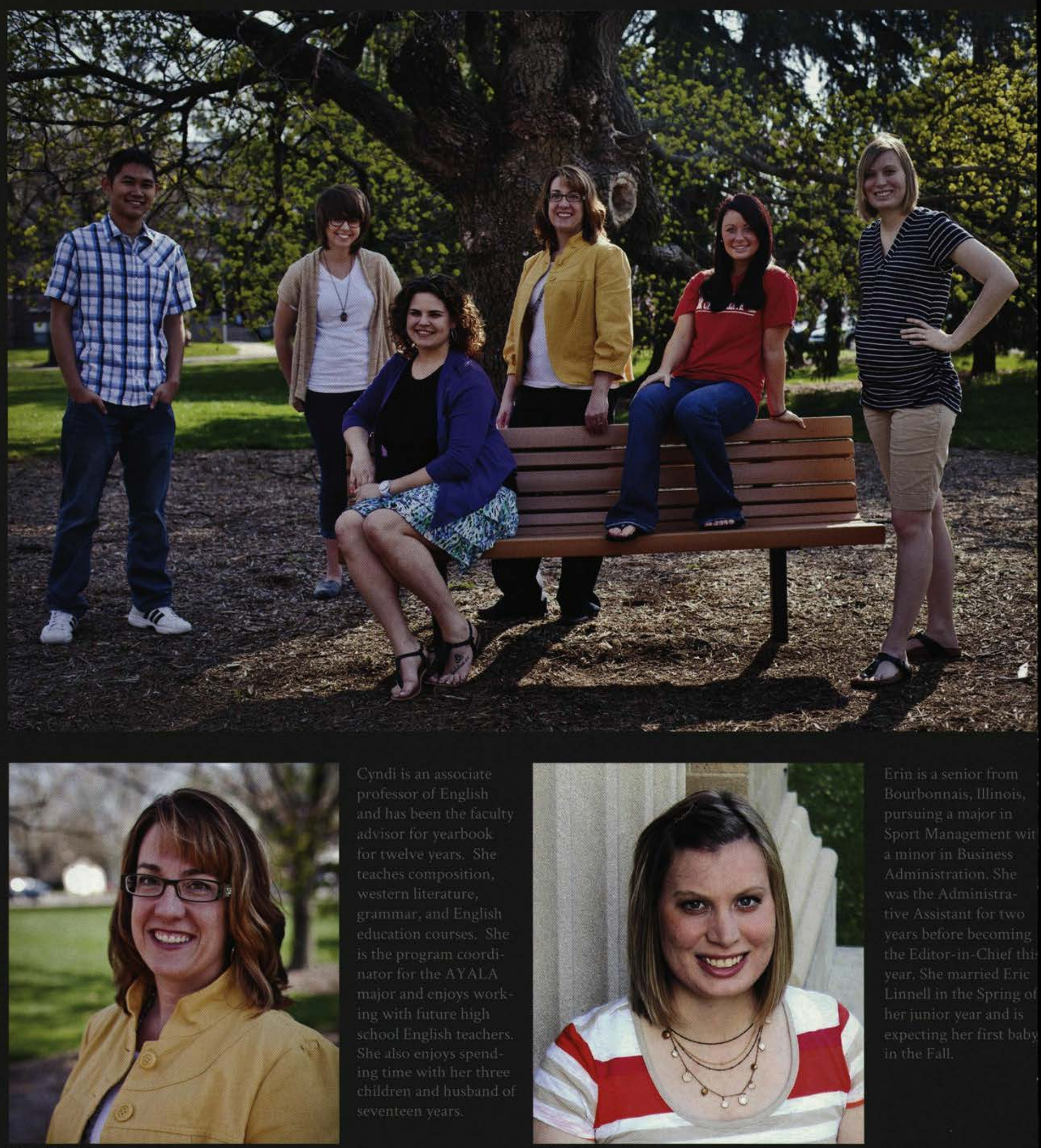

Cynthia Messer 
build skills in working with a team, organizing the workload, and producing a quality and creative chronicle of the year.

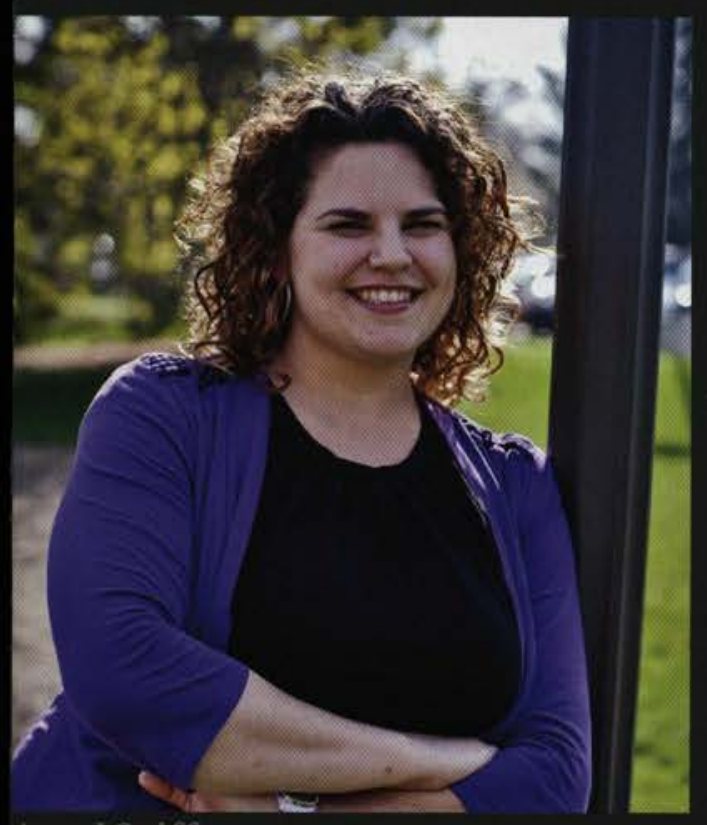

Apryl Sniffen

Copy Editor

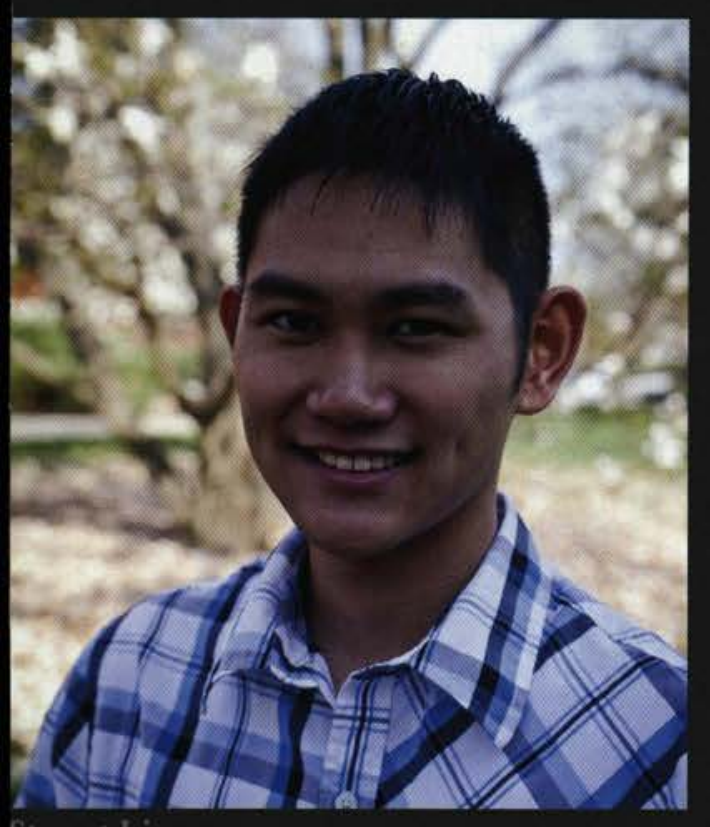

Stuart Li

Photography Edilor
Apryl is a senior

Technical and Profes-

sional Communications major from Peekskill, New York. She has been the Copy Editor of the veatbook for two years as well as a resident assistant in Printy Hall.

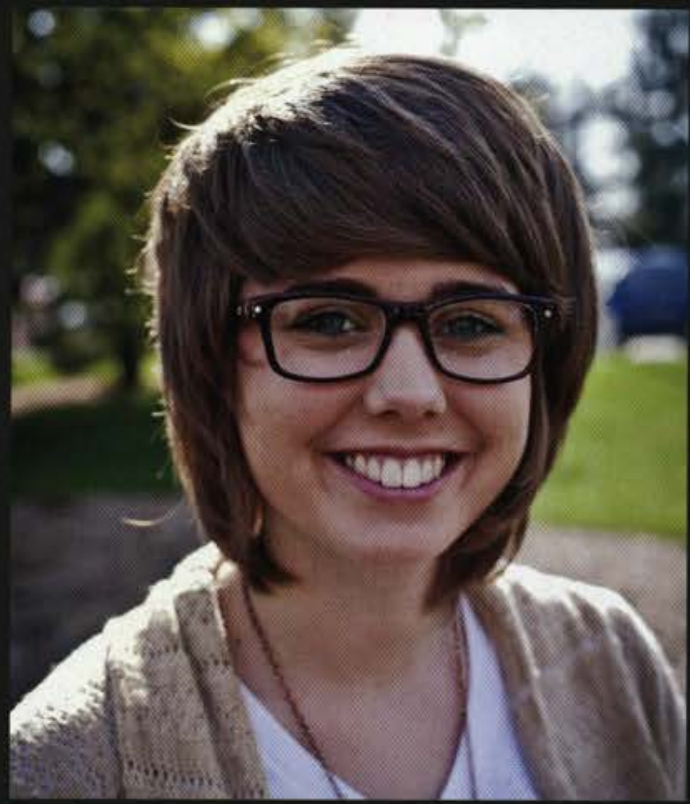

Kathryn Kramer

Layour Editor

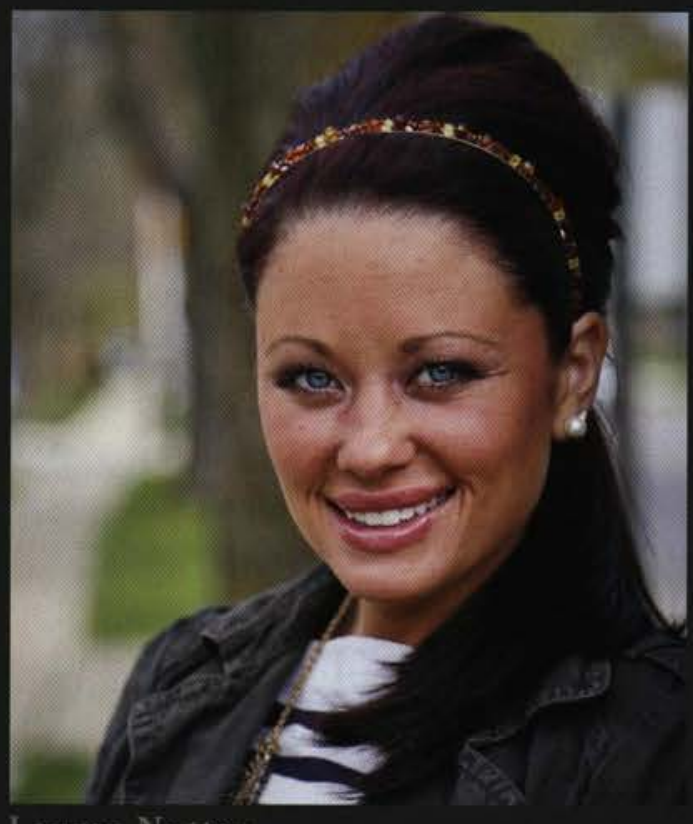

Lauren Nutter

Administrative Assistant

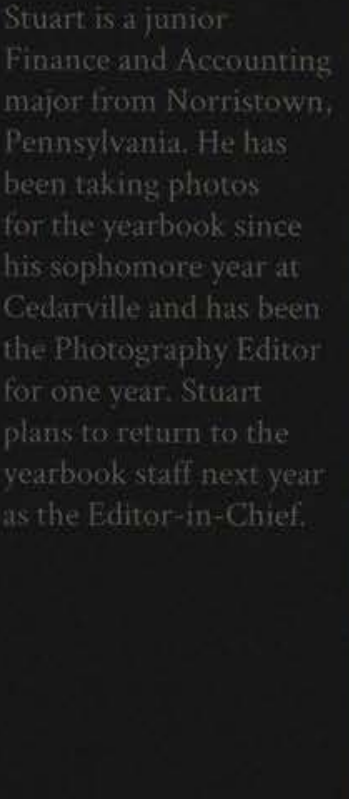
Pennsvlvanik. He has for theyear hook sing cedarville and has been mis the mofform-Chie
Kathryn is a junior Graphic Design major from Muskegon, Michigan. She has been the Layout Editor of the yearbook for two years and plans on returning as the Layout Editor next year. Kathryn enioys ant of all kinds. including painting woodworking, and designing. While at Cedarville, she has been 1. resident assistant in Printy Hall as well as 1 student designer for Greative Services 


\section{Annual Staff}

Yearbook production requires many hands -- and cameras and computers and late nights. Thank you for your work!

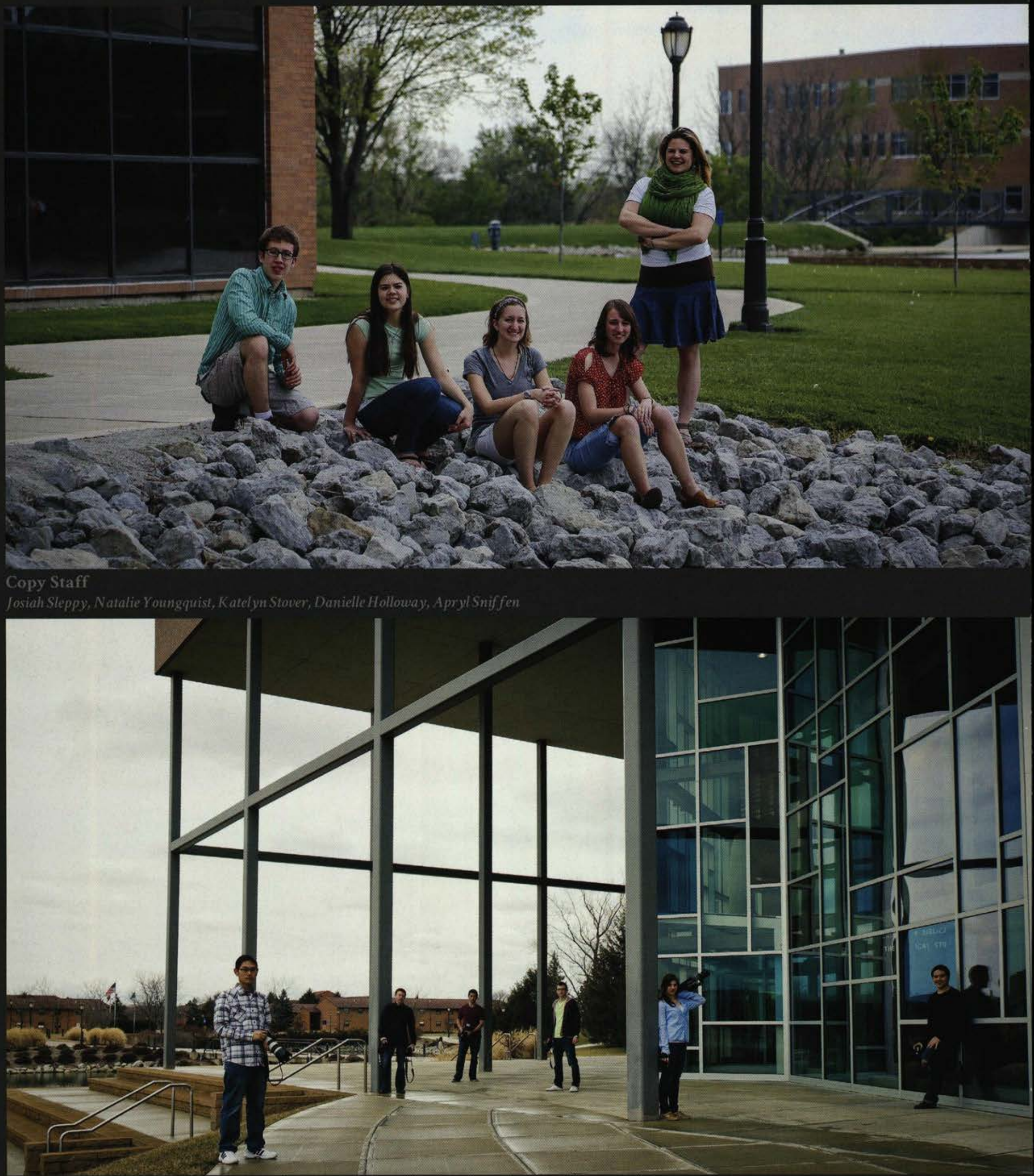




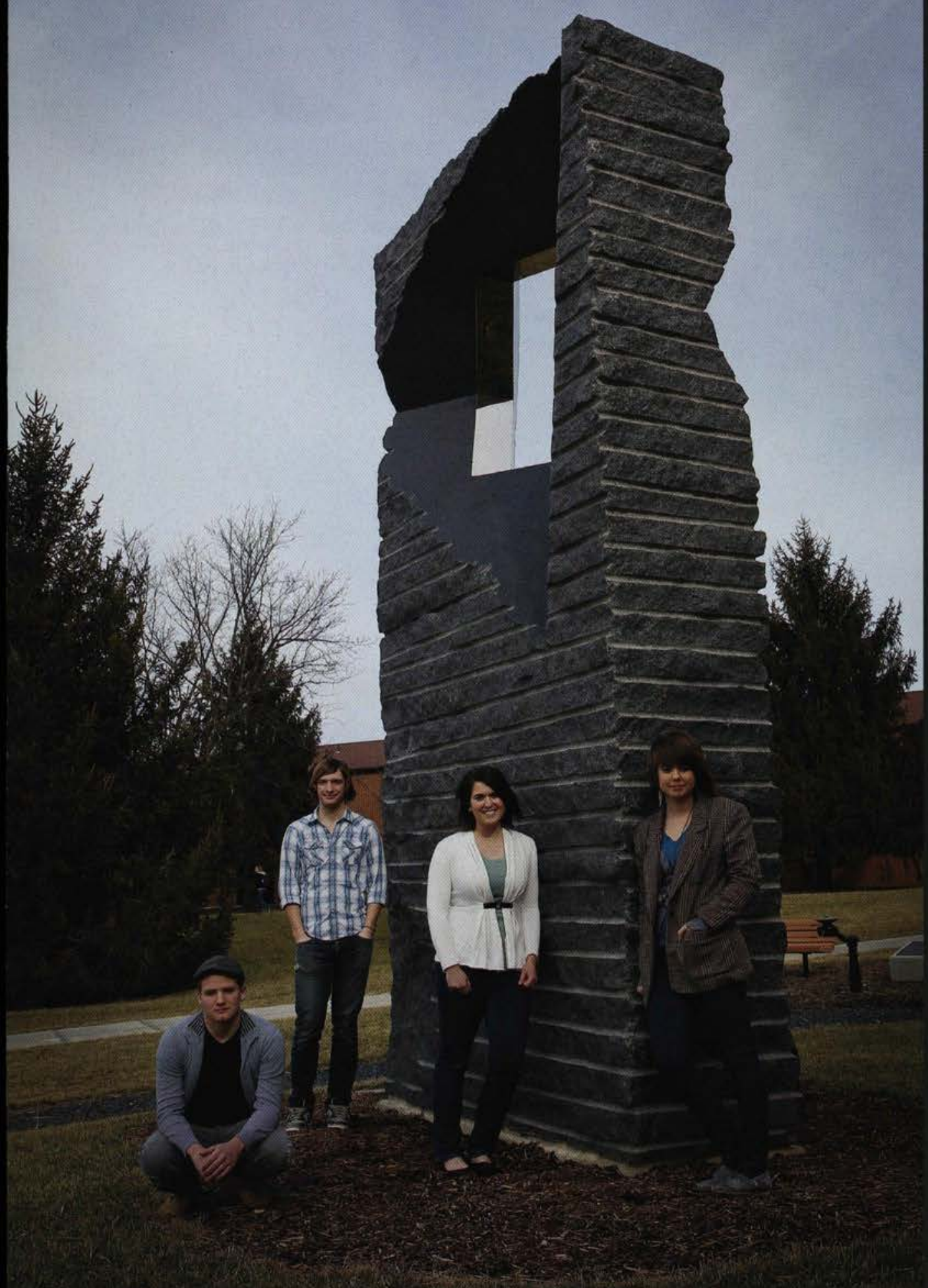

Layout Staff

Iustin Garne; Andrew Fancett. Keely Granger Kathron Kramer 


\section{Parent J Cotes}

\section{Rebekah Goodwin Lynch}

From the days of your childhood until this day of your dreams, you have never stopped chasing butterflies! Your passion for life and compassion for others have made you strong. When life in your body was difficult, the life in your spirit soared! Through perseverance, tenacity and sheer determination, you have accomplished what we once thought impossible. We are so proud of you. Congratulations on your college graduation.

Love, Momma and Daddy
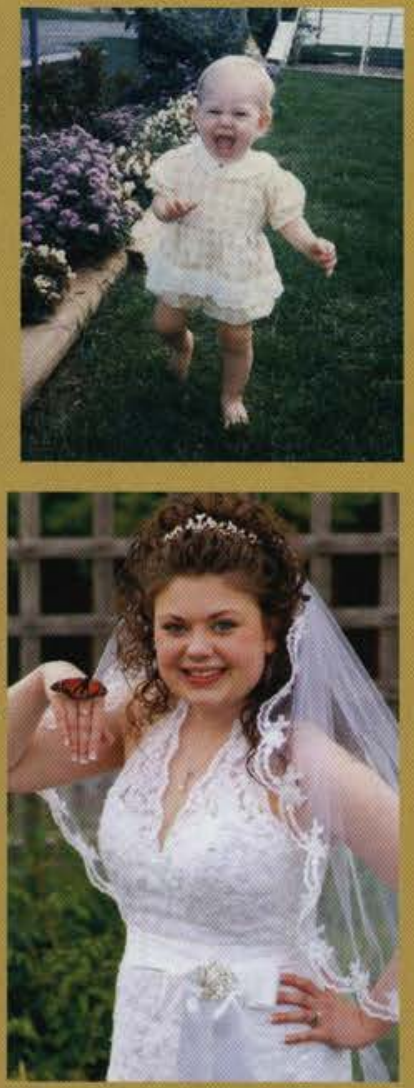

\section{Lauren Bell}

"I prayed for this child, and the Lord has granted what I asked of him." ISamuel 1:27

Throughout the stages of your life, we have been well pleased and blessed by you. Now you embark on the next stage of what the Lord has always had planned for you. We trust Him to give you the desires of your heart as you continue to serve Him.

We love you GBB, Dad and Mom

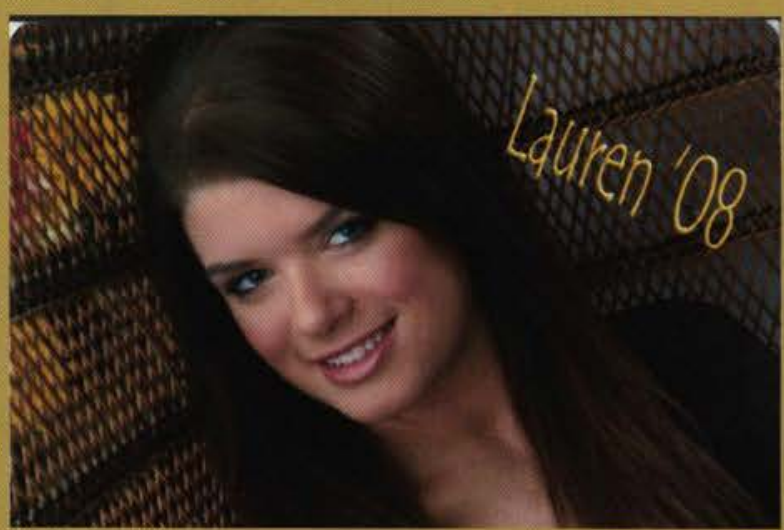

\section{JaneMarie Covel}

Even though we have missed you, it seems like these four years have passed very quickly. We know that God has been preparing you to be a shining light in the darkness. As you take the next step in your life journey, always remember that we love you, and are proud of you.

Love, Mom, Dad, \& Ricky

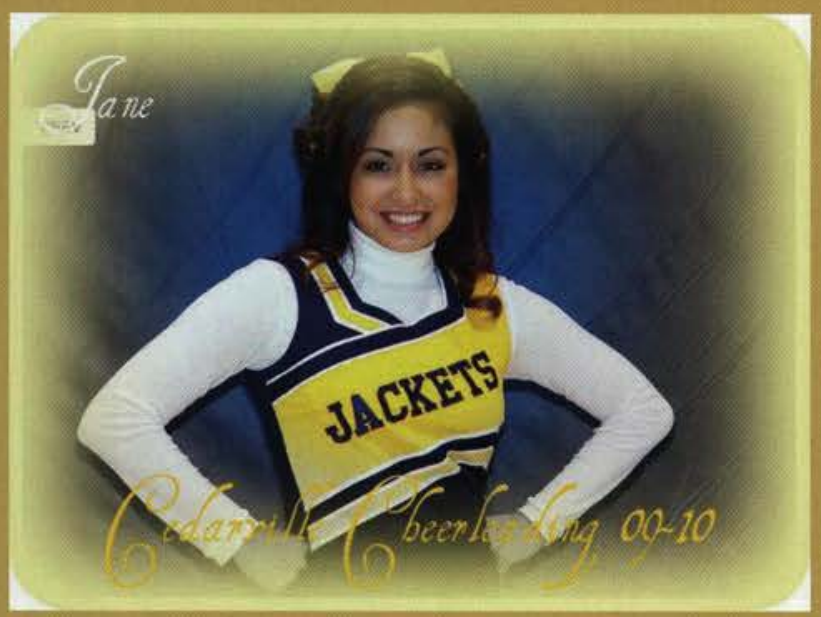

\section{Sean R. Gowdy}

Thanks for keeping your FOCUS on Christ! Congratulations.

Love,

Dad, Mom, and Liz

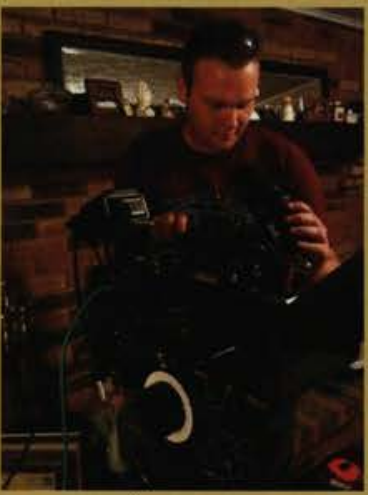

\section{Joel Dulin}

Joel, you have shown great Spiritual leadership and maturity and have brought much joy to us and others. We are proud of you in all areas of your life and are privileged to have you as our son. Bless-

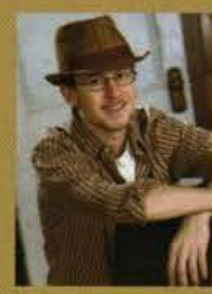
ings abound. Congratulations on this great accomplishment! We love you, Mom \& Dad It is by his deeds that a lad distinguishes himself. . Proverbs 20:11 


\section{Jennifer Giambalvo}

You're off to Great Places!

Today is your day!

Your mountain is waiting

So .... get on your way!

Congratulations, Jengi!

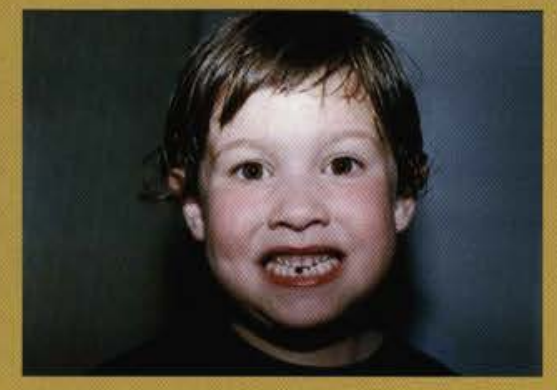

\section{Ashley Janczewski}

We are all so proud of you. You have

become a wonderful Christ-honoring

young woman. We are looking forward to

seeing you start the next phase of your life.

Love Dad, Donna, and Paul

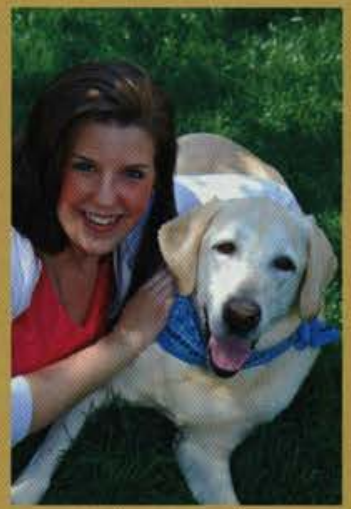

\section{Carl Heinly}

Carl, you've been using and

developing your God-given gift

of creating and constructing since

you were young. What a joy it is to

watch you grow and mature. We're

proud of you! We love you!

Love, Mom \& Dad

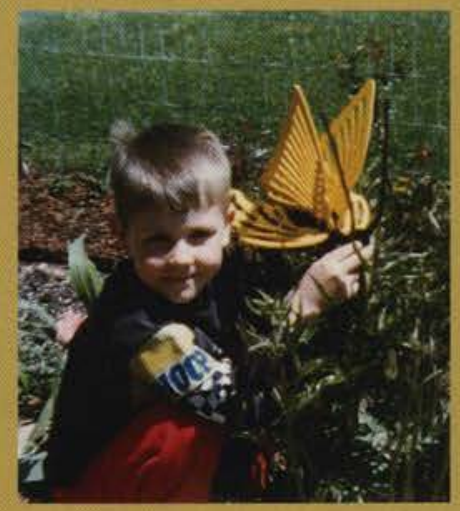

\section{Publisher}

The 2012 Miracle was published by Jostens, Inc. It was printed at their plant located in Clarksville, TN. The Jostens representative was Eric Howard, and the plant coordinator was Crystal Gault.

\section{Cover}

The cover was designed by Kathryn Kramer. The university seal was used on the cover and provided by Creative Services. It is a custom litho cover (process color with gloss lamination).

\section{PaperStock}

The paper for this book is a 80 \# gloss finish on all 256 pages.

\section{Color}

The 2012 Miracle was printed with four color procss ink.

\section{Design}

The 2012 Miracle design theme was created by Kathryn Kramer with the help of Cynthia Messer and Erin Linnell.

\section{Theme}

The 2012 Miracle theme was formulated by the Editors and Advisor celebrating Cedarville's 125 th anniversary.

\section{Production}

The 2012 Miracle was produced on HP computers and a Macbook Pro. Layouts were constructed using Adobe InDesign CS4, CS5 and CS5.5. Copy was designed in Microsoft Word and then imported into INDesign.

\section{Typography}

The main fonts for the 2012 Miracle are Crimson and Amperzand. Titles are 48 point Amperzand. Stories and captions are 10 point Crimson Roman with the first letter 11 point Amperzand. Taglines are 14 point Grimson Semibold Italic. Page numbers are 40 point Amperzand.

\section{Photography}

The majority of the photos were taken by the photography staff. Student submissions were also accepted. All team photos and several others were taken by Scott Huck, photographer fro Cedarville Unversity. Edging Imaging was used for class portraits and organization pictures.

\section{Inquiries}

The Miracle yearbook office may be contacted for additional information about this book's prodcution at miracle@cedarville.edu or (937)766-4995. 


\section{A Letter \\ from \\ the Editor}
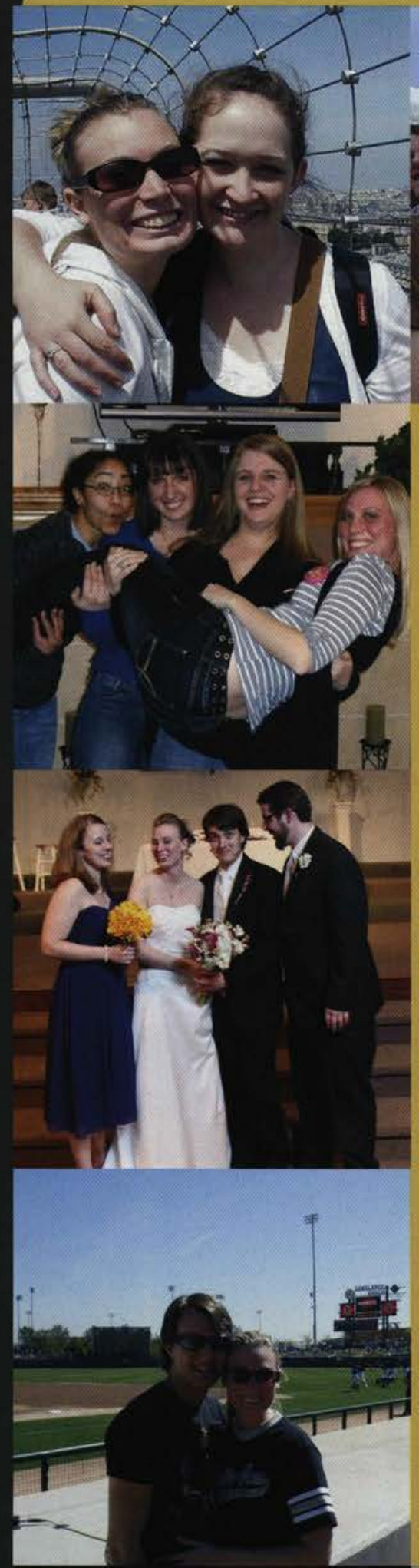

So...where did this school year go??

I can't believe that my senior year is over, I am married and having a baby. If you would have told me that I was going to be where I am now, I wouldn't have believed you. If you asked me if I was going to be editor of my senior yearbook, I would have said you were crazy, but here I am writing this letter after it is all over. I hope you all will enjoy this book and can look back at it years from now and experience all the memories over again. I hope you all can appreciate the blood (not really), sweat (literally), and tears (literally) that went into making this book and the dedication given by our advisors, editors and staff. Now to start thanking everyone for helping me make this possible. First off, my husband, Eric \#1- thanks for all your love and support through this whole year. Thanks for coming with me to the office for hours and hours at a time when I didn't want to be in the creepy office all by myself at night. Thanks for listening to my rants and frustrations. I love you baby and don't worry, its finally all over! Cyndi- There is so much for me to say to you. I have loved working for you these past 3 years. I have learned so much through your direction and guidance. Thanks for putting up with me these past 3 years and helping to shape me into the person I am today. Our Jostens Rep, Eric \#2- Eric, Eric, Eric...I am sorry for the billions of emails, texts, and calls that we have made to each other with my billions of questions (probably some very stupid ones). I appreciate all you have done to make this yearbook successful. You have showed me what great customer service is all about and I am SO thankful that you were our rep. Thanks for making all the trips out to Cedarville to help us stay on track and plan things. We couldn't have done it with out you. Our plant rep, Crystal-I probably have a billion emails with you as well. Thank you for always answering them and helping me out any way you could. I appreciate all the hard work and dedication you have shown me. I literally could not have done this book with out you! Kathryn- You have saved my butt a time or two...or more. Thanks for always answering my texts and emails and staying on top of things. Your creativity is amazing. You did a wonderful job on the design. I wish you the best of luck next year as you work on your senior yearbook and graduate! I loved getting to know you the past 2 years. Stuart- I pass the torch onto you. I wish you the best of luck. I hope that next year will run smoothly for you - that deadlines are met, pictures are taken, and portraits are smooth. Word of advise...stay on top of things so you don't have to finish the book over the summer like me. Lauren- Thanks for jumping into the crazy world of yearbook and Cedarville all at the same time. I know it was an adjustment getting used to the "Cedarville" way but you did a great job. Good luck next year! 20112012 Staff- Thanks for all your hard work. We couldn't have done it without you!

\section{Erin Linneld}

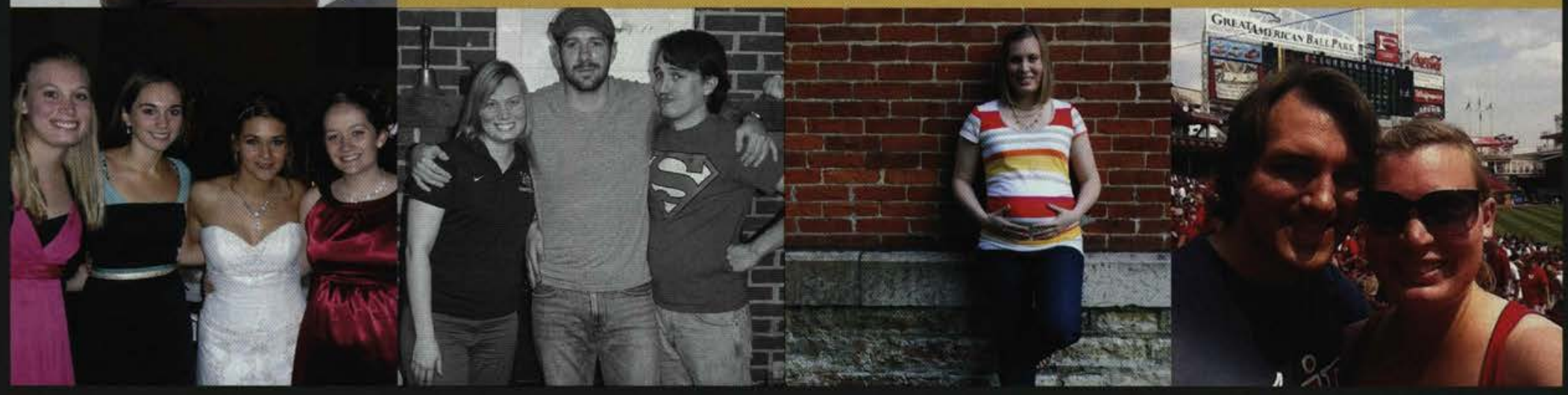




\section{Index}

\section{$A$}

Adams, Johin..

Adams, Kalina.

Adams, Mitchel

Adel, Tehseen

Adrian, Bryan

Adriansen, Damiel

Ahlgrim, Brianna

Aho, Eric.

Ahrens, Elizabeth

Albury, Annisa

Allen, Angela

Allen, Jonathan

Alley, Caleb,

Amling, Malia

Anderson, Calvin

Anderson, Emma

Anderson, Kell

Anderson, Madelyn

Anderson, Melody

Anderson, Michae

Anderson, Stephanie

Annecharico, Andres

Ansiel, Heidi.

Antoun, lacob

Antrican, Derek

April, Lauren

Ami, Sarah.

Arnold, Joshuit.

Arthur, Rachel

Ashley, Joel

Ashlev, fomathan

Ashmore, Ashley

Atkins, Jamie

Auch, Asthley

Ault, Kavla

\section{$\bar{B}$}

Bach, Moriah

Backer. Laura

Bacon, Ariel

Baechtle, Kristen

Baechtle; Sarah

Baglio, Anthony

Baird, Nathan

Baker, Joel.

Baker, Jonnah

Baker, Ryan.

Baldwin, Dane

Baldwin, Johin

Baldwwin, MeKinley

Balkus, Alexandra.

Banachosski, Jasmin

Bamz, David

Banz; Geneva.

Bapst, Jacob

Barclay, Samantha

Barfell, Kaitlyn

Barker, Jacob

Barnhart, Steven

Baron. Daniel

Baron, Rebekah

Barrett, Collin

Barron, Hannab

Bartholomew, Erica

Bartley, Erin.
Barton, David

Barulich, Anna

Bash, Andrew

Bates, Sarah.

Battis, Christine

Baumer, Jeanetta

Beach, Ryan,

Beachy, Rachel

Bearden, Molly

Beck, Audrey.

Becker, Meghan

Beckler. Joshua

Beekmain, Mayelii

Beelen, Alexander

Beikert, Ashtyn

Bell, Amanda

Bell, Lauren.

Bellanti, Brandon

Bellavia, Scot

Belth, Rachel.

Belton, Rebeccs

Belton, Ryan

Benjamin, Lauren

Benjamin, Tima

Bennett, Elizabeth

Bennet, loel

Bennett, Stephen.

Bennington, Christopher

Bernard, Kathleen

Bertolino, Nicole

Beverly, Nicole

Beverly, Rachel

Bewley, Molly.

Bewsey, Amber

Bhajian, Marian

Bielek. Emily.

Bissonette, Sydne

Blackburn, Valentin

Blackburn, Vawny

Blackwell, James.

Blagg, Ethan

Blood, Andrew

Blunt, joel.

Bobe, William

Bogoniewski, Elizabeth

Bolling, Queshonda

Boltz, David

Bond, Nathamiel.

Bomifas, David.

Bonifas, Jonathan

Bouws, Todd.

Boward, Alicia

Bowman, Rachel.

Boyd, Heather.

Boyd, Marie

Bradshaw, Deanne

Bradshaw, Jessica.

Bradshaw, Sarah

Bragg, Josiah.

Bratiksieck, Amylia

Bret, Chelsea.

Brewer, Megan

Brewer, Rebekah

Brindley, Amanda

Brittan, Sarah

Brittenham, Kaysie

Broad, Emily

Brooker, Matthew.

Brown, Abby.

Brown, Alexandra

Brown Andrea
194

108

205

.205

.205

16

108

205

205

108

72

61,185

…. 72

.205

$\ldots .72$

8,29

205

.... 108

7

108

161

.205

$\ldots 73$

.073

161

16

...16

188

.205

$\ldots .73$

108

108

206

…73

.161

.206

20

90,191

109

109

109

…73

109

.206

09,161

..206

.109

.161

.161

.206

.206

109

. .26

109

, 242

30,190

.....73

$|36,16|$

9

161

206

, 206

Brown, Caleb.

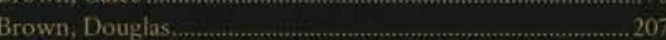

Brown, Jicob .................................................... 207

Brown, Kara .......................................................................

Brown, Mackenzie .....................................................................

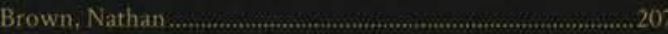

Brown, Zachery......................................................................... 136

Brownfield, Rachel .............................................. 26, 207

Brownfield, Sarah .....................................................26, 207

Browning, Colleen ………………… 19

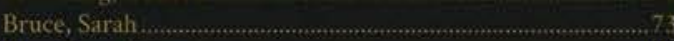

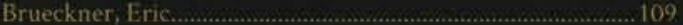

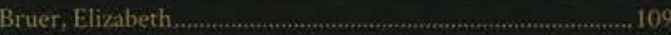

Bruning, Madison ……………………………………………... 73

Brush, David.

Bryan, Hannah

Bryant, Trevor

Buck, Logan.

Buckholz, Katelyn

Budd, Julia

Budds, Jennifer

Buehler, Tiffany

Bundenthal, Landon

Bundy, Joel.

Bundy, Jonathan

Bunton, Amanda

Burk, Carissa

Burkholder, Brittany

Burkholder, Lindsay.

Burkholder, Mary

Burrell, Nathaniel.

Burt, Zachary.

Burton, Rachel

Busch, Joshua.

Bush, Austin

Bush, William

.109

190
$\ldots .73$

. .73

.73

161

207

190

109

207

161

.16]

.207

.73

161

$30,109,190$

207

162

73

109

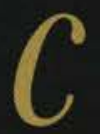

Cain, Aubrye.

Caldwell, Corey

190

Callahan, Lauren

Campbell, Grace

$32,73,192$

Campiell, Hannah

$32,33,192$

Campbell. Stephen

Cann, Carolyn

Cannon. Victoria

Gape, Daniel.

Garlson, Abigail

Garmichael, Amy

Carns, Meagan.

Carper, Andrea.

Carrell, Andrew.

Carroll, fill.

Carter, Robbie

Case, Carolyn

Cash, Sarih

Casillo, Margaret

Cass, Dianna

Castillo, Chelsea

Gates, Brian. 
Chapman, Denida

Chapman, Derrick

Chase, Amy.

Chavez, Mayr?

Cheeseman, Kimberly

Chen, Qiudong,

Cheney, Brian

Cheney, Matthew

Cherry, Elisa

Chester, Anthony

Christian, Benjamin

Christiansen, Brenna

Christiansen, Julie

Christiansen, Kelsey

Christiansen, Rutb

Chrystal, Stephanie.

Cianci, David

Clark, Heather

Glark, Jordan.

Glark, Lauren

Clark, Michael

Clark, Travis.

Classen, Kelly

Clemons, Josiah

Clore, Luke

Coates, William

Cochran, Hannah

Coleman, Julians

Coleman, McKalia.

Comeau, Morial

Comers, Andrew

Comley, Stephanie

Congrove, Michaela

Conrad, Briana

Cook, Laura

Cook, Patrick

Cooper, Julianne

Coover, Matthew

Cornelius, Hope

Cornish, Lindsay

Coules, John

Coules, Tiara.

Coulson, Kenneth

Countryman, Aaron

Covel, Janemarie

Cowart, Brittany

Cowden, Samue!

Cox, Elizibeth

Cox, Jerilyn

Crabtree, Jillian

Graig, Bayley.

Graig, Kristen

Crane, Miriam

Crank, Lindsay

Grawford, Rebekal

Crizer, Emily.

Cruise, Bethany

Gruise, Brandon

Crupi, Stephen

Cuddington, Amy

Culver, Emily,

Cumberland, Caleb

Cumby 111, Guyon

Cummings, Laura

Cundall, Gasey.

Cunliffe, Jennifer

Cunningham, Joshua

Curby, Cassie

Curby, Charissa

Curby, Levi

Curran, Rebecca
Curtis, Mariah

Gurwick, Elizabeth

Cushing, Marissa

Custer, Gavin.

Cvetich, Rebekah

\section{1}

D'Amico, Katelyn

D'Anna, Emily

D'Anna, Mark.

Dahnke, Jessica

Dalavai, Emilie

Dalton, Dustin

Daly, Samantha

Danielson, Pau

Dark. Rachel

Darst, Gasey

Daum, Alis:

Davenport, Miranda

David, Amands

Davidson, Nathaniel

Davies, Rebecca

Davis, Andrea

Davis, Elizabeth.

Davis, Jill

Davis, Virginia.

Day, Kristen

Decker, Jacquelyn

Deckert, Elisabeth

DeHart, Tabithat.

Deloye, Samuel.

Denen, Sarah

Deneseus, Nicole

Dennis, Becky

Dennison, foel

Depew, Molly.

DeRose, Rebecca

Devereaux, Brooke

DeVore, Sierra

DeVos, Gregor

DeWitt, Brittany

Diamond, Chelse

Dice, Joy.

Dick, Amy

Dietz, Brookel.yp

Dion, Bavid.

Dix. Matthey

Dix, Tyler.

Dixon, Ahters

Dixson, Benjamin

Dixson, lennifer

Docter, Stephanie

Dossett, Elizabeth

Douglas, Amy

Douglas, Lrdia

Doyle, Carson

Doyle, Jordan.

Doyle, Michelle

Drake, Katherine

Dreisbach, Hannab

Dresbach, Jordyn

Dresbach, Kvier

Dubie, Jacob

Dulmes, Michelle

Durant, Kelsey

Durbin, Christopher

Dyksterhouse, Felicia

Dykstra, Leanne

Dykstra, Nicole
Dyson. Jessica

111

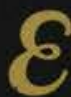

Earl, Jonathan

Eaton, Christophe

Ebben, Bethany

Edwards, Anna

Edwards, Heidi.

Eisner, Jordan

Elbert, Kellie:

Eldridge, Stephen

Elgersma, Sabrina

Ellis, Stephen.

Elwell, Hannah,

Enderle, Caleb

Englund, Andrew

Entmer, Abigail.

Entner, Elizabeth.

Erickson, Brian

Ervin, Clifton.

Esbenshade, Alexander

Esbenshade, Allison

Eustace, Abigail

Evans, Caleb

Evans, Jennife

Ewatt, Elizabeth

Fazo, Brandon

Ezzo, Matthew.

\section{$\sqrt{5}$}

Fanelli, Brian

Farleman, Latm?

Farley, Kaitlyn

Farran, Jacob

Farris, Mark

Eaulds, Christine

Fawcett, Andrew

Pehil, Sarah.

Feiler, Stepher

Felmer, Davió

Fernandez. Julia

Feucht, Elisabeth.

Fideler, Josepl

Field, Matthew.

Filcik, John.

Finter, Rebecca.

Eirebaugh, Stacia

Firmin, Sarah

Fitzpatrick, Anna

Fladda, Kelsey

Flaming, Aron

Fleetwood.Shelby

Fleming, Hannah.

Eluharr, Esther

Flynn, Christopher

Foerster, Chevenne:

Foley, Eric

Folkerts, Alexander

Fonseca, Rachel

Foote, Austin

Forsberg, Jonathar

Forsythe, Jacob.

Foster. Jonas.

Foster, Nikale

Fouch, Elena

Foulk. Casey.

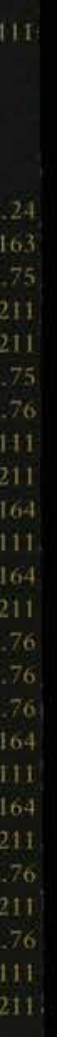




\section{Index}

Fourhman, Ryar

Fox, Douglas

Fox. Kyle

Francis, Ashley

Franklin, Aliann

Franklin, Brianna

Franklin, Zachary

Frazer, Michelle

Frazier, Ryan

Frazser, Shaun

Freda, Samuel

Frederick, Grace

Fredette, Luke.

Free, Aaron

Fulton, Taylor

Funke, Sarah

Eunkhouser, Mair

\section{G}

Gabbert, Kolby

Gabel, Amind

Gall, Christins

Gallagher, Joe

Gamberdella, Laurep

Gardner, Amber

Gardner, lennings

Gardner. Michael

Gardner, Scott

Garinger II, Christopher

Garneau, Morgan

Garner,Justin

Gates, Jordan.

Gatlin, Zachary.

Gauger, Natalie:

Geib, Carrie

Gerard, Brian.

Gerber, Jared.

Gernert, Ryan

Gibson, Breanne

Gilliland, Andrew

Girgis, Joseph.

Girtz: Kayla.

Girtz, Kyle

Glandon, Megam

Gollihue, Gasey

Gollihue, Kelly

Good, Kontney.

Goodliffe, Diane

Goodling, Mitchel

Goodman, Steven.

Goodrow, Samud

Gordon, Galeb

Gordon, Dane

Gordon, Deborah

Gordon, Joshua.

Gordon, Paul.

Gordon, Seth.

Gowdy, Sean.

Grafton, Sharon

Granger, Amy

Grant, Brian

Grant, Stephanie

Gray, Cassandra

Gray, Maitland

Graydon, Kristi

Grayton, Katie

Grear, Daniell.

Greely. Myles
Grcene, Kyles.

Greenwood, Rachel

Gregg/r., Austim

Grelen, Samantha

Grenier, Sarah

Grier, Jason

Griffin, Christopher

Griffith, Alyssa

Grimalds III, John.

Groen, Deborah

Groman, Joel.

Grondman. Julie.

Groot, Kate

Grout, Marthew

Gruet, Chelsea .

Gualtieri, Danie

Gunter, Angela

Gunter, Katherine

Gurge, Jonathan

Gustafson, Ryam

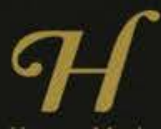

Hagen, Mark

Hagy, Brent.

Hall, Alice:.

Hall, Margaret

Hall, William.

Hallisy, Shamnon

Halsted, Brianna

Halwes, Sarah

Hankla, Rachel.

Harmah, Katelyn

Hannah, Kenneth

Hanson, Amber

Hardman, Rebecca

Harkness, Aaron

Harris, Amanda

Harris, Hannah.

Harrison, Rober

Hartman, Andrew

Hartman, Emily

Hartman, Hannah

Harvey, Olivia

Hassler, Bremna,

Haugen, Charis:

Hawkins, Brooke

Hayes, Amanda

Hayes, Brittany

Hayes, Christian

Heanssler, Micah.

Hecker, Brian.

Hedges, Tessi

Hedin, Satchell.

Heffernan, Deanne. 214

138,213

138,139

Hegle, Janalyn.

Heiden, Molly

Hein, Josephine

Heinly, Carl.

Hellwig, Brandon

Hellwig, Caitlynn:

Helmbrecht, Megan

Helton, Tara.

Hembekides, Paul.

Henderson, Thomas.

Hendricks, Tiffany

Henley. Susan

Hepworth, Karley

Herbert, Ashley

Herbert, Cassie
Herbert, Maryssa

78,196

213 Herman, Anna.

Herrera, Migued

Herrera, Rachel.

Herting. Andrew

Hickman, Daniel.

High, Brandon

Hilderbrand, Jessica

Hilditch, Jenna.

Hill, Amanda.

Hill, Stephanie

Hines, Hannah.

Hinks, Robert

Hinks, William

Hobba, Tayler.

Hoeflinger, Patrick

Hoekman, Helen.

Holck, Micah.

Holek. Timothy

Hollander, Jennifer.

Holloway, Danielle

Holloway, Seth

Holman, Karen

Holtzem, Lauren.

Hoober, Eric.

Hook, Hillary

Hoppe, Jeremy.

Horst, Rachel

Hotchkiss, Bethany

Hou, Freeman.

Houston, Rebekah

Howard, Kaitlynn

Howland, Britney

Hrdina, Robin.

Hric, Joshua.

Huddle, Kelsey.

Huffman, Alexandra

Hughes, Nathaniel.

Hulbert, Roxanne

Hull, Chandler.

Hulsey, Kristen

Hulsey, Lauren

Humberson, Lisa

Hundley, Allie

Hunt, Katelyn.

Hunter, Cathryn

Hunter, Graig.

Hurley, Elise

Hurton, Mary

Hurtubise, Ann:

Huschilt, Joanna

Huston, Alyssi.

Hutchings, fosiah

.78

190

192

165

136

114

215

215

114

215

114

165

78

183

3,215

...78

. .93

$32,192,215$

114.242

....78

79

.79

. .24

114

$\ldots 24$

215

.114

.1 .79
.114

114
79

114

166

166

.114

79

136

166

.79

215

114

.215

5, 180

.215

114

216

.26

.79

.79

$\ldots 114$
. .115

29,179

Imber, Samantha

Ingram, Caleb.

Iriana, Alexandra.

1saac, Rebekah

Isley, Chaney

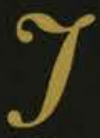

Jackson, Bryce.

Jahnke, Megan.

166

Jakucki, Katherine

$.138,216$ 
James, Zachary

Janczewski, Astiley.

Jeanneret, Elizabeth

lellison, Martin

lenerette, Kayls

lennings, Olivi

John, Tyler

Johnson, Brooke

Johnson, Chloe

Johnson, Erik

Johnson, Gregors

Johnson, Hayley

Johnson, Jennife

Johnson, Kaela

Johnson, Kendra

Johnson, Kirsten

Jahnson, Krista

Johnson; Michae

Johmson. Rachaie

Johnson, Rachel

Johnson, Tonva

Jones, Alaina

Iones, Elizabeth

Jones, Hannah

Jones, Zachary

Jungbauer, Sarah

Jupe, Linda,

\section{K}

Kane, Erik

Kapraly, Michael

Karhan, Joshur

Karhan, Sean

Kark, Rachel

Kark, Seth

Keck, Meredith.

Kee, Jeffrey.

Kee, Kevin

Keefe, Kelsey.

Kelliher, Hope

Kelly Jr. W William

Kelly, Amy

Kemmenoe, David

Kerstan, Katherine

Ketron, Keilah

Keys, Kristen:

Kim, Myeongseor

Kim, Seung

King, Dillon

King, Sara.

Kinnett, Ruchel

Kinsinger, Ella

Kirby, Laura

Kirk, Valerie

Kirkpatrick, Heather

Kitzmiller, Chase.

Klinger, Neil

Klink, Zicharsy

Klodnicki, Lauri

Kneeland, Stephen

Knepel, Jennifer

Knowland, John

snowland, Meredith

Knox, Cole.

Koch, Brittany

Koch, Lauren

Kohavi, Danicl

Koontz, Starla
Koranek. Matthew

Koski, Jonathon .............................................................

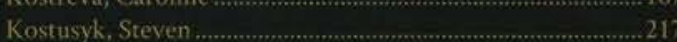

Kovac, Grant.....................................

Kramer, Kathryn ........................................................... 241, 243

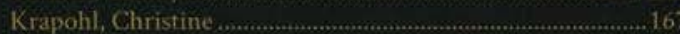

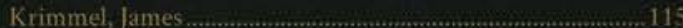

Krob, Jenelles

Krob, Jorian.

Kroening, Matthew …..................................................

Kroninger, Krista

Kuhin, Megan .................................................................. 115

Kuhta, Christopher........................................................16

Kuiken, Jesse.

Kuiken, Rachel

$32,192,193$

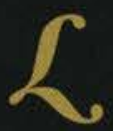

Lacombe, Tanir

Lamb, Eric.

Lamos Hannah

Lamy, Joseph

Lane, fames.

Lane, Lauren

Lamphier, Katherine

Larson, Galeb

Larson, Peter

Laskowske, Tieg.

Lassetter, Gabrielle

Lawhead, Jemna

Lawhorn, Brittany.

151, 166 Lawson, Rebece

Lawton, Timothy

Layer, Jacob.

Learst, Elizabeth.

Leber, Emily

Lee, Ethan

Lee, Jennifer.

Lee, Marthew

Lee, Zachary

Leese, Hiliny

Lehman, Michayla

LeMaster, Samue

Lenox, Benjamin

Leonzo, Johin.

Leonzo, Michael.

LePage, Meredith

Leszczynski, Joanna

Levesque, Adam

Lewis, Danie

Lewis, Jordin

Lewis, Kristen.

Li, Stuart

Liggitt III, Edward.

Lightner, Melody

billy, Kaylyn

Linden, Stephen

Linder, Natalie:

Lingaas, Katelyone

Linnell, Erin.

Linstad, Callie

Lintemuth, Ellen

Littlefield. Adam

Littrell, Kenneth.

lively, Mary

Locher: Apri

136.137 Lockwood, Adam

167 Lockwood. Alan
.217

Loeffler, Sarah

Logsdon, Katherine

Lorenzini, Zachary

Losch, Nathan

Lowe, Megan

Lowrance, Rachel

Lozada, Richard

Lucashu, Karen

Luce, Benjamin.

Luce, Zachary.

Eusk, Joshua

Lusk, Sarah.

Luther, Andrew

Lyman, Galeb

Lynch, Jeffrey.

Lynch, Rebekah

Lyons, Amelia

95,115

.217

$2,33,192$

167

129

217

.115

....80

167

.218

167

.167

80

.80

80
67

67

167

115

. 80

80
80

80

80

81

167

116.

.190

129

.136

168
168

.218

218
194

218

218
81

81
218

218
242

...81

.218

....84

.116

168 .

481

240

....81

110

4.81

.168

.81

.116

.168

168

\section{$\mathcal{M}$}

MacDougall, Daniel

MacGillivray, lane.

Mackenzie, Garoline

Mailloux, Lindsay.

Maithel, Sarah.

Makoski, Sarah

Manning, Rebekah

Marks, Kayla.

Marot, Caleb:

Marot, Luke

Marshall, Elizabeth.

Martella, Alexandria

Martin, Catherine

Martin, Laura

Martin, Peter

Martinson, Daniel

Mast, Krista

Mater, Karlee

Mathis, Alyssa

Matson, Dresden.

Mattes, Gina

Mattison, Rebeces

Maxwell, Caleb

Maxwell, Seth

Mayer, Gretchen

Mayme, Brittany

McAnallen, Laura

Mcclenahain, Ivy.

McClure, Alyssi

McConkey, Jennifer

McCoskey, Karen

McCrosky, Erim

McCurdy, Grant

MeDonild, Matthew

McEllhenney, Sarah

McFarlane, Mark.

McGee, Lindsay.

Marver, Stephen

Mekevitt, Dylan

McKinley, Marifo

Mckinley, Rachel

McLain, Matthew

Meleod, Alicia.

Mel eod, Craig.

Mel eod, Samuel

MeMahan, Mackenzie

McMichaeh, Paul.

McMillan, Timothy.

MeReynolds, Suzanne

\section{0}

116

21

168

168

218

116

81

190

81

.81

218

218

168

218

218

138

219

$\frac{219}{116}$

116

. .81

116

81

.. .81

. .81
219

168

.81 
Ray, Ruthie

Raymond, Courtne

Redfield, Melanic

Redic, Bryan

Redic, Thomas:

Redlien, Amsanda

Reed, Ann,

Reed, Matthew

Reed, Nathain

Reilly, Kyle,

Reisenweaver, Amy

Rethmeier, Eadie.

Rhodus, Tyler.

Rice Samuel

Rich, David.

Richard, Andrew

Richardson, Cory

Richardson, Rachel

Richied, Philip

Riehle, Brooke.

Rifner, Shawn.

Rigby, Daniel

Riggleman, David

Ripley, Adam

Ripperger, Kyle

Rizzardi, Kristina

Roberts, Kathryn

Roberts, Rebecca

Roberts, Tabitha.

Robertson, Andrew

Robertson, lath

Robinson, Daniel

Robinson, Lauryn

Rogers, Stephanie..

Rollins, Chance.

Ronco, Timothy.

Roose, Joshua.

Rose, Heather.

Roseberg. Scott.

Ross, David.

Rosso, Daniel.

Rost, Grant.

Roten, Michact

Rothhaar, Sarah.

Rowland, Litke

Ruby, Meagan.

Ruhiman, Melissa

Ruman, Deanna.

Rumbarger, Justin:

Russell, Bridget.

Russell, Stephanic

Ryan, Raegan.

Ryker, Sarah
Reineke, Marcus.

Robinson, Michael

.. .171

.83

.32

136

.83

83

119

.171

17.

.83

136

.119

224

.224

190

.40

190

.171

. .84

.119

119

224

.24

224

.119

171

.119

84

138

84

. .84

224

. .84

. .138

.30

.28

224

. .224

. .224

.171

.... 24

.119

.119

. .119

.224

.224

84

224

26,84

.171

$\ldots 84$

.225

.225

36,138

225

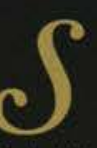

Sahulcik, Sarah

Salas, Maria

Salzler, Stephanie

Sanders fro, Larry

Sanders, Erik

Sanfilippo, Gabrielle.

SanGregory, Samantha

Santee, Brittany.

Santiso, Daniel.

.225

171

.225

.225

.225

.225

7,225

.119

171
Santoro, Justin.

Sauer, Danielle,

Saxe, Benjamin

Saxe, Jomathan

Scanlon, Hannah

Scarcella, Timothy

Scarpone, Daniell

Scarpone, Rebecca

Scarpuzzi, Rebekah

Schaefer; Allison

Scharold, Alison

Schick, Annelise

Schick, Kyle

Schindler, Stepliem

Schlabach, Timothy

Schmid, Anna

Schmidt, Katherine

Schmidt, Laurer

Schmidt, Sarah

Schmitz, Adam.

Schineider, Brituni.

Schneider, Hannah.

Schnepp, Rebecca:

Schoenwald, Matthew

Schroeder, Erich.

Schroeder, Niklaus:

Schulenburg, Breamna

Schuler, Lilian

Schumacher, Carly

Schwartz, Taylor.

Scott, Connor

Scott, Megan

Scott, Seth:

Seabold, Paul

Seals, Amanda

Seekins, Justip

Servi, Bethany.

Setzkorm, Kirsten

Severance, Emily

Seybold, Rahel.

Seybold, Susanne;

Shaffer, Isaac.

Sharp, Jessica.

Sharp, Joanne

Shaw, Lauren

Shenk, MeKenzie

Shepherd; Alexander

Sherman, Abby.

Shiff, Alexandra

Shimeall, Caroline

Shock. Hannah.

Shockley, Erin.

Shomo, Eric.

Short, Amanda

Short, Ashley

Shrum, Victoria

Shuck, Shayla

Shuia, Ethan.

Sides, Melissa.

Siefert, Nicole

Siemon, Aubrey

Sievert, Daniel

Silbak, Rose

Silvey, Rachel

Simpson, Lauren

Simpson, W illiam

Sinchair, Kaitlynn

Sincock, Grace.

Sjoguist, Adrian.

Sjoquist, Ryan.

Skrenta, Steele.

Slabach, Joel

99,121

Sleppy: Josiah.

Smith, Brittamy

Smith, Caleb

Smith, Chad

Smith, Clavton

Smith, Courtney

Smith, Jenna

Smith, Jordan-

Smith, Josiah.

Smith, Kendra

Smith, Laura

Smith, Mariah

Smith. Meagan

Smith, Rachel.

Smith, Samantha

Smith, Victoria.

Smith, Zachary

Smolinski, Samantha

Smyly, Duncan

Sniffen, Apryl

Snowden, Whitney

Snyder, Audrey.

Song, Stephanie.

Sorensen, William

Southworth, Aaro

Spain, Courtnie

Speros, Andrea

Speros, Olivia

Spiliotis, Danielle

Sprague, Colin

Spranger, Amy

Stacy, Samantha

Stafford, Ally

Staley, Joshua.

Stambach, Hailey

Stapleton, Landon

Stapleton, Steven.

Start, Gerrit

Stearns, Audrey

Stearns, Grace

Steele, Joshua.

Steetle, Rachel.

Stein, Alicyn...

Stephens, Scott

Stevens, Lillian

Stine, Lyndsay

Stitzinger, Abigail.

Stobbe, Lillian.

Stoltzfuis, Meliss:

Stonkus, John.

Storkel, Sarah

Stover, Katelyn.

Straw, Karyn

Strawser, Payton

Strayer, Hope.

Strayhorn, Ali,

Strejc, Stephanie

Strickland, Amber

Strickland, Michelle

Struble, Alexander.

Studebaker, Hayley.

Studebaker, Timothy

5,242

...121

....85

...121

32,226

.226

19,179

226

17.

.. .40
.227

32

.46

12.

227

.85

$227,241,242$

.121

27

.85

.85

121

138

153

85 


\section{Index}

Swick III, David

Switzer, Tori

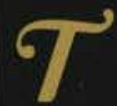

Tak, So

.228

Talbot, Alexandria ..................................................................85

Talbott, Sheila

Tarleton, Lindsay ................................................................ 173

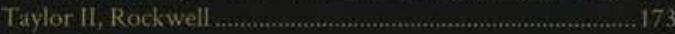

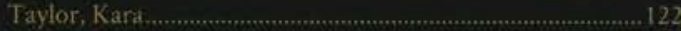

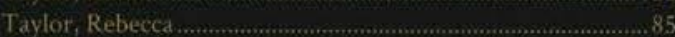

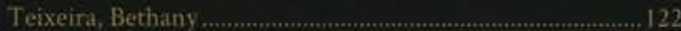

TerreBlanche, Bernardus ................................................173

Terrell, Meghan - 32, 192

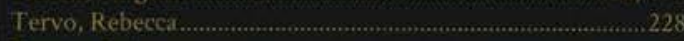

Tessier, Erin:

Thaver, Evan ..........................................................30, 190, 228

Thomas, Jeremy

Thompson, Ashley

Thompson, Eric

Thompson, Julin:

Thompson, Rache

Thompson, Sarah

Thong, Charissa

Thorpe, Greggory

Thurman, Aerial.

Thurman, Ryan.

Tomlinson, Abigai

Tomlinson, Enily

Trautman, Seth

Travis, Jeffrey

Trindal. Vienna

Troyer, Kelly..

Trover, Kristin

Troyer, Madison

Tucker, Colleen

Tucker, Hannah

Tucker, Jonathan

Tuggle, Thaddaeu

Turbett, Amanda.

Turing, Matthew

Turner, Molly,

Tuttle, Benjamin

Twinem, James

Tyler, Rachel.

\section{U}

Ujeich, Brempan

Vachino, Elise

Valarik; Rachel

Van Etten, Caytlin

Vin Oss, Elizabeth

Van Wyck, Emily

Van Zandt, Joshus

VanderHart, Clair

Van Matre, Louise

VanMeter, Andrea

Vasser, Melinda

Veith, Jomathan

Veldt, Hadassah

Vencill Kayla
Vendl. Anna

Vetter, Stephen.

Villwock. Devon

Vinciguerra, Jemnifer

Vivas Aguilar, Abraham

Voetberg Jr. Richard

Voland, Peter.

Voltz, Christopher

\section{$\omega$}

Wadman, Rachel

Wagner, Caleb

Wagner, David

Wagner, Hannah

Wagner, Marvann

Wagner, Rachel.

Wakefield, Radleigl

Waldrop, Rachel

Walker, Ethan.

Waller, Timothy

Wallin, Rebekah.

Walter, Jacob

Walton, Elizabeth

Wands, Amanda

Ward, Chelsae

Ward, fennifer.

Ward, Katherine

Ward, Laura

Ware, Elisabeth.

Washburne, Karen

Watkins, Kelsey

Watson, Clay

Watson, Erkat

Weaver, Diana.

Weber. Amber

Wegman, Hannal:

Weibel, Marie.

Weigand, Josee

Weir Kelsey

Weiser, Elizabeth

Wemple, Lucas

Wengerd, Jessica

West, Matthew

Westefeld, Barry

Weston, Zachary

Whearley, Joann?

White, Alexandro

Whitlock, Corey

Whitney, Darsy

Wicker, Allyson.

Widder, Rebecca

Wideman, Kayleigh

Wilcox, Kyle.

Wilcox, Rachel

Wilder, Nicholas

Wildman, Jane

Wiles, Krista

Willeford, Megan

Williams, Alexander

Williams, Brandop

Williams, Eauren.

Wills, Caroline

Wilson, Ashlec

Wilson, Bavid

Wilson, Kelsey

Wilson, Michelle

Wilson, Sarah.

.231
$90,180,182,229$

174

8

....86

229

229

122

174
.229
Wismer, Heather

W isniewski, Kadie

Wolf, Brian

Wolf, Chelsea

Wolff, Kristin?

Wong, Abigail

Wong, Luen

Wong, Rachel

Wood, Meredith

Woodard, Taylor

Wooliver, Krystal.

Worley, Ryan

Wright, David

Wright, Kristi

W'right, Kyle...

Wright, Nathan.

W underlich, Hannah

Wuobio: Amy

.24

.229

0. 190

h

230

(1)

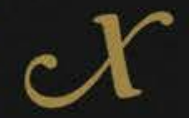

Xayathone, Alexander

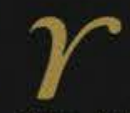

Yates, Seth...

Yeh, Benjamin

Yeh, Simon.

Yoder, Caitlin,

Yoder, David

Yoder, Michael

Yorgey, Mariss

York, Cameron

28.128

Yost. Joel.

Young, Lauren

Young, Wesley

Young, Zachary

Youngquist, Natalie

Yutzy, Kara.

175,185

Yutzy, Rache

28,192

.230 86

30)

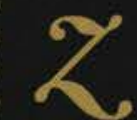

Zavodney, Ánna.

19,17

Zavodney, Julio

Zeiter, Rachel.

Zellurs, Lucas:

Zender,jordan:

Ziegler, Grace.

Ziegler, Morgan

Zirkle, Tia

Zwiebel, Heich

Zwirkoski. Sarah
86

175

176

887

87

87

253

.26

, 192

.231

.192

123

123

.123

231

48

175

136

190

.....231

16,87

.231

23

\section{8}




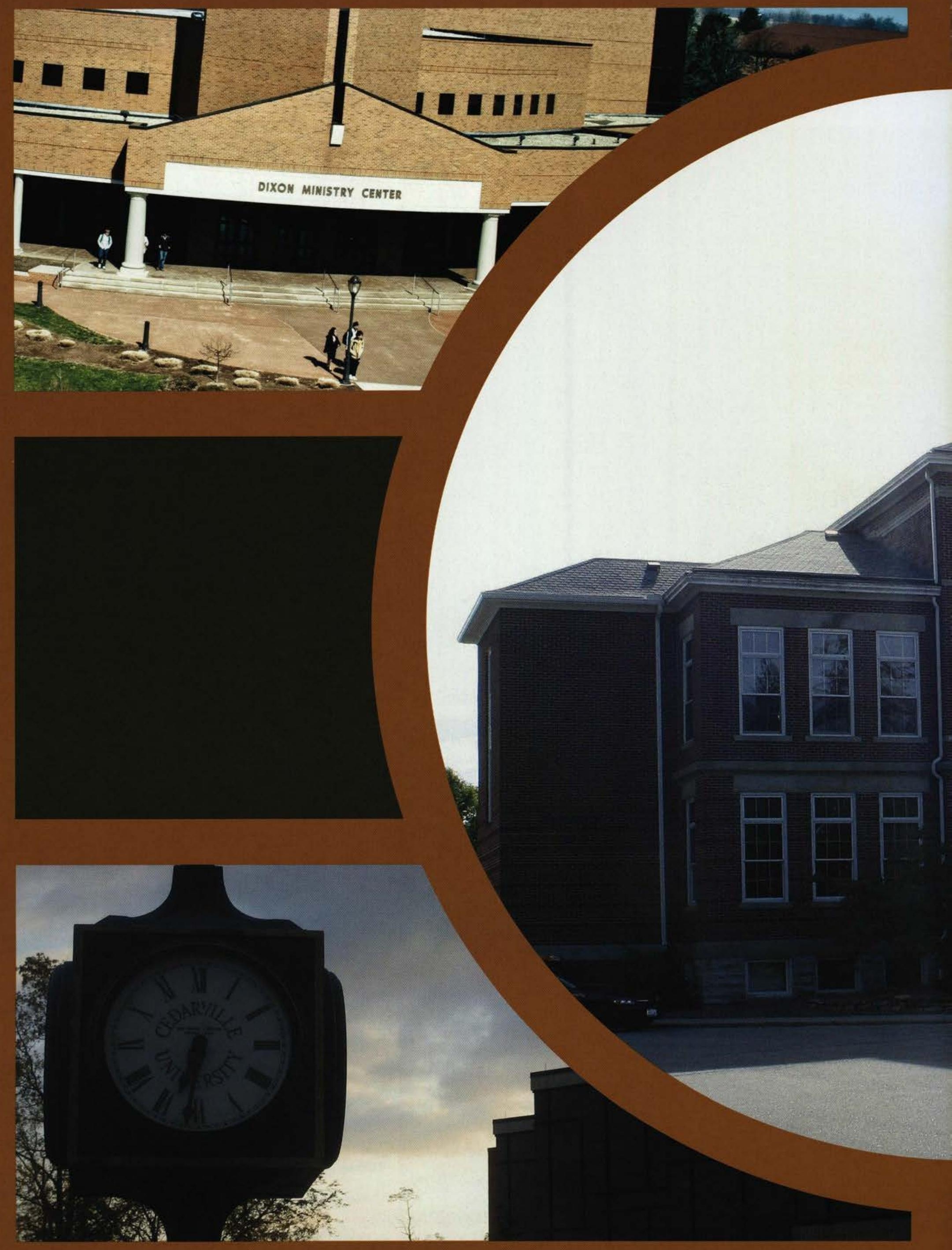




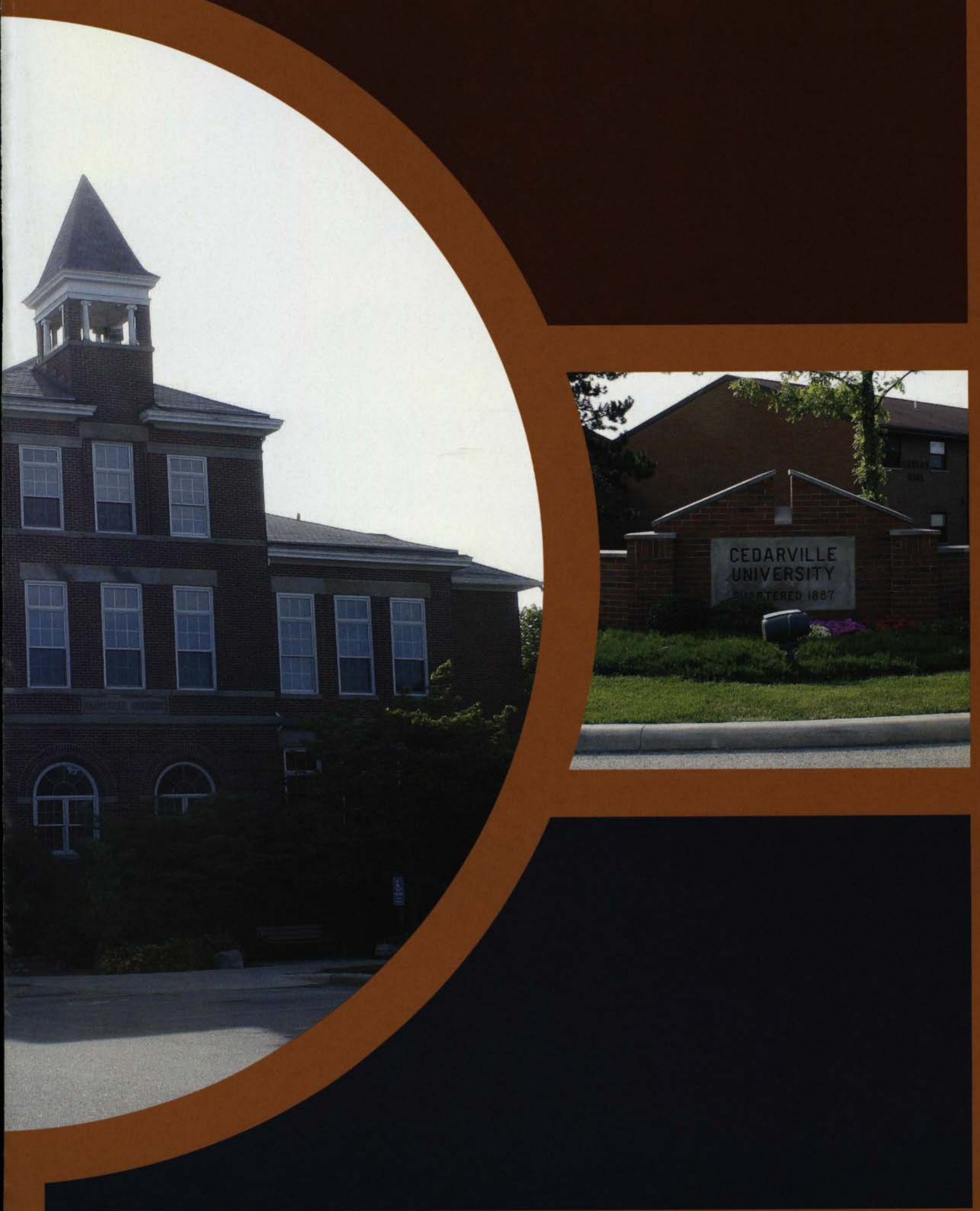


1887

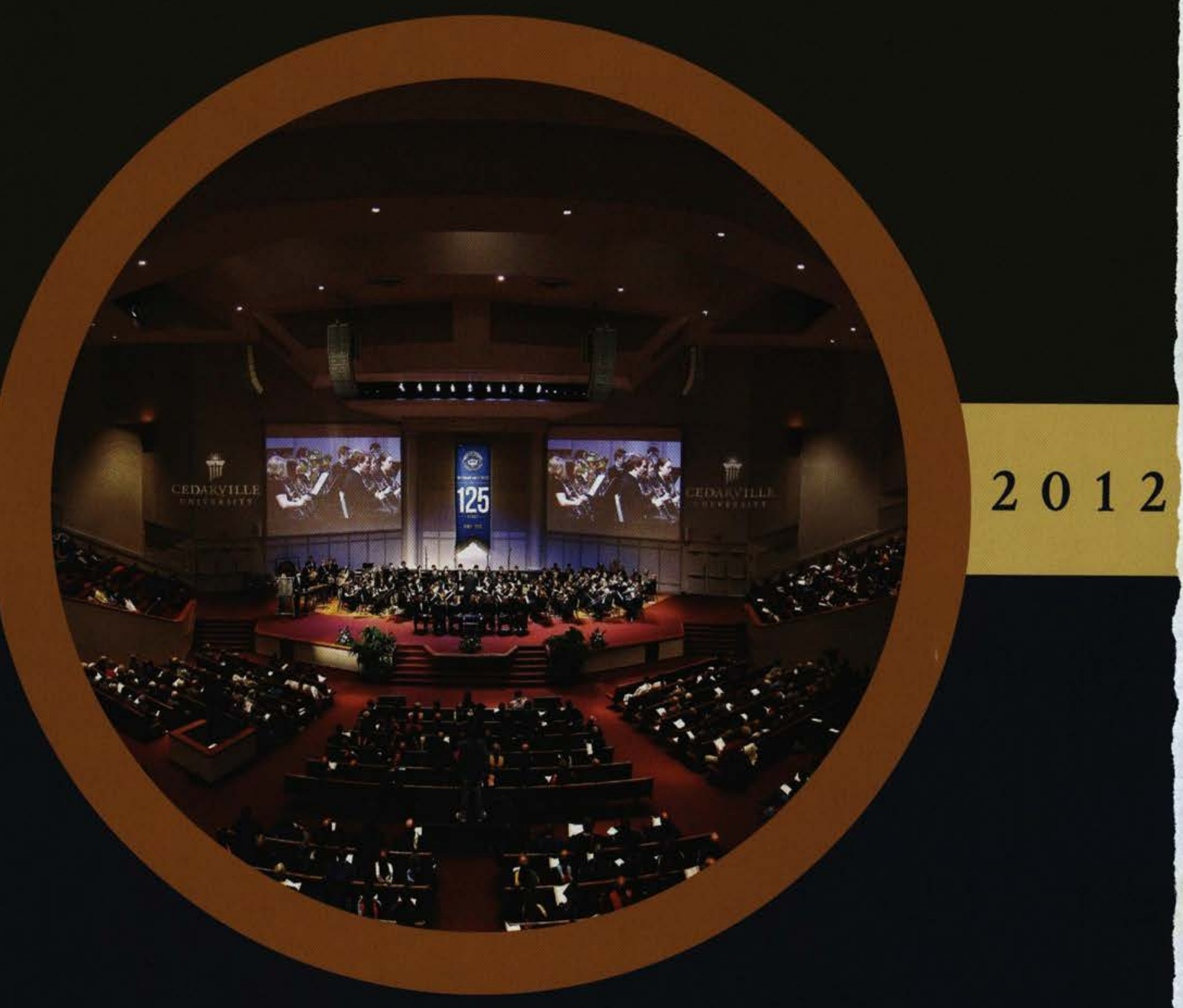





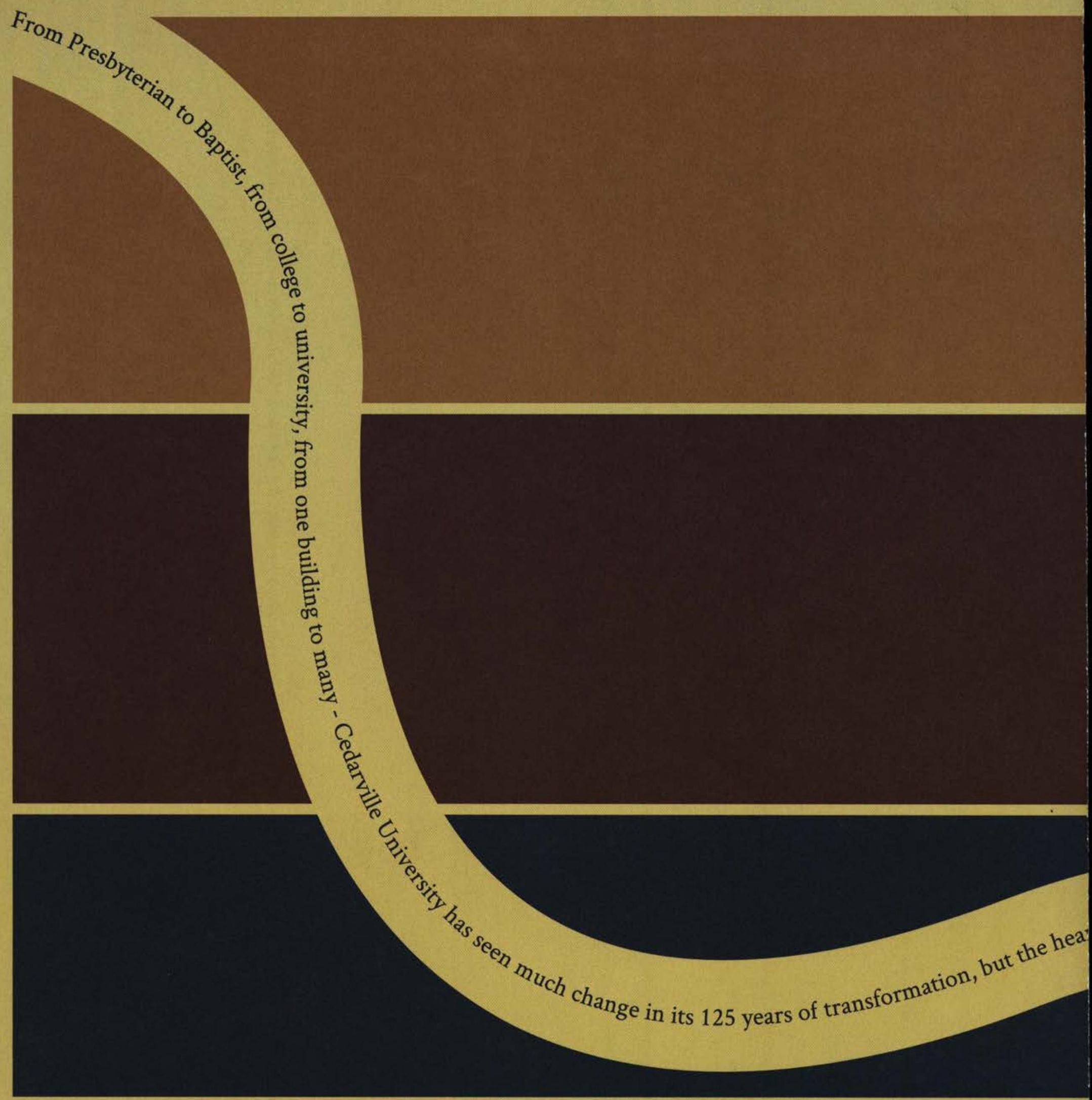


Cedarville has remained: to offer a Christ 


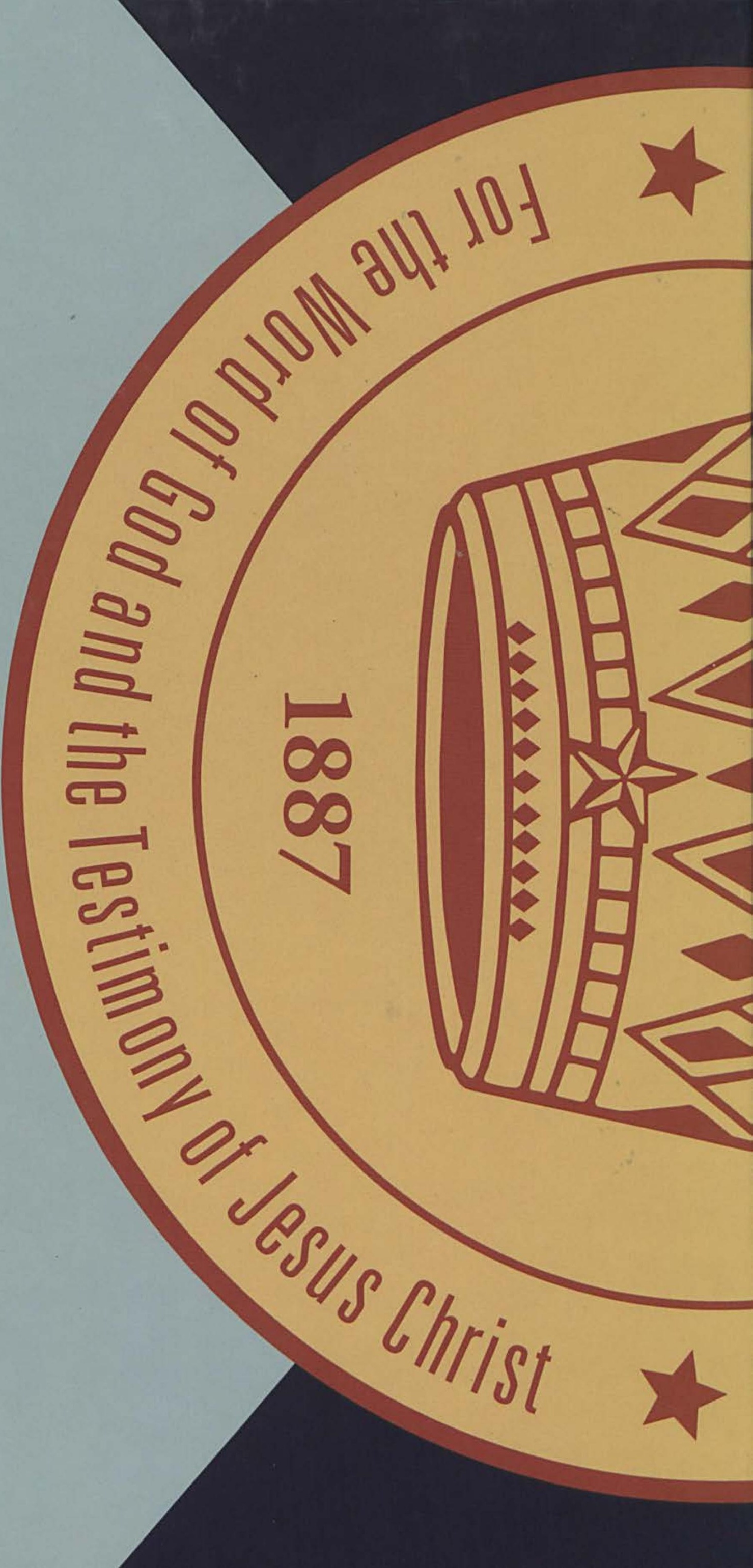

